\title{
Reoxigenação Superficial da Água em Canais Abertos: 0 Efeito da Recirculação Produzida por Bombeamento
}

Hemerson D. Pinheiro

Tese apresentada à Escola de Engenharia de São Carlos da Universidade de São Paulo, para a obtenção de Título de Doutor em Ciências no Programa de Hidráulica e Saneamento.

Orientador: Marcius F. Giorgetti 
Pinheiro, Hemerson D.

Reoxigenação superficial da água em canais abertos : o efeito da recirculação produzida por bombeamento / Hemerson D. Pinheiro; orientador Marcius F. Giorgetti. - São Carlos, 2011.

Tese (Doutorado-Programa de Pós-Graduação e Área de Concentração em Hidráulica e Saneamento) -- Escola de Engenharia de São Carlos da Universidade de São Paulo, 2011.

1. Reaeração superficial. 2. Coeficiente de reaeração $\left(\mathrm{K}_{2}\right)$. 3. Modelagem matemática. 4. oxigênio dissolvido $(O D)$. 5. Concentração de saturação de $O D$. I. Título. 
Título da tese: Reoxigenação superficial da água em canais abertos: o efeito da recirculação produzida por bombeamento.

Data da defesa: 26/08/2011:

Comissão Julgadora:

Prof. Titular Marcius Fantozzi Giorgetti (Orientador)

(Escola de Engenharia de São Carlos/EESC)

Prof. Titular Woodrow Nelson Lopes Roma

(Escola de Engenharia de São Carlos/EESC)

Prof. Associado Antonio Marozzi Righetto

(Escola de Engenharia de São Carlos/EESC)

Prof. Dr. Cristiano Poleto

(Universidade Tecnológica Federal do Paraná)

Prof. Dr. Leonardo Rios

(Escola de Engenharia de Piracicaba/EEP)
Resultado:

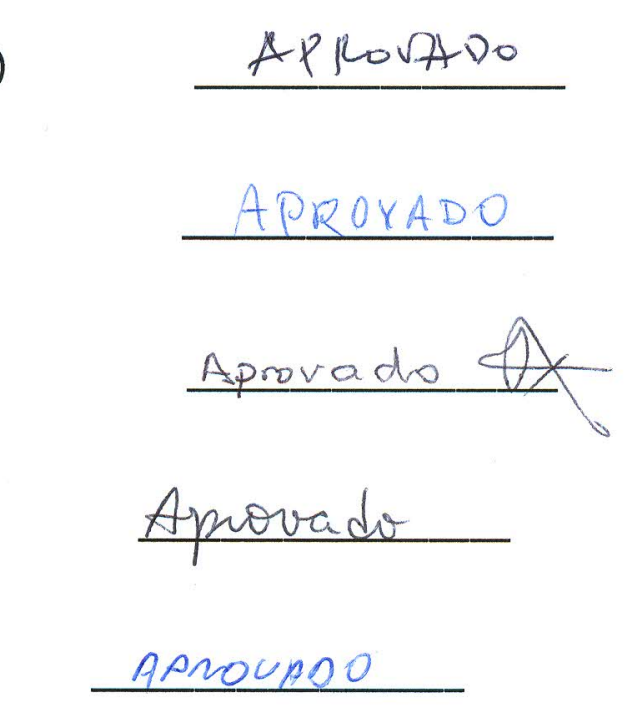

Coordenador do Programa de Pós-Graduação em Engenharia Hidráulica e Saneamento: Prof. Titular Edson Cezar Wendland

Presidente da Comissão de Pós-Graduação: Prof. Associado Paulo Cesar Lima Segantine 
Copyright (c) by Foxit Corporation, 2003 - 2010 For Evaluation Only.

À Nadia Eidt 
"Se tens que lidar com água, consulta primeiro a experiência, depois a razão." Leonardo da Vinci (1452-1519) 


\section{Agradecimentos}

À Nadia, sempre ao meu lado;

Ao Prof. Dr. Marcius F. Giorgetti, pela orientação, dedicação para a conclusão desta pesquisa de doutorado, paciência, confiança e boa vontade em atender-me assim que solicitado.

Ao Departamento de Hidráulica e Saneamento da Escola de Engenharia de São Carlos, Universidade de São Paulo, pela oportunidade de realização de meu doutorado;

Ao amigos do Laboratório de Modelagem Física e Matemática de Processos Ambientais Júlio e Daniel, e ao amigo André Simões;

Ao técnico de laboratório Roberto Bergamo pelo auxílio nas montagens e desmontagem dos equipamentos utilizados nesta pesquisa;

A todos os funcionários do Departamento de Hidráulica e Saneamento, em especial Rose, Pavi, Sá, Flávia e Fernanda;

Ao Conselho Nacional de Desenvolvimento Científico e Tecnológico (CNPq) pelo fornecimento da bolsa de estudos, processo 140243/2008-9 ;

À Agencia de Fomento à Pesquisa do Estado de São Paulo (FAPESP), pelo financiamento dos equipamentos utilizados na pesquisa, processo 2008/53451-1 (Auxílio Pesquisa - Regular);

A todos que, direta ou indiretamente, contribuíram para o desenvolvimento desta pesquisa. 


\section{Resumo}

\section{PINHEIRO, H. D. Reoxigenação Superficial da Água em Canais Abertos: O} Efeito da Recirculação Produzida por Bombeamento. Tese (Doutorado) - Escola de Engenharia de São Carlos, Departamento de Hidráulica e Saneamento, Universidade de São Paulo, São Carlos, 2011.

O coeficiente de reaeração constitui-se no principal parâmetro usado em modelos de qualidade na avaliação preventiva do efeito da descarga de resíduos orgânicos sobre a concentração do oxigênio dissolvido $(O D)$ em cursos de água naturais. Na literatura os valores observados para a concentração de saturação de $O D$ em procedimentos experimentais para a determinação das taxas de reaeração superficial são, geralmente, reportados como inferiores aos valores calculados para as condições de temperatura, salinidade e pressão em que os experimentos foram realizados. Esse fato interfere significativamente na determinação do coeficiente de reaeração superficial, $K_{2}$. Avalia-se neste trabalho a hipótese de que nessas situações a água é exposta a uma fonte de $O D$, que é a superfície em contato com a atmosfera, mas também a um sumidouro de $O D$, criado pelo próprio sistema de movimentação do fluido. O modelo matemático amplamente utilizado para estes fins não considera essa última possibilidade. Neste estudo foi comparada a eficácia deste modelo com um que considera a existência sumidouros do $O D$, o que justifica a baixa estimativa da concentração de saturação deste gás. Observou-se uma forte correlação entre a pressão na linha de sucção do sistema de recirculação e o valor do coeficiente de desoxigenação $K_{3}^{*}$, que quantifica a intensidade do sumidouro.

Palavras-chave: Reaeração superficial, coeficiente de reaeração $\left(K_{2}\right)$, modelagem matemática; oxigênio dissolvido $(O D)$, concentração de saturação de $O D$. 


\begin{abstract}
PINHEIRO, H. D. Surface Reoxygenation of Water in Open Channels: The Effect of Pumping Produced Recirculation. Thesis - School of Engineering of São Carlos, Departament of Hydraulics and Sanitation, University of São Paulo, São Carlos, 2011.
\end{abstract}

The reaeration coefficient constitutes the main parameter used in models for the quality assessment of the preventive effect of the discharge of organic wastes on the concentration of dissolved oxygen (DO) in natural waterways. In the literature the values observed for the saturation concentration of $D O$ in experimental procedures for determining the surface reaeration rates are generally reported as lower than the values calculated for the conditions of temperature, salinity and pressure at which the experiments were performed. This interferes significantly in the determination of surface reaeration coefficient, $K_{2}$. In this work the following hypothesis is evaluated: that in these situations the water is exposed to a source of $D O$, which is the surface in contact with the atmosphere, as well as an $D O$ sink, created by the pumping system. The mathematical model widely used does not consider this possibility. In this study the two kind of models were compared and the reasons for divergence were looked upon. There was a strong correlation between the pressure drop in the suction line of the recirculation system and a pseudo-coefficient of deoxygenation $K_{3}^{*}$, which quantifies the sink intensity.

Key -words:Surface reaeration; reaeration coefficient $\left(K_{2}\right)$, mathematical modeling, dissolved oxygen $(D O)$, saturated $D O$ concentration $\left(C_{s}\right)$. 


\section{Sumário}

Lista de Figuras $\quad$ v

$\begin{array}{ll}\text { Lista de Tabelas } & \text { xv }\end{array}$

Lista de Símbolos xvii

1 Introdução e Objetivos 1

2 Transferência Gasosa na Interface Ar-Água 9

2.1 Balanço de massa para o oxigênio dissolvido . . . . . . . . . . . . . 10

2.2 Coeficiente de Reaeração Superficial . . . . . . . . . . . . . . . . . . . . 12

2.3 Estimativa do coeficiente de reaeração superficial . . . . . . . . . . . . 15

2.3.1 Modelos Conceituais . . . . . . . . . . . . . . 16

2.3.2 Modelos Empíricos e Semi-Empíricos . . . . . . . . . . . . 25

2.4 Concentração de Saturação do Oxigênio . . . . . . . . . . . . . . . . 28

2.5 Efeito da temperatura sobre a transferência gasosa . . . . . . . . . . 35

2.6 Proposição do Novo Modelo . . . . . . . . . . . . . . . . . . . . . . 40

3 Materiais e Métodos $\quad 45$

4 Resultados e Discussões $\quad 69$

4.1 Verificação da Existência do Sumidouro de OD . . . . . . . . . . . . 70

4.2 Validação do Novo Modelo Matemático . . . . . . . . . . . . . . . . . . 74

4.3 Correlação entre o sumidouro de OD e a queda de pressão na tubulação de sucção do sistema de recirculação da água . . . . . . . . . . . . . . . 79 
5 Considerações Finais

Referências Bibliográficas

A Resultados Numéricos

B Resultados Gráficos 


\section{Lista de Figuras}

1.1 Curva de reoxigenação ajustada com o modelo clássico para os dados de Silveira (2004). . . . . . . . . . . . . . . . . . . 6

1.2 Curva ajustada com o modelo clássico para os dados de Chang (1985). 6

2.1 Volume de controle utilizado para o balanço de massa de oxigênio dissolvido. . . . . . . . . . . . . . . . . . . . . 10

2.2 Ilustração da Teoria dois Filmes de Whitman. . . . . . . . . . . . . 17

2.3 Modelo esquemático da teoria da renovação superfcial. . . . . . . . . . 24

2.4 Curva de reoxigenação superficial obtida para o experimento aleatório 130

2.5 Curva de reoxigenação superficial obtida para o experimento aleatório 231

2.6 Curva de reoxigenação superficial apresentada por Gulliver e Halverson (1989).

2.7 Desvio percentual entre os valores de $C_{s}$ calculados pela equação 2.42 e os obtidos experimentalmente por Benson e Krause Jr (1984); Montgomery et al. (1964); Murray e Riley (1969) e Carpenter (1966). . . . . . . . . .

2.8 Variação do coeficiente de difusividade molecular $D_{m}$ em relação à variação da temperatura da água. . . . . . . . . . . . . . . . . . . . . 3

2.9 Variação do coeficiente $K_{L}$ com relação á variação da temperatura -

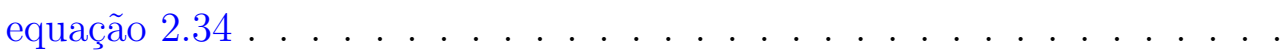

2.10 Variação do coeficiente $K_{L}$ com relação à variação da a temperatura equação $2.35 \ldots \ldots \ldots \ldots \ldots \ldots$

2.11 Variação do coeficiente $K_{L}$ em relação ao aumento da temperatura da água. . . . . . . . . . . . . . . . . . . . . 
3.1 Vista do canal de jusante para montante do escoamento. . . . . . . . . 48

3.2 Vista do canal de montante para jusante do escoamento. . . . . . . . . 49

3.3 Perfil vertical da calha do canal. . . . . . . . . . . . . . . . . . 50

3.4 Dispositivo utilizado para a transição do escoamento da tubulação de sucção para a calha do canal. . . . . . . . . . . . . . . . . . 51

3.5 Detalhe interno Dispositivo utilizado para a transição do escoamento da tubulação de sucção para a calha do canal . . . . . . . . . . . . . . . . 51

3.6 Sistema de controle da inclinação da calha do canal - sem inclinação. 52

3.7 Sistema de controle da inclinação da calha do canal - com inclinação. 52

3.8 Trocador de calor tipo ponta fria utilizado para manutenção da temperatura da água. . . . . . . . . . . . . . . . . . . 53

3.9 Detalhe da instalação dos trocadores de calor durante a realização dos experimentos. . . . . . . . . . . . . . . .

3.10 Vista superior da instalação dos trocadores de calor durante a realização dos experimentos. . . . . . . . . . . . . . . .

3.11 Inversor de frequência utilizado para o controle da rotação do motor da bomba utilizada para promover a recirculação da água no canal. . . . . . 54

3.12 Instalação utilizada para medição da vazão no canal . . . . . . . . . . 55

3.13 Válvula instalada no início da tubulação de sução. . . . . . . . . . . . . 55

3.14 Válvula instalada no início da tubulação de recalque. . . . . . . . . . . 55

3.15 Manômetro utilizado para aferir a vazão na tubulação de recirculação. . 56

3.16 Controlador de pressão e conversor de sinal para comunicação com o computador. . . . . . . . . . . . . . . . 57

3.17 Sistema medidor de pressão ligado ao computador. . . . . . . . . . . 57

3.18 Instalação dos transdutores ao longo da tubulação. . . . . . . . . . . . 57

3.19 Detalhe do transdutor de pressão e da tomada de pressão . . . . . . . 58

3.20 Desoxigenação da água no canal . . . . . . . . . . . . . . . . . . . . . . 59

3.21 Oxímetro $W T W^{\circledR}$ OXI $197 \ldots \ldots \ldots$

3.22 Oxímetro $W T W^{\circledR} O X I 340 i \ldots \ldots$ 
3.23 Sonda para oxigênio dissolvido $W T W^{\circledR}$ CellOx ${ }^{\circledR} 325 \quad \ldots \ldots \ldots$. . . . 61

3.24 Medidor multiparâmetros HQ40D . . . . . . . . . . . . . . 62

3.25 Sensor de oxigênio dissolvido por luminescência $L D O^{\circledR} 101 \ldots$. . . . . 62

3.26 Calibração da sonda LDO com o método de Winkler . . . . . . . . . . 65

3.27 Calibração da sonda Oxi 197 com o método de Winkler . . . . . . . . . 65

4.1 Exemplo 1: Ajuste do modelo clássico aos dados experimentais com utilização de $C_{s}$ variável e tabelado . . . . . . . . . . . . . . 71

4.2 Exemplo 2: Ajuste do modelo clássico aos dados experimentais com utilização de $C_{s}$ variável e tabelado . . . . . . . . . . . . . 71

4.3 Comparação entre os valores calculados para $C_{s}$ e os valores observados experimentalmente com uso do modelo clássico, $C_{s}^{*} \ldots \ldots \ldots$

4.4 Histograma das diferenças entre os valores calculados e os observados experimentalmente para a concentração de saturação do $O D$. . . . . .

4.5 Boxplot das diferenças entre os valores calculados e os observados experimentalmente para a concentração de saturação do $O D$. . . . . . . . 75

4.6 Ajuste dos dados do exemplo 1 ao modelo novo. . . . . . . . . . . . . 76

4.7 Ajuste dos dados do exemplo 2 ao modelo novo. . . . . . . . . . . . 76

4.8 Comparação entre $K_{2}$ obtido com os modelos clássico e novo. . . . . . . 77

4.9 Histograma da diferença entre $K_{2}$ obtido com o modelo clássico e $K_{2}$ obtido com o modelo novo. . . . . . . . . . . . . . . . 78

4.10 Boxplot da diferença entre $K_{2}$ obtido com o modelo clássico e $K_{2}$ obtido com o modelo novo. . . . . . . . . . . . . . . . . . .

4.11 Velocidade do escoamento na tubulação $0,45 \mathrm{~m} / \mathrm{s}$ para abertura de $100 \%$ da válvula instalada na sucção. . . . . . . . . . . . . . . . . . . . . . 80

4.12 Velocidade do escoamento na tubulação $0,45 \mathrm{~m} / \mathrm{s}$ para abertura de $50 \%$ da válvula instalada na sucção. . . . . . . . . . . . . . . . . . . . . 80

4.13 Velocidade do escoamento na tubulação $1,1 \mathrm{~m} / \mathrm{s}$ para abertura de $100 \%$ da válvula instalada na sucção. . . . . . . . . . . . . . . . . 
4.14 Velocidade do escoamento na tubulação $1,1 \mathrm{~m} / \mathrm{s}$ para abertura de $50 \%$ da válvula instalada na sucção. . . . . . . . . . . . . . . . . . . . . . 81

4.15 Diagrama de dispersão entre $K_{3}^{*}$ e a pressão na tubulação de sucção 82

4.16 Regressão linear entre $K_{3}^{*}$ e a pressão na tubulação de sucção . . . . . . 83

4.17 Resíduos padronizados versus $K_{3}^{*} \ldots \ldots$. . . . . . . . . . . 83

4.18 Resíduos padronizados versus pressão . . . . . . . . . . . . . . . . . . . 84

4.19 Gráfico de Probabilidade Normal . . . . . . . . . . . . . . . . 84

B.1 Curva de reoxigenação para o ensaio 1 . . . . . . . . . . . . . . . . 112

B.2 Curva de reoxigenação para o ensaio $2 \ldots \ldots$. . . . . . . . . 113

B.3 Curva de reoxigenação para o ensaio $3 \ldots \ldots$. . . . . . . . . . . . . . 114

B.4 Curva de reoxigenação para o ensaio 4 . . . . . . . . . . . . . . 115

B.5 Curva de reoxigenação para o ensaio $5 \ldots$. . . . . . . . . . 116

B.6 Curva de reoxigenação para o ensaio 6 . . . . . . . . . . . . . . . . . 117

B.7 Curva de reoxigenação para o ensaio 7 . . . . . . . . . . . . . . . . . . 118

B.8 Curva de reoxigenação para o ensaio 8 . . . . . . . . . . . . . . . . . . . 119

B.9 Curva de reoxigenação para o ensaio 9 . . . . . . . . . . . . . . 120

B.10 Curva de reoxigenação para o ensaio 10 . . . . . . . . . . . . . . . . . 121

B.11 Curva de reoxigenação para o ensaio 11 . . . . . . . . . . . . . . . . . . 122

B.12 Curva de reoxigenação para o ensaio $12 \ldots$. . . . . . . . . . . . . . 123

B.13 Curva de reoxigenação para o ensaio 13 . . . . . . . . . . . . . . . . . . 124

B.14 Curva de reoxigenação para o ensaio $14 \ldots$. . . . . . . . . . . . 125

B.15 Curva de reoxigenação para o ensaio 15 . . . . . . . . . . . . . 126

B.16 Curva de reoxigenação para o ensaio 16 . . . . . . . . . . . . . . . . . . 127

B.17 Curva de reoxigenação para o ensaio 17 . . . . . . . . . . . . . . 128

B.18 Curva de reoxigenação para o ensaio 18 . . . . . . . . . . . . . . . . 129

B.19 Curva de reoxigenação para o ensaio 19 . . . . . . . . . . . . . . . 130

B.20 Curva de reoxigenação para o ensaio 20 . . . . . . . . . . . . . . 131

B.21 Curva de reoxigenação para o ensaio 21 . . . . . . . . . . . . . . . 132

B.22 Curva de reoxigenação para o ensaio $22 \ldots$. . . . . . . . . . . . . . 133 
B.23 Curva de reoxigenação para o ensaio 23 . . . . . . . . . . . . . . 134

B.24 Curva de reoxigenação para o ensaio 24 . . . . . . . . . . . . . 135

B.25 Curva de reoxigenação para o ensaio $25 \ldots$. . . . . . . . . . 136

B.26 Curva de reoxigenação para o ensaio 26 . . . . . . . . . . . . 137

B.27 Curva de reoxigenação para o ensaio 27 . . . . . . . . . . . . . . 138

B.28 Curva de reoxigenação para o ensaio 28 . . . . . . . . . . . . . . 139

B.29 Curva de reoxigenação para o ensaio 29 . . . . . . . . . . . . . . . 140

B.30 Curva de reoxigenação para o ensaio 30 . . . . . . . . . . . . . . 141

B.31 Curva de reoxigenação para o ensaio 31 . . . . . . . . . . . . . . . . . 142

B.32 Curva de reoxigenação para o ensaio 32 . . . . . . . . . . . . . . . 143

B.33 Curva de reoxigenação para o ensaio 33 . . . . . . . . . . . . . . . . 144

B.34 Curva de reoxigenação para o ensaio 34 . . . . . . . . . . . . . . 145

B.35 Curva de reoxigenação para o ensaio 35 . . . . . . . . . . . . . 146

B.36 Curva de reoxigenação para o ensaio 36 . . . . . . . . . . . . . 147

B.37 Curva de reoxigenação para o ensaio 37 . . . . . . . . . . . . . . 148

B.38 Curva de reoxigenação para o ensaio 38 . . . . . . . . . . . . . . 149

B.39 Curva de reoxigenação para o ensaio 39 . . . . . . . . . . . . . 150

B.40 Curva de reoxigenação para o ensaio 40 . . . . . . . . . . . . 151

B.41 Curva de reoxigenação para o ensaio 41 . . . . . . . . . . . . . . . 152

B.42 Curva de reoxigenação para o ensaio $42 \ldots$. . . . . . . . . . . . 153

B.43 Curva de reoxigenação para o ensaio $43 \ldots$. . . . . . . . . . 154

B.44 Curva de reoxigenação para o ensaio $44 \ldots$. . . . . . . . . . 155

B.45 Curva de reoxigenação para o ensaio $45 \ldots$. . . . . . . . . . . 156

B.46 Curva de reoxigenação para o ensaio $46 \ldots$. . . . . . . . . 157

B.47 Curva de reoxigenação para o ensaio $47 \ldots$. . . . . . . . . . 158

B.48 Curva de reoxigenação para o ensaio 48 . . . . . . . . . . . . . . 159

B.49 Curva de reoxigenação para o ensaio 49 . . . . . . . . . . . . . . 160

B.50 Curva de reoxigenação para o ensaio 50 . . . . . . . . . . . . . . 161

B.51 Curva de reoxigenação para o ensaio 51 . . . . . . . . . . . . . . . 162 
B.52 Curva de reoxigenação para o ensaio $52 \ldots$. . . . . . . . . . . 163

B.53 Curva de reoxigenação para o ensaio 53 . . . . . . . . . . . . . . 164

B.54 Curva de reoxigenação para o ensaio 54 . . . . . . . . . . . . . . . . 165

B.55 Curva de reoxigenação para o ensaio $55 \ldots$. . . . . . . . . . . 166

B.56 Curva de reoxigenação para o ensaio 56 . . . . . . . . . . . . 167

B.57 Curva de reoxigenação para o ensaio 57 . . . . . . . . . . . . . . 168

B.58 Curva de reoxigenação para o ensaio 58 . . . . . . . . . . . . . . . . . 169

B.59 Curva de reoxigenação para o ensaio 59 . . . . . . . . . . . . . . 170

B.60 Curva de reoxigenação para o ensaio 60 . . . . . . . . . . . . . . . 171

B.61 Curva de reoxigenação para o ensaio 61 . . . . . . . . . . . . . . 172

B.62 Curva de reoxigenação para o ensaio 62 . . . . . . . . . . . . . . . . 173

B.63 Curva de reoxigenação para o ensaio 63 . . . . . . . . . . . . . . 174

B.64 Curva de reoxigenação para o ensaio 64 . . . . . . . . . . . . . . 175

B.65 Curva de reoxigenação para o ensaio $65 \ldots$. . . . . . . . . . . . 176

B.66 Curva de reoxigenação para o ensaio 66 . . . . . . . . . . . . . . . 177

B.67 Curva de reoxigenação para o ensaio $67 \ldots$. . . . . . . . . . . 178

B.68 Curva de reoxigenação para o ensaio 68 . . . . . . . . . . . . . . . 179

B.69 Curva de reoxigenação para o ensaio 69 . . . . . . . . . . . . . . . 180

B.70 Curva de reoxigenação para o ensaio 70 . . . . . . . . . . . . . . . 181

B.71 Curva de reoxigenação para o ensaio 71 . . . . . . . . . . . . . . . . 182

B.72 Curva de reoxigenação para o ensaio 72 . . . . . . . . . . . . . . . 183

B.73 Curva de reoxigenação para o ensaio 73 . . . . . . . . . . . . . . . . . . 184

B.74 Curva de reoxigenação para o ensaio $74 \ldots$. . . . . . . . . . . . . 185

B.75 Curva de reoxigenação para o ensaio $75 \ldots$. . . . . . . . . . 186

B.76 Curva de reoxigenação para o ensaio 76 . . . . . . . . . . . . . . 187

B.77 Curva de reoxigenação para o ensaio 77 . . . . . . . . . . . . . . . . 188

B.78 Curva de reoxigenação para o ensaio 78 . . . . . . . . . . . . . . . 189

B.79 Curva de reoxigenação para o ensaio 79 . . . . . . . . . . . . . . . . 190

B.80 Curva de reoxigenação para o ensaio 80 . . . . . . . . . . . . . . . . . . 191 
B.81 Curva de reoxigenação para o ensaio 81 . . . . . . . . . . . . . . . . 192

B.82 Curva de reoxigenação para o ensaio $82 \ldots$. . . . . . . . . . . 193

B.83 Curva de reoxigenação para o ensaio $83 \ldots$. . . . . . . . . . . . 194

B.84 Curva de reoxigenação para o ensaio $84 \ldots \ldots$. . . . . . . . . . 195

B.85 Curva de reoxigenação para o ensaio 85 . . . . . . . . . . . . . 196

B.86 Curva de reoxigenação para o ensaio $86 \ldots$. . . . . . . . . . 197

B.87 Curva de reoxigenação para o ensaio 87 . . . . . . . . . . . . . 198

B.88 Curva de reoxigenação para o ensaio 88 . . . . . . . . . . . . . . . 199

B.89 Curva de reoxigenação para o ensaio 89 . . . . . . . . . . . . . . 200

B.90 Curva de reoxigenação para o ensaio 90 . . . . . . . . . . . . . 201

B.91 Curva de reoxigenação para o ensaio 91 . . . . . . . . . . . . . . . 202

B.92 Curva de reoxigenação para o ensaio $92 \ldots$. . . . . . . . . . . 203

B.93 Curva de reoxigenação para o ensaio 93 . . . . . . . . . . . . . . 204

B.94 Curva de reoxigenação para o ensaio $94 \ldots$. . . . . . . . . . . . 205

B.95 Curva de reoxigenação para o ensaio $95 \ldots$. . . . . . . . . . 206

B.96 Curva de reoxigenação para o ensaio 96 . . . . . . . . . . . . 207

B.97 Curva de reoxigenação para o ensaio 97 . . . . . . . . . . . . 208

B.98 Curva de reoxigenação para o ensaio 98 . . . . . . . . . . . . . . 209

B.99 Curva de reoxigenação para o ensaio 99 . . . . . . . . . . . . . . . 210

B.100Curva de reoxigenação para o ensaio 100 . . . . . . . . . . . . . 211

B.101Curva de reoxigenação para o ensaio 101 . . . . . . . . . . . . . 212

B.102Curva de reoxigenação para o ensaio 102 . . . . . . . . . . . . 213

B.103Curva de reoxigenação para o ensaio 103 . . . . . . . . . . . . . . 214

B.104Curva de reoxigenação para o ensaio 104 . . . . . . . . . . . . . . 215

B.105Curva de reoxigenação para o ensaio $105 \ldots$. . . . . . . . . . 216

B.106Curva de reoxigenação para o ensaio 106 . . . . . . . . . . . 217

B.107Curva de reoxigenação para o ensaio 107 . . . . . . . . . . . . 218

B.108Curva de reoxigenação para o ensaio 108 . . . . . . . . . . . . . 219

B.109Curva de reoxigenação para o ensaio 109 . . . . . . . . . . . . . 220 
B.110Curva de reoxigenação para o ensaio 110 . . . . . . . . . . . . . . . 221

B.111Curva de reoxigenação para o ensaio 111 . . . . . . . . . . . . . . 222

B.112Curva de reoxigenação para o ensaio 112 . . . . . . . . . . . . . . . . . 223

B.113Curva de reoxigenação para o ensaio 113 . . . . . . . . . . . . . . . . 224

B.114Curva de reoxigenação para o ensaio 114 . . . . . . . . . . . . . 225

B.115Curva de reoxigenação para o ensaio 115 . . . . . . . . . . . . 226

B.116Curva de reoxigenação para o ensaio 116 . . . . . . . . . . . . . 227

B.117Curva de reoxigenação para o ensaio 117 . . . . . . . . . . . . 228

B.118Curva de reoxigenação para o ensaio 118 . . . . . . . . . . . . . . . 229

B.119Curva de reoxigenação para o ensaio 119 . . . . . . . . . . . . . . 230

B.120Curva de reoxigenação para o ensaio 120 . . . . . . . . . . . . . . . . 231

B.121Curva de reoxigenação para o ensaio 121 . . . . . . . . . . . . . . . 232

B.122Curva de reoxigenação para o ensaio 122 . . . . . . . . . . . . . 233

B.123Curva de reoxigenação para o ensaio 123 . . . . . . . . . . . . . . . 234

B.124Curva de reoxigenação para o ensaio 124 . . . . . . . . . . . . . . 235

B.125Curva de reoxigenação para o ensaio 125 . . . . . . . . . . . . . 236

B.126Curva de reoxigenação para o ensaio 126 . . . . . . . . . . . . . 237

B.127Curva de reoxigenação para o ensaio 127 . . . . . . . . . . . . . . . . . 238

B.128Curva de reoxigenação para o ensaio 128 . . . . . . . . . . . . . . 239

B.129Curva de reoxigenação para o ensaio 129 . . . . . . . . . . . . . . . 240

B.130Curva de reoxigenação para o ensaio 130 . . . . . . . . . . . . . 241

B.131Curva de reoxigenação para o ensaio 131 . . . . . . . . . . . . . . . . . 242

B.132Curva de reoxigenação para o ensaio 132 . . . . . . . . . . . . . . . . . 243

B.133Curva de reoxigenação para o ensaio 133 . . . . . . . . . . . . . . 244

B.134Curva de reoxigenação para o ensaio 134 . . . . . . . . . . . . . 245

B.135Curva de reoxigenação para o ensaio 135 . . . . . . . . . . . . . 246

B.136Curva de reoxigenação para o ensaio 136 . . . . . . . . . . . . . 247

B.137Curva de reoxigenação para o ensaio 137 . . . . . . . . . . . . . . . 248

B.138Curva de reoxigenação para o ensaio 138 . . . . . . . . . . . . . . . . . 249 
B.139Curva de reoxigenação para o ensaio 139 . . . . . . . . . . . . . 250

B.140Curva de reoxigenação para o ensaio 140 . . . . . . . . . . . . . 251

B.141Curva de reoxigenação para o ensaio 141 . . . . . . . . . . . . . . . 252

B.142Curva de reoxigenação para o ensaio 142 . . . . . . . . . . . . 253 


\section{Lista de Tabelas}

2.1 Modelos para predição do coeficiente de reaeração em rios . . . . . . 27

2.2 Valores encontrados na literatura para a concentração de saturação $C_{s}$. 33

2.3 Variação da espessura do filme líquido em relação à temperatura da água. 38

4.1 Estimativa dos parâmetros do modelo clássico com $C_{s}$ variável . . . . . 71

4.2 Estimativa dos parâmetros do modelo clássico com $C_{s}$ constante . . . . 72

4.3 Resultados do aplicativo MINITAB para aplicação do teste t para a diferença entre os valores calculados e os observados para a concentração de saturação de $O D$. . . . . . . . . . . . . . . . . . . . . 74

4.4 Estimativa dos parâmetros do novo modelo aos dados dos exemplos 1 e 276

4.5 Resultados do aplicativo MINITAB para aplicação do teste t para a diferença entre os valores de $K_{2}$ obtidos com o os dois modelos diferentes. 78

A.1 Resultados Obtidos com o Ajuste do Modelo Clássico com $C_{s}$ Variável . 102

A.2 Resultados Obtidos com o Ajuste do Modelo Clássico com $C_{s}$ Determinado105

A.3 Resultados Obtidos com o Ajuste do Modelo Novo . . . . . . . . . . . . 108 


\section{Lista de Símbolos}

$C_{s} \quad$ Concentração de Saturação de $O D$ no Meio Líquido $\left[M L^{-3}\right]$

$C_{s}^{*} \quad$ Concentração Experimental Limite de $O D\left[M L^{-3}\right]$

$C_{a / w}$ Concentração de Oxigênio que está na Fronteira Entre o Filmes Gasoso e Líquido $\left[M L^{-3}\right]$

$C_{a}$ Concentração de Oxigênio na Fronteira entre o Ar e o Filme Gasoso $\left[M L^{-3}\right]$

$C_{w / a}$ Concentração de Oxigênio que está na Fronteira entre o Filmes Líquido e o Gasoso $\left[M L^{-3}\right]$

$C_{w} \quad$ Concentração de Oxigênio na Fronteira entre a Água e o Filme Líquido $\left[M L^{-3}\right]$

$D_{a} \quad$ Coeficiente de Difusão Molecular do Oxigênio no $\operatorname{Ar}\left[L^{2} T^{-1}\right]$

$D_{w} \quad$ Coeficiente de Difusão Molecular do Oxigênio na Água $\left[L^{2} T^{-1}\right]$

$D B O$ Demanda Bioquímica de 0xigênio $[M]$

$f_{c} \quad$ Fator de correção da temperatura

$J \quad$ Fluxo de massa de oxigênio $\left[M(L T)^{-1}\right]$

$K_{2} \quad$ Coeficiente de reaeração superficial $\left[T^{-1}\right]$

$K_{H} \quad$ constante da Lei de Henry para o Gás a uma Dada Temperatura $\left[M L^{2} T^{-2} N^{-1} \Theta^{-1}\right]$

$K_{L} \quad$ Coeficiente global de transferência de massa de OD $\left[L T^{-1}\right]$ 
$O D \quad$ Oxigênio Dissolvido $[M]$

$P_{g} \quad$ Pressão Parcial do Gás sobre o Líquido $\left[M L^{-1} T^{-2}\right]$

RMSE Root mean square error - Raíz Quadrada do Erro Quadrático Médio

$V \quad$ Volume do líquido no volume de controle $\left[L^{3}\right]$

$z_{a} \quad$ Espessura do Filme Gasoso $[L]$

$z_{w} \quad$ Espessura do Filme Líquido $[L]$

APHA American Public Health Association

ASCE American Society of Civil Engineers

AWWA American Water Works Association

WPCF Water Pollution Control Federation 


\section{Capítulo 1}

\section{Introdução e Objetivos}

A descarga de efluentes e resíduos domésticos e industriais em cursos d'água pode provocar sérias reduções no nível de oxigênio dissolvido $(O D)$. A manutenção de níveis razoáveis da concentração deste gás em um rio é essencial para oxidar a matéria orgânica advinda destas descargas. Os microrganismos responsáveis pela degradação da matéria orgânica requerem oxigênio para respirar, e assim reduzem a disponibilidade de $O D$ disponível. Muitas vezes a taxa de remoção de oxigênio é maior que a taxa de reoxigenação atmosférica, isso causa graves problemas à flora e a fauna pertencentes ao ecossistema aquático. Neste caso, condições anaeróbicas prevalecem e a atividade microbiana pode resultar na produção de compostos tóxicos como $\mathrm{CH}_{4}, \mathrm{NH}_{3}$ e $\mathrm{H}_{2} \mathrm{~S}$.

Vários métodos foram desenvolvidos para medir os parâmetros pertinentes ao balanço de oxigênio. Geralmente, tais parâmetros são separados em cinco categorias:

1. parâmetros hidrológicos;

2. parâmetros hidráulicos;

3. fontes de $O D$;

4. sumidouros de $O D$.

Os corpos hídricos possuem uma capacidade natural para oxidar a matéria orgânica nele presente. Este fenômeno é conhecido como autodepuração. Tal capacidade os 
colocam como opção para disposição de efluentes urbanos e industriais, os tornando uma etapa do processo de tratamento do efluente.

O fato de um corpo hídrico receber efluentes urbanos ou industriais, não implica necessariamente em sua poluição ou contaminação, desde que não seja superada a sua capacidade de autodepuração. Porém, o uso incorreto do corpo hídrico como uma etapa no tratamento de efluentes influi diretamente na saúde da população servida por ele (Ohira, 2005; Garrafa, 2009; CETESB, 2005). Cerca de 80\% das doenças no mundo são doenças de veiculação hídrica, transmitidas principalmente através da ingestão de água contaminada (Hutton e Haller, 2004; WHO, 2008; WHO e UNICEF, 2010).

A capacidade específica de reaeração de um corpo d'água, é desta forma, um parâmetro de projeto para: (1) a determinação dos requerimentos para tratamento de efluentes domésticos e industriais, (2) a para a limitação do tamanho de parques industriais, (3) a seleção dos lugares mais apropriados para o estabelecimento de novas industrias, e (4) o planejamento integrado para o controle de poluição e uso múltiplo dos recursos hídricos.

Dentre as fontes de oxigênio, a taxa de reaeração atmosférica é reconhecida com um dos parâmetros mais importantes a serem determinados, já que a habilidade de um corpo d'água em assimilar resíduos orgânicos depende principalmente das características absortivas do oxigênio na água. O coeficiente de reaeração atmosférica, simbolizado por $K_{2}$, cuja unidade é o inverso da unidade de tempo $\left(\right.$ tempo $\left.^{-1}\right)$, quantifica as taxas de incorporação, ou reincorporação, do $O D$ à água.

São muitos os fatores que governam a concentração do $O D$ em um rio; seu consumo é devido, principalmente, à demanda bioquímica de oxigênio $(D B O)$ realizada pelos microrganismos na oxidação da matéria orgânica, pela respiração dos seres aquáticos (plantas e plâncton) e pela difusão através de camadas bentônicas. A incorporação do $O D$ no corpo d'água ocorre através da fotossíntese realizada pelas plantas aquáticas e da reaeração atmosférica, que, em geral, é o principal mecanismo de reposição de $O D$ ao meio aquático. 
Normalmente, a transferência de oxigênio ocorre da atmosfera para o volume de água, visto que os níveis de oxigênio dissolvido $(O D)$, na maioria dos escoamentos naturais, encontram-se abaixo dos valores de saturação.

As teorias propostas para explicar o mecanismo de transferência de massa na interface ar-água, ficam comprometidas devido à complexidade do mecanismo do escoamento presente em canais abertos. Essas teorias podem ser divididas em dois grupos: modelos conceituais e modelos semi-empíricos e empíricos.

Modelos matemáticos de qualidade da água são utilizados, principalmente em países desenvolvidos, como subsídio ao gerenciamento dos recursos hídricos. Exemplos desta aplicação são: a avaliação da qualidade ambiental para alocação de empreendimentos potencialmente geradores de poluição hídrica; a definição dos níveis de controle necessários para fontes poluidoras existentes em uma bacia hidrográfica, com o objetivo de atender aos padrões de qualidade; a delimitação de trechos críticos de poluição e a previsão das alterações da qualidade da água ao longo do tempo e do espaço decorrentes de descargas acidentais.

Porém, o uso generalizado de modelos matemáticos (conceituais, empíricos e semiempíricos) desenvolvidos para a estimativa indireta do coeficiente de reaeração em cursos d'água, pode resultar em valores completamente irreais quando aplicados fora da gama de características para as quais foram desenvolvidos.

A aplicação de modelos conceituais exige o uso de parâmetros que não são de fácil mensuração, como por exemplo, o tempo que uma camada permanece na superfície até ser substituída por outra não saturada de $O D$.

Os modelos semi-empíricos e empíricos normalmente produzem resultados divergentes para um mesmo escoamento. Essa tendência está ligada ao fato de eles poderem ter sido produzidos com dados coletados em condições hidrodinâmicas diferentes daquelas nas quais são aplicados. Isso restringe esse tipo de modelagem para os rios em que os parâmetros foram calibrados.

A medição do oxigênio dissolvido, in loco, é realizada através da técnica do balanço, ou da perturbação do equilíbrio, ou dos traçadores gasosos, etc. Algumas destas 
técnicas estão sujeitas a erros de grande escala, como é o caso, por exemplo, da técnica do balanço de oxigênio. Outras são mais precisas, porém muito onerosas, como é o caso da técnica dos traçadores gasosos.

Além do exposto, a concentração de oxigênio dissolvido $(O D)$ nos corpos hídricos é afetada por processos biológicos e químicos. Ao todo, o processo de transferência de massa na interface ar-água em um corpo hídrico, é afetado por 14 diferentes parâmetros (Gualtieri et al., 2002). O conhecimento das taxas em que estes processos ocorrem é de difícil quantificação. Assim, fazem-se necessários estudos em laboratório, onde é esperado um maior controle sobre as variáveis que interferem na quantificação do $O D$. Estes estudos consistem em obter curvas de reoxigenação a partir da perturbação da concentração de $O D$ em um dado volume de água, em que são conhecidas condições e níveis de agitação.

Geralmente, o volume em estudo está contido em um tanque ou em um canal. No tanque, a agitação é mantida ou por rotores, ou grades oscilantes ou mesmo jatos, enquanto que nos canais, devido à necessidade de uma grande distância entre os pontos de amostragem para se obter uma diferença de concentração detectável pelas sondas medidoras de $O D$, o volume é mantido em recirculação, proporcionada por uma bomba, e a agitação é provida pelas diferentes características da rugosidade do fundo do canal, velocidades e profundidade da lâmina d'água do escoamento.

O estudo da reoxigenação envolve a determinação de parâmetros que forneçam o melhor ajuste do modelo matemático escolhido à curva obtida experimentalmente (concentração de $O D$ versus tempo). Como os modelos matemáticos utilizados por, possivelmente, não considerarem a influência de todos os parâmetros envolvidos no processo, podem levar a resultados afetados de erros sistemáticos, resultando em uma estimativa equivocada do coeficiente de reaeração superficial, o $K_{2}$.

$\mathrm{O}$ valor de $K_{2}$ define indiretamente a quantidade de resíduos consumidores de oxigênio que pode ser lançada no corpo receptor sem comprometimento da qualidade da água. Se o coeficiente de reaeração é incorretamente estimado, e assim usado em um 
modelo de qualidade da água, as conclusões daí tiradas poderão conduzir a prejuízos de natureza financeira ou a sérios danos para o meio ambiente.

Quando, por exemplo, para um dado curso de água natural se adota um coeficiente de reaeração menor do que o verdadeiro, o grau requerido de tratamento dos resíduos indicado pelo modelo será maior do que o necessário e, em conseqüência, os custos associados serão mais elevados. Por outro lado, se o valor do coeficiente de reaeração empregado no modelo for maior do que o valor correto, então o grau de tratamento indicado será insuficiente e o padrão fixado para o $O D$ poderá ser violado e com isso, poderá comprometer da qualidade da água do corpo hídrico em questão.

Com base em considerações teóricas ou investigações práticas, os estudiosos do assunto têm apresentado diferentes métodos e equações para a estimativa de $K_{2}$, pois não há um senso comum em relação à influência de alguns parâmetros envolvidos no fenômeno de reaeração superficial, como exemplo, a influência da temperatura. Encontram-se na literatura estudos que mostram uma variação crescente do coeficiente de reaeração com o aumento da temperatura, independentemente das condições de turbulência do escoamento. Mas há também estudos que mostram um decréscimo do coeficiente de reaeração com o aumento da temperatura, para casos de escoamentos com baixa turbulência (Chao et al., 1987b,a; Howe, 1977).

Quanto à concentração de saturação de $O D$ no meio líquido, $C_{s}$, observa-se que na maioria dos trabalhos analisados, a concentração de $O D$ tende para um limite estável $C_{s}^{*}$ menor do que o valor da concentração de saturação de $O D, C_{s}$, tabelado para as mesmas condições de temperatura, pressão e salinidade em que o experimento foi realizado.

Como pode ser observado na figura 1.1, adaptada de (Silveira, 2004, p.92), o valor calculado da concentração de saturação do $O D$ no experimento foi $C_{s e}=7,85 \mathrm{mg} / \mathrm{L}$, enquanto que o valor tabelado para essa concentração nas condições de temperatura, salinidade e pressão em que foi realizado o experimento é de $C_{s t}=8,20 \mathrm{mg} / L$. 


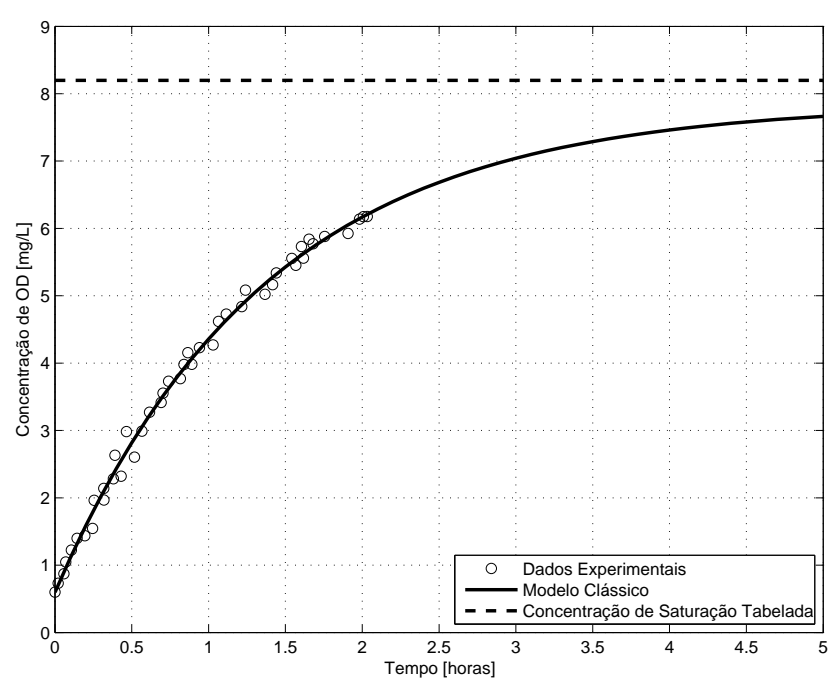

Figura 1.1: Curva de reoxigenação ajustada com o modelo clássico para os dados de Silveira (2004).

A figura 1.2, traz um dos resultados de outro pesquisador (Chang, 1985, p.84) em que há, também, uma diferença entre o valor calculado experimentalmente e o tabelado para a concentração de saturação do $O D$.

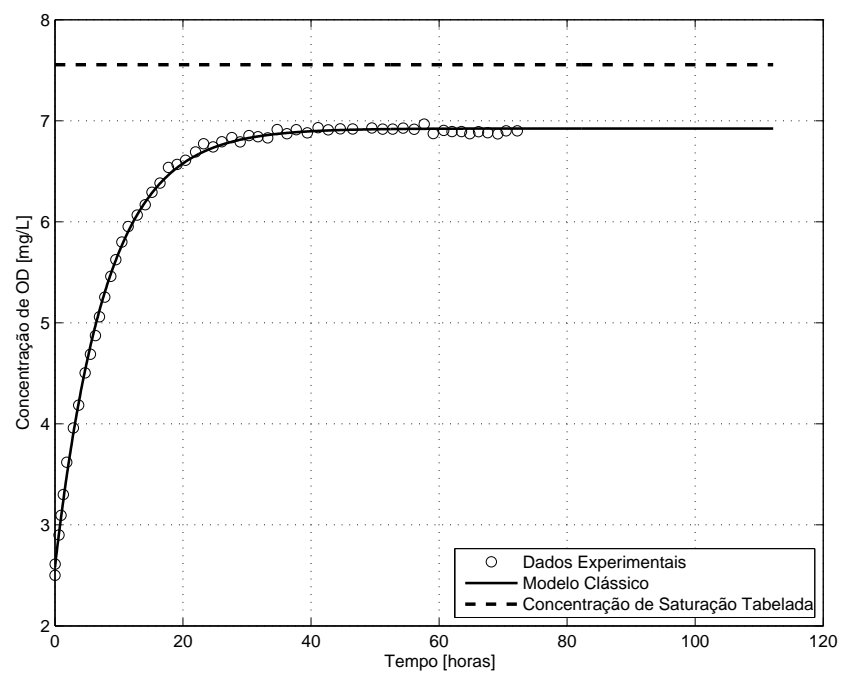

Figura 1.2: Curva ajustada com o modelo clássico para os dados de Chang (1985).

Diferenças nos valores da concentração de saturação, como a apresentada na figura 1.1, podem conduzir a erros significativos na estimativa do coeficiente de reaeração superficial $K_{2}$, da ordem de \pm 15 a $20 \%$. 
Os erros na estimativa dos parâmetros do modelo clássico para a determinação da capacidade de reaeração de um rio, podem estar relacionados à escolha de um modelo matemático inadequado para a análise dos dados. Idealmente, deve-se levar em consideração todos os fatores que interferem direta ou indiretamente no fenômeno modelado, o que nem sempre é possível quando os dados são obtidos no campo, porém, quando da realização de experimentos em laboratórios, há a possibilidade, senão de controlar, pelo menos observar todas as variáveis envolvidas.

Em uma primeira análise das figuras 1.1 e 1.2, verifica-se que nesses dois casos a concentração de saturação calculada para o experimento é inferior à do valor tabelado, ou seja, experimentalmente o que se obtêm é uma concentração experimental limite, e que neste texto será denominada por $C_{s}^{*}$. Essa diferença entre os valores calculados e tabelados pode estar relacionada à existência simultânea com a fonte de oxigênio, representada pela superfície da água, de um sumidouro de $O D$, possivelmente criado pelo próprio sistema de movimentação do fluido. Isso justificaria a baixa estimativa no valor calculado para a concentração de saturação do $O D$.

Os erros encontrados na predição do coeficiente de reaeração, $K_{2}$, quando utilizado um modelo específico para ajustar os dados experimentais, podem ser devidos a três causas: (1) erros experimentais nas medidas dos dados, de ordem aleatória ou sistemática; (2) erros apenas na parte do conjunto de dados que foi utilizada para avaliar os parâmetros do modelo, ou das constantes da correlação; (3) modelo inadequado, por exemplo, a utilização de variáveis não representativas ao processo ou mesmo a não utilização de variáveis determinantes do processo, ou uma análise matemática equivocada.

O objetivo deste trabalho é portanto, o de realizar uma investigação experimental, buscando a validação da hipótese lançada sobre a existência de sumidouros de $O D$, quando da realização de experimentos desta natureza em laboratório e, a partir da verificação desta, propor um novo modelo matemático que considere tal sumidouro e que possa quantificá-lo. 


\section{Capítulo 2}

\section{Transferência Gasosa na Interface}

\section{Ar-Água}

O fluxo de gás, $J\left[M L^{-1} T^{-2}\right]$, através da interface ar-água pode ser modelado através da seguinte equação

$$
J=-\left(D_{m}+D_{t}\right) \frac{\partial C}{\partial z}
$$

em que $D_{m}$ e $D_{t}$ são, respectivamente, os coeficientes de difusão molecular e turbulento; $\frac{\partial C}{\partial z}$ é o gradiente de concentração do gás sendo transferido; e $z$ é a direção perpendicular à superfície.

A equação 2.1 define que o processo de transferência de um gás depende das características físico-químicas do gás em análise $\left(D_{m}\right)$ e da interação entre a turbulência na atmosfera, na água e na interface ar-água $\left(D_{t}\right)$.

A maioria dos estudos sobre reaeração superficial, também denominada por reaeração atmosférica, tratam principalmente da transferência do oxigênio, por este ser o gás mais importante no processo de reaeração. A transferência de outros gases do ar para a água, pode, sem perda de generalidade, ser modelada com o mesmo desenvolvimento que se fará para o oxigênio. Segundo Rubin e Atkinson (2001), esta possibilidade se deve ao fato do coeficiente de transferência de massa ser independente 
de propriedades especificas do gás em estudo. A ênfase dada ao oxigênio deve-se à importância deste gás aos modelos de qualidade da água.

Antes de discutirmos os mecanismos que governam a transferência do oxigênio da atmosfera para a água, apresentaremos o balanço de massa deste gás, para um volume de controle.

\subsection{Balanço de massa para o oxigênio dissolvido}

Considere o volume de controle representado pela figura 2.1. A parte hachurada representa a área pela qual ocorre a reaeração, e $h$ é a profundidade média do volume de controle. O balanço de massa para o oxigênio, aplicado a este volume de controle, pode ser estabelecido pela seguinte equação:

[ $\left.\begin{array}{c}\text { Variação da massa } \\ \text { de } O D \text { no interior do } \\ \text { volume de controle }\end{array}\right]=\left[\begin{array}{c}\text { Massa de } O D \text { que } \\ \text { é transportada através } \\ \text { das fronteiras do } \\ \text { volume de controle }\end{array}\right]+\left[\begin{array}{c}\text { Massa de } O D \text { consumida } \\ \text { ou produzida por } \\ \text { processos bioquímicos } \\ \text { no interior do } \\ \text { volume de controle }\end{array}\right]$

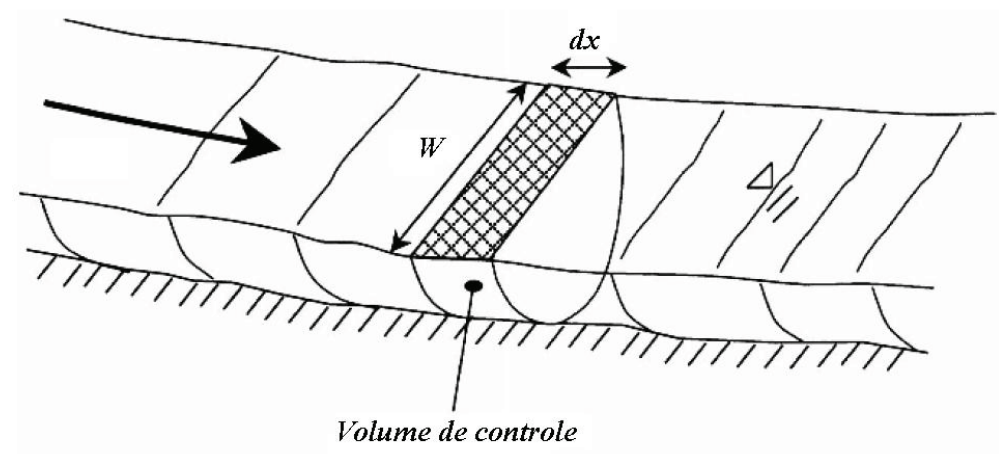

Figura 2.1: Volume de controle utilizado para o balanço de massa de oxigênio dissolvido.

A massa no interior do volume de controle é o produto entre a concentração média de $O D$ dentro do volume de controle, representado pela letra $\bar{C}$, pelo volume $V$, assim, 
a variação de $O D$, primeiro termo da equação 2.2 , é matematicamente representada por

$$
\frac{\partial(V \bar{C})}{\partial t}
$$

em que $\bar{C}$ é a concentração média de $O D$ e $V$ é o volume do volume de controle.

A transferência de massa de $O D$ através das fronteiras ocorrem por advecção e dispersão (nas faces direita e esquerda do volume de controle) e por difusão molecular na interface ar/água. Considerando o problema como unidimensional, a dispersão é utilizada ao invés da difusão e o principal interesse está na concentração média. Assim, os termos do transporte advectivo e dispersivo no lado esquerdo do volume de controle são matematicamente expressos pela seguinte equação

$$
\left(U \bar{C}-E_{L} \frac{\partial \bar{C}}{\partial x}\right) A
$$

em que $U$ é a velocidade média na seção transversal $=\mathrm{Q} / \mathrm{A}, Q$ é a vazão e $A$ é a área de seção transversal esquerda do volume de controle, $E_{L}$ é o coeficiente de dispersão longitudinal, o qual pode ser escrito em função da direção $x$ e, possivelmente, do tempo t. Os termos advectivos e dispersivos para quantificar o transporte de massa no lado direito do volume de controle são escritos utilizando uma expansão da série de Taylor, despresando os termos de ordem superior,

$$
\left[\left(U \bar{C}+\frac{\partial(U \bar{C})}{\partial x} d x\right)-E_{L} \frac{\partial \bar{C}}{\partial x}-\frac{\partial}{\partial x}\left(E_{L} \frac{\partial \bar{C}}{\partial x}\right) d x\right]\left(A+\frac{\partial A}{\partial x} d x\right)
$$

A principal forma de transferência de $O D$, através das fronteiras do volume de controle, não se dá nem por dispersão, nem por advecção através dos lados direito e esquerdo, e sim pela transferência devido à reaeração superficial que ocorre na parte superior do volume de controle. Seja $J$ o fluxo (transferência de massa por unidade de área) de $O D$ da atmosfera para o interior do volume de controle. Assim a variação de massa de $O D$ relativa a reaeração é dada pela multiplicação do fluxo $J$ pela área da superfície $W d x$, ou seja: 


$$
J W d x
$$

O último termo da equação 2.2 será simbolizado por $R^{\prime}$, e quantifica a massa que é gerada ou consumida por processos químicos ou biológicos no interior do volume de controle por unidade de tempo.

Utilizando o termo $R^{\prime}$ e as equações de 2.3 a 2.6, o balanço de $O D$ no interior do volume de controle, notando que 2.4 é adicionada enquanto que 2.5 é subtraída, é escrito da seguinte forma:

$$
\begin{aligned}
\frac{\partial(V \bar{C})}{\partial t} & =A d x\left[-\frac{\partial(U \bar{C})}{\partial x}+\frac{\partial}{\partial x}\left(E_{L} \frac{\partial \bar{C}}{\partial x}\right)\right] \\
& +\frac{\partial A}{\partial x} d x^{2}\left[-\frac{\partial(U \bar{C})}{\partial x}+\frac{\partial}{\partial x}\left(E_{L} \frac{\partial \bar{C}}{\partial x}\right)\right]+J W d x+R^{\prime}
\end{aligned}
$$

Os termos não lineares da equação 2.7 podem ser desprezados, pois $d x$ é muito pequeno. O termo $V=A d x$ é constante, assim pode-se multiplicar os dois lados da equação por $1 / V$.

Seja $M=J W d x / V(=J W / H$, em que $H$ é a profundidade média $)$ taxa de variação de massa por unidade de volume por unidade de tempo devido a reaeração, e $R=R^{\prime} / V$ a taxa de produção ou decaimento de massa por unidade de volume e tempo. Fazendo estas substituições na equação 2.7 e rearranjando os termos, temos que a variação da concentração de $O D$ no volume de controle é, matematicamente, representada pela equação 2.8 .

$$
\frac{\partial \bar{C}}{\partial t}+U \frac{\partial \bar{C}}{\partial x}=\frac{\partial}{\partial x}\left(E_{L} \frac{\partial \bar{c}}{\partial x}\right)+R+M
$$

\subsection{Coeficiente de Reaeração Superficial}

Na modelagem do $O D$ para águas superficiais, o principal fator a ser determinado é a taxa de reaeração superficial, ou seja, a taxa pela qual o oxigênio é transportado através 
da interface ar-água, desde que a atmosfera seja a principal fonte de oxigênio. Esse processo físico ocorre quando há um desequilíbrio entre a concentração de saturação de $O D$ (para uma dada condição de temperatura, pressão e salinidade) e a concentração do oxigênio na água.

A seção anterior, seção 2.1, tratou da modelagem matemática para a quantificação da concentração de $O D$ em um dado volume de controle, equação 2.8. A seguir, trataremos da quantificação do fluxo de massa de $O D$ oriundo da atmosfera, o termo $M$ da equação 2.8 .

Segundo a primeira Lei de Fick, a massa da substância que passa através de uma sessão pela unidade de tempo é proporcional ao gradiente de concentração na mesma direção. Esta lei descreve o fluxo de um soluto em condições de equilíbrio, como mostra a equação para fluxo unidimensional (direção $z$ ):

$$
J=\frac{d m}{d t}=-D_{m} A \frac{d C}{d z}
$$

em que $m$ é a massa da substância dissolvida, $t$ é o tempo, $C$ a concentração da substância dissolvida, $D_{m}$ é o coeficiente de difusão molecular da substância dissolvida, $A$ é a área através da qual a substância passa, e $z$ é a distância na direção perpendicular à superfície, o sinal negativo indica que o transporte ocorre da região de maior concentração para a de menor concentração.

Considerando que o fluxo de massa de oxigênio através da interface ar-água é proporcional ao déficit de $O D$ na água, o qual é definido como a diferença entre a concentração de saturação ${ }^{1}$ de $O D$ e a concentração atual do gás no volume líquido, temos

$$
J=\frac{d m}{d t}=K_{L}\left(C_{s}-C\right)
$$

em que $J$ é o fluxo de massa de oxigênio, $C$ é a concentração de $O D, C_{S}$ é a concentração de saturação do $O D$, e $K_{L}$ é coeficiente global de transferência de massa de oxigênio.

\footnotetext{
${ }^{1} \mathrm{~A}$ concentração de saturação é definida em termos da temperatura, pressão e salinidade e será discutida na seção 2.4
} 
A massa $m$ do soluto que está se dissolvendo é dada pela multiplicação do volume $V$ pela concentração $C$, em que $V$ é constante; assim, a equação 2.9 pode ser reescrita de forma a obter:

$$
\frac{d C}{d t}=D \frac{A}{V} \frac{d C}{d z}
$$

A equação 2.11 foi descrita para uma substância qualquer; comparando-a com a equação 2.10, obtida para o volume de controle considerado na seção 2.1, com profundidade média $H$ e sob a hipótese de mistura completa, ou seja, em qualquer ponto do volume considerado, a concentração de $O D$ é a mesma, obtêm-se a seguinte equação para a taxa de variação de massa do $O D$ devido ao fluxo de $O D$ da atmosfera para o volume líquido

$$
\frac{d C}{d t}=\frac{J A}{V}=K_{L} \frac{A}{V}\left(C_{s}-C\right)=\frac{K_{L}}{H}\left(C_{s}-C\right)
$$

A área $A$ da superfície em que ocorre o fluxo de oxigênio para o volume líquido é de difícil obtenção, consequentemente $H$ também o é, o termo $K_{L} \frac{A}{V}$, ou $\frac{K_{L}}{H}$, da equação 2.12 é escrito em termos de um coeficiente global de reaeração, ou simplesmente, coeficiente de reaeração superficial, $K_{2}$, com dimensão $\left[T^{-1}\right]$.

$$
K_{2}=K_{L} \frac{A}{V}=\frac{K_{L}}{H}
$$

Assim, o modelo clássico utilizado nos estudos sobre a reaeração superficial é dado pela equação 2.14

$$
\frac{d C}{d t}=K_{2}\left(C_{s}-C\right)
$$

em que $d C / d t$ é a variação temporal da concentração de $O D$ no volume de água em estudo, $C$ é a concentração de $O D$ no volume, $C_{s}$ é a concentração de saturação de $O D$ para as condições experimentais e $K_{2}$ é o coeficiente de reaeração superficial. 


\subsection{Estimativa do coeficiente de reaeração superfi- cial}

Encontra-se na literatura um grande número de modelos para a estimativa de $K_{L}$ ou $K_{2}$; alguns são puramente empíricos (O'Connor e dobbins (1958); Churchill et al. (1962); Owens et al. (1964); Bennett e Rathbun (1972); etc.), outros conceituais ou semi-empíricos (Teoria dos Dois Filmes; Teorias da Penetração, de Higbie, e da Renovação Superficial, de Dankwerts; Teorias da Penetração do Filme, de Dobbins e de Torr e Marchello; etc.). Esse grande número demonstra que ainda não há um completo entendimento do mecanismo de absorção do oxigênio presente na atmosfera pela água.

Bennett e Rathbun (1972) afirmam que os modelos conceituais são, de fato, equações que interpretam a interação entre as condições físicas que governam a transferência de massa em uma interface gás-líquido. Para Schulz (1989), diferentes caminhos são seguidos para essa interpretação, tendo sido desenvolvidos trabalhos que consideram "estruturas superficiais", trabalhos que admitem certas "condições de escoamento" junto à superfície, trabalhos que consideram o movimento das moléculas de oxigênio na fase gasosa e trabalhos que apresentam várias destas facetas concomitantemente.

A medição do coeficiente de reaeração exige um esforço considerável, tanto no campo quanto e em laboratório. Em muitos casos, o tempo necessário e os recursos técnicos e financeiros podem não estar disponíveis. Assim, os coeficientes de reaeração são muitas vezes previstos a partir de características do canal e do escoamento.

Os modelos semi-empíricos resultam da combinação de modelos conceituais com análises de regressão-correlação de dados experimentais, enquanto que os modelos empíricos resultam unicamente da análise de regressão, pelo método dos mínimos quadrados, de variáveis consideradas pertinentes pelo investigador, ou que são resultantes da análise dimensional de parâmetros hidráulicos e propriedades do gás e líquido Bennett e Rathbun (1972). 
Na sessão 2.3.2, a tabela 2.1 traz algumas equações propostas para estimar $K_{2}$ a partir das características do escoamento. Em McCutcheon (1989), há uma relação de 34 diferentes fórmulas para predição de $K_{2}$. Em geral, estas equações baseiam-se na premissa de que $K_{2}$ é proporcional à velocidade, ao gradiente de energia, à difusividade molecular, etc., e inversamente proporcional à profundidade do canal, à gravidade, etc.. Porém, esses tipos de modelo são de uso restrito, e só podem ser aplicados para escoamentos com as mesmas características daquele em que os coeficientes foram estimados.

\subsubsection{Modelos Conceituais}

Neste trabalho são apresentadas quatro teorias que são frequentemente utilizadas para descrever o processo de transferência de gás em águas naturais:

1. Teoria dos Dois Filmes (Whitman, 1923; Lewis e Whitman, 1924);

2. Teoria da Penetração (Higbie, 1935);

3. Teoria da Renovação Superficial (Danckwerts, 1951, 1955), e

4. Teoria da Penetração do Filme (Dobbins, 1956).

A descrição de outros modelos conceituais (teoria cinética, teoria de penetração de filme, modelo de amortecimento de turbilhões, modelo dos grandes turbilhoes e modelo de difusão turbulenta) não apresentados neste estudo, podem ser encontradas em Bennett e Rathbun (1972), Schulz (1989, 1985), Barbosa (1997, 1989), Moog e Jirka (1999), Gualtieri e Gualtieri (2004); Gualtieri et al. (2002), Herlina (2005), entre outros..

\section{Modelo dos Dois Filmes}

Devido à simplicidade da forma e a facilidade de aplicação do moledo, a teoria dos dois filmes é uma das mais utilizadas para caracterizar a transferência gasosa na interface ar-água. Proposta por Lewis e Whitman (1924), esta teoria estabelece que a troca 
gasosa é controlada por dois filmes laminares: um do lado gasoso e outro no lado líquido. A figura 2.2 ilustra o modelo.

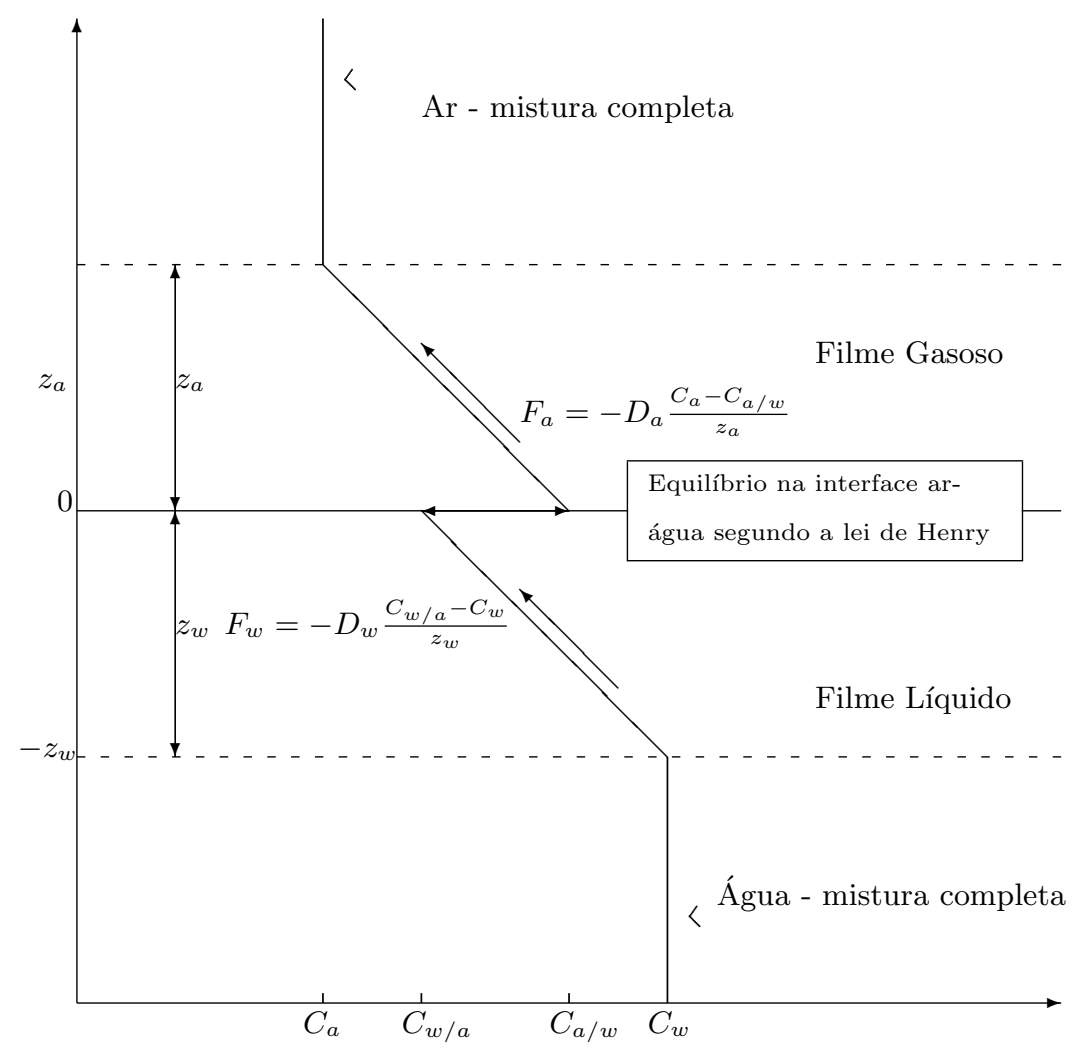

Figura 2.2: Ilustração da Teoria dois Filmes de Whitman.

A primeira lei de Fick estabelece que o gradiente de concentração, $d C / d z$, através de uma camada de espessura $z_{a}$, por exemplo, pode, eventualmente torna-se constante se as concentrações nas fronteiras das camadas $C_{a}$ ou $C_{a / w}$, são mantidas constantes por tempo suficiente para permitir que o perfil de concentração torne-se estável, e desde que não haja reações químicas no interior destas regiões. Como o gradiente é a diferença de concentração na camada dividida pela espessura da mesma, o fluxo molecular de ar, $F_{a}$, através desta, pode ser expresso pela equação 2.15 .

$$
F_{a}=-D_{a} \frac{d C}{d z} \approx-D_{a} \frac{C_{a}-C_{a / w}}{z_{a}}
$$

em que $D_{a}$ é o coeficiente de difusão molecular do oxigênio no ar, que varia com a temperatura do ar, $\left[L^{2} T^{-1}\right] ; C_{a}$ é a concentração de oxigênio na fronteira entre o ar e 
o filme gasoso, $\left[M L^{-3}\right] ; C_{a / w}$ é a concentração de oxigênio no ar que está na fronteira entre o filmes gasoso e líquido, $\left[M L^{-3}\right]$, e $z_{a}$ é a espessura do filme gasoso, $[L]$.

De forma análoga pode-se descrever o fluxo de oxigênio através do filme líquido, $F_{w}$.

$$
F_{w} \approx-D_{w} \frac{C_{w / a}-C_{w}}{z_{a}}
$$

Na equação 2.16 temos que $D_{w}$ é o coeficiente de difusão molecular o oxigênio na água (depende da temperatura da água), $\left[L^{2} T^{-1}\right] ; C_{w}$ é a concentração de oxigênio na água na fronteira entre a água e o filme líquido, $\left[M L^{-3}\right] ; C_{w / a}$ é a concentração de oxigênio na água que está na fronteira entre os filmes líquido e gasoso, $\left[M L^{-3}\right]$; $z_{w}$ é a espessura do filme líquido, $\left[L^{-1}\right]$.

Segundo Whitman (1923), a taxa global de transferência de oxigênio do ar para a água pode ser avaliada a partir da influência das resistências dos dois filmes. Sejam

$$
\begin{gathered}
K_{w}=\frac{D_{w}}{z_{w}} \\
K_{a}=\frac{D_{a}}{z_{a}}
\end{gathered}
$$

em que $K_{w}$ é a velocidade de transferência do oxigênio na água $\left[L T^{-1}\right]$ e $K_{a}$ é a velocidade de transferência no ar $\left[L R^{-1}\right]$. A velocidade de transferência é a medida do quão rápido a concentração do oxigênio na interface ar-água se aproxima do equilíbrio. Assim, as equações 2.15 e 2.16 podem ser escritas como:

$$
\begin{gathered}
F_{a}=-K_{a}\left(C_{a}-C_{a / w}\right) \\
F_{w}=-K_{w}\left(C_{w} / a-C_{w}\right)
\end{gathered}
$$


Quando esse processo de troca gasosa entre ar-água entra em regime permanente, o fluxo de oxigênio através de cada camada pode ser considerado o mesmo. Assim $F_{a}=F_{w}=F$, em que:

$$
F=-K_{a}\left(C_{a}-C_{a / w}\right)=-K_{w}\left(C_{w} / a-C_{w}\right)
$$

Supondo que a camada de moléculas de ar acima da interface está sempre em equilíbrio (filme gasoso) com a camada de moléculas de água (filme líquido) imediatamente abaixo, temos

$$
H=\frac{C_{a / w}}{C_{w / a}}
$$

em que $H$ é a constante da lei de Henry $\left.\left[\left(m o l L_{a}^{-3}\right) /\left(m o l L_{w}^{-3}\right)\right)\right]$. Esta constante é a proporção da concentração de oxigênio na fase gasosa para que a fase líquida esteja em

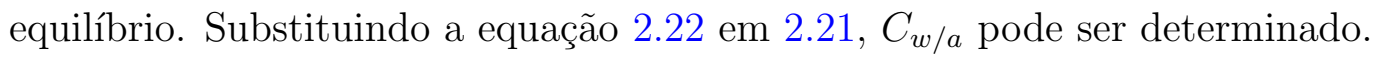

$$
\begin{gathered}
K_{w}\left(C_{w / a}-C_{w}\right)=\left(C_{a}-H C_{w / a}\right) \\
C_{w / a}=\frac{C_{a} C_{a}+K_{w} C_{w}}{K_{w}+H K_{a}}
\end{gathered}
$$

Substituindo 2.23 na equação 2.21, temos:

$$
\begin{gathered}
F=-K_{w}\left(\frac{K_{a} C_{a}+K_{w} C_{w}}{K_{w}+H K_{a}}-C_{w}\right) \\
F=-K_{w}\left(\frac{K_{a}}{C_{w}+K_{a} H} C_{a}+\frac{K_{w}-K_{w}-K_{a} H}{K_{w}+K_{a} H} C_{w}\right) \\
F=\frac{-K_{w} K_{a}}{K_{w}+K_{a} H} C_{a}+\frac{K_{w} K_{a} H}{K_{w}+K_{a} H} C_{w}
\end{gathered}
$$




$$
\begin{gathered}
F=\frac{K_{w} K_{a} H}{K_{w}+K_{a} H}\left(C_{w}-\frac{C_{a}}{H}\right) \\
F=\frac{1}{\frac{K_{w}+K_{a} H}{K_{w} K_{a} H}}\left(C_{w}-\frac{C_{a}}{H}\right) \\
F=\frac{1}{\frac{1}{K_{w}}+\frac{1}{K_{a} H}}\left(C_{w}-\frac{C_{a}}{H}\right)
\end{gathered}
$$

Se o fluxo $F$ for escrito em termos da velocidade global de transferência de massa de oxigênio, $K_{L}$ da equação 2.10 , a equação 2.24 pode ser reescrita como

$$
F=K_{L}\left(C_{w}-\frac{C_{a}}{H}\right)
$$

em que

$$
\frac{1}{K_{L}}=\frac{1}{K_{w}}+\frac{1}{K_{a} H}
$$

As velocidades de transferência podem ser expressas em termos de resistências, como $R=1 / K_{L}$. A equação 2.26 mostra que o coeficiente global de transferência gasosa, $K_{L}$, é a combinação das taxas de transferência no ar $\left(K_{a}\right)$ e na água $\left(K_{w}\right)$. Assim, a equação 2.26 torna-se:

$$
R=\frac{R_{a}}{H}+R_{w}
$$

A equação 2.27 é análoga à expressão apresentada por Whitman (1923), em que $R_{a}$ é a resistência no filme gasoso e $R_{w}$ no filme líquido.

Em síntese, a teoria dos dois filmes proposta por Whitman (1923), considera os filmes como duas resistências à difusão do gás no volume liquido, uma no filme líquido e outra no filme gasoso. Os filmes na interface ar-líquido são muito finos, e a quantidade do soluto neles, em qualquer instante, pode ser desconsiderada quando comparada com 
a quantidade que difunde através deles. Assim, quando o ar atmosférico é dissolvido em um volume de água não saturada de oxigênio, este gás, devido a sua baixa solubilidade na água, se difunde tão lentamente através do filme líquido que apenas uma pequena diferença de concentração pode ser observada no filme gasoso.

Do exposto anteriormente, o líquido na interface pode ser considerado saturado com o oxigênio dissolvido. Por fim, como a taxa de transferência de oxigênio através do filme gasoso é muito maior em relação ao filme líquido, pode-se considerar que o processo de reaeração é controlado apenas pelo filme líquido, assim,

$$
K_{L}=\frac{D_{w}}{z_{w}}
$$

A equação 2.28 sugere que o efeito da turbulência sobre o coeficiente de transferência, $K_{L}$, para o modelo dos dois filmes, é representado pela espessura do filme líquido, $z_{w}$.

Se não for verificada a hipótese de que as variações de concentração nos dois filmes são lentas o suficiente para que o regime permanente seja atingido, outro modelo será necessário para avaliar o fluxo de gás na interface ar-água.

\section{Teoria da Penetração}

Segundo Higbie (1935), a teoria dos dois filmes não pode ser aplicada em situações de alta dispersão turbulenta, pois o período de contato entre o líquido e o ar não seria suficiente para estabelecer o gradiente de concentração no filme líquido, por causa do fluxo turbulento. Com essa hipótese, Higbie (1935) propôs que o movimento turbulento traz constantemente, do interior do volume líquido para a superfície, massas de líquidos não saturadas de $O D$, ou seja, as moléculas de água são expostas ao ar por um determinado período e depois são substituídas por outras moléculas ainda não-saturadas. Assim, supondo que a transferência de gases através de líquidos com uma profundidade infinita obedece à Lei de Fick, o autor desenvolveu a teoria da penetração, que propõe que a taxa de transferência de massa $K_{L}$, equação 2.10 , é determinada por: 


$$
K_{L}=2 \sqrt{\frac{D_{w}}{\pi t_{e}}}
$$

em que $t_{e}$ é o tempo de exposição que os elementos superficiais atingem antes de serem substituídos por outros elementos. As idades dos elementos diferenciais do filme laminar superficial, podem ser estimadas de acordo com a função de distribuição $\phi(t)$, tal que:

$$
\phi(t)=\left\{\begin{array}{cl}
\frac{1}{t_{e}} & 0 \leq t \leq t_{e} \\
0 & t>t_{e}
\end{array}\right.
$$

Segundo Barbosa (1997), o mecanismo presente na teoria da penetração é capaz de descrever o fato de existir um aumento do coeficiente de transferência com a elevação do nível de turbulência, cujo reflexo então, se faz sentir na diminuição do tempo de exposição $t_{e}$ (equação 2.29). Contudo, o caráter aleatório da turbulência ainda opõemse à idéia da substituição de todos os elementos superficiais com a mesma idade limite.

\section{Teoria da Renovação Superficial}

Seguindo o raciocínio de Higbie, Danckwerts (1951) propôs um outro modelo para a determinação do $K_{2}$, a teoria da renovação superficial. Esta teoria é uma extensão do modelo da penetração, pois também considera que o oxigênio dissolvido não tem tempo suficiente para penetrar no filme líquido e estabelecer um perfil linear de concentração, condição característica de um regime permanente. Porém, esse modelo se opõe à hipótese de que há uma contínua substituição dos elementos superficiais por elementos da porção líquida inferior, a principal hipótese de Higbie (1935). Para Danckwerts (1951, 1955), devido à ação dos turbilhões que se estendem do leito até à superfície, o tempo de permanência dos elementos fluidos não é o mesmo para todos elementos, ou seja, os tempos de exposição são variados e qualquer elemento superficial teria, independente de sua idade, a mesma chance de ser substituído.

Danckwerts (1951), definiu como "taxa de renovação superficial", s, a taxa com a qual os elementos fluidos são levados do interior do volume líquido para a superfície, 
e admitiu que $s$ é distribuída aleatoriamente, e é constante durante o processo de reaeração. Essa taxa média de absorção por unidade de área de uma superfície turbulenta $(N)$ foi descrita pela expressão:

$$
N=\frac{\frac{d m}{d t}}{d A}=\sqrt{D_{w} s}\left(C_{s}-C_{0}\right)
$$

ou seja

$$
K_{L}=\sqrt{D_{w} s}
$$

em que $s$ é a taxa de renovação superficial do líquido $\left[T^{-1}\right] ; D_{w}$ o coeficiente de difusão molecular do oxigênio na água $\left[L^{2} T^{-1}\right] ; C_{0}$ é a concentração inicial de $O D$ no líquido $\left[M L^{-3}\right]$.

\section{Teoria da Penetração do Filme}

Dobbins (1956), combinou a teoria dos dois filmes, proposta por Lewis e Whitman (1924), com a teoria da renovação superficial de Danckwerts (1951, 1955), e elaborou o modelo da penetração do filme. A hipótese fundamental para este modelo é a de existir na superfície líquida um filme de pequena espessura, através do qual a transferência de oxigênio é controlada por difusão molecular. O oxigênio que incide sobre esse filme é continuamente transferido para o volume líquido de forma aleatória.

A difusão molecular que controla a transferência gasosa na camada laminar é descrita pela equação diferencial 2.33:

$$
\frac{d C}{d t}=D_{w} \frac{d^{2} C}{d z^{2}}
$$

Para solucionar a equação 2.33, Dobbins (1956) considerou, a partir da análise da equação 2.3, as seguintes condições iniciais e de contorno:

$$
\begin{array}{llll}
\text { para } t=0 \quad \text { e } & 0<z<z_{w}, & C=C_{0} \\
\text { para } t>0 \quad \text { e } z=0, & C=C_{s} \\
\text { para } t>0 \quad \text { e } z=z_{w}, & C=C_{0}
\end{array}
$$




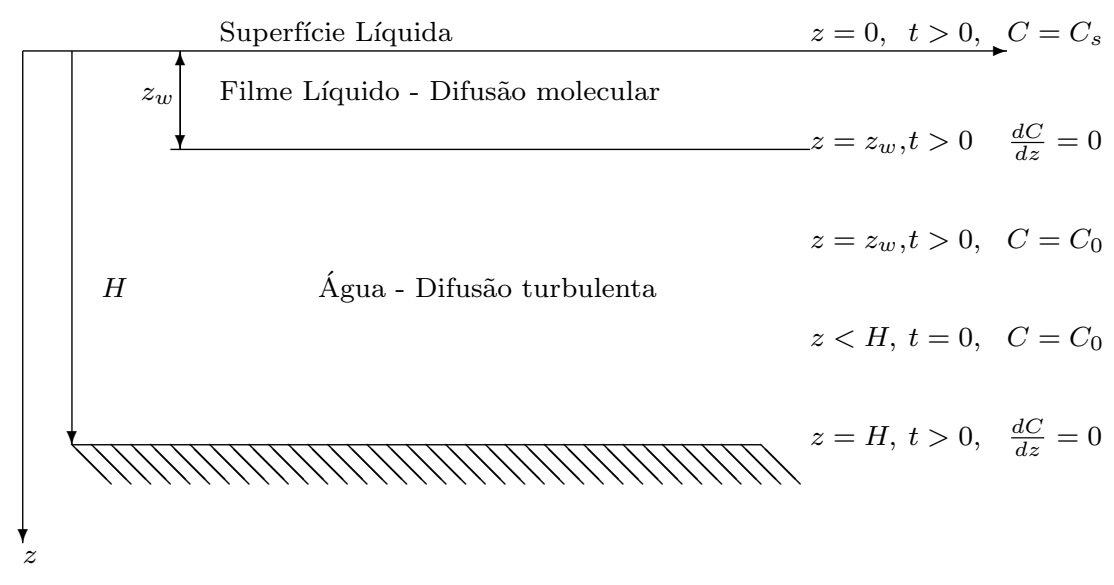

Figura 2.3: Modelo esquemático da teoria da renovação superfcial.

em que $z$ é a distância da superfície na direção perpendicular $[L] ; C_{0}$ e $C_{s}$ são, respectivamente, a concentração inicial e a concentração de saturação do $O D$ na água $\left[M L^{-3}\right]$; $z_{w}$ é a espessura do filme líquido $[L]$. A figura 2.3 ilustra tais condições.

Com essas condições de contorno, a integração da equação 2.33 resulta na seguinte equação para $K_{L}$ :

$$
K_{L}=\sqrt{D_{w} s} \cdot \operatorname{coth}\left(\sqrt{\frac{s z_{w}^{2}}{D_{w}}}\right)
$$

em que $D_{w}$ é o coeficiente de difusividade do $O D$ na água $\left[L^{2} T^{-1}\right] ; s$ a taxa de renovação do filme superficial $\left[T^{-1}\right]$.

Analisando a equação 2.34, quando a taxa de renovação do filme, s, se aproxima de zero, o valor de $K_{L}$ tende a $D_{w} / z_{w}$, o mesmo resultado obtido por Whitman (1923); Lewis e Whitman (1924) (equação 2.28). Entretanto, quando o valor de $s z_{w}^{2} / D_{w}$ é maior que $3, K_{L}$ é igual a $\sqrt{D_{w} s}$, o que confirma a teoria da renovação superficial, sugerida por Danckwerts na equação 2.32 .

Para a situação em que não exista um filme laminar, O'Connor e Dobbins (1958), propuseram outro modelo para a estimativa de $K_{L}$ (equação 2.35). Para tanto utilizamse das seguintes condições condições para solucionar a equação 2.33:

$$
\begin{array}{llll}
\text { para } t=0 \quad \text { e } & 0<z<H, & C=C \\
\text { para } t>0 & \text { e } \quad z=0, & C=C_{s} \\
\text { para } t>0 & \text { e } \quad z=H, & C=0
\end{array}
$$


Com essas condições, a integração da equação 2.33, resultou na expressão:

$$
K_{L}=\sqrt{D_{w} s} \cdot \tanh \left(\sqrt{\frac{s H^{2}}{D_{w}}}\right)
$$

Para esse modelo, assume-se que o corpo d'água permanece em repouso por um certo intervalo de tempo, durante o qual o oxigênio é absorvido por difusão molecular e, para uma frequência $s$, há, instantaneamente, a condição de mistura completa a partir da superfície livre até o fundo do corpo d'água. Esse modelo é de interesse apenas hipotético, pois em geral, espera-se que exista um filme na superfície líquida (Jensen, 1991).

Embora alguns parâmetros dos modelos conceituais tenham sido úteis na descrição do fenômeno da absorção ou dessorção gasosa, eles não foram clara ou diretamente relacionados às variáveis hidrodinâmicas mensuráveis dos sistemas. Desta forma, especificamente para a descrição da absorção do oxigênio pela água em agitação, tem sido difícil definir com confiança um modelo que possa prever, de maneira generalizada, a taxa de reoxigenação dos escoamentos naturais ou mesmo em laboratório (Barbosa, 1989).

\subsubsection{Modelos Empíricos e Semi-Empíricos}

Em cursos de águas naturais, sem as condições ideais possibilitadas em laboratórios, é impossível medir a espessura $z$ dos filmes ou o tempo de exposição $t_{e}$ ou $s$, o que torna a estimativa de $k_{L}$ ou $K_{2}$ uma questão de difícil solução. Estes valores dependem da difusividade do $O D$ e da espessura do filme.

A difusividade varia significativamente com a temperatura, como mostra a figura 2.8 da seção 2.5. Mudanças na velocidade do vento que incide sobre a superfície podem, também, afetar a velocidade de transferência (Boyd e Teichert-Coddington, 1992; O'Connor, 1983). À medida que a velocidade do vento aumenta, a turbulência causada por este na superfície também aumenta. Isso faz com que a espessura dos filmes decresçam, ocasionando o aumento da velocidade de transferência. Essa constatação 
é reportada em trabalhos que tratam tanto de experimentos realizados em laboratório (Penman, 1948; Liss, 1973) quanto em campo (Wanninkhof, 1992).

Para contornar a dificuldade que há em medir taxa de renovação superficial, $s$, em águas em movimento, O'Connor e Dobbins (1958), através de uma discussão sobre as características turbulentas do escoamento, expressaram $s$ em termos da relação entre a flutuação vertical da velocidade horizontal $(\bar{u})$ e do comprimento de mistura vertical $(\bar{l})$.

$$
s=\frac{\bar{u}}{\bar{l}}
$$

Para canais profundos, o comprimento de mistura pode, aproximadamente, ser representado como $10 \%$ da profundidade média do canal, $H$, enquanto que a flutuação da velocidade pode ser estimada como $10 \%$ da velocidade horizontal média do escoamento, $U$. (Chang, 1985). Assim, a taxa de renovação superficial pode ser simplificada para:

$$
s=\frac{\bar{u}}{\bar{l}}=\frac{0.1 U}{0.1 H}=\frac{U}{H}
$$

Substituindo a equação 2.37 na equação 2.32, tem-se:

$$
K_{L}=\sqrt{D_{m} \frac{U}{H}}
$$

ou

$$
K_{2}=\frac{D_{m}^{0,5} U^{0,5}}{H^{1,5}}
$$

Moog e Jirka (1998) propuseram duas equações empíricas baseadas na declividade do canal (ver tabela 2.1). No mesmo trabalho, os autores concluíram que a declividade é um componente essencial para a predição de $K_{2}$, quando da utilização de equações empíricas. O uso dessa variável é reafirmada por Jain e Jha (2005).

Em uma revisão da equação da reaeração proposta por Thackston e Krenkel (1969) (equação 7 da tabela 2.1), Thackston e Dawson (2001) propõem, com o objetivo de 
melhorar os resultados encontrados anteriormente, uma nova forma e valores para as constantes da equação 7 da tabela 2.1. Como conclusão, os autores sugeriram que a equação obtida por eles, equação 15 da tabela 2.1, não deve ser aplicada para os números de Froude muito elevados, onde a influência da turbulência prevalece.

A tabela 2.1 apresenta algumas equações utilizadas na estimativa do $K_{2}$.

Tabela 2.1: Modelos para predição do coeficiente de reaeração em rios

\begin{tabular}{|c|c|c|}
\hline \multicolumn{2}{|c|}{ Autor } & $\begin{array}{l}\text { Equação para } K_{2} \\
{\left[\text { dia }^{-1} \text { a } 20^{\circ} \mathrm{C}\right]}\end{array}$ \\
\hline (1) & O’Connor e Dobbins (1958) & $K_{2}=3,90 U^{0,5} H^{-1,5}$ \\
\hline$(2)$ & Churchill et al. (1962) & $K_{2}=5,010 U^{0,969} H^{-1,673}$ \\
\hline$(3)$ & Krenkel e Orlob (1962) & $K_{2}=173(S U)^{0,67} H^{-0,66}$ \\
\hline (4) & Owens et al. (1964) & $K_{2}=5,35 U^{0,67} H^{-1,85}$ \\
\hline$(5)$ & Langbein e Durum (1967) & $K_{2}=5,14 U H^{-1,33}$ \\
\hline (6) & Cadwallader e McDonnell (1969) & $K_{2}=186(S U)^{0,5} H^{-1}$ \\
\hline$(7)$ & Thackston e Krenkel (1969) & $K_{2}=24,9\left(1-F_{R}^{0,5}\right) U H^{-1}$ \\
\hline (8) & Parkhurst e Pomeroy (1972) & $K_{2}=23\left(1+0,17 F_{R}^{2}\right)(S U)^{0,375} H^{-1}$ \\
\hline (9) & Tsivoglou e Wallace (1972) & $K_{2}=31200 U$ para $Q<0,28 m^{3} s^{-1}$ \\
\hline (10) & & $K_{2}=15200 U$ para $Q>0,28 m^{3} s^{-1}$ \\
\hline (11) & Smoot (1988) & $K_{2}=543 S^{0,6236} U^{0,5325} H^{-0,7258}$ \\
\hline (12) & Moog e Jirka (1998) & $K_{2}=1740 U^{0,46} S^{0,79} H^{0,74}$ para $S>0,00$ \\
\hline (13) & & $K_{2}=5,59 S^{0,16} H^{0,73}$ para $S<0,00$ \\
\hline (14) & Jha et al. (2001) & $K_{2}=5,79 U^{0,5} H^{-0,25}$ \\
\hline$(15)$ & Thackston e Dawson (2001) & $K_{2}=0,000025\left(1+9 F_{r}^{0,25}\right)(9,81 S U)^{0,5} H^{-1}$ \\
\hline
\end{tabular}

Na tabela 2.1, temos que $U$ é a velocidade do escoamento $\left[m s^{1}\right], H$ é a profundidade $[m], S$ é a declividade do fundo do canal, $F_{r}$ é o número de Foude.

Na literatura mais recente sobre o problema, encontram-se trabalhos que utilizamse de redes neurais artificiais para predição do $K_{2}$, como é o exemplo dos autores Jain e Jha (2005) e de métodos estatísticos, como Jensen (1991). Tais trabalhos utilizam-se de dados experimentais coletados em campo ou laboratório, para calibração e validação de tais modelo. Porém, os dados utilizados para tanto são, na sua grande maioria, extraídos de trabalhos pulicados anteriormente, como por exemplo, os dados encontrados em Owens et al. (1964), O'Connor e Dobbins (1958), Churchill et al. (1962) e Tsivoglou e Wallace (1972). 


\subsection{Concentração de Saturação do Oxigênio}

A proporção de oxigênio no ar atmosférico é essencialmente constante, em torno de 20,95\% por volume (Hutchinson, 1957). O oxigênio é pouco solúvel na água, e sua solubilidade pode ser obtida pela Lei de Henry (Sawyer et al., 2003). Esta lei estabelece que a massa de qualquer gás que irá se dissolver em um dado volume de líquido, a uma temperatura constante, é diretamente proporcional a pressão que o gás exerce sobre o líquido, e pode ser representada pela seguinte equação:

$$
H_{e}=\frac{P_{g}}{C_{s}}
$$

em que $C_{s}$ é a concentração do gás dissolvido no líquido, em estado de equilíbrio, ou seja, a concentração de saturação do gás no volume líquido analisado; $P_{g}$ é a pressão parcial do gás sobre o líquido, e $H_{e}$ é a constante da Lei de Henry para o gás, relativo à temperatura em questão. Para o oxigênio dissolvido, a constante da Lei de Henry tem sido avaliada desde 1889 (McCutcheon, 1989). A constante da Lei de Henry é medida em unidade pressão por unidade de concentração. Para pressões inferiores a 1 atm, a constante é, praticamente, função somente da temperatura.

Valores tabelados para a concentração de saturação do oxigênio na água, podem ser encontrados nos Standard Methods, publicados pela APHA et al. (2005) e pela ASCE (2007), e em diversas outras publicações que tratam da determinação da concentração de saturação de $O D$ na água (Benson e Krause Jr, 1984; Weiss, 1970; Carpenter, 1966; Montgomery et al., 1964; Elmore e Hayes, 1960; Truesdale et al., 1955; Truesdale e Downing, 1954).

Embora os valores de saturação estejam disponíveis em tabelas (APHA et al., 2005; Lewis, 2006; ASCE, 2007), ou possam ser estimados através de equações, com precisão de $0,31 \%$, ainda encontra-se muita divergência dos valores de $C_{s}$ determinados por fórmulas e tabelas e os encontrados nos estudos sobre reaeração, como pode ser observado nas figuras 1.1 e 1.2 da introdução do presente trabalho e na figura 2.4 desta seção. 
Na maioria dos trabalhos consultados, os autores seguem a recomendação da ASCE (ASCE, 2007), que sugere que os três parâmetros da equação $2.41, C_{s}, C_{0}$ e $K_{2}$ sejam todos estimados em um único procedimento, o "NLLS - non-linear least square", ou seja, ajustas os parâmetros da equação 2.41 através de uma regressão não linear utilizandose do método dos mínimos quadrados para minimizar o erro entre a curva ajustada e os dados experimentais.

Por este método, os parâmetros $C_{s}, K_{2}$ e $C_{0}$ são obtidos através de um ajuste entre os valores experimentais, plotados em uma curva concentração versus tempo, com a equação 2.41. Neste ajuste, a melhor estimativa dos parâmetros é encontrada quando o valor que minimiza o erro residual, erro este obtido pela soma dos quadrados da diferença entre os valores estimados pela equação 2.41 e os dados obtidos experimentalmente, seja mínimo. Ou seja, quando a diferença entre a concentração de $O D$ medida experimentalmente em um dado tempo e o valor predito para o $O D$, pela equação 2.41, no mesmo tempo tende a zero. Segundo Stenstrom et al. (2006), esse é o método mais preciso para a estimativa da velocidade de reaeração superficial. Essa proposta é adotada até hoje e foi justificada como a melhor forma de estimação do coeficiente de reaeração, pela primeira vez, por Brown (1979) e Stenstrom et al. (1981).

Valores equivocados na estimativa de $C_{s}$, permitem a introdução de erros que podem influenciar o valor da taxa de transferência gasosa, $K_{L}$, de \pm 15 a $20 \%$ (Stenstrom et al., 2006), considerando as mesmas condiões de temperatura e pressão. Portanto, é de fundamental importância a correta estimativa deste parâmetro.

Retomando à equação 2.14 e integrando-a com a condição inicial $C(0)=C_{0}$, ou seja, a concentração no instante $t=0$ é $C_{0}$, temos:

$$
C(t)=C_{s}-\left(C_{s}-C_{0}\right) e^{-K_{2} t}
$$

em que $C$ é a concentração do gás dissolvido na água no instante de tempo $t, C_{s}$ é a concentração de equilíbrio do gás na água e $K_{2}$ é o coeficiente de reaeração. Para gases presentes na atmosfera, $C_{s}$ é também conhecida como concentração de saturação. 
Como pode ser verificado a partir de uma análise de sensibilidade dos parâmetros da equação 2.41, a determinação da concentração de $O D$ depende fortemente da concentração de saturação $C_{S}$, o que influencia diretamente na estimativa de $K_{2}$.

O método de estimação, citado anteriormente e que será utilizado neste trabalho, foi utilizado nas estimativas dos parâmetros da equação 2.41 para o exemplo experimental representado pela figura 2.4. Nesta figura tem-se os resultados de um experimento de reoxigenação realizado em um canal no Laboratório de Modelagem Física e Matemática de Processos Ambientais da Escola de Engenharia de São Carlos, Universidade de São Paulo. A linha contínua do gráfico representa o ajuste da curva representada pela equação 2.41 aos dados do experimento. Para o ajuste foi utilizado o método dos mínimos quadrados.

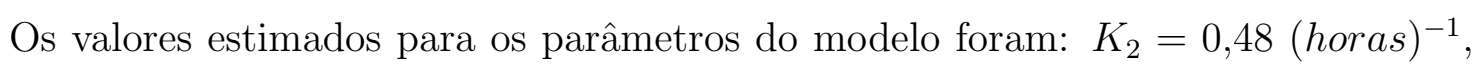
$C_{s e}=7,35 \mathrm{mg} / L$ e $C_{0}=3,15 \mathrm{mg} / L$. A linha tracejada representa o valor da concentração de saturação tabelada para as condições de temperatura, pressão e salinidade em que o experimento foi realizado, $C_{s}=8,38 \mathrm{mg} / \mathrm{L}$.

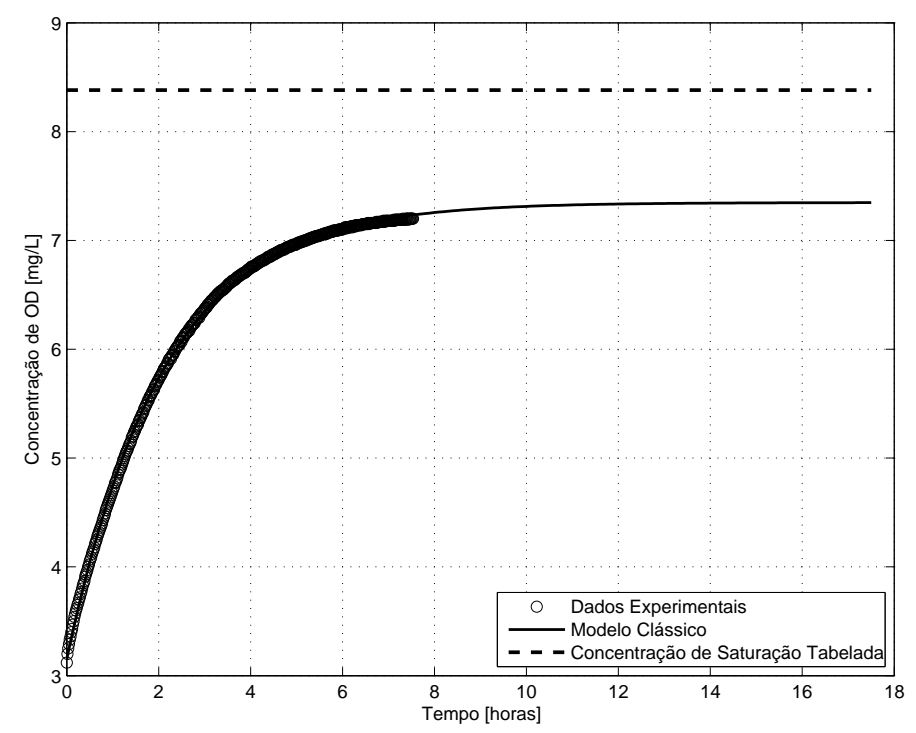

Figura 2.4: Curva de reoxigenação superficial obtida para o experimento aleatório 1

Como pode-se verificar na figura 2.4, o método conduz a um excelente ajuste entre os dados experimentais e o modelo clássico (equação 2.41). Porém, nesta mesma figura, e em outros exemplos já citados, verifica-se que os valores calculados experimentalmente 
para a concentração de saturação de $O D$, apresentam-se consideravelmente inferiores aos valores tabelados, considerados neste trabalho como o valor correto da concentração de saturação para as condições experimentais em análise. Esse tipo de erro é encontrado tanto nos estudos destinados à compreensão, quanto à quantificação de $K_{L}$.

Ao utilizar-se do mesmo modelo matemático, equação 2.41, os mesmos dados experimentais do exemplo anterior e o mesmo método de estimativa dos parâmetros, mas considerando o valor tabelado para a concentração de saturação, $C_{s}=8,38 \mathrm{mg} / \mathrm{L}$, tem-se, para o mesmo experimento representado pela figura 2.4, os seguintes valores: $K_{2}=0,24$ (horas $^{-1}$ e $C_{0}=3,70 \mathrm{mg} / \mathrm{L}$. A figura 2.5 ilustra o ajuste dos dados experimentais ao modelo representado pela equação 2.41 com os novos coeficientes calculados.

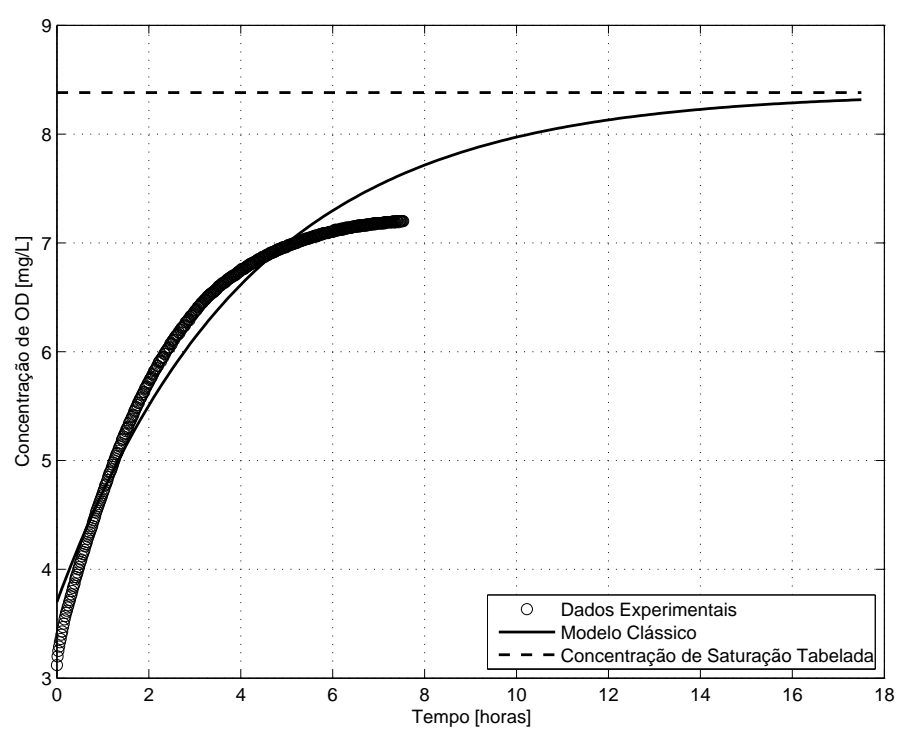

Figura 2.5: Curva de reoxigenação superficial obtida para o experimento aleatório 2

Qual dos dois ajustes, o representado pela figura 2.4 ou pela figura 2.5, melhor representa o fenômeno de reoxigenação superficial para os exemplos citados?

Em Gulliver e Halverson (1989), em estudos sobre transferência gasosa entre a superfície líquida e a atmosfera em canais abertos (Gulliver e Halverson, 1989, p.1782), apresenta como um dos resultados, figura 2.6, um outro exemplo de erro encontrado na estimativa de $C_{s}$. Neste resultado pode-se verificar, também, um valor de $C_{s}^{*}$ inferior ao valor tabelado 
Os valores estimados foram: $C_{s}^{*}=11,95 \mathrm{mg} / \mathrm{L} ; K_{2}=0,26 \mathrm{horas}^{-1}$ Se for utilizado o valor $C_{s}=12,62 \mathrm{mg} / L$ tem-se $K_{2}=0,23$.

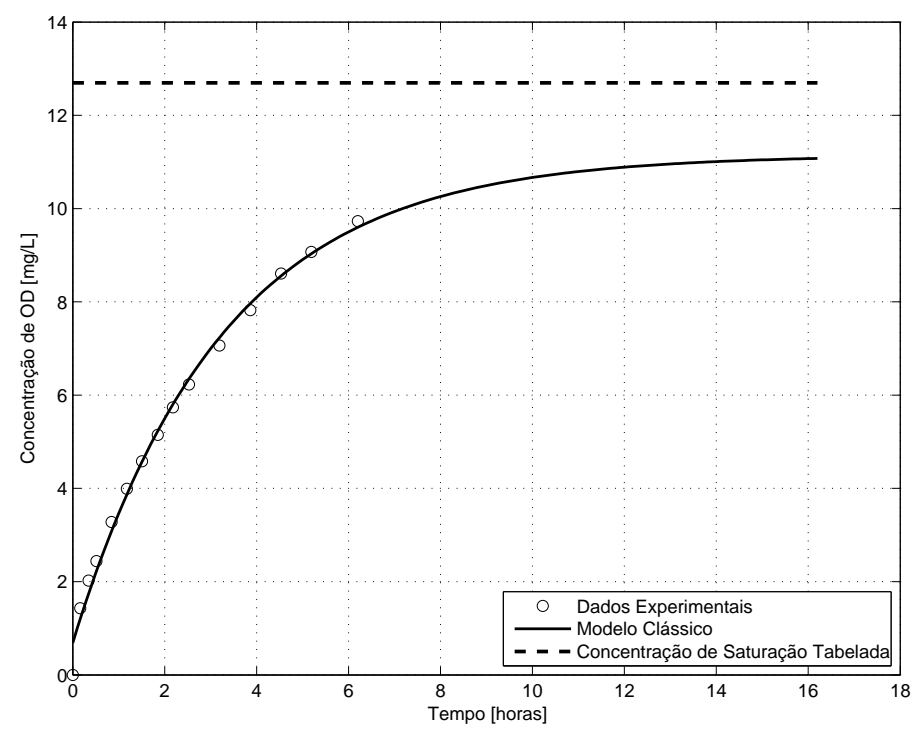

Figura 2.6: Curva de reoxigenação superficial apresentada por Gulliver e Halverson (1989).

Como citado anteriormente, o erro que tem sido relatado a respeito da concentração de saturação, não é, necessariamente, de responsabilidade do método matemático utilizado na determinação do coeficiente de reaeração superficial, e pode sim ser devido ao modelo utilizado (equação 2.14 ou 2.41), denominado neste trabalho como modelo clássico.

Estão disponíveis na literatura inúmeros estudos dedicados à determinação experimental de $C_{s}$ (APHA et al., 2005; ASCE, 2007; Benson e Krause Jr, 1984; Weiss, 1970; Carpenter, 1966; Montgomery et al., 1964; Elmore e Hayes, 1960; Truesdale et al., 1955; Truesdale e Downing, 1954). A tabela 2.2 apresenta os resultados de alguns estudos para a determinação de $C_{s}$ às temperaturas de $20^{\circ} \mathrm{C}$ e $30^{\circ} \mathrm{C}$, com pressão atmosférica de $760 \mathrm{mmHg}$ e salinidade zero.

A média e o desvio padrão foram calculados para essas medidas, e também reportados na tabela 2.2. Os valores relativos ao desvio padrão são de 0,01 e 0,02 para $20^{\circ}$ e $30^{\circ} \mathrm{C}$, respectivamente, o que garante que a concentração de saturação é uma propriedade física que pode ser determinada com precisão. 
Tabela 2.2: Valores encontrados na literatura para a concentração de saturação $C_{s}$

\begin{tabular}{lcc}
\hline \multicolumn{1}{c}{ Referência } & \multicolumn{2}{c}{$C_{s}[\mathrm{~mm} / \mathrm{L}]$} \\
& $20^{\circ} \mathrm{C}$ & $30^{\circ} \mathrm{C}$ \\
\hline Benson e Krause Jr (1984) & 9,09 & 7,56 \\
Carpenter (1966) & 9,07 & 7,54 \\
Green e Carritt (1967) & 9,10 & 7,53 \\
Montgomery et al. (1964) & 9,08 & 7,57 \\
Murray e Riley (1969) & 9,07 & 7,54 \\
Weiss (1970) & 9,07 & 7,53 \\
\hline Média & 9,08 & 7,55 \\
Desvio padrão & 0,01 & 0,02 \\
\hline
\end{tabular}

Benson e Krause Jr (1984) compararam os resultados obtidos experimentalmente para a concentração de saturação, de água destilada para temperaturas entre $0^{\circ}$ e $40^{\circ} \mathrm{C}$ e pressão atmosférica entre 0,5 e 1,1 atm, com os valores obtidos pela equação 2.42. A figura 2.7 ilustra, também, a comparação entre os valores determinados pela equação 2.42 com experimentais de outros autores. Benson e Krause Jr (1984) concluem ainda que os desvios encontrados não excedem a 0,7\%, para baixas temperaturas, e a $0,4 \%$ para temperaturas próximas a $40^{\circ} \mathrm{C}$.

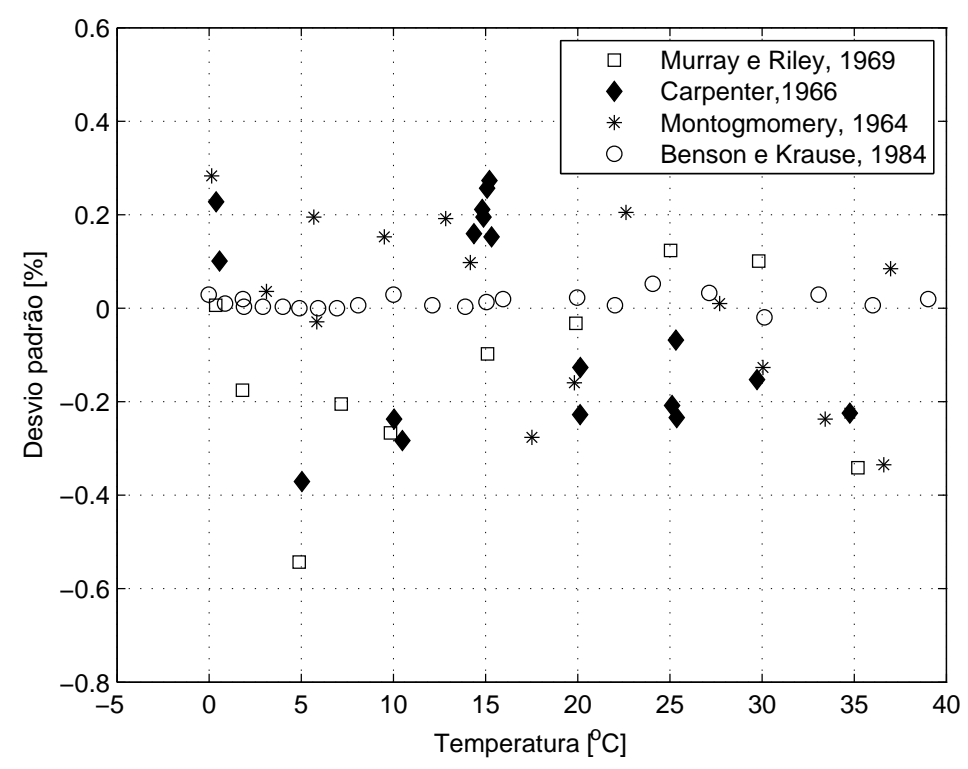

Figura 2.7: Desvio percentual entre os valores de $C_{s}$ calculados pela equação 2.42 e os obtidos experimentalmente por Benson e Krause Jr (1984); Montgomery et al. (1964); Murray e Riley (1969) e Carpenter (1966). 
A equação utilizada para a comparação citada anteriormente, e que será utilizada neste trabalho para a determinação da concentração de saturação, relaciona a temperatura e a clorinidade, é expressa por:

$$
\begin{aligned}
\ln \left(C_{s}\right)= & -139,34411+\frac{1,575701 \times 10^{5}}{T}-\frac{6,642308 \times 10^{7}}{T^{2}}+\frac{1,243800 \times 10^{1} 0}{T^{3}} \\
& -\frac{8,621949 \times 10^{11}}{T^{4}}-(C h l)\left(0,031929-\frac{19,428}{T}+\frac{3,8673 \times 10^{3}}{T^{2}}\right)
\end{aligned}
$$

em que $C_{s}$ é a concentração de saturação do oxigênio dissolvido calculada em $m g / L$ para $1 \mathrm{~atm}$; $T$ é a temperatura da água em Kelvin e $C h l$ é a clorinidade, em $p p m$. A equação 2.42 é válida para temperaturas entre $0^{\circ}$ e $40^{\circ} \mathrm{C}$ e clorinidade entre 0 e 28 ppm. Os coeficientes foram determinados por Benson e Krause Jr (1984).

Os efeitos da variação da pressão atmosférica devido às condições climáticas e elevação são corrigidos pela seguinte expressão

$$
C_{s}^{\prime}=C_{s} P\left[\frac{\left(1-P_{w v} / P\right)(1-X P}{\left(1-P_{w v}\right)(1-X)}\right]
$$

em que $C_{s}^{\prime}$ é a concentração de saturação à pressão não padronizada, $[\mathrm{mm} / \mathrm{L}] ; C_{s}$ é a concentração de saturação a $1 \mathrm{~atm}$ de pressão atmosférica (calculada pela equação 2.42,) $[\mathrm{mg} / L] ; P$ é a pressão atmosférica $[\mathrm{atm}] ; P_{w v}$ é a pressão parcial de vapor da água, $[\mathrm{atm}]$; e $X$ é o segundo coeficiente do virial do oxigênio. A pressão parcial de vapor de água pode ser determinada pela equação

$$
\ln \left(P_{w v}\right)=11,8571-\frac{3840,70}{T}-\frac{216961}{T^{2}}
$$

em que $T$ é a temperatura da água em Kelvin. E $X$ é dado por

$$
X=0,000975-1,426 \times 10^{-5} T+6,436 \times 10^{-8} T^{2}
$$

em que $T$ é a temperatura $\mathrm{em}^{\circ} \mathrm{C}$. 


\subsection{Efeito da temperatura sobre a transferência ga-} sosa

Segundo Barbosa (1989), a observação geral é que a temperatura afeta a velocidade das moléculas de oxigênio tanto na água, quanto no ar acima da superfície livre. Em conseqüência, uma elevação na temperatura deve corresponder um aumento da taxa de difusão molecular do soluto gasoso no filme líquido superficial. Esse aumento é justificado pelo fato de a difusividade molecular, e espessura do filme líquido, dependerem das propriedades físicas da água (viscosidade, massa específica e tensão superficial).

A primeira descrição sobre o efeito da temperatura do processo de transferência gasosa entre a atmosfera e a água pode ser encontrada nos estudos de Streeter (1926). Neste estudo Streeter usou um modelo exponencial, similar à equação de Van't HoffArrhenius que é utilizada para avaliar a dependência da temperatura tanto de reações químicas quanto biológicas (2.46). O fator para correção do efeito da temperatura sobre $K_{L}$ pode ser definido como:

$$
f_{c}=\frac{K_{L}(T)}{K_{L}\left(T_{R}\right)}
$$

em que $f_{c}$ é o fator de correção da temperatura; $K_{L}(T)$ é o valor de $K_{L}$ à temperatura $T\left[{ }^{\circ} C\right] ; K_{L}\left(T_{r}\right)$ é o valor de $K_{L}$ à temperatura de referência $T_{r}\left[{ }^{\circ} C\right]$, assim, o modelo de Streeter (1926) é definido pela equação:

$$
f_{c}=\theta^{T-T_{r}}
$$

em que $\theta$ é o coeficiente de temperatura.

Com base em dados obtidos em um canal artificial, Streeter et al. (1936) determinaram que $\theta=1,047$. Segundo Jensen (1991), outros pesquisadores tem reportado que $\theta$ pode variar entre 1,008 e 1,047. Porém, o valor mais frequente, e também recomendado 
por agências de pesquisa ${ }^{2}$ como a APHA, AWA, WPCF e ASCE, é $\theta=1,0241$, valor este determinado experimentalmente por Elmore e West (1961).

A temperatura tomada como referência para apresentação de $K_{2}$ ou $K_{L}$, é frequentemente $T_{r}=20{ }^{\circ} \mathrm{C}$, assim, combinando as equações 2.46 e 2.47 temos:

$$
K_{2}(T)=K_{2}(20) \theta^{T-20}
$$

ou

$$
K_{2}(T)=K_{2}(20) 1,0241^{T-20}
$$

em que $K_{2}(20)$ é o coeficiente de reaeração à temperatura $T=20{ }^{\circ} C$.

Ao analisar a equação 2.48, fica claro que esta é aplicável aos modelos empíricos e semi-empíricos apresentados na seção 2.3.2. Mas para o caso dos modelos conceituais, como por exemplo os representados pelas equações 2.34 e 2.35 (Dobbins, 1956; O’Connor e Dobbins, 1958), não há um consenso na literatura.

Possivelmente, o motivo para essa falta de consenso na aplicabilidade da equação 2.48 para os modelos conceituais está na correção do valor da difusividade molecular do oxigênio na água (McCutcheon, 1989).

A figura 2.8 ilustra a variação do coeficiente de difusividade do oxigênio na água para diferentes temperaturas, em que os valores da difusividade do oxigênio $\left(D_{m}\right)$ foram obtidos a partir de quatro equações diferentes:

$$
D_{m}=\frac{0.714 * 10^{-7} T}{\mu}
$$

em que $T$ é a temperatura em $K$ e $\mu$ é a viscosidade da água à temperatura $T$. A equação 2.50 foi citada por Chang (1985).

$$
\begin{gathered}
D_{m}=\left(D_{m}\right)_{20}(1,031)^{(T-20)} \\
D_{m}=\left(D_{m}\right)_{20}(1,1)^{(T-20)}
\end{gathered}
$$

\footnotetext{
${ }^{2}$ APHA - American Public Health Association; AWWA - American Water Works Association; WPCF - Water Pollution Control Federation; ASCE - American Society of Civil Engineers.
} 
em que $\left(D_{m}\right)_{20}=2,037 \times 10^{-5} \mathrm{~cm}^{2} \mathrm{~s}^{-1}$ é a difusividade do oxigênio a $20^{0} \mathrm{C}$ e $T$ é a temperatura da água em graus Celsius. A equação 2.51 foi proposta por Rich (1973), o qual garante ser esta a mais aceita para estimativa do $D_{m}$. E a equação 2.52 foi sugerida por Velz (1984).

$$
D_{m}=\frac{\left(D_{m}\right)_{20} \mu_{20} T}{293 \mu_{T}}
$$

em que $\left(D_{m}\right)_{20}=2,13 \times 10^{-9} m^{2} s^{-1}$ é a difusividade do oxigênio a $20^{0} C, T$ é a temperatura da água em Kelvin e $\mu_{20}$ é a viscosidade dinâmica da água a $20^{0} C$ e $\mu_{T}$ é a viscosidade à temperatura $T$ em graus Celcius. A equação 2.53 foi proposta por Gulliver e Halverson (1989).

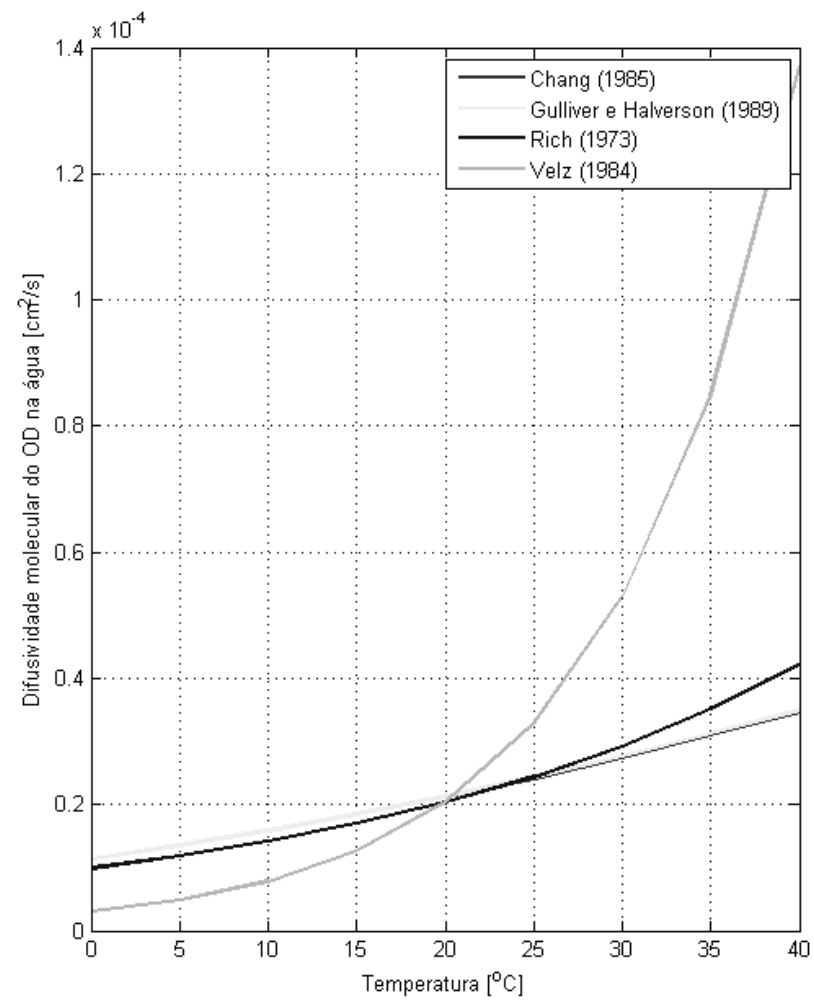

Figura 2.8: Variação do coeficiente de difusividade molecular $D_{m}$ em relação à variação da temperatura da água.

Como pode ser verificado na figura 2.8, as equações 2.53 e 2.50 produzem valores de $D_{M}$ praticamente iguais, e próximos aos valores determinados pela equação 2.51, 
enquanto que os valores estimados pela equação 2.52 são, exceto para valores iguais ou próximos da temperatura de $20^{\circ} \mathrm{C}$, muito diferentes das outras estimativas.

Embora o valor de $\theta=1,0241$ (equação 2.48), seja aceito pela maioria pesquisadores citados neste trabalho, não está clara a validade de $\theta$ ser uma constante. Considerando que o coeficiente de difusividade molecular varia em função da temperatura, não é coerente aceitar-se $\theta$ como uma constante para todas as condições dos escoamentos naturais, quando da utilização de modelos conceituais.

As figuras 2.9 e 2.10 retratam a variação do coeficiente de transferência global de $O D, K_{L}$, com a temperatura, para os modelos conceituais descritos, respectivamente, por Dobbins (1956) e O'Connor e Dobbins (1958) (equações 2.34 e 2.35). Os valores apresentados nestas figuras foram obtidos a partir de simulações que consideraram a variação da espessura do filme, em relação à temperatura, e diferentes taxas de renovação superficial, s. A variação do filme com a temperatura está na tabela 2.3, adaptada de Chang (1985).

Tabela 2.3: Variação da espessura do filme líquido em relação à temperatura da água.

\begin{tabular}{cc}
\hline $\begin{array}{c}\text { Temperatura } \\
{\left[{ }^{\circ} \mathrm{C}\right]}\end{array}$ & $\begin{array}{c}\text { Espessura do filme } \\
{\left[10^{-3} \mathrm{~cm}\right]}\end{array}$ \\
\hline 5 & 0,0312 \\
10 & 0,027715 \\
15 & 0,023735 \\
20 & 0,020565 \\
25 & 0,018133 \\
30 & 0,015921 \\
35 & 0,013931 \\
40 & 0,01231 \\
45 & 0,011057 \\
\hline
\end{tabular}

Pesquisas realizadas na Escola de Engenharia de São Carlos (EESC) da Universidade de São Paulo (USP) têm oferecido importantes contribuições a questão da reaeração superficial questão, principalmente em relação à modelagem matemática do processo (Silveira, 2004; Maia, 2003; Széliga, 2003; Costa, 1999; Barbosa, 1997; Mello, 1996; Oliveira, 1996; Rodrigues, 1996; Carreira, 1995; Carvalho, 1995; Giorgetti et al., 1995; Costa, 1992; Barbosa, 1989; Schulz, 1989; Roma, 1988; Schulz, 1985). 
2.5. Efeito da temperatura sobre a transferência gasosa

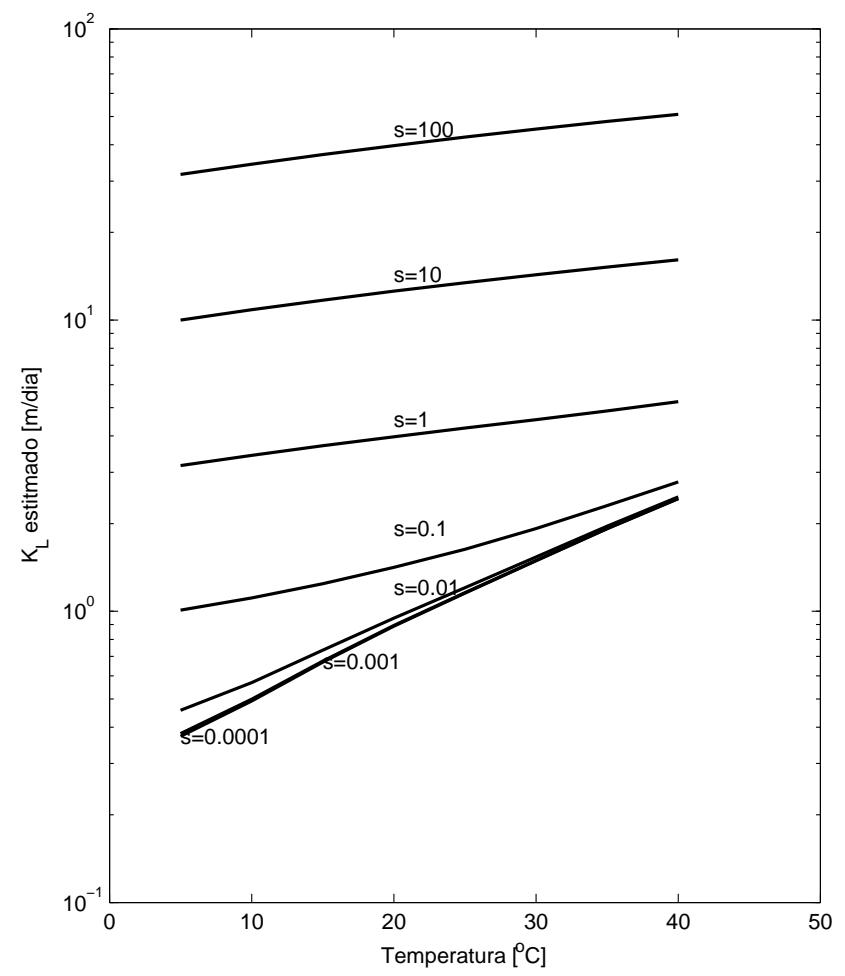

Figura 2.9: Variação do coeficiente $K_{L}$ com relação á variação da temperatura - equação 2.34

Os autores citados anteriormente, se dedicaram ao desenvolvimento de modelos matemáticos e de metodologias alternativas, simplificadas e confiáveis para a previsão dos parâmetros envolvidos na reoxigenação da água.

Giorgetti et al. (1995)inseriu um termo de ordem zero na equação diferencial 2.14 para representar a utilização do $O D$ por microorganismos, obtendo a mesma equação 2.57 , cuja solução, dada a condição inicial $C(0)=C_{0}$, é

$$
\frac{d C}{d t}=K_{2}\left(C_{s}-C\right)+K_{3}^{\prime} C_{s}
$$

A solução da equação 2.54, dada a condição inicial $C(0)=C_{0}$, é:

$$
C(t)=\frac{D_{2}-K_{3}^{\prime}}{K_{2}} C_{s}\left(C_{0}-\frac{D_{2}-K_{3}^{\prime}}{K_{2}} C_{s}\right) e^{-K_{2} t}
$$

em que $K_{2}$ é o coeficiente de reaeração superficial; $C_{s}$ é a concentração de saturação tabelada para as condições de pressão, salinidade e temperatura da água; $C_{0}$ é a concen- 


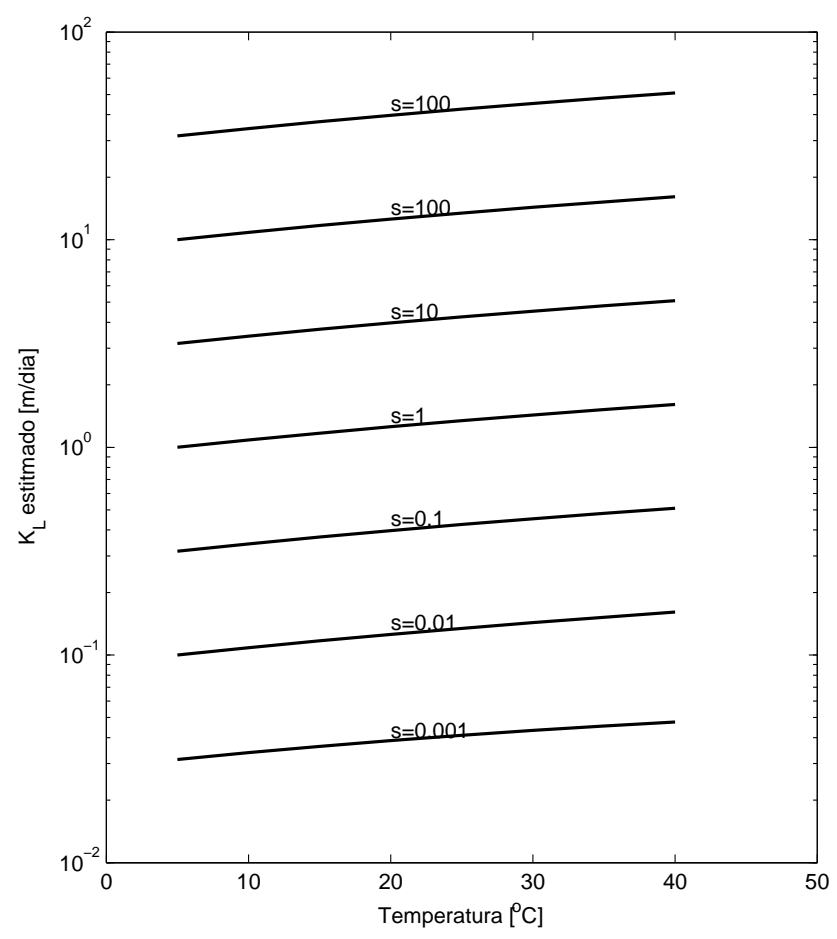

Figura 2.10: Variação do coeficiente $K_{L}$ com relação à variação da a temperatura equação 2.35

tração de $O D$ no instante $t=0 ; C(t)$ é a concentração de $O D$ no instante $t$ qualquer; e $K_{3}^{\prime}$ é um coeficiente de desoxigenação, com a mesma unidade de $K_{2}$, ou seja, o inverso do tempo.

Maia (2003), com base no trabalho de Giorgetti et al. (1995), inseriu artificialmente um consumo de oxigênio no processo de reoxigenação, produzindo valores da concentração de equilíbrio inferiores aos valores de $C_{s}$ fisicamente observáveis. Um borbulhamento sub-superficial de nitrogênio (stripping), com vazão controlada, foi utilizado como sumidouro de oxigênio. O modelo matemático utilizado contemplou a existência de um sumidouro de oxigênio, porém com descrição diferente a dada para a equação 2.55 .

\subsection{Proposição do Novo Modelo}

Os erros encontrados quando da estimativa do coeficiente de reaeração, citados anteriormente, quando utilizado o modelo clássico da reaeração superficial, equação 2.14, já 
justificam a proposição de um novo modelo para a estimativa deste coeficiente, quando do estudo em laboratório.

$$
\frac{d C}{d t}=K_{2}\left(C_{s}-C\right)
$$

Dois outros exemplos de erros de modelagem matemática no estudo da reaeração superficial são encontrados em Howe (1977) e Chao et al. (1987b,a).

O primeiro erro é devido a uma interpretação equivocada dos dados, somada à falhas de procedimentos experimentais. Estas falhas levaram o autor (Howe, 1977) a propor uma nova forma para a correção do valor de $K_{2}$ em relação à temperatura.

Howe (1977) utilizou-se de poucos dados experimentais e de uma análise estatística não apropriada para estimação dos parâmetros do modelo clássico da reaeração superficial (equação 2.14).

Para estimativa dos parâmetros do modelo, Howe (1977) utilizou o método logarítmico, que segundo Stenstrom et al. (1981), não é o mais adequado para tanto. Assim, com base em apenas dois ensaios de reaeração, para temperaturas de 20,5 e $30{ }^{\circ} C$, cujas curvas, concentração versus tempo, consistiram de 5 e 4 pontos, respectivamente, Howe propôs que para baixas taxas de renovação superficial, o valor de $K_{2}$, contrariando os demais pesquisadores da área, decrescia com o aumento da temperatura. Os experimentos citados por Howe foram realizados em um tanque com volume de aproximadamente 4 mil litros de água, agitada por grades oscilantes.

A proposta de Howe (1977) para a correção de $K_{2}$ foi:

$$
K_{2}(T)=\frac{K_{2}(20)}{\theta^{(T-20)}}
$$

A equação 2.56 se difere da forma apresentada por Streeter (1926) e outros, e conduz à um decrescimento no valor de $K_{2}$ com o aumento da temperatura.

Nas discussões que seguiram ao trabalho de Howe (1977), Brown e Stenstrom (1980) e Rathbun (1981) contestaram os resultados, se apoiando em justificar a falta de uma quantidade maior de dados e as incertezas envolvidas nas estimativas e o método uti- 
lizado para a estimativa dos parâmetros. Porém não questionaram o modelo utilizado para tanto, o modelo clássico representado pela equação 2.14 .

O segundo exemplo de erro, encontrado em Chao et al. (1987b) e Chao et al. (1987a), levou os autores, na tentativa de comprovar a nova teoria proposta por Howe (1977), a uma equivocada interpretação do modelo proposto por O'Connor e Dobbins (1958).

O modelo proposto por O'Connor e Dobbins (1958), equação 2.35 da página 25, como já discutido, é uma situação hipotética, que considera a ausência de um filme controlando a transferência gasosa na interface ar-água, fato este observável nas condições de contorno que o autor utilizou para descrever o modelo.

$$
K_{L}=\sqrt{D_{w} s} \cdot \tanh \left(\sqrt{\frac{s H^{2}}{D_{w}}}\right)
$$

Na equação 2.35, no termo tanh está a profundidade $H$ da lâmina d'água do escoamento, porém Chao et al. (1987b) e Chao et al. (1987a) ignoram tal fato, e utilizam a espessura do filme. Os resultados obtidos a partir deste erro comprovariam os resultados, já contestados, de Howe (1977).

A figura da 2.10 (40) é uma simulação correta do modelo de O'Connor e Dobbins (1958); nesta simulação foi utilizada uma profundidade de 0,5 m, e pode-se observar que o valor de $K_{L}$ aumenta, mesmo para valores muito pequenos da taxa de renovação superficial, o que contraria os resultados de Howe (1977) e Chao et al. (1987b,a), porém são aceitos como verdadeiros pela maioria dos estudiosos da área.

A figura (figura 2.11) ilustra a situação proposta por Chao et al. (1987b,a). Nesta fica evidente o decréscimo de $K_{L}$ com o aumento da temperatura para baixos valores da taxa de renovação superficial $s$. Porém, foram utilizados a espessura do filme para a dada temperatura, que é consideravelmente inferior à profundidade da lâmina d'água de qualquer escoamento natural e/ou experimental.

A existência de sumidouros provenientes do aparato experimental não está prevista no modelo clássico usado para a determinação de $K_{2}$. Assim, a hipótese deste trabalho é que, a não consideração dessa possibilidade, pode ter levado os autores aqui citados, aos erros apresentados nas figuras 1.1, 1.2, 2.6 e 2.11. 


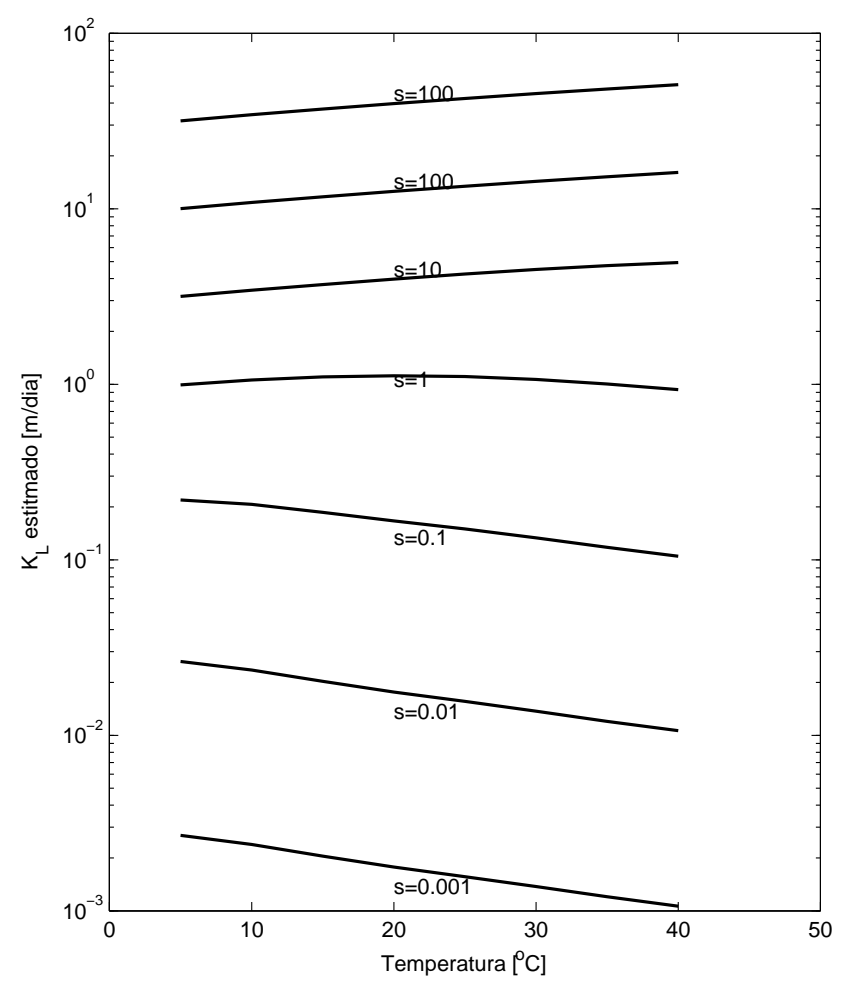

Figura 2.11: Variação do coeficiente $K_{L}$ em relação ao aumento da temperatura da água.

A partir da análise dos resultados obtidos experimentalmente no laboratório de Modelagem Física e Matemática de Processos Ambientais, da Escola de Engenharia de São Carlos da Universidade de São Paulo, pretende-se validar a hipótese aqui levantada, qual seja, a existência de sumidouros de $O D$ nos equipamentos utilizados para esse tipo de estudo. Para tanto, o capítulo 4 apresentará análises estatísticas comparando os resultados obtidos com o modelo clássico contra os obtidos pelo novo modelo que será apresentado no decorrer desta seção.

Em um sistema com agitação da água, composto por um agitador rotativo, pode haver a formação de vórtices nas bordas das pás do rotor, especialmente sob condições de altas velocidades de rotação e com certos tipos de rotores. Estes vórtices possuem zonas de baixa pressão no seu centro. Em canais com recirculação, essas zonas de baixa pressão podem ocorrer na linha de sucção da bomba.

Sabe-se que quando há zonas de baixa pressão em um fluido, parte dos gases dissolvidos pode migrar para a fase gasosa, ocorrendo a formação de microbolhas que 
se desprendem e são levadas de volta à atmosfera, constituindo-se, portanto, em sumidouro do oxigênio dissolvido. No caso dos experimentos realizados em canais, as microbolhas que sequestram o $O D$ são formadas na linha de sucção, e podem, devido às altas velocidade do escoamento, não permaneceram por tempo suficiente no escoamento para que o $O D$ seja reincorporado ao líquido na forma molecular.

Silveira (2004), no estudo sobre a relação entre a umidade relativa do ar e o coeficiente transferência gasosa, propôs como justificativa para a baixa estimativa dos valores calculados para $C_{s}^{*}$ para seus experimentos, a existência de um sumidouro de $O D$. Segundo o autor, o modelo utilizado para tanto, qual seja, o modelo clássico, aqui representado pela equação 2.14, não era capaz fornecer, com eficiência, o melhor ajuste dos dados experimentais ao fenômeno em estudo. Assim, o autor sugeriu a inserção de um novo parâmetro no modelo clássico, com a responsabilidade de representar o possível sumidouro.

O parâmetro inserido no modelo clássico é suposto ser proporcional à concentração de $O D$ do volume líquido em estudo, assim, a equação 2.14 torna-se:

$$
\frac{d C}{d t}=K_{2}\left(C_{s}-C\right)-K_{3}^{\prime} C
$$

A solução da equação 2.57, dada a condição inicial $C(0)=C_{0}$, é:

$$
C(t)=\frac{K_{2}}{K_{2}+K_{3}^{\prime}} C_{s}-\left(\frac{K_{2}}{K_{2}+K_{3}^{\prime}} C_{s}-C_{0}\right) e^{-\left(K_{2}+K_{3}^{\prime}\right) t}
$$

em que $K_{2}$ é o coeficiente de reaeração superficial; $C_{s}$ é a concentração de saturação tabelada para as condições de pressão, salinidade e temperatura da água; $C_{0}$ é a concentração de $O D$ no instante $t=0 ; C(t)$ é a concentração de $O D$ no instante $t$ qualquer; e $K_{3}^{\prime}$ é um coeficiente de desoxigenação, com a mesma unidade de $K_{2}$, ou seja, o inverso do tempo.

A equação 2.58 é idêntica a equação 2.41 quando $K_{3}^{\prime}$ se iguala a zero, assim o novo modelo pode ser utilizado, também, em situações em que seja comprovada a não existência de sumidouros. 


\section{Capítulo 3}

\section{Materiais e Métodos}

Para verificar e validar a hipótese desenvolvida nos capítulos anteriores, quanto à existência de sumidouros de $O D$ por causas não previstas e a inadequação do modelo matemático utilizado para tanto, foi construído um canal com recirculação da água. Neste canal foi executada uma série de ensaios para estudos da reoxigenação superficial, para diferentes características do escoamento na tubulação de sução do sistema de recirculação da água.

Os experimentos sobre reaeração aqui tratados foram realizados no Laboratório de Fenômenos de Transporte, no setor de Modelagem Física e Matemática de Processos Ambientais do Departamento de Hidráulica e Saneamento da Escola de Engenharia de São Carlos, Universidade de São Paulo.

Esse tipo de canal, artificial com recirculação, é frequentemente utilizado em estudos dessa natureza. O sistema de recirculação é utilizado para garantir a diferença de concentração de $O D$ entre um ponto de medida e outro. Sem a recirculação da água em estudo seria necessário um canal muito extenso, caso contrário o erro inerente do sensor de $O D$ poderia ser maior que a diferença de concentração obtida para pequenas extensões.

A seguir é apresentada a descrição dos equipamentos e suas funções na execução dos experimentos que constam neste trabalho.

- Canal com calha de 6 metros de comprimento; 
- Conjunto motor-bomba da marca Mark, modelo BSD-8, com potência de 5 hp;

- Registros tipo esfera para controle da vazão/pressão do escoamento nas tubulações de recalque e sucção;

- Medidor de vazão tipo orifício - instalado na tubulação de recalque;

- Inversor de frequência modelo Altivar 31, da marca Telemecanic 5,5kW/7,5HP, utilizado para controle da rotação do motor da bomba responsável pela recirculação da água no canal;

- Oxímetro da marca WTW, modelo OXI 197 com sonda da mesma marca modelo CellOx 325;

- Oxímetro da marca WTW, modelo Oxi 340i com sonda da mesma marca modelo CellOx 325;

- 2 medidores multi parâmetros da marca Hack, modelo HQ40D, com sonda de oxigênio dissolvido da mesma marca, modelo LDO101;

- Gás nitrogênio para desoxigenar a água utilizada nos experimentos;

- 3 trocadores de calor tipo ponta fria, fabricado sob encomenda, Terroni Equipamentos científico, com potência de 500W cada;

- Destilador de água; todos os ensaios foram realizados com água destilada;

- Tubulação de PVC branco de 3"; foi utilizado o mesmo diâmetro tanto para o recalque, quanto para a sucção da água recirculada no canal;

- Datalloger e transdutores de pressão - utilizados para verificação e registro da variação da pressão na tubulação de recirculação da água no canal.;

- Manômetros em U, com mercúrio como fluido manométrico. Os manômetros foram utilizados para a medição da pressão ao longo da tubulação e para calibração dos instrumentos eletrônicos medidores de pressão; 
- Determinação da concentração de $O D$ através do método de Winkler para calibração dos medidores de $O D$.

O canal projetado e construído para a pesquisa aqui relatada é composto por uma calha de 6 metros de comprimento; dois elementos de transição do escoamento, instalados nas duas extremidades da calha; uma base sustentada por duas colunas, apoiadas diretamente no piso; tubulação de recalque e de sucção; medidor de vazão, tipo orifício (instalado na tubulação de recalque) e um conjunto moto-bomba, responsável pela recirculação da água durante os experimentos.

O canal possui um projeto original. A principal diferença deste para os demais é que ele não possui reservatório para a água em circulação. Assim, a única fonte de oxigênio, à qual a água em estudo é submetida, está na superfície livre formada na calha no contato com a atmosfera. Os trechos da superfície livre formados nos elementos de transição do canal foram protegidos com isopor, recortado no formato do elemento, o que impede o contato da água com a atmosfera. Como o isopor flutua sobre esta superfície, considerou-se que o escoamento na calha não sofreu influência desse dispositivo. As figuras 3.1 e 3.2 ilustram o canal e seus componentes. 


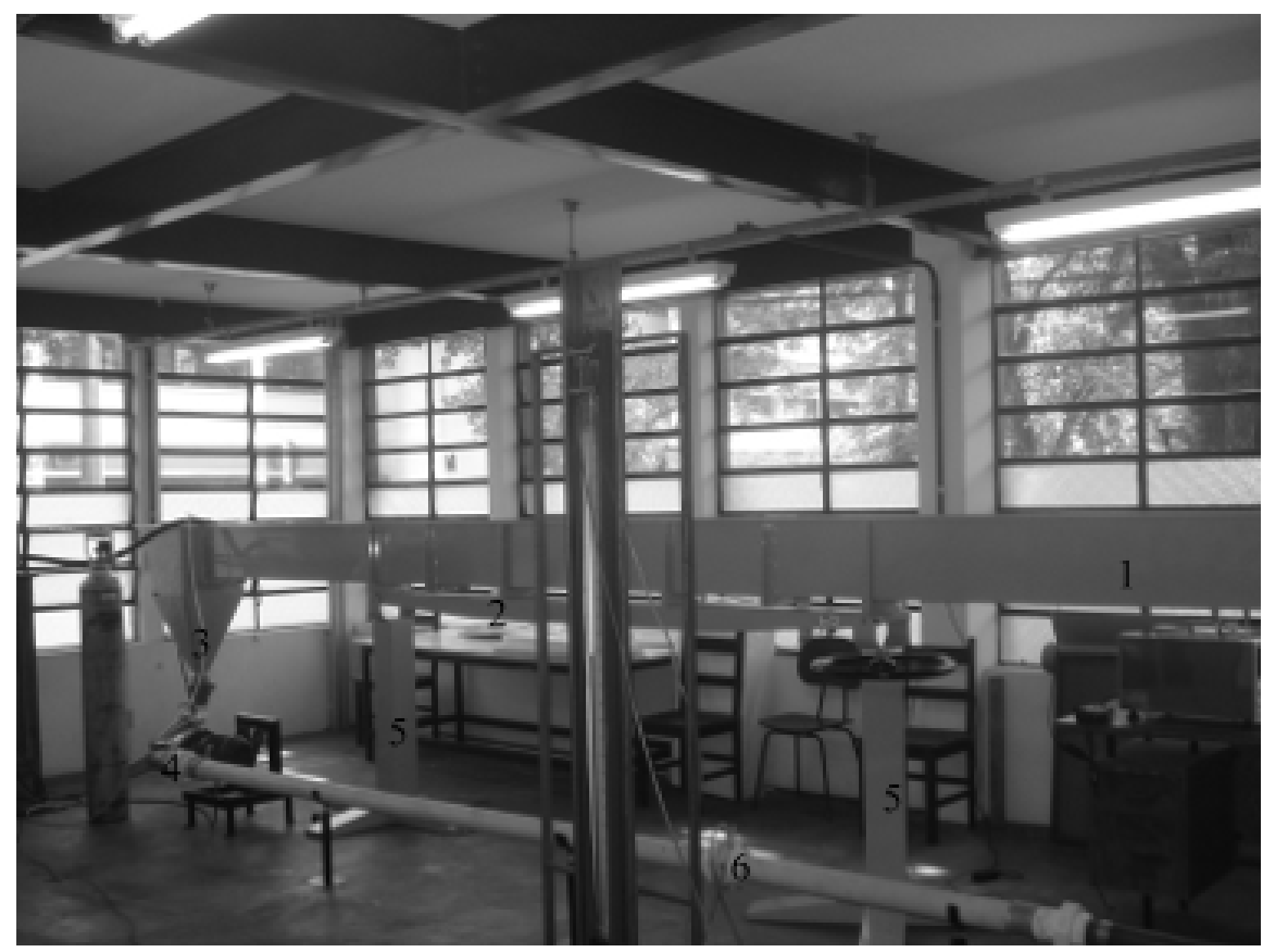

Figura 3.1: Vista do canal de jusante para montante do escoamento.

Na figura 3.1 temos que:

1 Calha

2 Base de sustentação da calha

3 Elemento de transição do escoamento

4 Bomba

5 Colunas de sustentação

6 Medidor de vazão tipo orifício 


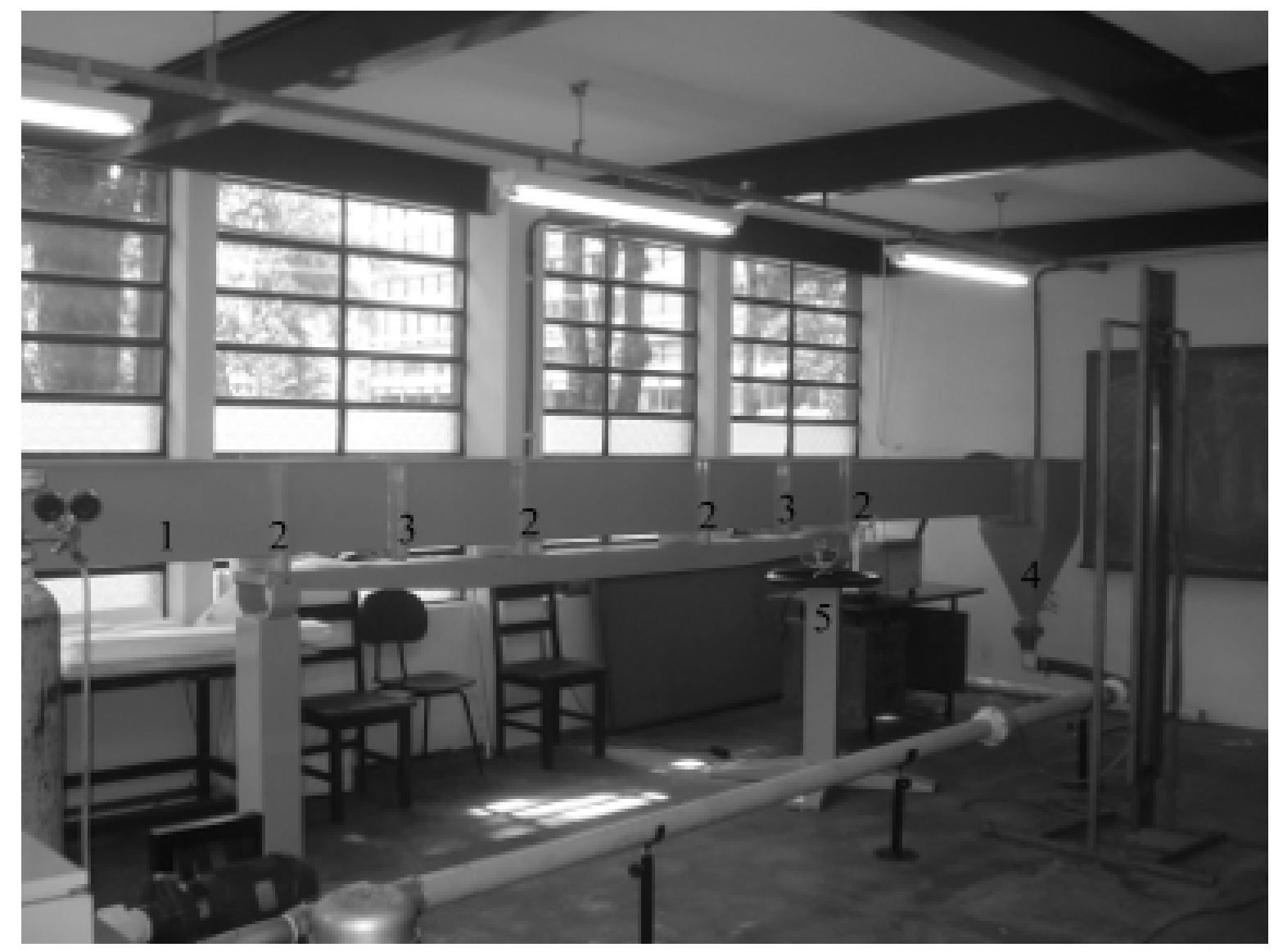

Figura 3.2: Vista do canal de montante para jusante do escoamento.

1 Calha

2 Suportes para fixação da calha junto à base

3 Conexão entre as partes da calha

4 Elemento de transição do escoamento

5 Volante para controlar a inclinação da calha 
A calha do canal, com $6 m$ de extensão, foi construída em três seções idênticas de $2 m$ de comprimento cada. O material utilizado foi chapa de aço com $2 \mathrm{~mm}$ de espessura, dobrada em "U", como ilustra a figura 3.3. Os encaixes entre as seções, e também entre a calha e os elementos de transição do escoamento, figura 3.4, são realizados com parafusos e vedação para as uniões. Para evitar corrosão, todos os componentes do canal receberam acabamento em pintura automotiva, que possibilitou também uma baixa rugosidade relativa.

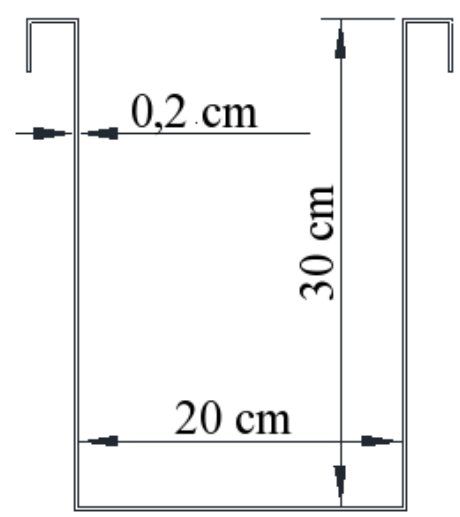

Figura 3.3: Perfil vertical da calha do canal.

A construção da calha em três partes foi idealizada para que possibilite, futuramente, a substituição da seção central, hoje confeccionada em ferro, por uma de acrílico ou vidro, e seja possível a observação da turbulência causada pelos diferentes revestimentos que o leito da calha pode receber.

Os elementos de transição, figuras 3.4 e 3.5, têm a função de estabilizar o escoamento na entrada e saída da calha. Foram confeccionados em fibra de vidro, e para tanto, foi necessária a construção de um modelo em madeira para moldar a fibra. A mesma pintura utilizada na calha foi aplicada nos elementos de transição.

Nas colunas que sustentam a base, na qual a calha está apoiada, foi instalado um mecanismo que possibilita obter diferentes inclinações da calha. A inclinação é variada através do ajuste de uma rosca infinita através do giro de um volante instalado na cabeceira do canal (figuras 3.6 e 3.7). 


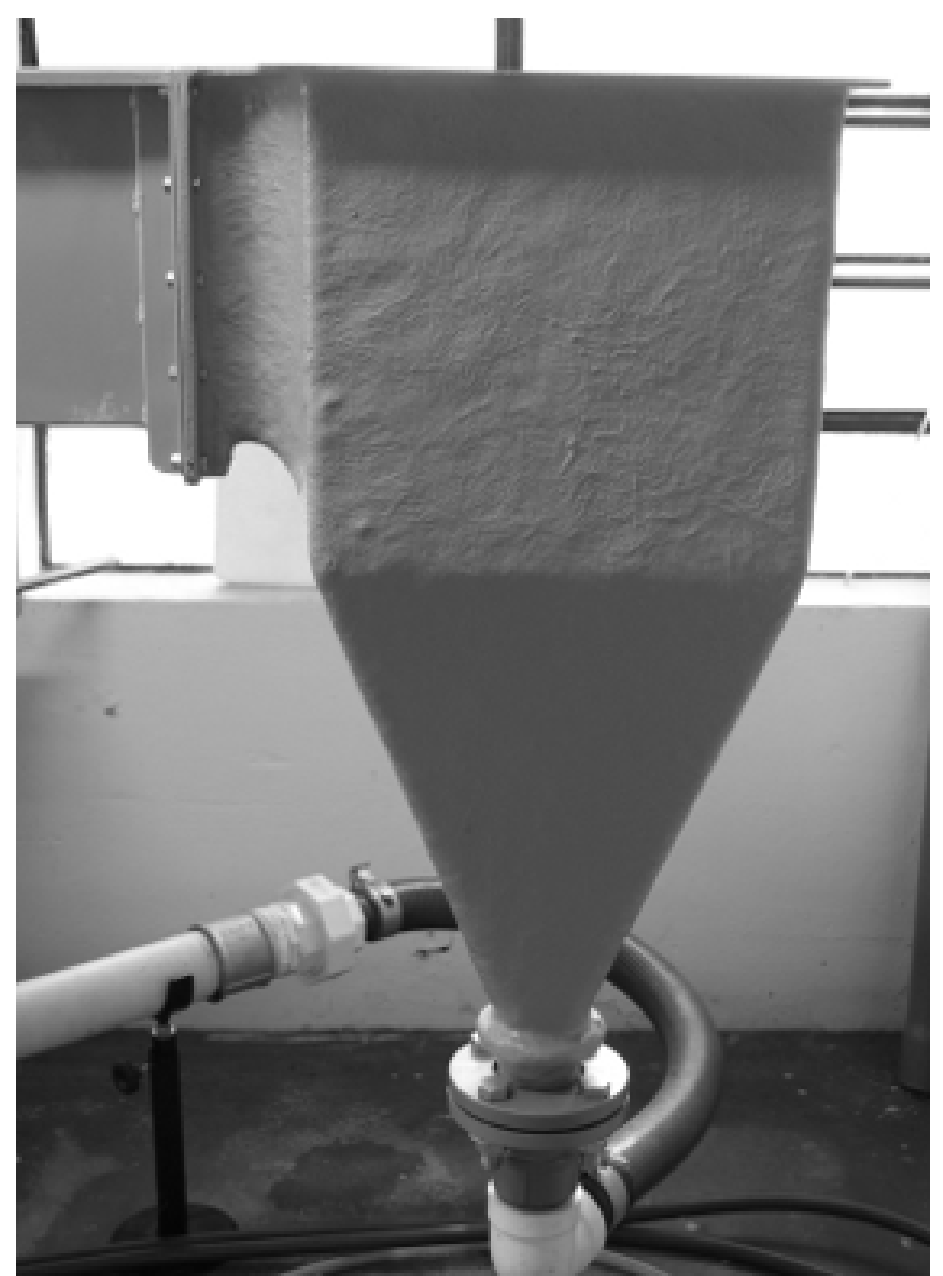

Figura 3.4: Dispositivo utilizado para a transição do escoamento da tubulação de sucção para a calha do canal.

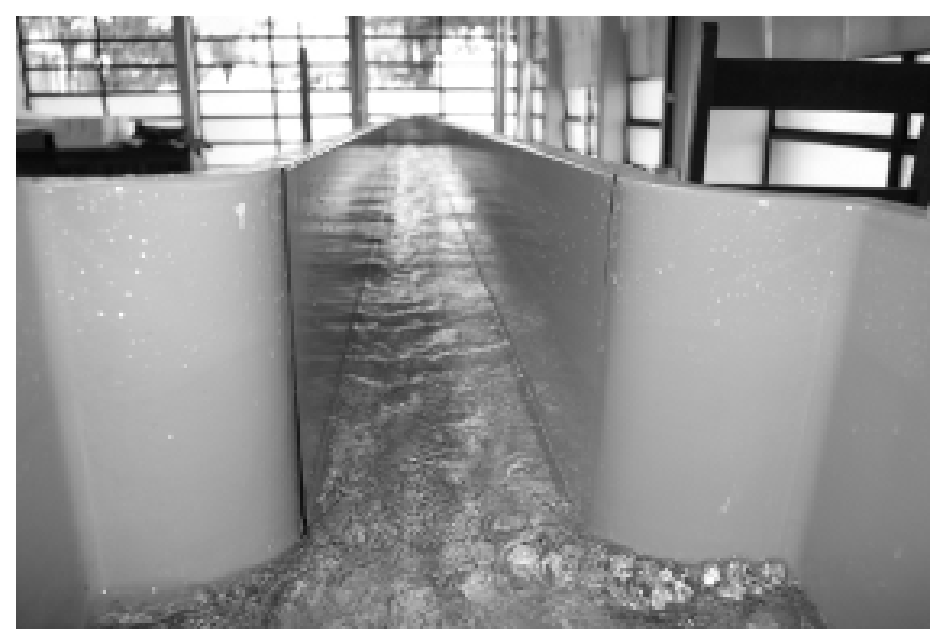

Figura 3.5: Detalhe interno Dispositivo utilizado para a transição do escoamento da tubulação de sucção para a calha do canal

O atrito da água no rotor da bomba e nas paredes da tubulação que compõem o recalque e a sucção do sistema de recirculação do canal, liberam energia para a água, 


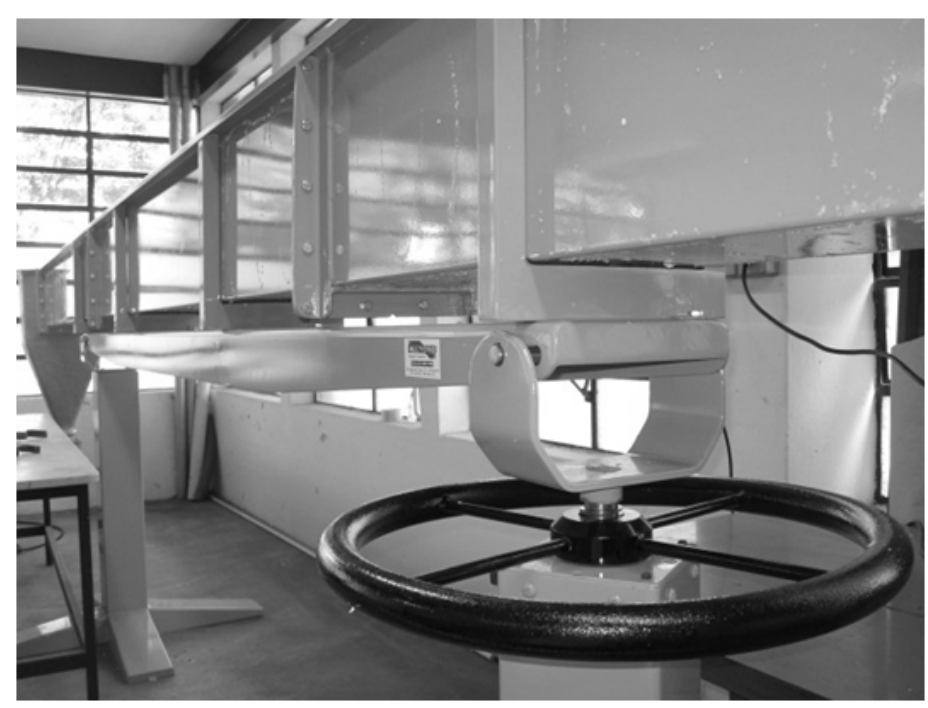

Figura 3.6: Sistema de controle da inclinação da calha do canal - sem inclinação.

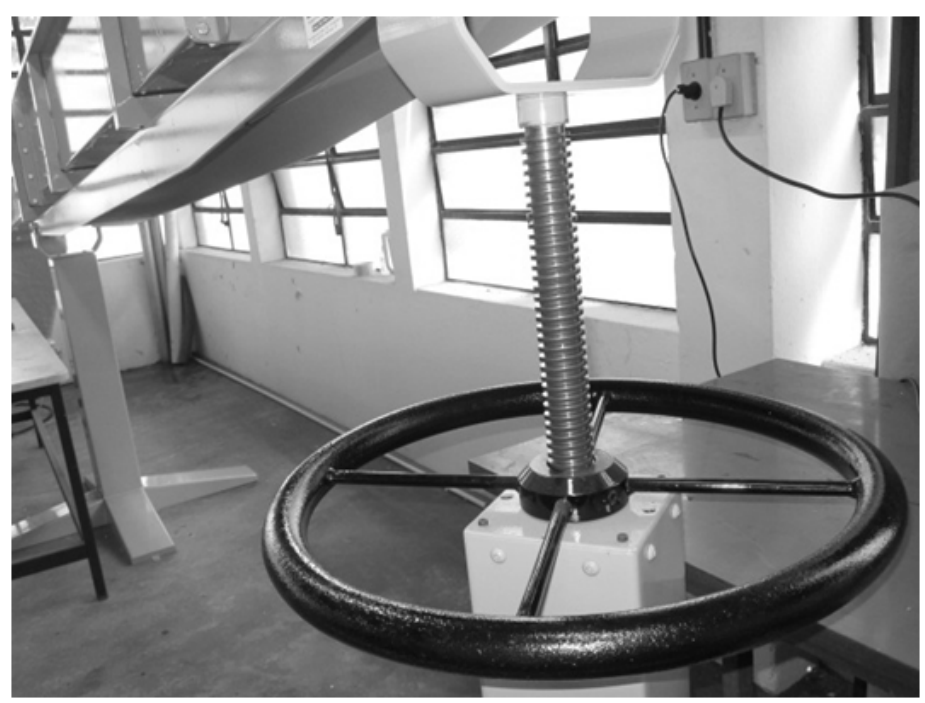

Figura 3.7: Sistema de controle da inclinação da calha do canal - com inclinação.

promovendo o aquecimento desta. Assim, para minimizar o aumento da temperatura da água durante os ensaios, foram utilizados trocadores de calor.

Inicialmente foi proposta a instalação de um trocador de calor na tubulação de recalque. Porém, estudos sobre a eficiência desse dispositivo e a interferência que o mesmo causaria ao escoamento, mostraram inviável a inserção deste naquele local. Para contornar tal problema, o trocador foi substituído por duas unidades de troca de calor mais versáteis, e que causam menos interferência no escoamento. Estes novos trocadores de calor foram inseridos diretamente no líquido, no elemento que faz a transição do escoamento entre a tubulação de recalque e a calha do canal. 
As figuras 3.8, 3.9 e 3.10 ilustram os trocadores de calor e sua instalação para realização dos experimentos no canal.

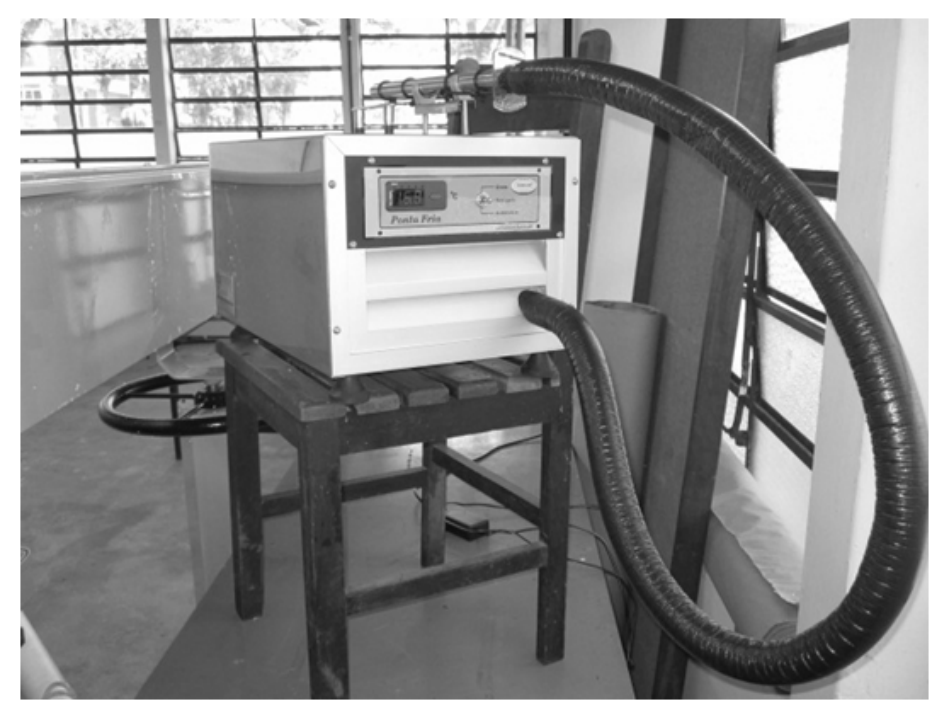

Figura 3.8: Trocador de calor tipo ponta fria utilizado para manutenção da temperatura da água.

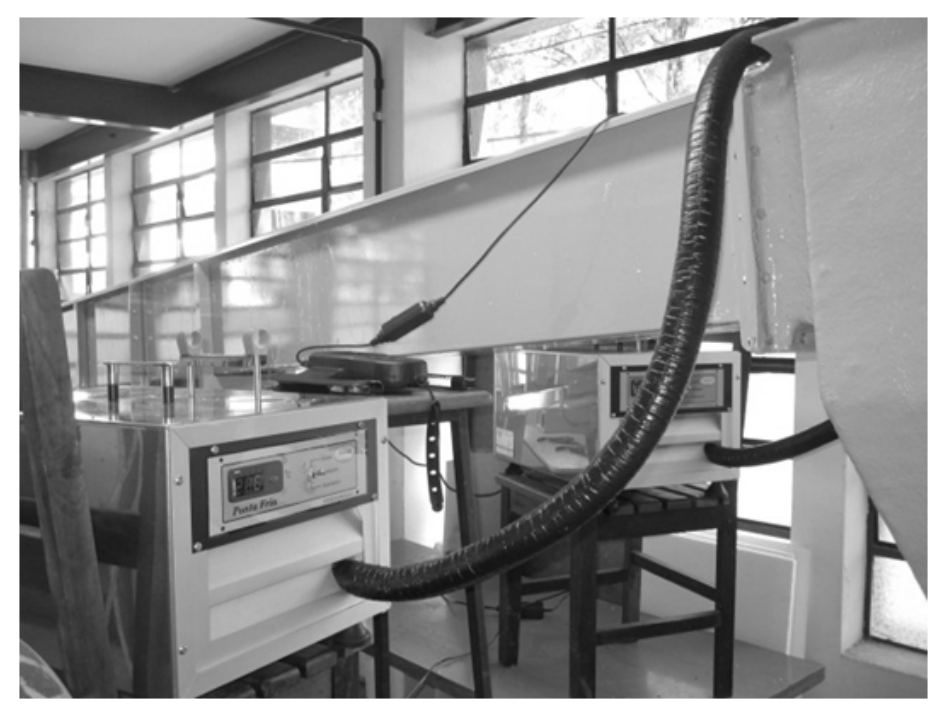

Figura 3.9: Detalhe da instalação dos trocadores de calor durante a realização dos experimentos.

A vazão no canal é controlada por duas válvulas do tipo esfera e por um inversor de freqüência que controla a rotação do motor da bomba (figura 3.11). A velocidade no canal, para uma determinada vazão, é controlada pela inclinação e pela rugosidade do leito do canal. Quanto à medição da vazão, esta foi feita através de um medidor do tipo orifício, instalado na tubulação de recalque, figura 3.12 . 


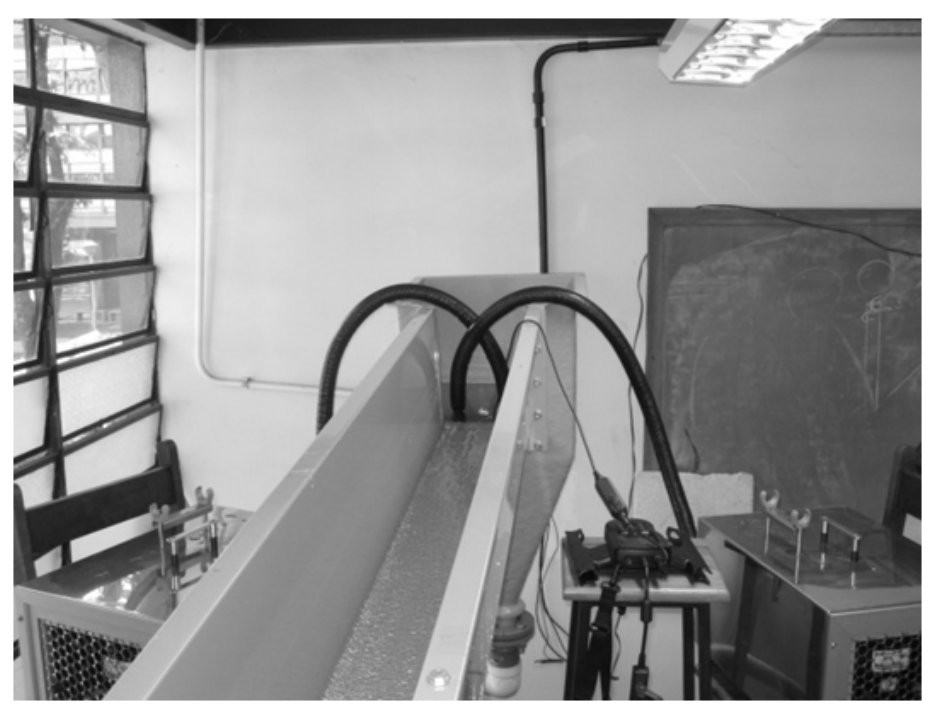

Figura 3.10: Vista superior da instalação dos trocadores de calor durante a realização dos experimentos.

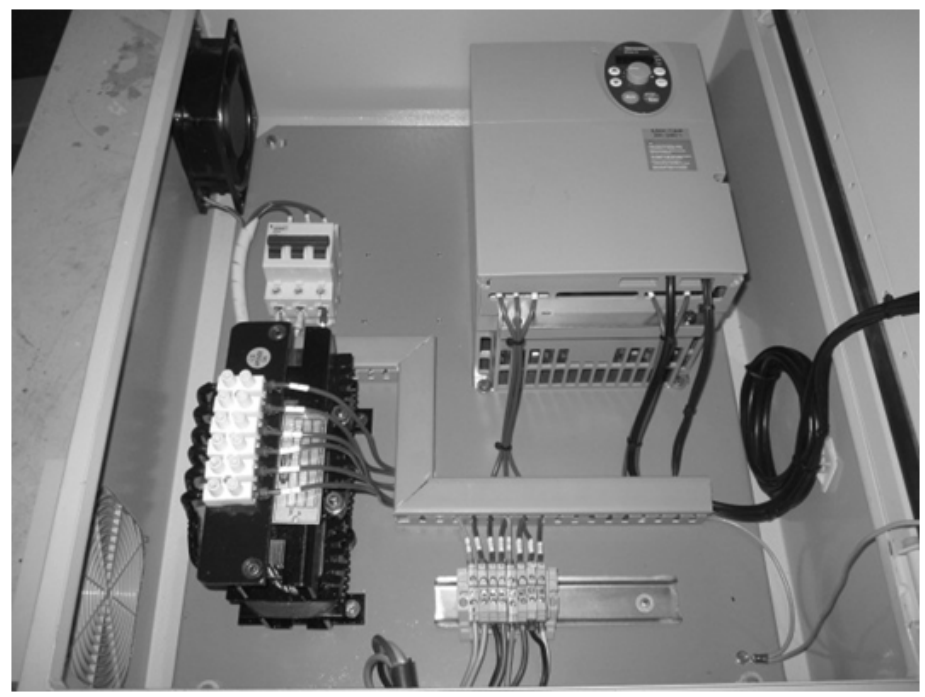

Figura 3.11: Inversor de frequência utilizado para o controle da rotação do motor da bomba utilizada para promover a recirculação da água no canal.

As duas válvulas que auxiliaram no controle da vazão foram instaladas no início da tubulação de sucção, figura 3.13, e no início da tubulação de recalque, figura 3.14. Diferentes graus de abertura das válvulas, em conjunto com a variação da rotação do motor da bomba, viabilizaram a variação da vazão e da pressão na linha de sucção.

A medição da vazão foi realizada através de um medidor tipo de orifício instalado na tubulação de recalque, como ilustrado na figura 3.12. O orifício foi dimensionado com base nas vazões máximas que a bomba pode proporcionar ao escoamento na tu- 


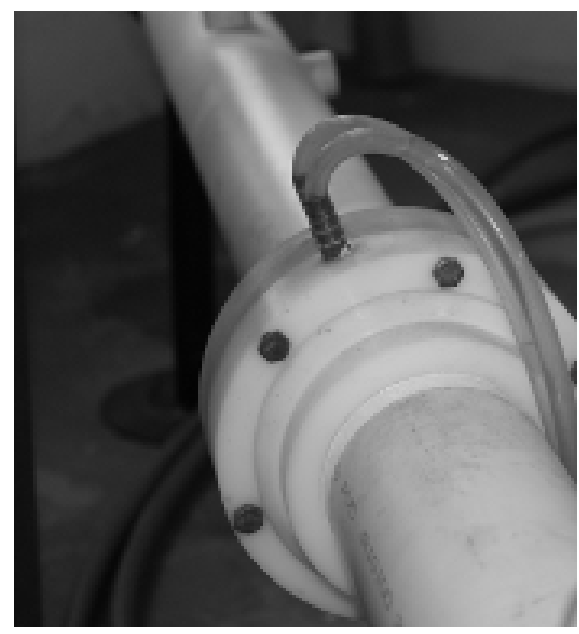

Figura 3.12: Instalação utilizada para medição da vazão no canal

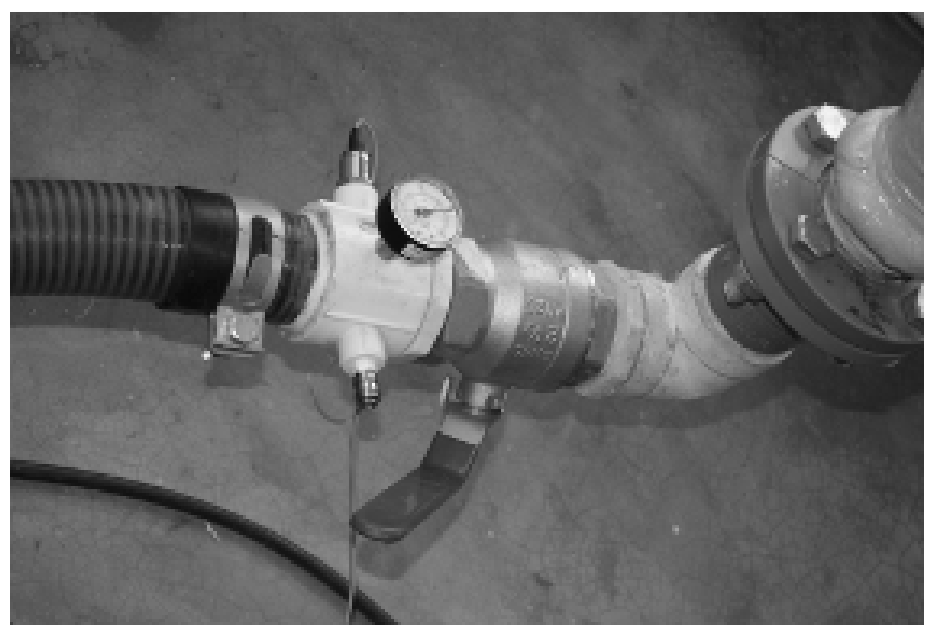

Figura 3.13: Válvula instalada no início da tubulação de sução.

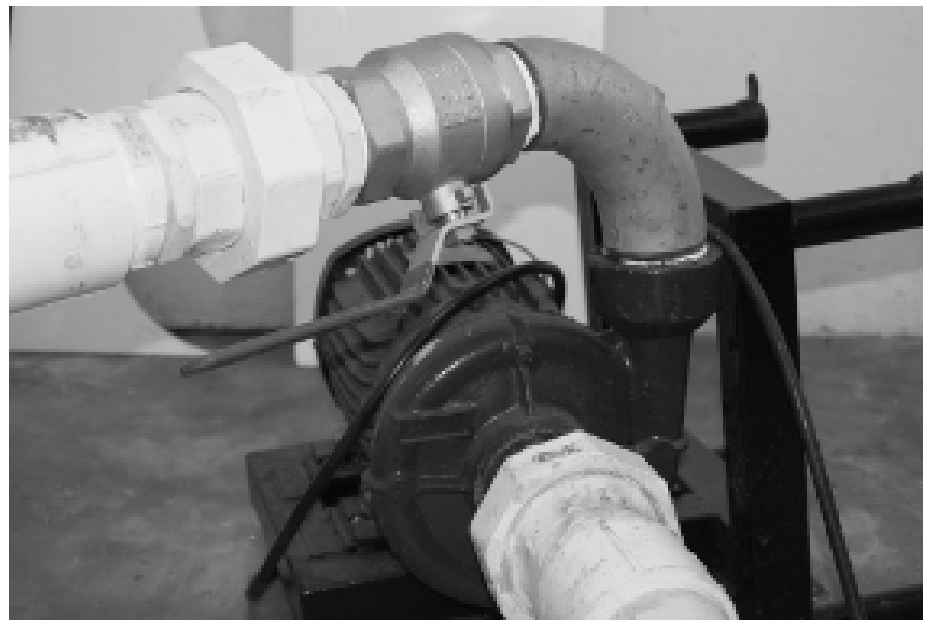

Figura 3.14: Válvula instalada no início da tubulação de recalque.

bulação responsável pela recirculação. A calibração do medidor de vazão foi realizada no Laboratório de Hidráulica da EESC. 
Com o conhecimento da vazão na tubulação, obtida a partir da leitura do desnível das colunas de mercúrio do manômetro instalado no medidor de vazão, da largura da calha e altura média da lâmina d'água do escoamento, foi calculada a velocidade média do escoamento na calha.

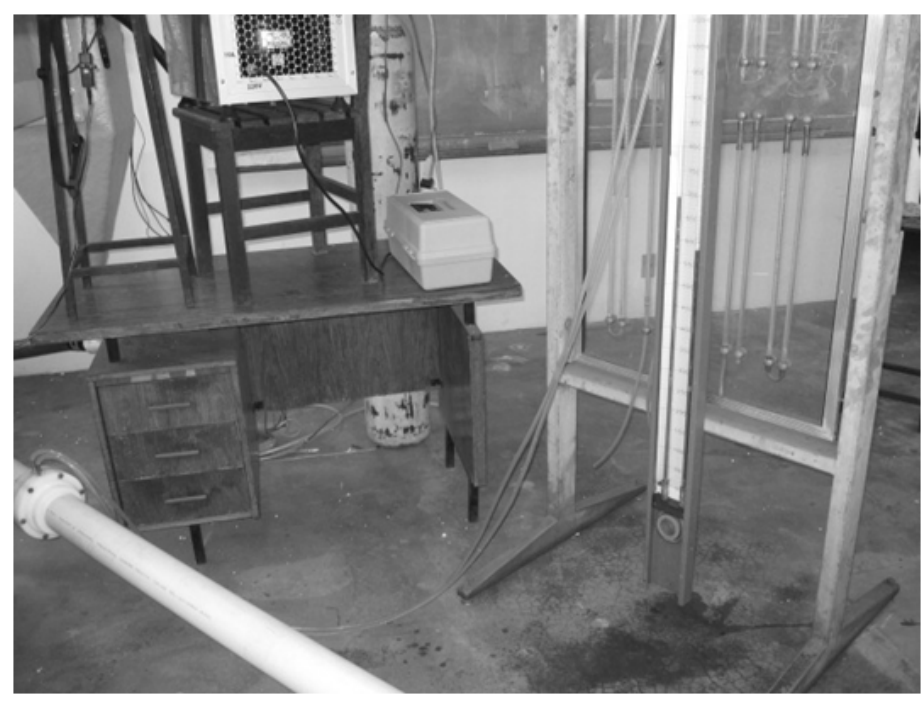

Figura 3.15: Manômetro utilizado para aferir a vazão na tubulação de recirculação.

A variação da pressão, tanto na linha de sucção quanto de recalque, foi medida e registrada em tempo real. Para tanto foi utilizado um sistema composto por transdutores de pressão e vácuo, modelo SB69, e um controlador de pressão, modelo PCT-400Ri Plus, ambos da marca a Full Gauge ${ }^{\circledR}$. Este sistema é ligado a um computador através de um conversor de sinal de dados USB/RS485, modelo Conver32, marca Sitrad ${ }^{\circledR}$, e software da mesma empresa. O fornecimento e a instalação dos equipamentos ficaram sob a responsabilidade da empresa Terroni Equipamentos Científicos, instalada na cidade de São Carlos.

Os transdutores foram instalados com um intervalo de distância de um metro entre um e outro. Foram colocadas, também, em paralelo a cada transdutor, uma tomada de pressão com engate rápido. Essa instalação possibilitou a utilização de um manômetro (em "U" com mercúrio como fluido manométrico) para calibração dos transdutores. 


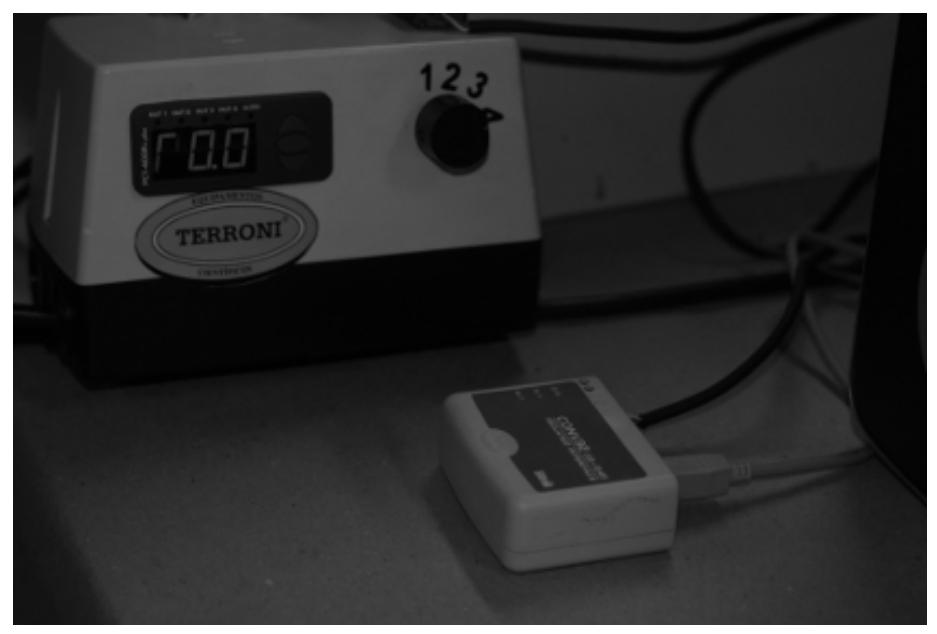

Figura 3.16: Controlador de pressão e conversor de sinal para comunicação com o computador.

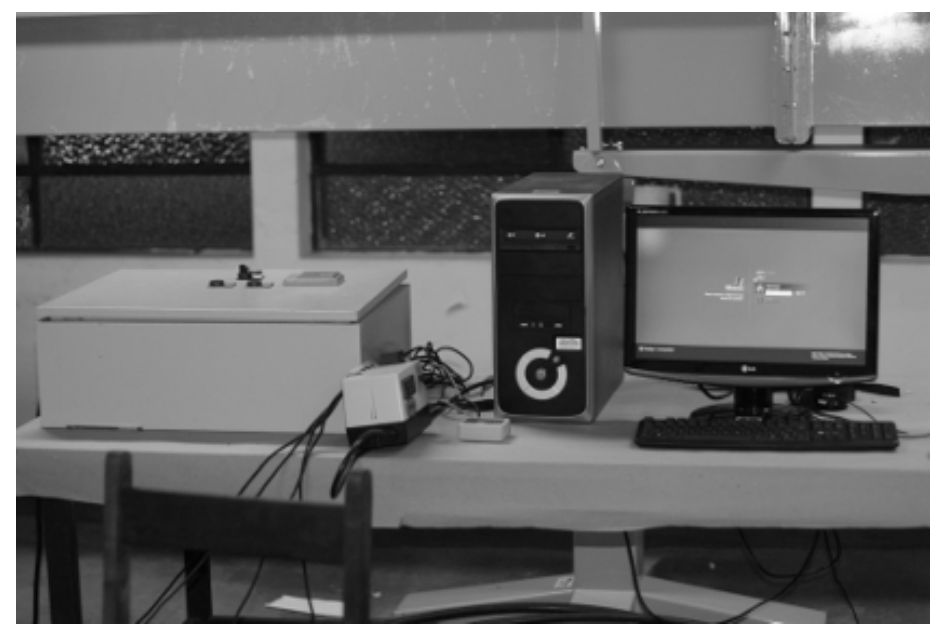

Figura 3.17: Sistema medidor de pressão ligado ao computador.

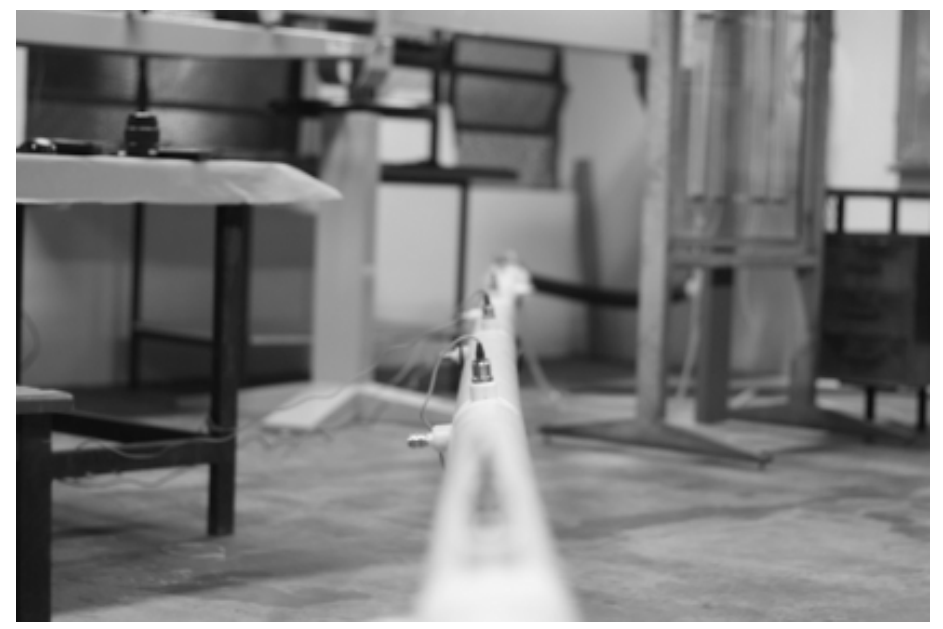

Figura 3.18: Instalação dos transdutores ao longo da tubulação. 


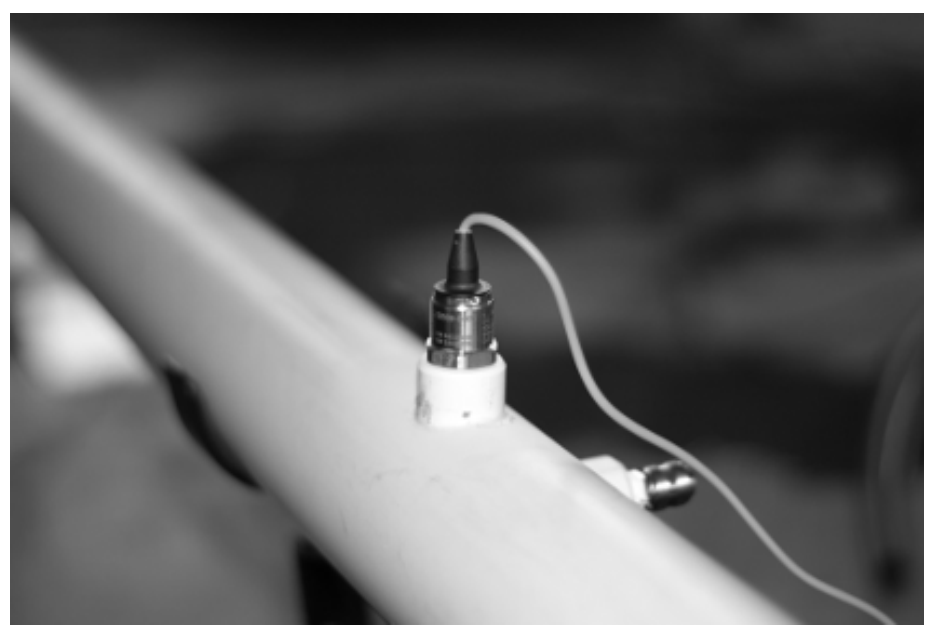

Figura 3.19: Detalhe do transdutor de pressão e da tomada de pressão

Para evitar a influência da salinidade nas concentrações de $O D$ observadas durante os experimentos utilizou-se, em todos os ensaios, água destilada. Devido ao grande volume utilizado nos experimentos, a água destilada era reservada em quantidade suficiente (300 a 500 litros) para a realização dos ensaios. Como os tempos de exposição dessa água à atmosfera são longos o suficiente para que ocorra a dissolução de sólidos no volume em análise, um sensor de condutividade, da marca Vernier, foi utilizado para que as correções em relação à salinidade pudessem ser realizadas.

Para desoxigenar a água submetida a reaeração, foi utilizado um processo de "stripping". Neste processo, o volume de água estudado é submetido a um borbulhamento sub-superficial de gás nitrogênio. Neste processo há a transferência do oxigênio dissolvido no meio líquido para as bolhas de nitrogênio, devido à diferença de concentração de oxigênio existente nos dois sistemas. Ao escaparem para a atmosfera, as bolhas de nitrogênio levam consigo moléculas de oxigênio. Quanto maior for o número de bolhas de nitrogênio e menor o diâmetro destas, mais eficiente será o processo de deaeração. Assim, para otimizar o procedimento, utilizou-se um difusor (pedra porosa), de modo a diminuir o diâmetro das bolhas de nitrogênio e aumentar o tempo de permanência das mesmas no meio líquido.

A vantagem desse método é que evita-se a geração de subprodutos que podem interferir nos dados coletados, como quando se utiliza sulfito para reduzir a concentração de $O D$ no volume de água em estudo. 


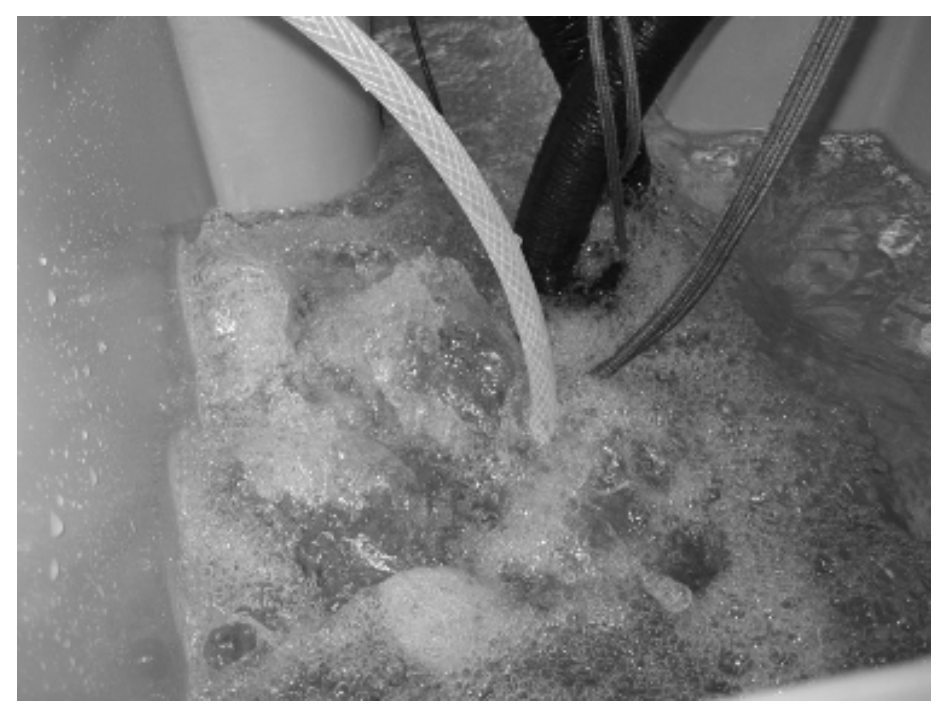

Figura 3.20: Desoxigenação da água no canal

Nos primeiros ensaios foram utilizadas duas sondas polarográficas tipo Clark, fabricadas pela $W T W^{\circledR}$, modelo $C e l l O x^{\circledR} 325$. Estas sondas são conectadas aos medidores de $O D$, os oxímetros, que convertem o sinal de corrente elétrica enviado para a sonda, em massa de oxigênio dissolvido. Com essas sondas foram utilizados dois modelos diferentes de oxímetros para coleta dos dados, também fabricados pela $W T W^{\circledR}$. Um oxímetro era o modelo OXI197, e o outro modelo OXI340i.

Estas sondas são do tipo "membrana-coberta" de oxigênio dissolvido, formadas por dois eletrodos, um catodo e um anodo, envoltos por uma solução eletrolítica e colocados dentro de uma membrana de teflon, por onde o oxigênio é difundido. Estas sondas avaliam o oxigênio dissolvido associando-o com a corrente elétrica enviada pelo oxímetro aos eletrodos. A corrente enviada aos eletrodos é proporcional à pressão parcial (não à concentração) de oxigênio na solução. A membrana isola os eletrodos necessários para esta redução do oxigênio do meio externo. A solução eletrolítica faz com que a corrente flua de um eletrodo para o outro, e previne que outros elementos não gasosos e eletroquimicamente ativos interfiram nas medições.

Esses tipos de sensores são continuamente polarizados com uma voltagem suficientemente negativa para causar a redução do oxigênio a íon de hidróxido no catodo e o metal de prata oxidado para cloreto de prata no anodo dentro da membrana. A corrente associada com este processo é proporcional à presença de oxigênio na solução 
fora da membrana. Porém quando esta reação eletroquímica progride, o oxigênio é consumido no meio, resultando em uma diminuição na corrente medida (e no conteúdo aparente de oxigênio) se a solução externa não é agitada rapidamente.

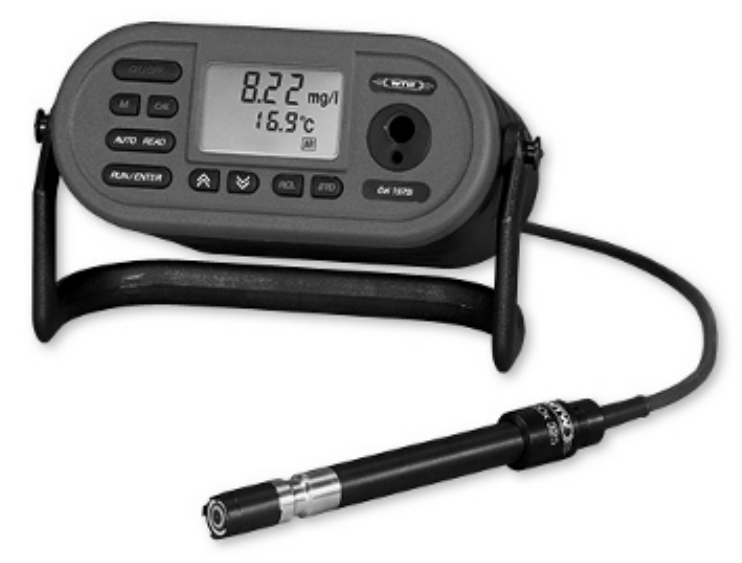

Figura 3.21: Oxímetro $W T W^{\circledR} O X I 197$

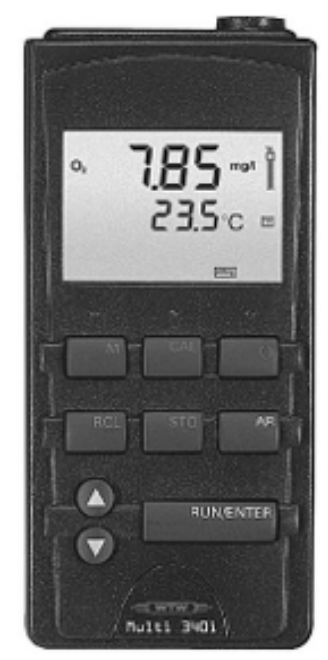

Figura 3.22: Oxímetro $W T W^{\circledR} O X I 340 i$

Em experimentos com um longo tempo de duração, como os realizados neste estudo, os dados perdem qualidade no decorrer do ensaio, devido ao desgaste da solução contida na membrana. Por este fato, é necessária a constante substituição da solução e consequentemente, a calibração do sensor. Para evitar esse tipo de problema, foram utilizadas sondas que determinam a concentração de $O D$ através de processos de luminescência, da marca $\operatorname{Hach}^{\circledR}$ (oxímetro modelo HQ 40d e sonda $L D O^{\circledR} 101$ ). 


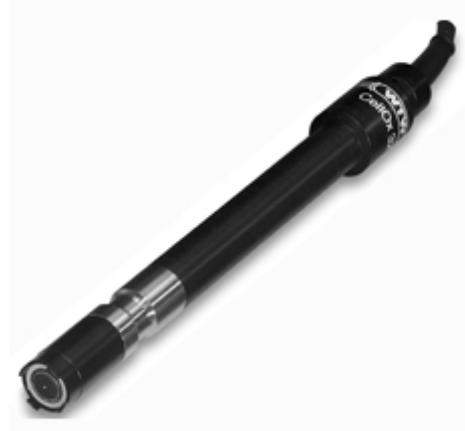

Figura 3.23: Sonda para oxigênio dissolvido $W T W^{\circledR}$ CellOx ${ }^{\circledR} 325$

Essa nova tecnologia patenteada pela $\operatorname{Hach}^{\circledR}$ (Patente \# 691205) baseia-se na quantificação da extinção da luz de um traçador luminescente embutido em um plástico rígido e permeável ao oxigênio. O traçador luminescente é excitado por um flash de luz azul de um LED (Diodo Emissor de Luz). O Traçador responde a esse flash emitindo uma luminescência de cor vermelha, a qual é quantificada por um detector posicionado dentro do sensor. Quanto maior for a intensidade da luminescência medida, menor será a concentração de oxigênio dissolvido, e vice-versa. Nas figuras 3.24 e 3.25, estão ilustrados o oxímetro e a sonda utilizados neste estudo. A maior vantagem desse tipo de sensor está em não precisar de constante calibração e de poder ser utilizado em experimentos com longo tempo de duração.

Além de medir a concentração de OD, o medidor desenvolvido pela Hach também registra a temperatura da água.

Tanto a sonda eletrolítica, quanto a que utiliza luminescência, foram calibradas pelo método Winkler. Este método de determinação de $O D$ na água, foi proposto por L. W. Winkler em 1888. Posteriormente, várias modificações foram introduzidas neste método, visando a eliminação de interferências provocadas por diversas substâncias presentes na água e que prejudicavam a precisão da análise. Este método original é considerado, ainda hoje, o mais preciso na determinação da concentração de $O D$. Os reagentes usados são: Solução de sulfato manganoso (480g em 1 litro d'água destilada), solução alcalina-iodada (500g NaOH + 135g Nal em 1 litro de água), ácido sulfúrico concentrado $(\mathrm{d}=1,83)$, solução $0,025 \mathrm{~N}$ de tiossulfato de sódio e solução de amido $(5 \mathrm{~g}$ de amido de batata em 1 litro d'água). 
A sonda que utiliza luminescência para a determinação do $O D$ mostrou-se a mais eficiente, quando comparada com a eletrolítica, pois não necessita de ser polarizada antes da realização dos ensaios. Assim, após as análises comparativas, sondas versus Winkler, os experimentos foram realizados com a sonda LDO 101.

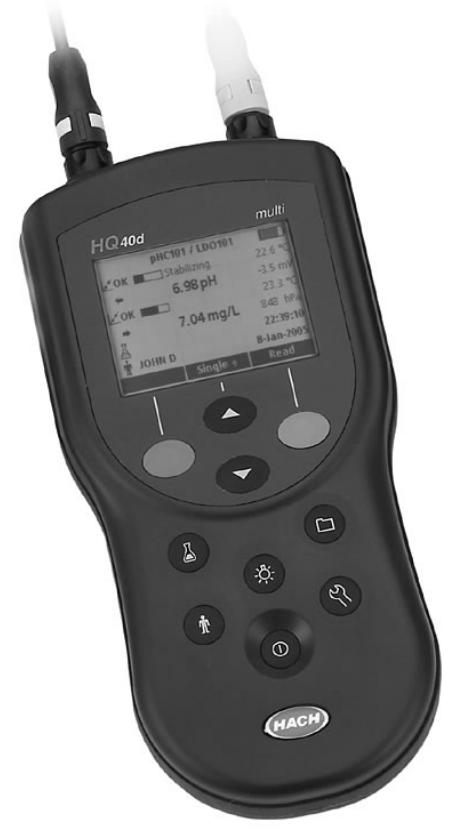

Figura 3.24: Medidor multiparâmetros HQ40D

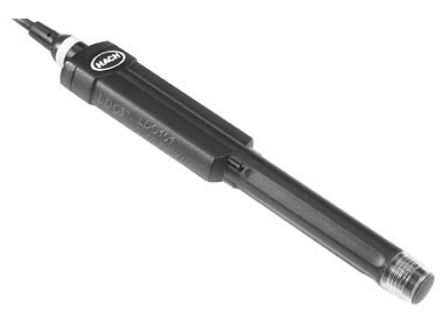

Figura 3.25: Sensor de oxigênio dissolvido por luminescência $L D O{ }^{\circledR} 101$

Os dados coletados automaticamente pelos equipamentos descritos anteriormente, foram transmitidos para um computador e dispostos em planilhas eletrônicas, como é o caso do oxigênio dissolvido, temperatura da água, pressão da tubulação e condutividade da água. À estas planilhas foram adicionadas outras variáveis cuja coleta não foi automatizada, como é o caso da temperatura ambiente, rotação do motor da bomba, pressão diferencial no orifício, profundidade da lâmina de água na calha, pressão ba- 
rométrica (obtida em um barômetro de mercúrio que está instalado em um laboratório ao lado do qual os experimentos foram realizados) e comprimento da linha de sucção.

Cada ensaio gerou uma planilha, contendo, além dos dados da variação de $O D$, informações suficientes sobre as demais variáveis envolvidas no processo. Podendo, quando necessário, identificar cada ensaio.

Para análise dos dados foram desenvolvidas duas rotinas no software Matlab ${ }^{\circledR}$. Uma foi responsável pelo cálculo da reaeação, utilizando-se das variáveis citadas no parágrafo anterior. A segunda rotina foi responsável pelas análises e testes numéricos necessários para a verificação das hipóteses levantadas.

De acordo com Brown e Stenstrom (1980), os tempos de amostragem para os quais modelos como o da equação 2.41 são mais sensíveis são $t=0, t=1 / K_{2}$ e $t \cong \infty$ (quando $C(t) \cong C_{s}$. Esses tempos correspondem aos pontos em que a sensitividade dos parâmetros $C_{0}, K_{2}$ e $C_{s}$ é máxima, respectivamente.

O tempo de cada ensaio no canal foi estimado com base nas equações apresentadas na tabela 2.1 da seção 2.3.2. Porém, por se tratar de um equipamento inédito, as durações dos primeiros ensaios chegaram a $t=2 / K_{2}$ e $t=4 / K_{2}$, ou seja, para concentrações de $86 \%$ e $98 \%$ do valor da concentração de saturação, respectivamente. Tais ensaios serviram para calibrar o processo, e assim, diminuir o tempo de amostragem para até $1 / K_{2}$

Para determinação do valor da concentração de saturação do oxigênio dissolvido para as condições experimentais, $C_{s}$, foi utilizada a equação 2.42 ; para a correção destes valores em relação à pressão atmosférica, estes foram corrigidos pela equação 2.43. Segundo McCutcheon (1989), os valores calculados experimentalmente para $C_{s}$ são, em média, 0,14\% diferentes do valores determinados por estas equações (Weiss (1970) e Wilde et al. (1997)).

Os ensaios realizados no canal seguiram a seguinte ordem de procedimentos:

1. O canal é abastecido com água destilada, com volume suficiente para obter-se a lâmina desejada na calha; 
2. Ajusta-se inclinação da calha e a rotação do motor para obter-se a velocidade esperada para o escoamento com a lâmina imposta no item anterior e aciona-se o sistema de controle da temperatura, instalado nos elementos de transição;

3. São instalados também, nos elementos de transição, os sensores de $O D$, temperatura e condutividade;

4. Instala-se o difusor de gás nitrogênio no elemento de transição a montante do escoamento (nesta posição o tempo utilizado para a desoxigenação foi menor que o necessário quando o difusor é instalado a jusante do escoamento);

5. Inicia-se o processo de stripping que só é interrompido quando a concentração de $O D$ está por volta de 3 a $4 \mathrm{mg} / \mathrm{L}$;

6. Espera-se a turbulência causada pelo stripping desaparecer (cerca de 5 minutos) e inicia-se o processo de coleta dos dados da variação da concentração;

7. A aquisição de dados é finalizada quando a concentração de $O D$ observada na calha atinge $80 \%$ da concentração de saturação.

8. Os dados da variação da concentração de $O D$ durante o tempo ensaiado são armazenados em planilhas eletrônicas, e nestas são adicionadas as demais características que configuram o experimento, assim, cada ensaio fica univocamente identificado em uma planilha;

9. Os dados desta planilha são trabalhados nas rotinas desenvolvidas no Matlab ${ }^{\circledR}$;

10. Cada ensaio produz uma única curva concentração versus tempo, e destas são extraídos os dados necessários para o cálculo dos parâmetros da reaeração superficial;

11. A repetição dos itens acima produz um novo conjunto de dados, contendo informações sobre os coeficientes envolvidos no processo de reaeração, para diferentes velocidades, lâminas e rugosidade do canal; 
Para os ensaios realizados no canal, estabeleceram-se características semelhantes aos dos casos já estudados, para que, uma vez comprovadas as hipóteses deste trabalho, estas fossem validadas utilizando-se dados de outros autores.

Dois processos de calibração foram executados para garantir a qualidade dos dados coletados com as sondas de $O D$. Os resultados desses procedimentos são apresentados nas figuras 3.26 e 3.27. A figura 3.26 ilustra a calibração do sensor $L D O$ enquanto a figura 3.27 ilustra a calibração realizada para o sensor Oxi 197.
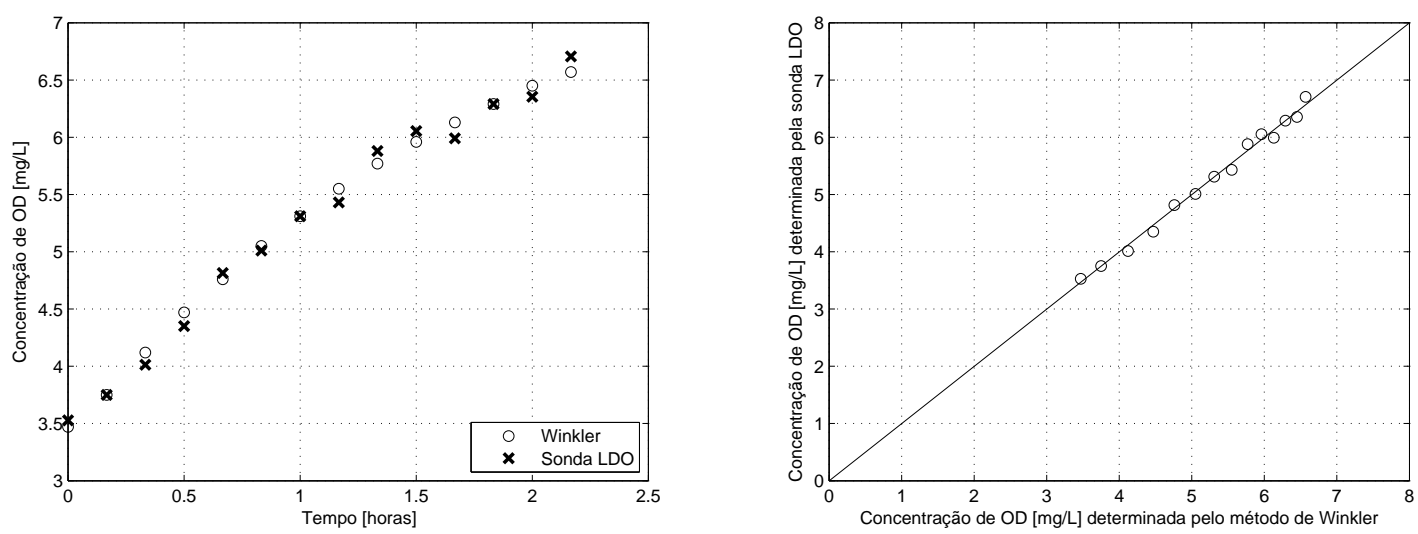

Figura 3.26: Calibração da sonda LDO com o método de Winkler
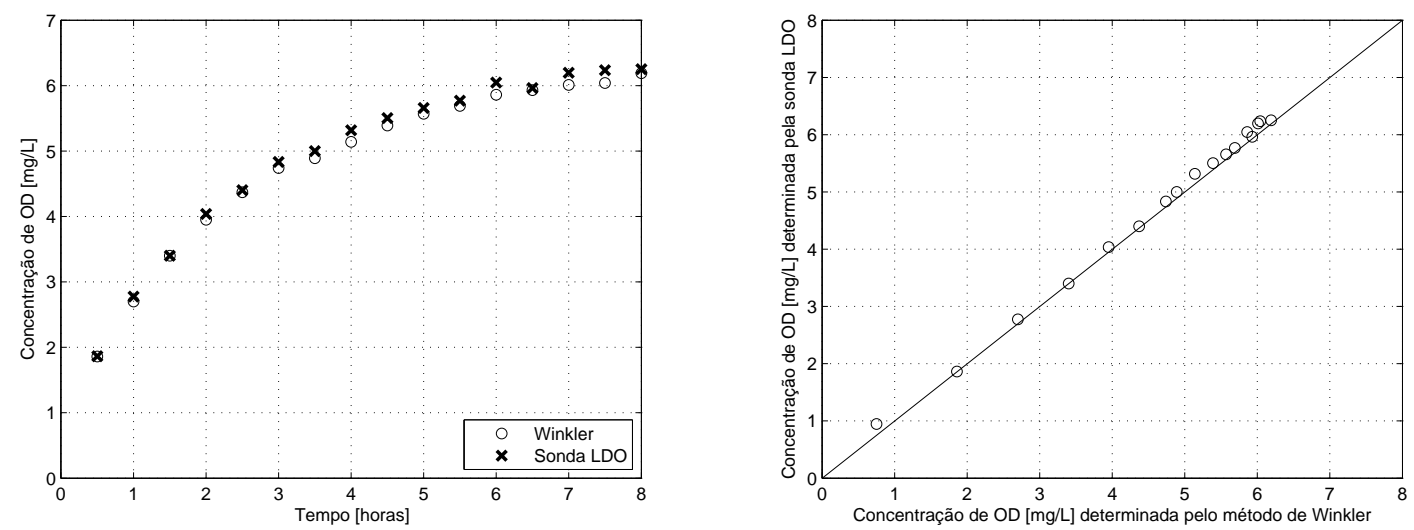

Figura 3.27: Calibração da sonda Oxi 197 com o método de Winkler

Na figura 3.26 temos que a calibração apresentou um coeficiente de correlação de 0,9992 e desvio padrão de 0,0668 $\mathrm{mg} / \mathrm{L}$ para a sonda $L D O$. Para a sonda amperométrica, Oxi197, a calibração com o método Winkler apresentou um coeficiente de correlação de 0,9959 e desvio padrão de 0,0954 mg/L. Segundo as normas APHA et al. (2005), estes valores estão de acordo com o esperado para esse tipo de experimento. 
Com relação à quantidade de amostras para cada ensaio, as normas recomendam que, para a regressão, são necessárias entre 10 e 15 amostras, dentro dos tempos de ensaio sugeridos anteriormente. No caso de equipamentos com registro automático das concentrações, a amostragem ocorreu a cada cinco minutos para níveis mais altos de agitação, e a cada dez minutos para os outros níveis.

O ajuste dos modelos matemáticos (equações 2.41 e 2.58) aos dados experimentais foi realizado através de técnicas de regressão não linear. Seja $Y$ a variável resposta e $X_{1}, X_{2}, \cdots, X_{p}$, variáveis preditoras não aleatórias. Admite-se que a relação entre a variável resposta e as variáveis preditoras é da forma

$$
Y=f\left(x_{1}, x_{2}, \cdots, x_{p} ; \theta\right)+\epsilon
$$

em que $\theta$ é um vetor de $k$ parâmetros, $f$ é uma função real não linear (de forma conhecida), e $\epsilon$ é um erro aleatório aditivo de valor esperado nulo. No problema aqui modelado, a forma da equação $f$ é dada pelas equações 2.58 e 2.41 , e vetor $\theta$ é constituído pela concentração de saturação $\left(C_{s}\right)$, pelo coeficiente de reaeração superficial $\left(K_{2}\right)$ e pela concentração inicial de $O D\left(C_{0}\right)$. Para a estimação e inferência destes parâmetros será realizada pelo método dos mínimos quadrados.

Assim, com base em $n$ observações $\left\{\left(x_{1(i)}, x_{2(i)}, \cdots, x_{p(i)}, y_{i}\right)\right\}_{1}^{n}$, o estimador de $\theta$ é o vetor $\hat{\theta}$ que minimiza a soma dos quadrados dos resíduos $e_{i}=y_{i}-\hat{y}_{i}=y_{i}-$ $f\left(x_{1(i)}, x_{2(i)}, \cdots, x_{p(i)} ; \theta\right)$, que por definição é

$$
\min _{\theta} \sum_{1=i}^{n}\left[y_{i}-f\left(x_{1(i)}, x_{2(i)}, \cdots, x_{p(i)} ; \theta\right)^{2}\right]
$$

A obtenção dos estimadores $\hat{\theta}$ exige algoritmos numéricos adequados e não é computacionalmente trivial. Neste trabalho o método utilizado é o de Nelder-Mead, ou método Simplex, conforme descrito em Lagarias et al. (1999). O algoritmo foi implementado em uma rotina do software $M a t L a b^{\circledR}$.

Há um grande número de critérios estatísticos que podem ser utilizados para comparar a qualidade de ajuste à equação do modelo. Segundo Jain e Jha (2005), em estudos 
sobre reaeração superficial, os critérios mais utilizados são a raíz quadrada do erro quadrático médio $(R M S E)$, o coeficiente de determinação $\left(R^{2}\right)$ e erro multiplicativo médio $(M M E)$.

O RMSE é calculado usando a seguinte equação:

$$
\left(\sum_{n}^{i=1} \frac{\left(K_{P}-K_{M}\right)^{2}}{n}\right)^{1 / 2}
$$

em que $K_{P}$ e $K_{M}$ são respectivamente, os valores preditos e os valores medidos do coeficiente de reaeração $K_{2}$, e $n$ é o número de pontos amostrais. O modelo é considerado bom se os valores preditos forem próximos do valor calculado, o que produz um erro pequeno.

O coeficiente de determinação, $R^{2}$, é calculado por:

$$
R^{2}=1-\frac{S_{e e}}{S_{y y}}
$$

em que $S_{e e}$ é a soma dos quadrados dos erros, ou seja, a diferença entre o valor calculado e o estimado, e $S_{y y}$ é a soma dos quadrados dos desvios dos valores observados da $K_{2}$ em relação à média dos valores observados. O valor de $R^{2}$ uma medida da proporção da variabilidade do valor calculado que é explicada pela variabilidade do valor observado, ou seja, é a variância que é explicada pelo modelo.

As incertezas na estimativa do coeficiente de reaeração, podem ser, também, representadas pelo $M M E$ (Moog e Jirka, 1998), que é definido como

$$
M M E=\exp \left[\frac{\sum_{N}^{i=1}\left|\ln \left(K_{P} / K_{M}\right)\right|}{N}\right]
$$

Se o modelo considerado produzir bons resultados, os valos de $K_{P}$ e $K_{M}$ estarão muito próximos, e o valor do $M M E$ se aproximará da unidade. A diferença entre os métodos $R M S E$ e $M M E$, é que o primeiro utiliza a diferença de magnitude entre valor observado e o previsto, enquanto o segundo utiliza a relação entre os valores. 


\section{Capítulo 4}

\section{Resultados e Discussões}

Os valores observados para a concentração de saturação de $O D$ em procedimentos experimentais para a determinação das taxas de reaeração superficial são, geralmente, reportados como inferiores aos valores calculados para as condições de temperatura, salinidade e pressão em que os experimentos foram realizados. Esse fato interfere significativamente na determinação do coeficiente de reaeração superficial, $K_{2}$, do experimento.

Como foi discutido no Capítulo 1, o autor acredita que o problema descrito no parágrafo anterior pode estar vinculado à inadequação do modelo utilizado para a determinação dos parâmetros envolvidos no fenômeno da reaeração. O modelo matemático amplamente utilizado para esses tipos de estudos, denominado neste texto como modelo clássico (equação 2.41), não prevê a possibilidade da existência de um sumidouro de $O D$, que, caso seja considerado, justificaria os baixos valores observados para $C_{s}$. Assim, acredita-se que um modelo que considere tal situação possa descrever com maior precisão o fenômeno da reaeração superficial em sistemas com recirculação de água.

Em estudos realizados em laboratórios os pesquisadores consideram que, por se trabalhar com água limpa, destilada na maioria dos casos, não exista nenhum tipo sumidouro, químico ou biológico, de $O D$. Mas não atentam para a possibilidade da existência de um sumidouro físico, provocado pelos equipamentos responsáveis pela agitação e ou recirculação do líquido em estudo. Esses estudos afirmam ainda que, 
na determinação do coeficiente de reaeração, os três parâmetros envolvidos no modelo clássico, $K_{2}, C_{s}$ e $C_{0}$, devem ser obtidos em uma única vez, através de uma regressão não-linear da equação 2.41 com a curva concentração de $O D$ versus tempo, obtida experimentalmente APHA et al. (2005); ASCE (2007); Stenstrom et al. (2006, 1981).

\subsection{Verificação da Existência do Sumidouro de OD}

Como visto na seção 2, não há base conceitual que justifique ser a concentração de saturação, $C_{s}$, um parâmetro variável no processo de reaeração superficial quando são mantidas constantes as condições de ensaio, como acontece em experimentos realizados em laboratório. Assim, o autor concorda que método citado no parágrafo anterior é o mais preciso para a estimação dos parâmetros envolvidos na reaeração superficial, e o utiliza neste trabalho. Porém, a concentração de saturação de é uma propriedade física do processo, e deve ser estimada a partir das condições de temperatura, salinidade e pressão atmosférica em que o experimento foi realizado.

Para verificar as hipóteses levantadas neste trabalho, um conjunto de 142 experimentos foram conduzidos no canal descrito no Capítulo 3. Os resultados obtidos para esse conjunto de experimentos são apresentados em sua totalidade na tabela A.1. Na discussão que se segue, foram escolhidos, aleatoriamente, dois destes ensaios que estão representados nas figuras 4.1 e 4.2. As tabelas 4.1 e 4.2 trazem os resultados no ajuste do modelo clássico para esses dois exemplos.

Os ajustes do modelo clássico aos dados experimentais foram realizados considerandose duas situações: a primeira com $C_{s}$ como um parâmetro livre, ou seja, determinado através do processo de estimação utilizando-se o método dos mínimos quadrados; na segunda situação de ajuste considerou-se $C_{s}$ como um parâmetro que pode ser determinado a partir das condições de pressão, temperatura e salinidade da água. Para esses dois exemplos e todos aqueles apresentados na tabela A.1, a concentração de saturação foi calculada pela equação 2.42 .

Observa-se nas figuras 4.1 e 4.2, que com aproximadamente 6 horas de ensaio, a concentração experimental limite, $C_{s}^{*}$, foi atingida. Esta porém, está abaixo da 
Figura 4.1: Exemplo 1: Ajuste do modelo clássico aos dados experimentais com utilização de $C_{s}$ variável e tabelado

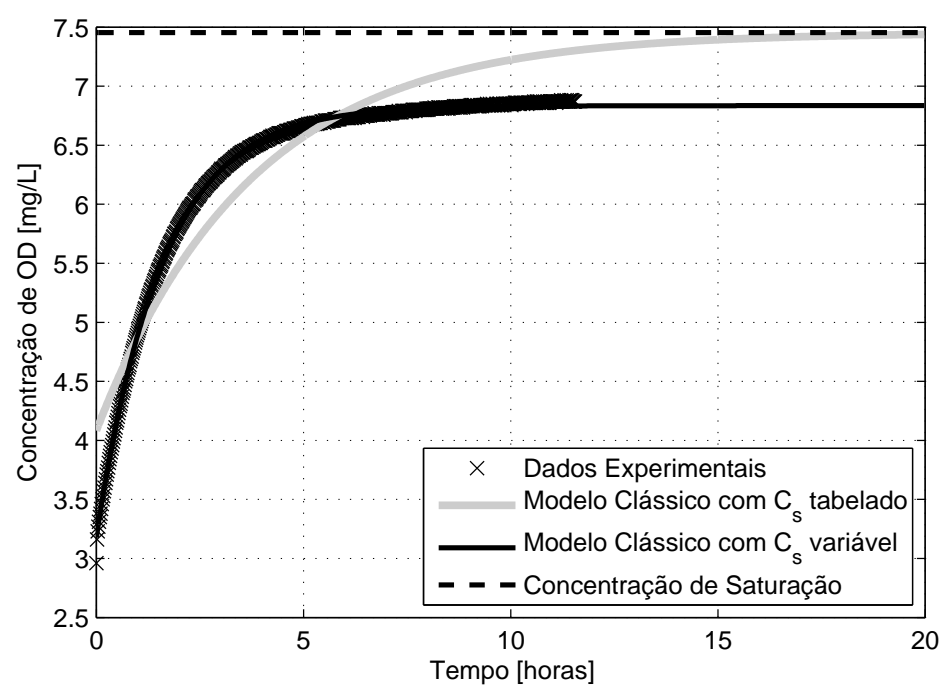

Figura 4.2: Exemplo 2: Ajuste do modelo clássico aos dados experimentais com utilização de $C_{s}$ variável e tabelado

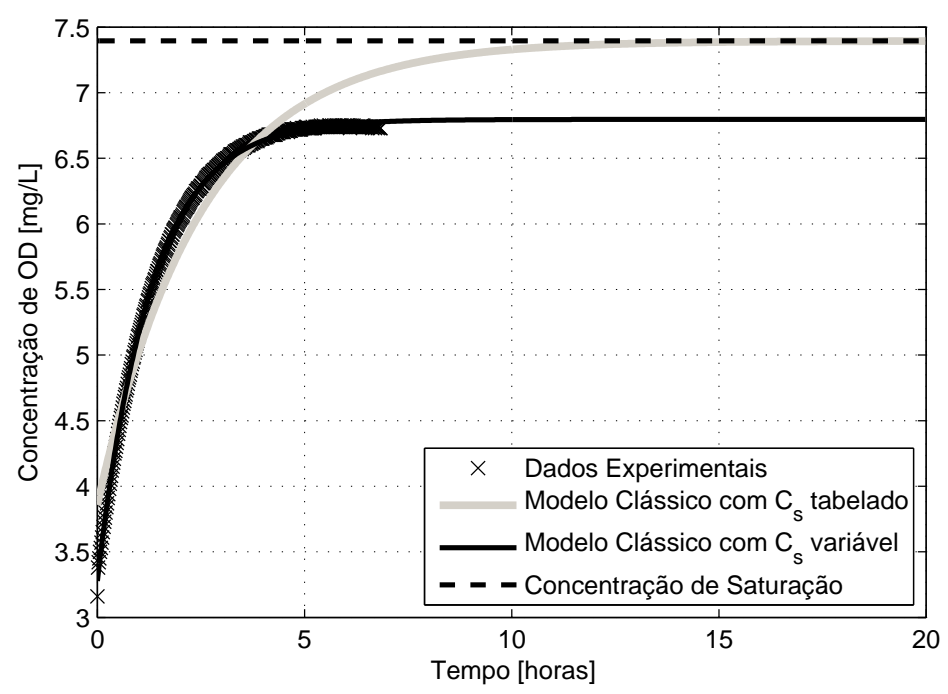

Tabela 4.1: Estimativa dos parâmetros do modelo clássico com $C_{s}$ variável

\begin{tabular}{cccccc}
\hline & $\begin{array}{c}C_{0} \\
{[m g / L]}\end{array}$ & $\begin{array}{c}C_{s} \\
{[m g / L]}\end{array}$ & $\begin{array}{c}K_{2} \\
{\left[\text { horas }^{-1}\right]}\end{array}$ & $\begin{array}{c}\text { RMSE } \\
{[\mathrm{mg} / L]}\end{array}$ & $\begin{array}{c}\text { MME } \\
{[\mathrm{mg} / \mathrm{L}]}\end{array}$ \\
\hline Exemplo 1 & 3,18 & 6,84 & 0,63 & 0,021 & 1,000042 \\
Exemplo 2 & 3,28 & 6,79 & 0,773 & 0,019 & 0,999984 \\
\hline
\end{tabular}

concentração de saturação calculada para as condições experimentais em que os ensaios citados foram realizados (linha pontilhada). 
Tabela 4.2: Estimativa dos parâmetros do modelo clássico com $C_{s}$ constante

\begin{tabular}{cccccc}
\hline & $\begin{array}{c}C_{0} \\
{[m g / L]}\end{array}$ & $\begin{array}{c}C_{s} \\
{[m g / L]}\end{array}$ & $\begin{array}{c}K_{2} \\
{\left[\text { horas }^{-1}\right]}\end{array}$ & $\begin{array}{c}\text { RMSE } \\
{[\mathrm{mg} / L]}\end{array}$ & $\begin{array}{c}\text { MME } \\
{[\mathrm{mg} / \mathrm{L}]}\end{array}$ \\
\hline Exemplo 1 & 4,08 & 7,45 & 0,268 & 0,299 & 1,012856 \\
Exemplo 2 & 3,86 & 7,39 & 0,399 & 0,227 & 1,008409 \\
\hline
\end{tabular}

Ao utilizar-se do modelo clássico com o valor de $C_{s}$ determinado pela equação 2.42 , obtêm-se um ajuste pouco satisfatório entre o modelo clássico e os dados experimentais, como pode ser verificado quando se comparam as linhas que representam os ajustes, o que pode ser verificado também nos valores de $R M S E$ e $M M E$ apresentados nas tabelas 4.1 e 4.2 .

Quanto menor for o valor $R M S E$, melhor é o ajuste do modelo aos dados experimentais. E quanto mais próximo da unidade estiver o valor de $M M E$, melhor será o ajuste. Desta comparação, conclui-se que o modelo clássico, quando se considera $C_{s}$ como uma variável do modelo, produz o melhor ajuste. Porém, o valor encontrado para $C_{s}^{*}$ é $8,2 \%$ menor do que o valor considerado correto, para o exemplo 1 , e e $8,1 \%$ para o exemplo 2.

Dois procedimentos foram utilizados para verificar se o conjunto total de experimentos apresenta a mesma a diferença encontrada nos exemplos 1 e 2 entre os valores da concentração experimental limite, $C_{s}^{*}$, e os calculados para a concentração de saturação de $O D, C_{s}$. A comprovação dessa diferença valida a hipótese de que há um sumidouro de $O D$ não contemplado pelo modelo clássico, quando tal modelo é utilizado em canais artificiais que utilizam-se de bombas para promover a recirculação da água em estudo.

O primeiro procedimento utilizado para verificar a existência do sumidouro de $O D$ é um procedimento gráfico apresentado na figura 4.3. Neste procedimento são comparados os valores de $C_{s}^{*}$ com os valores esperados para $C_{s}$, ou seja, aqueles calculados para as condições de temperatura, pressão atmosférica e salinidade em que os ensaios foram executados.

Os valores observados para a concentração de saturação estariam corretos se os pontos experimentais apresentados na figura 4.3 estivessem sobre a reta com inclinação 


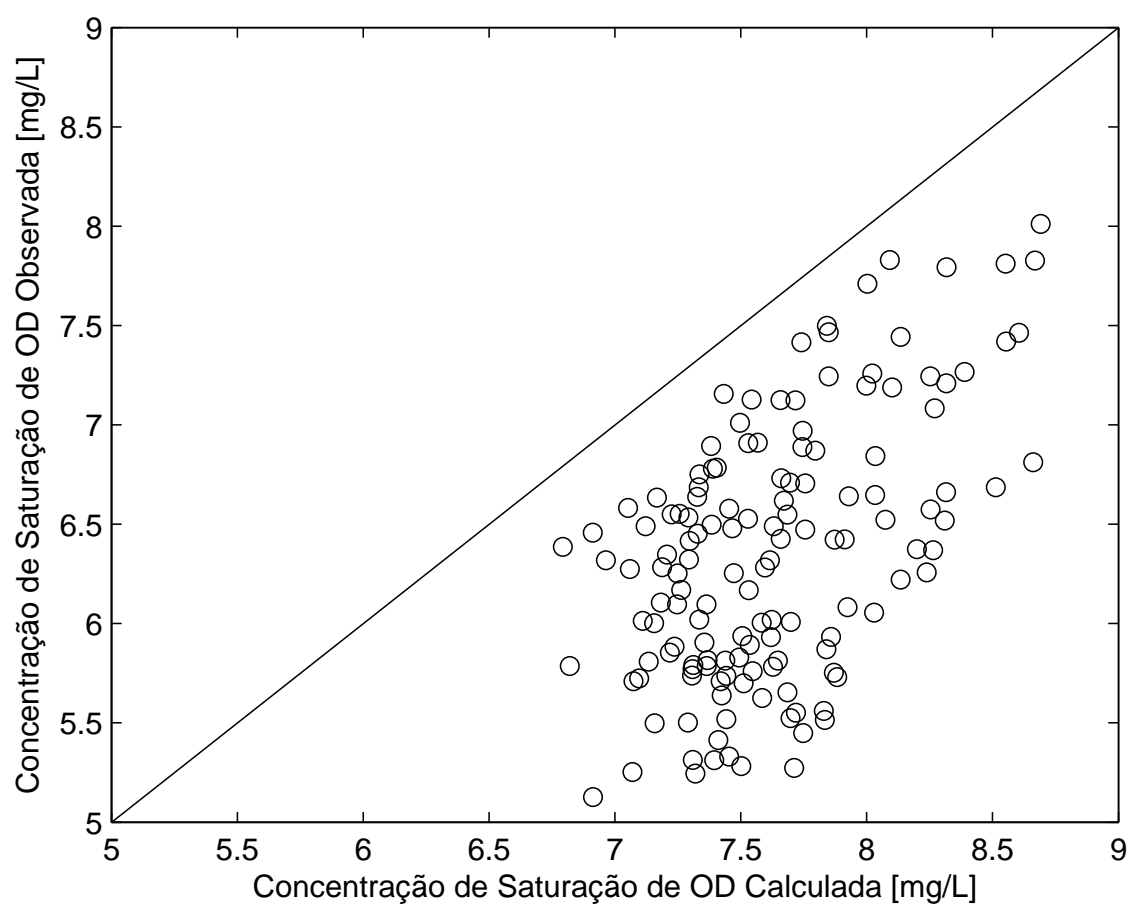

Figura 4.3: Comparação entre os valores calculados para $C_{s}$ e os valores observados experimentalmente com uso do modelo clássico, $C_{s}^{*}$.

de $45^{\circ}$, o que não se verifica. A diferença entre o valor observado e o valor esperado pode ser medida pela afastamento dos pontos amostrais em relação à reta mencionada, e quanto mais distante um ponto estiver da reta, maior será a diferença entre o valor observado experimentalmente $\left(C_{s}^{*}\right)$ e o valor considerado correto para as condições experimentais $\left(C_{s}\right)$.

Como pode-se verificar na figura 4.3, os valores observados para $C_{s}^{*}$ são, em todos os ensaios realizados, inferiores aos valores corretos, o que comprova, na ausência de sumidouros químicos ou biológicos de $O D$, a existência de sumidouros físicos causados pelo próprio processo experimental, uma vez que, como discutido anteriormente, não há explicação teórica que justifique a diferença entre o valor da concentração de saturação de $O D$ observado experimentalmente, $C_{s}^{*}$ e o valor calculado pela equação 2.42 .

O segundo procedimento para avaliar se há diferença entre os valores observados e os valores esperados para a concentração de saturação de $O D$ foi um procedimento estatístico. Nesse procedimento, um teste de hipótese sobre o valor médio das diferenças foi utilizado. Como o número de elementos da amostra é maior que 40 (são 142 pontos), 
o Teorema do Limite Central garante que a média das diferenças entre os valores observados e calculados tem, aproximadamente, uma distribuição normal. Assim, foi considerando como hipótese nula o valor da média das diferenças ser igual a zero e, como hipótese alternativa, o valor da média ser diferente de zero.

Assim, aplicando-se o teste t, para um nível de confiança de 95\%, tem-se os seguintes resultados, apresentados na tabela 4.3. Como o p-valor, encontrado no teste, é menor que 0,01 , a hipótese nula pode ser rejeitada no nível de significância 0,05 ou 0,01 , comprovando a existência de um sumidouro de $O D$, o que explica a baixa estimativa do valor da concentração limite de saturação.

Tabela 4.3: Resultados do aplicativo MINITAB para aplicação do teste t para a diferença entre os valores calculados e os observados para a concentração de saturação de $O D$.

\begin{tabular}{lccc}
\hline Média das diferenças & {$[m g / L]$} & $=$ & 1,272 \\
Desvio Padrão & {$[m g / L]$} & $=$ & 0,554 \\
$\mathrm{t}$ & - & $=$ & 27,330 \\
$\mathrm{p}$-Valor & - & $=$ & 0,000 \\
\hline
\end{tabular}

A figura 4.4 mostra o histograma das diferenças entre os valores calculados e observados para a concentração de saturação de $O D$. Um boxplot dessas diferenças aparece na figura 4.5. Ele está localizado consideravelmente à direita de zero, sugerindo que a média das diferenças é maior que zero.

Comprovada a existência de um sumidouro físico de $O D$, resta verificar a hipótese de que este sumidouro é devido às condições de pressão impostas na linha de sucção do sistema de recirculação da água em análise.

\subsection{Validação do Novo Modelo Matemático}

Antes de verificarmos a hipótese levantada no parágrafo anterior, analisaremos o ajuste aos dados experimentais proporcionado pelo novo modelo proposto na seção 2.6, aqui denominado por Modelo Novo, 2.57 e 2.58. Para tanto utilizaremos, também, os exemplos 1 e 2 citados anteriormente, agora apresentados nas figuras 4.6 e 4.7; os resultados 


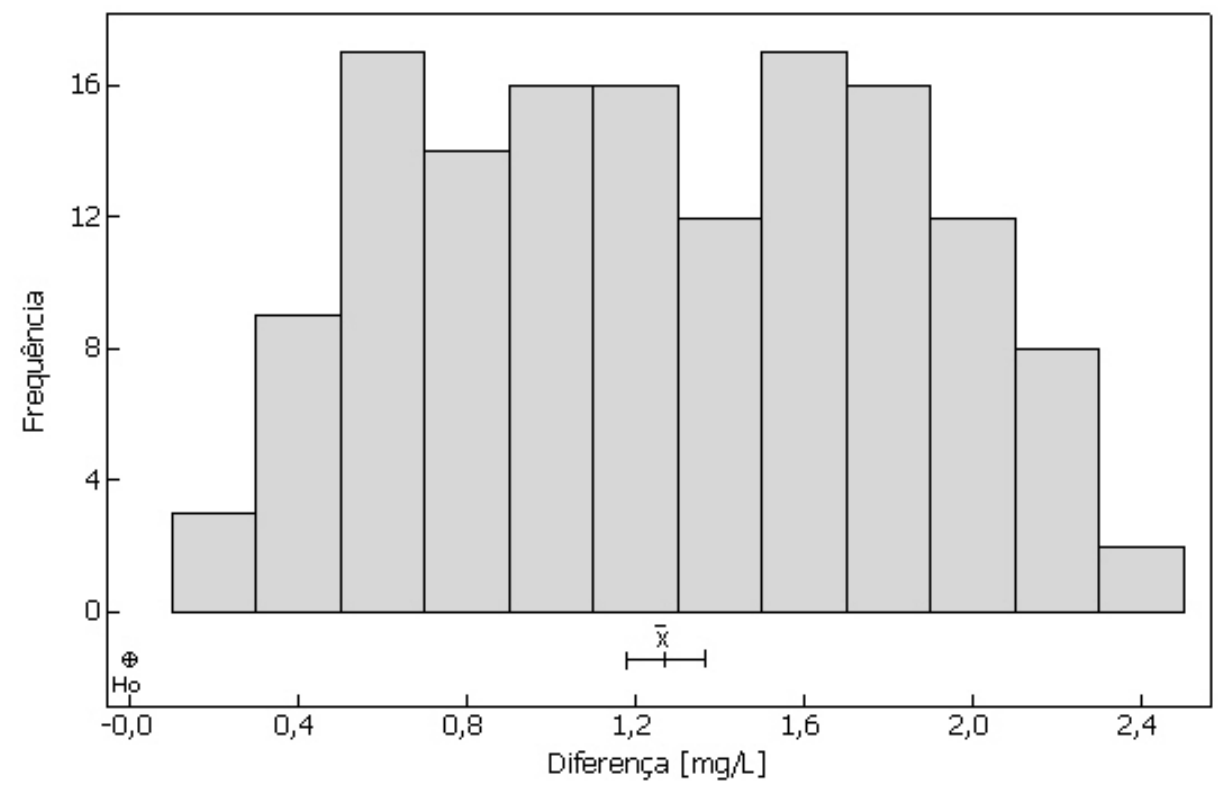

Figura 4.4: Histograma das diferenças entre os valores calculados e os observados experimentalmente para a concentração de saturação do $O D$.
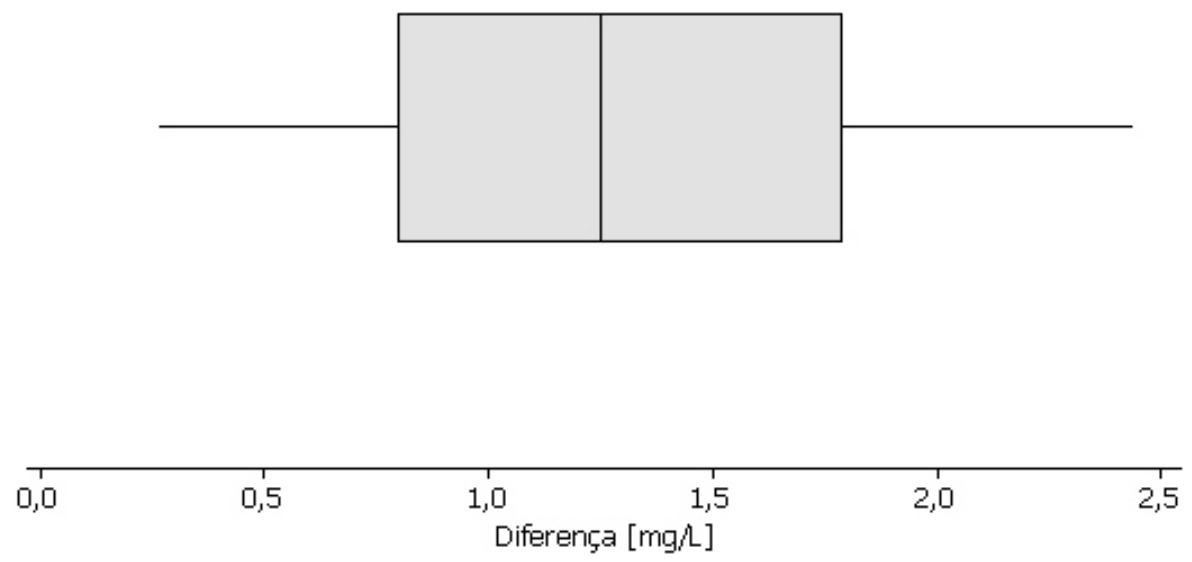

Figura 4.5: Boxplot das diferenças entre os valores calculados e os observados experimentalmente para a concentração de saturação do $O D$.

do ajuste são apresentados na tabela 4.4. Os demais resultados estão sumarizados na tabela A.1 e nas figuras respectivas, também constantes do Anexo 5.

Pode-se verificar nas figuras 4.6 e 4.7 que, mesmo considerando-se $C_{s}$ como uma constante, o modelo possibilita um excelente ajuste aos dados experimentais. Os valores 


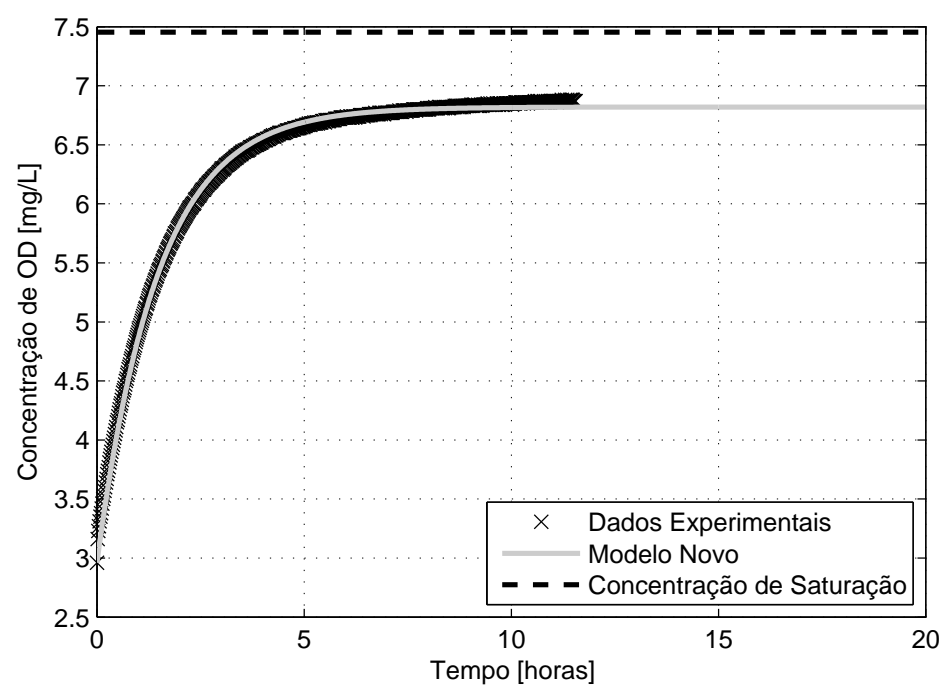

Figura 4.6: Ajuste dos dados do exemplo 1 ao modelo novo.

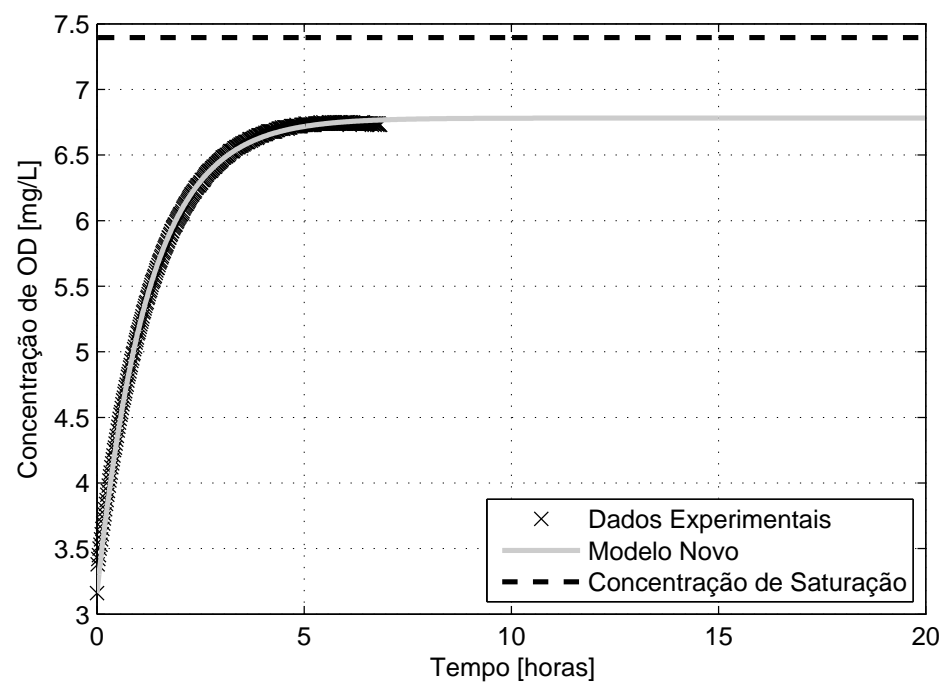

Figura 4.7: Ajuste dos dados do exemplo 2 ao modelo novo.

Tabela 4.4: Estimativa dos parâmetros do novo modelo aos dados dos exemplos 1 e 2

\begin{tabular}{ccccccc}
\hline & $C_{0}$ & $C_{s}$ & $K_{2}$ & $k_{3}$ & $R M S E$ & $M M E$ \\
{$[m g / L]$} & {$[m g / L]$} & {$\left[\right.$ horas $\left.^{-1}\right]$} & {$\left[\right.$ horas $\left.^{-1}\right]$} & {$[-]$} & {$[-]$} \\
\hline Exemplo 1 & 3,176 & 7,454 & 0,623 & 0,058 & 0,021 & 1,000 \\
Exemplo 2 & 3,278 & 7,394 & 0,740 & 0,067 & 0,019 & 1,000 \\
\hline
\end{tabular}

de $R M S E$ e $M M E$ para os dois ajustes, apresentados na tabela 4.4, comprovam essa afirmação. 
Para compararmos os resultados obtidos para $K_{2}$ com o modelo clássico e o novo modelo, recorremos aos mesmos recursos utilizados para compararmos os valores obti$\operatorname{dos}$ para $C_{s}^{*}$ e $C_{s}$.

A figura 4.8 trás um gráfico comparando os valores de $K_{2}$ obtidos para os dois diferentes modelos. No eixo $x$ estão representados os valores de $K_{2}$ obtidos através do ajuste realizado com o modelo novo, enquanto que o eixo $y$ traz os resultados obtidos com o modelo clássico. Como podemos observar, são poucos os pontos situados sobre a reta com $45^{\circ}$ de inclinação, o que indica a existência de diferenças entre os valores de $K_{2}$ determinados pelos dois modelos.

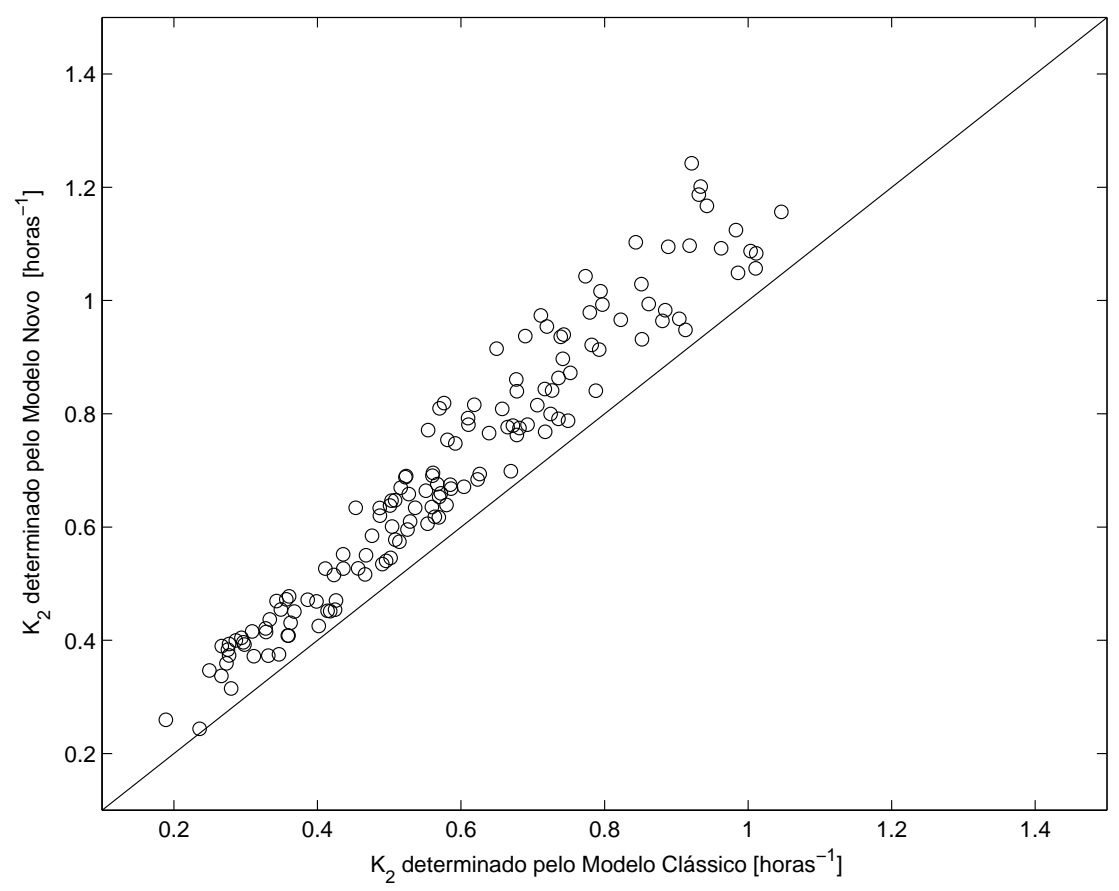

Figura 4.8: Comparação entre $K_{2}$ obtido com os modelos clássico e novo.

Verifica-se na figura 4.8 e na tabela A.2 que os valores calculados de $K_{2}$ com o uso do modelo clássico são, na totalidade dos casos, superiores aos valores correspondentes quando da utilização do modelo novo.

Aplicando o teste t para as diferenças entre os valores de $K_{2}$ obtidos com os diferentes métodos, e considerando como hipótese nula que o valor médio das diferenças é zero, temos, para um nível de confiança de 95\%, os resultados apresentados na tabela 4.5 . 
Tabela 4.5: Resultados do aplicativo MINITAB para aplicação do teste t para a diferença entre os valores de $K_{2}$ obtidos com o os dois modelos diferentes.

\begin{tabular}{lccc}
\hline Média das diferenças & {$[\mathrm{mg} / \mathrm{L}]$} & $=$ & $-0,1155$ \\
Desvio Padrão & {$[\mathrm{mg} / L]$} & $=$ & 0,0632 \\
$\mathrm{t}$ & - & $=$ & $-21,7800$ \\
P-Valor & - & $=$ & 0,000 \\
\hline
\end{tabular}

As figuras 4.9 e 4.10 trazem, respectivamente, o histograma e um boxplot das diferenças. O boxplot apresentado na figura 4.10 confirma o que observamos na figura 4.8, ou seja, que $K_{2}$ determinado pelo modelo clássico é superior ao determinado pelo novo modelo.

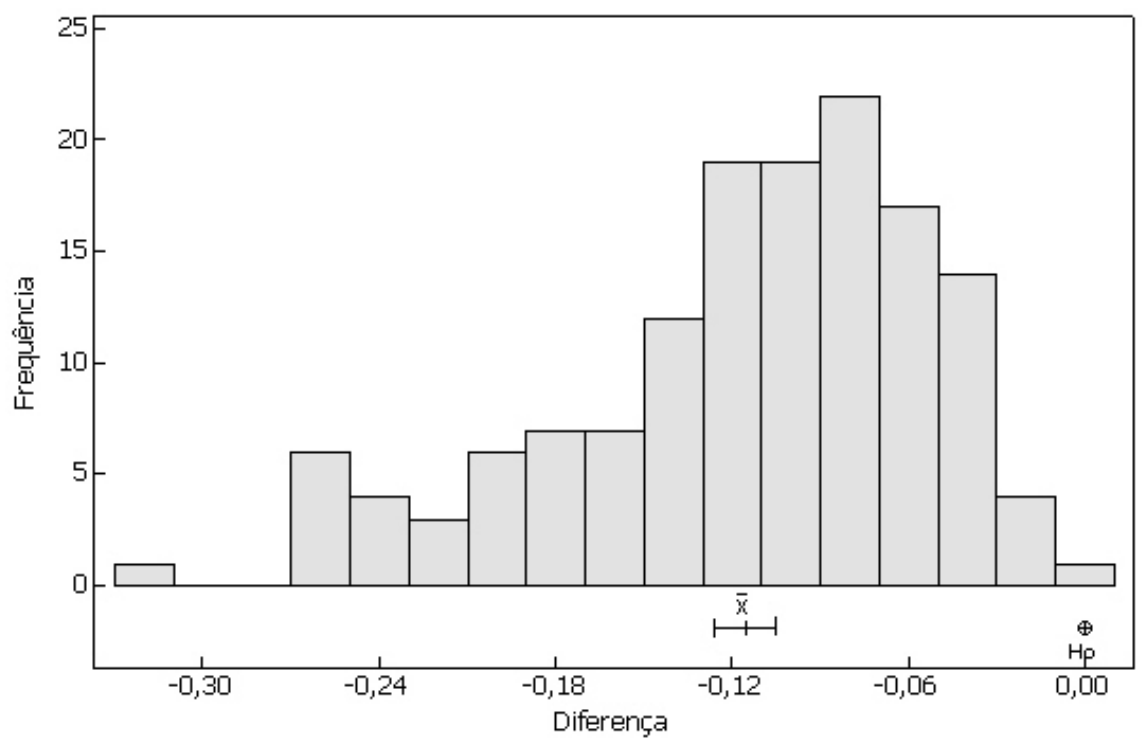

Figura 4.9: Histograma da diferença entre $K_{2}$ obtido com o modelo clássico e $K_{2}$ obtido com o modelo novo. 
4.3. Correlação entre o sumidouro de OD e a queda de pressão na tubulação de sucção do sistema de recirculação da água

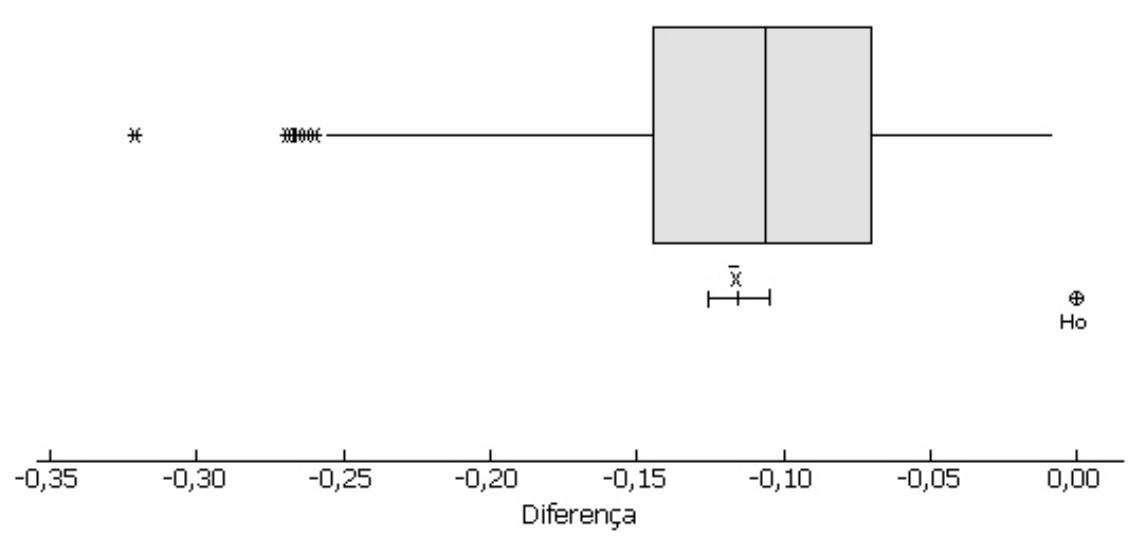

Figura 4.10: Boxplot da diferença entre $K_{2}$ obtido com o modelo clássico e $K_{2}$ obtido com o modelo novo.

\subsection{Correlação entre o sumidouro de OD e a queda de pressão na tubulação de sucção do sistema de recirculação da água}

Para verificar a hipótese lançada sobre a existência de um sumidouro de $O D$ na linha de sucção do sistema de recirculação da água, durante os ensaios de reoxigenação, foram instalados na tubulação de sucção sensores de pressão para observação desse parâmetro, como descrito no capítulo 3 .

As informações obtidas pelos sensores de pressão são apresentadas na forma de um sinal com ruído. Para exemplificar essa situação, são apresentados os resultados da medida da pressão na tubulação de sucção para quatro ensaios: (1) para uma abertura de $100 \%$ da válvula instalada na sucção e velocidade de 0,45 m/s, figura 4.11; (2) considerando a mesma velocidade na linha de sucção, 0,40 m/s, porém com a abertura de $50 \%$ da válvula, figura 4.12;.(3) para uma abertura de 100\% da válvula instalada na sucção e velocidade de $1,1 \mathrm{~m} / \mathrm{s}$, figura 4.13; e (4) considerando a a velocidade de $1,1 \mathrm{~m} / \mathrm{s}$ e abertura de $50 \%$ da válvula, figura $4.12 ;$. 

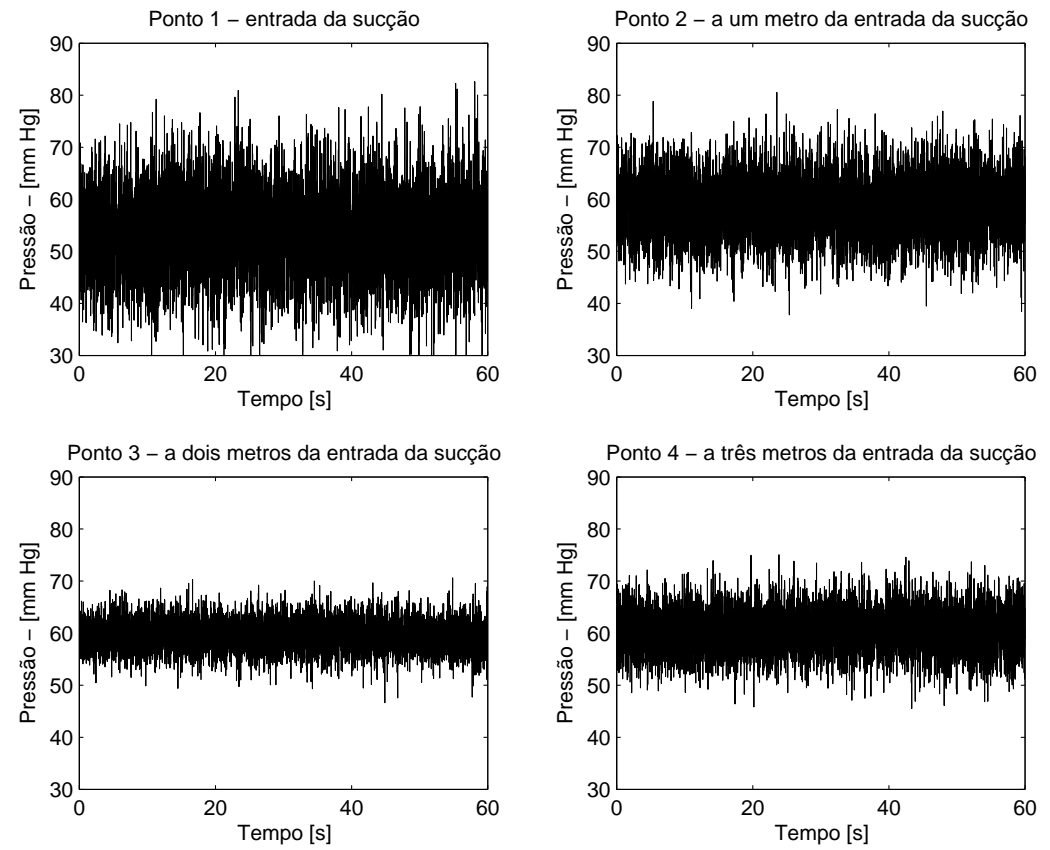

Figura 4.11: Velocidade do escoamento na tubulação $0,45 \mathrm{~m} / \mathrm{s}$ para abertura de $100 \%$ da válvula instalada na sucção.
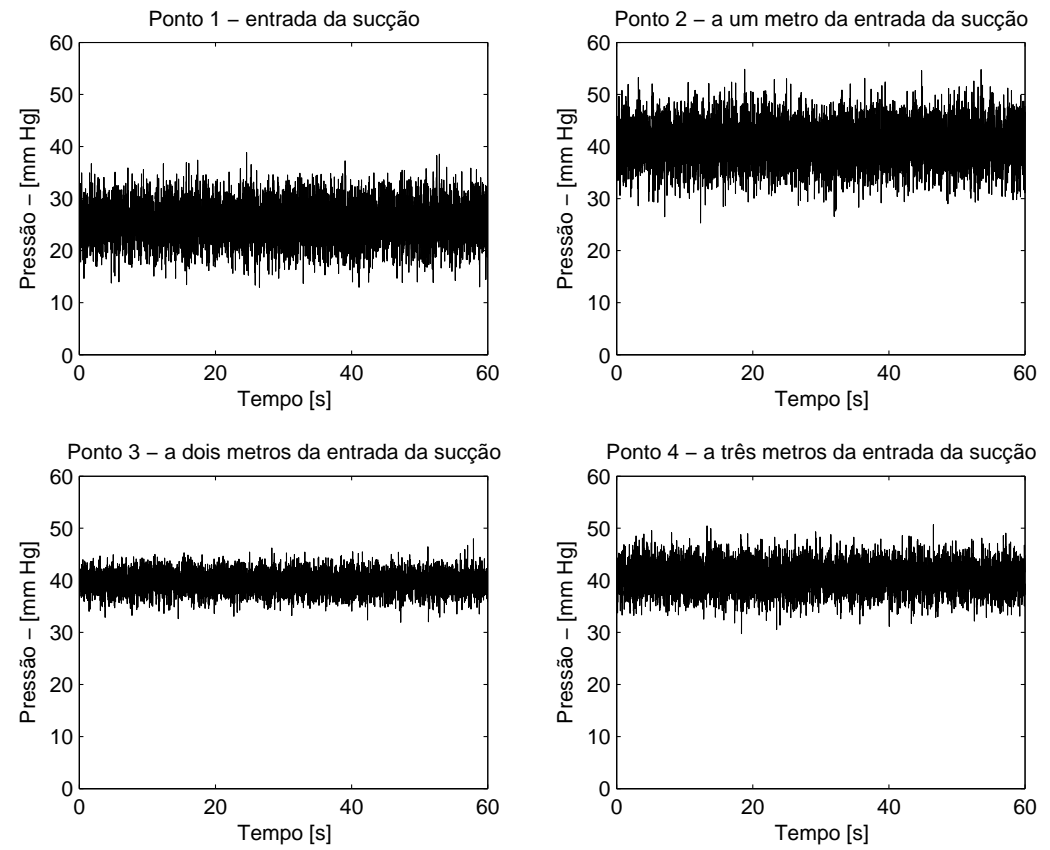

Figura 4.12: Velocidade do escoamento na tubulação $0,45 \mathrm{~m} / \mathrm{s}$ para abertura de $50 \%$ da válvula instalada na suç̧ão.

Para obter-se um valor numérico que melhor representasse a pressão na tubulação de sucção, foram avaliados o valor médio do sinal e o desvio padrão de cada um dos quatro sinais observados na tubulação de sucção. O sinal que apresentou a menor 
4.3. Correlação entre o sumidouro de OD e a queda de pressão na tubulação de sucção do sistema de recirculação da água
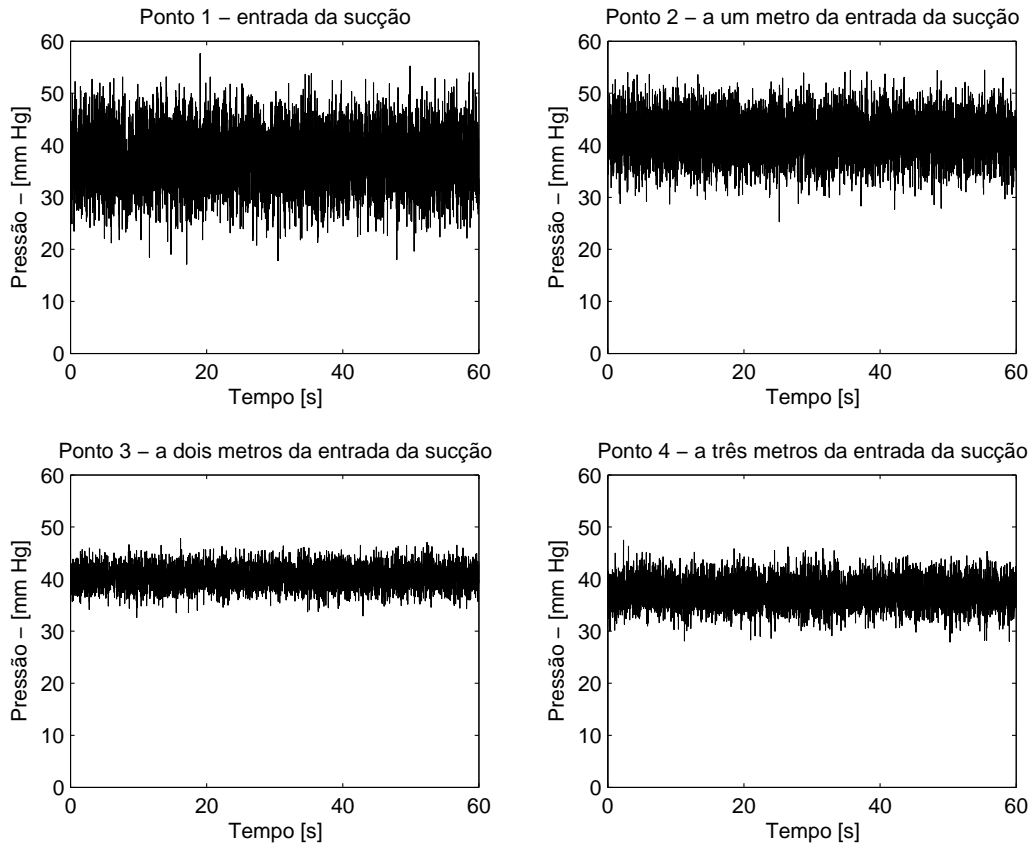

Figura 4.13: Velocidade do escoamento na tubulação $1,1 \mathrm{~m} / \mathrm{s}$ para abertura de $100 \%$ da válvula instalada na sucção.
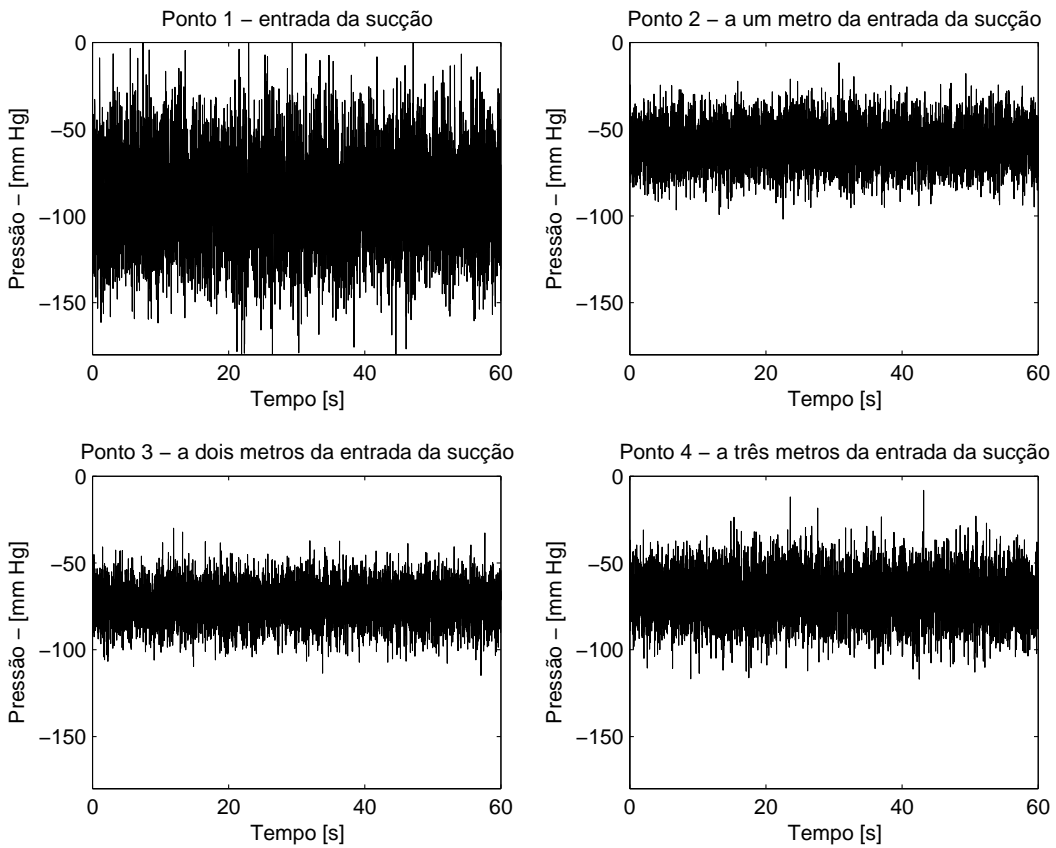

Figura 4.14: Velocidade do escoamento na tubulação $1,1 \mathrm{~m} / \mathrm{s}$ para abertura de $50 \%$ da válvula instalada na sucção.

variância, para todas as condições de ensaio, foi o produzido pelo sensor instalado a dois metros do início da linha de sução. Os resultados para avaliação da pressão, para todos os ensaios, constam na tabela A.1 do apêndice 5 . 
Para avaliarmos a influência da pressão na tubulação de sucção sobre o valor do coeficiente de desoxigenação $K_{3}^{*}$, foi analisada a correlação entre estas duas variáveis.

A figura 4.15 apresenta o diagrama de dispersão entre as variáveis $K_{3}^{*}$ e a pressão na tubulação de sucção. Verifica-se que na medida em que decai a pressão na tubulação de sucção aumenta o valor de $K_{3}^{*}$.

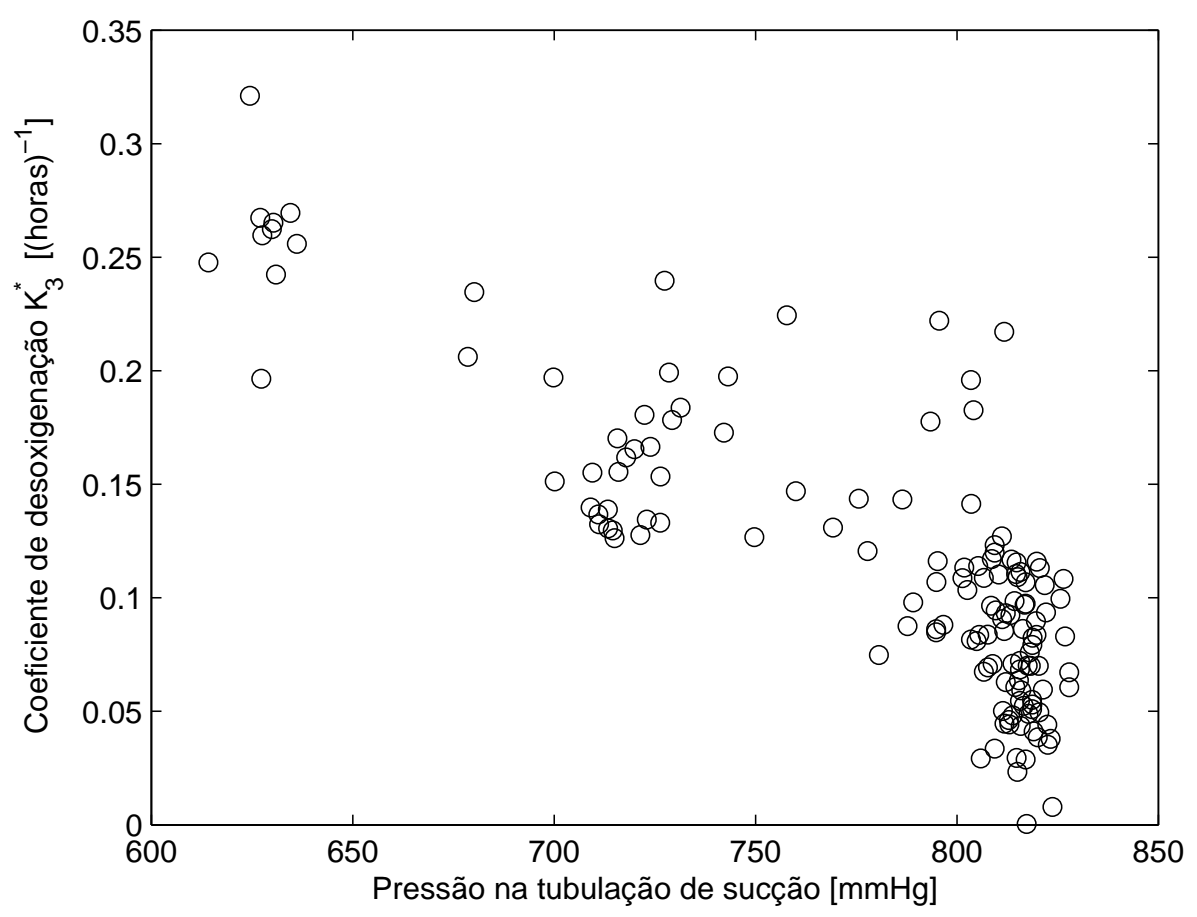

Figura 4.15: Diagrama de dispersão entre $K_{3}^{*}$ e a pressão na tubulação de sucção

Supondo ser linear a correlação entre as variáveis $K_{3}^{*}$ e pressão na tubulação de sucção, obtemos os seguintes resultados estatísticos:

- Reta de regressão linear: $K_{3}^{*}=0,8290-0,000917 p$, em que $p$ é o valor da pressão na tubulação.

- Coeficiente de determinação $R^{2}=0,687$, para um intervalo de confiança de $95 \%$.

A figura 4.16 traz graficamente os resultados apresentados anteriormente. A linha vertical pontilhada equivale à pressão de $690 \mathrm{mmHg}$, e representa a pressão atmosférica média durante os ensaios.

A avaliação da regressão apresentada é realizada com base nos resíduos obtidos entre os valores estimados para $K_{3}^{*}$ pelo modelo novo e os resultados com base na reta 
4.3. Correlação entre o sumidouro de OD e a queda de pressão na tubulação de sucção do sistema de recirculação da água

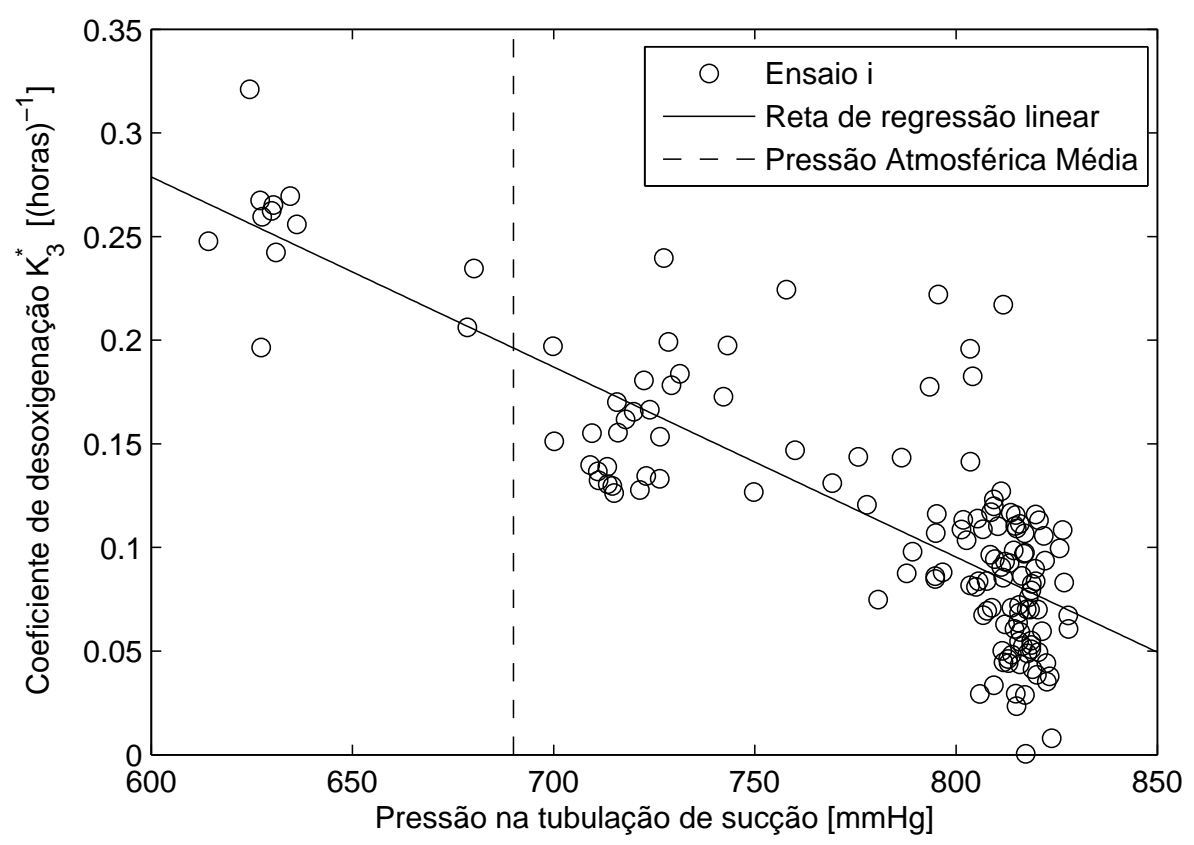

Figura 4.16: Regressão linear entre $K_{3}^{*}$ e a pressão na tubulação de sucção

de regressão linear. Nas figuras 4.17 e 4.18 temos que poucos pontos que representam os resíduos padronizados, estão fora do intervalo $(-2,2)$, ou seja, a maioria dos resíduos estão a 2 desvios padrão do valor esperado 0 .

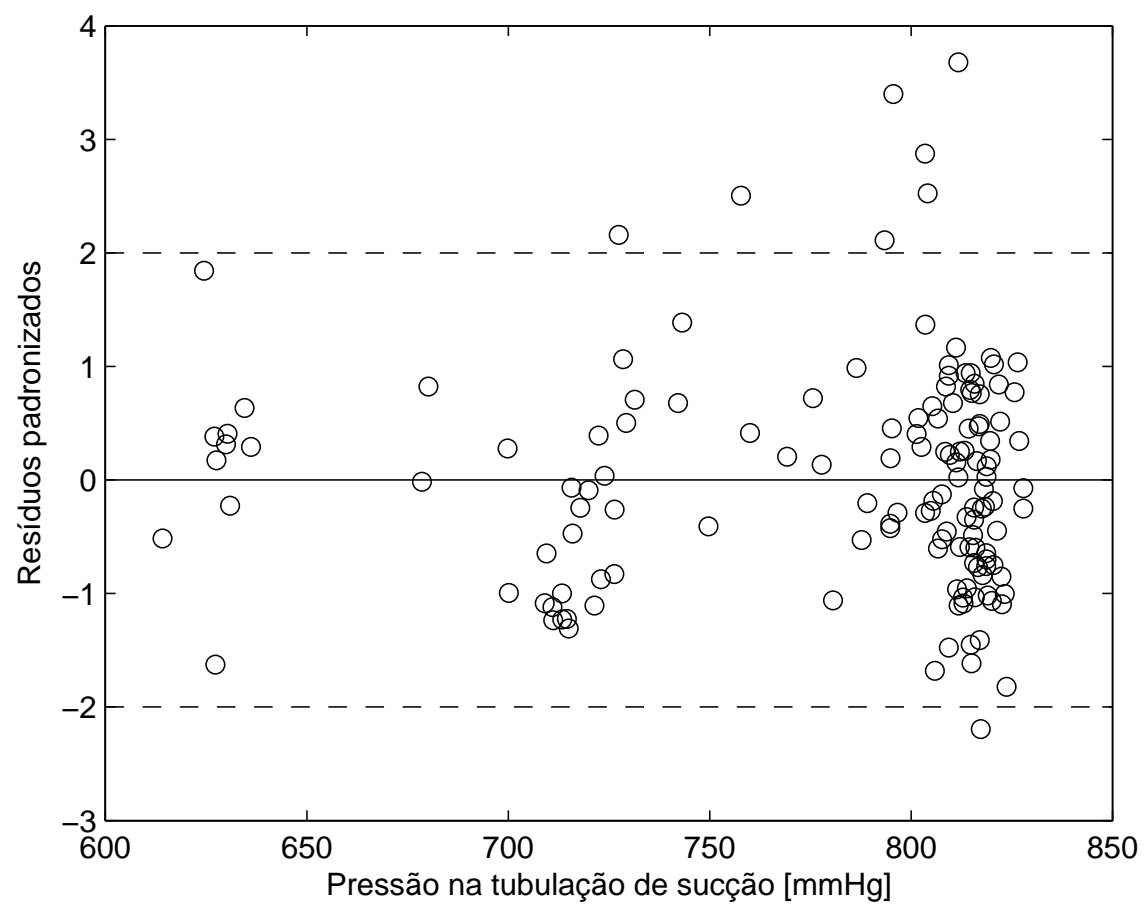

Figura 4.17: Resíduos padronizados versus $K_{3}^{*}$ 


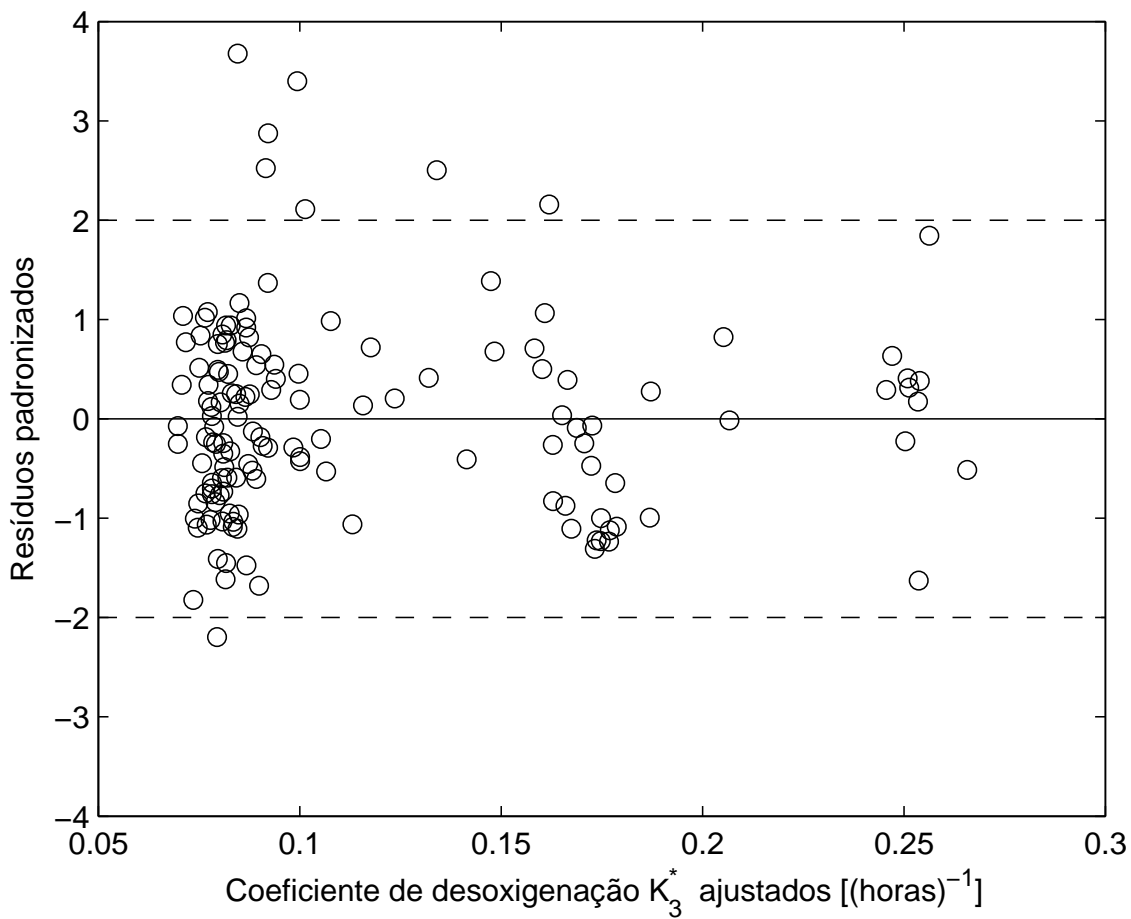

Figura 4.18: Resíduos padronizados versus pressão

Na figura 4.19 temos o gráfico de probabilidade normal dos resíduos padronizados. O gráfico é razoavelmente reto, o que garante uma distribuição normal dos resíduos.

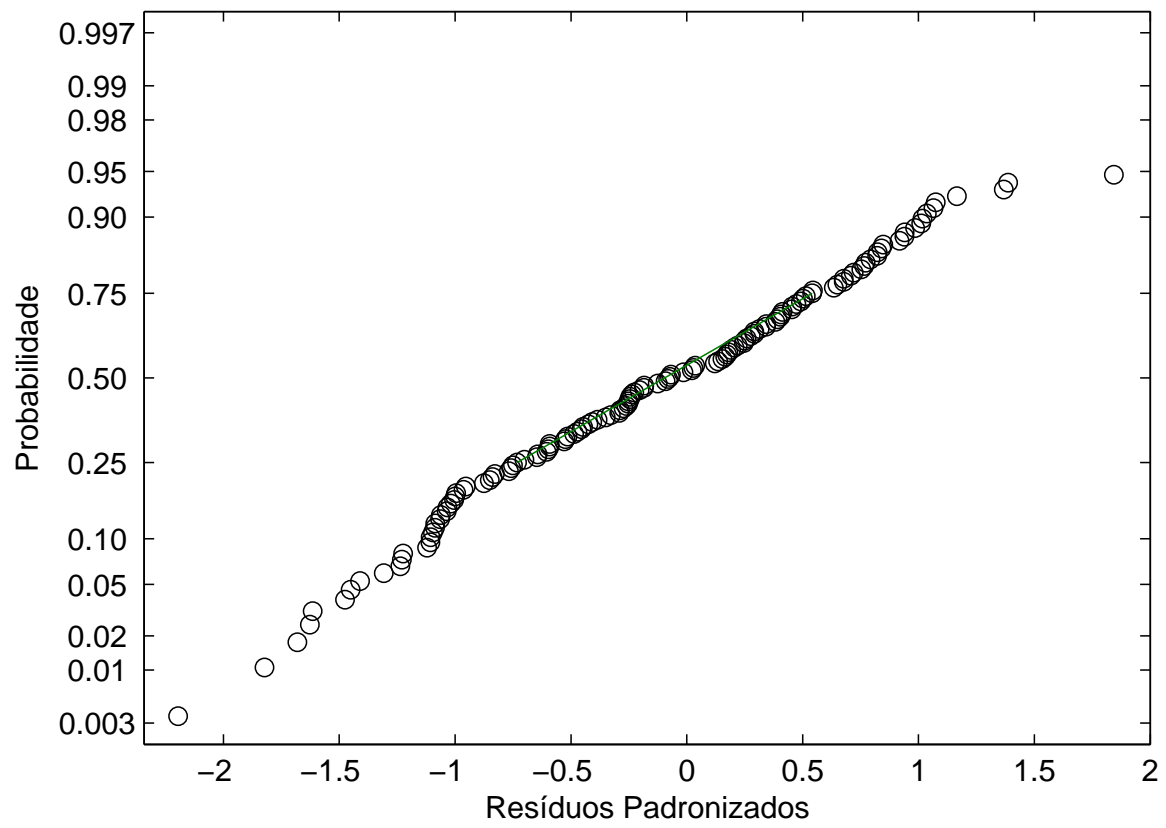

Figura 4.19: Gráfico de Probabilidade Normal 
4.3. Correlação entre o sumidouro de OD e a queda de pressão na tubulação de sucção do sistema de recirculação da água

Como nenhum dos gráficos apresentados nas figuras 4.17 e 4.18 exibem padrões distintos em relação a distribuição dos resíduos e, como verificado na figura 4.19, a distribuição dos erros é aproximadamente normal, pode-se afirmar, dentro de um intervalo de confiança de $95 \%$, que o valor do coeficiente de desoxigenação $K_{3}^{3}$ varia linearmente com a pressão na tubulação de sucção durante os ensaios de reoxigenação realizados neste estudo. 


\section{Capítulo 5}

\section{Considerações Finais}

O coeficiente de reaeração superficial , $K_{2}$, constitui-se no principal parâmetro usado em modelos de qualidade na avaliação preventiva do efeito da descarga de resíduos orgânicos sobre a concentração do oxigênio dissolvido $(O D)$ em cursos de água naturais. Este parâmetro determina a que taxas o oxigênio encontrado na atmosfera é incorporado à água. Estudos para o entendimento da troca gasosa entre ar e água são, na maioria das vezes, realizados em laboratório, em tanques com agitação mecânica, ou em canais com recirculação de água.

Quando um volume de água é exposto à atmosfera, a concentração de $O D$ nesse volume tende à concentração de saturação $C_{s}$, que é determinada pelas condições de temperatura, alcalinidade e pressão que a água é submetida. No Capítulo 2, foram citados alguns exemplos encontrados na literatura em que a concentração de $O D$ tende para um limite estável $C_{s}^{*}$ menor do que $C_{s}$. E esse valor inferior interfere significativamente na determinação do coeficiente de reaeração superficial, $K_{2}$.

O Capítulo 2 apresentou estudos que comprovam ser a concentração de saturação uma variável determinável no modelo matemático que representa a troca de oxigênio na interface ar-água, ou seja, no ajuste do modelo matemático aos dados experimentais não há a necessidade de se estimar $C_{s}$, pois esta pode ser determinada, pela equação 2.42 por exemplo, com erros que não excedem a 0,7\%, para baixas temperaturas, e a 0,4\% para temperaturas próximas a $40^{\circ} \mathrm{C}$. 
Nos experimentos realizados para essa tese, um processo de strippingfoi utilizado para promover o déficit de $O D$ necessário para obtenção da curva de reaeração. Esse processo não gera subprodutos químicos ou biológicos, que acarretariam em consumo do oxigênio dissolvido durante o processo de reoxigenação do volume de água em estudo.

Observou-se nos 142 experimentos realizados para os fins desta tese, assim como nos exemplos citados no Capítulo 2, que a concentração de saturação $C_{s}$ não atingiu o valor esperado, qual seja, o valor determinado pelas condições de temperatura, salinidade e pressão atmosférica em que os experimentos foram realizados. Em média, o valor da concentração experimental limite $\left(C_{s}^{*}\right)$ foi $16,7 \%$ menor que o valor da concentração de saturação, $C_{s}$. O que comprova a existência de um sumidouro de $O D$, não considerado nos estudos de reoxigenação realizados em laboratório.

Ao não considerar-se a existência dos sumidouros de $O D$ nesse tipo de estudo, são produzidos erros significativos na estimativa do coeficiente de reaeração superficial $K_{2}$. Nos estudos aqui realizados, ao estimar-se $K_{2}$ a partir de dados experimentais, considerando $C_{s}$ como uma variável a ser determinada (como é feito nos estudos dessa natureza), foram obtidos valores de $K_{2}$, em média, $52,7 \%$ superiores aos valores estimados para $K_{2}$ quanto utiliza-se o mesmo modelo,considerando porém, $C_{s}$ como uma constante determinada pelas condições experimentais a que a água é submetida.

Isso posto, comprovou-se a ineficácia do modelo matemático que não contempla a presença de sumidouros de $O D$ nessas condições experimentais. Pois nas duas situações consideradas no parágrafo anterior temos: ou uma estimativa equivocada para o valor da concentração de saturação, ou um valor não representativo para o coeficiente de reaeração, uma vez que o modelo ajustado nesta segunda situação é o que apresenta o maior erro de estimação.

Considerando que não há explicação teórica para a baixa estimativa da concentração de saturação de $O D$ obtida pelo modelo clássico, uma vez que esta concentração é determinada pelas condições de pressão, temperatura e alcalinidade a que a água em estudo é submetida, foi proposto um modelo que considerou um coeficiente de desoxigenação para representar o sumidouro de $O D$ não contemplado no modelo clássico. 
Com este novo modelo, equação 2.58, foi possível estimar, a partir dos mesmos dados experimentais, o coeficiente de reaeração com o menor erro de estimação, quando comparado com o erro obtido nas situações citadas anteriormente. Os valores obtidos para $K_{2}$ nesta nova situação apresentaram-se, em média, $21 \%$ inferiores aos obtidos pelo modelo clássico, com $C_{s}$ variável, e 44,3\% superiores aos valores de $K_{2}$ estimados com o modelo clássico, quando considera-se o valor real de $C_{s}$.

O trabalho propôs a hipótese de que o sumidouro de $O D$, observado nesse tipo de procedimento experimental, é criado pelo próprio sistema de movimentação do fluido. No caso dos experimentos aqui relatados, qual seja, canal artificial com recirculação de água, pode ocorrer um sumidouro de oxigênio na linha de sucção da bomba, pois quando há zonas de baixa pressão em um fluido, parte dos gases dissolvidos migra para a fase gasosa, ocorrendo a formação de micro bolhas. Dependendo da velocidade de escoamento na tubulação, essas micro-bolhas são levadas de volta à atmosfera.

Por fim, verificou-se uma correlação linear entre a queda de pressão na linha de sucção e o valor do coeficiente de desoxigenação $K_{3}^{*}$ introduzido no modelo clássico. E acredita-se que os parâmetros da reaeração superficial estimados a partir desse o novo modelo, represente melhor o fenômeno.

Este estudo utilizou-se de um sensor baseado na luminescência, tecnologia relativamente nova que dispensa a utilização de soluções eletrolíticas no interior do sensor e de calibrações constantes, o que garante uma melhor representatividade dos dados coletados em experimentos de longa duração. Em relação aos estudos anteriores, em que sondas amperométricas ou apenas o método de Winkler eram utilizados para obter a concentração de $O D$ durante a reoxigenação da água, o que limitava a quantidade de pontos amostrais, esse novo sensor garante, também, uma maior quantidade de pontos para a curva de reoxigenação, o que minimiza o erro de estimação.

Como contemplado pela literatura, e verificado nos resultados experimentais, a temperatura da água em estudo deve ser mantida o mais constante possível durante os ensaios. Embora tenha-se conseguido certo controle sobre esse fator, o autor acredita 
que deve-se projetar um sistema melhor que o utilizado nesse estudo, para que ocorra a menor interferência possível da temperatura sobre os resultados experimentais.

Outra mudança que o autor sugere aos procedimentos experimentais é a utilização de um sistema de medição da pressão na tubulação de sucção; e também a variação do comprimento e diâmetro desta tubulação. Neste trabalho essas duas características foram mantidas constantes, e o sistema de medição e aquisição de dados relativos à pressão se mostrou instável para longos períodos de amostragem. 


\section{Referências Bibliográficas}

APHA, AWWA, e WEFA (2005). Standard methods for the examination of water and wastewater. American Public Health Association, American Water Works Association, and Water Environment Federation, Washington, DC.

ASCE (2007). Measurement of Oxygen in Clean Water, ASCE/SEI 2-06. ASCE American Society of Civil Engineers (Michael Stenstrom - editor), Reston, Virginia.

Barbosa, A. R. (1989). Desenvolvimento de metodologia para a determinação do coeficiente de reaeração dos escoamentos naturais da água com o emprego de traçador gasoso. Dissertação de mestrado, Escola de Engenharia de São Carlos, Universidade de São Paulo, Brasil.

Barbosa, A. R. (1997). Uso de traçadores na determinação de parâmetros de qualidade em escoamentos naturais da água. Tese de doutorado, Escola de Engenharia de São Carlos, Universidade de São Paulo, Brasil.

Bennett, J. P. e Rathbun, R. E. (1972). Reaeration in Open-Channel Flow. Geological Survey Proffessional Paper 737.

Benson, B. e Krause Jr, D. (1984). The concentration and isotopic fractionation of oxygen dissolved in freshwater and seawater in equilibrium with the atmosphere. Limnology and oceanography, 29(3):620-632.

Boyd, C. E. e Teichert-Coddington, D. (1992). Relationship between wind speed and reaeration in small aquaculture ponds. Aquacultural Engineering, 11(2):121 - 131. 
Brown, L. (1979). Oxygen Transfer Parameter Estimation. Em Proc. Workshop Toward an Oxygen Transfer Standard, EPA-600/9-78-021, EPA, Cincinnati, Ohio.

Brown, L. C. e Stenstrom, M. K. (1980). Proposed modification of $k_{2}$-temperature relation. Journal of the Environmental Engineering Division, 106(6):1193-1196.

Cadwallader, T. e McDonnell, A. (1969). A multivariate analysis of reaeration data. Water Research, 3(10):731-742.

Carpenter, J. (1966). New measurements of oxygen solubility in pure and natural water. Limnology and Oceanography, 11(2):264-277.

Carreira, M. F. (1995). Relação entre o coeficiente de absorção de massa $K_{L} e$ parâmetros de turbulência superficial obtidos por método óptico. Dissertação de mestrado, Escola de Engenharia de São Carlos, Universidade de São Paulo, Brasil.

Carvalho, G. S. d. (1995). Determinação do coeficiente de transferência gasosa de hidrocarbonetos e sua relação com o coeficiente de reaeração. Dissertação de mestrado, Escola de Engenharia de São Carlos, Universidade de São Paulo, Brasil.

CETESB (2005). Coleta e preservação de amostras de água para consumo humano, em atendimento à Portaria 518-MS, de 25/03/2004, volume 1. CETESB - Companhia de Tecnologia de Saneamento Ambiental.

Chang, S. C. (1985). Temperature effect on reaeration coefficient at low oxygenation rate. Thesis, doctor of philosophy, Departament of Civil Engineering, North Carolina State University, United States.

Chao, A. C., Chang, D. S., Charles Smallwood, J., e Galler, W. S. (1987a). Effect of temperature on oxygen transfer - laboratory studies. Journal of Environmental Engineering, 113(5):1089-1101.

Chao, A. C., Chang, D. S., Charles Smallwood, J., e Galler, W. S. (1987b). Influence of temperature on oxygen transfer. Journal of Environmental Engineering, 113(4):722735. 
Churchill, M., Elmore, H., e Buckingham, R. (1962). The prediction of stream reaeration rates. Em Advances in water pollution research: proceedings of the international conference, pg. 89. Symposium Publications Division, Pergamon Press.

Costa, O. S. (1992). Análise do efeito da umidade atmosférica sobre o coeficiente de reoxigenação. Dissertação de mestrado, Escola de Engenharia de São Carlos, Universidade de São Paulo, Brasil.

Costa, O. S. (1999). Contribuição à Metodologia para Determinação Indireta do Coeficiente de Reaeração dos Escoamentos Naturais de Água com Emprego do Método da Sonda Solúvel. Tese de doutorado, Escola de Engenharia de São Carlos, Universidade de São Paulo, Brasil.

Danckwerts, P. V. (1951). Significance of liquid-film coefficients in gas absorption. Industrial and Engineering Chemistry, 43(6):1460-1467.

Danckwerts, P. V. (1955). Gas absorption accompanied by chemical reaction. A.I.Ch.E. $J, 51: 456-463$.

Dobbins, W. (1956). The nature of the oxygen transfer coefficient in aeration systems. Biological Treatment of Sewage and Industrial Wastes, 1.

Elmore, H. e Hayes, T. (1960). Solubility of atmospheric oxygen in water. Em Proc. Am. Sot. Civil Engrs, volume 86, pgs. 41-53.

Elmore, H. e West, W. (1961). Effect of water temperature on stream reaeration. $87: 59-71$.

Garrafa, P. (2009). Avaliação da qualidade virológica do efluente doméstico tratado e disponibilizado para reúso na cidade de São Paulo. Tese de doutorado, Instituto de Ciências Biomédicas, Universidade de São Paulo, Brasil.

Giorgetti, M. F.and Roma, W. N. L., Kurten, M., e Manzolli, I. M. (1995). Reoxygenation and Deoxygenation of Industrial Waste Water in a Batch Reactor - Experiments 
and Modeling. Em Proc. Third International Symposium on Air-Water Gas Transfer, Heidelberg.

Green, E. e Carritt, D. (1967). New tables for oxygen saturation of seawater. JOURNAL OF MARINE RESEARCH.

Gualtieri, C. e Gualtieri, P. (2004). Turbulence-based models for gas transfer analysis with channel shape factor influence. Environmental Fluid Mechanics, 4:249-271.

Gualtieri, C., Gualtieri, P., e Doria, G. P. (2002). Dimensional analysis of reaeration rate in streams. Journal of Environmental Engineering, 128(1):12-18.

Gulliver, J. e Halverson, M. (1989). Air-water gas transfer in open channels. Water Resources Research, 25(8):1783-1793.

Herlina, V. (2005). Gas Transfer at the Air-Water Interface in a Turbulent Flow Environment. Dissertation, Institute of hydromechanical of Karlsruhe University, Alemanha.

Higbie, R. (1935). The rate of absorption of a pure gas into still liquid during short periods of exposure. Journal of the American Institute of Chemical Engineers, 31(5):365387.

Howe, R. H. (1977). Proposed modification of $k_{2}$-temperature relation. Journal of the Environmental Engineering Division, 103(4):729-732.

Hutchinson, G. E. (1957). A treatise on Limnology, volume I. John Wiley and Sons.

Hutton, G. e Haller, L. (2004). Evaluations of the costs and benefits of water and sanitation improvements at the global level. World Health Organization.

Jain, S. e Jha, R. (2005). Comparing the stream re-aeration coefficient estimated from ANN and empirical models. Hydrological Sciences Journal, 50(6):1037-1052.

Jensen, N. (1991). Effect of temperature on gas transfer at low surface renewal rates, pgs. 106-115. Selected Papers from the Second International Symposium on Gas Transfer at Water Surfaces. 
Jha, R., Ojha, C., e Bhatia, K. (2001). Refinement of predictive reaeration equations for a typical Indian river. Hydrological Processes, 15(6):1047-1060.

Krenkel, P. e Orlob, G. (1962). Turbulent diffusion and the reaeration coefficient. J. San. Eng. Dive., ASCE, 88:53-58.

Lagarias, J., Reeds, J., Wright, M., e Wright, P. (1999). Convergence properties of the Nelder-Mead simplex method in low dimensions. SIAM Journal on Optimization, $9(1): 112-147$.

Langbein, W. e Durum, W. (1967). The aeration capacity of streams, USGS Circular No. 542. US Geological Survey, 542(6).

Lewis, M. E. (2006). Dissolved oxygen - capítulo A6. IN. Field measurements: U.S. Geological Survey Techniques of Water-Resources Investigations, book 9, acessado em abril/2010 em http://pubs.water.usgs.gov/twri9A6.

Lewis, W. K. e Whitman, W. G. (1924). Principles of gas absorption. Ind. and Engr Chem., 16(12):1215-1220.

Liss, P. (1973). Processes of gas exchange across an air-water interface. Deep Sea Research and Oceanographic Abstracts, 20(3):221 - 238.

Maia, G. N. (2003). Análise dos Parâmetros Cinéticos no Fenômeno da Reoxigenação e Desoxigenação da Água. Dissertação de mestrado, Escola de Engenharia de São Carlos, Universidade de São Paulo, Brasil.

McCutcheon, S. (1989). Water Quality Modeling. Volume I: Transport and Surface Exchange in Rivers. Water Quality Modeling Series. CRC Press, Inc.

Mello, E. D. (1996). Sistema óptico para avaliação do coeficiente de reaeração superficial em corpos d'água. Dissertação de mestrado, Escola de Engenharia de São Carlos, Universidade de São Paulo, Brasil. 
Montgomery, H., Thom, N., e Cockburn, A. (1964). Determination of dissolved oxygen by the Winkler method and the solubility of oxygen in pure water and sea water. Journal of Applied Chemistry, 14(7):280-296.

Moog, D. e Jirka, G. (1998). Analysis of reaeration equations using mean multiplicative error. Journal of Environmental Engineering, 124(2):104-110.

Moog, D. B. e Jirka, G. H. (1999). Air-water gas transfer in uniform channel flow. Journal of Hydraulic Engineering, 125(1):3-10.

Murray, C. e Riley, J. (1969). The solubility of gases in distilled water and sea waterII. Oxygen. Em Deep Sea Research and Oceanographic Abstracts, volume 16, pgs. 311-320. Elsevier.

O'Connor, D. (1983). Wind effects on gas-liquid transfer coefficients. Journal of Environmental Engineering, 109(3):731-752.

O'Connor, D. e Dobbins, W. (1958). Mechanism of reaeration in natural streams. Transactions of the American Society of Civil Engineers, 123:641-684.

Ohira, T. H. (2005). Fronteira de eficiência em serviços de saneamento no Estado de São Paulo. Dissertação de mestrado, Escola Superior de Agricultura Luiz de Queiroz, Universidade de São Paulo, Brasil.

Oliveira, F. C. (1996). Estudo da influencia da umidade atmosférica sobre o coeficiente de reaeração superficial. Dissertação de mestrado, Escola de Engenharia de São Carlos, Universidade de São Paulo, Brasil.

Owens, M., Edwards, R., e Gibbs, J. (1964). Some Reaeration Studies ion Streams. Internat. Jour. Air Water Poll, 8:469-486.

Parkhurst, J. e Pomeroy, R. (1972). Oxygen absorption in streams. Journal of the Sanitary Engineering Division, 98(1):101-124. 
Penman, H. L. (1948). Natural evaporation from open water, bare soil and grass. Proceedings of the Royal Society of London. Series A, Mathematical and Physical Sciences, 193(1032):pp. 120-145.

Rathbun, R. E. (1981). Discussion of: Proposed modification of $k_{2}$-temperature relation. Journal of the Environmental Engineering Division, 107(5):1111-1112.

Rich, L. (1973). Environmental system engineering. McGraw-Hill, Kogakusha.

Rodrigues, I. C. (1996). Determinação do coeficiente de reaeração superficial de um corpo d'água com o uso de sondas solúveis esféricas. Dissertação de mestrado, Escola de Engenharia de São Carlos, Universidade de São Paulo, Brasil.

Roma, W. N. L. (1988). Medida dos parâmetros de turbulência superficial e sua interrelação com o coeficiente de reaeração. Tese de livre docência, Escola de Engenharia de São Carlos, Universidade de São Paulo, Brasil.

Rubin, H. e Atkinson, J. (2001). Environmental Fluid Mechanics. Marcel Dekker, Inc.

Sawyer, C. N., McCarty, P. L., e Parkin, G. F. (2003). Chemistry for Environmental Engineering and Scienc. McGraw-Hill, 5th edition.

Schulz, H. E. (1985). Investigação do mecanismo de reoxigenação da água em escoamento e sua correlação com o nível de turbulência junto à superfície. Dissertação de mestrado, Escola de Engenharia de São Carlos, Universidade de São Paulo, Brasil.

Schulz, H. E. (1989). Investigação do mecanismo de reoxigenação da água em escoamento e sua correlação com o nível de turbulência junto à superfície. Tese de doutorado, Escola de Engenharia de São Carlos, Universidade de São Paulo, Brasil.

Silveira, A. (2004). Influência da Umidade Atmosférica sobre o Mecanismo de Transferência de Gases através da Interface Água-Atmosfera. Tese de doutorado, Escola de Engenharia de São Carlos, Universidade de São Paulo, Brasil.

Smoot, J. (1988). An examination of stream reaeration coefficients and hydraulic conditions in a pool-and-riffle stream. Virginia Polytechnic Institute and State University. 
Stenstrom, M., Hwang, H., e Brown, L. (1981). Oxygen Transfer Parameter Estimation. Journal of the Environmental Engineering Division, 107(2):379-398.

Stenstrom, M., Leu, S., e Jiang, P. (2006). Theory to Practice: Oxygen Transfer and the New ASCE Standard. Proceedings of the Water Environment Federation, 2006(7):4838-4852.

Streeter, H. (1926). The Rate of Atmospheric Reaeration of Sewage Polluted Streams. Transactions of the American Society of Civil Engineers, 89(1):1351-1364.

Streeter, H., Wright, C., e Kehr, R. (1936). Measures of natural oxidation in polluted streams. III. An experimental study of atmospheric reaeration under stream-flow conditions. Sewage Works Journal, 8(2):282-316.

Széliga, M. R. (2003). Sistema óptico baseado em visão computacional para obtenção de niveis de turbulência na superfície de escoamentos livres com aplicação na determinação de parâmetros relacionados com a reoxigenação do meio líquido. Tese de doutorado, Escola de Engenharia de São Carlos, Universidade de São Paulo, Brasil.

Thackston, E. e Krenkel, P. (1969). Reaeration prediction in natural streams. Journal of the Sanitary Engineering Division, 95(SA1):65-94.

Thackston, E. L. e Dawson, J. W. (2001). Recalibration of a reaeration equation. Journal of Environmental Engineering, 127(4):317-321.

Truesdale, G. e Downing, A. (1954). Solubility of oxygen in water. Nature, 173(1236).

Truesdale, G., Downing, A., e Lowden, G. (1955). The solubility of oxygen in pure water and sea-water. J. appl. Chem, 5(2):53-62.

Tsivoglou, E. e Wallace, J. (1972). Characterization of Stream Reaeration Capacity. Technical report, DC EPA-R3-72-012.

Velz, C. (1984). Applied stream sanitation. John Wiley and Sons Inc., New York, NY. 
Wanninkhof, R. (1992). Relationship between wind speed and gas exchange over the ocean. Journal of Geophisics Research, 26(1-2):7373-7382.

Weiss, R. (1970). The solubility of nitrogen, oxygen and argon in water and seawater. Deep Sea Research and Oceanographic Abstracts, 17(4):721-735.

Whitman, W. G. (1923). The two-film theory of gas absorption. Chem. and Met. Engr., 29(4):146-148.

WHO (2008). The Global Burden of disease - 2004 Update. WHO Press - World Health Organization.

WHO e UNICEF (2010). Progress on Sanitation and Drinking-water: 2010 Update. WHO Press - World Health Organization.

Wilde, F., Radtke, D., Gibs, J., e Iwatsubo, R. (1997). National field manual for the collection of water-quality data: US Geological Survey Techniques of WaterResources Investigations, book 9, chapter 6. A6, variously paged. 
Apêndice A

Resultados Numéricos 
Tabela A.1: Resultados Obtidos com o Ajuste do Modelo Clássico com $C_{s}$ Variável

\begin{tabular}{|c|c|c|c|c|c|c|c|c|}
\hline Ensaio & $\begin{array}{c}(1) \\
\text { Velocidade } \\
{[\mathrm{m} / \mathrm{s}]}\end{array}$ & $\begin{array}{c}(2) \\
\text { Vazão } \\
{\left[\mathrm{m}^{3} / \mathrm{s}\right]}\end{array}$ & $\begin{array}{c}(3) \\
\text { Pressão } \\
{[m m H g]}\end{array}$ & $\begin{array}{c}(4) \\
C_{s}^{*} \\
{[m g / L]}\end{array}$ & $\begin{array}{c}(5) \\
K_{2} \\
{\left[\text { horas }^{-1}\right]}\end{array}$ & $\begin{array}{c}(6) \\
C_{0} \\
{[m g / L]}\end{array}$ & $\begin{array}{c}(7) \\
\text { RMSE } \\
{[m g / L]}\end{array}$ & $\begin{array}{c}(8) \\
\mathrm{MME} \\
{[m g / L]}\end{array}$ \\
\hline 1 & 0,6527 & 0,0031 & 627,55 & 6,220 & 1,103 & 2,390 & 0,0271 & 1,0000 \\
\hline 2 & 0,6527 & 0,0031 & 680,19 & 6,055 & 0,954 & 1,214 & 0,0171 & 0,9998 \\
\hline 3 & 0,7929 & 0,0037 & 808,68 & 5,932 & 0,477 & 1,736 & 0,0228 & 0,9998 \\
\hline 4 & 0,7929 & 0,0037 & 826,87 & 6,423 & 0,451 & 3,110 & 0,0317 & 1,0000 \\
\hline 5 & 1,0008 & 0,0047 & 807,63 & 7,244 & 1,087 & 3,696 & 0,0282 & 1,0000 \\
\hline 6 & 1,0009 & 0,0047 & 714,56 & 6,870 & 1,092 & 2,629 & 0,0216 & 1,0001 \\
\hline 7 & 0,8512 & 0,0040 & 678,57 & 6,423 & 1,095 & 2,099 & 0,0189 & 0,9999 \\
\hline 8 & 1,1633 & 0,0055 & 630,97 & 5,515 & 0,819 & 2,614 & 0,0291 & 1,0001 \\
\hline 9 & 1,1633 & 0,0055 & 630,35 & 5,560 & 0,915 & 0,333 & 0,0127 & 1,0016 \\
\hline 10 & 0,8452 & 0,0040 & 819,63 & 6,527 & 0,675 & 3,227 & 0,0051 & 1,0000 \\
\hline 11 & 0,8453 & 0,0040 & 722,42 & 5,331 & 0,634 & 1,672 & 0,0212 & 1,0001 \\
\hline 12 & 0,8579 & 0,0040 & 811,74 & 5,312 & 0,771 & 1,794 & 0,0194 & 0,9999 \\
\hline 13 & 0,6532 & 0,0031 & 811,23 & 6,096 & 0,527 & 2,725 & 0,0277 & 1,0001 \\
\hline 14 & 0,6530 & 0,0031 & 814,83 & 6,008 & 0,527 & 2,141 & 0,0288 & 1,0002 \\
\hline 15 & 0,6529 & 0,0031 & 827,88 & 6,971 & 0,671 & 3,152 & 0,0089 & 1,0000 \\
\hline 16 & 0,5655 & 0,0027 & 820,31 & 6,490 & 0,469 & 2,358 & 0,0256 & 1,0002 \\
\hline 17 & 0,5653 & 0,0027 & 821,78 & 6,082 & 0,455 & 0,881 & 0,0185 & 1,0006 \\
\hline 18 & 0,9462 & 0,0045 & 614,21 & 5,654 & 0,937 & 3,320 & 0,0125 & 1,0000 \\
\hline 19 & 0,9464 & 0,0045 & 727,41 & 5,282 & 0,810 & 2,380 & 0,0067 & 1,0000 \\
\hline 20 & 0,9464 & 0,0045 & 715,71 & 5,893 & 0,781 & 3,154 & 0,0173 & 1,0000 \\
\hline 21 & 0,9463 & 0,0045 & 805,55 & 6,911 & 0,964 & 5,411 & 0,0063 & 1,0000 \\
\hline 22 & 0,9465 & 0,0045 & 634,51 & 5,519 & 1,043 & 3,719 & 0,0064 & 1,0000 \\
\hline 23 & 0,9465 & 0,0045 & 629,93 & 5,414 & 0,974 & 2,768 & 0,0067 & 1,0000 \\
\hline 24 & 0,9464 & 0,0045 & 627,32 & 5,937 & 0,940 & 3,159 & 0,0134 & 1,0000 \\
\hline 25 & 0,4840 & 0,0023 & 636,17 & 6,519 & 1,187 & 2,776 & 0,0077 & 1,0000 \\
\hline 26 & 0,4840 & 0,0023 & 728,54 & 6,574 & 0,979 & 3,534 & 0,0092 & 1,0000 \\
\hline 27 & 0,4840 & 0,0023 & 711,16 & 7,208 & 0,994 & 3,719 & 0,0125 & 1,0000 \\
\hline 28 & 0,4841 & 0,0023 & 757,80 & 6,522 & 1,167 & 3,246 & 0,0272 & 1,0000 \\
\hline 29 & 0,5361 & 0,0025 & 787,74 & 7,419 & 0,660 & 3,463 & 0,0070 & 1,0000 \\
\hline 30 & 0,5361 & 0,0025 & 726,35 & 6,685 & 0,620 & 2,934 & 0,0057 & 1,0000 \\
\hline 31 & 0,5361 & 0,0025 & 816,62 & 7,812 & 0,606 & 2,648 & 0,0048 & 1,0000 \\
\hline 32 & 0,5360 & 0,0025 & 804,92 & 7,463 & 0,610 & 1,703 & 0,0060 & 1,0000 \\
\hline 33 & 0,5360 & 0,0025 & 813,89 & 8,012 & 0,617 & 4,642 & 0,0071 & 1,0000 \\
\hline 34 & 0,6605 & 0,0031 & 806,72 & 7,826 & 0,694 & 4,089 & 0,0119 & 1,0000 \\
\hline 35 & 0,6607 & 0,0031 & 726,40 & 6,369 & 0,669 & 2,966 & 0,0047 & 1,0000 \\
\hline 36 & 0,6607 & 0,0031 & 769,22 & 6,661 & 0,658 & 3,871 & 0,0056 & 1,0000 \\
\hline 37 & 0,6687 & 0,0032 & 803,47 & 7,244 & 0,668 & 3,585 & 0,0106 & 1,0000 \\
\hline 38 & 0,6687 & 0,0032 & 719,92 & 6,257 & 0,688 & 2,728 & 0,0205 & 0,9963 \\
\hline 39 & 0,6687 & 0,0032 & 818,70 & 7,793 & 0,841 & 4,754 & 0,0099 & 1,0000 \\
\hline 40 & 0,6998 & 0,0033 & 815,10 & 7,267 & 0,815 & 3,324 & 0,0053 & 1,0000 \\
\hline 41 & 0,6999 & 0,0033 & 815,81 & 7,083 & 0,776 & 2,736 & 0,0110 & 1,0000 \\
\hline 42 & 0,9895 & 0,0047 & 731,39 & 6,812 & 0,861 & 2,920 & 0,0186 & 1,0000 \\
\hline 43 & 0,9898 & 0,0047 & 627,06 & 6,374 & 1,201 & 2,435 & 0,0128 & 1,0000 \\
\hline 44 & 0,9899 & 0,0047 & 810,40 & 7,258 & 1,156 & 2,892 & 0,0086 & 1,0000 \\
\hline 45 & 0,9899 & 0,0047 & 786,49 & 6,843 & 0,966 & 3,424 & 0,0088 & 1,0000 \\
\hline 46 & 0,8447 & 0,0040 & 796,65 & 7,188 & 0,781 & 2,255 & 0,0224 & 1,0001 \\
\hline 47 & 0,8448 & 0,0040 & 793,42 & 6,647 & 1,029 & 2,890 & 0,0229 & 1,0000 \\
\hline 48 & 1,0480 & 0,0049 & 723,89 & 5,699 & 0,690 & 2,216 & 0,0245 & 0,9999 \\
\hline 49 & 1,0481 & 0,0049 & 804,10 & 5,710 & 0,792 & 2,807 & 0,0121 & 1,0000 \\
\hline 50 & 1,0480 & 0,0049 & 777,82 & 6,480 & 0,913 & 3,601 & 0,0222 & 1,0000 \\
\hline
\end{tabular}


Continuação da Tabela A.1.

\begin{tabular}{|c|c|c|c|c|c|c|c|c|}
\hline Ensaio & $\begin{array}{c}1) \\
\text { Velocidade } \\
{[\mathrm{m} / \mathrm{s}]}\end{array}$ & $\begin{array}{c}(2) \\
\text { Vazão } \\
{\left[\mathrm{m}^{3} / \mathrm{s}\right]}\end{array}$ & $\begin{array}{c}(3) \\
\text { Pressão } \\
{[m m H g]}\end{array}$ & $\begin{array}{c}(4) \\
C_{s}^{*} \\
{[m g / L]}\end{array}$ & $\begin{array}{c}(5) \\
K_{2} \\
{\left[\text { horas }^{-1}\right]}\end{array}$ & $\begin{array}{c}(6) \\
C_{0} \\
{[m g / L]}\end{array}$ & $\begin{array}{c}(7) \\
\mathrm{RMSE} \\
{[m g / L]}\end{array}$ & $\begin{array}{c}(8) \\
\mathrm{MME} \\
{[m g / L]}\end{array}$ \\
\hline 51 & 1,0482 & 0,0049 & 699,86 & 5,817 & 0,936 & 2,945 & 0,0208 & 1,0000 \\
\hline 52 & 1,0481 & 0,0049 & 795,60 & 5,814 & 1,016 & 2,708 & 0,0578 & 1,0000 \\
\hline 53 & 0,3422 & 0,0016 & 823,75 & 7,829 & 0,244 & 4,127 & 0,0048 & 1,0000 \\
\hline 54 & 0,3423 & 0,0016 & 817,07 & 5,551 & 0,347 & 2,421 & 0,0053 & 1,0000 \\
\hline 55 & 0,3424 & 0,0016 & 813,77 & 5,770 & 0,337 & 3,072 & 0,0047 & 1,0000 \\
\hline 56 & 0,3422 & 0,0016 & 817,29 & 7,711 & 0,315 & 4,138 & 0,0051 & 1,0000 \\
\hline 57 & 0,3424 & 0,0016 & 823,27 & 6,785 & 0,452 & 3,704 & 0,0038 & 1,0000 \\
\hline 58 & 0,3424 & 0,0016 & 813,31 & 6,019 & 0,515 & 3,229 & 0,0062 & 1,0000 \\
\hline 59 & 0,3423 & 0,0016 & 825,72 & 5,870 & 0,396 & 2,292 & 0,0055 & 1,0000 \\
\hline 60 & 0,3423 & 0,0016 & 715,04 & 5,753 & 0,469 & 2,373 & 0,0065 & 1,0000 \\
\hline 61 & 0,3423 & 0,0016 & 819,03 & 6,888 & 0,373 & 3,882 & 0,0055 & 1,0000 \\
\hline 62 & 0,3423 & 0,0016 & 809,39 & 5,274 & 0,390 & 2,213 & 0,0060 & 1,0000 \\
\hline 63 & 0,5108 & 0,0024 & 813,57 & 5,448 & 0,394 & 2,183 & 0,0080 & 1,0000 \\
\hline 64 & 0,5111 & 0,0024 & 815,65 & 6,097 & 0,431 & 3,234 & 0,0062 & 1,0000 \\
\hline 65 & 0,5110 & 0,0024 & 809,63 & 5,638 & 0,393 & 2,507 & 0,0051 & 1,0000 \\
\hline 66 & 0,5111 & 0,0024 & 809,37 & 6,634 & 0,451 & 3,918 & 0,0070 & 1,0000 \\
\hline 67 & 0,5109 & 0,0024 & 820,47 & 6,731 & 0,408 & 3,494 & 0,0056 & 1,0000 \\
\hline 68 & 0,5108 & 0,0024 & 814,72 & 5,731 & 0,404 & 2,326 & 0,0098 & 1,0000 \\
\hline 69 & 0,5111 & 0,0024 & 801,80 & 5,244 & 0,400 & 3,050 & 0,0056 & 1,0000 \\
\hline 70 & 0,5109 & 0,0024 & 826,49 & 5,523 & 0,384 & 2,428 & 0,0056 & 1,0000 \\
\hline 71 & 0,5111 & 0,0024 & 808,84 & 5,314 & 0,259 & 3,116 & 0,0053 & 1,0000 \\
\hline 72 & 0,5109 & 0,0024 & 815,00 & 7,128 & 0,425 & 4,049 & 0,0076 & 1,0000 \\
\hline 73 & 0,6851 & 0,0032 & 817,07 & 5,253 & 0,416 & 2,343 & 0,0128 & 1,0000 \\
\hline 74 & 0,6847 & 0,0032 & 808,46 & 5,625 & 0,373 & 2,487 & 0,0287 & 1,0001 \\
\hline 75 & 0,6847 & 0,0032 & 816,34 & 6,004 & 0,415 & 2,842 & 0,0059 & 1,0000 \\
\hline 76 & 0,6849 & 0,0032 & 819,79 & 5,501 & 0,472 & 2,681 & 0,0049 & 1,0000 \\
\hline 77 & 0,6847 & 0,0032 & 802,62 & 5,760 & 0,437 & 2,705 & 0,0100 & 1,0000 \\
\hline 78 & 0,6849 & 0,0032 & 817,74 & 6,452 & 0,408 & 3,464 & 0,0047 & 1,0000 \\
\hline 79 & 0,6847 & 0,0032 & 794,84 & 5,814 & 0,359 & 3,151 & 0,0049 & 1,0000 \\
\hline 80 & 0,6849 & 0,0032 & 813,02 & 6,637 & 0,470 & 4,140 & 0,0056 & 1,0000 \\
\hline 81 & 0,6847 & 0,0032 & 812,13 & 5,932 & 0,421 & 2,893 & 0,0057 & 1,0000 \\
\hline 82 & 0,6846 & 0,0032 & 817,08 & 7,124 & 0,375 & 4,550 & 0,0069 & 1,0000 \\
\hline 83 & 0,4951 & 0,0023 & 827,90 & 6,254 & 0,372 & 3,145 & 0,0069 & 1,0000 \\
\hline 84 & 0,4951 & 0,0023 & 814,85 & 7,011 & 0,454 & 3,882 & 0,0061 & 1,0000 \\
\hline 85 & 0,4950 & 0,0023 & 819,76 & 6,710 & 0,653 & 3,554 & 0,0061 & 1,0000 \\
\hline 86 & 0,4950 & 0,0023 & 820,57 & 6,318 & 0,664 & 3,220 & 0,0066 & 1,0000 \\
\hline 87 & 0,4952 & 0,0023 & 715,98 & 5,791 & 0,748 & 2,880 & 0,0062 & 1,0000 \\
\hline 88 & 0,4951 & 0,0023 & 742,18 & 5,737 & 0,754 & 3,050 & 0,0075 & 1,0000 \\
\hline 89 & 0,4952 & 0,0023 & 811,20 & 6,170 & 0,844 & 3,293 & 0,0068 & 1,0000 \\
\hline 90 & 0,4951 & 0,0023 & 818,69 & 6,893 & 0,768 & 4,086 & 0,0052 & 1,0000 \\
\hline 91 & 0,4951 & 0,0023 & 811,80 & 6,779 & 0,540 & 3,990 & 0,0093 & 1,0000 \\
\hline 92 & 0,4951 & 0,0023 & 818,37 & 6,578 & 0,595 & 3,761 & 0,0096 & 1,0000 \\
\hline 93 & 0,7444 & 0,0035 & 811,75 & 6,168 & 0,472 & 2,978 & 0,0087 & 1,0000 \\
\hline 94 & 0,7445 & 0,0035 & 815,84 & 6,750 & 0,545 & 3,846 & 0,0048 & 1,0000 \\
\hline 95 & 0,7443 & 0,0035 & 795,22 & 6,019 & 0,552 & 3,004 & 0,0066 & 1,0000 \\
\hline 96 & 0,7444 & 0,0035 & 822,42 & 6,908 & 0,535 & 3,878 & 0,0093 & 1,0000 \\
\hline 97 & 0,7447 & 0,0035 & 759,99 & 5,498 & 0,634 & 2,765 & 0,0063 & 1,0000 \\
\hline 98 & 0,7446 & 0,0035 & 821,37 & 6,535 & 0,574 & 3,619 & 0,0090 & 1,0000 \\
\hline 99 & 0,7445 & 0,0035 & 815,65 & 6,685 & 0,618 & 3,831 & 0,0069 & 1,0000 \\
\hline
\end{tabular}


Continuação da Tabela A.1.

\begin{tabular}{|c|c|c|c|c|c|c|c|c|}
\hline Ensaio & $\begin{array}{c}(1) \\
\text { Velocidade } \\
{[\mathrm{m} / \mathrm{s}]}\end{array}$ & $\begin{array}{c}(2) \\
\text { Vazão } \\
{\left[\mathrm{m}^{3} / \mathrm{s}\right]}\end{array}$ & $\begin{array}{c}(3) \\
\text { Pressão } \\
{[m m H g]}\end{array}$ & $\begin{array}{c}(4) \\
C_{s}^{*} \\
{[m g / L]}\end{array}$ & $\begin{array}{c}(5) \\
K_{2} \\
\left.\text { horas }^{-1}\right]\end{array}$ & $\begin{array}{c}(6) \\
C_{0} \\
{[m g / L]}\end{array}$ & $\begin{array}{c}(7) \\
\text { RMSE } \\
{[m g / L]}\end{array}$ & $\begin{array}{c}(8) \\
\mathrm{MME} \\
{[m g / L]}\end{array}$ \\
\hline 100 & 0,7446 & 0,0035 & 811,44 & 6,552 & 0,517 & 4,137 & 0,0153 & 1,0000 \\
\hline 101 & 0,7447 & 0,0035 & 789,17 & 6,013 & 0,634 & 3,277 & 0,0066 & 1,0000 \\
\hline 102 & 0,7446 & 0,0035 & 817,56 & 6,322 & 0,527 & 3,484 & 0,0099 & 1,0000 \\
\hline 103 & 0,9907 & 0,0047 & 815,97 & 6,319 & 0,639 & 3,678 & 0,0080 & 1,0000 \\
\hline 104 & 0,9905 & 0,0047 & 801,37 & 5,809 & 0,585 & 2,946 & 0,0065 & 1,0000 \\
\hline 105 & 0,9905 & 0,0047 & 818,07 & 6,346 & 0,635 & 3,374 & 0,0064 & 1,0000 \\
\hline 106 & 0,9905 & 0,0047 & 816,83 & 6,002 & 0,601 & 3,095 & 0,0096 & 1,0000 \\
\hline 107 & 0,9903 & 0,0047 & 713,33 & 5,738 & 0,647 & 2,816 & 0,0060 & 1,0000 \\
\hline 108 & 0,9905 & 0,0047 & 814,50 & 6,490 & 0,684 & 3,801 & 0,0068 & 1,0000 \\
\hline 109 & 0,9906 & 0,0047 & 723,01 & 5,724 & 0,695 & 3,076 & 0,0075 & 1,0000 \\
\hline 110 & 0,9903 & 0,0047 & 710,97 & 5,786 & 0,638 & 3,328 & 0,0151 & 1,0000 \\
\hline 111 & 0,9903 & 0,0047 & 807,74 & 6,498 & 0,578 & 3,510 & 0,0094 & 1,0000 \\
\hline 112 & 0,9905 & 0,0047 & 818,81 & 6,106 & 0,550 & 3,646 & 0,0105 & 1,0000 \\
\hline 113 & 0,6768 & 0,0032 & 806,66 & 6,426 & 0,676 & 2,965 & 0,0054 & 1,0000 \\
\hline 114 & 0,6768 & 0,0032 & 805,92 & 7,416 & 0,699 & 4,072 & 0,0045 & 1,0000 \\
\hline 115 & 0,6765 & 0,0032 & 818,69 & 7,443 & 0,931 & 3,659 & 0,0068 & 1,0000 \\
\hline 116 & 0,6770 & 0,0032 & 822,54 & 7,156 & 0,948 & 3,993 & 0,0068 & 1,0000 \\
\hline 117 & 0,6767 & 0,0032 & 812,91 & 7,499 & 1,057 & 3,957 & 0,0060 & 1,0000 \\
\hline 118 & 0,6770 & 0,0032 & 803,46 & 5,905 & 0,993 & 2,830 & 0,0110 & 1,0000 \\
\hline 119 & 0,6767 & 0,0032 & 729,29 & 6,640 & 1,097 & 3,215 & 0,0187 & 1,0000 \\
\hline 120 & 0,6766 & 0,0032 & 814,29 & 7,197 & 0,983 & 3,659 & 0,0108 & 1,0000 \\
\hline 121 & 0,6768 & 0,0032 & 743,18 & 5,782 & 0,816 & 2,944 & 0,0166 & 1,0000 \\
\hline 122 & 0,6767 & 0,0032 & 820,09 & 7,465 & 0,788 & 4,091 & 0,0064 & 1,0000 \\
\hline 123 & 1,0169 & 0,0048 & 822,09 & 6,415 & 0,775 & 3,337 & 0,0096 & 1,0000 \\
\hline 124 & 1,0170 & 0,0048 & 780,64 & 6,550 & 0,800 & 3,685 & 0,0083 & 1,0000 \\
\hline 125 & 1,0170 & 0,0048 & 700,17 & 5,883 & 0,809 & 2,887 & 0,0041 & 1,0000 \\
\hline 126 & 1,0166 & 0,0048 & 709,51 & 6,282 & 0,897 & 2,924 & 0,0047 & 1,0000 \\
\hline 127 & 1,0165 & 0,0048 & 818,69 & 7,125 & 0,791 & 3,865 & 0,0077 & 1,0000 \\
\hline 128 & 1,0165 & 0,0048 & 794,92 & 6,619 & 0,779 & 3,408 & 0,0062 & 1,0000 \\
\hline 129 & 1,0165 & 0,0048 & 805,30 & 6,705 & 0,841 & 3,529 & 0,0131 & 1,0000 \\
\hline 130 & 1,0165 & 0,0048 & 721,39 & 6,549 & 0,863 & 3,298 & 0,0105 & 1,0000 \\
\hline 131 & 1,0170 & 0,0048 & 713,42 & 5,854 & 0,691 & 3,171 & 0,0133 & 1,0000 \\
\hline 132 & 1,0167 & 0,0048 & 775,66 & 5,829 & 0,647 & 3,017 & 0,0122 & 1,0000 \\
\hline 133 & 1,3547 & 0,0064 & 815,37 & 6,457 & 0,968 & 3,642 & 0,0110 & 1,0000 \\
\hline 134 & 1,3549 & 0,0064 & 709,08 & 5,787 & 0,922 & 3,044 & 0,0065 & 1,0000 \\
\hline 135 & 1,3535 & 0,0064 & 749,73 & 6,473 & 0,766 & 3,185 & 0,0124 & 1,0000 \\
\hline 136 & 1,3550 & 0,0064 & 812,15 & 6,386 & 1,049 & 3,885 & 0,0069 & 1,0000 \\
\hline 137 & 1,3545 & 0,0064 & 815,65 & 6,583 & 1,083 & 3,906 & 0,0092 & 1,0000 \\
\hline 138 & 1,3542 & 0,0064 & 809,40 & 6,252 & 0,872 & 3,727 & 0,0132 & 1,0000 \\
\hline 139 & 1,3548 & 0,0064 & 624,50 & 5,127 & 1,242 & 2,392 & 0,0336 & 1,0000 \\
\hline 140 & 1,3543 & 0,0064 & 803,54 & 6,284 & 1,125 & 3,400 & 0,0095 & 1,0000 \\
\hline 141 & 1,3545 & 0,0064 & 717,88 & 5,710 & 0,840 & 3,727 & 0,0132 & 1,0000 \\
\hline 142 & 1,3545 & 0,0064 & 794,84 & 6,275 & 0,762 & 3,898 & 0,0135 & 1,0000 \\
\hline
\end{tabular}


Tabela A.2: Resultados Obtidos com o Ajuste do Modelo Clássico com $C_{s}$ Determinado

\begin{tabular}{|c|c|c|c|c|c|c|c|c|}
\hline Ensaio & $\begin{array}{c}(1) \\
\text { Velocidade } \\
{[\mathrm{m} / \mathrm{s}]}\end{array}$ & $\begin{array}{c}(2) \\
\text { Vazão } \\
{\left[\mathrm{m}^{3} / \mathrm{s}\right]}\end{array}$ & $\begin{array}{c}(3) \\
\text { Pressão } \\
{[m m H g]}\end{array}$ & $\begin{array}{c}(4) \\
C_{s} \\
{[m g / L]}\end{array}$ & $\begin{array}{c}(5) \\
C_{0} \\
{[m g / L]}\end{array}$ & $\begin{array}{c}(6) \\
K_{2} \\
\text { horas }^{-1} \text { ] }\end{array}$ & $\begin{array}{c}(7) \\
\text { RMSE } \\
{[m g / L]}\end{array}$ & $\begin{array}{c}(8) \\
\mathrm{MME} \\
{[m g / L]}\end{array}$ \\
\hline 1 & 0,6527 & 0,0031 & 627,55 & 8,135 & 5,256 & 0,040 & 0,4945 & 1,0060 \\
\hline 2 & 0,6527 & 0,0031 & 680,19 & 8,029 & 2,541 & 0,274 & 0,4432 & 1,0164 \\
\hline 3 & 0,7929 & 0,0037 & 808,68 & 7,858 & 2,523 & 0,166 & 0,2910 & 1,0078 \\
\hline 4 & 0,7929 & 0,0037 & 826,87 & 7,872 & 4,523 & 0,079 & 0,3835 & 1,0060 \\
\hline 5 & 1,0008 & 0,0047 & 807,63 & 7,849 & 4,674 & 0,428 & 0,3320 & 1,0144 \\
\hline 6 & 1,0009 & 0,0047 & 714,56 & 7,796 & 3,710 & 0,420 & 0,3585 & 1,0122 \\
\hline 7 & 0,8512 & 0,0040 & 678,57 & 7,913 & 3,143 & 0,370 & 0,3644 & 1,0097 \\
\hline 8 & 1,1633 & 0,0055 & 630,97 & 7,834 & 4,498 & 0,038 & 0,3838 & 1,0045 \\
\hline 9 & 1,1633 & 0,0055 & 630,35 & 7,830 & 1,385 & 0,313 & 0,3797 & 1,0346 \\
\hline 10 & 0,8452 & 0,0040 & 819,63 & 7,529 & 3,380 & 0,409 & 0,0664 & 1,0007 \\
\hline 11 & 0,8453 & 0,0040 & 722,42 & 7,454 & 3,340 & 0,086 & 0,4417 & 1,0108 \\
\hline 12 & 0,8579 & 0,0040 & 811,74 & 7,394 & 2,970 & 0,154 & 0,3713 & 1,0090 \\
\hline 13 & 0,6532 & 0,0031 & 811,23 & 7,363 & 3,518 & 0,175 & 0,2680 & 1,0056 \\
\hline 14 & 0,6530 & 0,0031 & 814,83 & 7,698 & 3,292 & 0,137 & 0,3618 & 1,0086 \\
\hline 15 & 0,6529 & 0,0031 & 827,88 & 7,746 & 3,581 & 0,379 & 0,1747 & 1,0043 \\
\hline 16 & 0,5655 & 0,0027 & 820,31 & 7,631 & 2,954 & 0,223 & 0,2262 & 1,0059 \\
\hline 17 & 0,5653 & 0,0027 & 821,78 & 7,924 & 2,173 & 0,150 & 0,4324 & 1,0212 \\
\hline 18 & 0,9462 & 0,0045 & 614,21 & 7,685 & 3,900 & 0,193 & 0,2029 & 1,0019 \\
\hline 19 & 0,9464 & 0,0045 & 727,41 & 7,502 & 3,228 & 0,158 & 0,2775 & 1,0045 \\
\hline 20 & 0,9464 & 0,0045 & 715,71 & 7,536 & 4,295 & 0,119 & 0,3175 & 1,0041 \\
\hline 21 & 0,9463 & 0,0045 & 805,55 & 7,567 & 5,832 & 0,263 & 0,1399 & 1,0015 \\
\hline 22 & 0,9465 & 0,0045 & 634,51 & 7,442 & 4,492 & 0,104 & 0,2225 & 1,0016 \\
\hline 23 & 0,9465 & 0,0045 & 629,93 & 7,410 & 3,358 & 0,236 & 0,2082 & 1,0027 \\
\hline 24 & 0,9464 & 0,0045 & 627,32 & 7,506 & 4,348 & 0,142 & 0,3272 & 1,0043 \\
\hline 25 & 0,4840 & 0,0023 & 636,17 & 8,310 & 4,227 & 0,225 & 0,4247 & 1,0073 \\
\hline 26 & 0,4840 & 0,0023 & 728,54 & 8,254 & 4,446 & 0,225 & 0,2934 & 1,0036 \\
\hline 27 & 0,4840 & 0,0023 & 711,16 & 8,316 & 4,769 & 0,296 & 0,3371 & 1,0065 \\
\hline 28 & 0,4841 & 0,0023 & 757,80 & 8,074 & 4,562 & 0,213 & 0,3865 & 1,0057 \\
\hline 29 & 0,5361 & 0,0025 & 787,74 & 8,554 & 3,731 & 0,381 & 0,1129 & 1,0014 \\
\hline 30 & 0,5361 & 0,0025 & 726,35 & 8,513 & 3,086 & 0,326 & 0,0661 & 1,0006 \\
\hline 31 & 0,5361 & 0,0025 & 816,62 & 8,552 & 2,750 & 0,475 & 0,0465 & 1,0007 \\
\hline 32 & 0,5360 & 0,0025 & 804,92 & 8,605 & 1,872 & 0,436 & 0,0752 & 1,0021 \\
\hline 33 & 0,5360 & 0,0025 & 813,89 & 8,691 & 4,848 & 0,399 & 0,0884 & 1,0011 \\
\hline 34 & 0,6605 & 0,0031 & 806,72 & 8,668 & 4,488 & 0,386 & 0,1639 & 1,0029 \\
\hline 35 & 0,6607 & 0,0031 & 726,40 & 8,264 & 3,140 & 0,320 & 0,0746 & 1,0007 \\
\hline 36 & 0,6607 & 0,0031 & 769,22 & 8,315 & 4,176 & 0,254 & 0,1214 & 1,0009 \\
\hline 37 & 0,6687 & 0,0032 & 803,47 & 8,253 & 3,841 & 0,388 & 0,1091 & 1,0014 \\
\hline 38 & 0,6687 & 0,0032 & 719,92 & 8,239 & 3,128 & 0,270 & 0,1533 & 0,9987 \\
\hline 39 & 0,6687 & 0,0032 & 818,70 & 8,318 & 4,967 & 0,550 & 0,0915 & 1,0015 \\
\hline 40 & 0,6998 & 0,0033 & 815,10 & 8,389 & 3,850 & 0,394 & 0,2061 & 1,0038 \\
\hline 41 & 0,6999 & 0,0033 & 815,81 & 8,270 & 2,992 & 0,467 & 0,1098 & 1,0018 \\
\hline 42 & 0,9895 & 0,0047 & 731,39 & 8,661 & 3,487 & 0,330 & 0,2209 & 1,0033 \\
\hline 43 & 0,9898 & 0,0047 & 627,06 & 8,199 & 3,109 & 0,434 & 0,2552 & 1,0049 \\
\hline 44 & 0,9899 & 0,0047 & 810,40 & 8,022 & 3,177 & 0,763 & 0,1247 & 1,0027 \\
\hline 45 & 0,9899 & 0,0047 & 786,49 & 8,034 & 4,000 & 0,395 & 0,2155 & 1,0036 \\
\hline 46 & 0,8447 & 0,0040 & 796,65 & 8,101 & 2,516 & 0,527 & 0,1156 & 1,0028 \\
\hline 47 & 0,8448 & 0,0040 & 793,42 & 8,034 & 3,960 & 0,300 & 0,3554 & 1,0072 \\
\hline 48 & 1,0480 & 0,0049 & 723,89 & 7,511 & 4,143 & 0,069 & 0,4590 & 1,0080 \\
\hline 49 & 1,0481 & 0,0049 & 804,10 & 7,420 & 3,994 & 0,125 & 0,3402 & 1,0050 \\
\hline
\end{tabular}


Continuação da Tabela A.2.

\begin{tabular}{|c|c|c|c|c|c|c|c|c|}
\hline Ensaio & $\begin{array}{c}(1) \\
\text { Velocidade } \\
{[\mathrm{m} / \mathrm{s}]}\end{array}$ & $\begin{array}{c}(2) \\
\text { Vazão } \\
{\left[\mathrm{m}^{3} / \mathrm{s}\right]}\end{array}$ & $\begin{array}{c}(3) \\
\text { Pressão } \\
{[m m H g]}\end{array}$ & $\begin{array}{c}(4) \\
C_{s} \\
{[m g / L]}\end{array}$ & $\begin{array}{c}(5) \\
C_{0} \\
{[m g / L]}\end{array}$ & $\begin{array}{c}(6) \\
K_{2} \\
\left.\text { horas }^{-1}\right]\end{array}$ & $\begin{array}{c}(7) \\
\text { RMSE } \\
{[m g / L]}\end{array}$ & $\begin{array}{c}(8) \\
\mathrm{MME} \\
{[m g / L]}\end{array}$ \\
\hline 50 & 1,0480 & 0,0049 & 777,82 & 7,466 & 4,282 & 0,314 & 0,2408 & 1,0044 \\
\hline 51 & 1,0482 & 0,0049 & 699,86 & 7,368 & 4,225 & 0,138 & 0,3557 & 1,0052 \\
\hline 52 & 1,0481 & 0,0049 & 795,60 & 7,439 & 4,287 & 0,123 & 0,4220 & 1,0065 \\
\hline 53 & 0,3422 & 0,0016 & 823,75 & 8,092 & 4,148 & 0,218 & 0,0111 & 1,0001 \\
\hline 54 & 0,3423 & 0,0016 & 817,07 & 7,719 & 2,612 & 0,145 & 0,0798 & 1,0009 \\
\hline 55 & 0,3424 & 0,0016 & 813,77 & 7,309 & 3,231 & 0,156 & 0,0662 & 1,0005 \\
\hline 56 & 0,3422 & 0,0016 & 817,29 & 8,002 & 4,159 & 0,279 & 0,0108 & 1,0001 \\
\hline 57 & 0,3424 & 0,0016 & 823,27 & 7,405 & 3,767 & 0,332 & 0,0282 & 1,0002 \\
\hline 58 & 0,3424 & 0,0016 & 813,31 & 7,335 & 3,394 & 0,257 & 0,0700 & 1,0006 \\
\hline 59 & 0,3423 & 0,0016 & 825,72 & 7,840 & 2,416 & 0,203 & 0,0536 & 1,0006 \\
\hline 60 & 0,3423 & 0,0016 & 715,04 & 7,870 & 2,490 & 0,227 & 0,0514 & 1,0005 \\
\hline 61 & 0,3423 & 0,0016 & 819,03 & 7,744 & 3,983 & 0,240 & 0,0446 & 1,0003 \\
\hline 62 & 0,3423 & 0,0016 & 809,39 & 7,712 & 2,448 & 0,144 & 0,0962 & 1,0013 \\
\hline 63 & 0,5108 & 0,0024 & 813,57 & 7,748 & 2,347 & 0,170 & 0,0698 & 1,0009 \\
\hline 64 & 0,5111 & 0,0024 & 815,65 & 7,246 & 3,459 & 0,215 & 0,0924 & 1,0010 \\
\hline 65 & 0,5110 & 0,0024 & 809,63 & 7,424 & 2,662 & 0,187 & 0,0659 & 1,0007 \\
\hline 66 & 0,5111 & 0,0024 & 809,37 & 7,167 & 3,992 & 0,326 & 0,0334 & 1,0003 \\
\hline 67 & 0,5109 & 0,0024 & 820,47 & 7,660 & 3,565 & 0,274 & 0,0319 & 1,0002 \\
\hline 68 & 0,5108 & 0,0024 & 814,72 & 7,883 & 2,474 & 0,188 & 0,0641 & 1,0007 \\
\hline 69 & 0,5111 & 0,0024 & 801,80 & 7,320 & 3,295 & 0,119 & 0,0966 & 1,0007 \\
\hline 70 & 0,5109 & 0,0024 & 826,49 & 7,698 & 2,559 & 0,171 & 0,0559 & 1,0006 \\
\hline 71 & 0,5111 & 0,0024 & 808,84 & 7,309 & 3,233 & 0,097 & 0,0489 & 1,0002 \\
\hline 72 & 0,5109 & 0,0024 & 815,00 & 7,543 & 4,111 & 0,336 & 0,0287 & 1,0003 \\
\hline 73 & 0,6851 & 0,0032 & 817,07 & 7,070 & 2,773 & 0,140 & 0,1619 & 1,0026 \\
\hline 74 & 0,6847 & 0,0032 & 808,46 & 7,585 & 3,693 & 0,062 & 0,3454 & 1,0058 \\
\hline 75 & 0,6847 & 0,0032 & 816,34 & 7,583 & 2,961 & 0,218 & 0,0513 & 1,0004 \\
\hline 76 & 0,6849 & 0,0032 & 819,79 & 7,290 & 2,872 & 0,201 & 0,0796 & 1,0008 \\
\hline 77 & 0,6847 & 0,0032 & 802,62 & 7,547 & 2,887 & 0,199 & 0,0768 & 1,0008 \\
\hline 78 & 0,6849 & 0,0032 & 817,74 & 7,329 & 3,581 & 0,256 & 0,0509 & 1,0004 \\
\hline 79 & 0,6847 & 0,0032 & 794,84 & 7,648 & 3,319 & 0,150 & 0,0698 & 1,0005 \\
\hline 80 & 0,6849 & 0,0032 & 813,02 & 7,326 & 4,241 & 0,299 & 0,0439 & 1,0003 \\
\hline 81 & 0,6847 & 0,0032 & 812,13 & 7,619 & 3,018 & 0,209 & 0,0541 & 1,0004 \\
\hline 82 & 0,6846 & 0,0032 & 817,08 & 7,717 & 4,651 & 0,251 & 0,0445 & 1,0004 \\
\hline 83 & 0,4951 & 0,0023 & 827,90 & 7,472 & 3,307 & 0,204 & 0,0694 & 1,0007 \\
\hline 84 & 0,4951 & 0,0023 & 814,85 & 7,496 & 4,027 & 0,324 & 0,0635 & 1,0010 \\
\hline 85 & 0,4950 & 0,0023 & 819,76 & 7,696 & 3,667 & 0,407 & 0,0496 & 1,0004 \\
\hline 86 & 0,4950 & 0,0023 & 820,57 & 7,615 & 3,384 & 0,354 & 0,0705 & 1,0006 \\
\hline 87 & 0,4952 & 0,0023 & 715,98 & 7,311 & 3,034 & 0,365 & 0,0666 & 1,0006 \\
\hline 88 & 0,4951 & 0,0023 & 742,18 & 7,443 & 3,251 & 0,313 & 0,0839 & 1,0007 \\
\hline 89 & 0,4952 & 0,0023 & 811,20 & 7,264 & 3,580 & 0,404 & 0,1171 & 1,0015 \\
\hline 90 & 0,4951 & 0,0023 & 818,69 & 7,382 & 4,188 & 0,551 & 0,0455 & 1,0005 \\
\hline 91 & 0,4951 & 0,0023 & 811,80 & 7,389 & 4,102 & 0,364 & 0,0498 & 1,0005 \\
\hline 92 & 0,4951 & 0,0023 & 818,37 & 7,453 & 3,996 & 0,320 & 0,0980 & 1,0012 \\
\hline 93 & 0,7444 & 0,0035 & 811,75 & 7,532 & 3,132 & 0,253 & 0,0669 & 1,0006 \\
\hline 94 & 0,7445 & 0,0035 & 815,84 & 7,336 & 3,927 & 0,390 & 0,0361 & 1,0003 \\
\hline 95 & 0,7443 & 0,0035 & 795,22 & 7,623 & 3,192 & 0,259 & 0,0794 & 1,0007 \\
\hline 96 & 0,7444 & 0,0035 & 822,42 & 7,530 & 4,117 & 0,328 & 0,0998 & 1,0017 \\
\hline 97 & 0,7447 & 0,0035 & 759,99 & 7,157 & 3,137 & 0,223 & 0,1445 & 1,0018 \\
\hline 98 & 0,7446 & 0,0035 & 821,37 & 7,292 & 4,006 & 0,286 & 0,1502 & 1,0029 \\
\hline 99 & 0,7445 & 0,0035 & 815,65 & 7,333 & 3,946 & 0,413 & 0,0507 & 1,0005 \\
\hline
\end{tabular}


Continuação da Tabela A.2.

\begin{tabular}{|c|c|c|c|c|c|c|c|c|}
\hline Ensaio & $\begin{array}{c}(1) \\
\text { Velocidade } \\
{[\mathrm{m} / \mathrm{s}]}\end{array}$ & $\begin{array}{c}(2) \\
\text { Vazão } \\
{\left[\mathrm{m}^{3} / \mathrm{s}\right]}\end{array}$ & $\begin{array}{c}(3) \\
\text { Pressão } \\
{[m m H g]}\end{array}$ & $\begin{array}{c}(4) \\
C_{s} \\
{[m g / L]}\end{array}$ & $\begin{array}{c}(5) \\
C_{0} \\
{[m g / L]}\end{array}$ & $\begin{array}{c}(6) \\
K_{2} \\
{\left[\text { horas }^{-1}\right]}\end{array}$ & $\begin{array}{c}(7) \\
\mathrm{RMSE} \\
{[\mathrm{mg} / L]}\end{array}$ & $\begin{array}{c}(8) \\
\mathrm{MME} \\
{[m g / L]}\end{array}$ \\
\hline 100 & 0,7446 & 0,0035 & 811,44 & 7,257 & 4,246 & 0,318 & 0,0491 & 1,0004 \\
\hline 101 & 0,7447 & 0,0035 & 789,17 & 7,111 & 3,569 & 0,291 & 0,1169 & 1,0015 \\
\hline 102 & 0,7446 & 0,0035 & 817,56 & 7,294 & 3,647 & 0,297 & 0,0697 & 1,0007 \\
\hline 103 & 0,9907 & 0,0047 & 815,97 & 6,964 & 4,000 & 0,334 & 0,1270 & 1,0025 \\
\hline 104 & 0,9905 & 0,0047 & 801,37 & 7,135 & 3,102 & 0,298 & 0,0664 & 1,0006 \\
\hline 105 & 0,9905 & 0,0047 & 818,07 & 7,207 & 3,492 & 0,399 & 0,0520 & 1,0005 \\
\hline 106 & 0,9905 & 0,0047 & 816,83 & 7,156 & 3,346 & 0,294 & 0,1032 & 1,0013 \\
\hline 107 & 0,9903 & 0,0047 & 713,33 & 7,306 & 3,064 & 0,281 & 0,1022 & 1,0011 \\
\hline 108 & 0,9905 & 0,0047 & 814,50 & 7,122 & 4,042 & 0,394 & 0,1005 & 1,0017 \\
\hline 109 & 0,9906 & 0,0047 & 723,01 & 7,096 & 3,534 & 0,238 & 0,1713 & 1,0023 \\
\hline 110 & 0,9903 & 0,0047 & 710,97 & 7,365 & 3,551 & 0,251 & 0,0918 & 1,0007 \\
\hline 111 & 0,9903 & 0,0047 & 807,74 & 7,384 & 3,672 & 0,344 & 0,0697 & 1,0007 \\
\hline 112 & 0,9905 & 0,0047 & 818,81 & 7,182 & 3,962 & 0,230 & 0,1226 & 1,0014 \\
\hline 113 & 0,6768 & 0,0032 & 806,66 & 7,659 & 3,210 & 0,361 & 0,1024 & 1,0013 \\
\hline 114 & 0,6768 & 0,0032 & 805,92 & 7,740 & 4,112 & 0,594 & 0,0186 & 1,0002 \\
\hline 115 & 0,6765 & 0,0032 & 818,69 & 8,135 & 3,763 & 0,681 & 0,0475 & 1,0005 \\
\hline 116 & 0,6770 & 0,0032 & 822,54 & 7,432 & 4,042 & 0,805 & 0,0237 & 1,0003 \\
\hline 117 & 0,6767 & 0,0032 & 812,91 & 7,842 & 4,022 & 0,878 & 0,0309 & 1,0004 \\
\hline 118 & 0,6770 & 0,0032 & 803,46 & 7,356 & 3,012 & 0,494 & 0,0787 & 1,0008 \\
\hline 119 & 0,6767 & 0,0032 & 729,29 & 7,929 & 3,322 & 0,654 & 0,0516 & 1,0004 \\
\hline 120 & 0,6766 & 0,0032 & 814,29 & 7,999 & 3,791 & 0,663 & 0,0597 & 1,0006 \\
\hline 121 & 0,6768 & 0,0032 & 743,18 & 7,628 & 3,080 & 0,368 & 0,0604 & 1,0005 \\
\hline 122 & 0,6767 & 0,0032 & 820,09 & 7,850 & 4,155 & 0,641 & 0,0300 & 1,0003 \\
\hline 123 & 1,0169 & 0,0048 & 822,09 & 7,297 & 3,612 & 0,421 & 0,1146 & 1,0017 \\
\hline 124 & 1,0170 & 0,0048 & 780,64 & 7,225 & 4,083 & 0,404 & 0,1542 & 1,0034 \\
\hline 125 & 1,0170 & 0,0048 & 700,17 & 7,237 & 3,086 & 0,401 & 0,0840 & 1,0009 \\
\hline 126 & 1,0166 & 0,0048 & 709,51 & 7,596 & 3,026 & 0,530 & 0,0458 & 1,0004 \\
\hline 127 & 1,0165 & 0,0048 & 818,69 & 7,658 & 3,933 & 0,604 & 0,0316 & 1,0003 \\
\hline 128 & 1,0165 & 0,0048 & 794,92 & 7,671 & 3,514 & 0,482 & 0,0475 & 1,0004 \\
\hline 129 & 1,0165 & 0,0048 & 805,30 & 7,756 & 3,673 & 0,498 & 0,0639 & 1,0006 \\
\hline 130 & 1,0165 & 0,0048 & 721,39 & 7,685 & 3,396 & 0,530 & 0,0446 & 1,0003 \\
\hline 131 & 1,0170 & 0,0048 & 713,42 & 7,218 & 4,086 & 0,147 & 0,2776 & 1,0040 \\
\hline 132 & 1,0167 & 0,0048 & 775,66 & 7,493 & 3,217 & 0,281 & 0,0840 & 1,0008 \\
\hline 133 & 1,3547 & 0,0064 & 815,37 & 6,912 & 4,340 & 0,414 & 0,2409 & 1,0118 \\
\hline 134 & 1,3549 & 0,0064 & 709,08 & 6,820 & 3,306 & 0,448 & 0,1076 & 1,0015 \\
\hline 135 & 1,3535 & 0,0064 & 749,73 & 7,756 & 3,370 & 0,414 & 0,0800 & 1,0008 \\
\hline 136 & 1,3550 & 0,0064 & 812,15 & 6,793 & 4,101 & 0,665 & 0,0922 & 1,0024 \\
\hline 137 & 1,3545 & 0,0064 & 815,65 & 7,053 & 4,060 & 0,730 & 0,0686 & 1,0012 \\
\hline 138 & 1,3542 & 0,0064 & 809,40 & 7,248 & 4,137 & 0,346 & 0,1560 & 1,0021 \\
\hline 139 & 1,3548 & 0,0064 & 624,50 & 6,913 & 3,881 & 0,113 & 0,3764 & 1,0058 \\
\hline 140 & 1,3543 & 0,0064 & 803,54 & 7,187 & 3,639 & 0,604 & 0,1008 & 1,0014 \\
\hline 141 & 1,3545 & 0,0064 & 717,88 & 7,074 & 4,096 & 0,239 & 0,1382 & 1,0012 \\
\hline 142 & 1,3545 & 0,0064 & 794,84 & 7,059 & 4,400 & 0,285 & 0,1816 & 1,0032 \\
\hline
\end{tabular}


Tabela A.3: Resultados Obtidos com o Ajuste do Modelo Novo

\begin{tabular}{|c|c|c|c|c|c|c|c|c|c|}
\hline Ensaio & $\begin{array}{c}(1) \\
\text { Velocidade } \\
{[\mathrm{m} / \mathrm{s}]}\end{array}$ & $\begin{array}{c}(2) \\
\text { Vazão } \\
{\left[\mathrm{m}^{3} / \mathrm{s}\right]}\end{array}$ & $\begin{array}{c}(3) \\
\text { Pressão } \\
{[m m H g]}\end{array}$ & $\begin{array}{c}(4) \\
C_{s} \\
{[m g / L]}\end{array}$ & $\begin{array}{c}(5) \\
C_{0} \\
{[m g / L]}\end{array}$ & $\begin{array}{c}(6) \\
K_{2} \\
{\left[\text { horas }^{-1}\right]}\end{array}$ & $\begin{array}{c}(7) \\
K_{3}^{*} \\
\text { [horas }^{-1} \text { ] }\end{array}$ & $\begin{array}{c}(8) \\
\mathrm{RMSE} \\
{[m g / L]}\end{array}$ & $\begin{array}{c}(9) \\
\mathrm{MME} \\
{[m g / L]}\end{array}$ \\
\hline 1 & 0,6527 & 0,0031 & 627,55 & 8,135 & 2,157 & 0,843 & 0,260 & 0,0271 & 1,0000 \\
\hline 2 & 0,6527 & 0,0031 & 680,19 & 8,029 & 1,436 & 0,720 & 0,235 & 0,0171 & 0,9998 \\
\hline 3 & 0,7929 & 0,0037 & 808,68 & 7,858 & 1,704 & 0,360 & 0,117 & 0,0228 & 0,9998 \\
\hline 4 & 0,7929 & 0,0037 & 826,87 & 7,872 & 3,040 & 0,368 & 0,083 & 0,0317 & 1,0000 \\
\hline 5 & 1,0008 & 0,0047 & 807,63 & 7,849 & 3,749 & 1,004 & 0,084 & 0,0282 & 1,0000 \\
\hline 6 & 1,0009 & 0,0047 & 714,56 & 7,796 & 2,548 & 0,963 & 0,130 & 0,0216 & 1,0001 \\
\hline 7 & 0,8512 & 0,0040 & 678,57 & 7,913 & 2,152 & 0,889 & 0,206 & 0,0189 & 0,9999 \\
\hline 8 & 1,1633 & 0,0055 & 630,97 & 7,834 & 2,506 & 0,576 & 0,242 & 0,0291 & 1,0001 \\
\hline 9 & 1,1633 & 0,0055 & 630,35 & 7,830 & 0,224 & 0,650 & 0,265 & 0,0127 & 1,0016 \\
\hline 10 & 0,8452 & 0,0040 & 819,63 & 7,529 & 3,216 & 0,585 & 0,090 & 0,0051 & 1,0000 \\
\hline 11 & 0,8453 & 0,0040 & 722,42 & 7,454 & 1,456 & 0,453 & 0,181 & 0,0212 & 1,0001 \\
\hline 12 & 0,8579 & 0,0040 & 811,74 & 7,394 & 1,676 & 0,554 & 0,217 & 0,0194 & 0,9999 \\
\hline 13 & 0,6532 & 0,0031 & 811,23 & 7,363 & 2,438 & 0,436 & 0,091 & 0,0277 & 1,0001 \\
\hline 14 & 0,6530 & 0,0031 & 814,83 & 7,698 & 2,120 & 0,411 & 0,116 & 0,0288 & 1,0002 \\
\hline 15 & 0,6529 & 0,0031 & 827,88 & 7,746 & 3,190 & 0,604 & 0,067 & 0,0089 & 1,0000 \\
\hline 16 & 0,5655 & 0,0027 & 820,31 & 7,631 & 2,066 & 0,399 & 0,070 & 0,0256 & 1,0002 \\
\hline 17 & 0,5653 & 0,0027 & 821,78 & 7,924 & 0,821 & 0,349 & 0,106 & 0,0185 & 1,0006 \\
\hline 18 & 0,9462 & 0,0045 & 614,21 & 7,685 & 3,402 & 0,690 & 0,248 & 0,0125 & 1,0000 \\
\hline 19 & 0,9464 & 0,0045 & 727,41 & 7,502 & 2,333 & 0,570 & 0,240 & 0,0067 & 1,0000 \\
\hline 20 & 0,9464 & 0,0045 & 715,71 & 7,536 & 3,084 & 0,610 & 0,170 & 0,0173 & 1,0000 \\
\hline 21 & 0,9463 & 0,0045 & 805,55 & 7,567 & 5,405 & 0,881 & 0,084 & 0,0063 & 1,0000 \\
\hline 22 & 0,9465 & 0,0045 & 634,51 & 7,442 & 3,694 & 0,774 & 0,269 & 0,0064 & 1,0000 \\
\hline 23 & 0,9465 & 0,0045 & 629,93 & 7,410 & 2,732 & 0,711 & 0,262 & 0,0067 & 1,0000 \\
\hline 24 & 0,9464 & 0,0045 & 627,32 & 7,506 & 3,138 & 0,743 & 0,196 & 0,0134 & 1,0000 \\
\hline 25 & 0,4840 & 0,0023 & 636,17 & 8,310 & 2,796 & 0,931 & 0,256 & 0,0077 & 1,0000 \\
\hline 26 & 0,4840 & 0,0023 & 728,54 & 8,254 & 3,508 & 0,780 & 0,199 & 0,0092 & 1,0000 \\
\hline 27 & 0,4840 & 0,0023 & 711,16 & 8,316 & 3,762 & 0,862 & 0,132 & 0,0125 & 1,0000 \\
\hline 28 & 0,4841 & 0,0023 & 757,80 & 8,074 & 3,364 & 0,943 & 0,224 & 0,0272 & 1,0000 \\
\hline 29 & 0,5361 & 0,0025 & 787,74 & 8,554 & 3,445 & 0,572 & 0,087 & 0,0070 & 1,0000 \\
\hline 30 & 0,5361 & 0,0025 & 726,35 & 8,513 & 2,956 & 0,487 & 0,133 & 0,0057 & 1,0000 \\
\hline 31 & 0,5361 & 0,0025 & 816,62 & 8,552 & 2,641 & 0,553 & 0,052 & 0,0048 & 1,0000 \\
\hline 32 & 0,5360 & 0,0025 & 804,92 & 8,605 & 1,741 & 0,529 & 0,081 & 0,0060 & 1,0000 \\
\hline 33 & 0,5360 & 0,0025 & 813,89 & 8,691 & 4,668 & 0,569 & 0,048 & 0,0071 & 1,0000 \\
\hline 34 & 0,6605 & 0,0031 & 806,72 & 8,668 & 4,159 & 0,626 & 0,067 & 0,0119 & 1,0000 \\
\hline 35 & 0,6607 & 0,0031 & 726,40 & 8,264 & 2,974 & 0,516 & 0,153 & 0,0047 & 1,0000 \\
\hline 36 & 0,6607 & 0,0031 & 769,22 & 8,315 & 3,823 & 0,527 & 0,131 & 0,0056 & 1,0000 \\
\hline 37 & 0,6687 & 0,0032 & 803,47 & 8,253 & 3,508 & 0,586 & 0,082 & 0,0106 & 1,0000 \\
\hline 38 & 0,6687 & 0,0032 & 719,92 & 8,239 & 2,687 & 0,522 & 0,166 & 0,0205 & 0,9963 \\
\hline 39 & 0,6687 & 0,0032 & 818,70 & 8,318 & 4,637 & 0,788 & 0,053 & 0,0099 & 1,0000 \\
\hline 40 & 0,6998 & 0,0033 & 815,10 & 8,389 & 3,300 & 0,706 & 0,109 & 0,0053 & 1,0000 \\
\hline 41 & 0,6999 & 0,0033 & 815,81 & 8,270 & 2,619 & 0,665 & 0,111 & 0,0110 & 1,0000 \\
\hline 42 & 0,9895 & 0,0047 & 731,39 & 8,661 & 2,943 & 0,677 & 0,184 & 0,0186 & 1,0000 \\
\hline 43 & 0,9898 & 0,0047 & 627,06 & 8,199 & 2,507 & 0,934 & 0,267 & 0,0128 & 1,0000 \\
\hline 44 & 0,9899 & 0,0047 & 810,40 & 8,022 & 2,920 & 1,046 & 0,110 & 0,0086 & 1,0000 \\
\hline 45 & 0,9899 & 0,0047 & 786,49 & 8,034 & 3,351 & 0,823 & 0,143 & 0,0088 & 1,0000 \\
\hline 46 & 0,8447 & 0,0040 & 796,65 & 8,101 & 2,019 & 0,693 & 0,088 & 0,0224 & 1,0001 \\
\hline 47 & 0,8448 & 0,0040 & 793,42 & 8,034 & 2,968 & 0,851 & 0,178 & 0,0229 & 1,0000 \\
\hline 48 & 1,0480 & 0,0049 & 723,89 & 7,511 & 2,320 & 0,524 & 0,166 & 0,0245 & 0,9999 \\
\hline 49 & 1,0481 & 0,0049 & 804,10 & 7,420 & 2,820 & 0,610 & 0,183 & 0,0121 & 1,0000 \\
\hline 50 & 1,0480 & 0,0049 & 777,82 & 7,466 & 3,622 & 0,793 & 0,121 & 0,0222 & 1,0000 \\
\hline
\end{tabular}


Continuação da Tabela A.3.

\begin{tabular}{|c|c|c|c|c|c|c|c|c|c|}
\hline Ensaio & $\begin{array}{c}(1) \\
\text { Velocidade } \\
{[\mathrm{m} / \mathrm{s}]}\end{array}$ & $\begin{array}{c}(2) \\
\text { Vazão } \\
{\left[m^{3} / s\right]}\end{array}$ & $\begin{array}{c}(3) \\
\text { Pressão } \\
{[m m H g]}\end{array}$ & $\begin{array}{c}(4) \\
C_{s} \\
{[m g / L]}\end{array}$ & $\begin{array}{c}(5) \\
C_{0} \\
{[m g / L]}\end{array}$ & $\begin{array}{c}(6) \\
K_{2} \\
{\left[\text { horas }^{-1}\right]}\end{array}$ & $\begin{array}{c}(7) \\
K_{3}^{*} \\
{\left[\text { horas }^{-1}\right]}\end{array}$ & $\begin{array}{c}(8) \\
\text { RMSE } \\
{[m g / L]}\end{array}$ & $\begin{array}{c}(9) \\
\mathrm{MME} \\
{[m g / L]}\end{array}$ \\
\hline 51 & 1,0482 & 0,0049 & 699,86 & 7,368 & 2,966 & 0,739 & 0,197 & 0,0208 & 1,0000 \\
\hline 52 & 1,0481 & 0,0049 & 795,60 & 7,439 & 2,795 & 0,794 & 0,222 & 0,0578 & 1,0000 \\
\hline 53 & 0,3422 & 0,0016 & 823,75 & 8,092 & 4,136 & 0,236 & 0,008 & 0,0048 & 1,0000 \\
\hline 54 & 0,3423 & 0,0016 & 817,07 & 7,719 & 2,443 & 0,249 & 0,097 & 0,0053 & 1,0000 \\
\hline 55 & 0,3424 & 0,0016 & 813,77 & 7,309 & 3,085 & 0,266 & 0,071 & 0,0047 & 1,0000 \\
\hline 56 & 0,3422 & 0,0016 & 817,29 & 8,002 & 4,135 & 0,280 & 0,000 & 0,0105 & 1,0001 \\
\hline 57 & 0,3424 & 0,0016 & 823,27 & 7,405 & 3,693 & 0,414 & 0,038 & 0,0038 & 1,0000 \\
\hline 58 & 0,3424 & 0,0016 & 813,31 & 7,335 & 3,226 & 0,423 & 0,092 & 0,0062 & 1,0000 \\
\hline 59 & 0,3423 & 0,0016 & 825,72 & 7,840 & 2,295 & 0,297 & 0,100 & 0,0055 & 1,0000 \\
\hline 60 & 0,3423 & 0,0016 & 715,04 & 7,870 & 2,340 & 0,343 & 0,126 & 0,0065 & 1,0000 \\
\hline 61 & 0,3423 & 0,0016 & 819,03 & 7,744 & 3,895 & 0,331 & 0,041 & 0,0055 & 1,0000 \\
\hline 62 & 0,3423 & 0,0016 & 809,39 & 7,712 & 2,209 & 0,267 & 0,123 & 0,0060 & 1,0000 \\
\hline 63 & 0,5108 & 0,0024 & 813,57 & 7,748 & 2,226 & 0,277 & 0,117 & 0,0080 & 1,0000 \\
\hline 64 & 0,5111 & 0,0024 & 815,65 & 7,246 & 3,209 & 0,363 & 0,068 & 0,0062 & 1,0000 \\
\hline 65 & 0,5110 & 0,0024 & 809,63 & 7,424 & 2,499 & 0,298 & 0,094 & 0,0051 & 1,0000 \\
\hline 66 & 0,5111 & 0,0024 & 809,37 & 7,167 & 3,966 & 0,418 & 0,034 & 0,0070 & 1,0000 \\
\hline 67 & 0,5109 & 0,0024 & 820,47 & 7,660 & 3,496 & 0,359 & 0,050 & 0,0056 & 1,0000 \\
\hline 68 & 0,5108 & 0,0024 & 814,72 & 7,883 & 2,339 & 0,294 & 0,110 & 0,0098 & 1,0000 \\
\hline 69 & 0,5111 & 0,0024 & 801,80 & 7,320 & 3,036 & 0,286 & 0,113 & 0,0056 & 1,0000 \\
\hline 70 & 0,5109 & 0,0024 & 826,49 & 7,698 & 2,411 & 0,275 & 0,108 & 0,0056 & 1,0000 \\
\hline 71 & 0,5111 & 0,0024 & 808,84 & 7,309 & 3,109 & 0,189 & 0,071 & 0,0053 & 1,0000 \\
\hline 72 & 0,5109 & 0,0024 & 815,00 & 7,543 & 4,039 & 0,402 & 0,023 & 0,0076 & 1,0000 \\
\hline 73 & 0,6851 & 0,0032 & 817,07 & 7,070 & 2,292 & 0,309 & 0,107 & 0,0128 & 1,0000 \\
\hline 74 & 0,6847 & 0,0032 & 808,46 & 7,585 & 2,312 & 0,277 & 0,096 & 0,0287 & 1,0001 \\
\hline 75 & 0,6847 & 0,0032 & 816,34 & 7,583 & 2,803 & 0,328 & 0,086 & 0,0059 & 1,0000 \\
\hline 76 & 0,6849 & 0,0032 & 819,79 & 7,290 & 2,695 & 0,356 & 0,116 & 0,0049 & 1,0000 \\
\hline 77 & 0,6847 & 0,0032 & 802,62 & 7,547 & 2,674 & 0,333 & 0,103 & 0,0100 & 1,0000 \\
\hline 78 & 0,6849 & 0,0032 & 817,74 & 7,329 & 3,436 & 0,360 & 0,049 & 0,0047 & 1,0000 \\
\hline 79 & 0,6847 & 0,0032 & 794,84 & 7,648 & 3,129 & 0,273 & 0,086 & 0,0049 & 1,0000 \\
\hline 80 & 0,6849 & 0,0032 & 813,02 & 7,326 & 4,118 & 0,426 & 0,044 & 0,0056 & 1,0000 \\
\hline 81 & 0,6847 & 0,0032 & 812,13 & 7,619 & 2,888 & 0,328 & 0,093 & 0,0057 & 1,0000 \\
\hline 82 & 0,6846 & 0,0032 & 817,08 & 7,717 & 4,556 & 0,346 & 0,029 & 0,0069 & 1,0000 \\
\hline 83 & 0,4951 & 0,0023 & 827,90 & 7,472 & 3,133 & 0,311 & 0,061 & 0,0069 & 1,0000 \\
\hline 84 & 0,4951 & 0,0023 & 814,85 & 7,496 & 3,867 & 0,425 & 0,029 & 0,0061 & 1,0000 \\
\hline 85 & 0,4950 & 0,0023 & 819,76 & 7,696 & 3,571 & 0,570 & 0,084 & 0,0061 & 1,0000 \\
\hline 86 & 0,4950 & 0,0023 & 820,57 & 7,615 & 3,231 & 0,551 & 0,113 & 0,0066 & 1,0000 \\
\hline 87 & 0,4952 & 0,0023 & 715,98 & 7,311 & 2,914 & 0,592 & 0,155 & 0,0062 & 1,0000 \\
\hline 88 & 0,4951 & 0,0023 & 742,18 & 7,443 & 3,111 & 0,581 & 0,173 & 0,0075 & 1,0000 \\
\hline 89 & 0,4952 & 0,0023 & 811,20 & 7,264 & 3,339 & 0,717 & 0,127 & 0,0068 & 1,0000 \\
\hline 90 & 0,4951 & 0,0023 & 818,69 & 7,382 & 4,072 & 0,717 & 0,051 & 0,0052 & 1,0000 \\
\hline 91 & 0,4951 & 0,0023 & 811,80 & 7,389 & 3,906 & 0,496 & 0,045 & 0,0093 & 1,0000 \\
\hline 92 & 0,4951 & 0,0023 & 818,37 & 7,453 & 3,674 & 0,525 & 0,070 & 0,0096 & 1,0000 \\
\hline 93 & 0,7444 & 0,0035 & 811,75 & 7,532 & 2,989 & 0,386 & 0,085 & 0,0087 & 1,0000 \\
\hline 94 & 0,7445 & 0,0035 & 815,84 & 7,336 & 3,859 & 0,502 & 0,044 & 0,0048 & 1,0000 \\
\hline 95 & 0,7443 & 0,0035 & 795,22 & 7,623 & 3,019 & 0,436 & 0,116 & 0,0066 & 1,0000 \\
\hline 96 & 0,7444 & 0,0035 & 822,42 & 7,530 & 3,875 & 0,490 & 0,044 & 0,0093 & 1,0000 \\
\hline 97 & 0,7447 & 0,0035 & 759,99 & 7,157 & 2,806 & 0,487 & 0,147 & 0,0063 & 1,0000 \\
\hline 98 & 0,7446 & 0,0035 & 821,37 & 7,292 & 3,595 & 0,514 & 0,060 & 0,0090 & 1,0000 \\
\hline 99 & 0,7445 & 0,0035 & 815,65 & 7,333 & 3,865 & 0,564 & 0,055 & 0,0069 & 1,0000 \\
\hline
\end{tabular}


Continuação da Tabela A.3.

\begin{tabular}{|c|c|c|c|c|c|c|c|c|c|}
\hline Ensaio & $\begin{array}{c}(1) \\
\text { Velocidade } \\
{[\mathrm{m} / \mathrm{s}]}\end{array}$ & $\begin{array}{c}(2) \\
\text { Vazão } \\
{\left[\mathrm{m}^{3} / \mathrm{s}\right]}\end{array}$ & $\begin{array}{c}(3) \\
\text { Pressão } \\
{[m m H g]}\end{array}$ & $\begin{array}{c}(4) \\
C_{s} \\
{[m g / L]}\end{array}$ & $\begin{array}{c}(5) \\
C_{0} \\
{[m g / L]}\end{array}$ & $\begin{array}{c}(6) \\
K_{2} \\
{\left[\text { horas }^{-1}\right]}\end{array}$ & $\begin{array}{c}(7) \\
K_{3}^{*} \\
{\left[\text { horas }^{-1}\right]}\end{array}$ & $\begin{array}{c}(8) \\
\text { RMSE } \\
{[m g / L]}\end{array}$ & $\begin{array}{c}(9) \\
\mathrm{MME} \\
{[m g / L]}\end{array}$ \\
\hline 100 & 0,7446 & 0,0035 & 811,44 & 7,257 & 3,943 & 0,466 & 0,050 & 0,0153 & 1,0000 \\
\hline 101 & 0,7447 & 0,0035 & 789,17 & 7,111 & 3,276 & 0,536 & 0,098 & 0,0066 & 1,0000 \\
\hline 102 & 0,7446 & 0,0035 & 817,56 & 7,294 & 3,370 & 0,457 & 0,070 & 0,0099 & 1,0000 \\
\hline 103 & 0,9907 & 0,0047 & 815,97 & 6,964 & 3,663 & 0,580 & 0,059 & 0,0080 & 1,0000 \\
\hline 104 & 0,9905 & 0,0047 & 801,37 & 7,135 & 2,974 & 0,476 & 0,109 & 0,0065 & 1,0000 \\
\hline 105 & 0,9905 & 0,0047 & 818,07 & 7,207 & 3,382 & 0,559 & 0,076 & 0,0064 & 1,0000 \\
\hline 106 & 0,9905 & 0,0047 & 816,83 & 7,156 & 3,045 & 0,504 & 0,097 & 0,0096 & 1,0000 \\
\hline 107 & 0,9903 & 0,0047 & 713,33 & 7,306 & 2,824 & 0,508 & 0,139 & 0,0060 & 1,0000 \\
\hline 108 & 0,9905 & 0,0047 & 814,50 & 7,122 & 3,801 & 0,623 & 0,061 & 0,0068 & 1,0000 \\
\hline 109 & 0,9906 & 0,0047 & 723,01 & 7,096 & 3,094 & 0,561 & 0,134 & 0,0075 & 1,0000 \\
\hline 110 & 0,9903 & 0,0047 & 710,97 & 7,365 & 3,149 & 0,501 & 0,137 & 0,0151 & 1,0000 \\
\hline 111 & 0,9903 & 0,0047 & 807,74 & 7,384 & 3,409 & 0,508 & 0,069 & 0,0094 & 1,0000 \\
\hline 112 & 0,9905 & 0,0047 & 818,81 & 7,182 & 3,528 & 0,468 & 0,082 & 0,0105 & 1,0000 \\
\hline 113 & 0,6768 & 0,0032 & 806,66 & 7,659 & 2,941 & 0,567 & 0,109 & 0,0054 & 1,0000 \\
\hline 114 & 0,6768 & 0,0032 & 805,92 & 7,740 & 4,062 & 0,669 & 0,029 & 0,0045 & 1,0000 \\
\hline 115 & 0,6765 & 0,0032 & 818,69 & 8,135 & 3,705 & 0,852 & 0,079 & 0,0068 & 1,0000 \\
\hline 116 & 0,6770 & 0,0032 & 822,54 & 7,432 & 3,961 & 0,913 & 0,035 & 0,0068 & 1,0000 \\
\hline 117 & 0,6767 & 0,0032 & 812,91 & 7,842 & 3,944 & 1,011 & 0,046 & 0,0060 & 1,0000 \\
\hline 118 & 0,6770 & 0,0032 & 803,46 & 7,356 & 2,735 & 0,797 & 0,196 & 0,0110 & 1,0000 \\
\hline 119 & 0,6767 & 0,0032 & 729,29 & 7,929 & 3,078 & 0,919 & 0,178 & 0,0187 & 1,0000 \\
\hline 120 & 0,6766 & 0,0032 & 814,29 & 7,999 & 3,564 & 0,884 & 0,099 & 0,0108 & 1,0000 \\
\hline 121 & 0,6768 & 0,0032 & 743,18 & 7,628 & 2,795 & 0,618 & 0,197 & 0,0166 & 1,0000 \\
\hline 122 & 0,6767 & 0,0032 & 820,09 & 7,850 & 4,068 & 0,749 & 0,039 & 0,0064 & 1,0000 \\
\hline 123 & 1,0169 & 0,0048 & 822,09 & 7,297 & 3,402 & 0,681 & 0,094 & 0,0096 & 1,0000 \\
\hline 124 & 1,0170 & 0,0048 & 780,64 & 7,225 & 3,688 & 0,725 & 0,075 & 0,0083 & 1,0000 \\
\hline 125 & 1,0170 & 0,0048 & 700,17 & 7,237 & 2,882 & 0,657 & 0,151 & 0,0041 & 1,0000 \\
\hline 126 & 1,0166 & 0,0048 & 709,51 & 7,596 & 2,927 & 0,742 & 0,155 & 0,0047 & 1,0000 \\
\hline 127 & 1,0165 & 0,0048 & 818,69 & 7,658 & 3,860 & 0,736 & 0,055 & 0,0077 & 1,0000 \\
\hline 128 & 1,0165 & 0,0048 & 794,92 & 7,671 & 3,385 & 0,672 & 0,107 & 0,0062 & 1,0000 \\
\hline 129 & 1,0165 & 0,0048 & 805,30 & 7,756 & 3,412 & 0,727 & 0,114 & 0,0131 & 1,0000 \\
\hline 130 & 1,0165 & 0,0048 & 721,39 & 7,685 & 3,221 & 0,736 & 0,128 & 0,0105 & 1,0000 \\
\hline 131 & 1,0170 & 0,0048 & 713,42 & 7,218 & 3,076 & 0,560 & 0,131 & 0,0133 & 1,0000 \\
\hline 132 & 1,0167 & 0,0048 & 775,66 & 7,493 & 2,888 & 0,503 & 0,144 & 0,0122 & 1,0000 \\
\hline 133 & 1,3547 & 0,0064 & 815,37 & 6,912 & 3,666 & 0,904 & 0,064 & 0,0110 & 1,0000 \\
\hline 134 & 1,3549 & 0,0064 & 709,08 & 6,820 & 3,040 & 0,782 & 0,140 & 0,0065 & 1,0000 \\
\hline 135 & 1,3535 & 0,0064 & 749,73 & 7,756 & 3,077 & 0,639 & 0,127 & 0,0124 & 1,0000 \\
\hline 136 & 1,3550 & 0,0064 & 812,15 & 6,793 & 3,876 & 0,986 & 0,063 & 0,0069 & 1,0000 \\
\hline 137 & 1,3545 & 0,0064 & 815,65 & 7,053 & 3,912 & 1,011 & 0,072 & 0,0092 & 1,0000 \\
\hline 138 & 1,3542 & 0,0064 & 809,40 & 7,248 & 3,572 & 0,752 & 0,120 & 0,0132 & 1,0000 \\
\hline 139 & 1,3548 & 0,0064 & 624,50 & 6,913 & 2,370 & 0,921 & 0,321 & 0,0336 & 1,0000 \\
\hline 140 & 1,3543 & 0,0064 & 803,54 & 7,187 & 3,349 & 0,983 & 0,141 & 0,0095 & 1,0000 \\
\hline 141 & 1,3545 & 0,0064 & 717,88 & 7,074 & 3,682 & 0,678 & 0,162 & 0,0132 & 1,0000 \\
\hline 142 & 1,3545 & 0,0064 & 794,84 & 7,059 & 3,894 & 0,678 & 0,085 & 0,0135 & 1,0000 \\
\hline
\end{tabular}


Apêndice B

Resultados Gráficos 


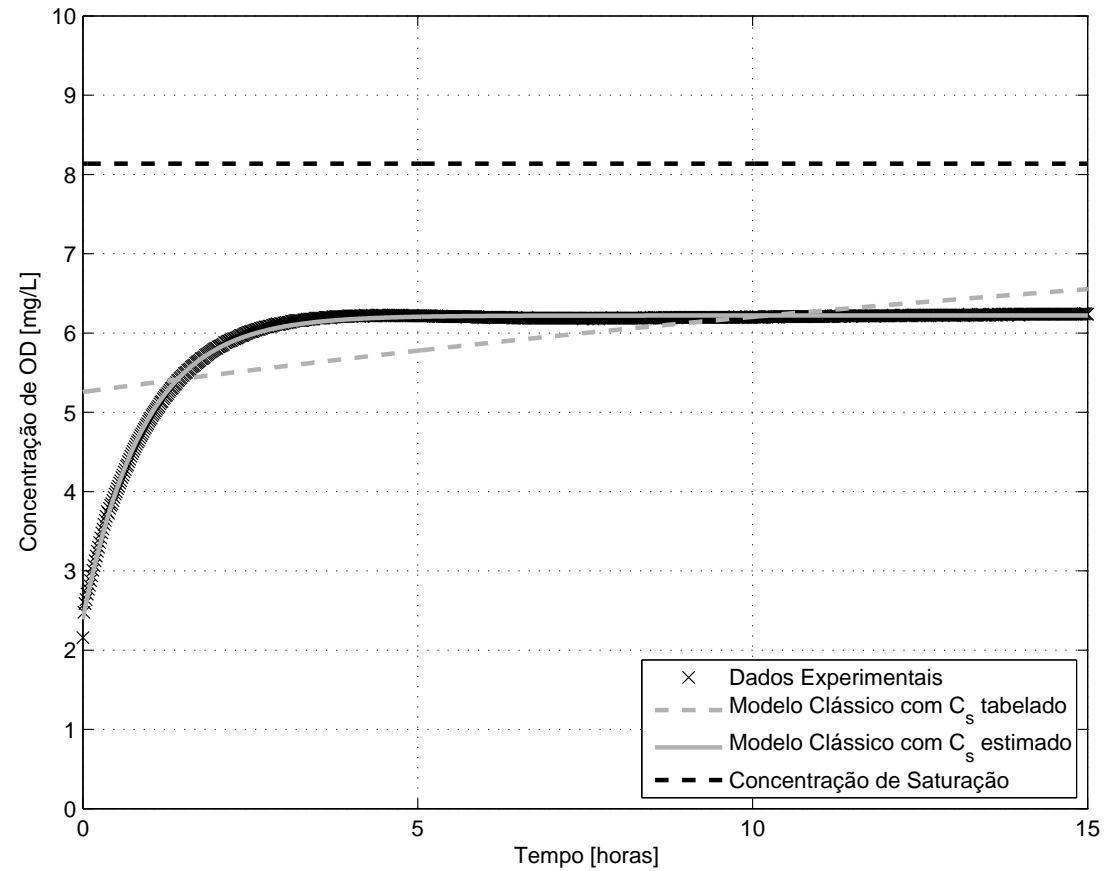

(a) Ajuste com o Modelo Clássico

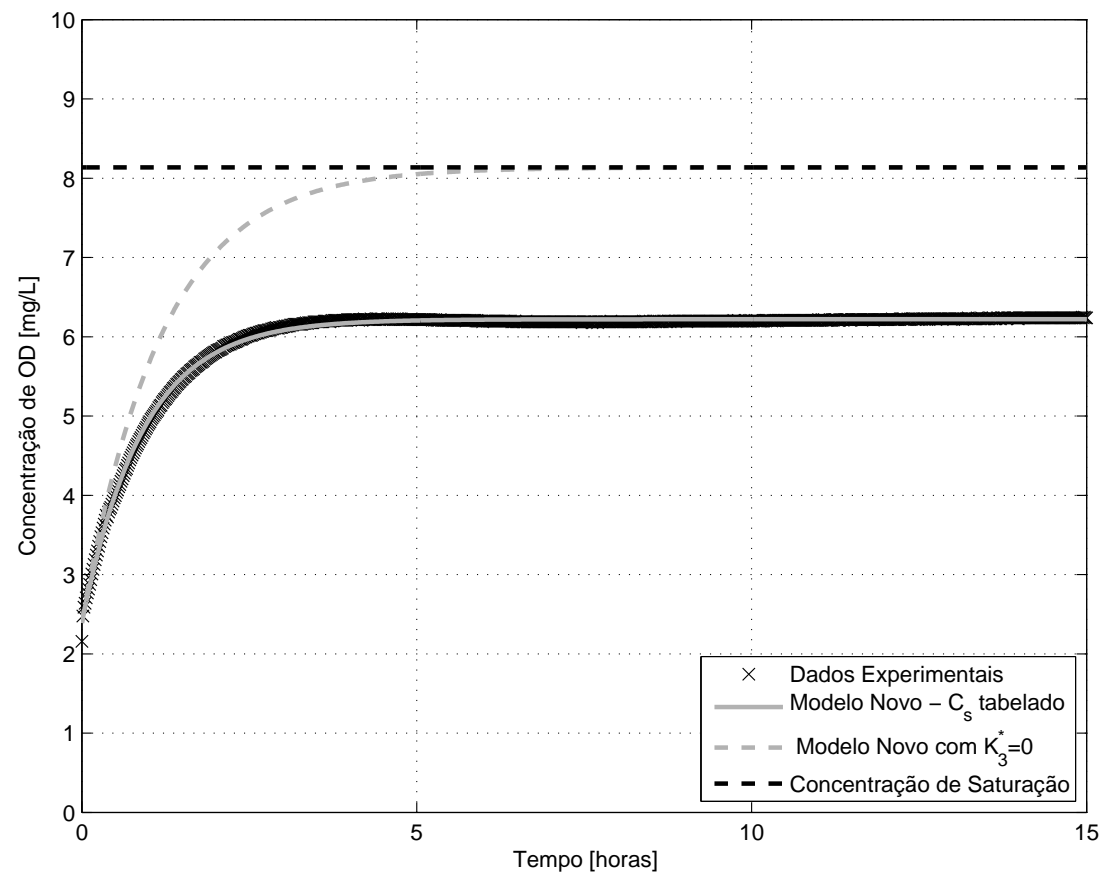

(b) Ajuste com o Modelo Novo

Figura B.1: Curva de reoxigenação para o ensaio 1 


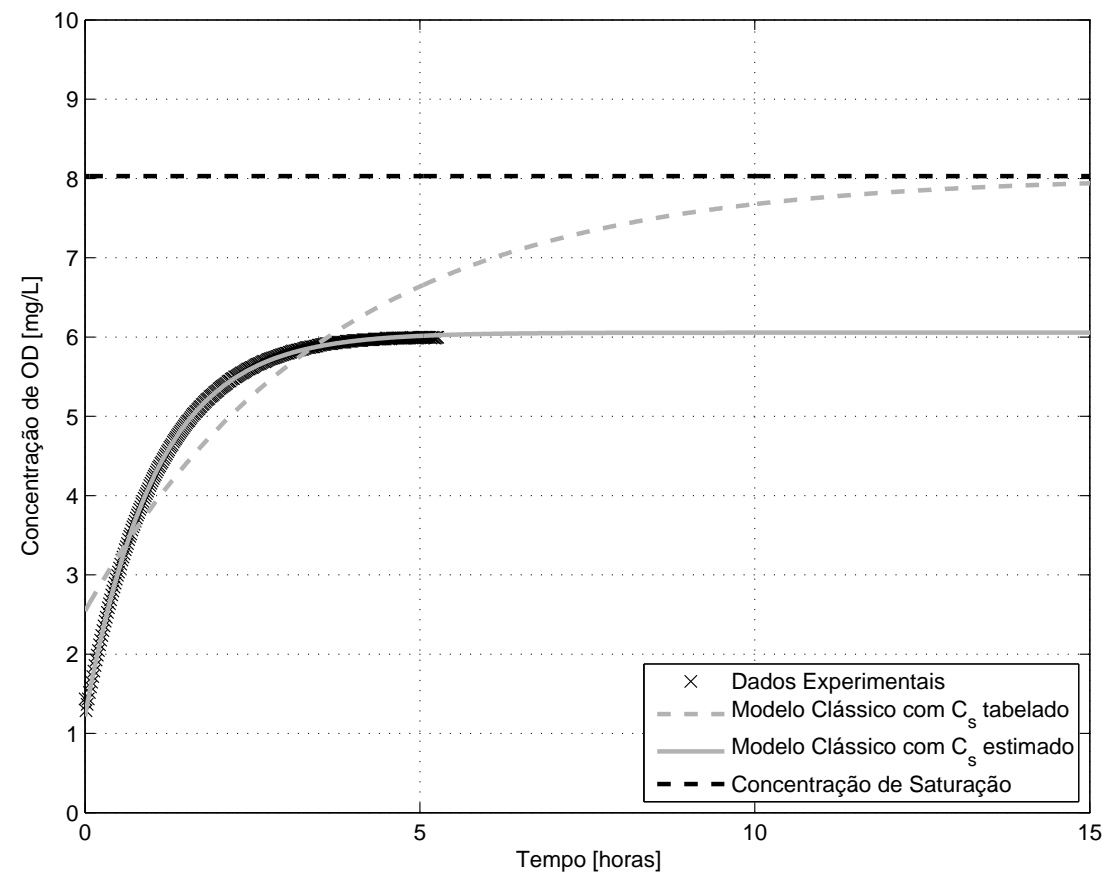

(a) Ajuste com o Modelo Clássico

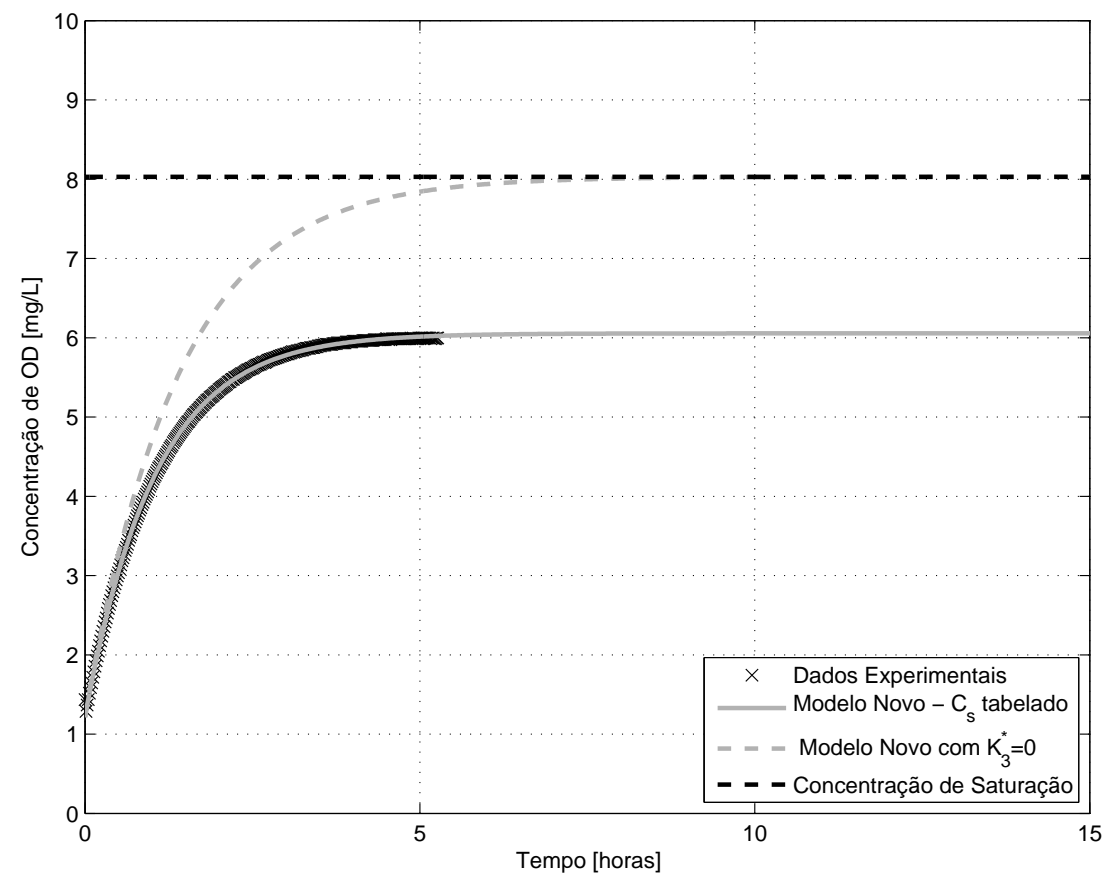

(b) Ajuste com o Modelo Novo

Figura B.2: Curva de reoxigenação para o ensaio 2 


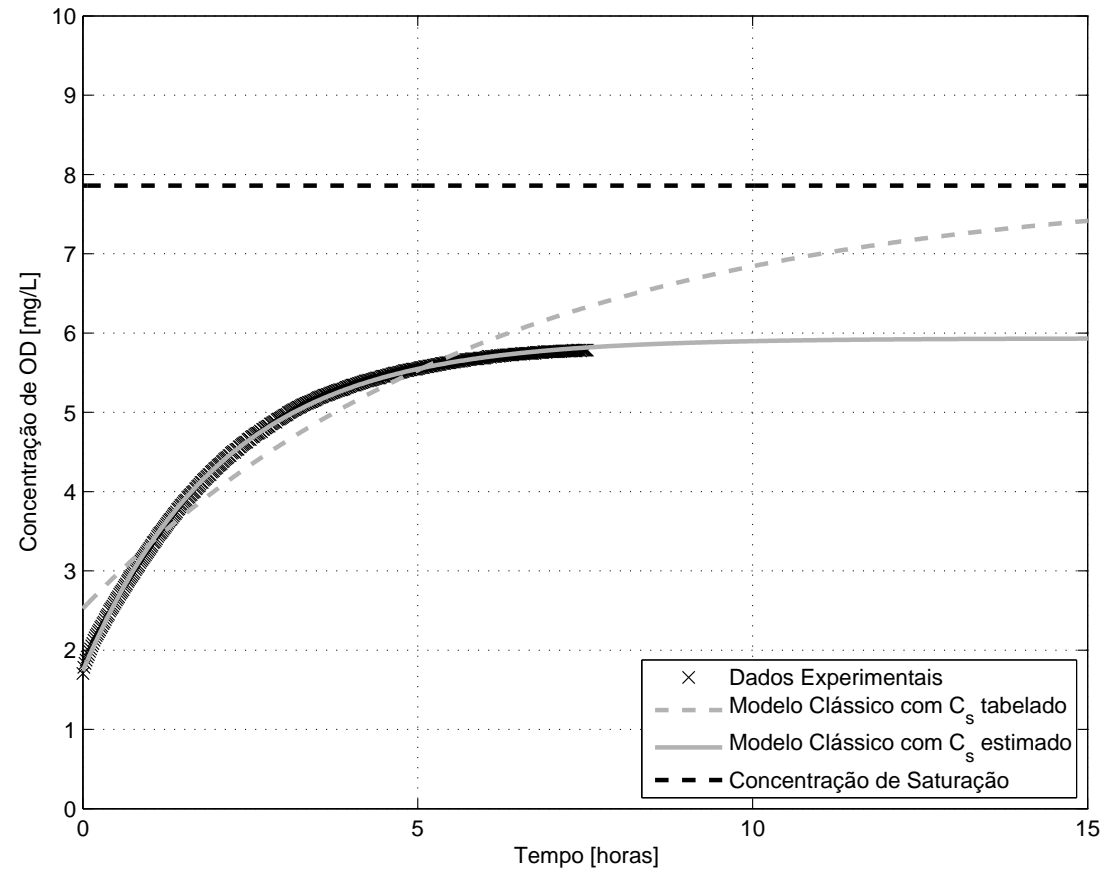

(a) Ajuste com o Modelo Clássico

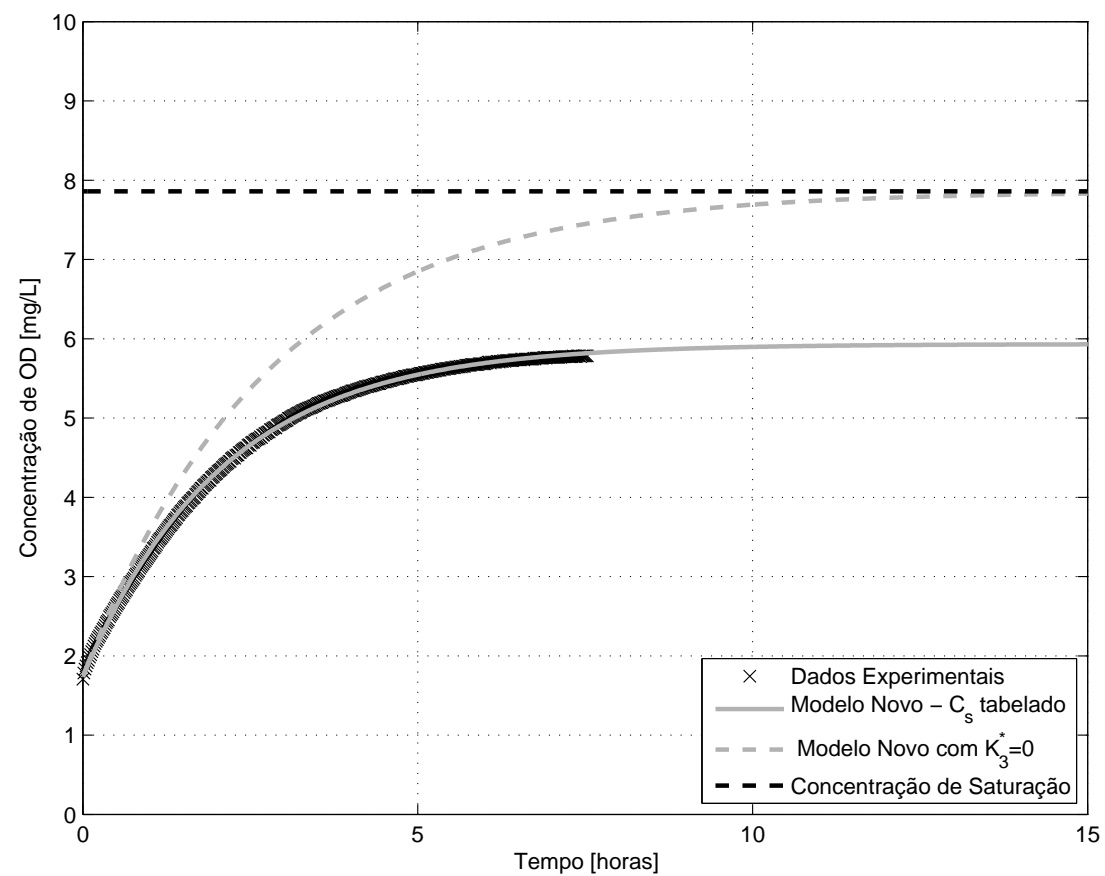

(b) Ajuste com o Modelo Novo

Figura B.3: Curva de reoxigenação para o ensaio 3 


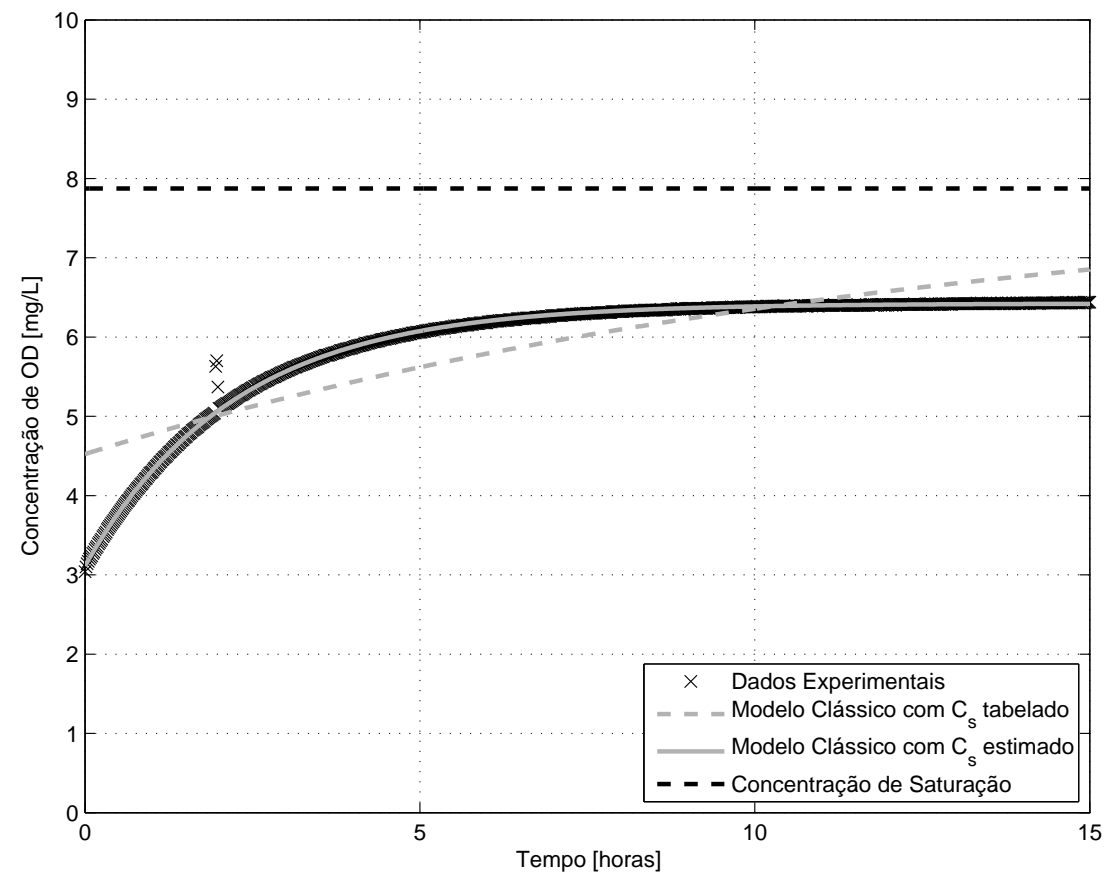

(a) Ajuste com o Modelo Clássico

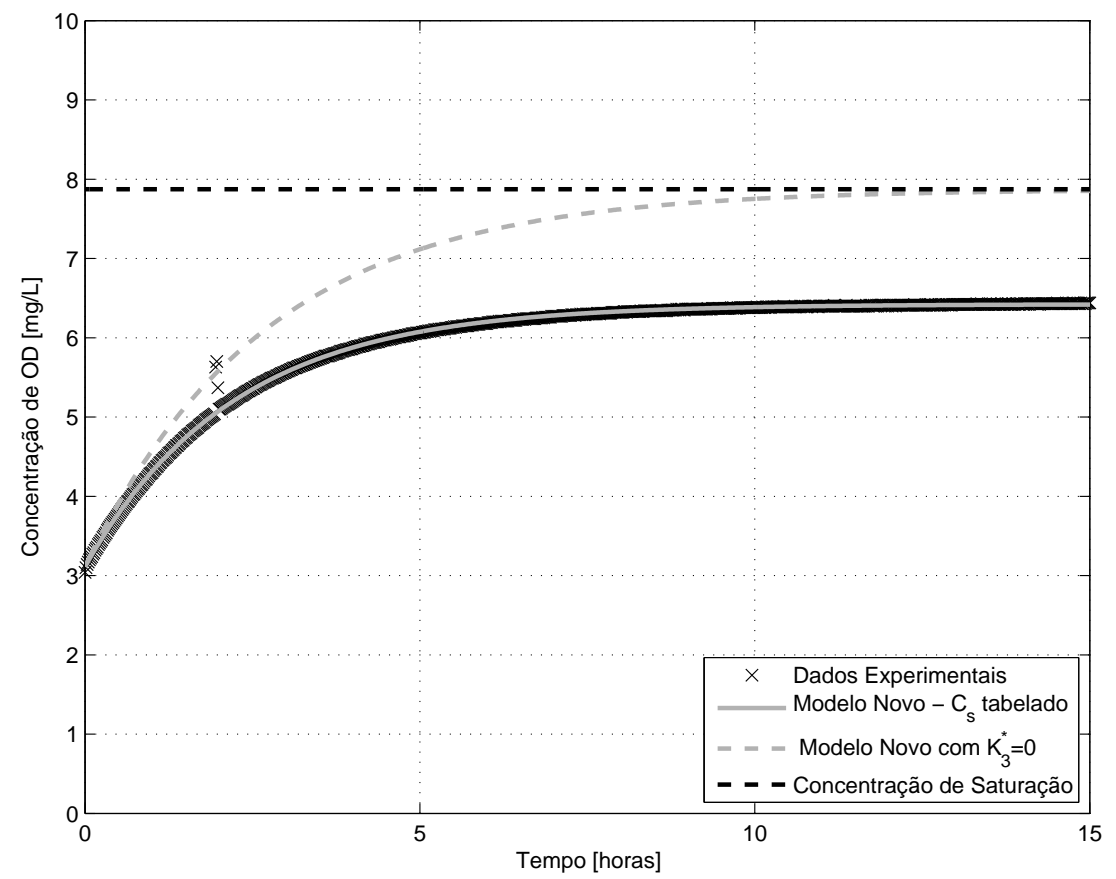

(b) Ajuste com o Modelo Novo

Figura B.4: Curva de reoxigenação para o ensaio 4 


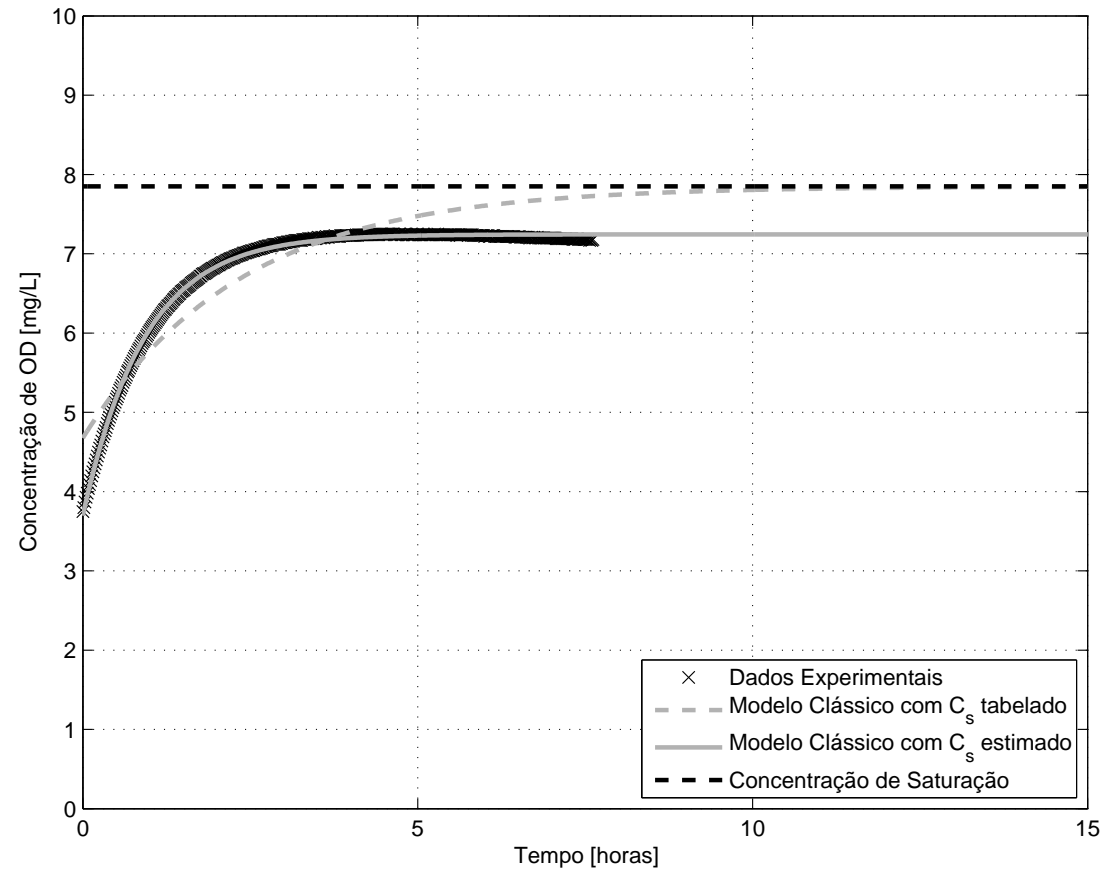

(a) Ajuste com o Modelo Clássico

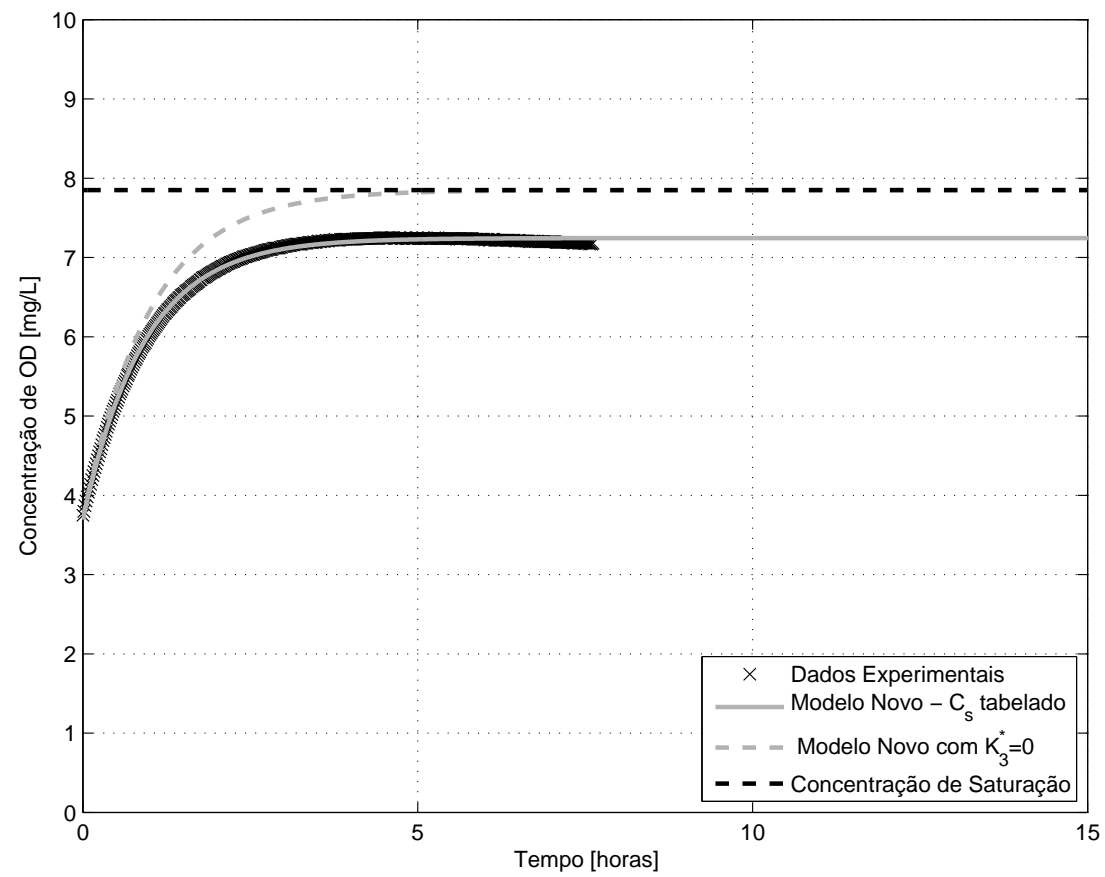

(b) Ajuste com o Modelo Novo

Figura B.5: Curva de reoxigenação para o ensaio 5 


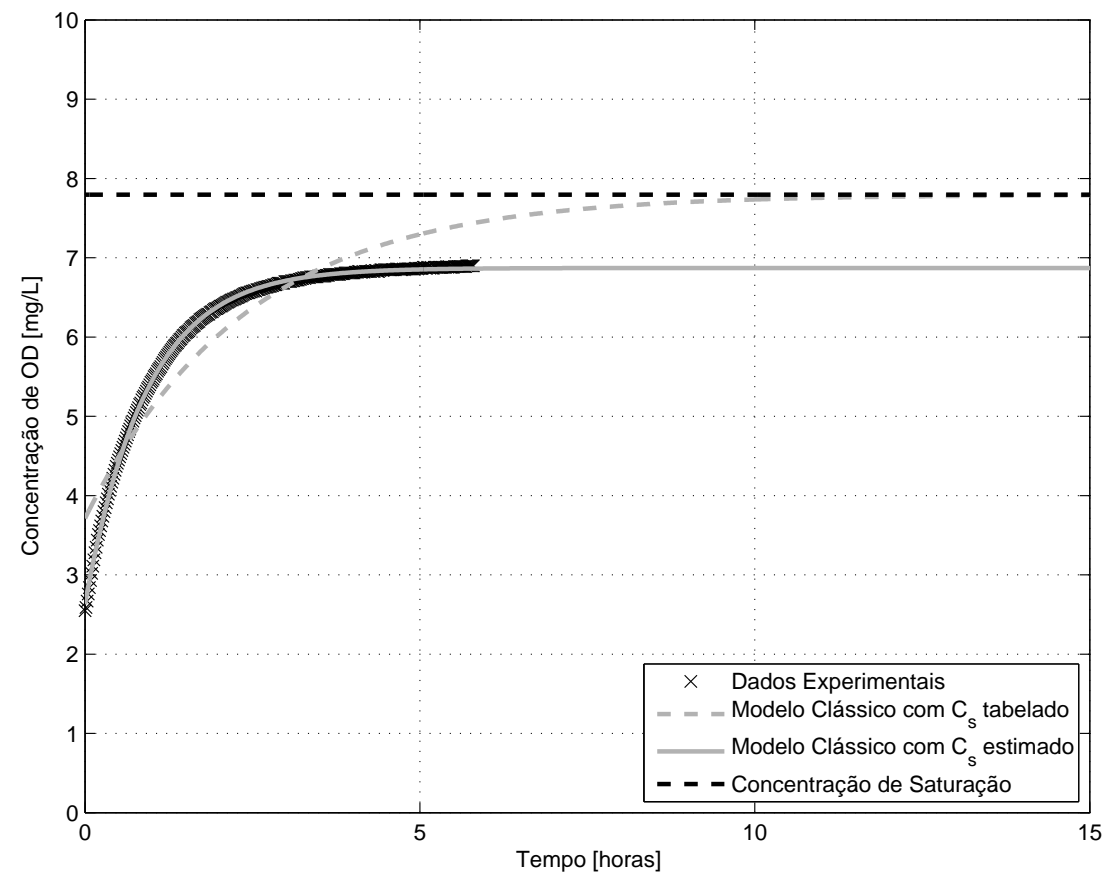

(a) Ajuste com o Modelo Clássico

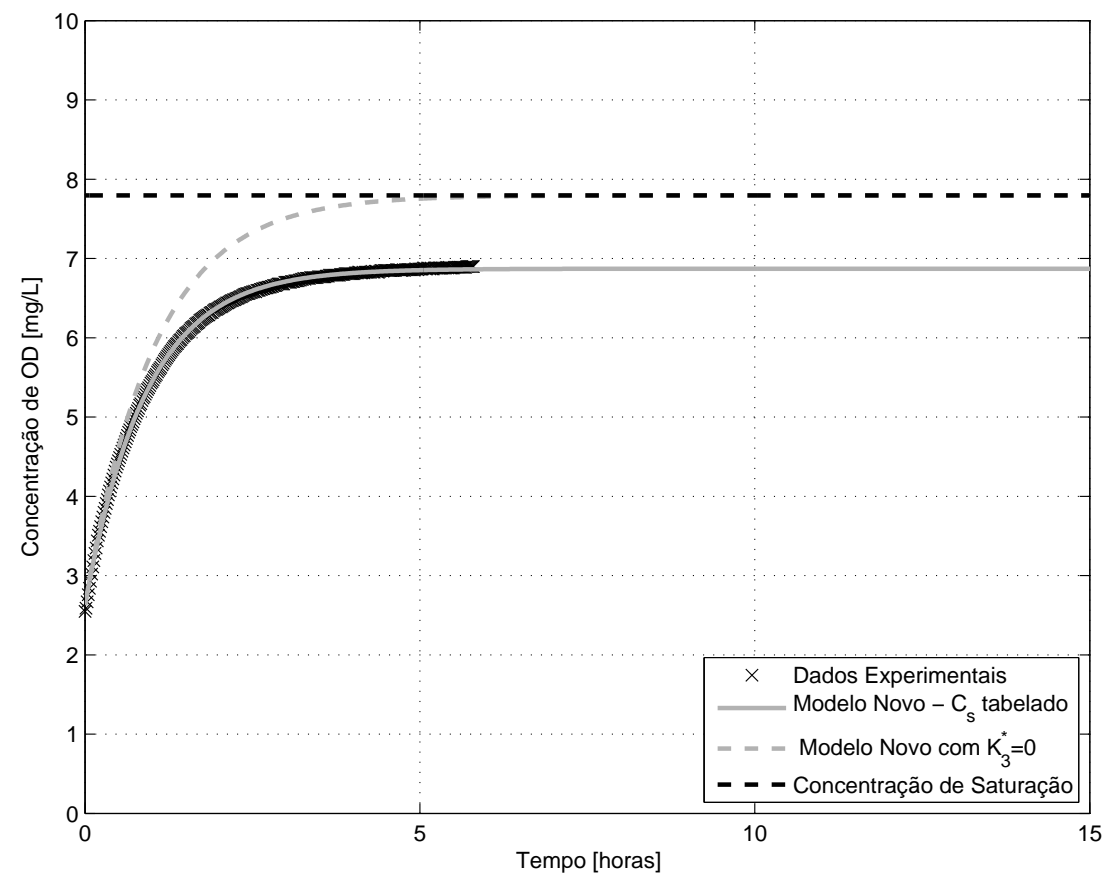

(b) Ajuste com o Modelo Novo

Figura B.6: Curva de reoxigenação para o ensaio 6 


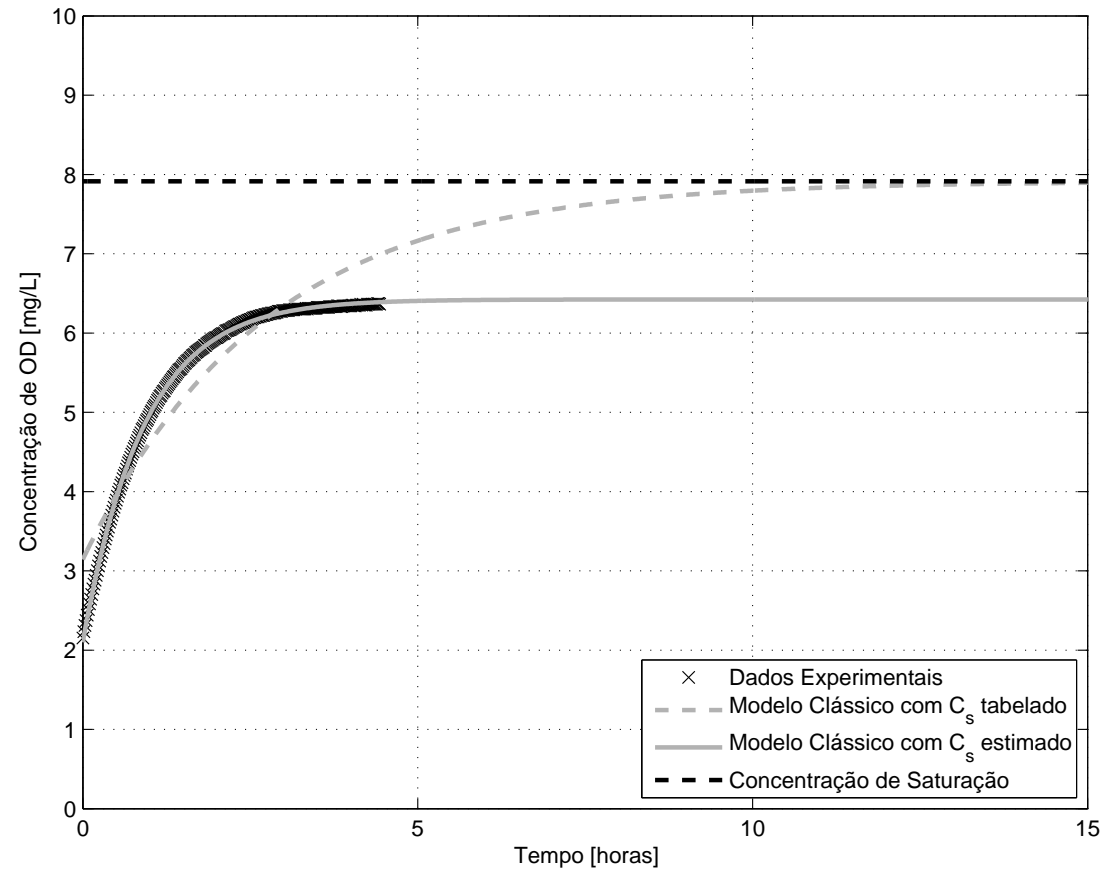

(a) Ajuste com o Modelo Clássico

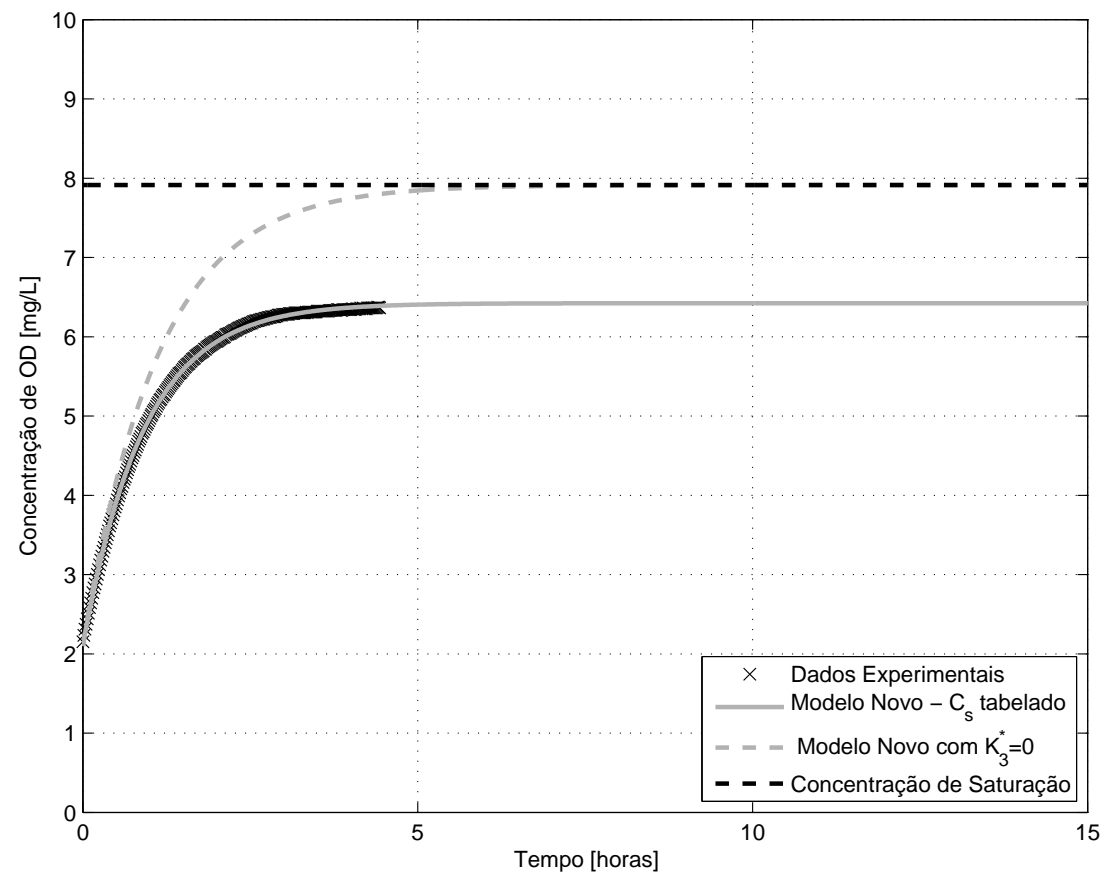

(b) Ajuste com o Modelo Novo

Figura B.7: Curva de reoxigenação para o ensaio 7 


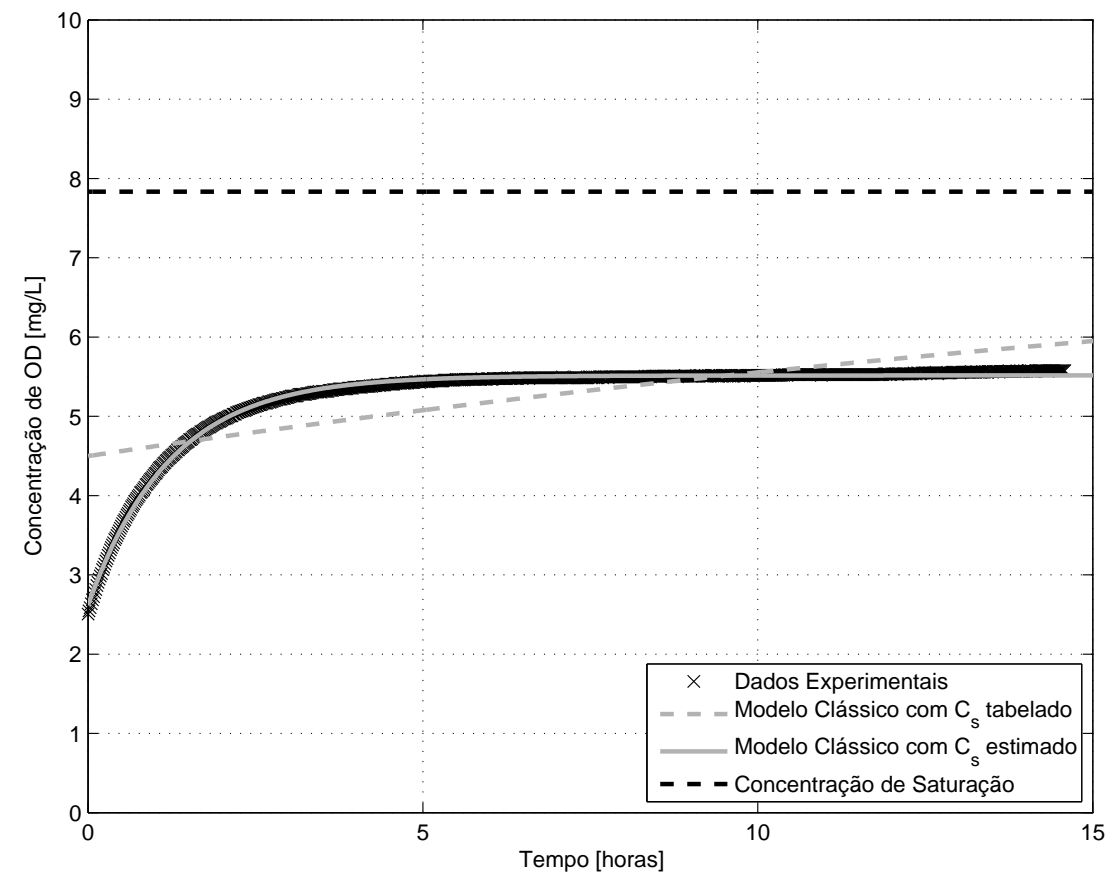

(a) Ajuste com o Modelo Clássico

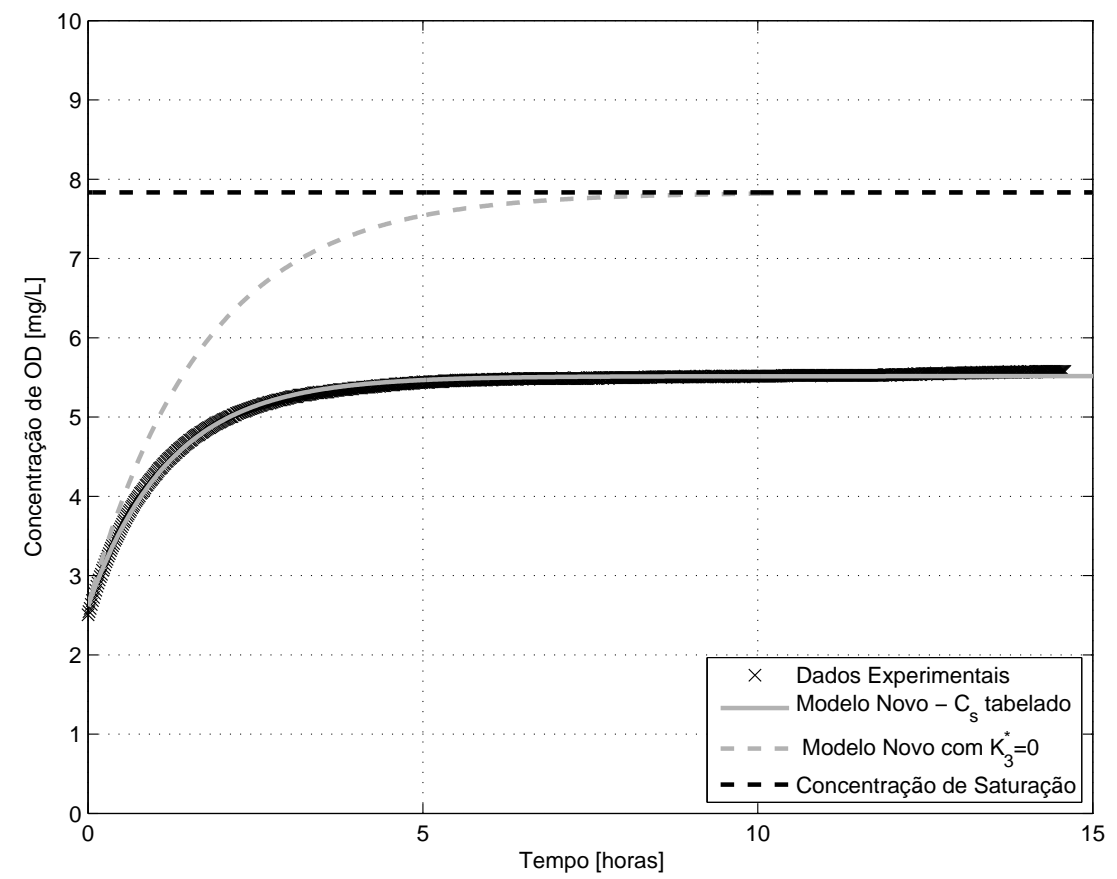

(b) Ajuste com o Modelo Novo

Figura B.8: Curva de reoxigenação para o ensaio 8 


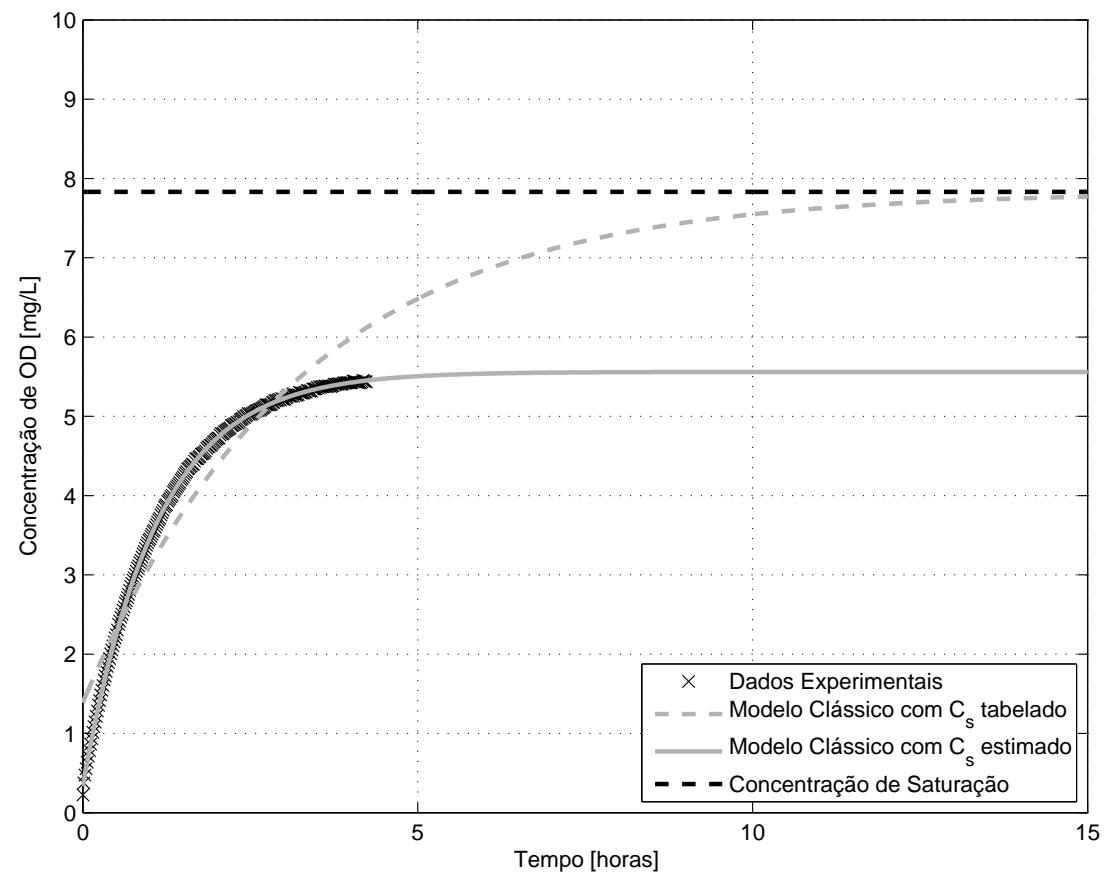

(a) Ajuste com o Modelo Clássico

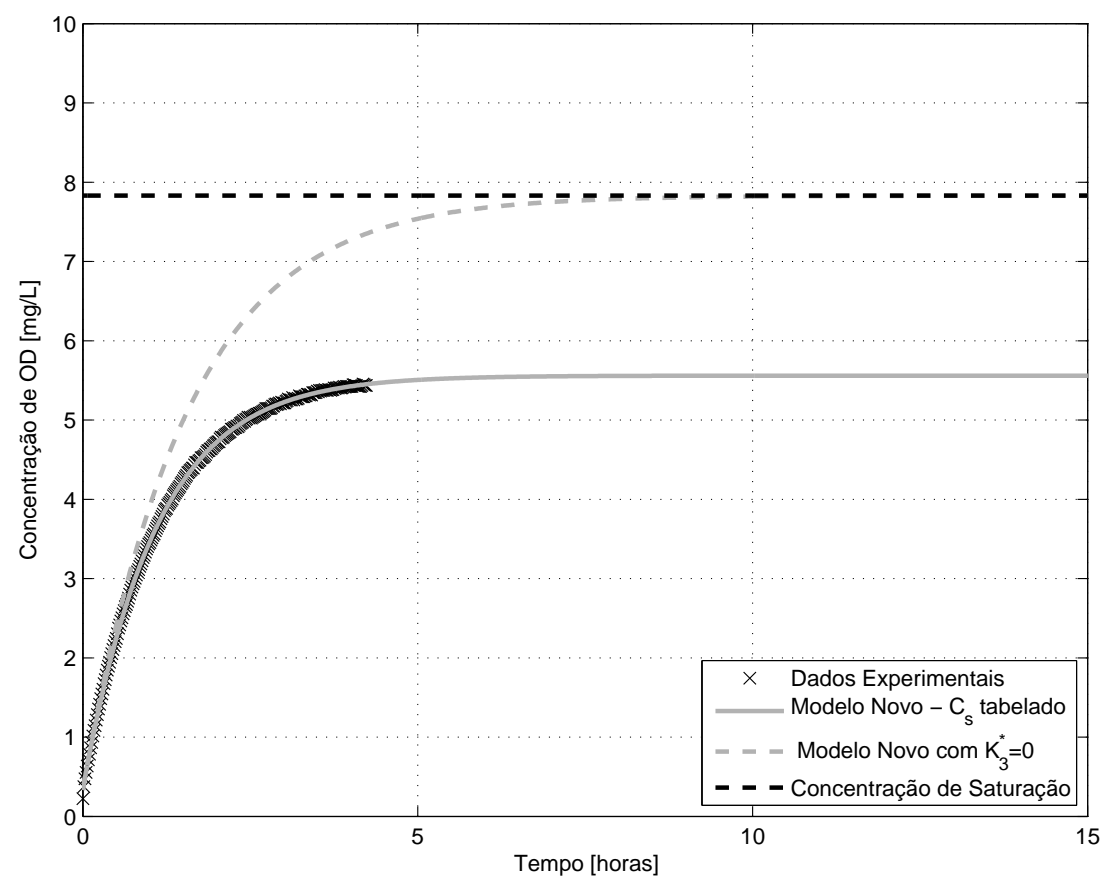

(b) Ajuste com o Modelo Novo

Figura B.9: Curva de reoxigenação para o ensaio 9 


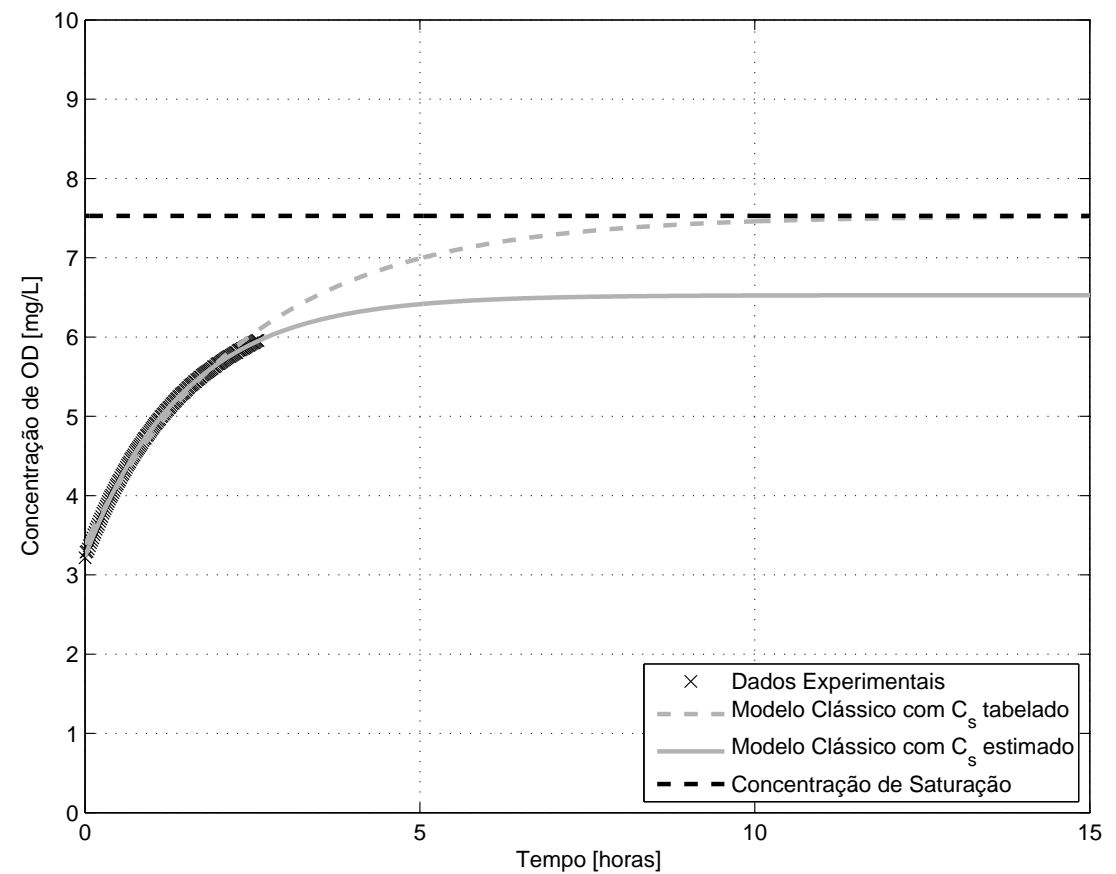

(a) Ajuste com o Modelo Clássico

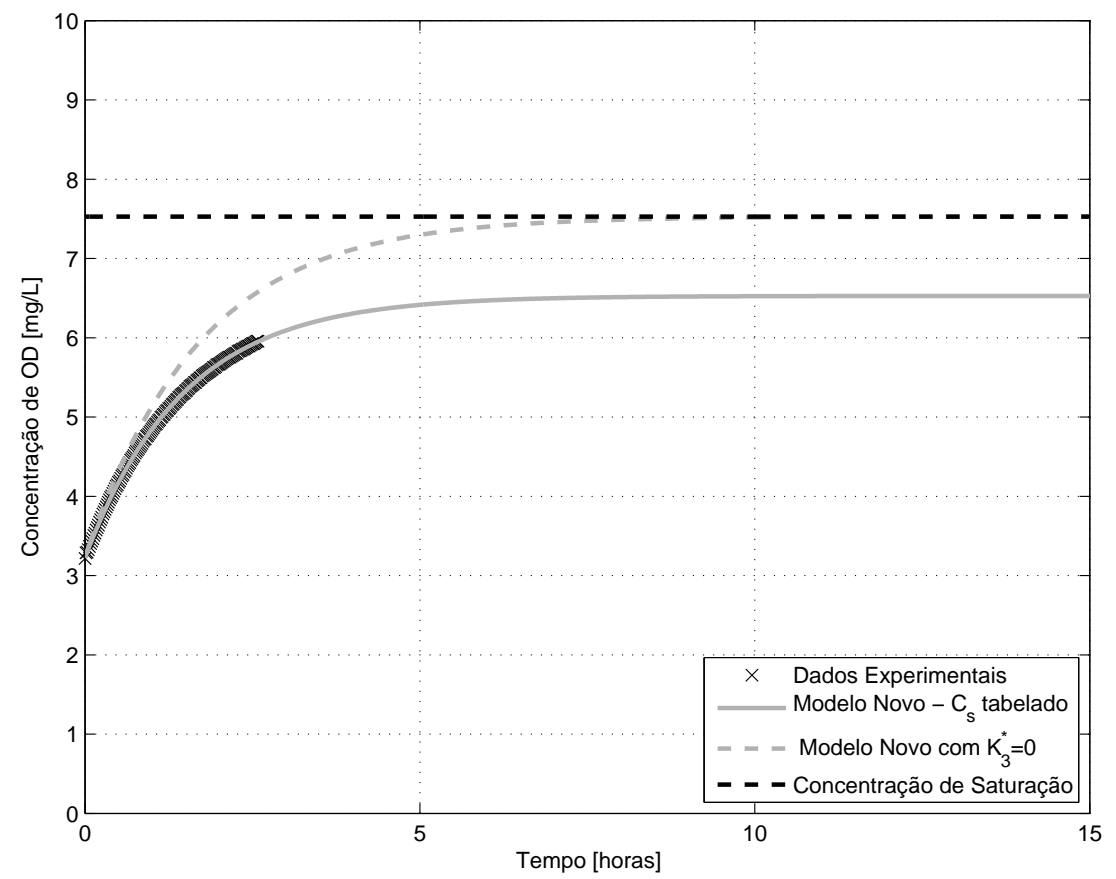

(b) Ajuste com o Modelo Novo

Figura B.10: Curva de reoxigenação para o ensaio 10 


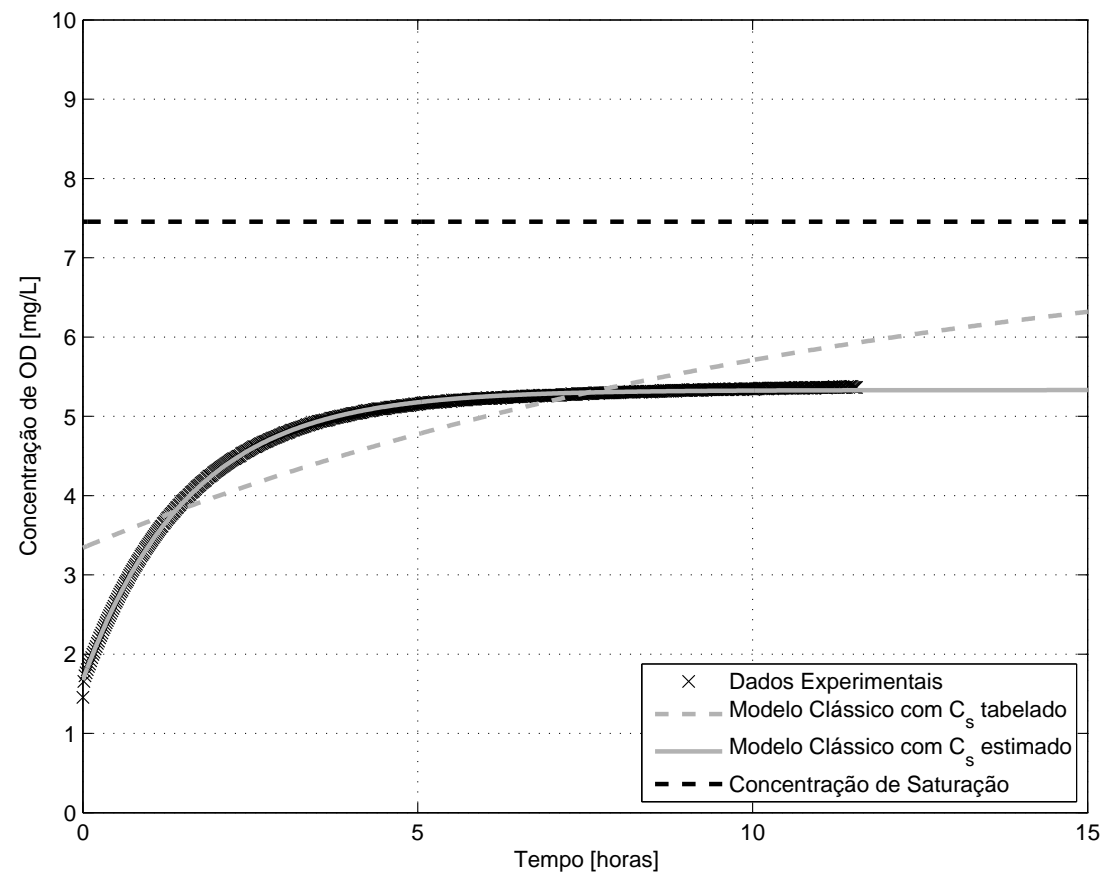

(a) Ajuste com o Modelo Clássico

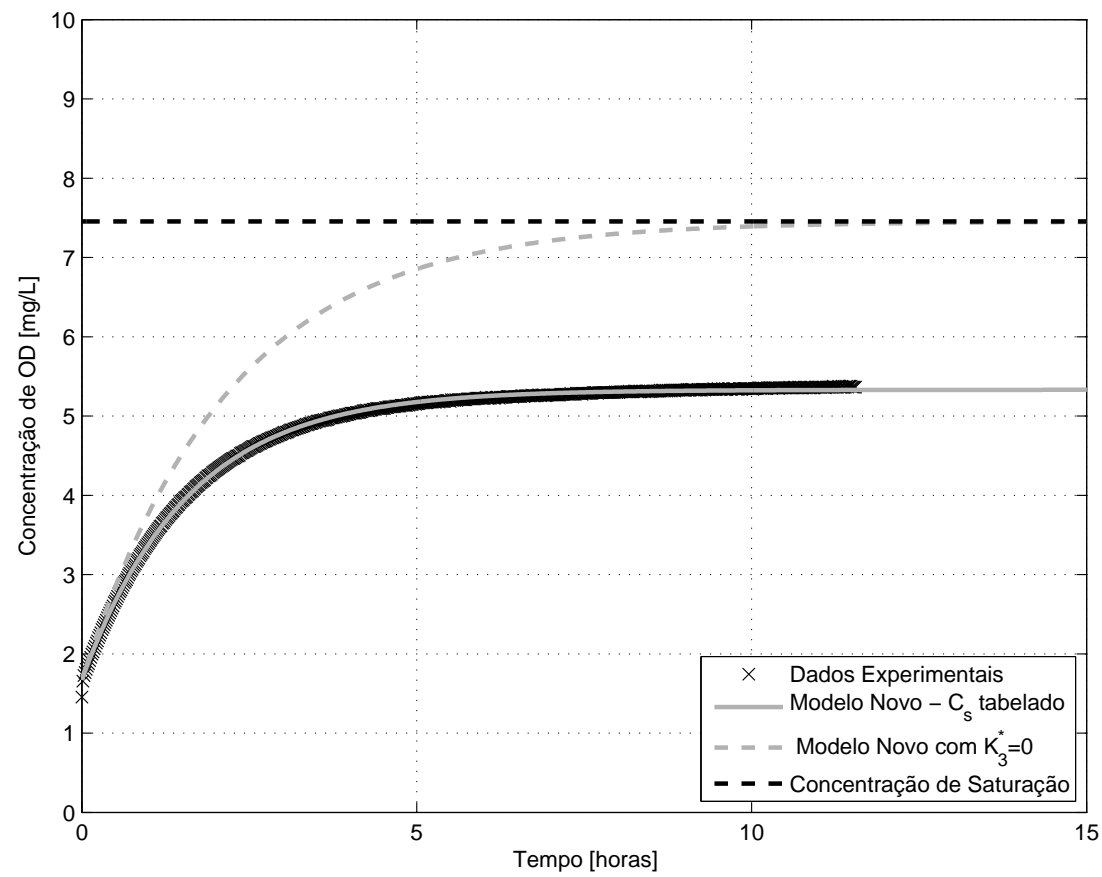

(b) Ajuste com o Modelo Novo

Figura B.11: Curva de reoxigenação para o ensaio 11 


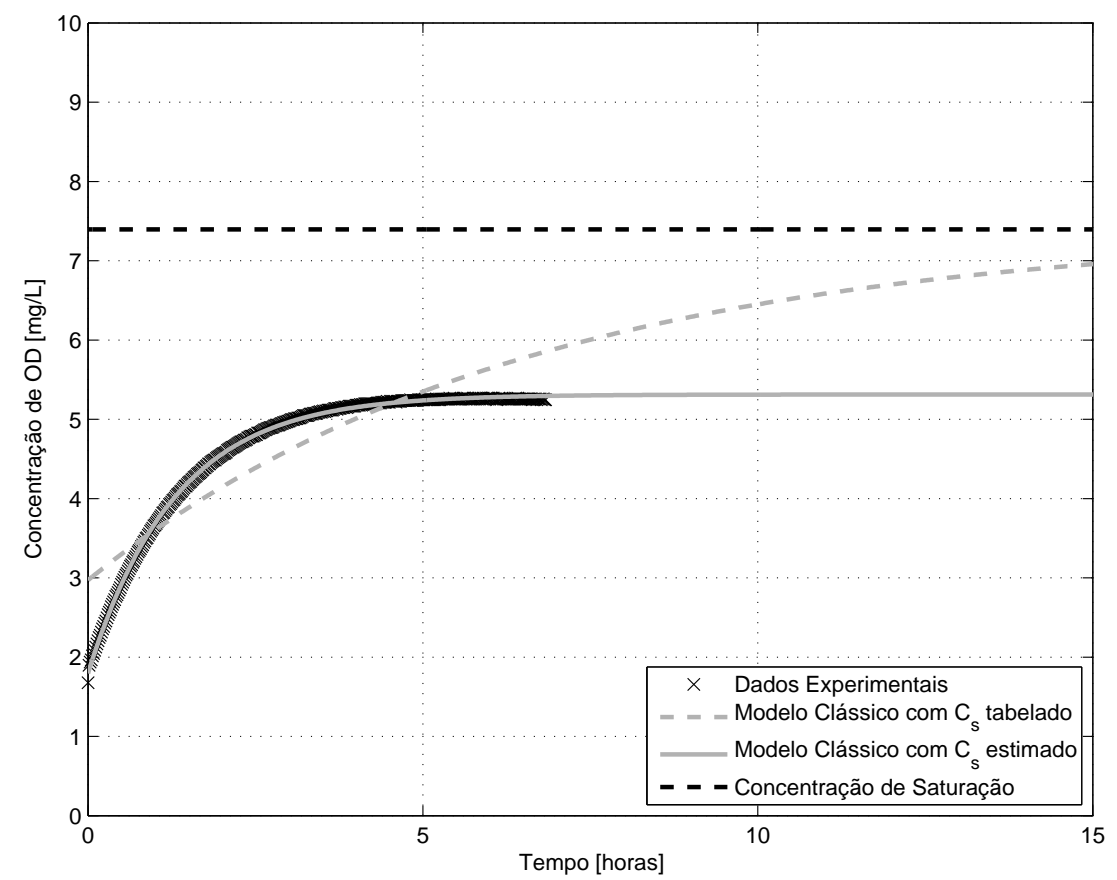

(a) Ajuste com o Modelo Clássico

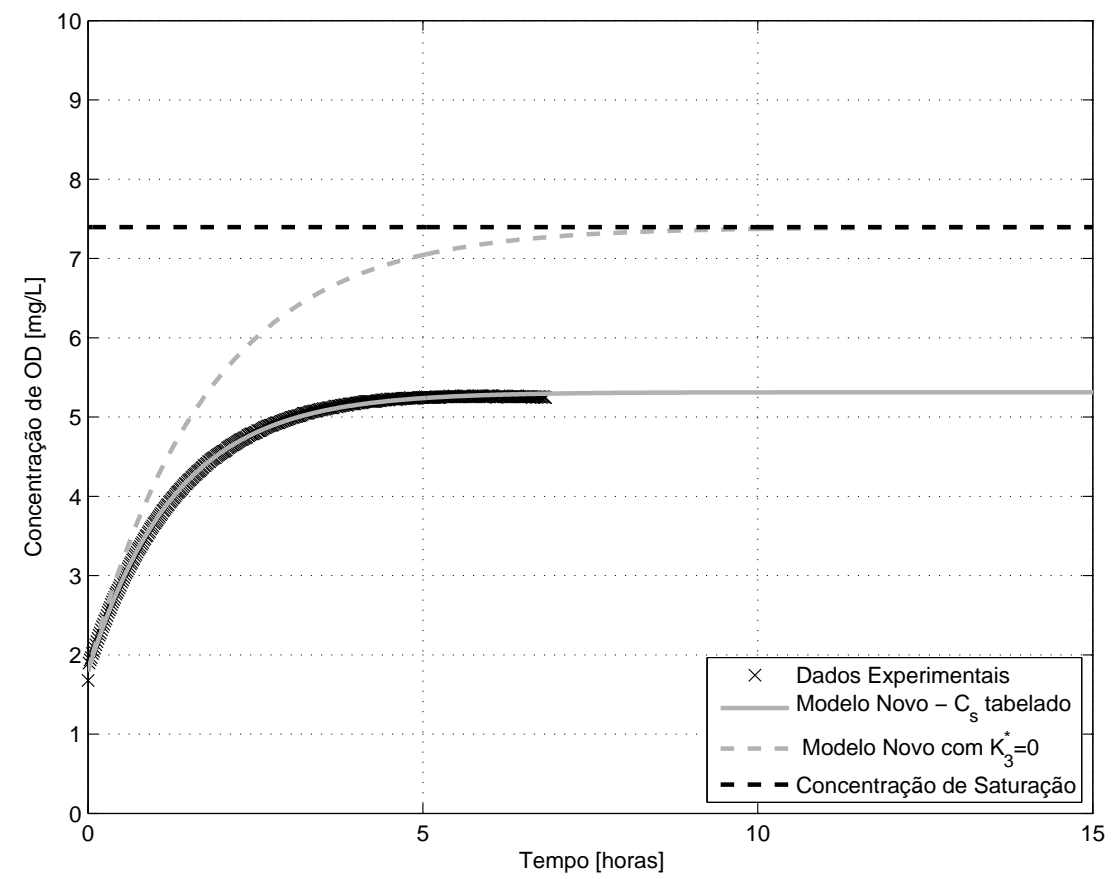

(b) Ajuste com o Modelo Novo

Figura B.12: Curva de reoxigenação para o ensaio 12 


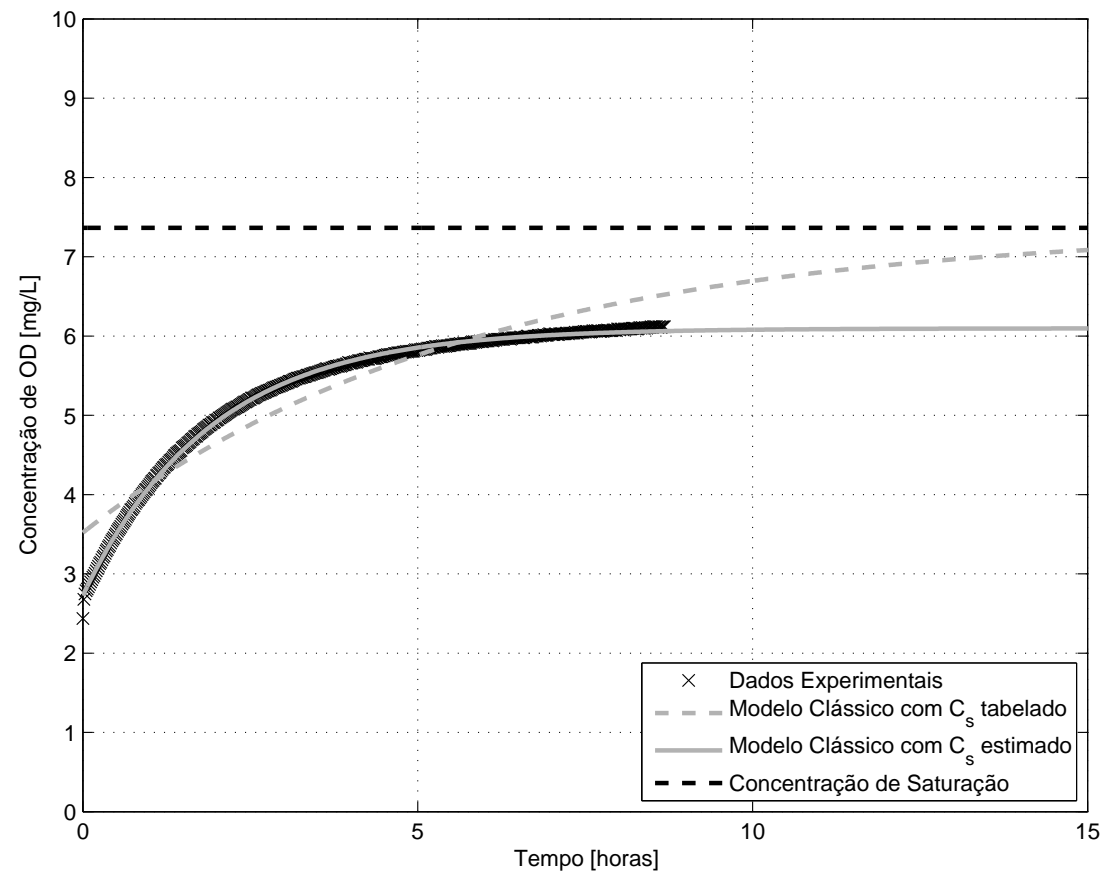

(a) Ajuste com o Modelo Clássico

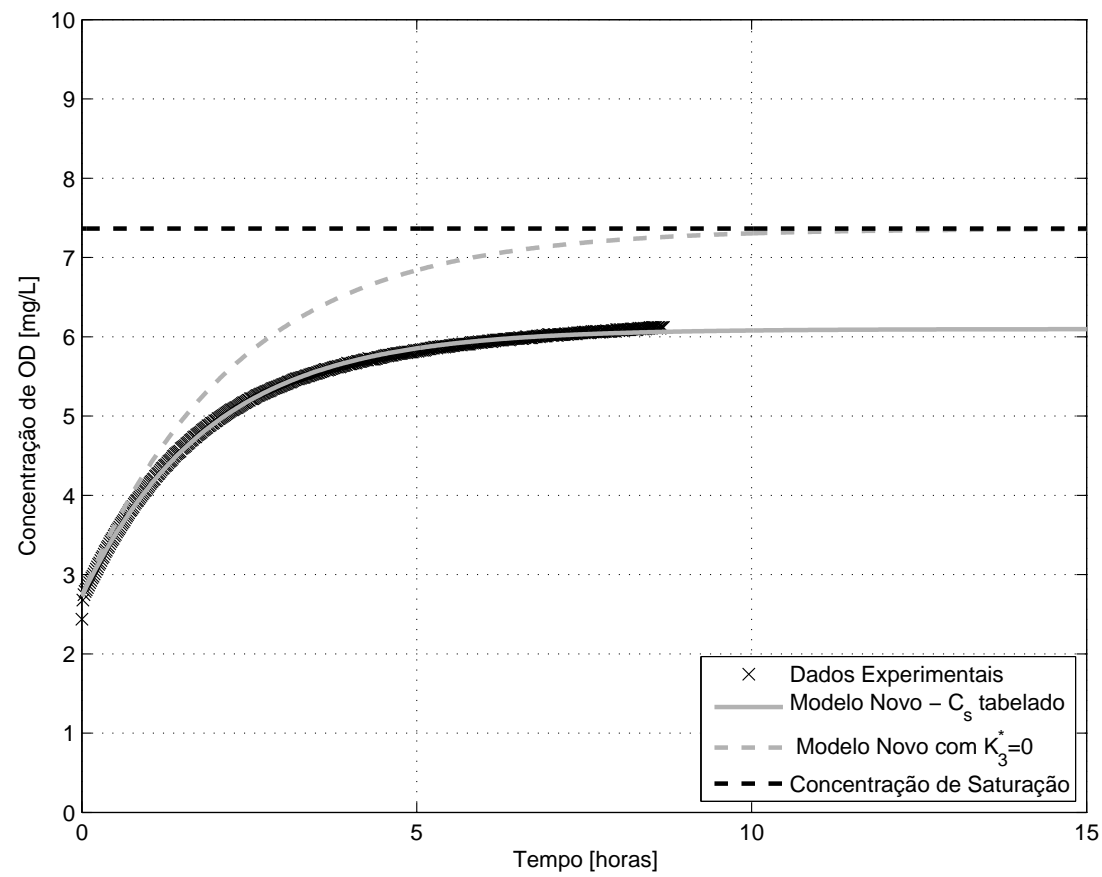

(b) Ajuste com o Modelo Novo

Figura B.13: Curva de reoxigenação para o ensaio 13 


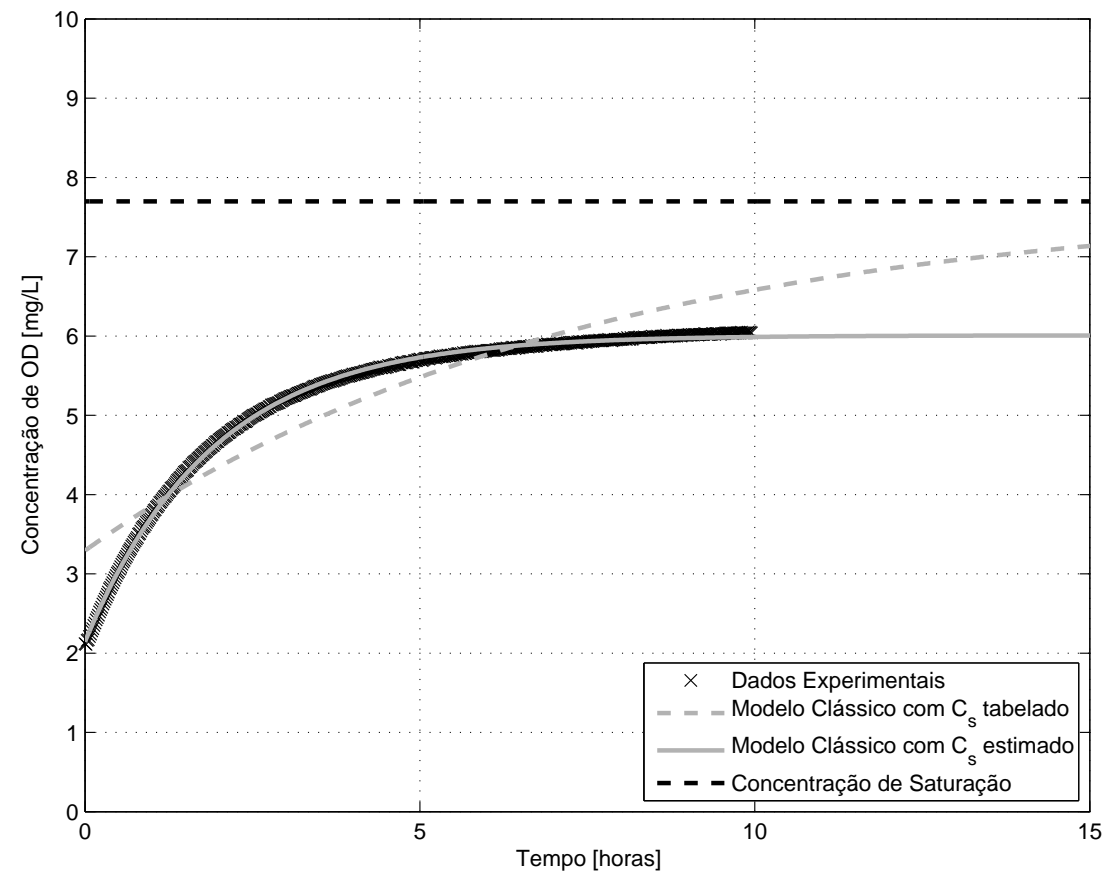

(a) Ajuste com o Modelo Clássico

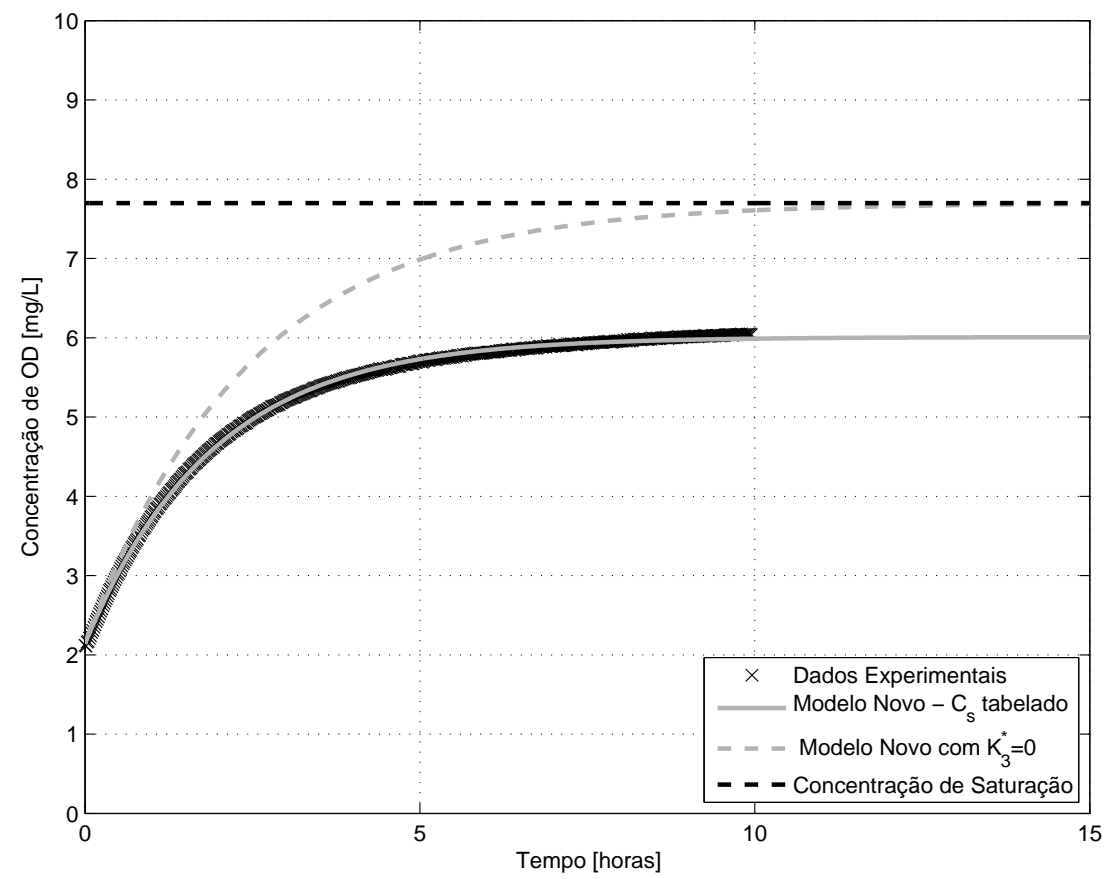

(b) Ajuste com o Modelo Novo

Figura B.14: Curva de reoxigenação para o ensaio 14 


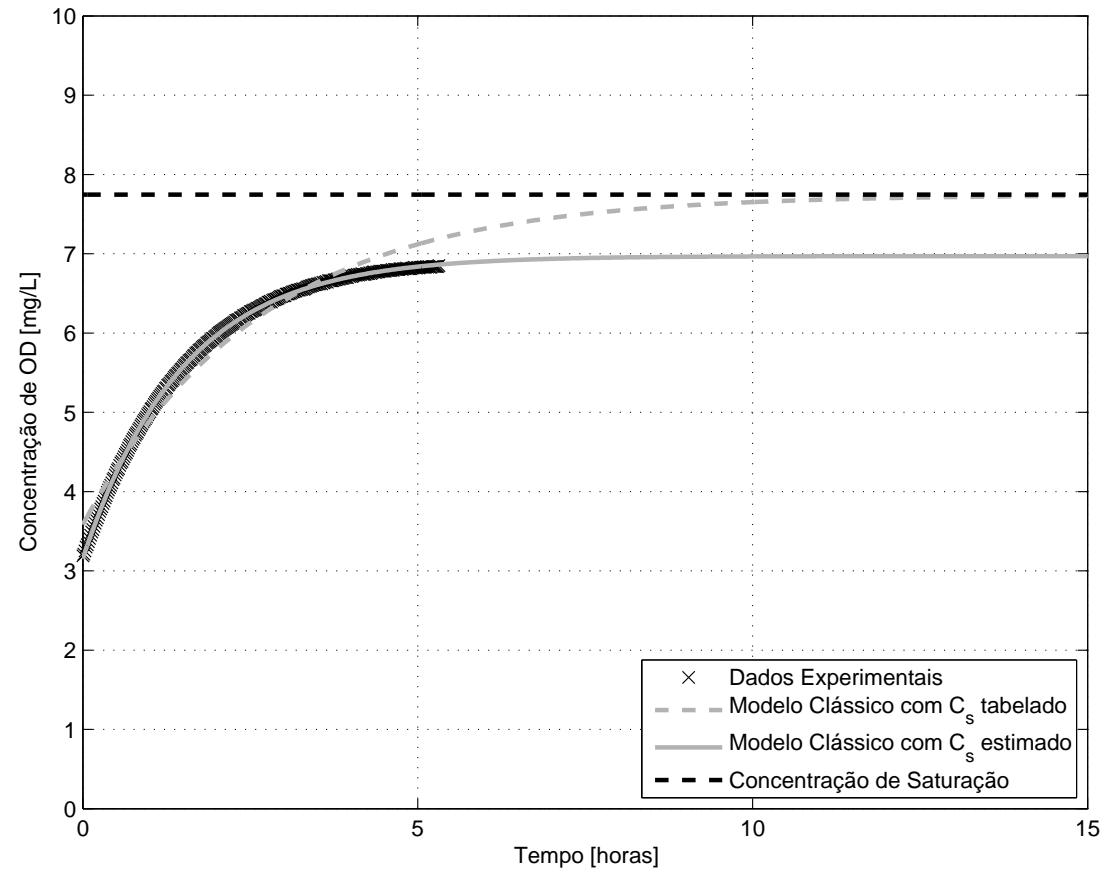

(a) Ajuste com o Modelo Clássico

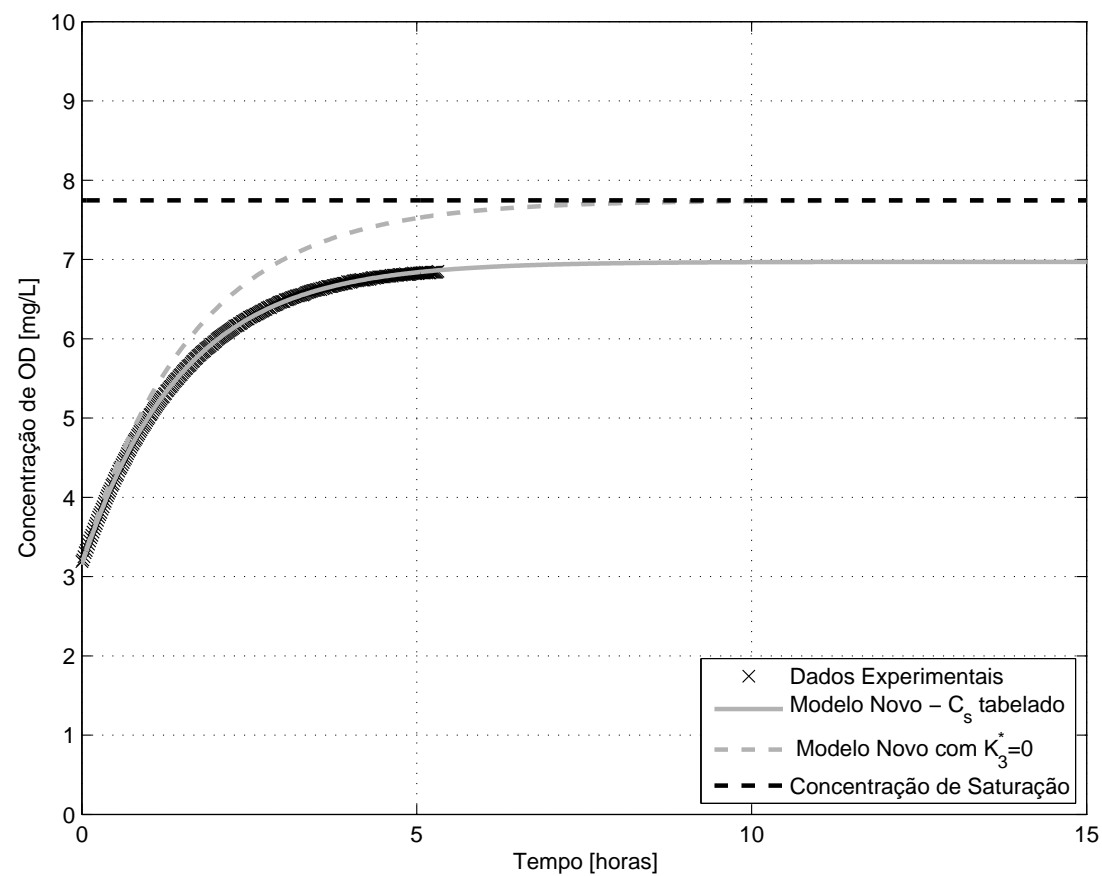

(b) Ajuste com o Modelo Novo

Figura B.15: Curva de reoxigenação para o ensaio 15 


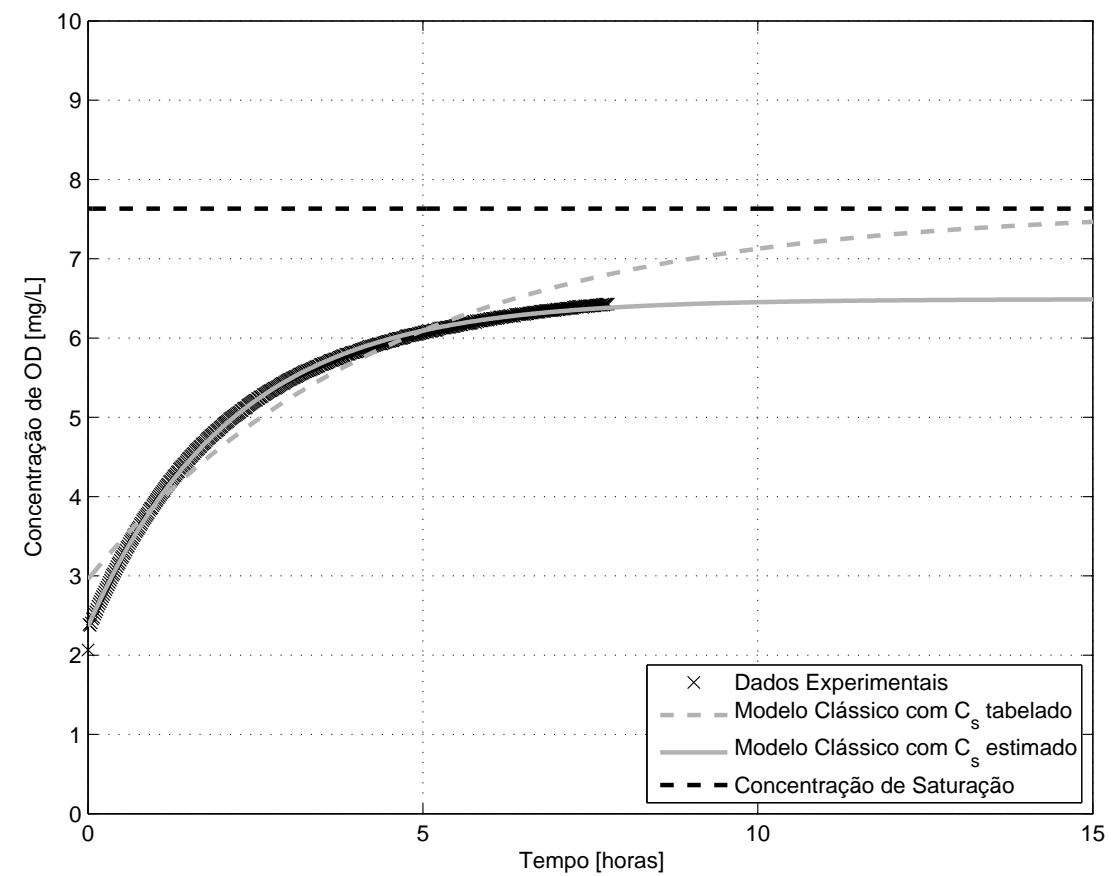

(a) Ajuste com o Modelo Clássico

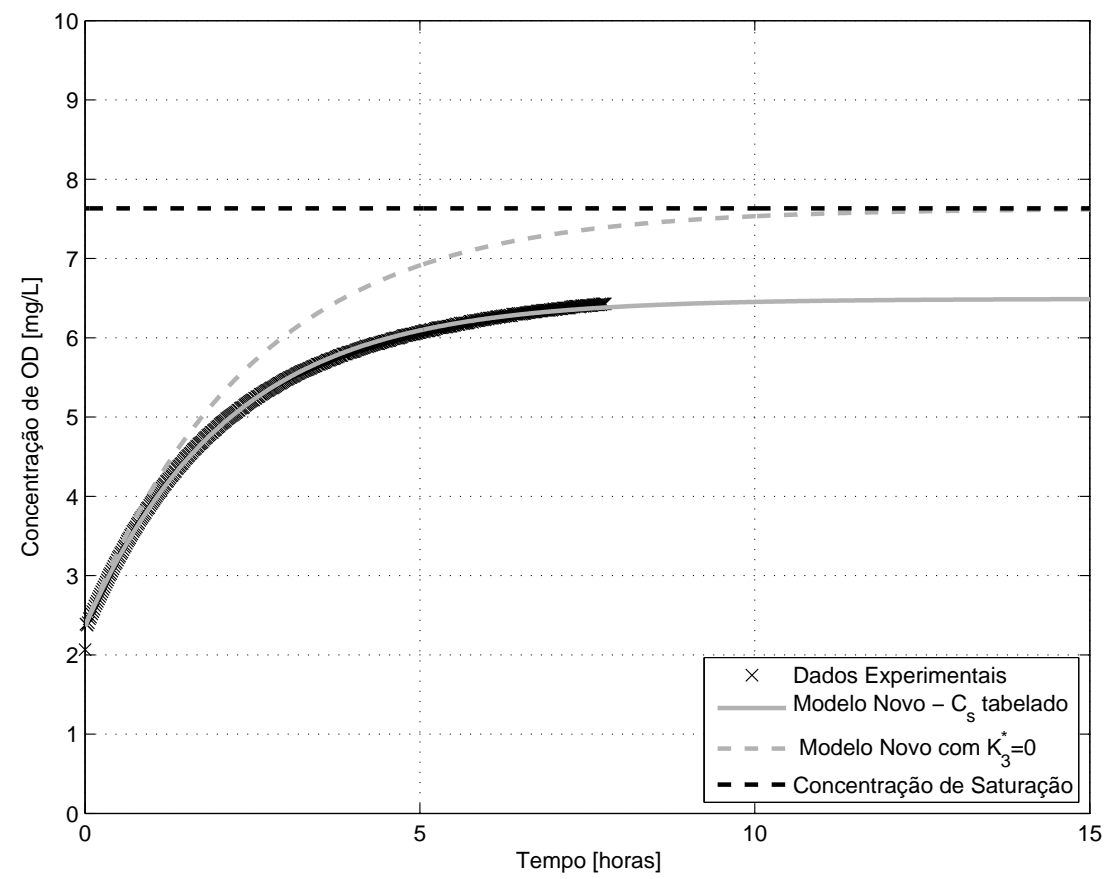

(b) Ajuste com o Modelo Novo

Figura B.16: Curva de reoxigenação para o ensaio 16 


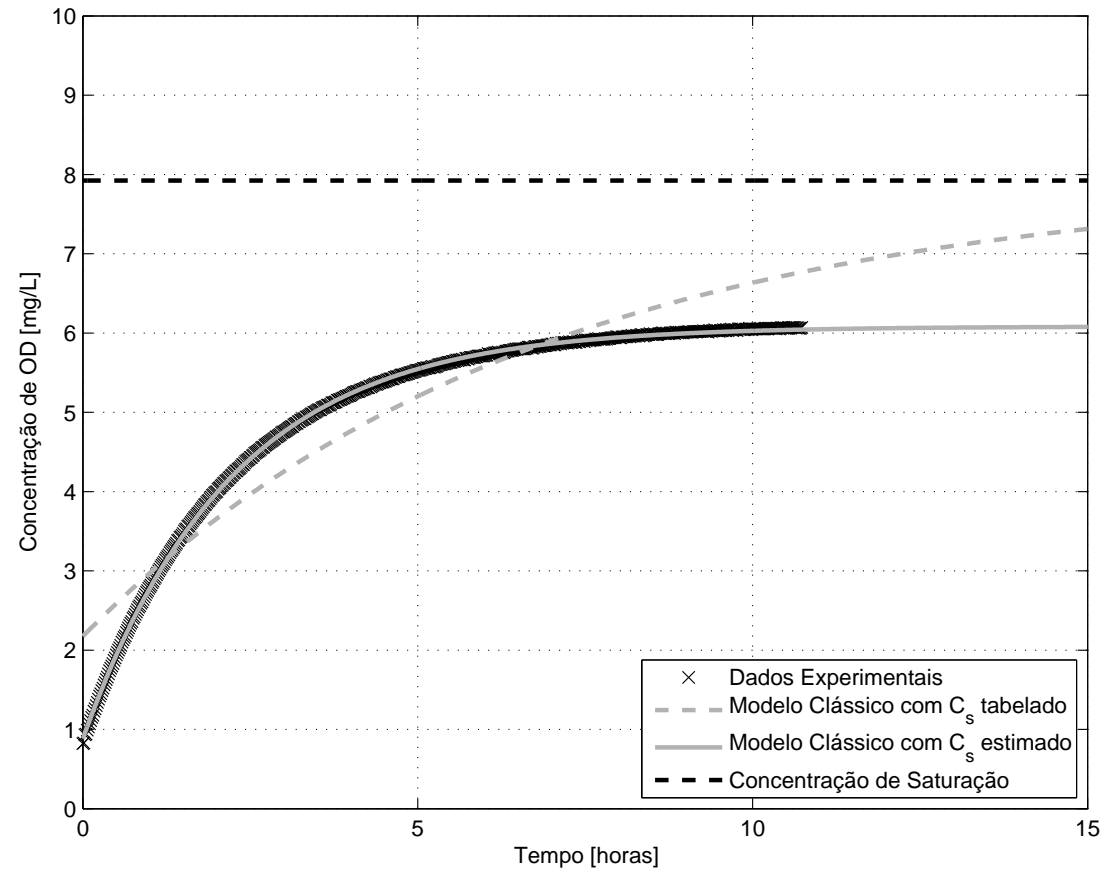

(a) Ajuste com o Modelo Clássico

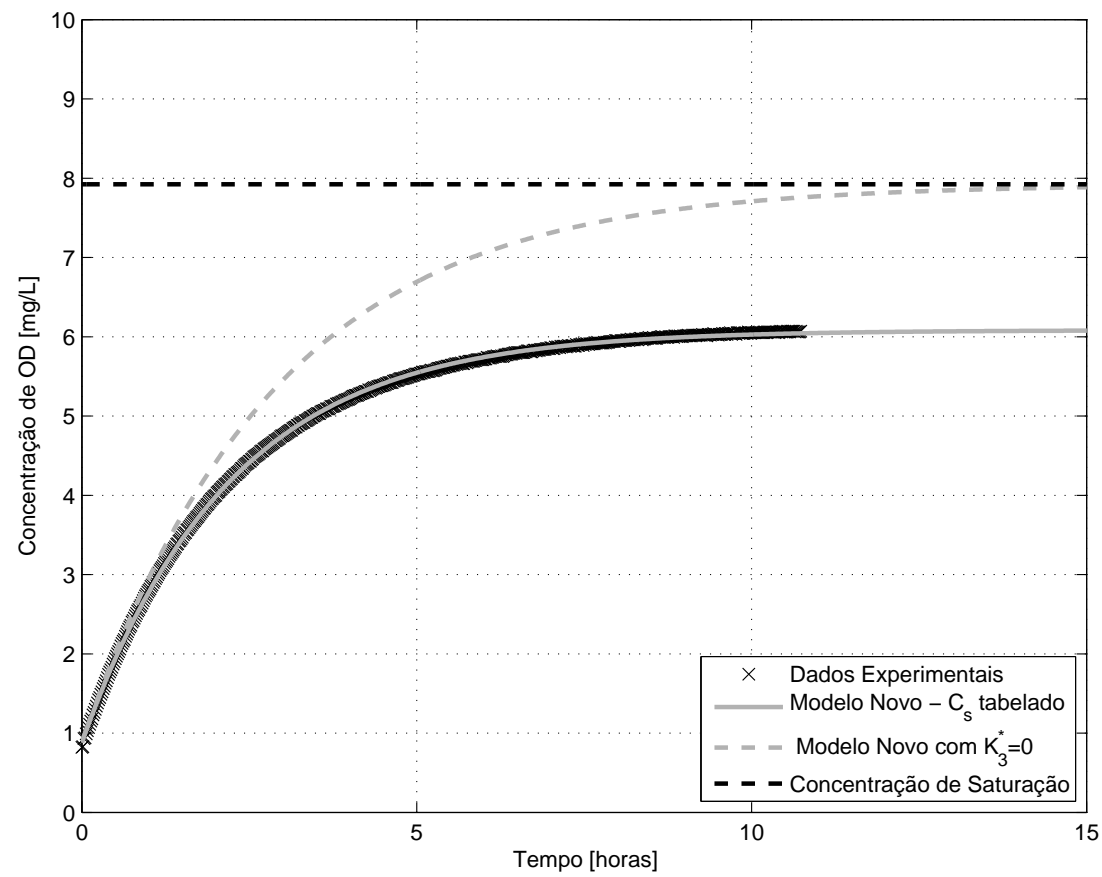

(b) Ajuste com o Modelo Novo

Figura B.17: Curva de reoxigenação para o ensaio 17 


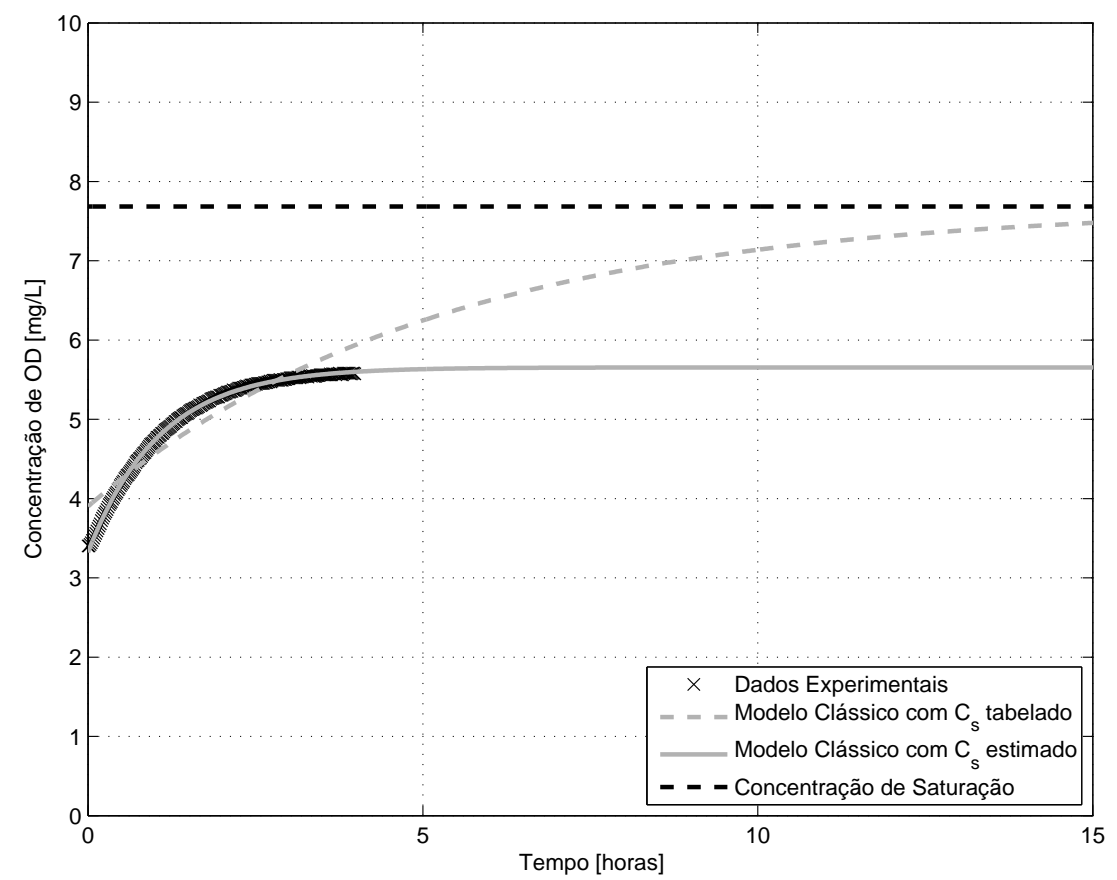

(a) Ajuste com o Modelo Clássico

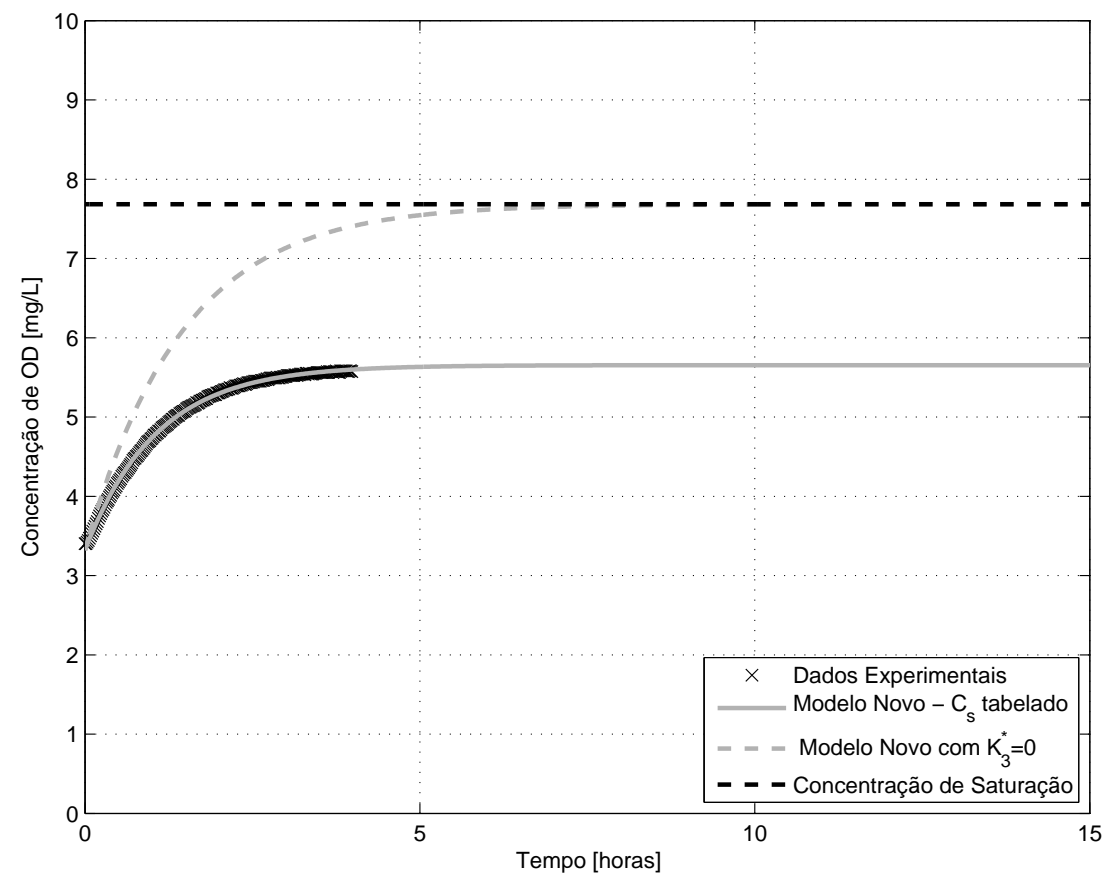

(b) Ajuste com o Modelo Novo

Figura B.18: Curva de reoxigenação para o ensaio 18 


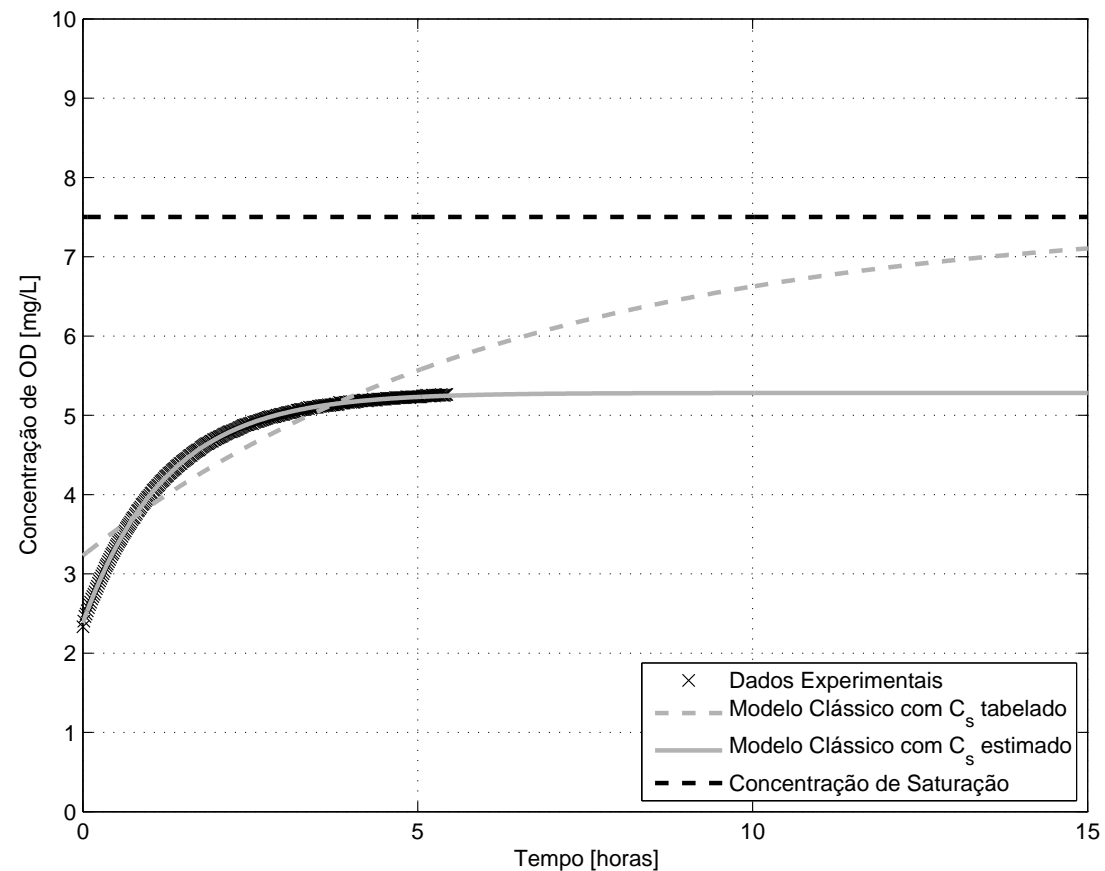

(a) Ajuste com o Modelo Clássico

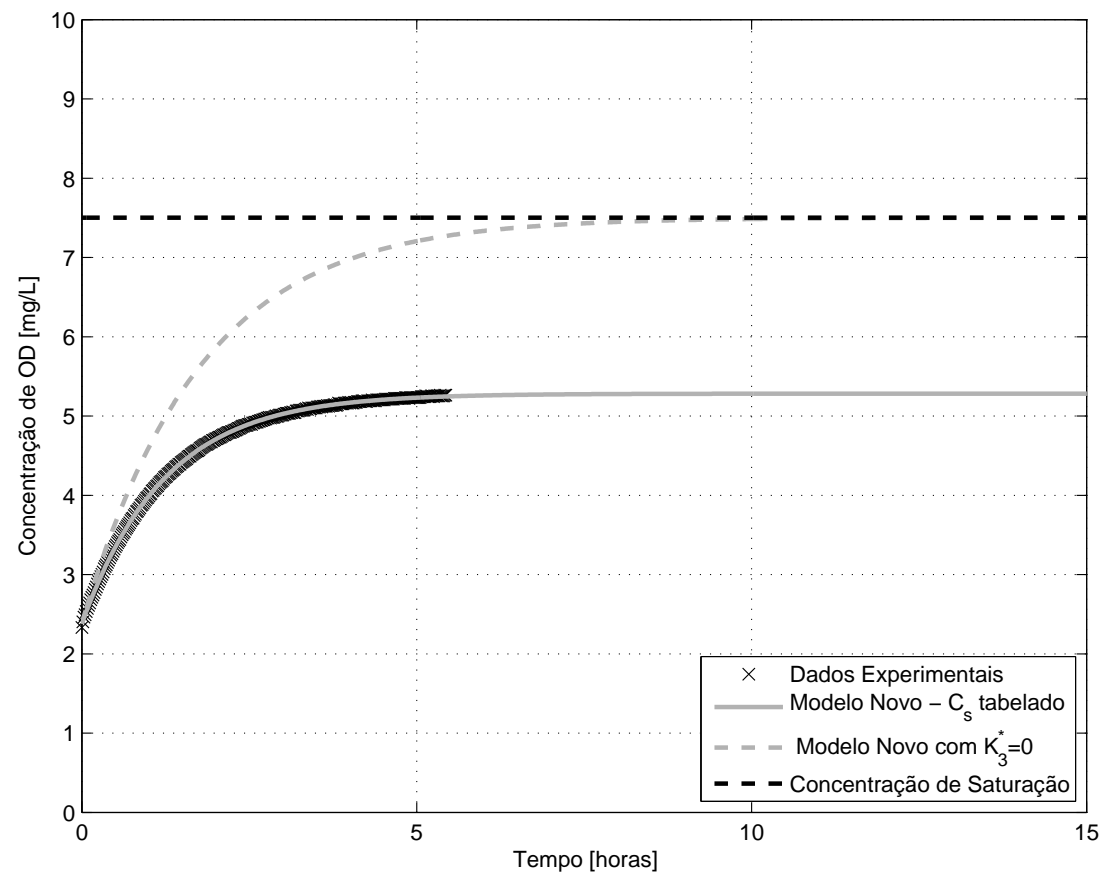

(b) Ajuste com o Modelo Novo

Figura B.19: Curva de reoxigenação para o ensaio 19 


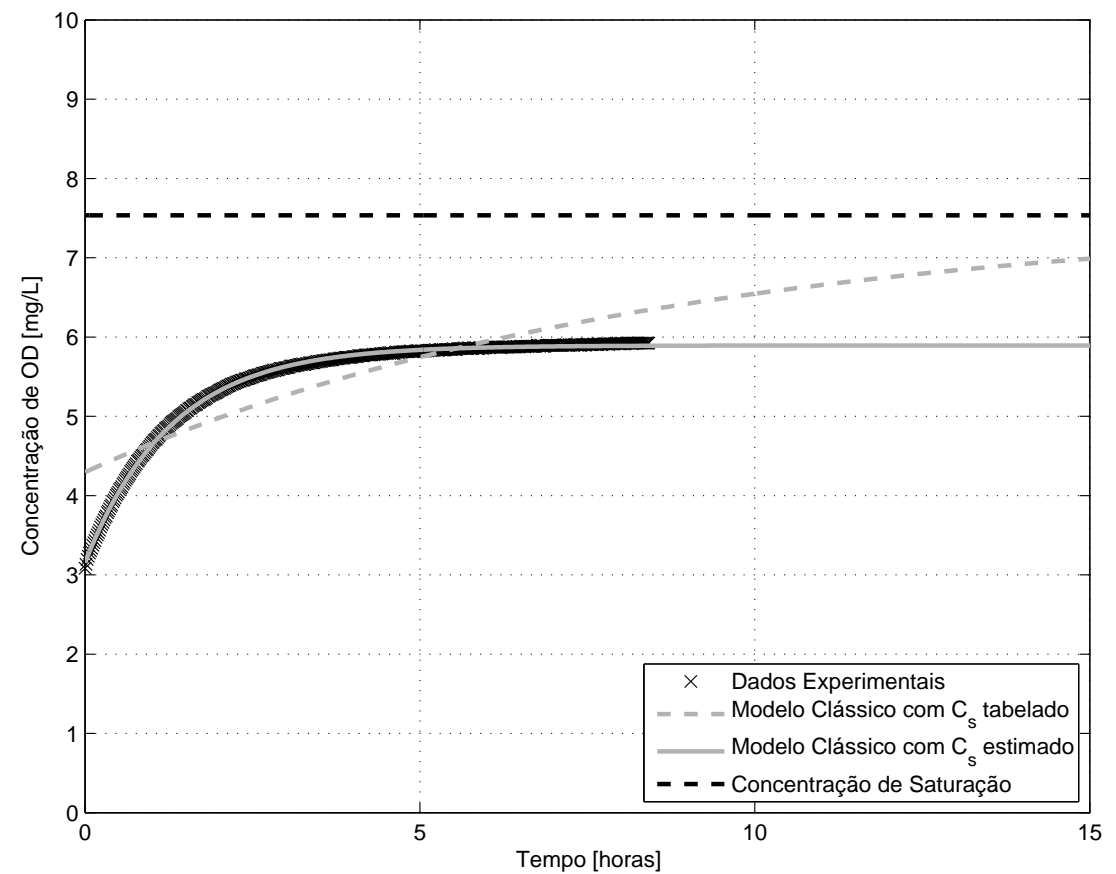

(a) Ajuste com o Modelo Clássico

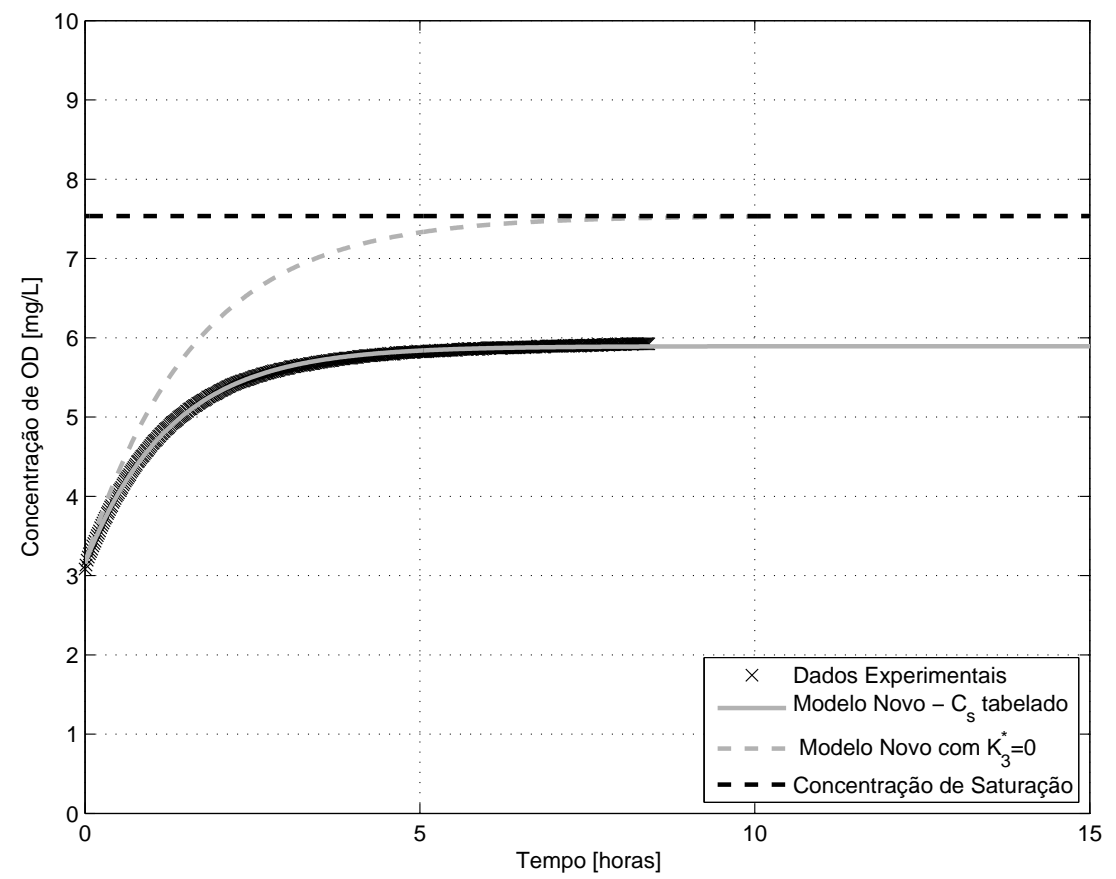

(b) Ajuste com o Modelo Novo

Figura B.20: Curva de reoxigenação para o ensaio 20 


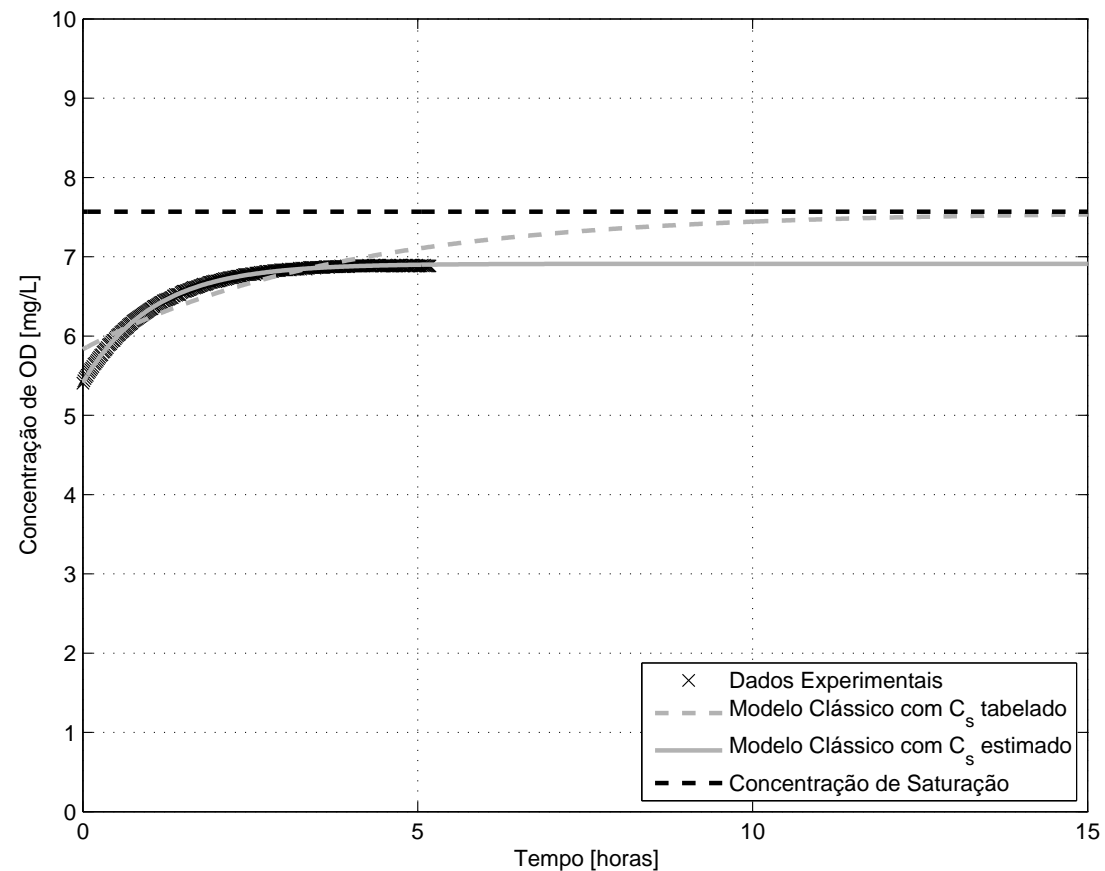

(a) Ajuste com o Modelo Clássico

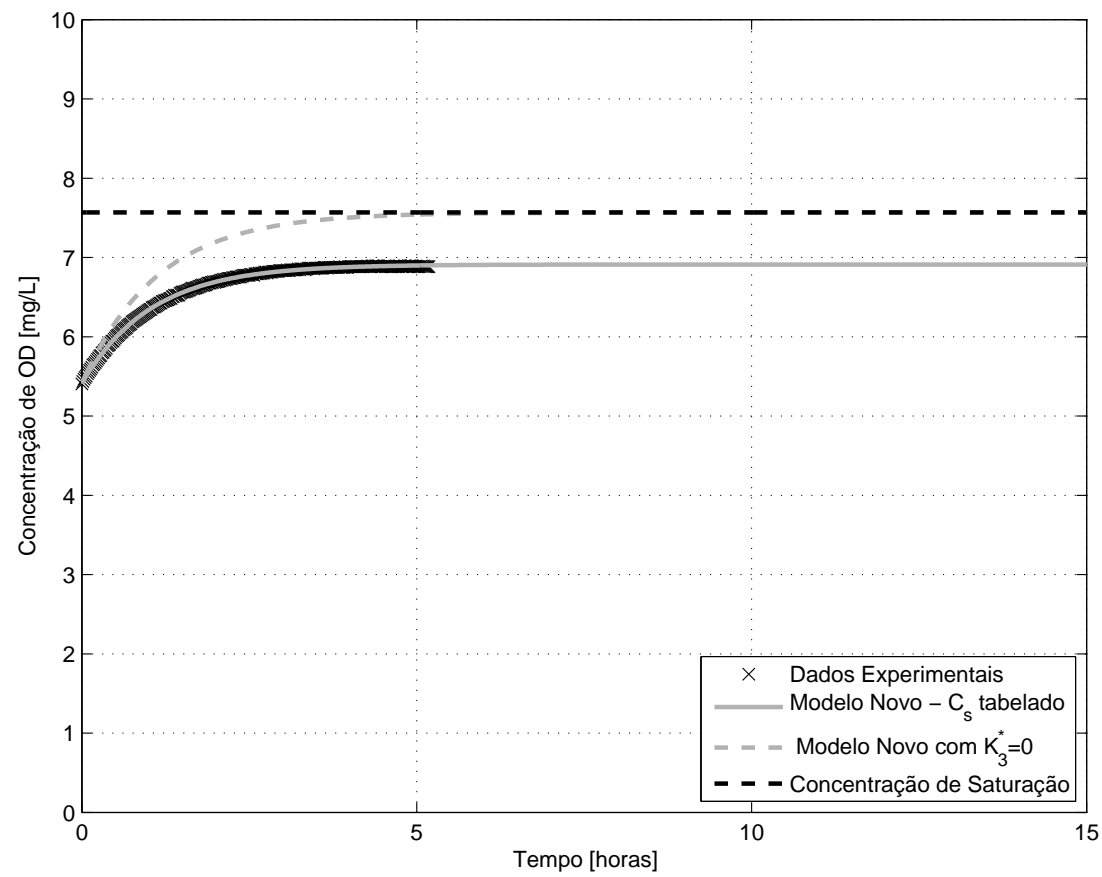

(b) Ajuste com o Modelo Novo

Figura B.21: Curva de reoxigenação para o ensaio 21 


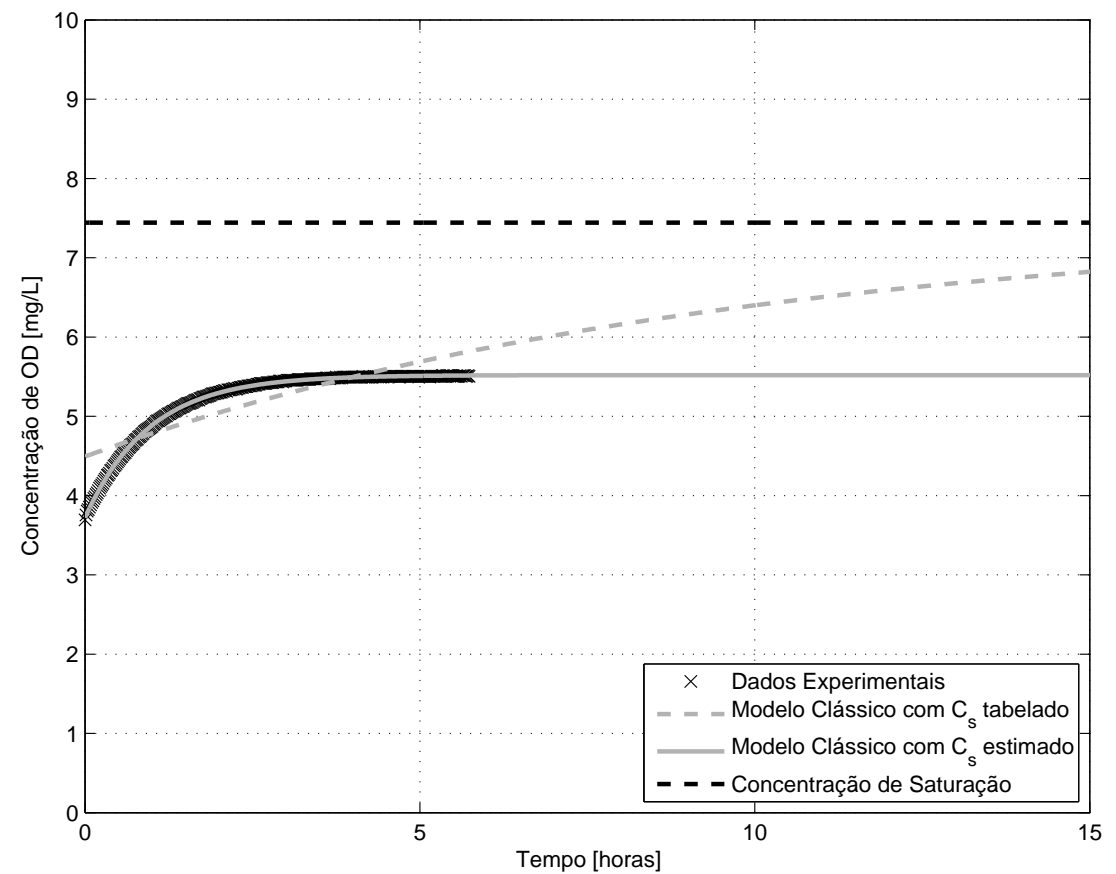

(a) Ajuste com o Modelo Clássico

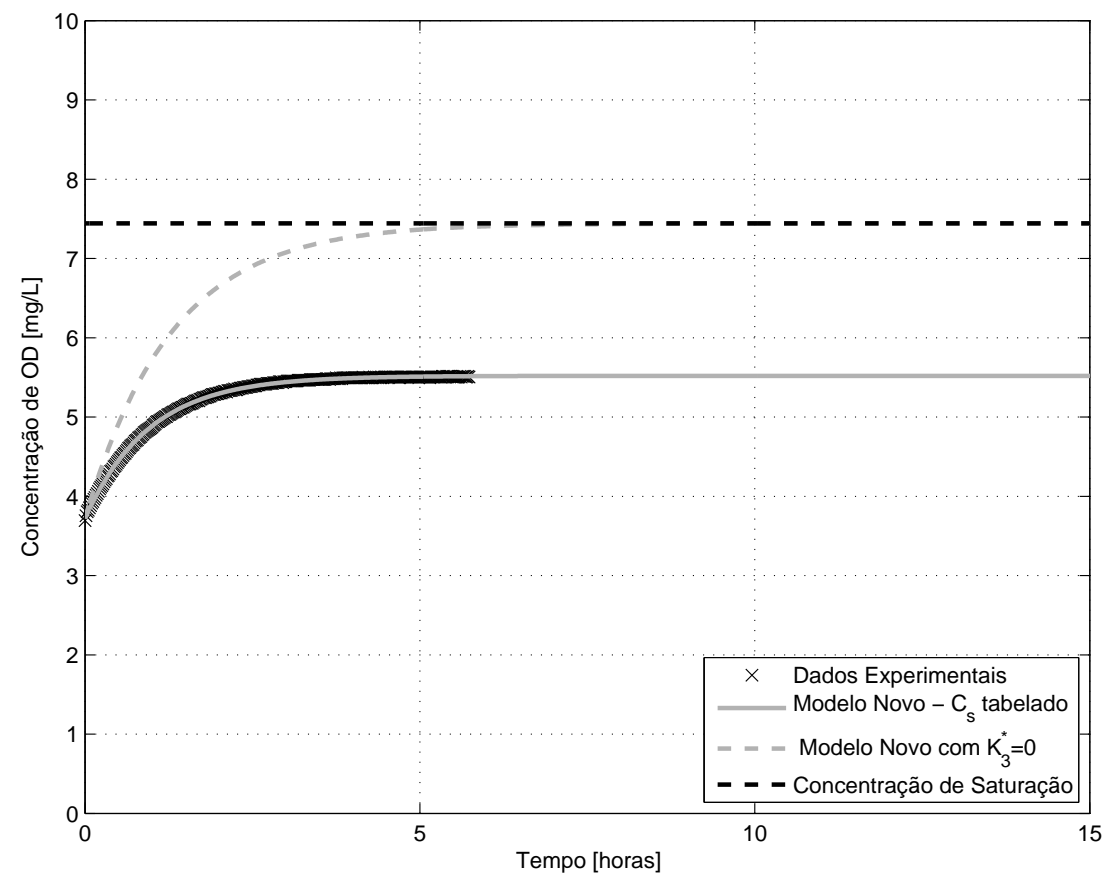

(b) Ajuste com o Modelo Novo

Figura B.22: Curva de reoxigenação para o ensaio 22 


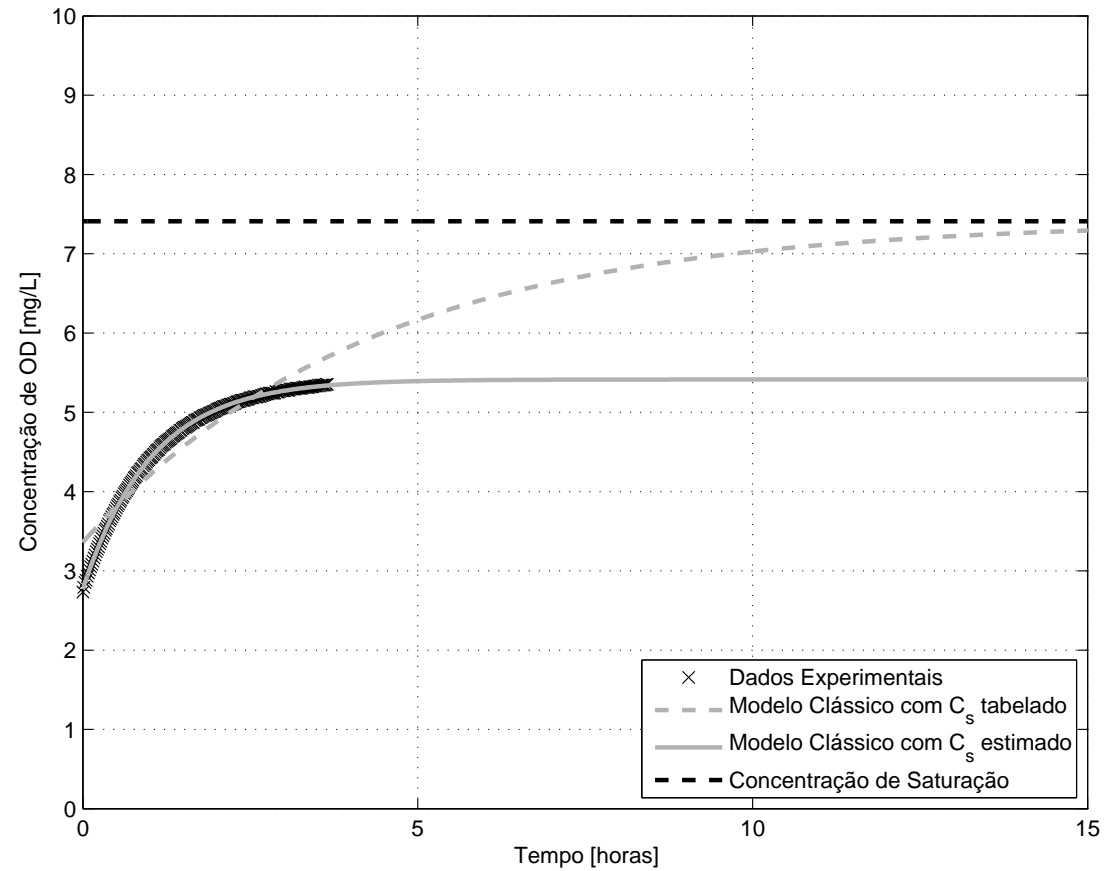

(a) Ajuste com o Modelo Clássico

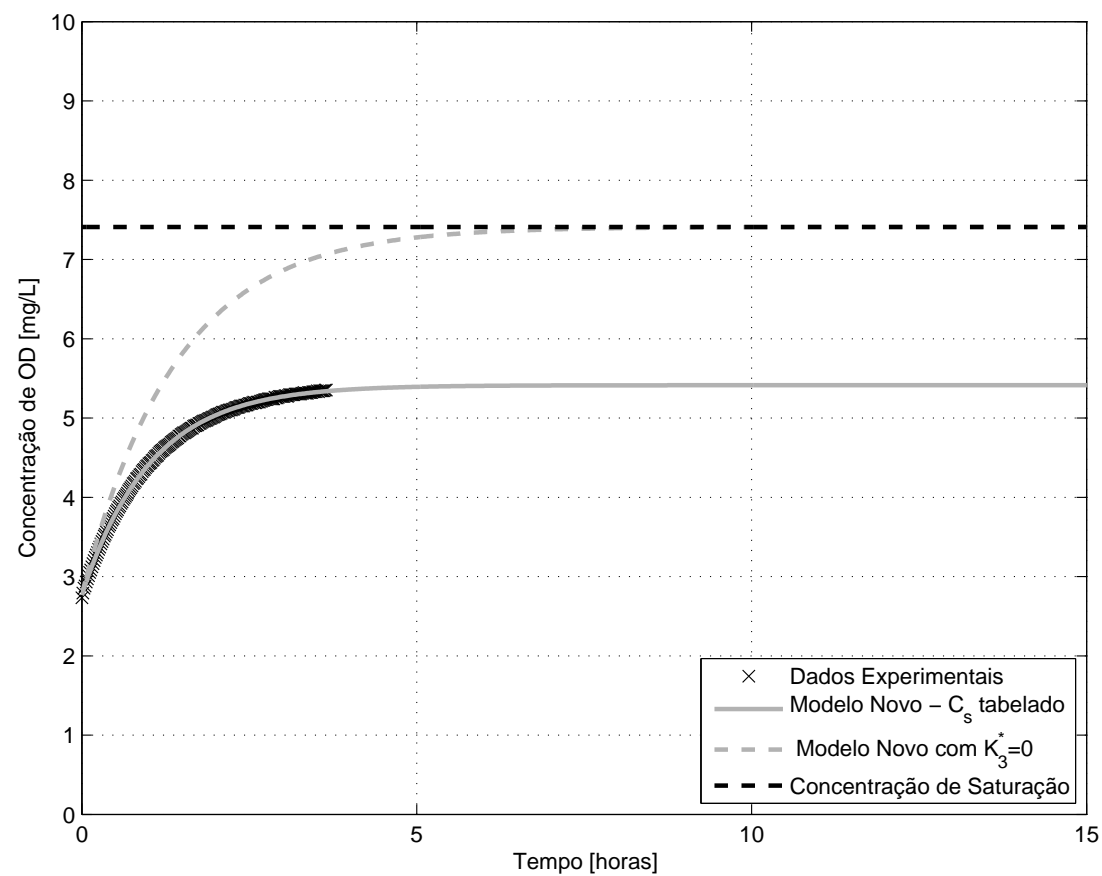

(b) Ajuste com o Modelo Novo

Figura B.23: Curva de reoxigenação para o ensaio 23 


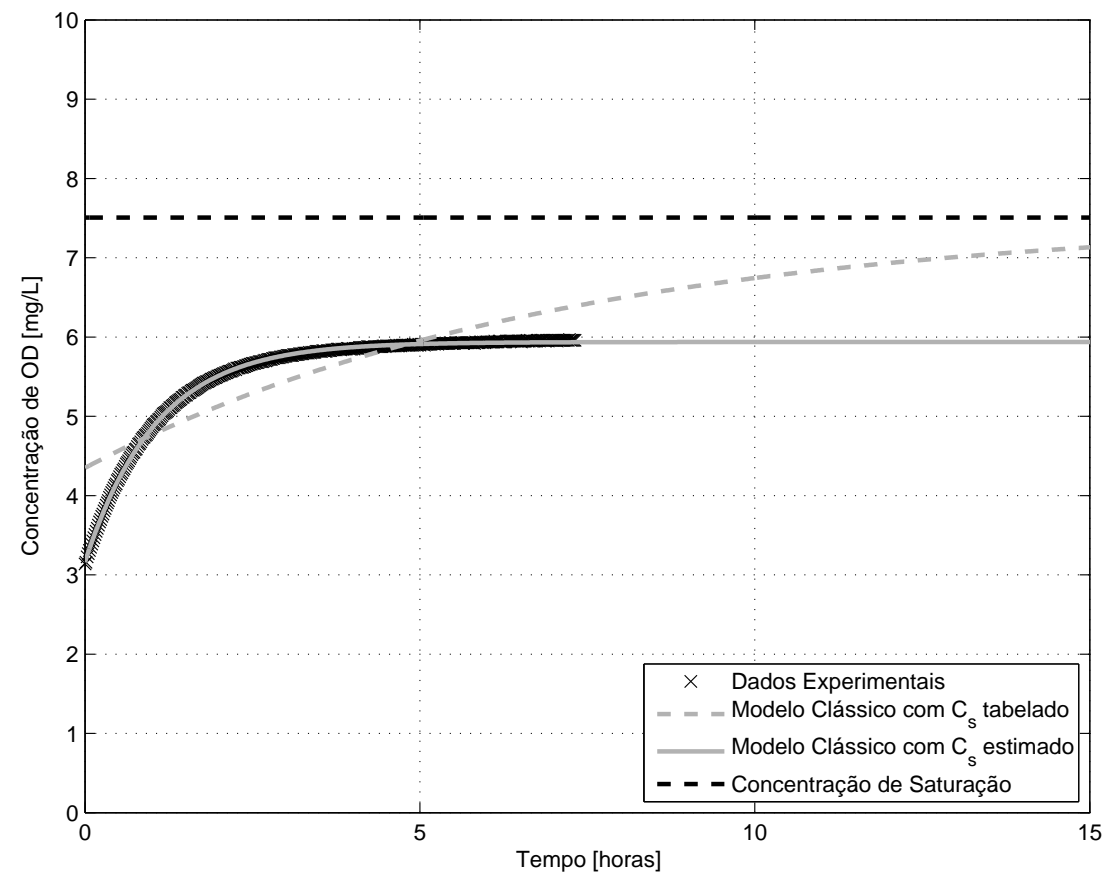

(a) Ajuste com o Modelo Clássico

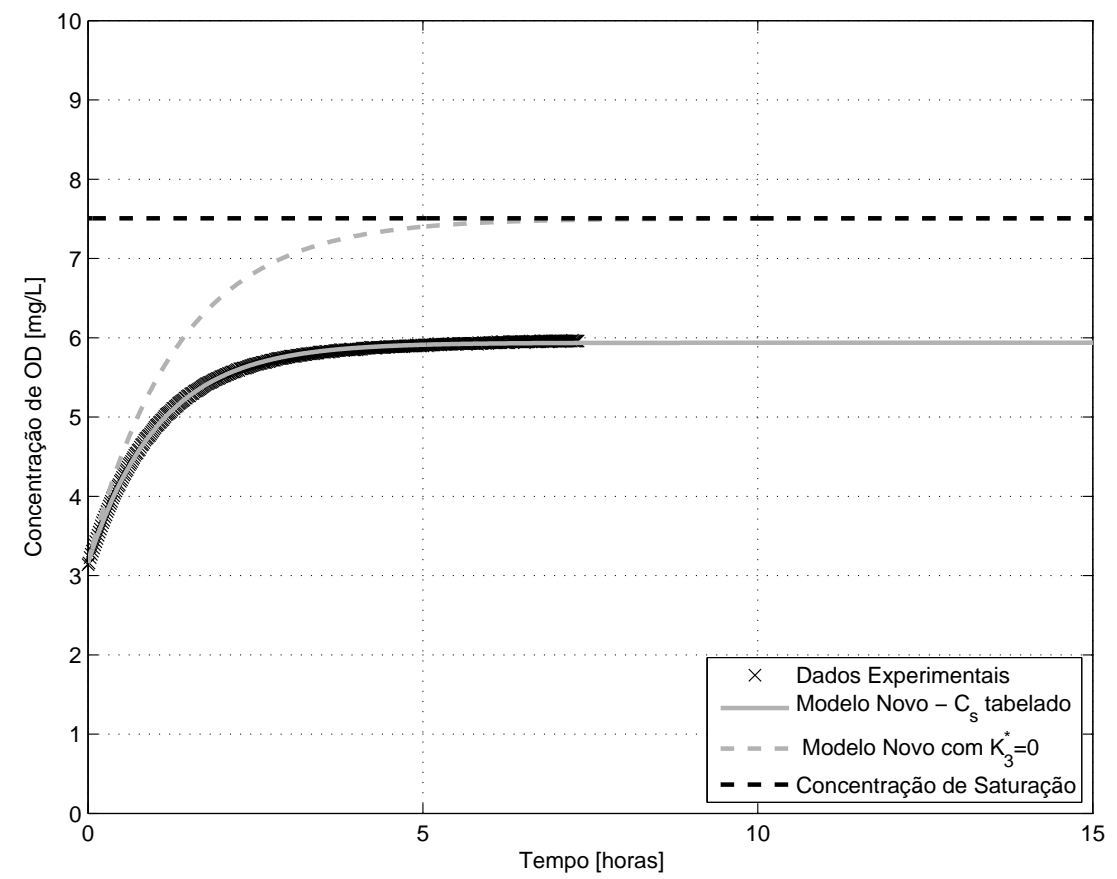

(b) Ajuste com o Modelo Novo

Figura B.24: Curva de reoxigenação para o ensaio 24 


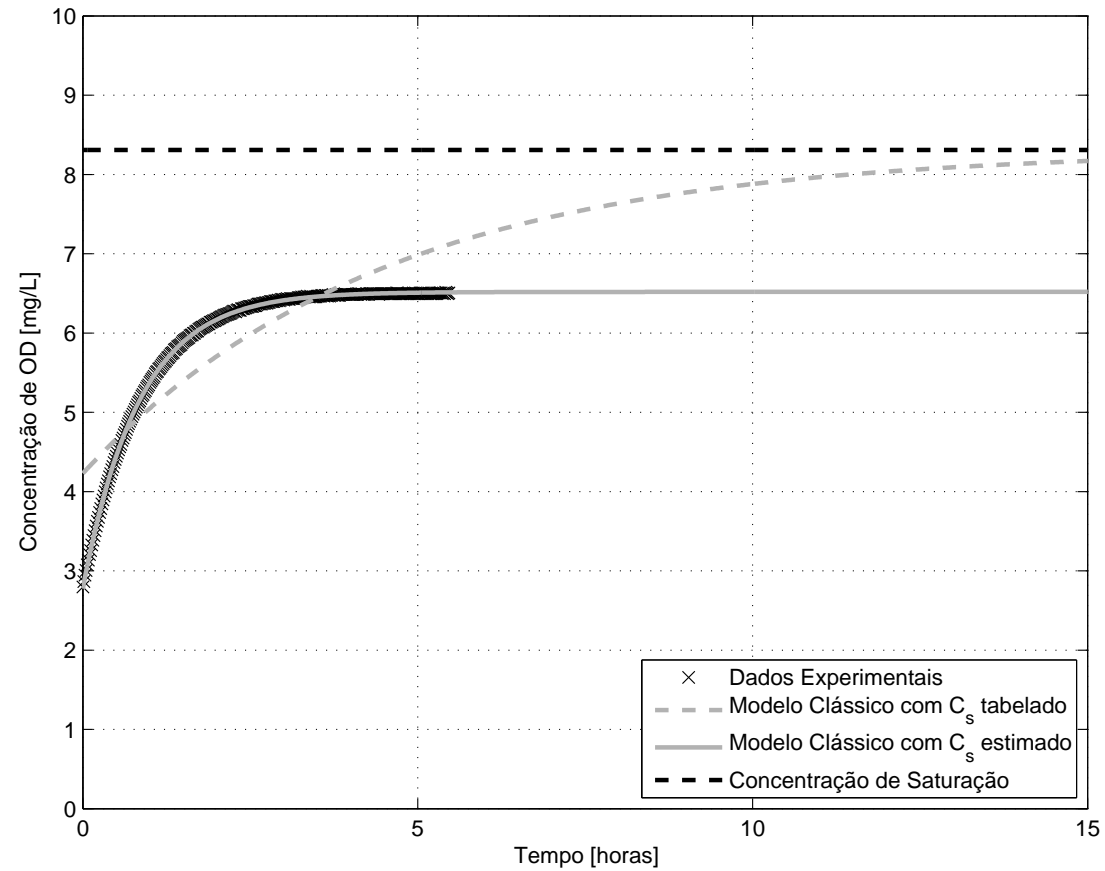

(a) Ajuste com o Modelo Clássico

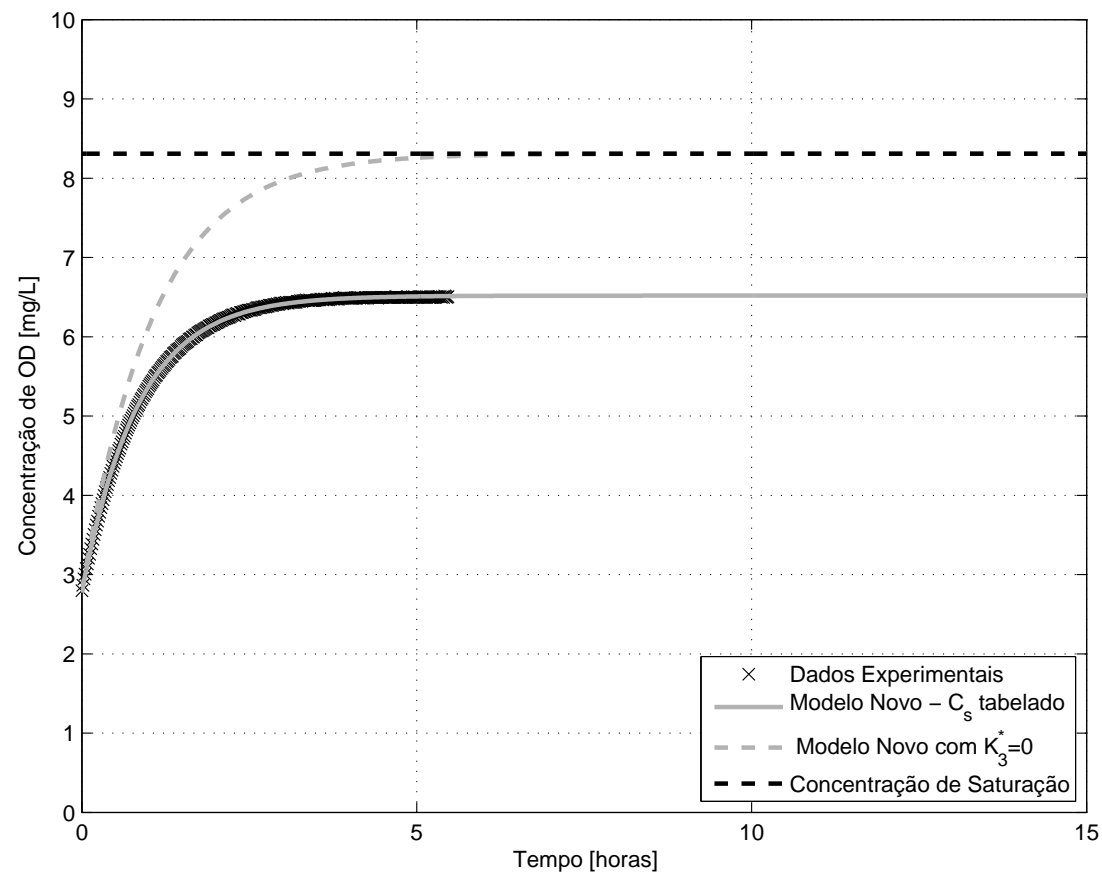

(b) Ajuste com o Modelo Novo

Figura B.25: Curva de reoxigenação para o ensaio 25 


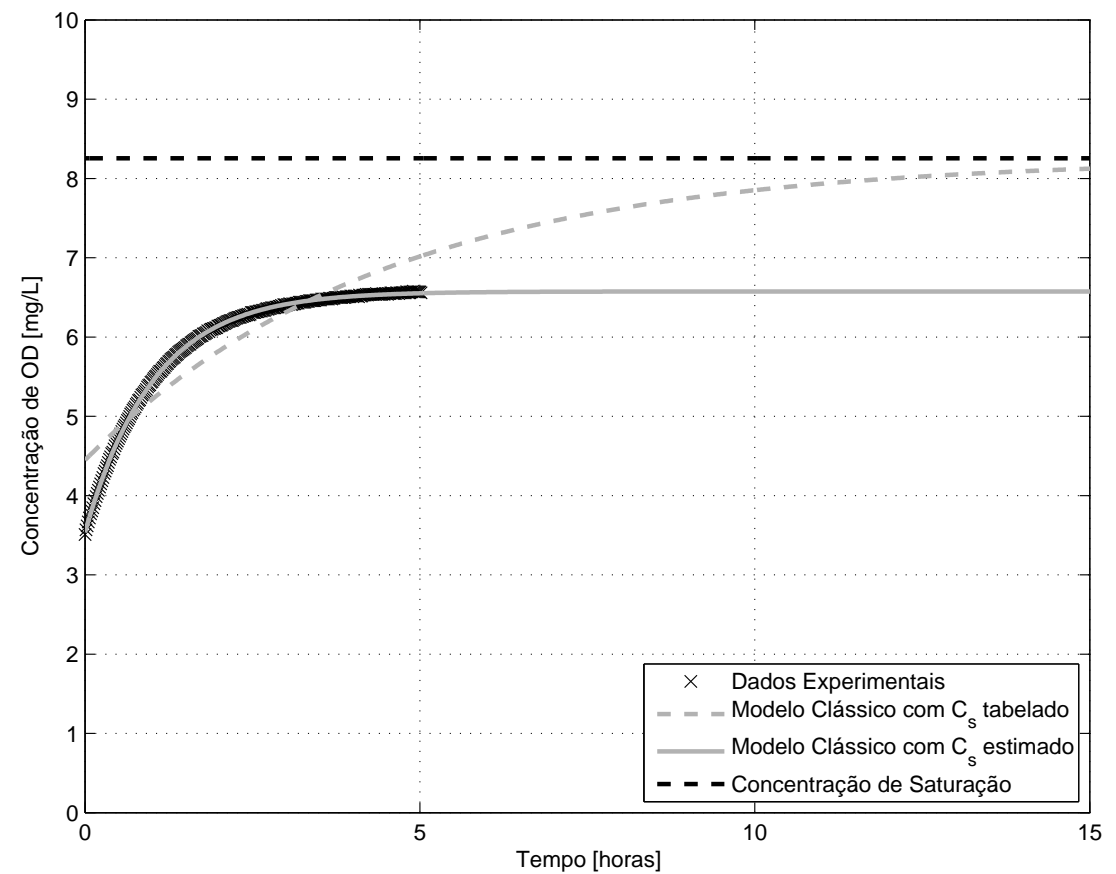

(a) Ajuste com o Modelo Clássico

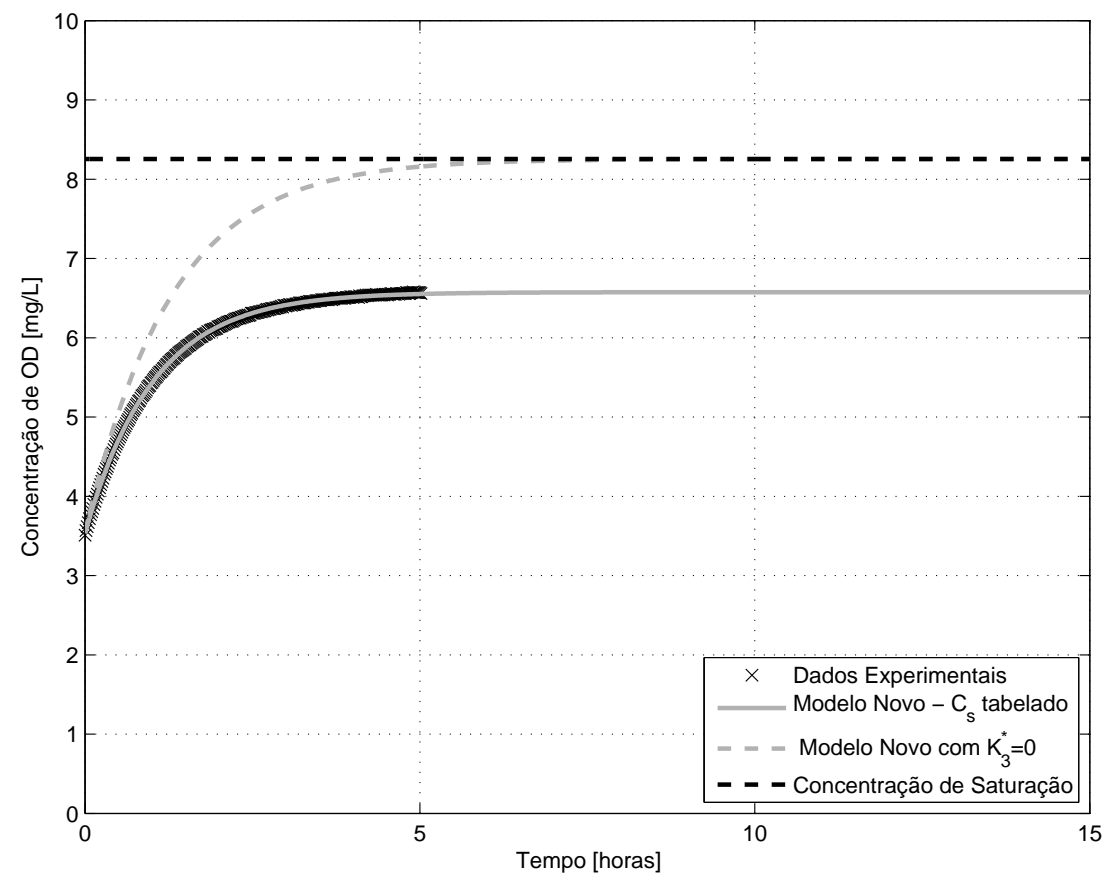

(b) Ajuste com o Modelo Novo

Figura B.26: Curva de reoxigenação para o ensaio 26 


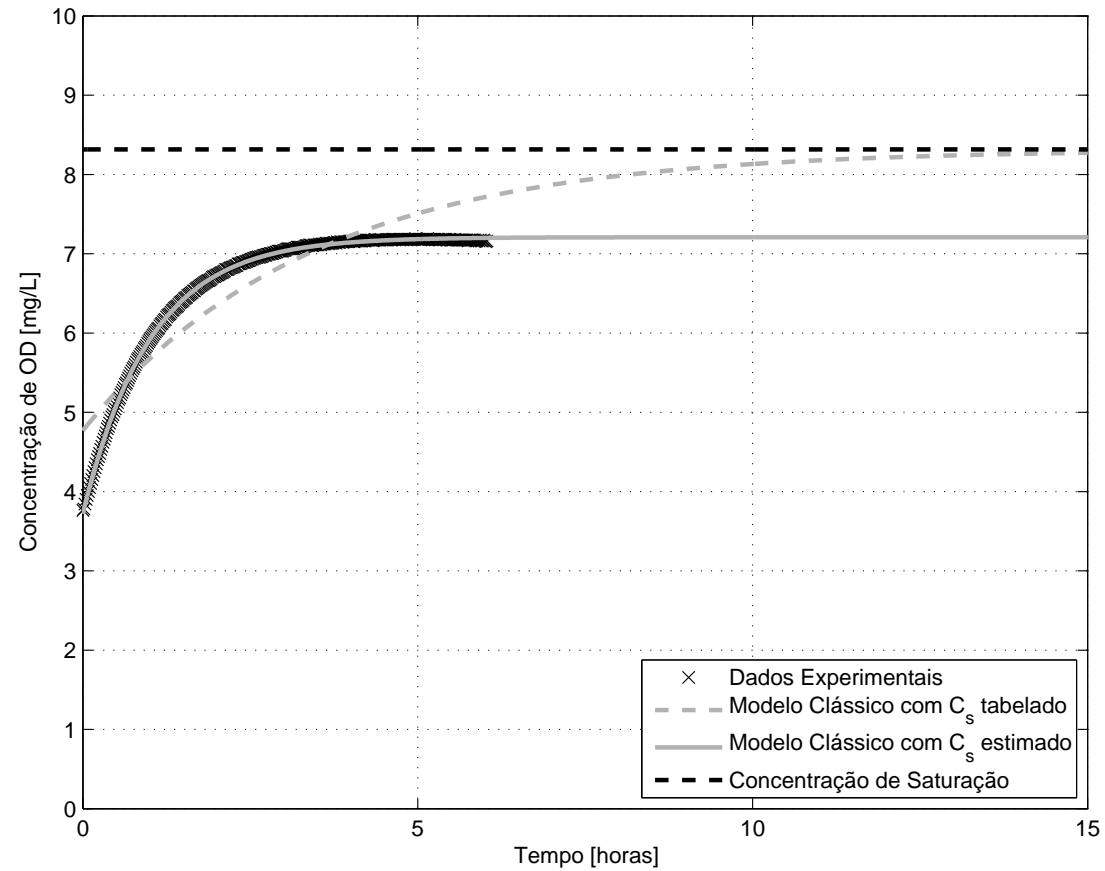

(a) Ajuste com o Modelo Clássico

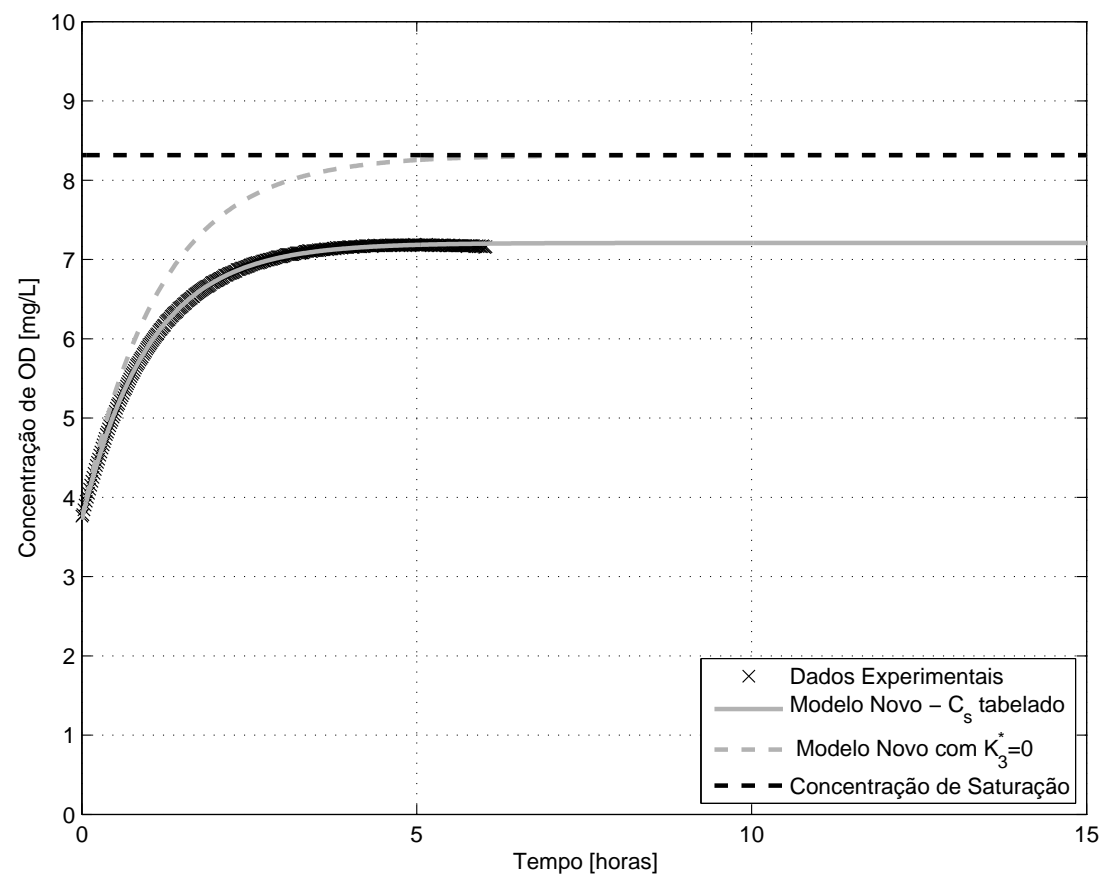

(b) Ajuste com o Modelo Novo

Figura B.27: Curva de reoxigenação para o ensaio 27 


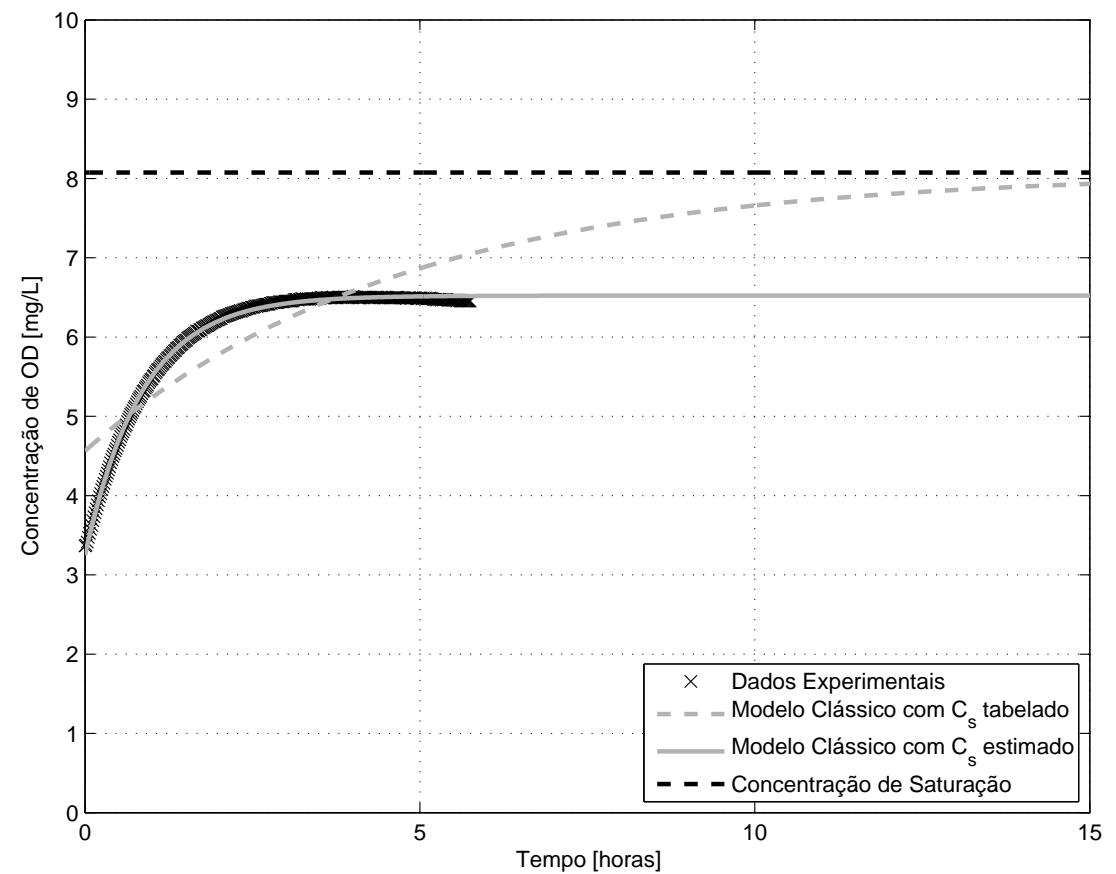

(a) Ajuste com o Modelo Clássico

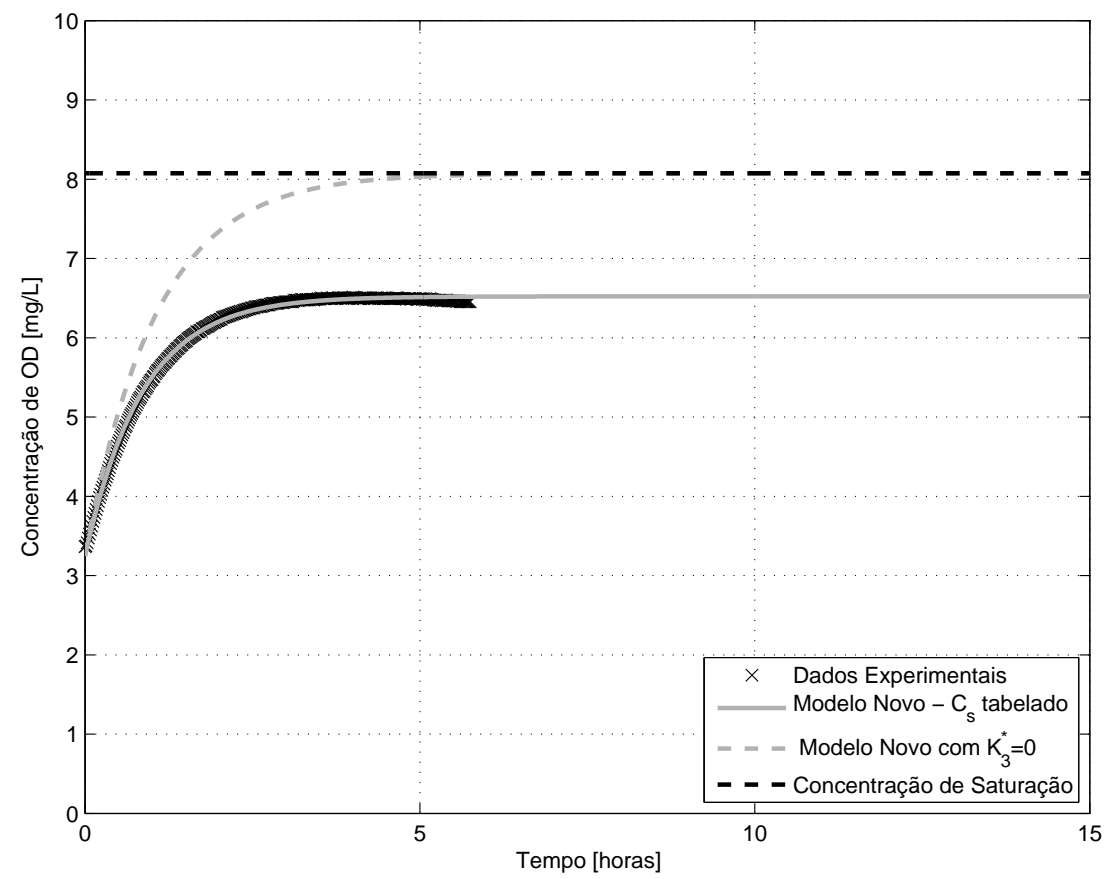

(b) Ajuste com o Modelo Novo

Figura B.28: Curva de reoxigenação para o ensaio 28 


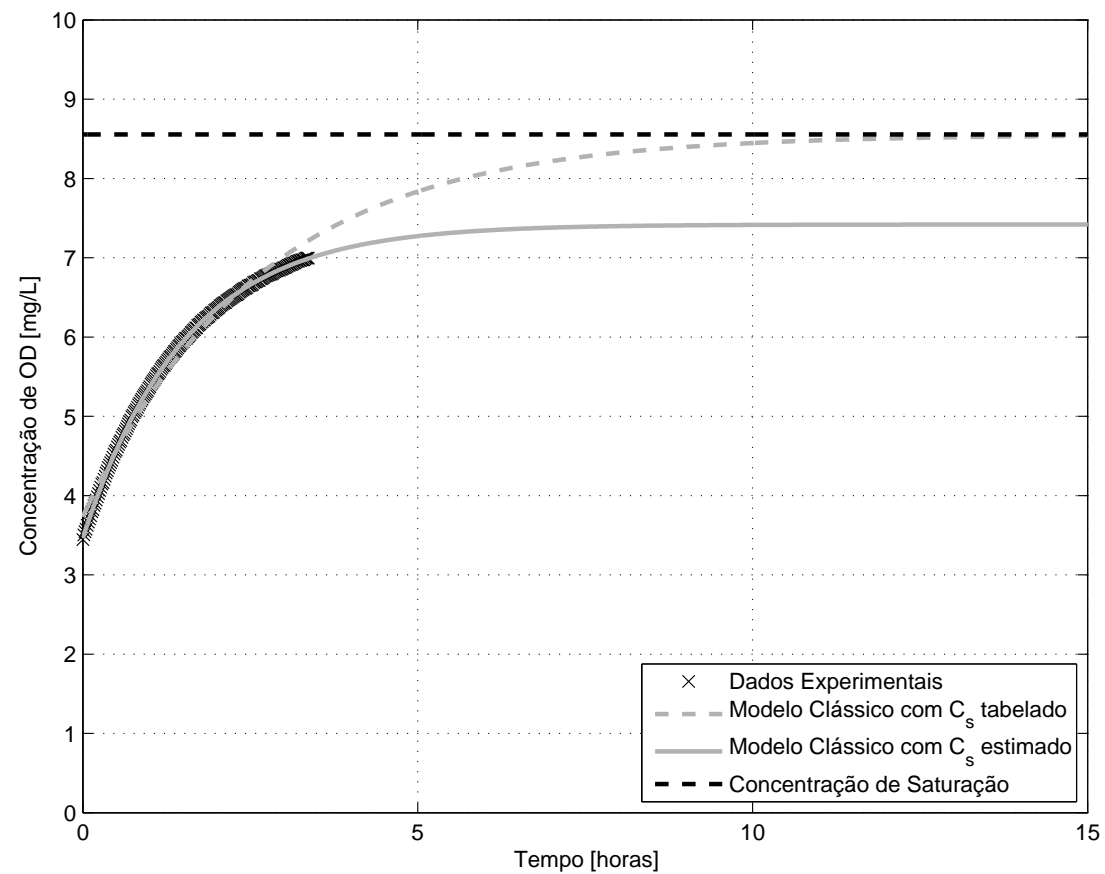

(a) Ajuste com o Modelo Clássico

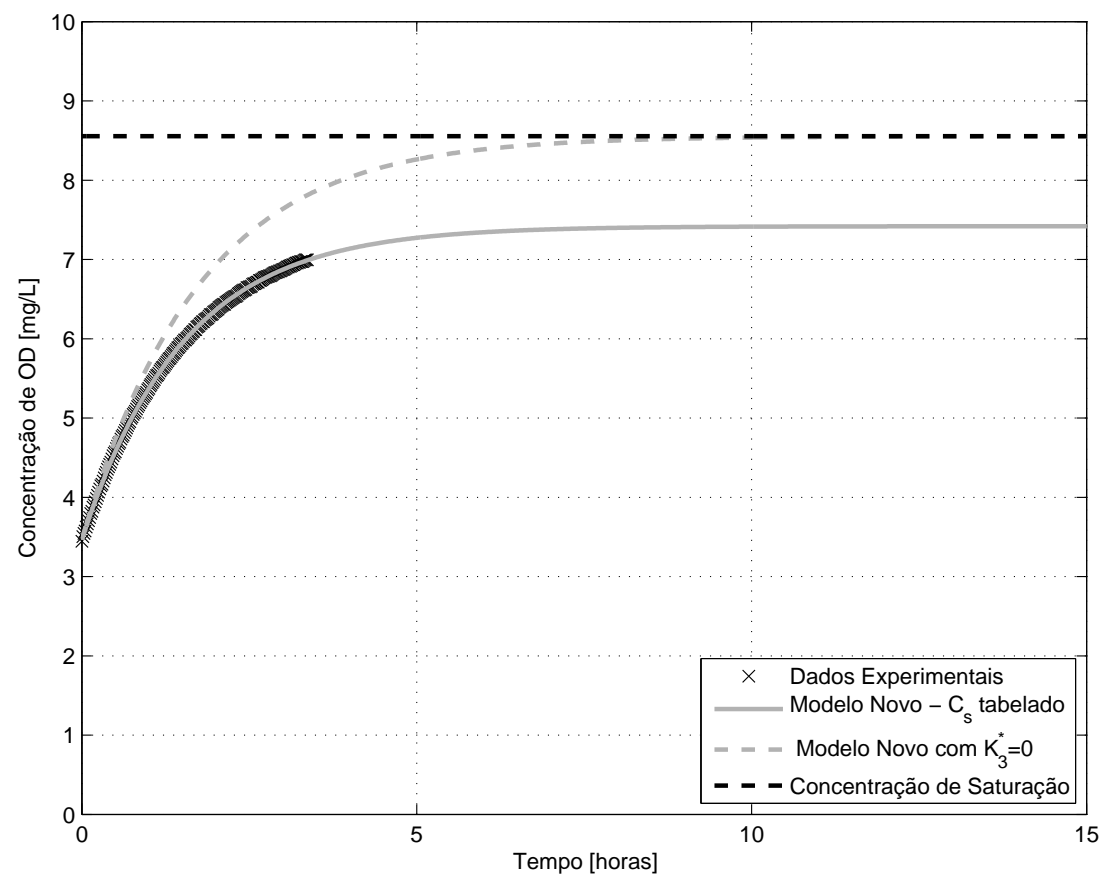

(b) Ajuste com o Modelo Novo

Figura B.29: Curva de reoxigenação para o ensaio 29 


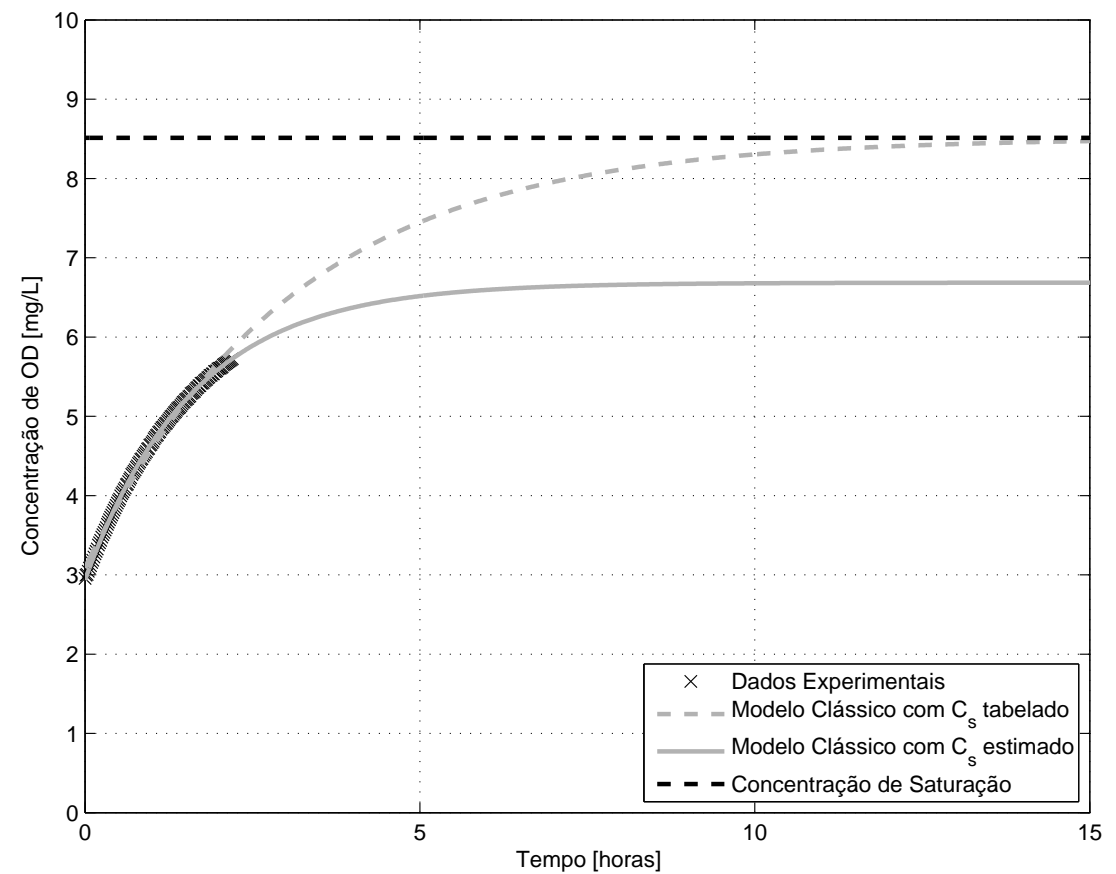

(a) Ajuste com o Modelo Clássico

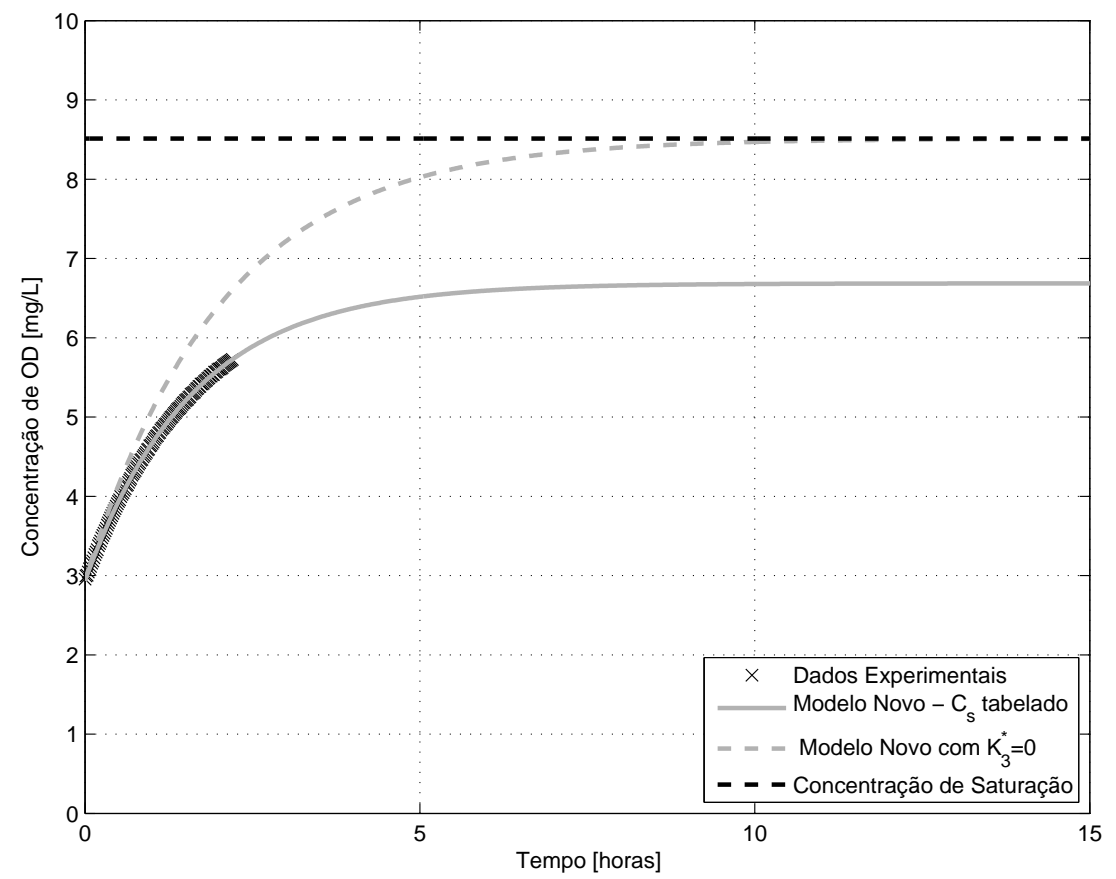

(b) Ajuste com o Modelo Novo

Figura B.30: Curva de reoxigenação para o ensaio 30 


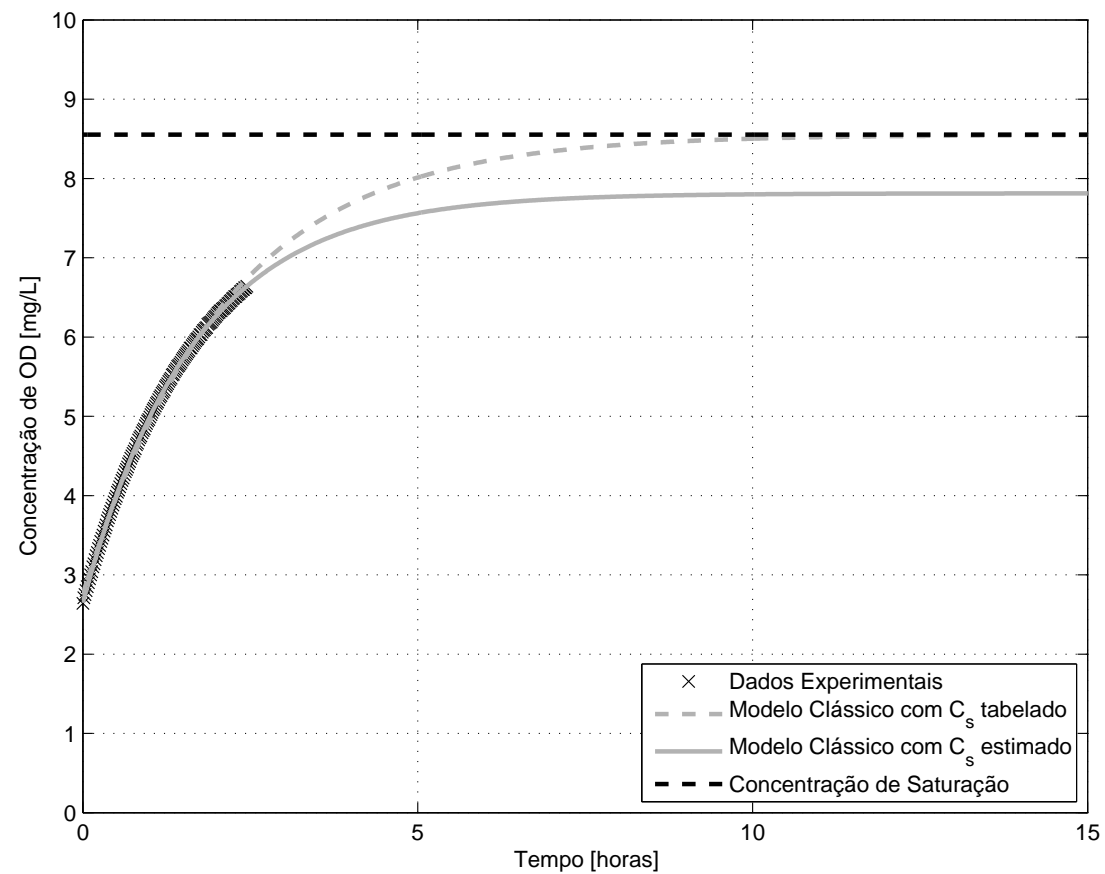

(a) Ajuste com o Modelo Clássico

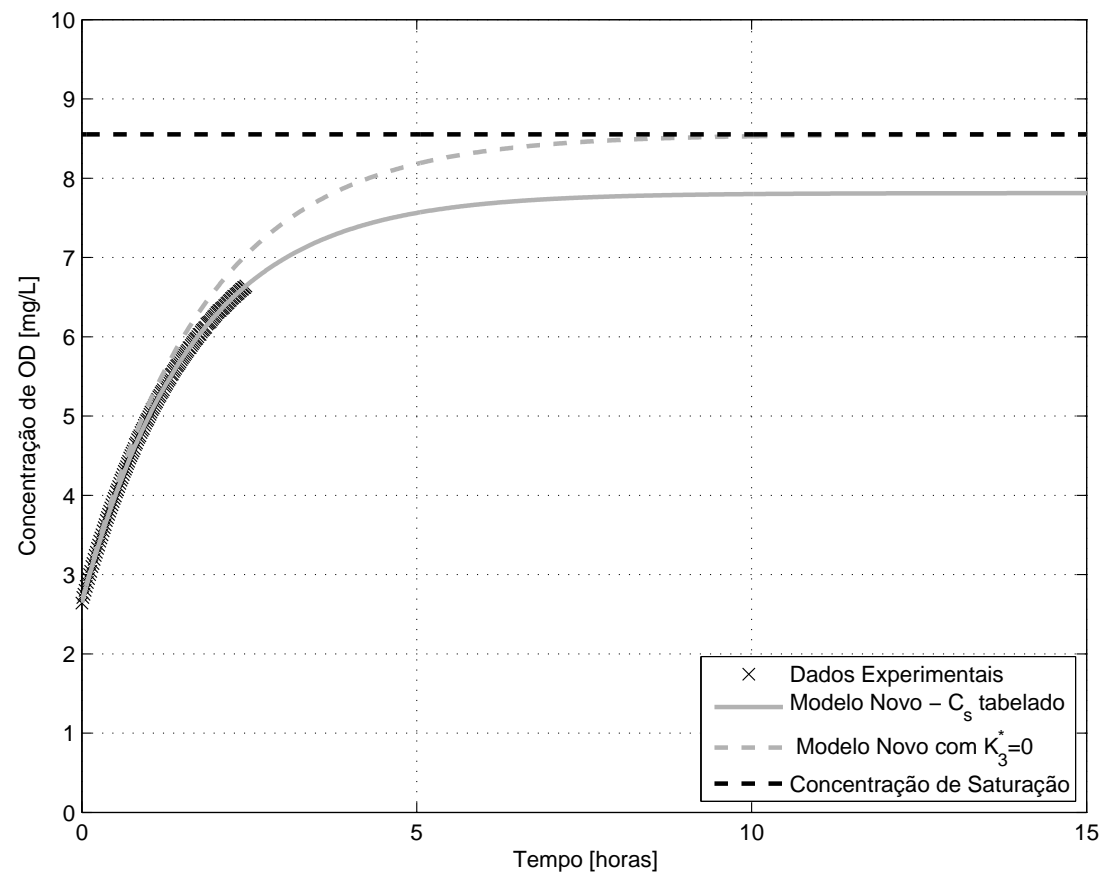

(b) Ajuste com o Modelo Novo

Figura B.31: Curva de reoxigenação para o ensaio 31 


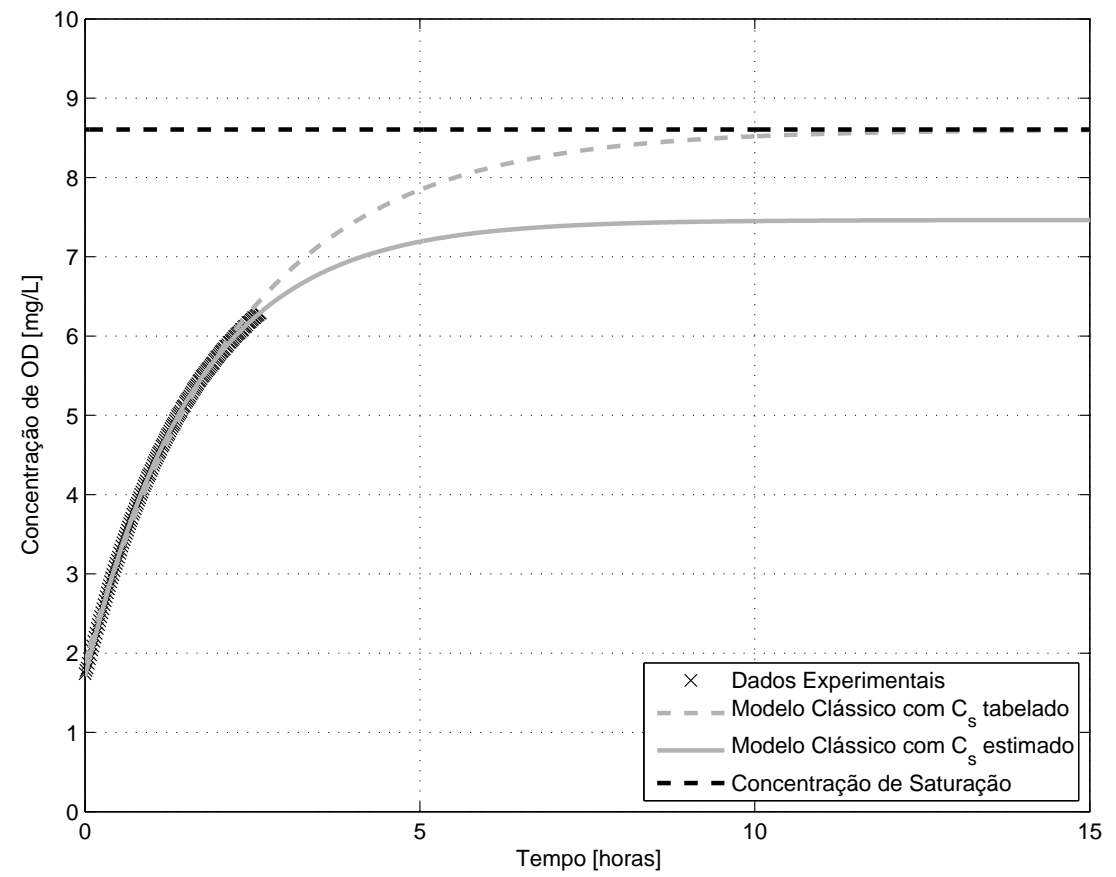

(a) Ajuste com o Modelo Clássico

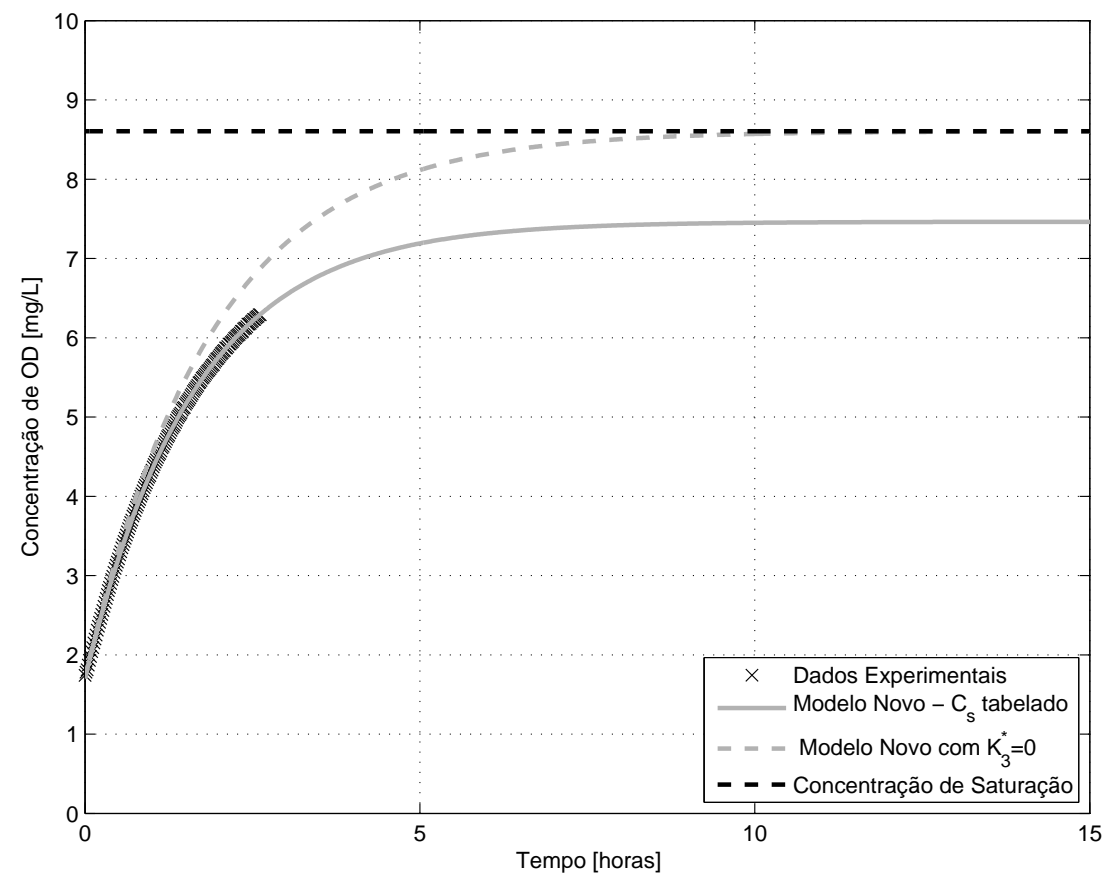

(b) Ajuste com o Modelo Novo

Figura B.32: Curva de reoxigenação para o ensaio 32 


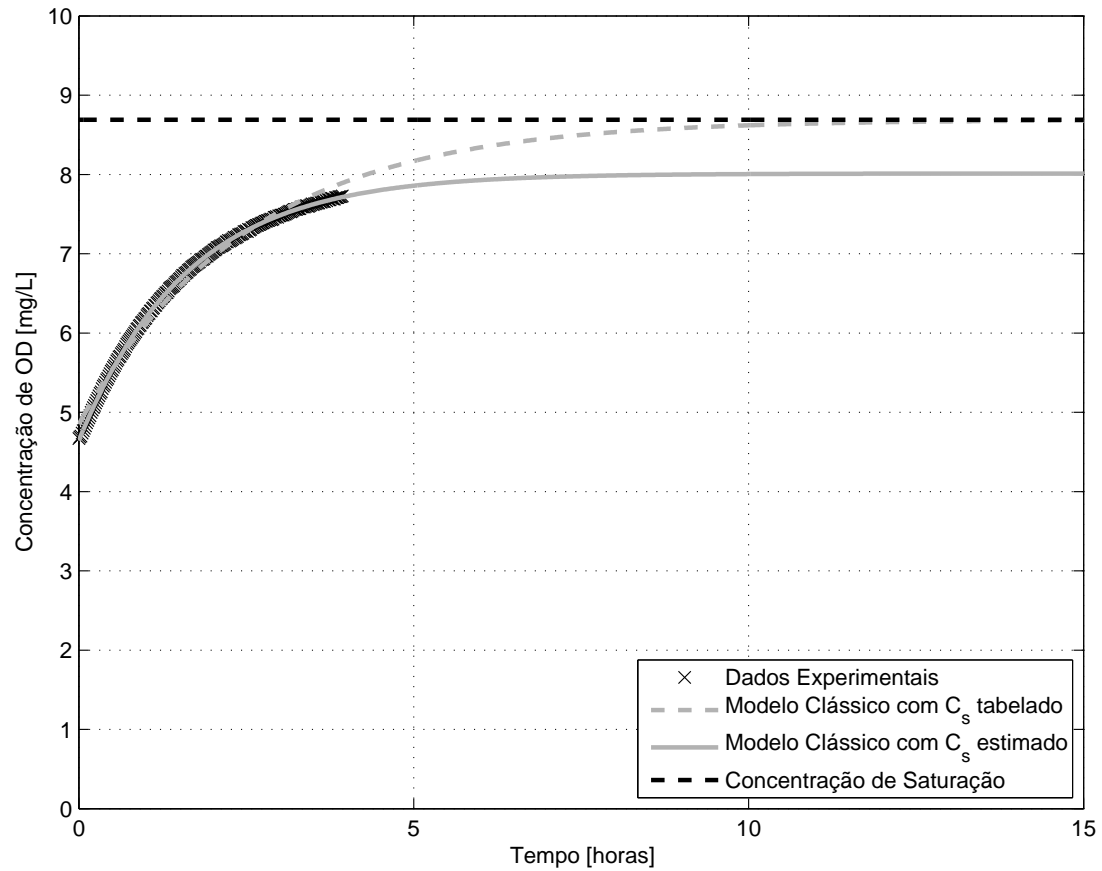

(a) Ajuste com o Modelo Clássico

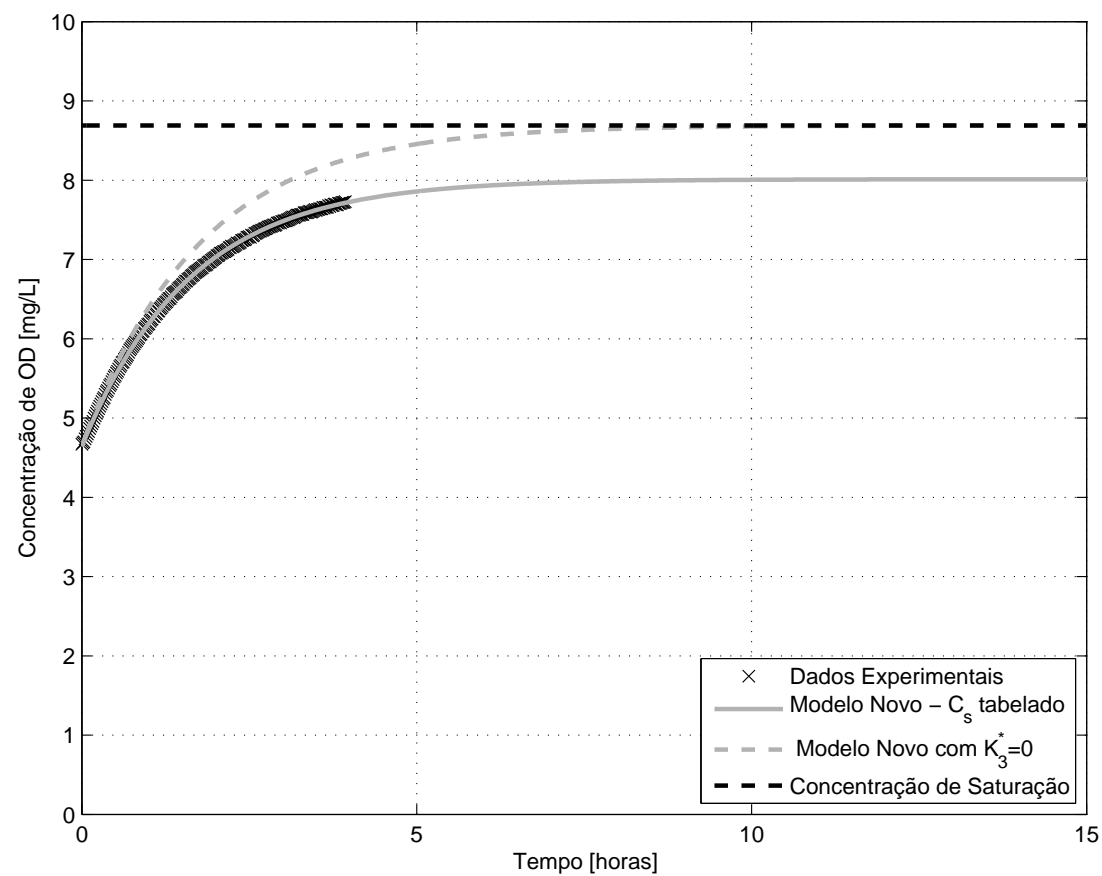

(b) Ajuste com o Modelo Novo

Figura B.33: Curva de reoxigenação para o ensaio 33 


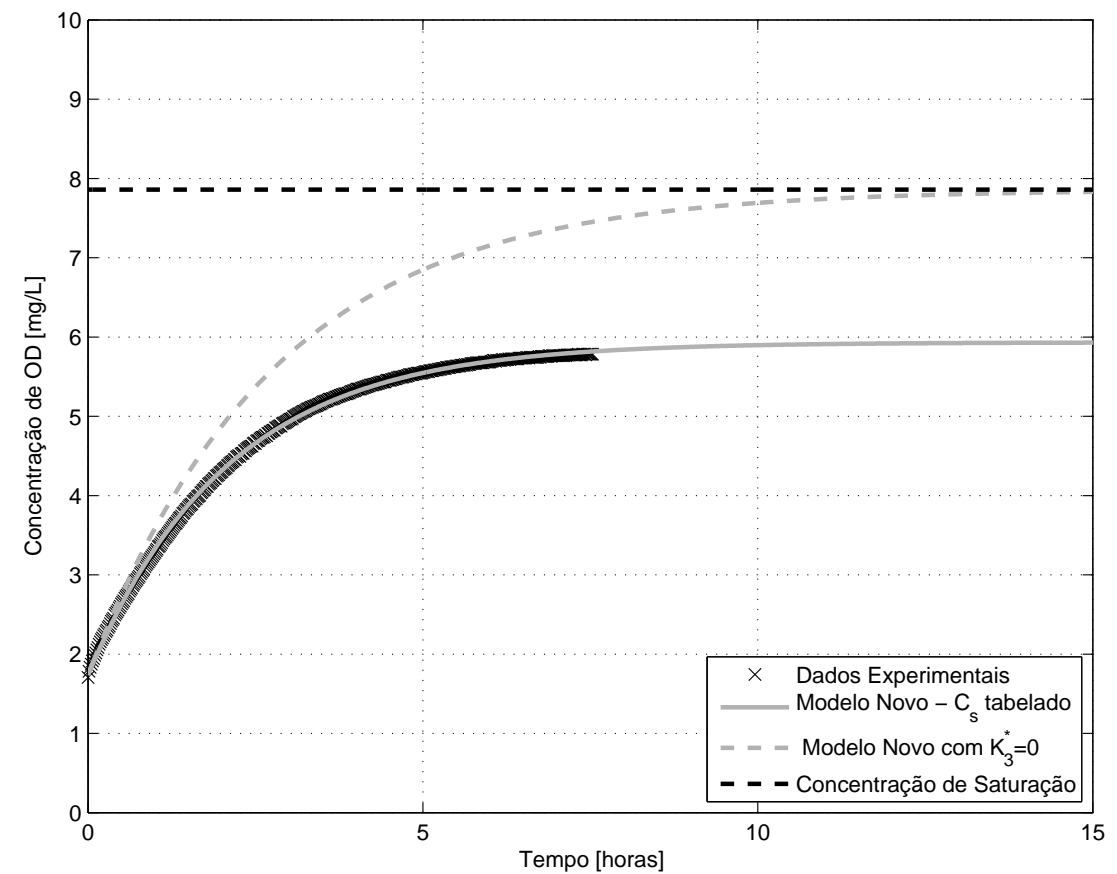

(a) Ajuste com o Modelo Clássico

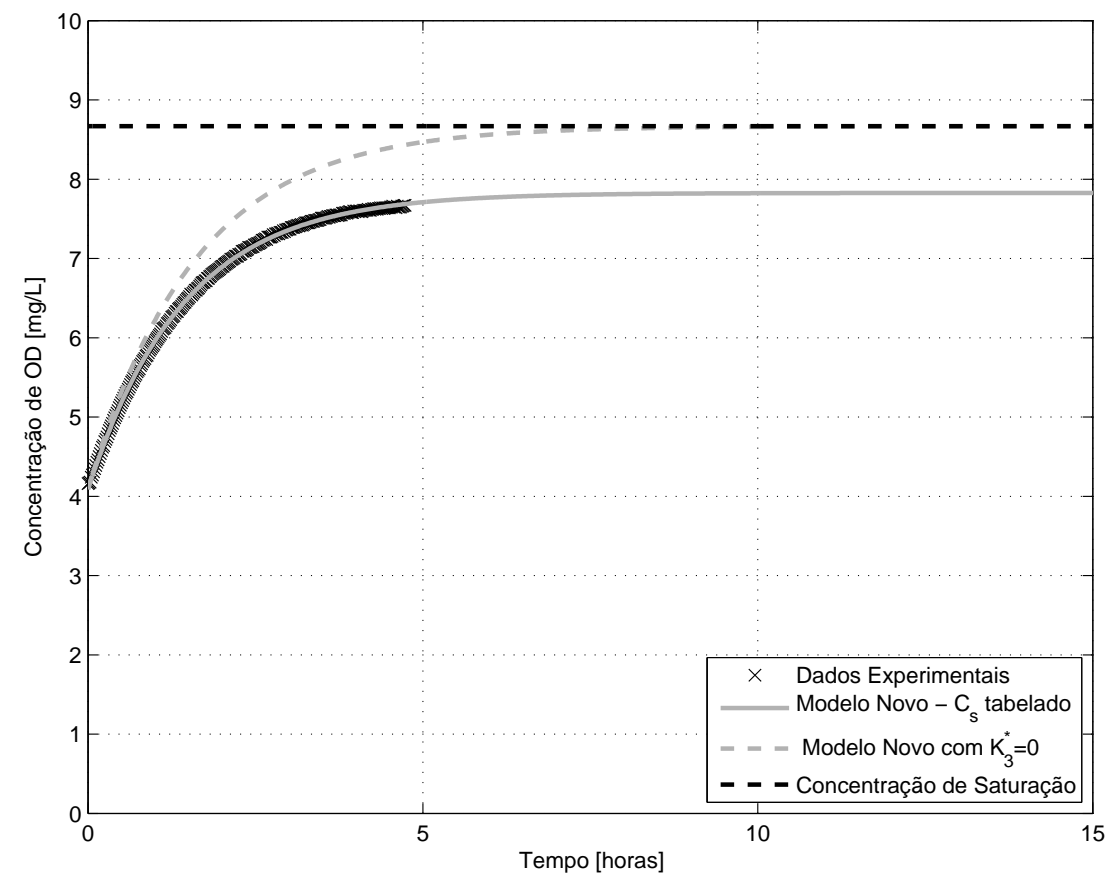

(b) Ajuste com o Modelo Novo

Figura B.34: Curva de reoxigenação para o ensaio 34 


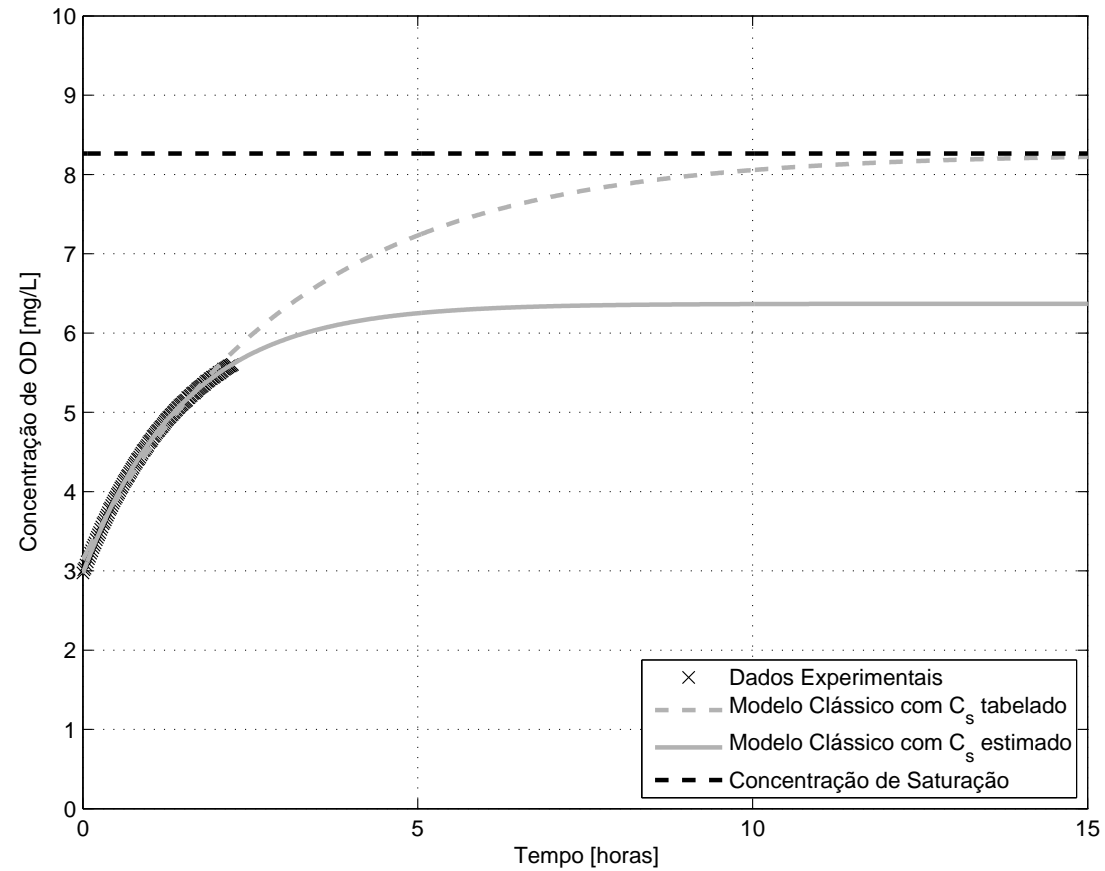

(a) Ajuste com o Modelo Clássico

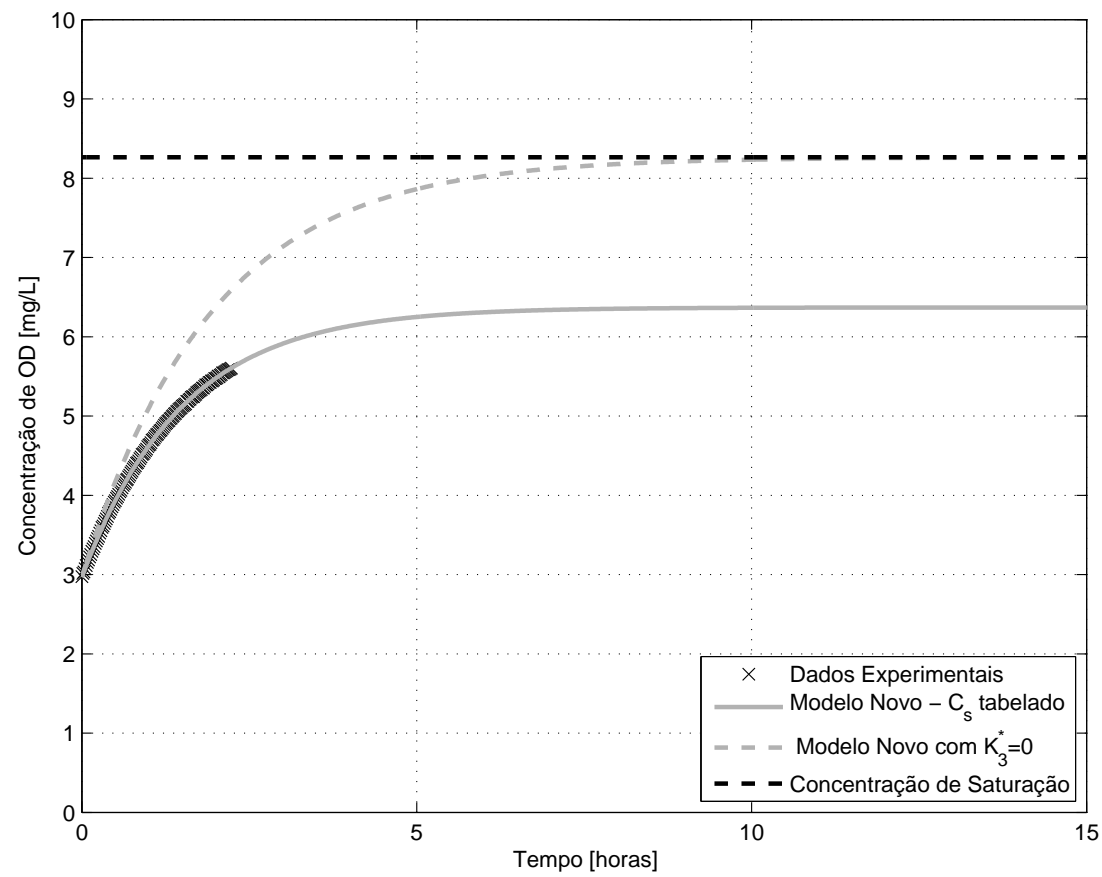

(b) Ajuste com o Modelo Novo

Figura B.35: Curva de reoxigenação para o ensaio 35 


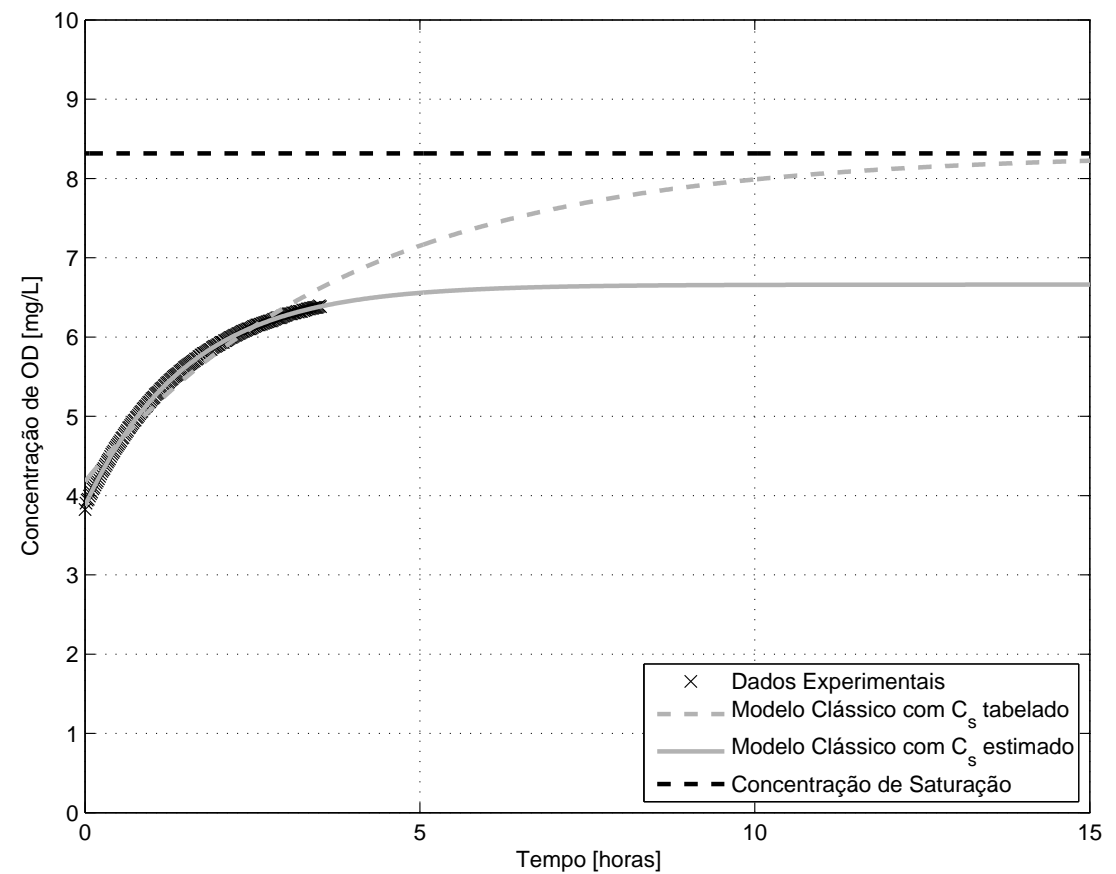

(a) Ajuste com o Modelo Clássico

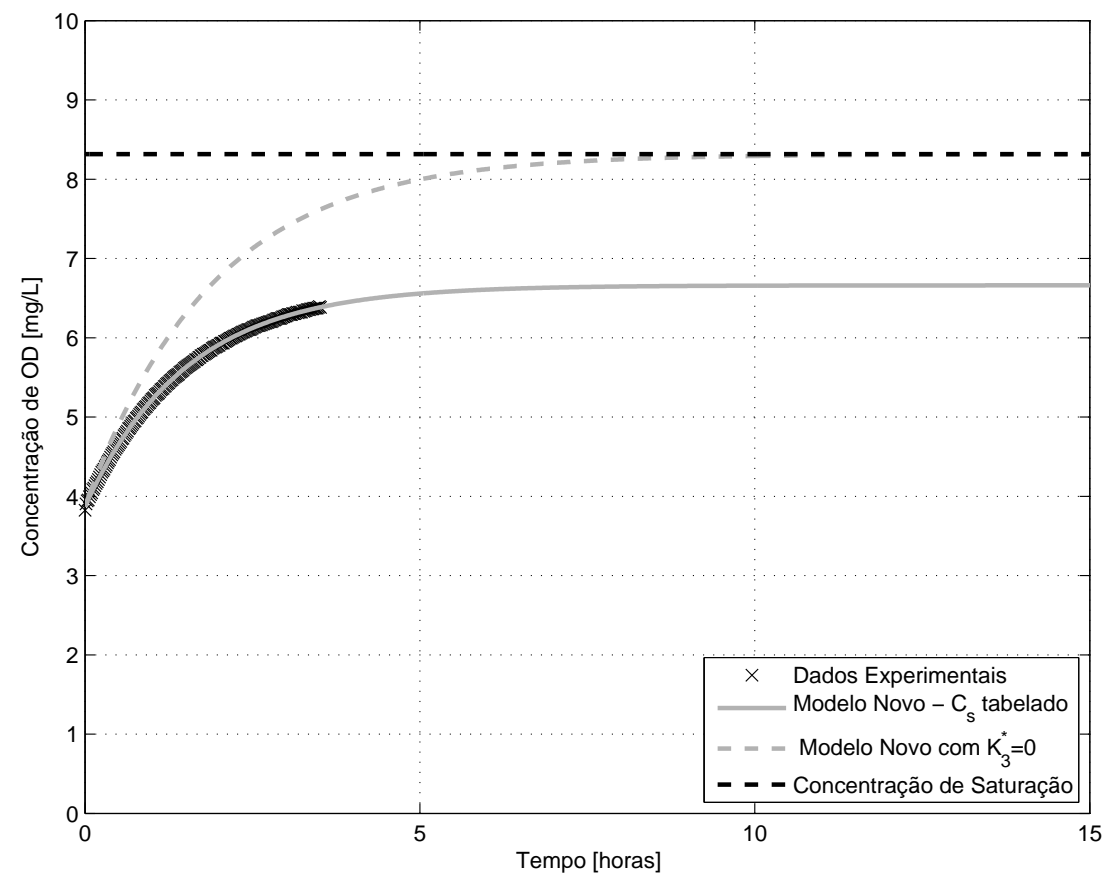

(b) Ajuste com o Modelo Novo

Figura B.36: Curva de reoxigenação para o ensaio 36 


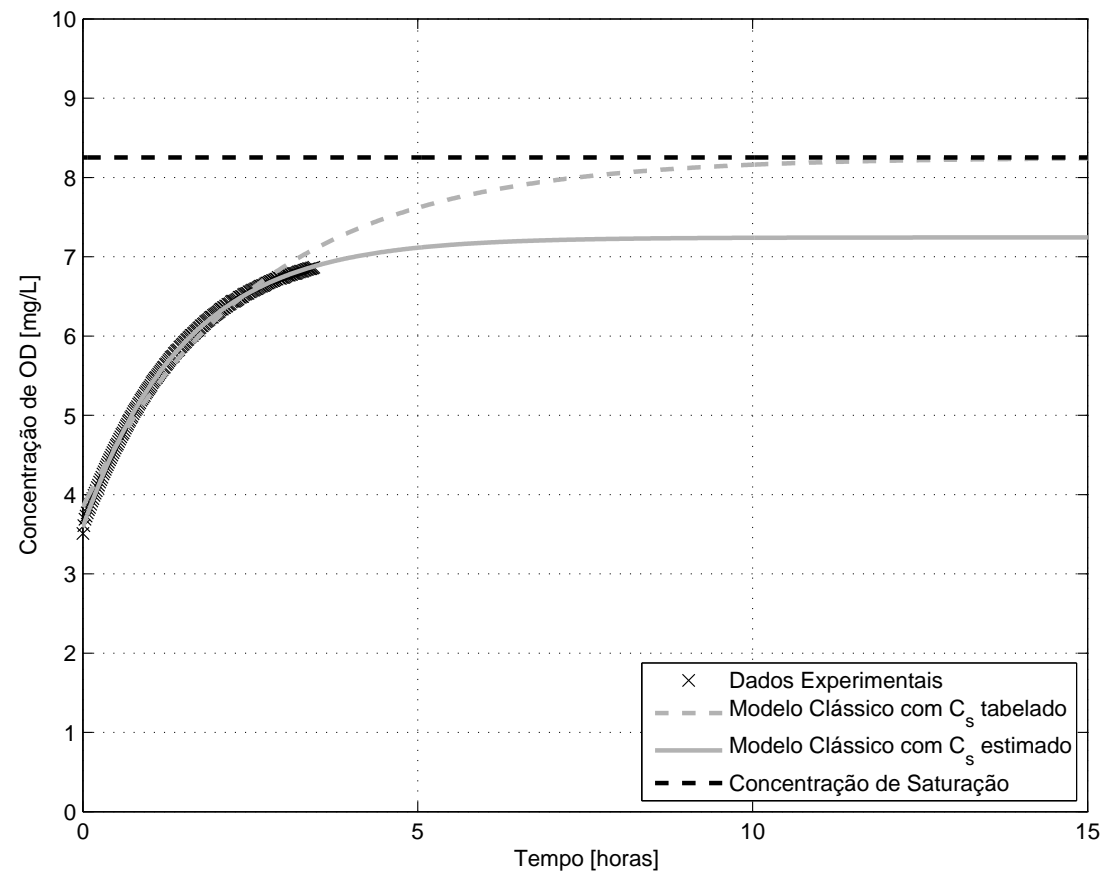

(a) Ajuste com o Modelo Clássico

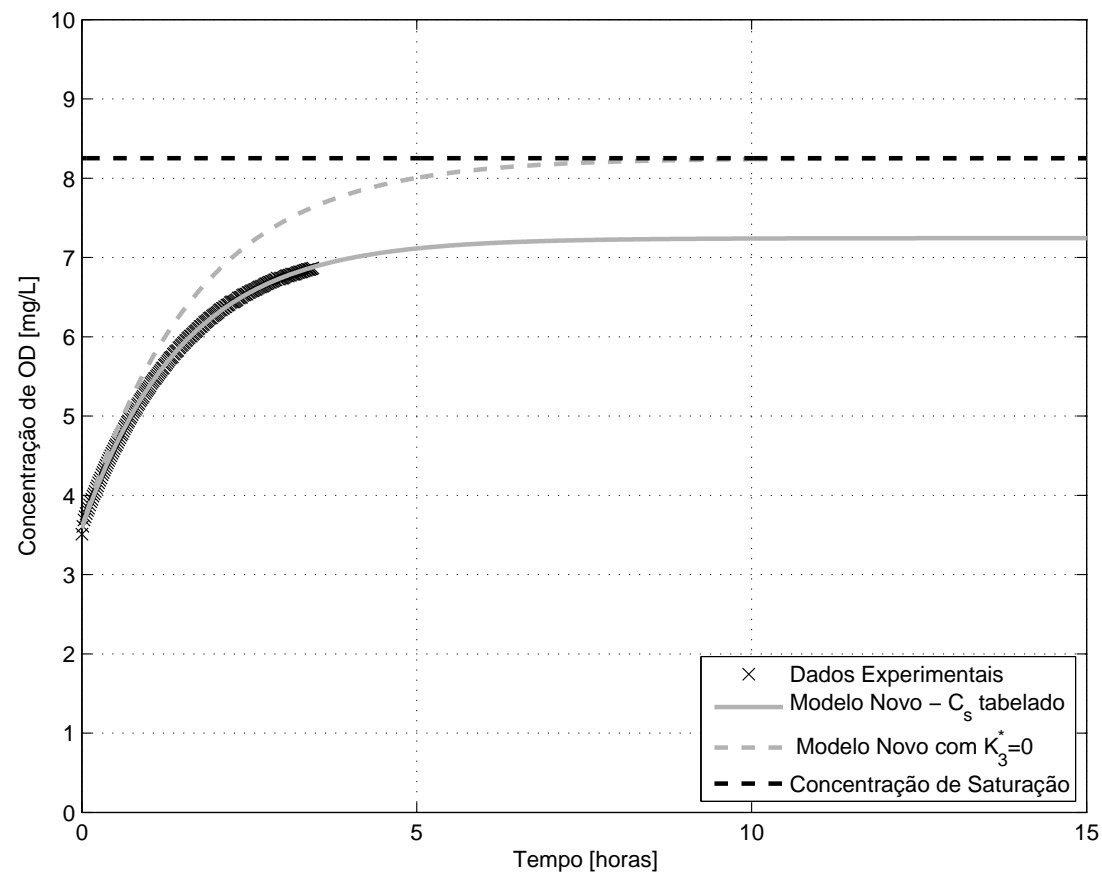

(b) Ajuste com o Modelo Novo

Figura B.37: Curva de reoxigenação para o ensaio 37 


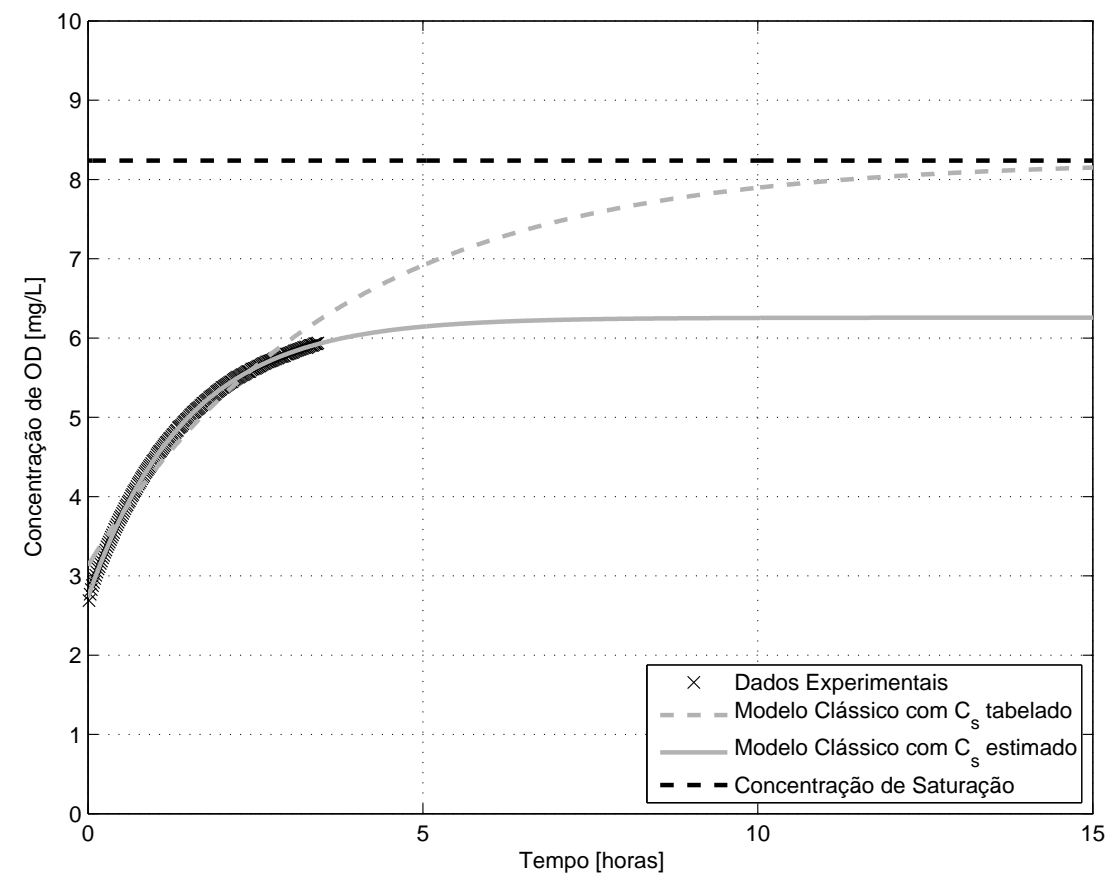

(a) Ajuste com o Modelo Clássico

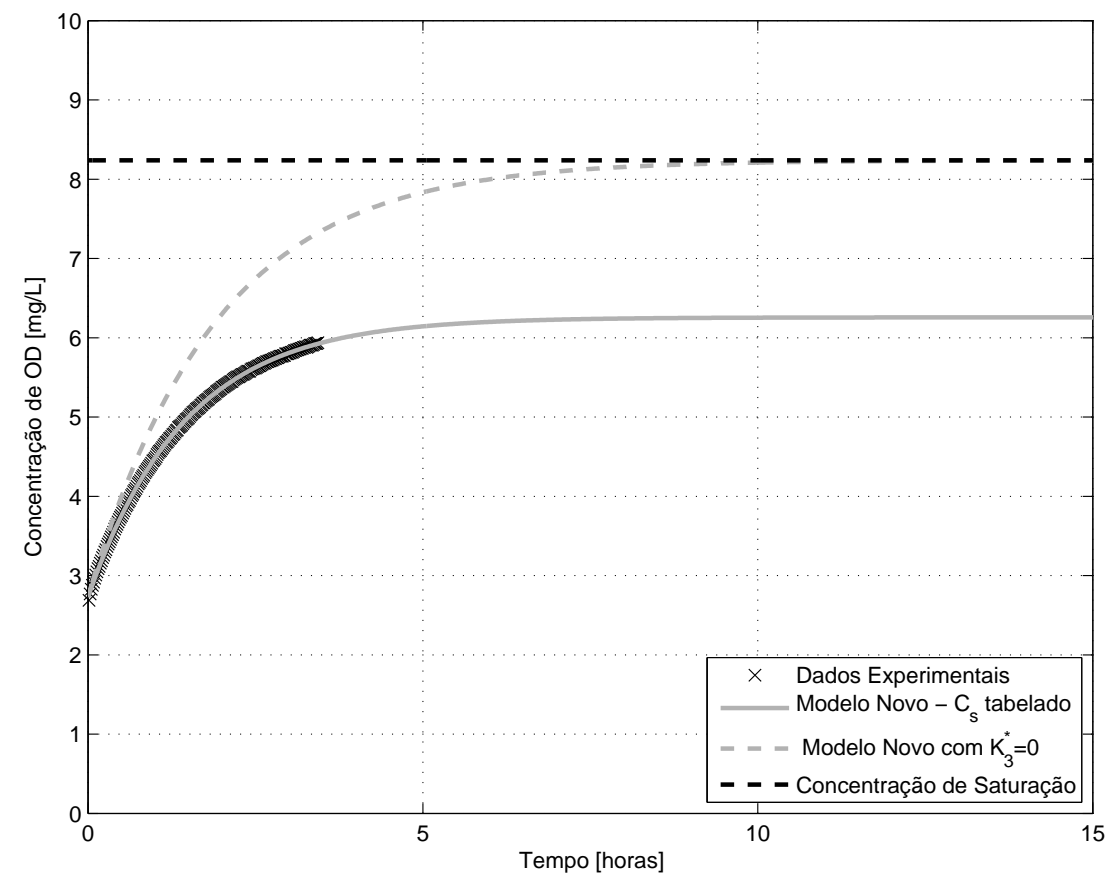

(b) Ajuste com o Modelo Novo

Figura B.38: Curva de reoxigenação para o ensaio 38 


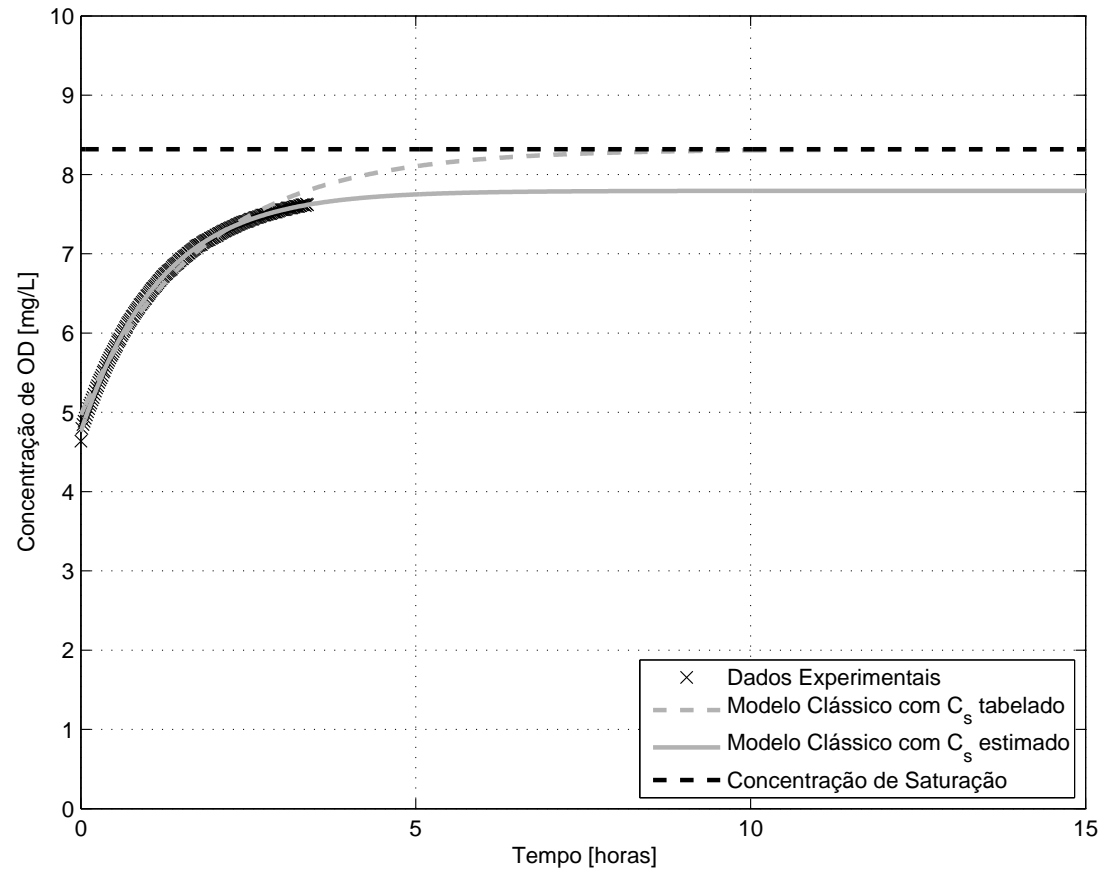

(a) Ajuste com o Modelo Clássico

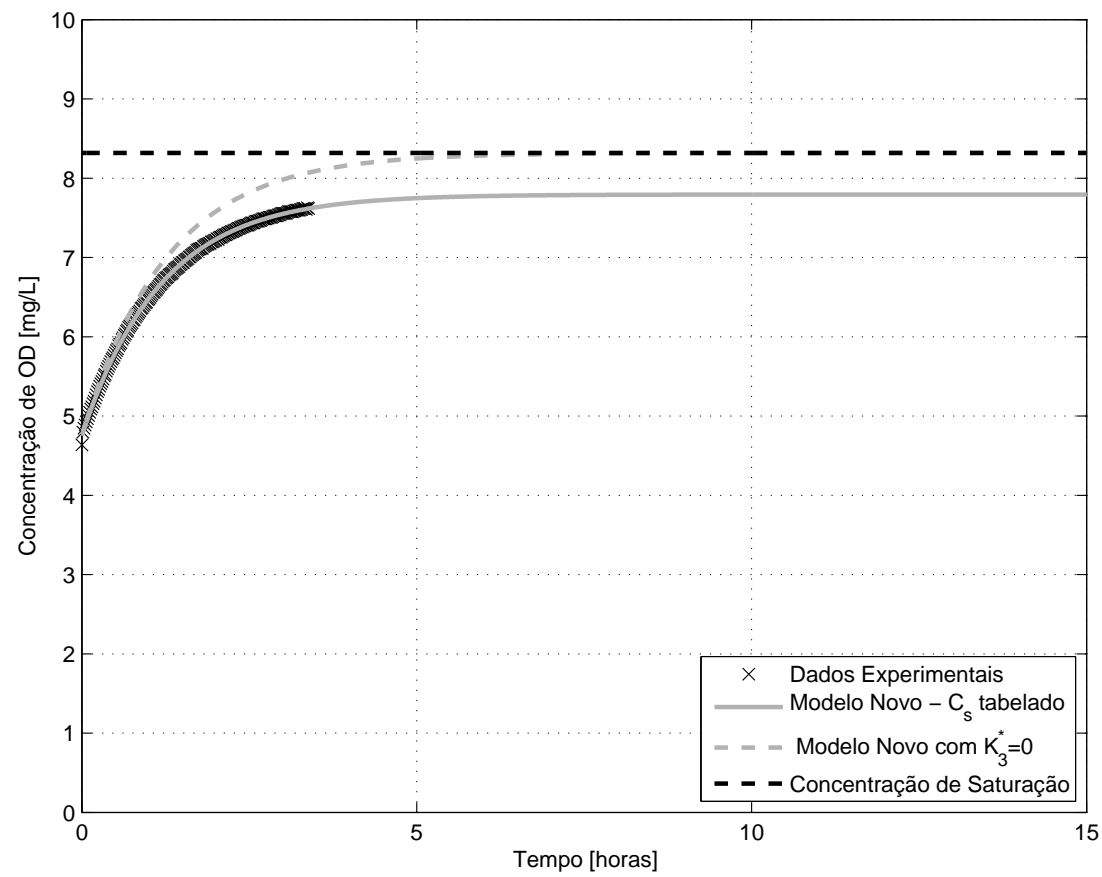

(b) Ajuste com o Modelo Novo

Figura B.39: Curva de reoxigenação para o ensaio 39 


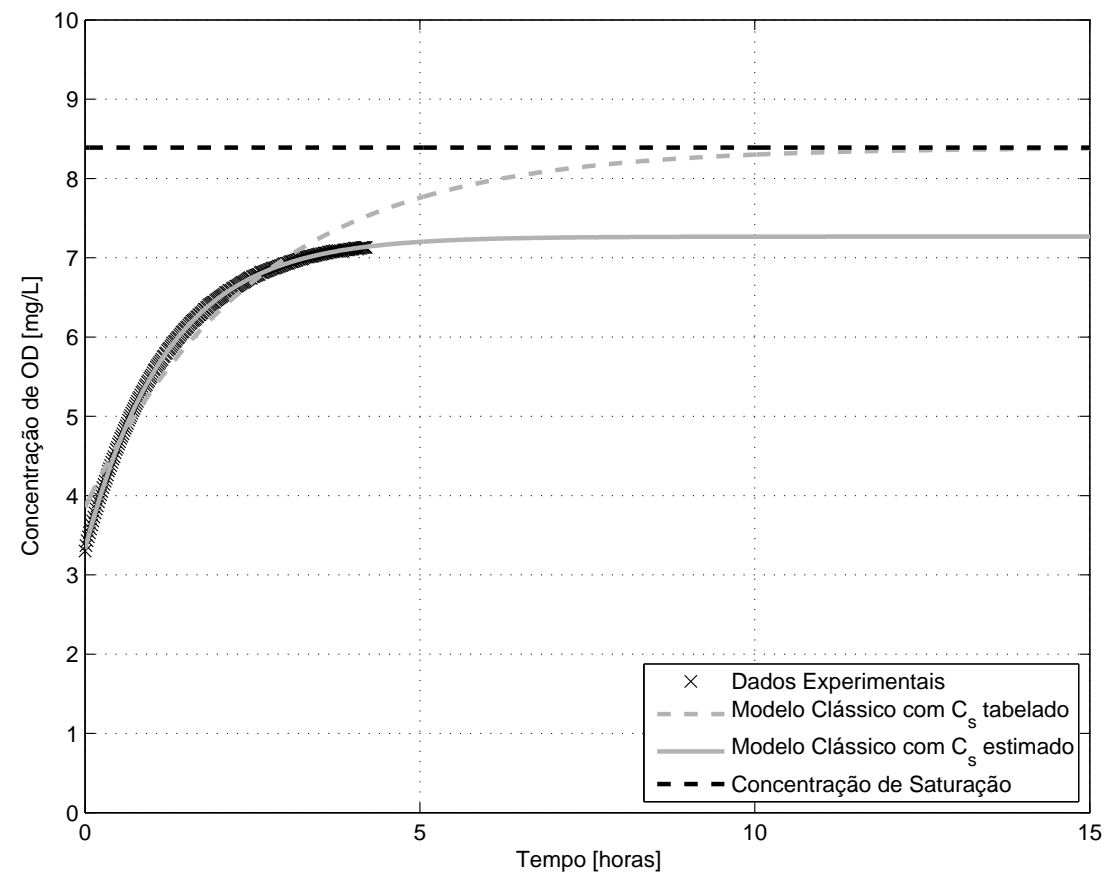

(a) Ajuste com o Modelo Clássico

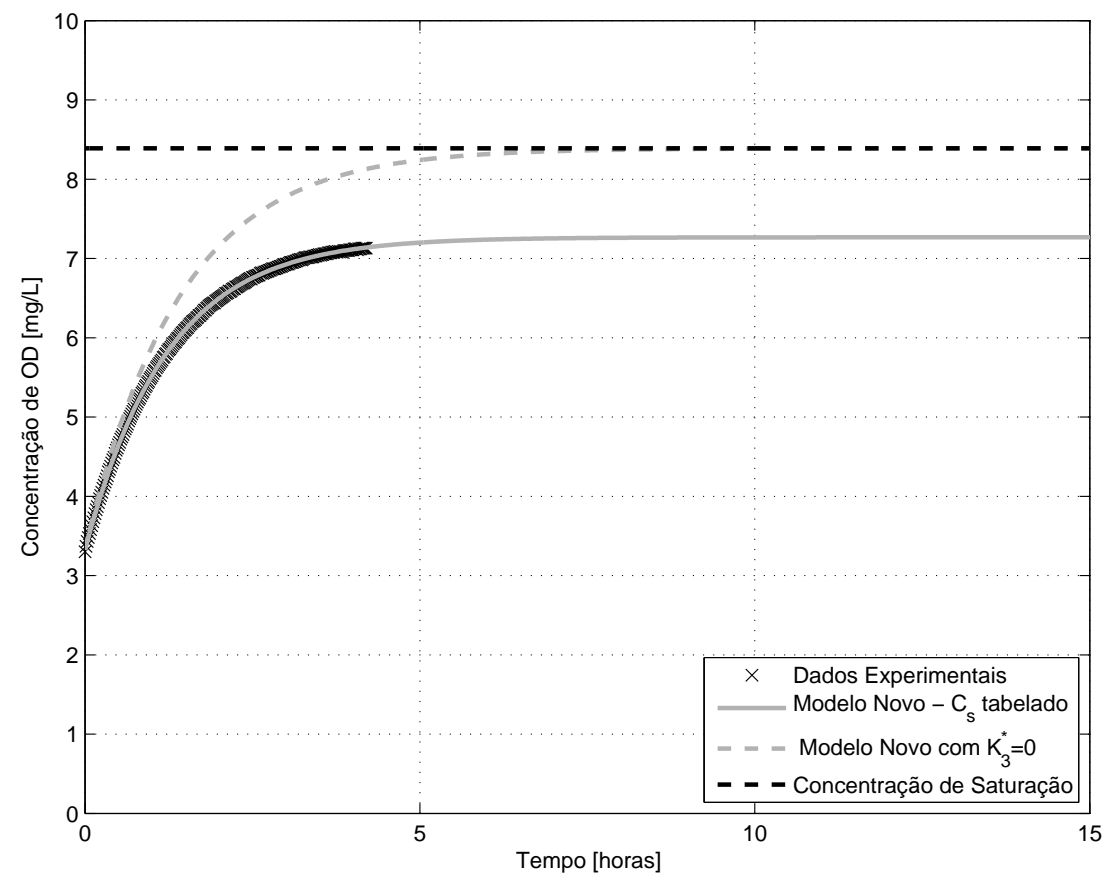

(b) Ajuste com o Modelo Novo

Figura B.40: Curva de reoxigenação para o ensaio 40 


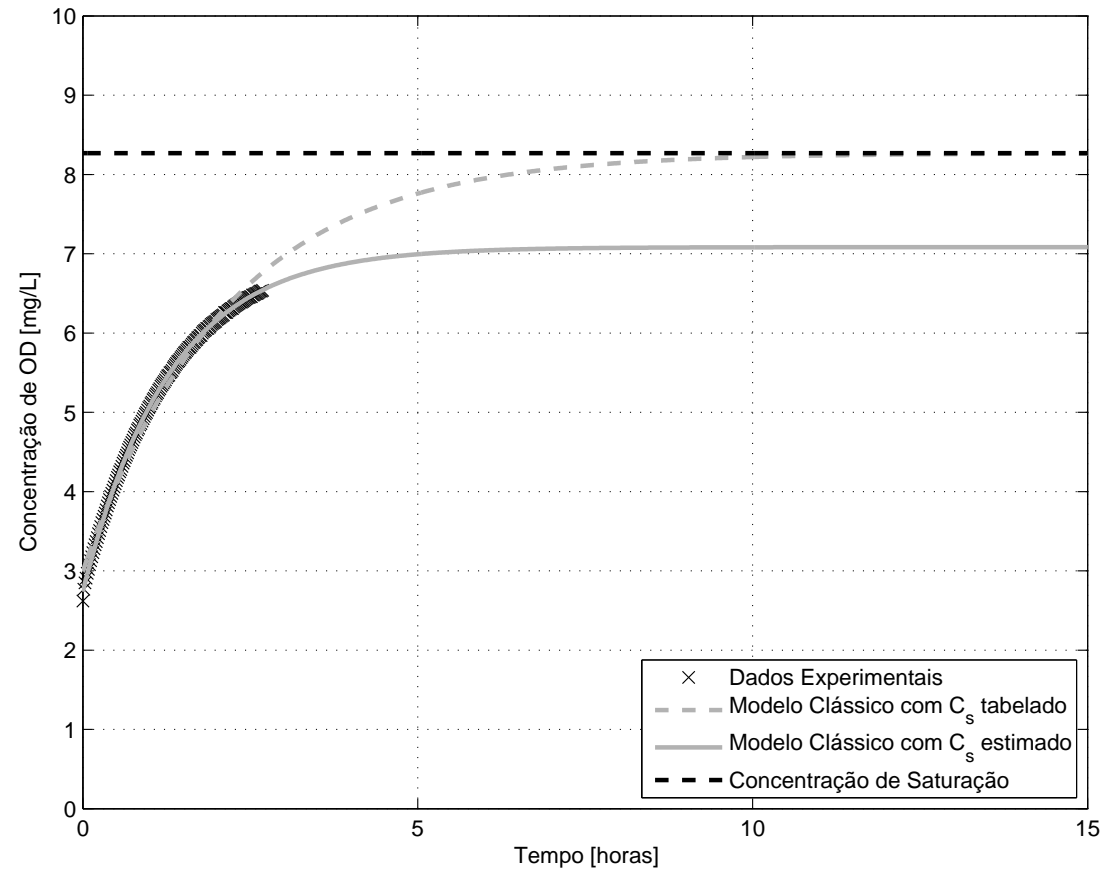

(a) Ajuste com o Modelo Clássico

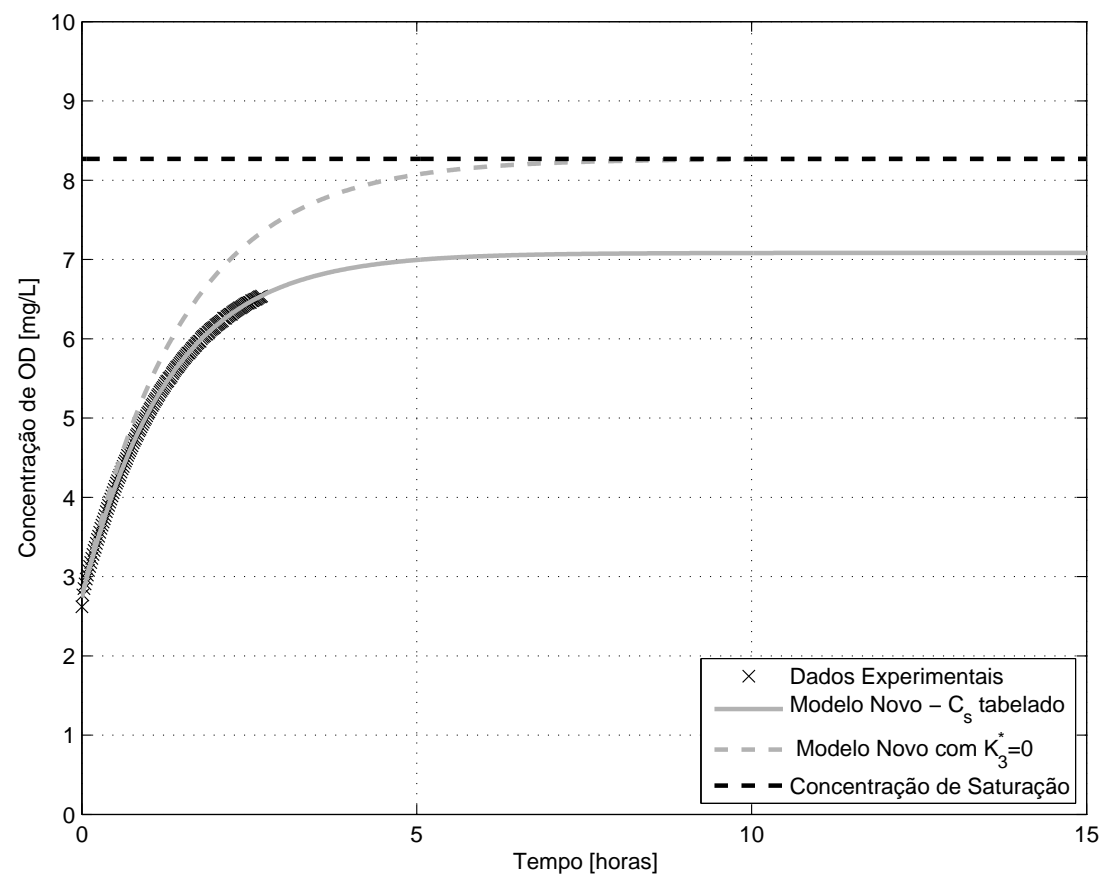

(b) Ajuste com o Modelo Novo

Figura B.41: Curva de reoxigenação para o ensaio 41 


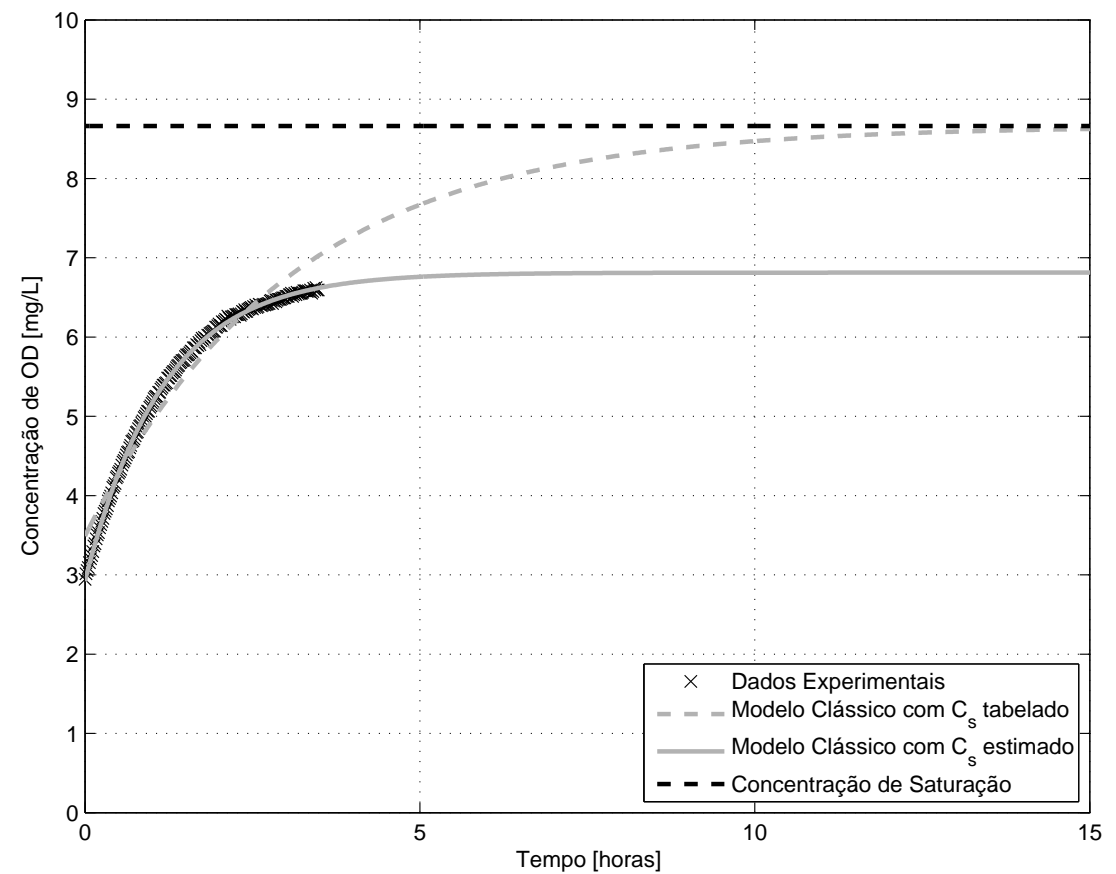

(a) Ajuste com o Modelo Clássico

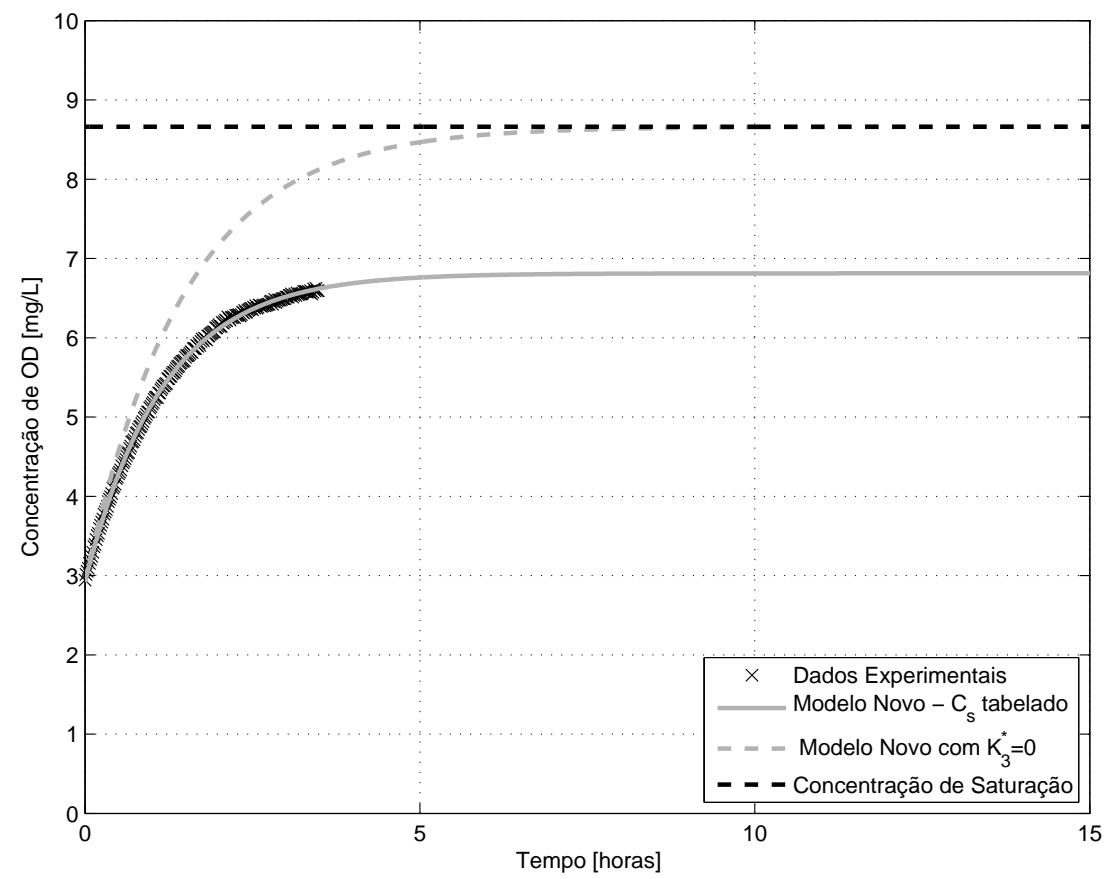

(b) Ajuste com o Modelo Novo

Figura B.42: Curva de reoxigenação para o ensaio 42 


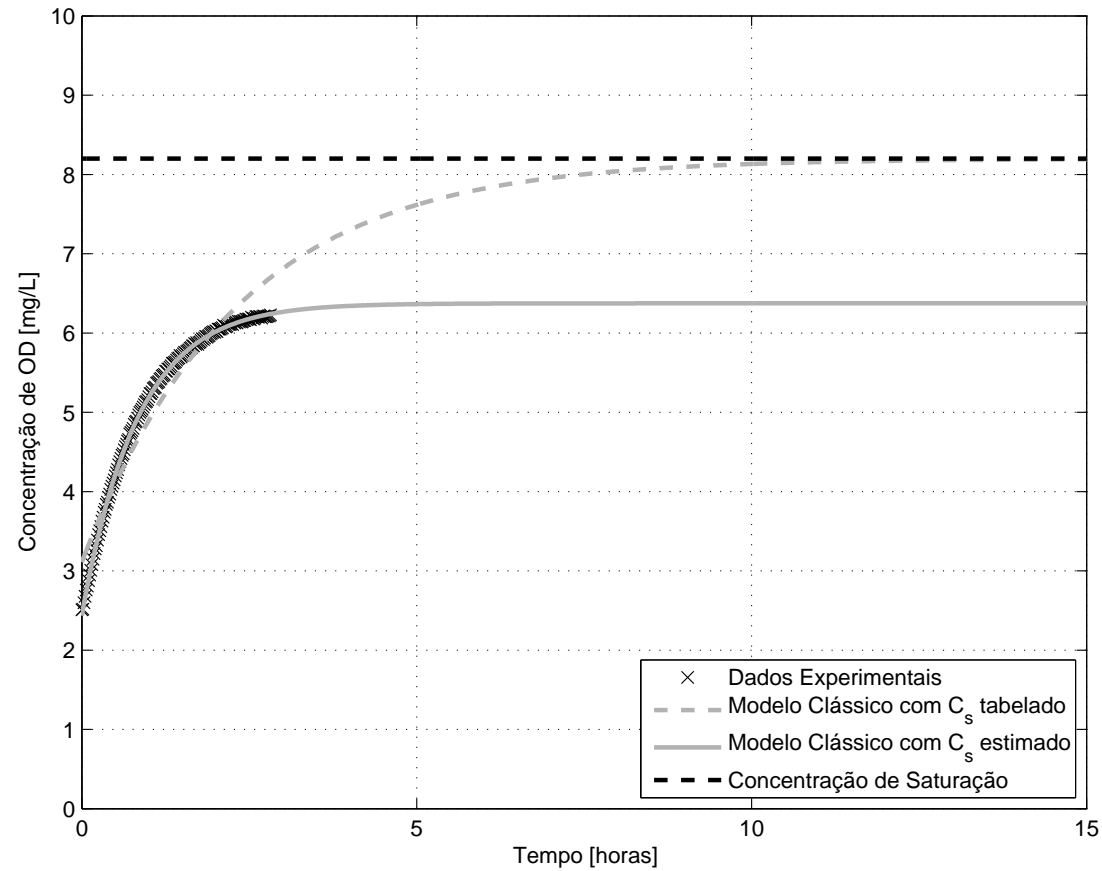

(a) Ajuste com o Modelo Clássico

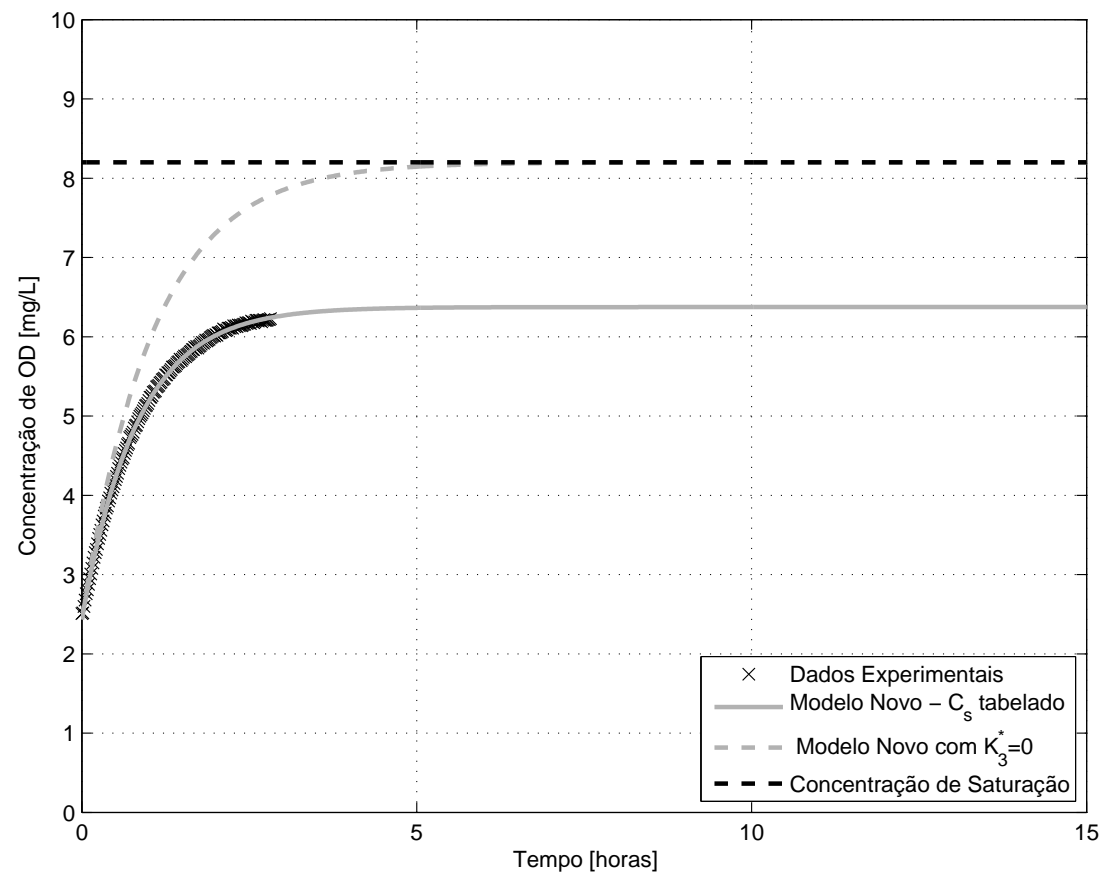

(b) Ajuste com o Modelo Novo

Figura B.43: Curva de reoxigenação para o ensaio 43 


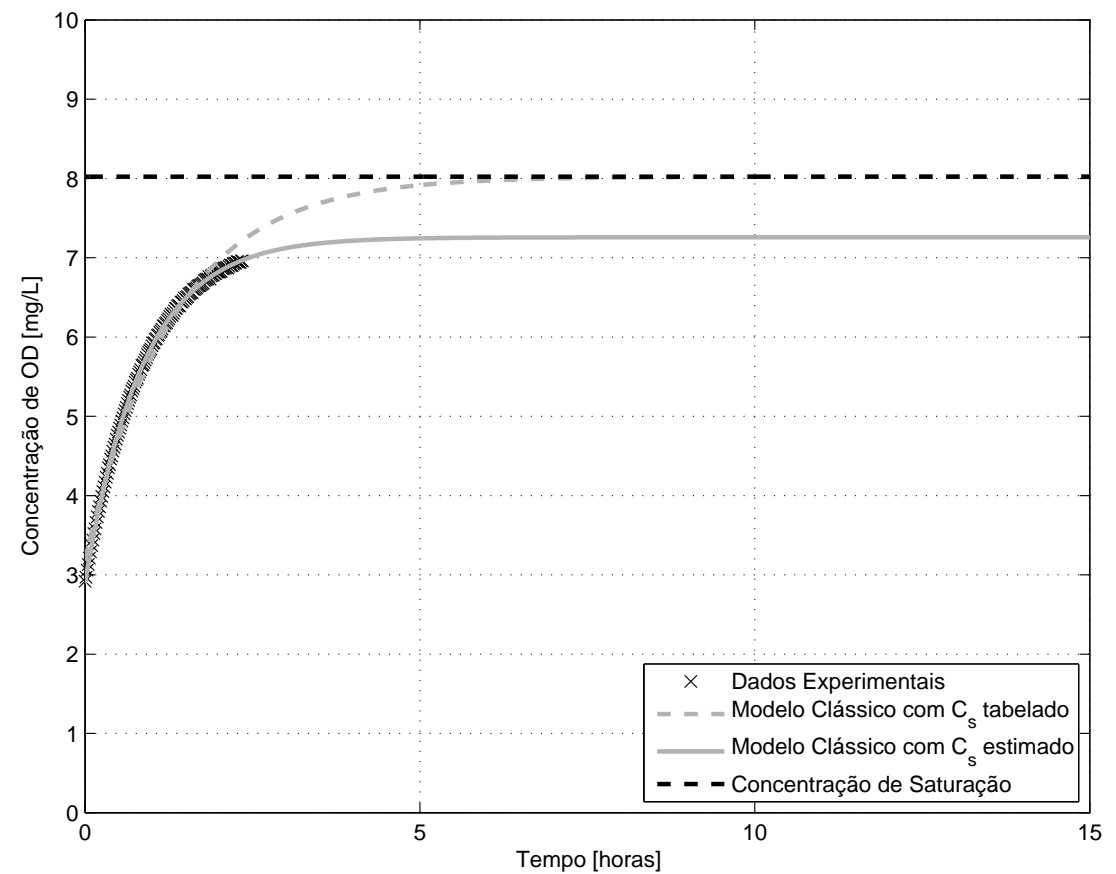

(a) Ajuste com o Modelo Clássico

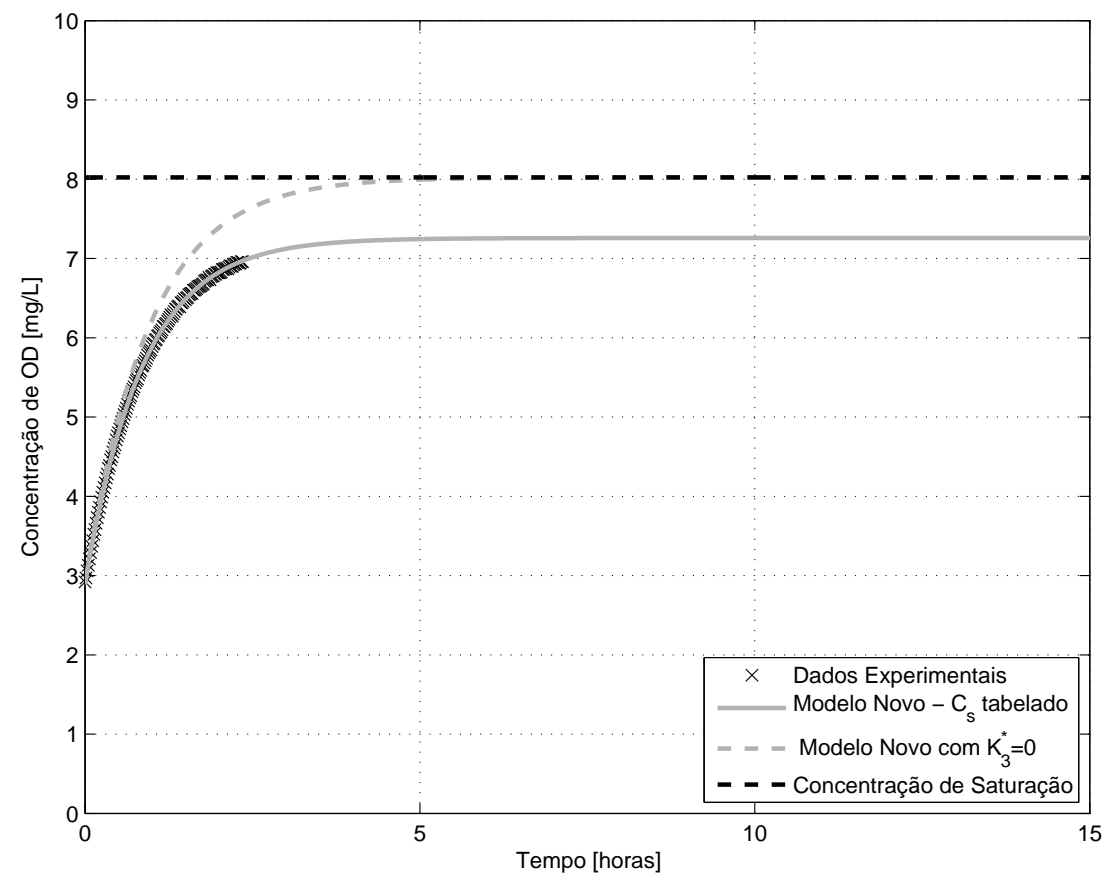

(b) Ajuste com o Modelo Novo

Figura B.44: Curva de reoxigenação para o ensaio 44 


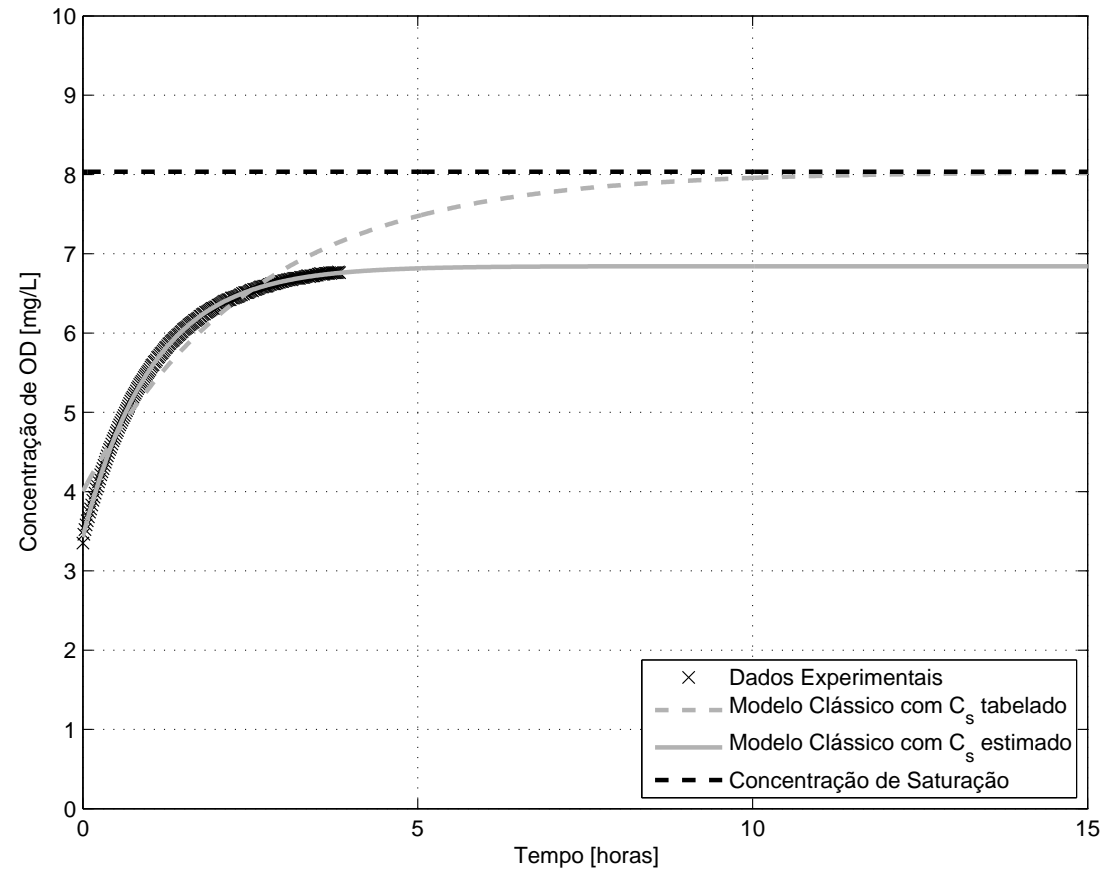

(a) Ajuste com o Modelo Clássico

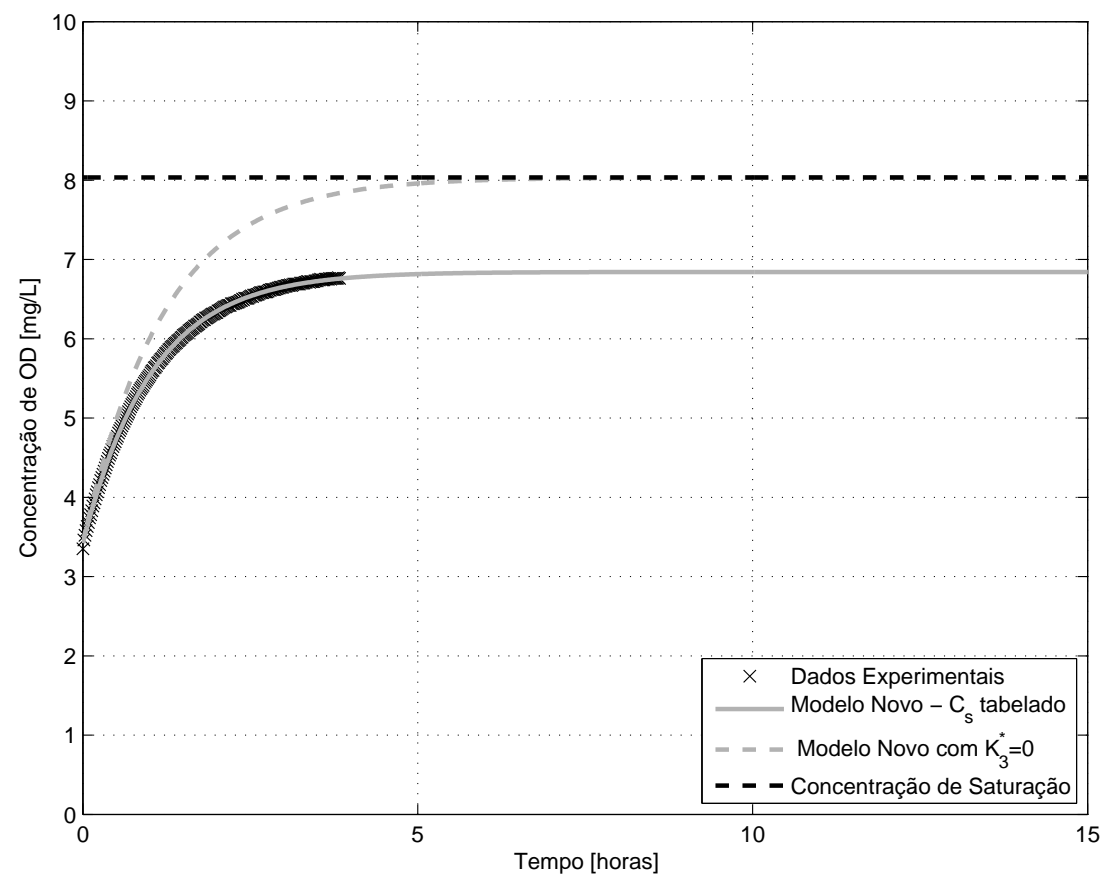

(b) Ajuste com o Modelo Novo

Figura B.45: Curva de reoxigenação para o ensaio 45 


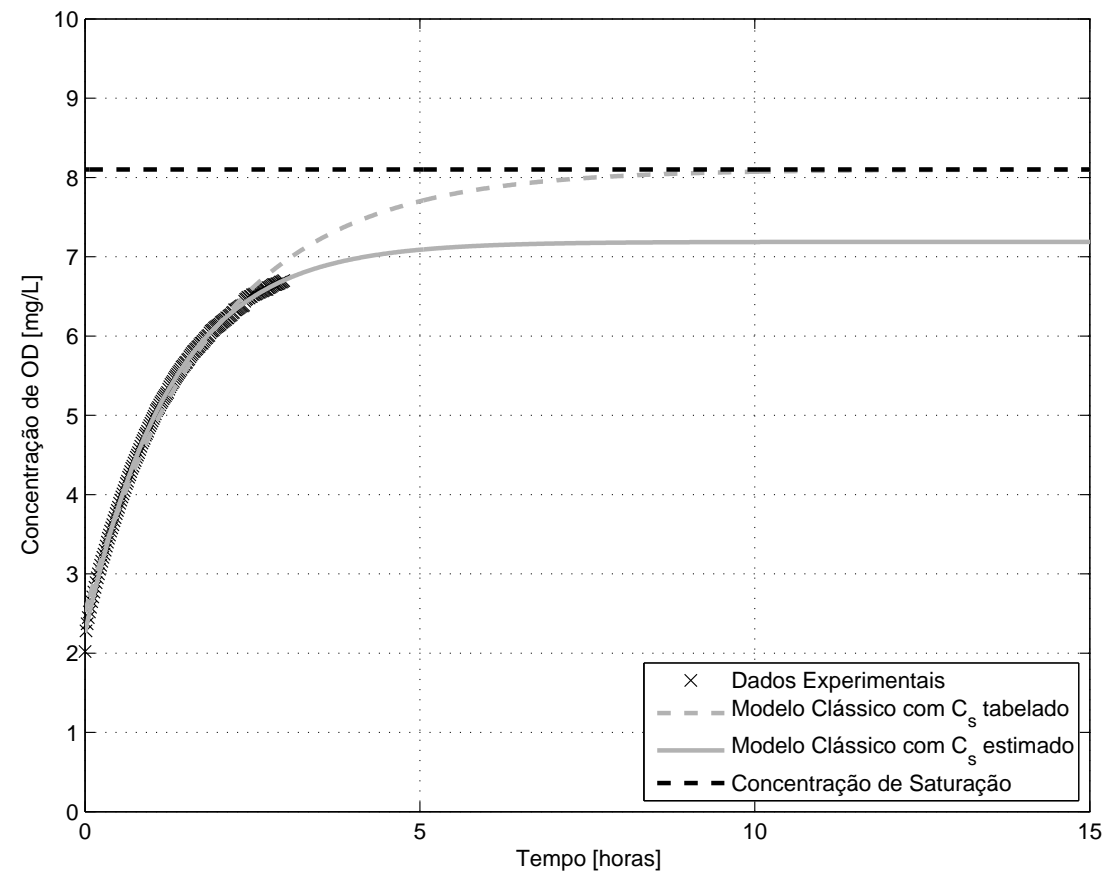

(a) Ajuste com o Modelo Clássico

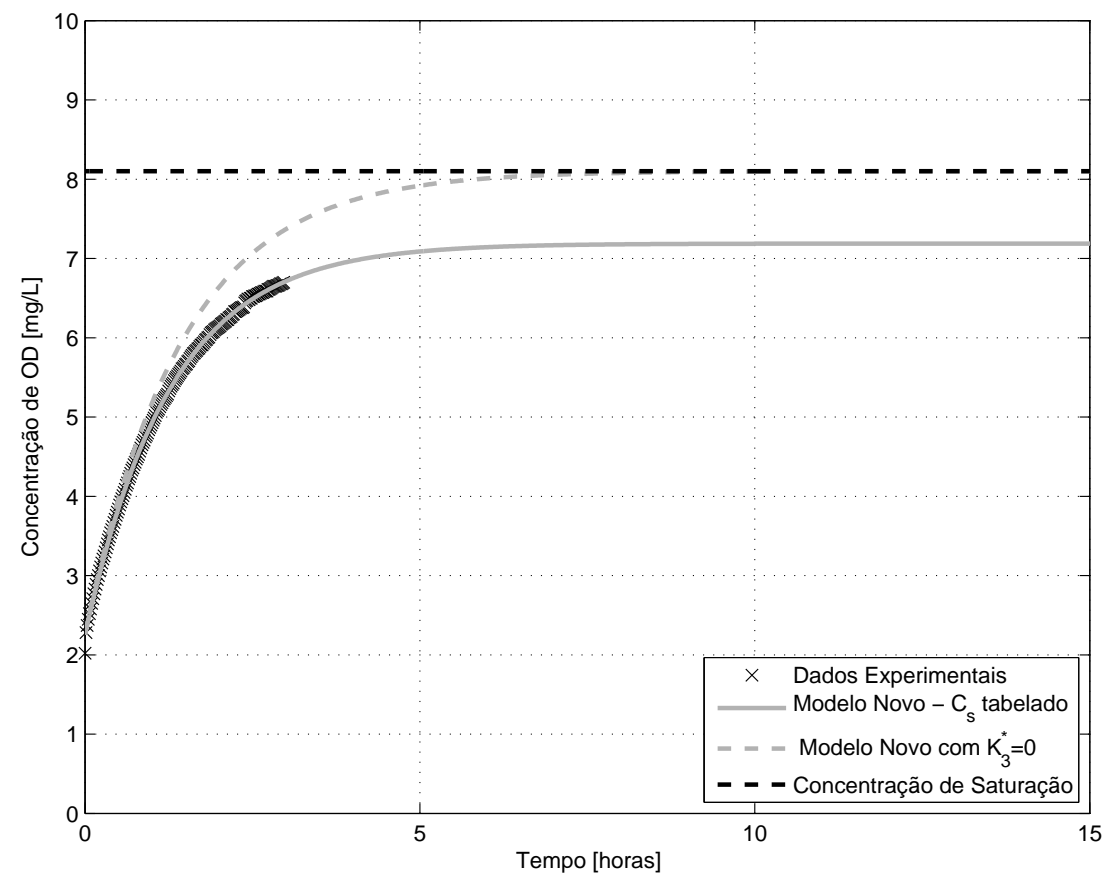

(b) Ajuste com o Modelo Novo

Figura B.46: Curva de reoxigenação para o ensaio 46 


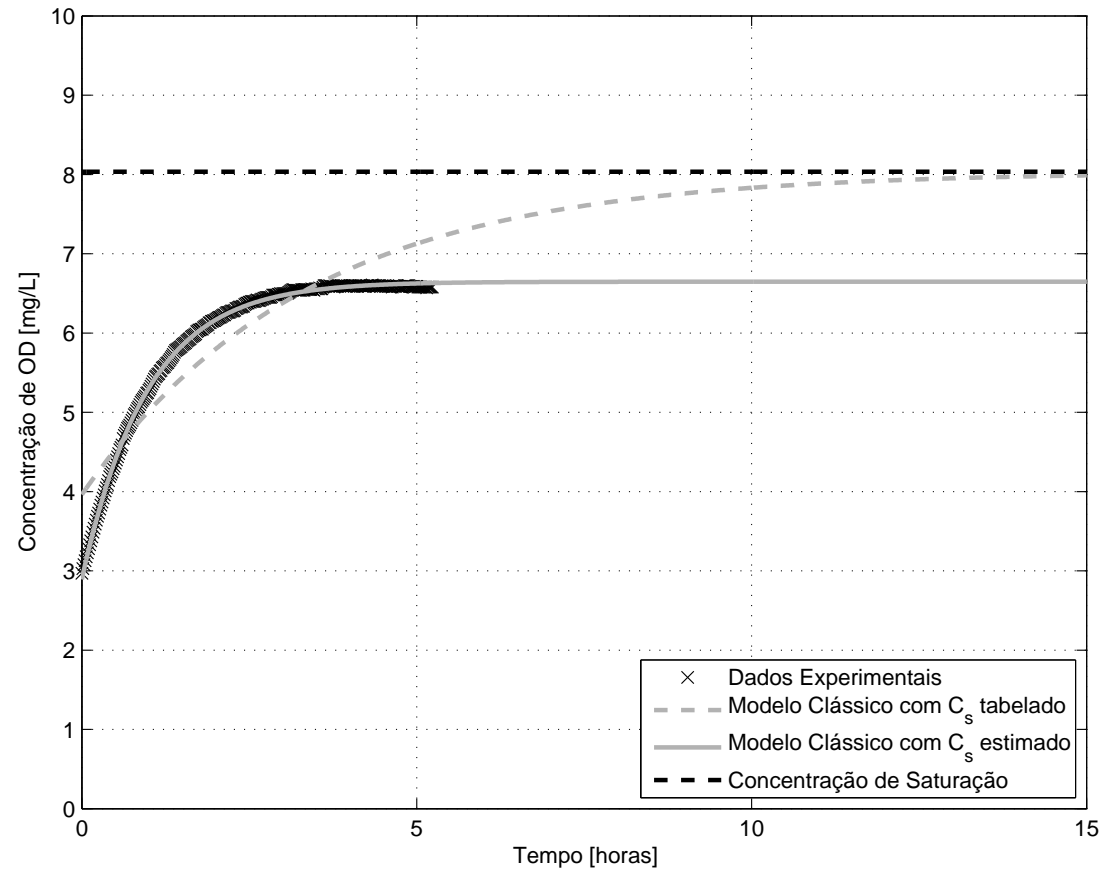

(a) Ajuste com o Modelo Clássico

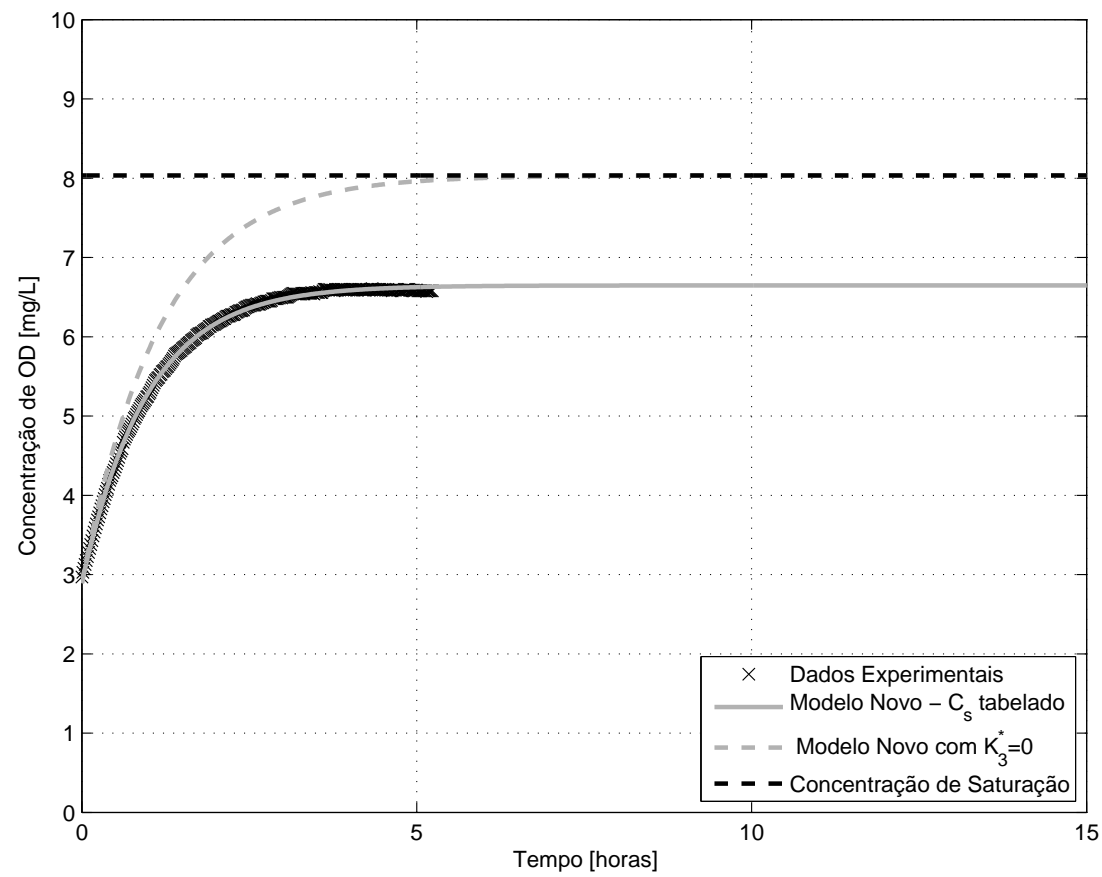

(b) Ajuste com o Modelo Novo

Figura B.47: Curva de reoxigenação para o ensaio 47 


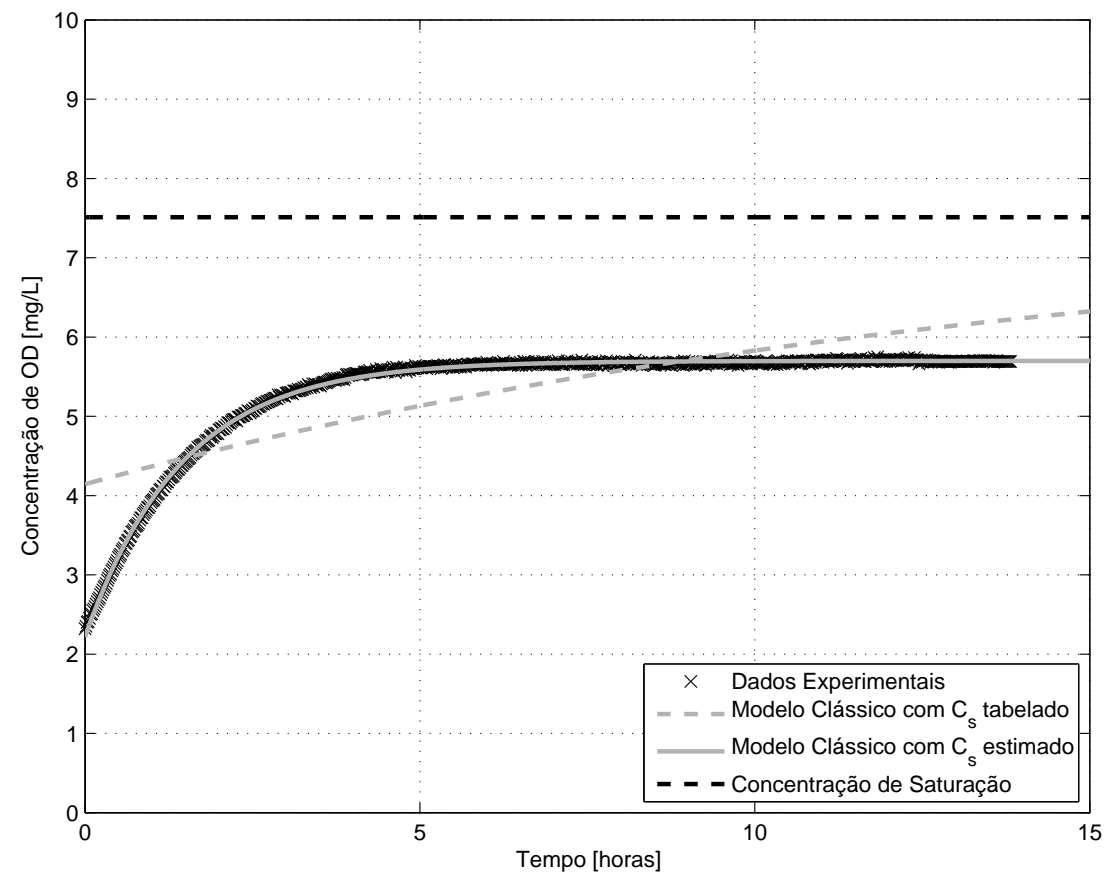

(a) Ajuste com o Modelo Clássico

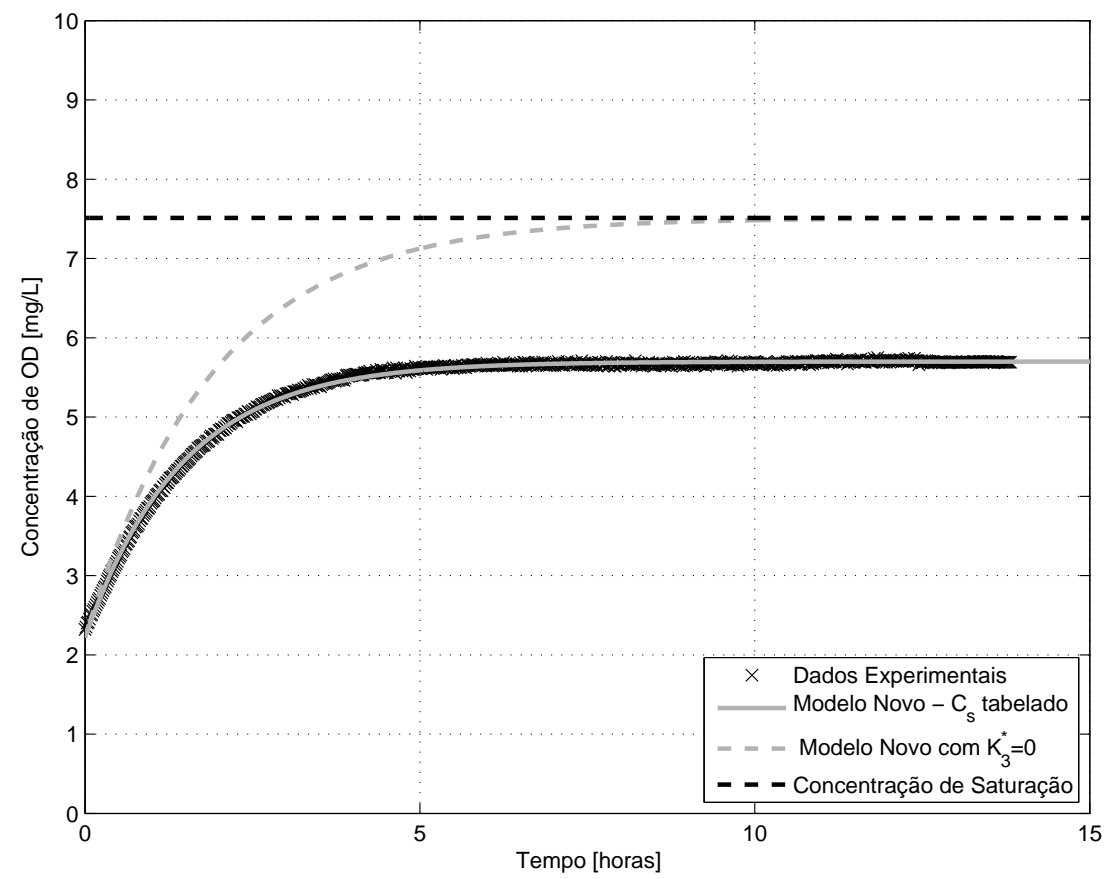

(b) Ajuste com o Modelo Novo

Figura B.48: Curva de reoxigenação para o ensaio 48 


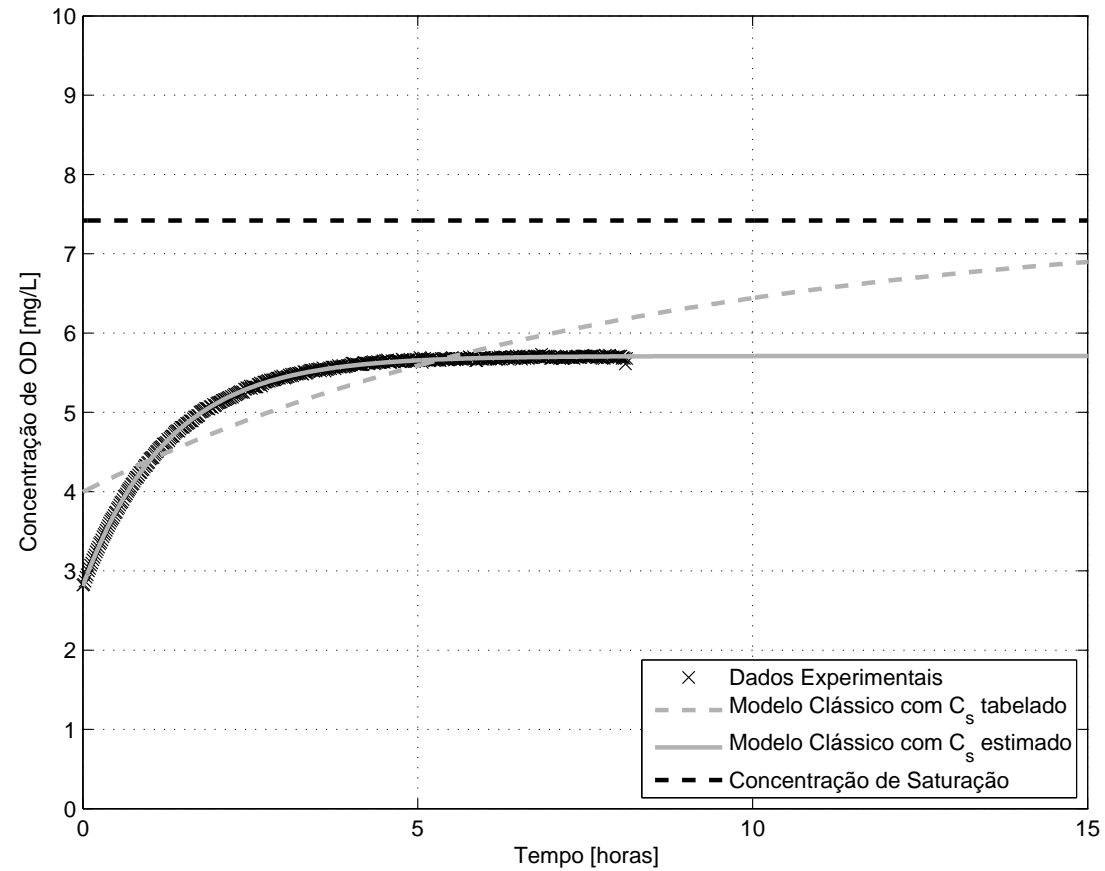

(a) Ajuste com o Modelo Clássico

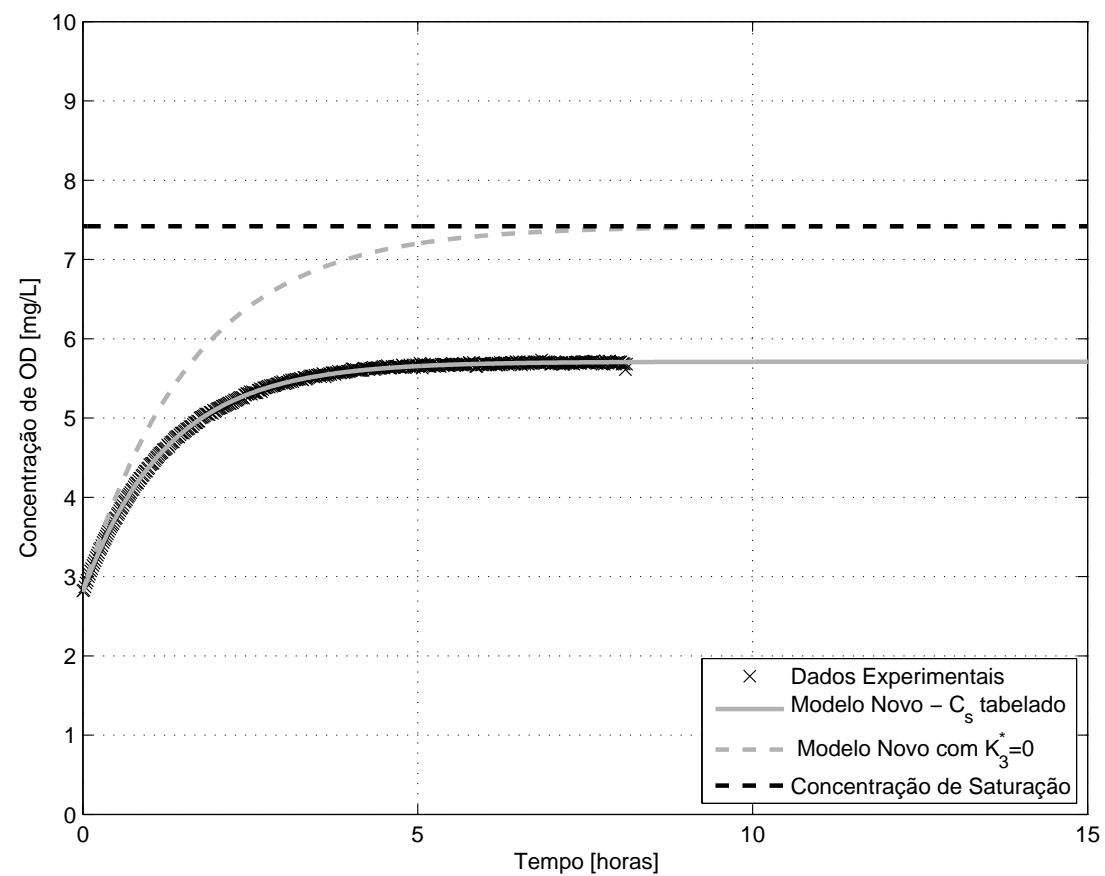

(b) Ajuste com o Modelo Novo

Figura B.49: Curva de reoxigenação para o ensaio 49 


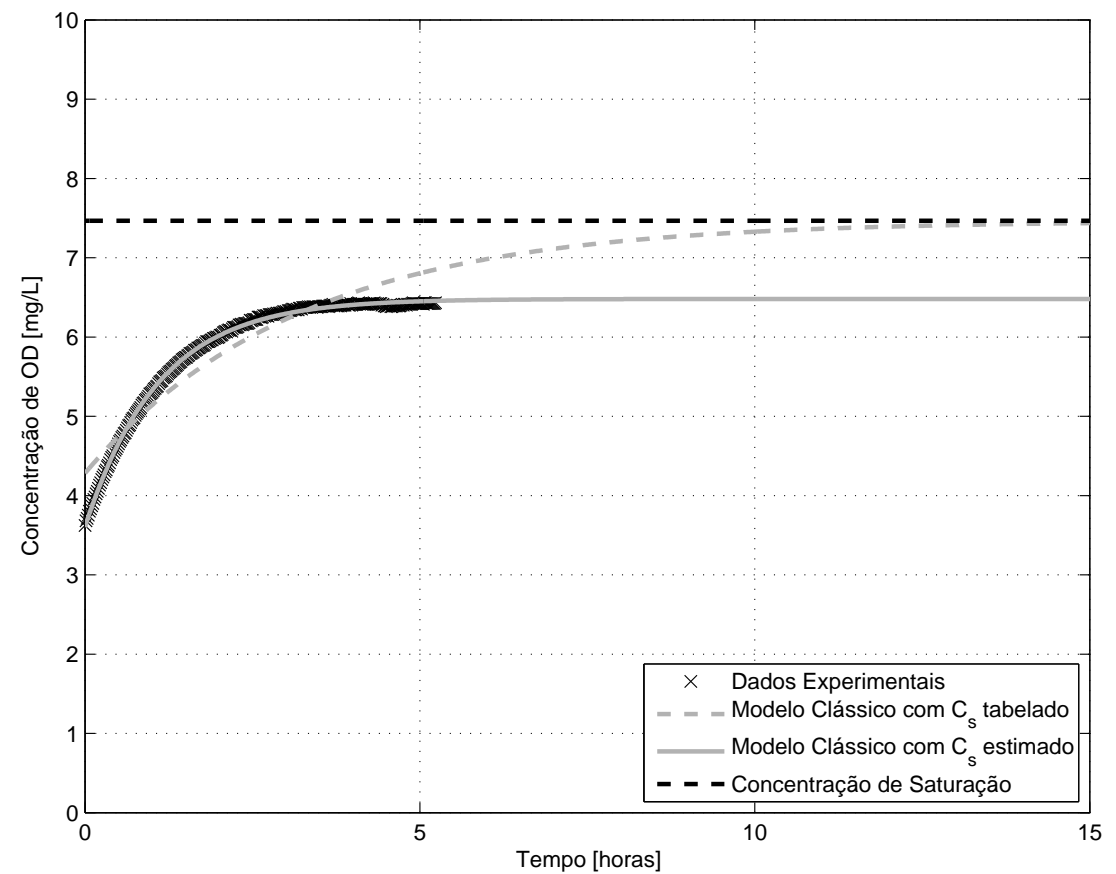

(a) Ajuste com o Modelo Clássico

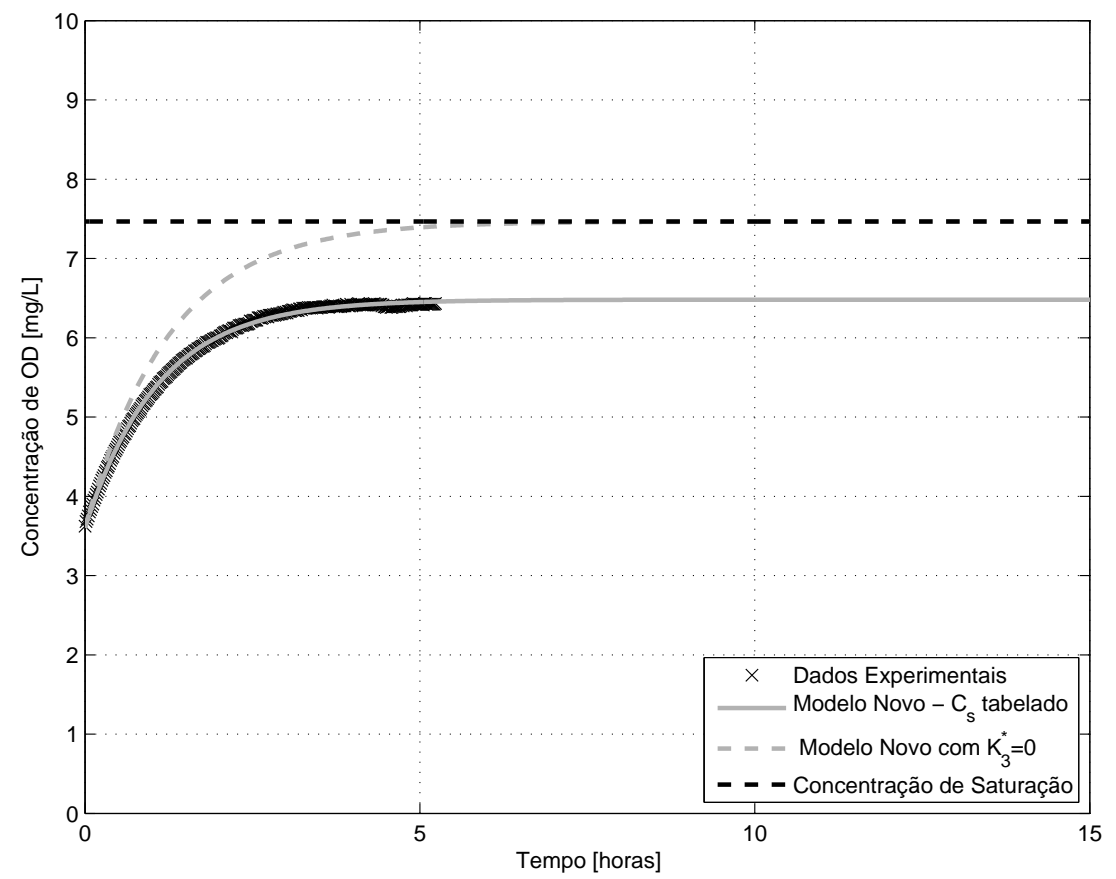

(b) Ajuste com o Modelo Novo

Figura B.50: Curva de reoxigenação para o ensaio 50 


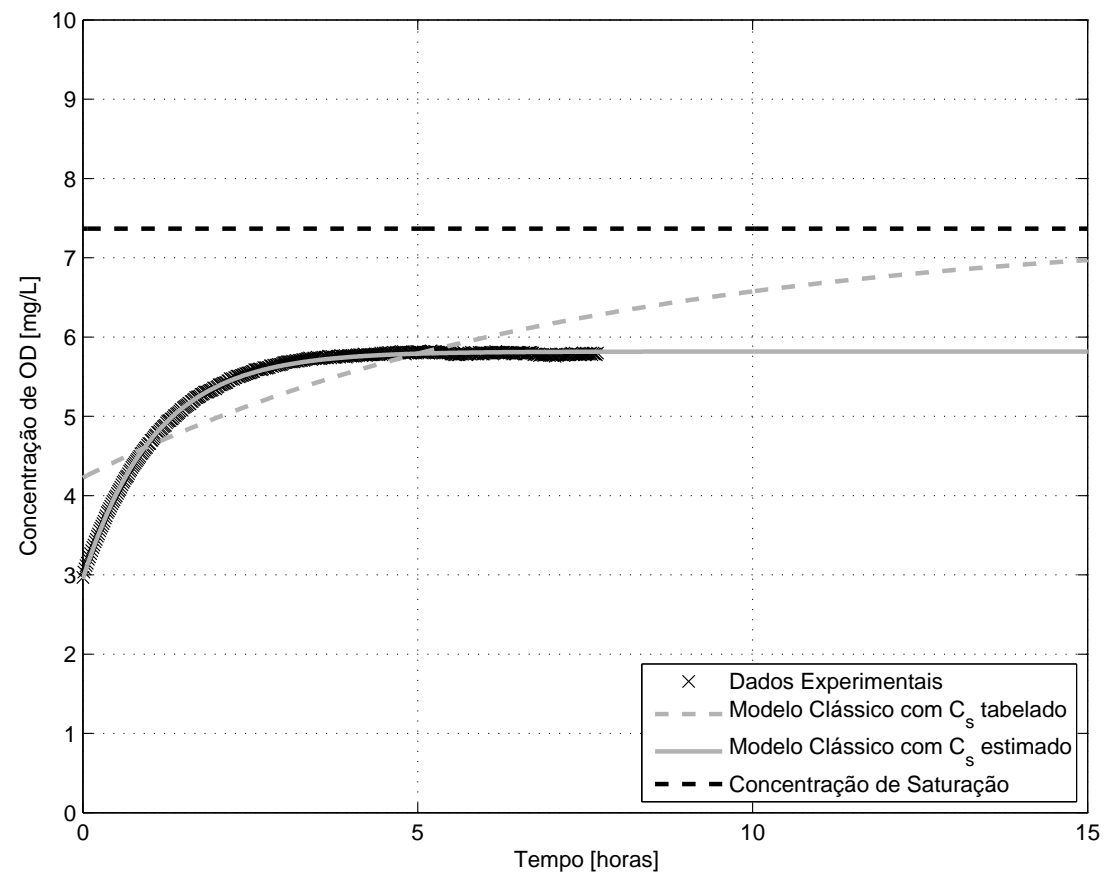

(a) Ajuste com o Modelo Clássico

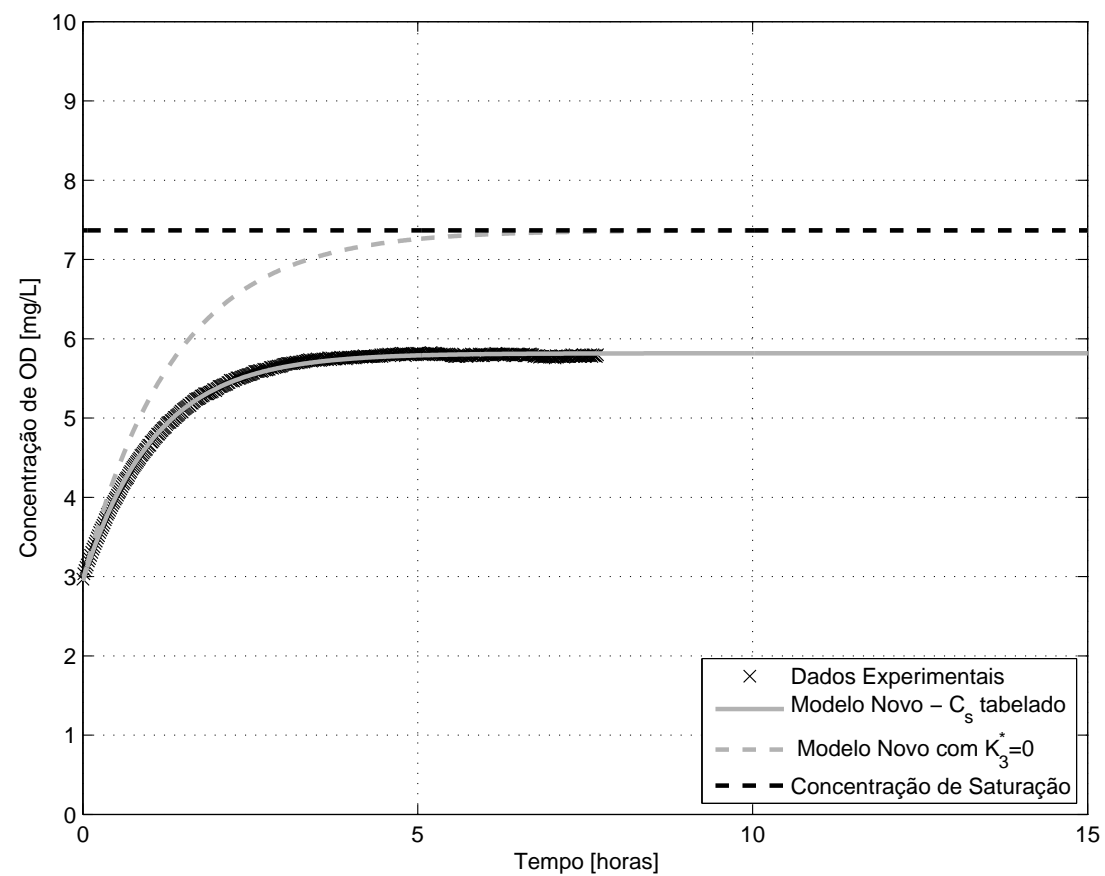

(b) Ajuste com o Modelo Novo

Figura B.51: Curva de reoxigenação para o ensaio 51 


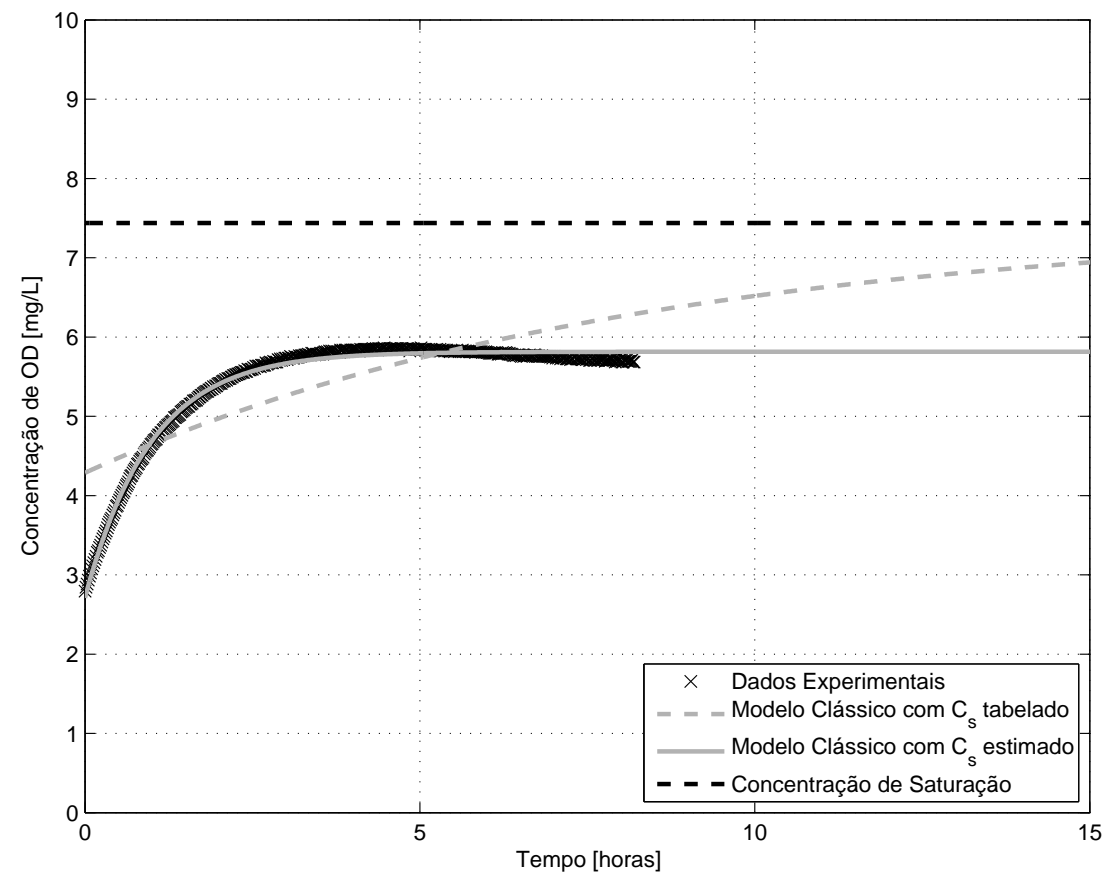

(a) Ajuste com o Modelo Clássico

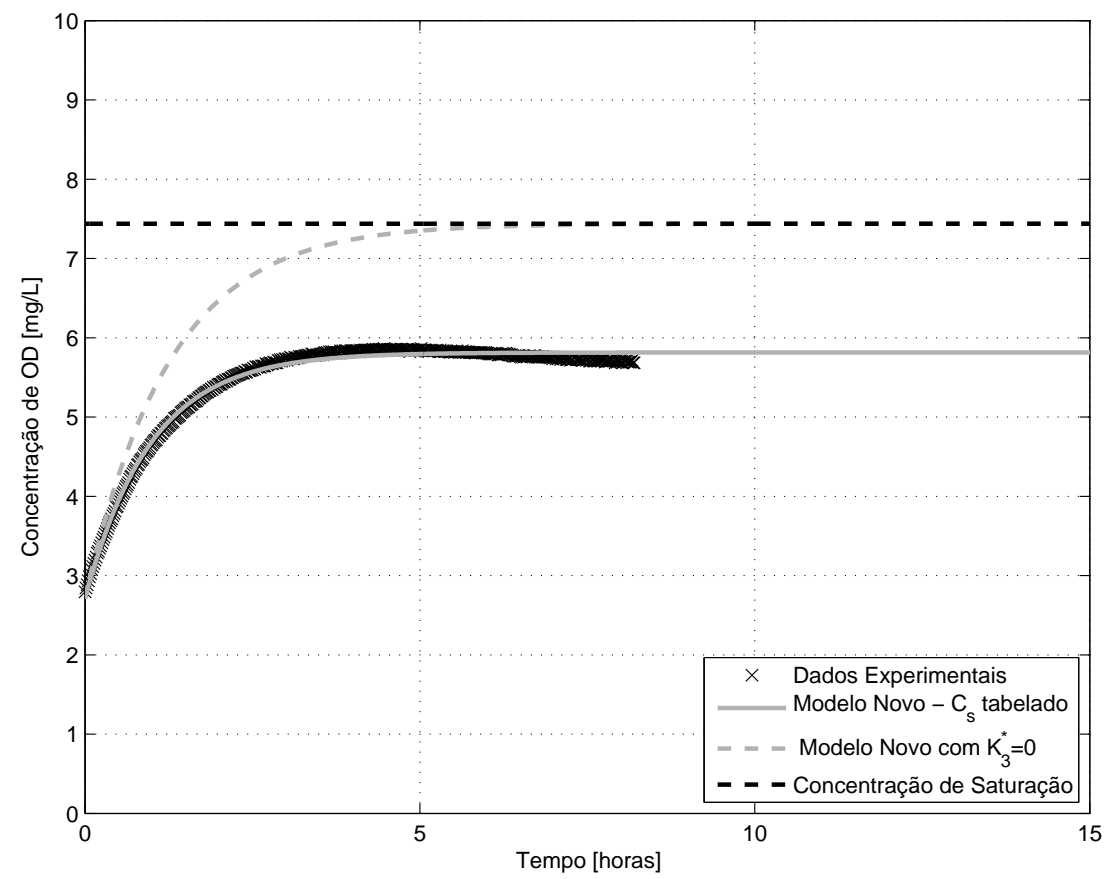

(b) Ajuste com o Modelo Novo

Figura B.52: Curva de reoxigenação para o ensaio 52 


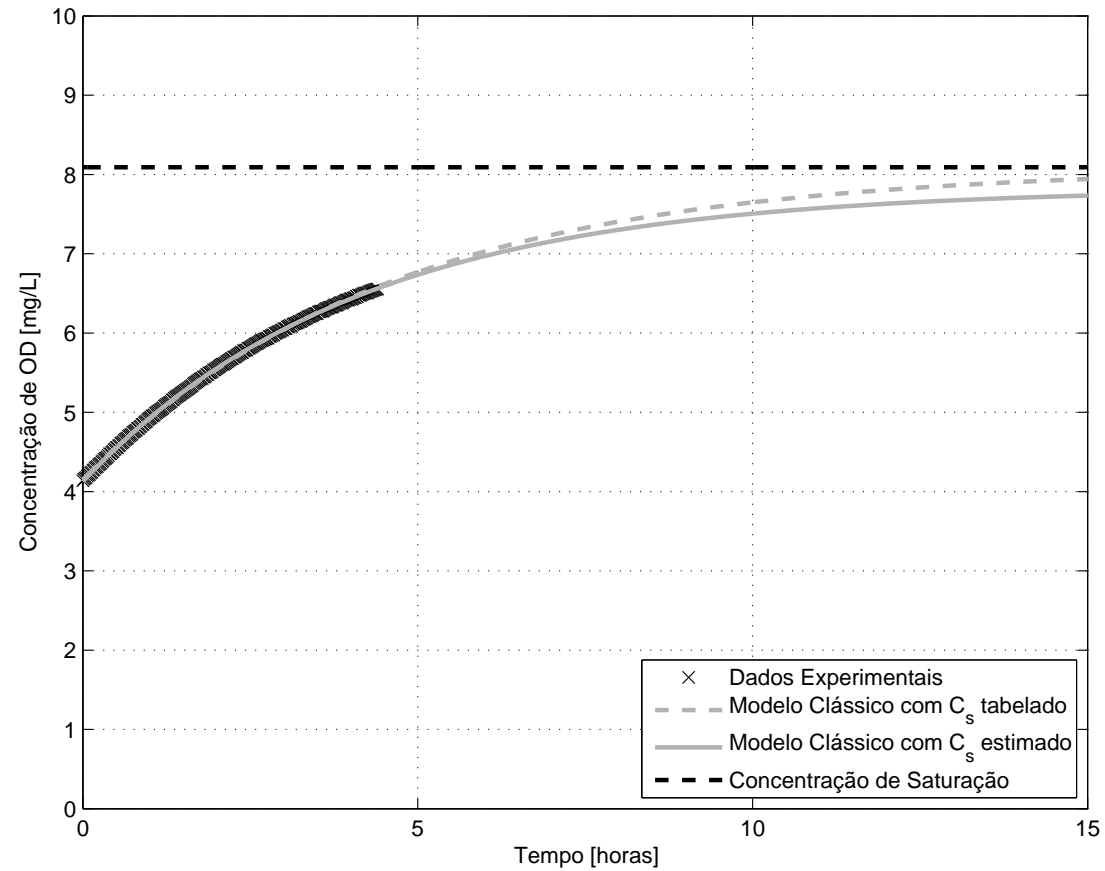

(a) Ajuste com o Modelo Clássico

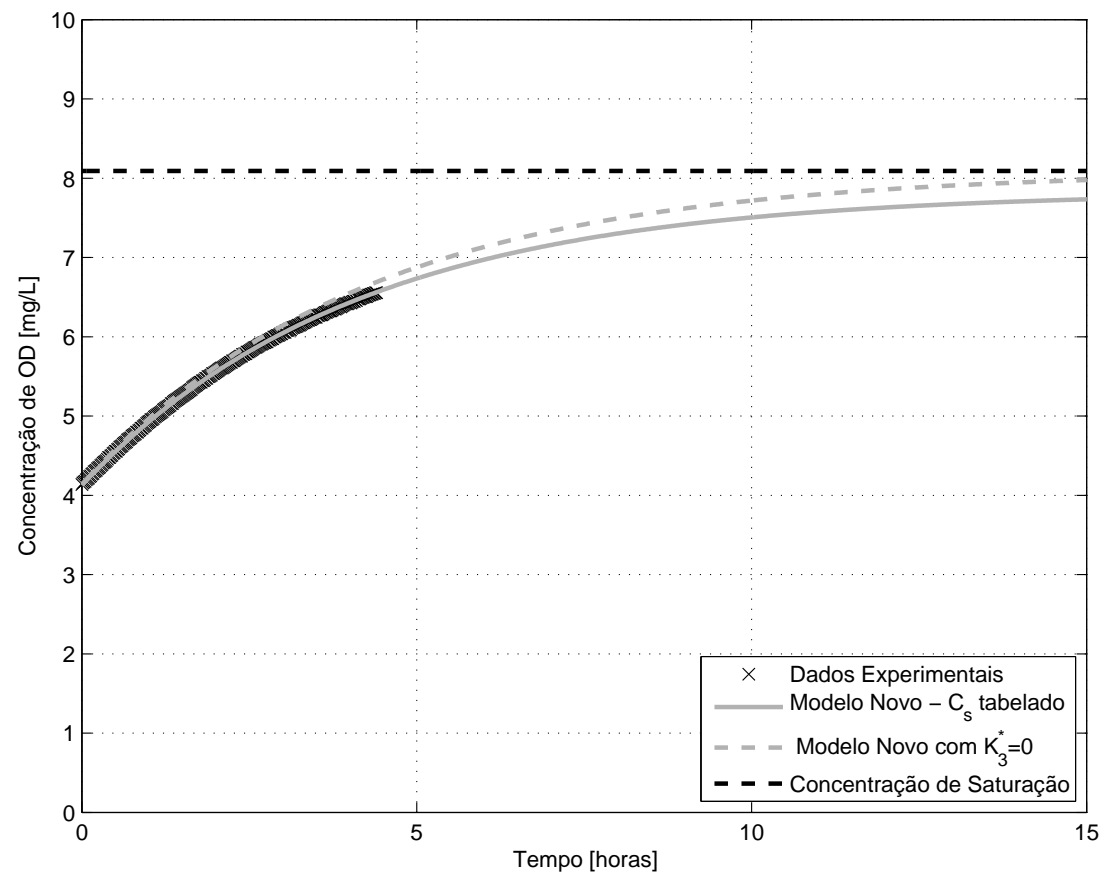

(b) Ajuste com o Modelo Novo

Figura B.53: Curva de reoxigenação para o ensaio 53 


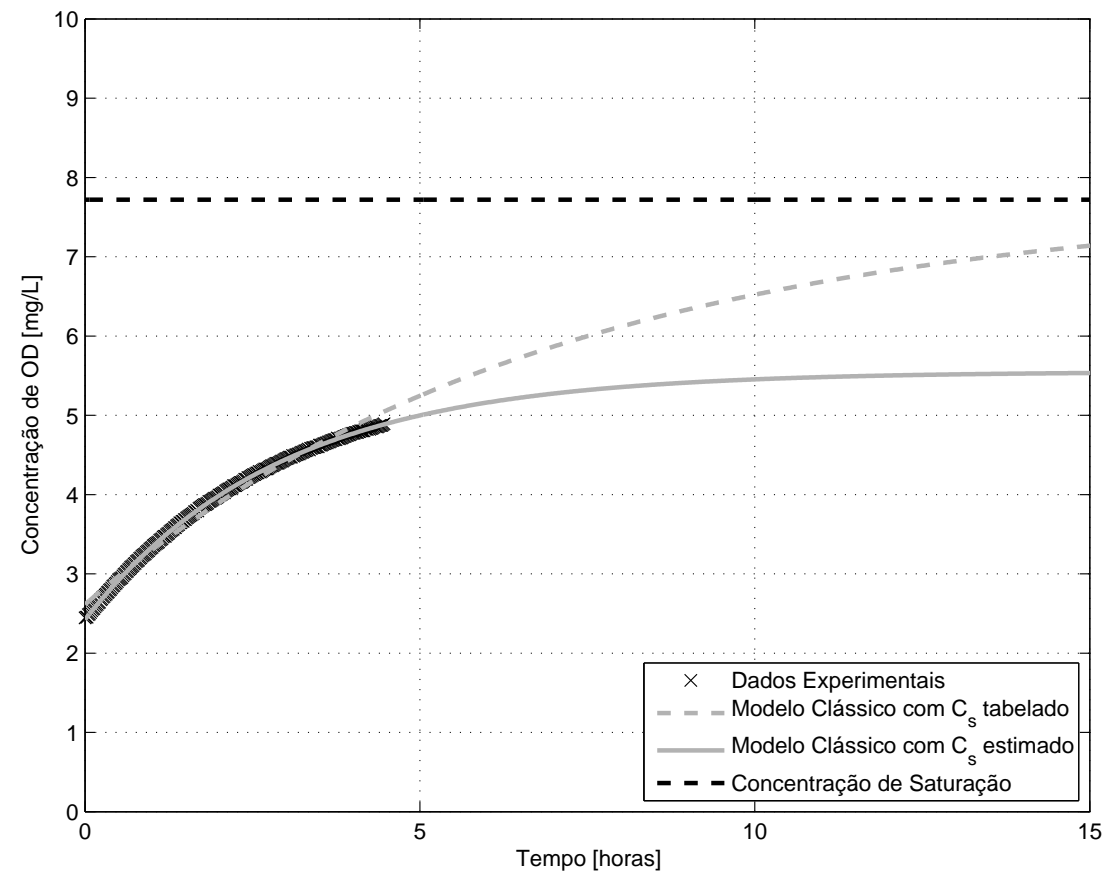

(a) Ajuste com o Modelo Clássico

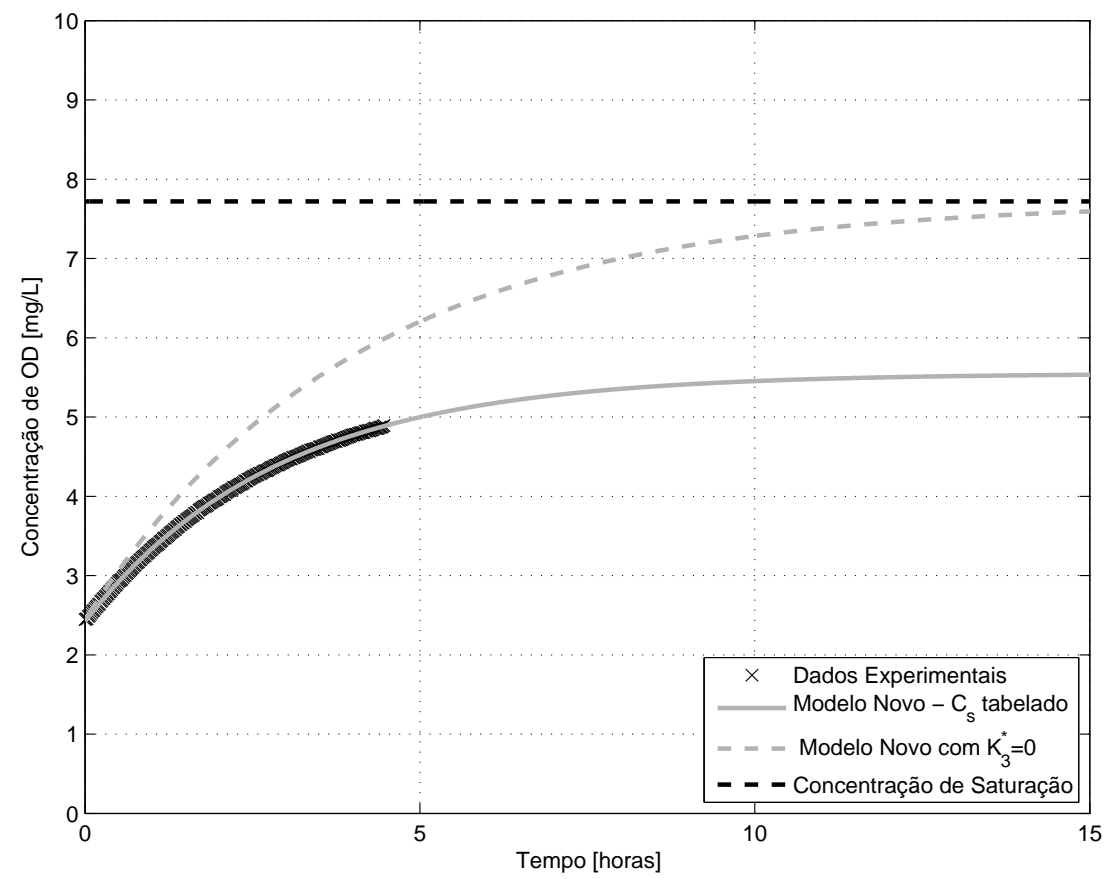

(b) Ajuste com o Modelo Novo

Figura B.54: Curva de reoxigenação para o ensaio 54 


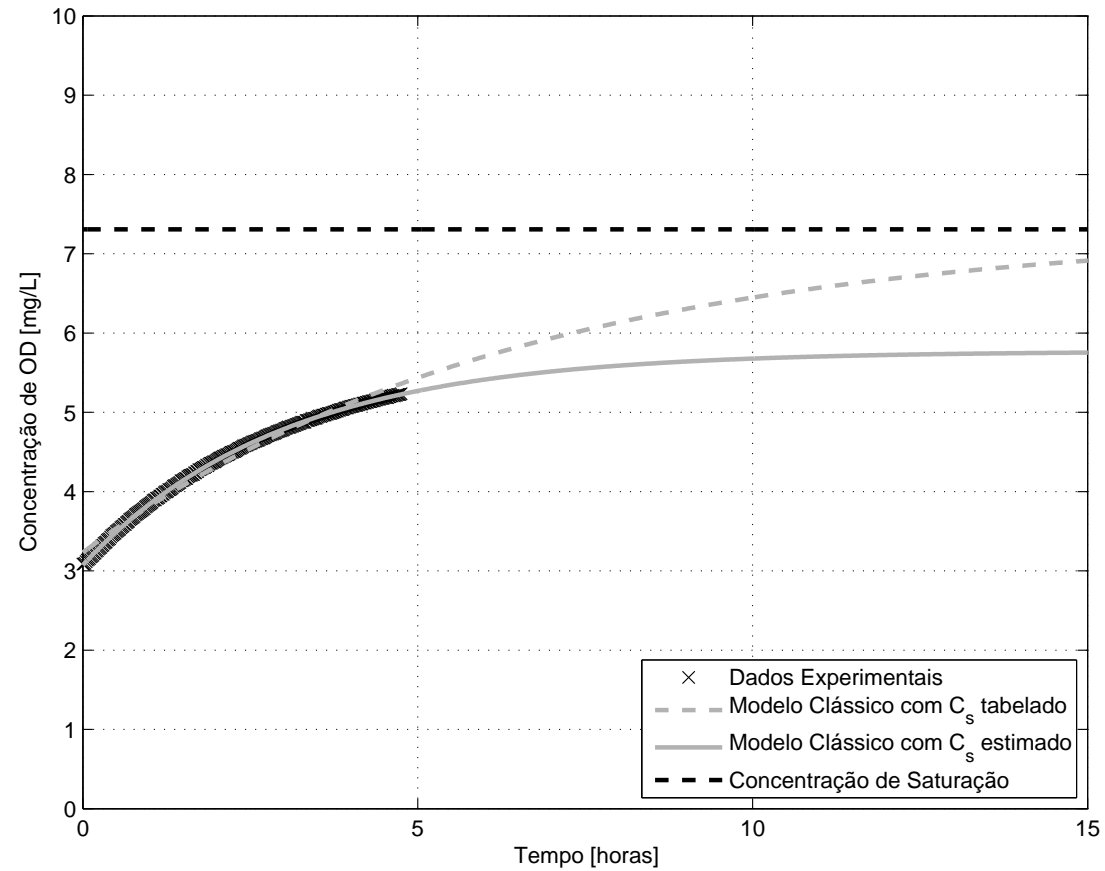

(a) Ajuste com o Modelo Clássico

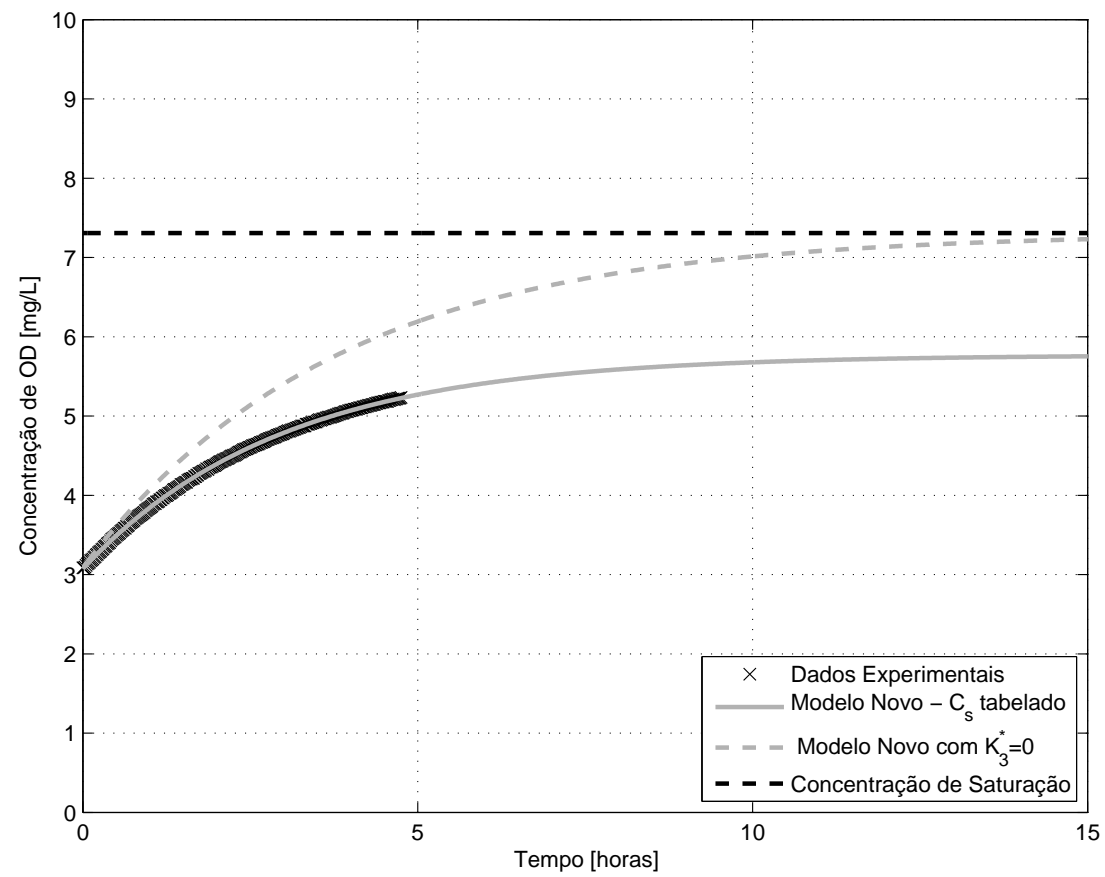

(b) Ajuste com o Modelo Novo

Figura B.55: Curva de reoxigenação para o ensaio 55 


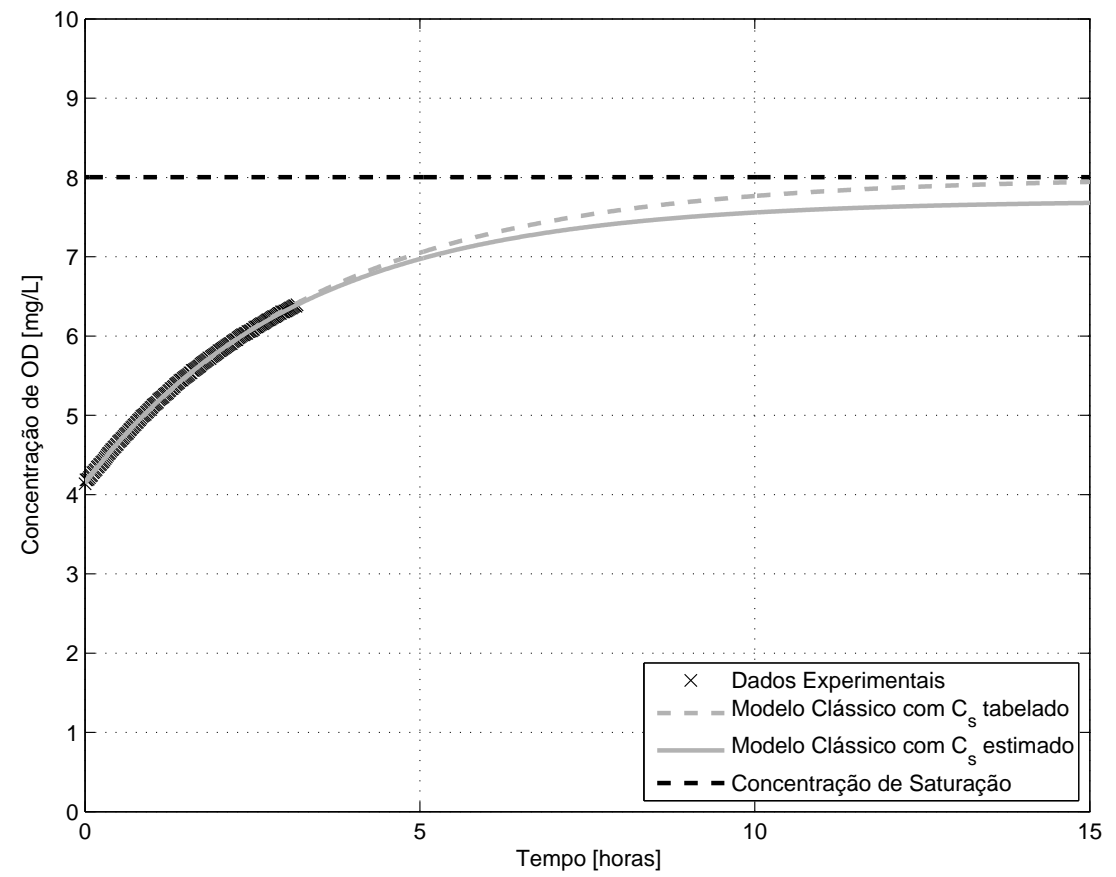

(a) Ajuste com o Modelo Clássico

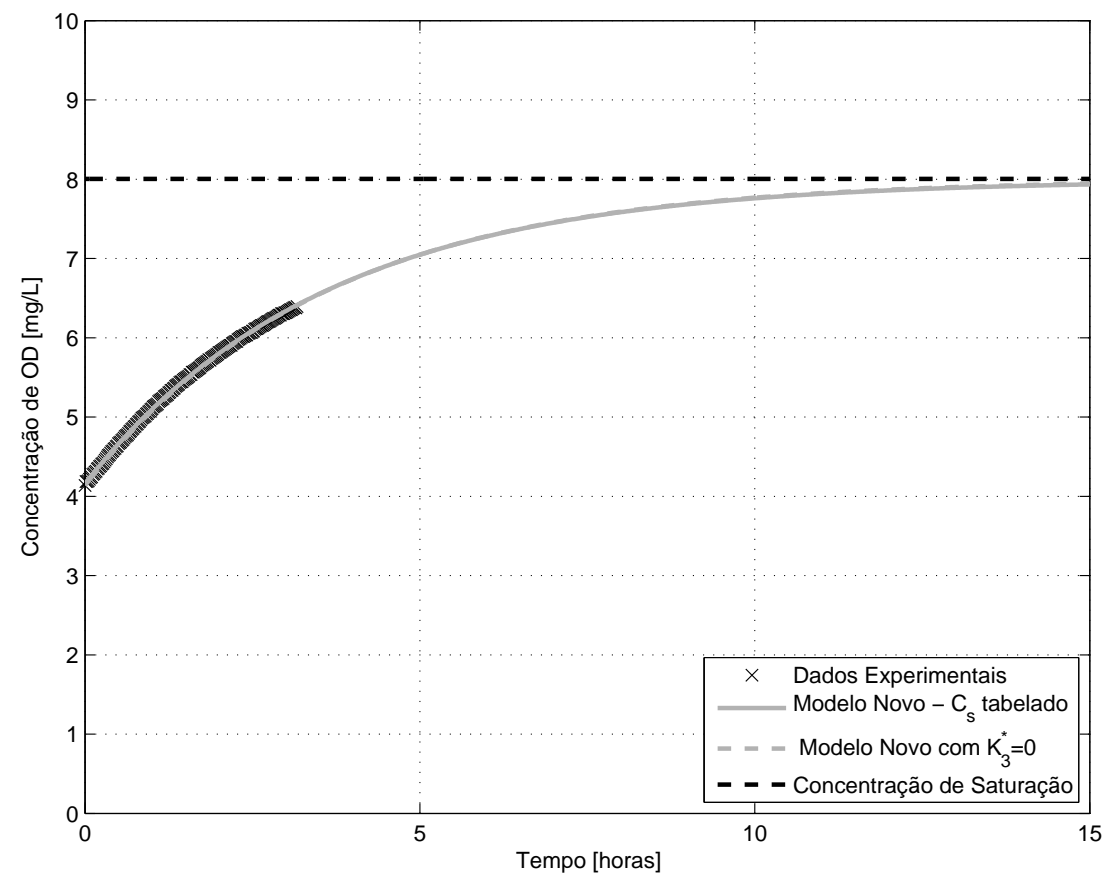

(b) Ajuste com o Modelo Novo

Figura B.56: Curva de reoxigenação para o ensaio 56 


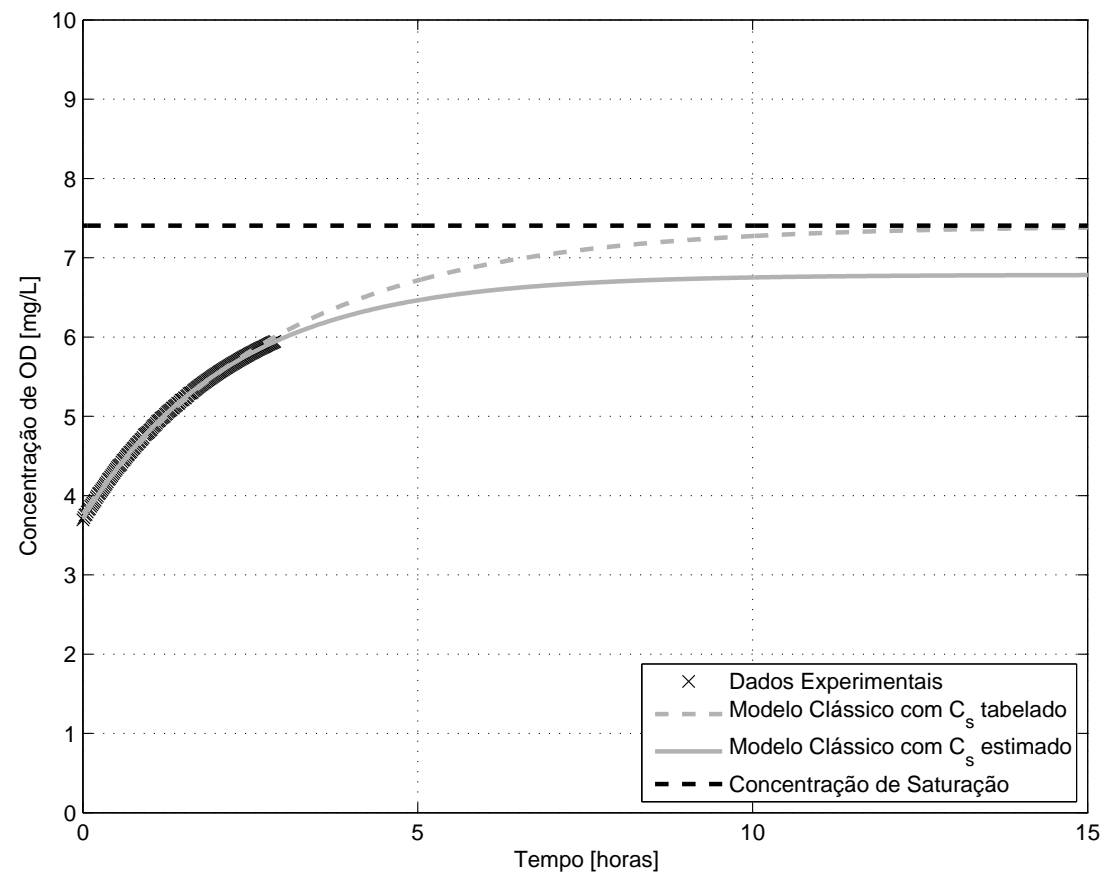

(a) Ajuste com o Modelo Clássico

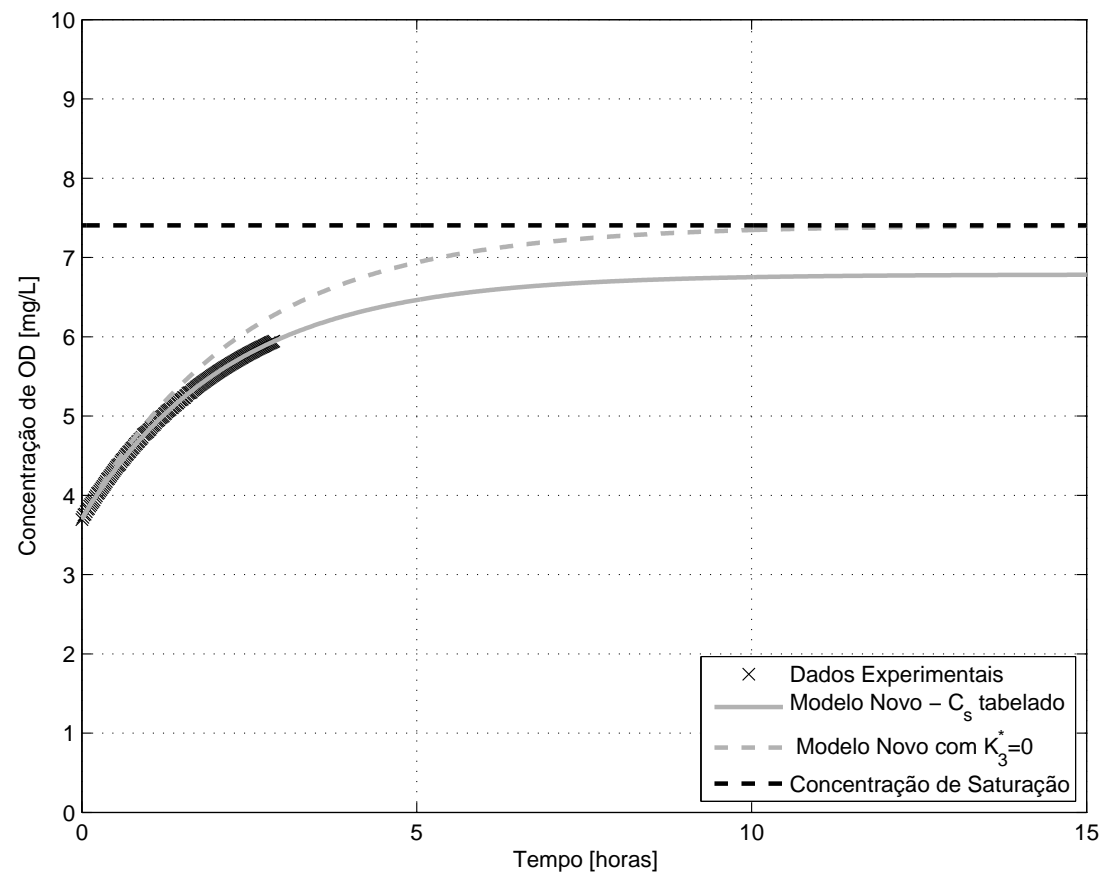

(b) Ajuste com o Modelo Novo

Figura B.57: Curva de reoxigenação para o ensaio 57 


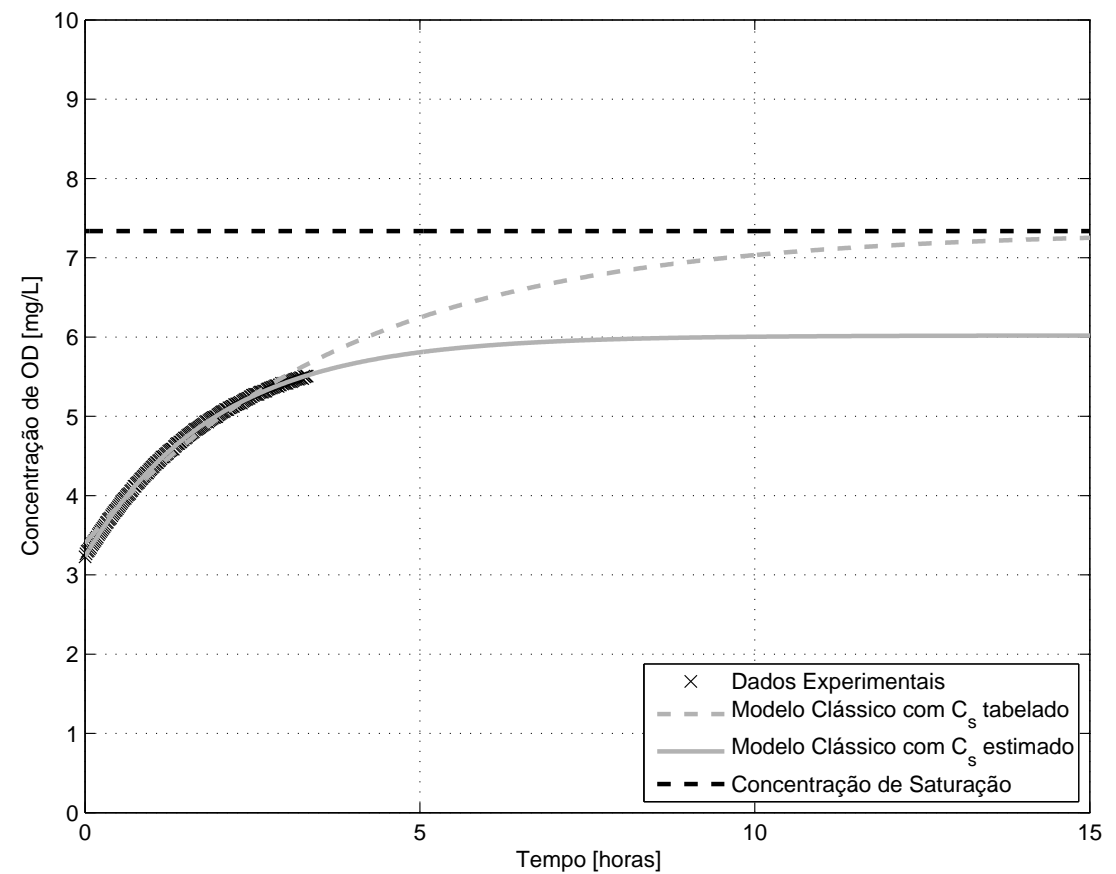

(a) Ajuste com o Modelo Clássico

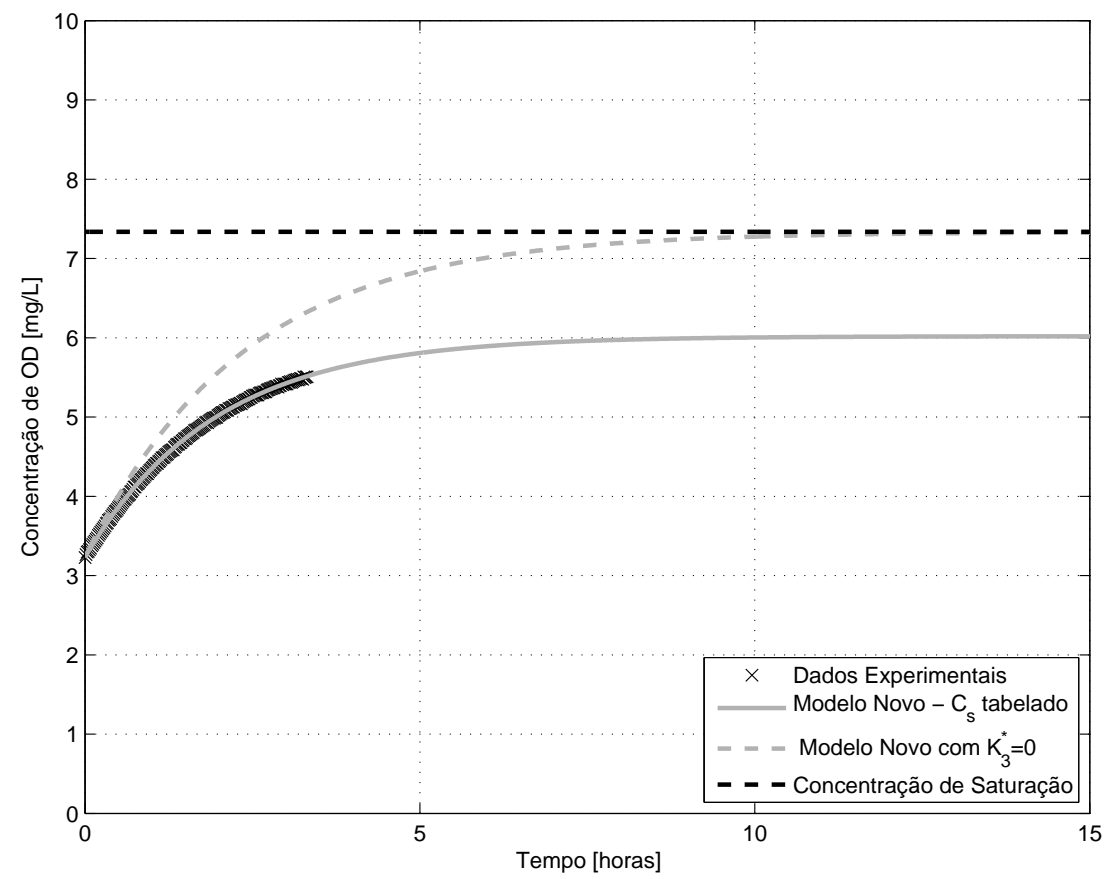

(b) Ajuste com o Modelo Novo

Figura B.58: Curva de reoxigenação para o ensaio 58 


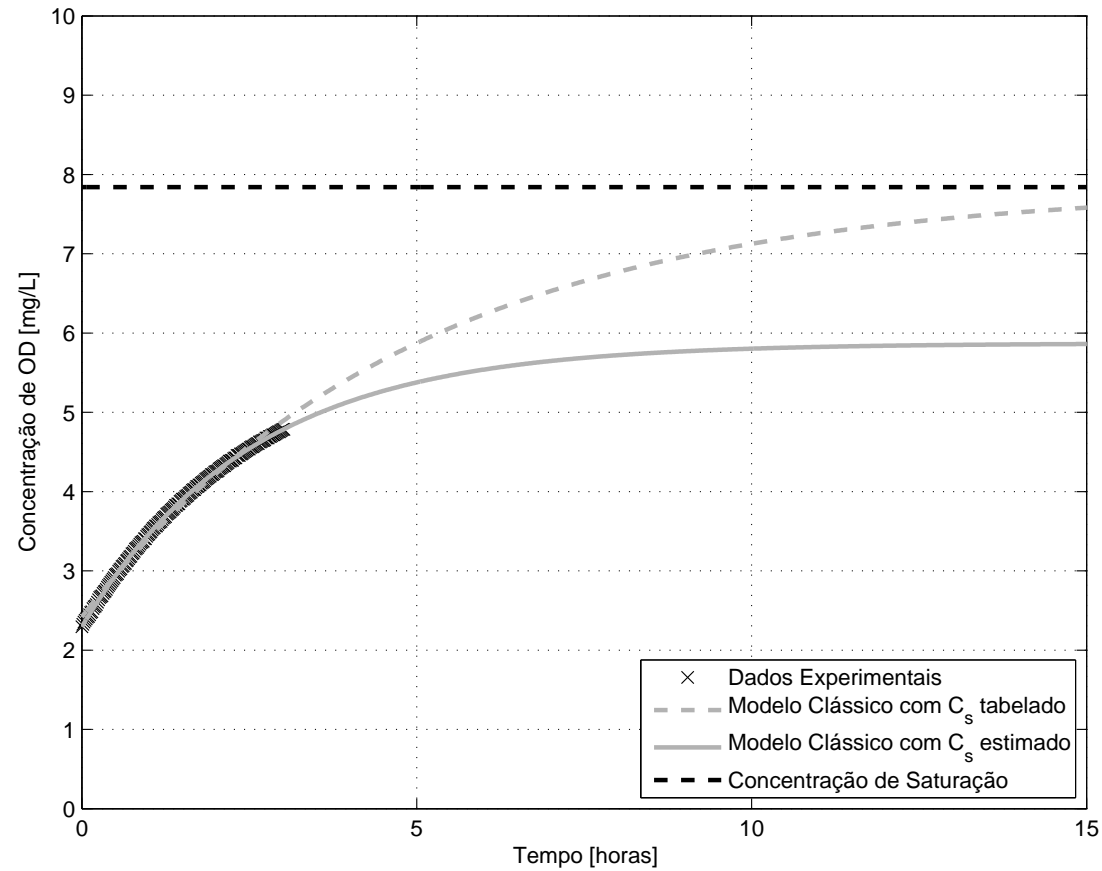

(a) Ajuste com o Modelo Clássico

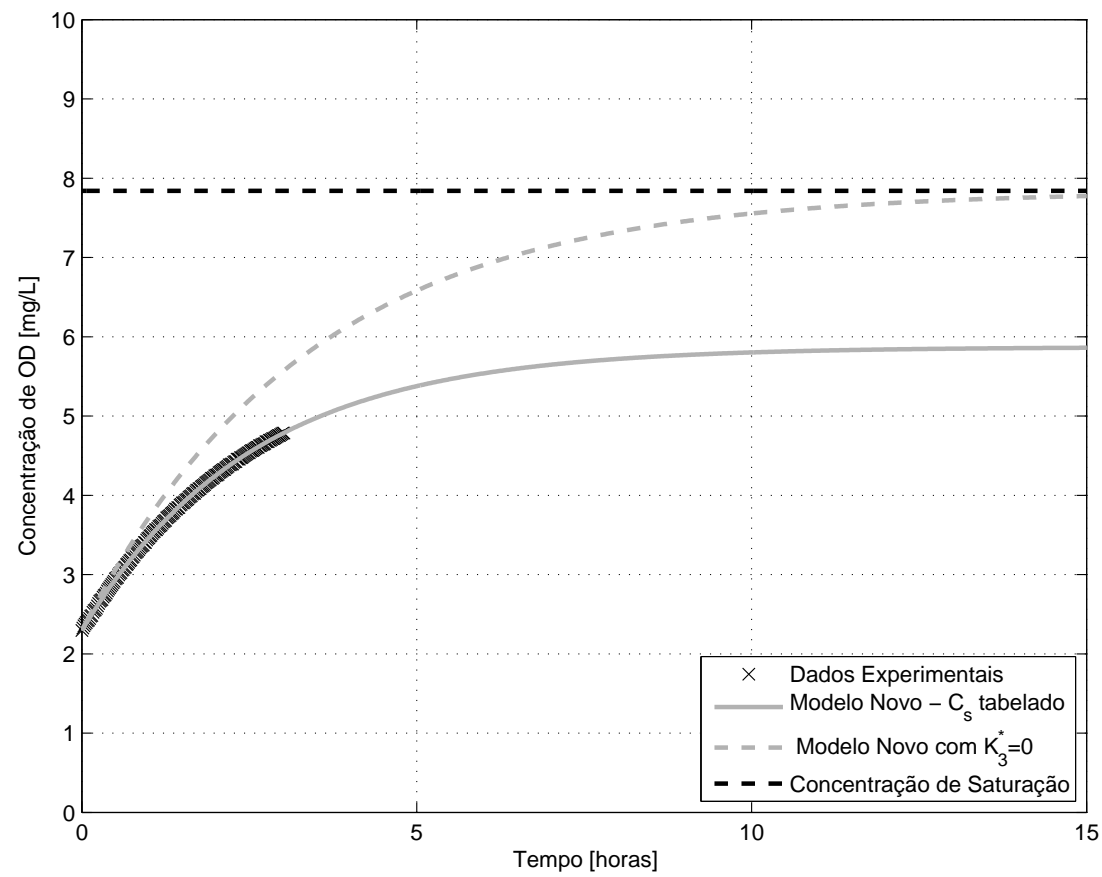

(b) Ajuste com o Modelo Novo

Figura B.59: Curva de reoxigenação para o ensaio 59 


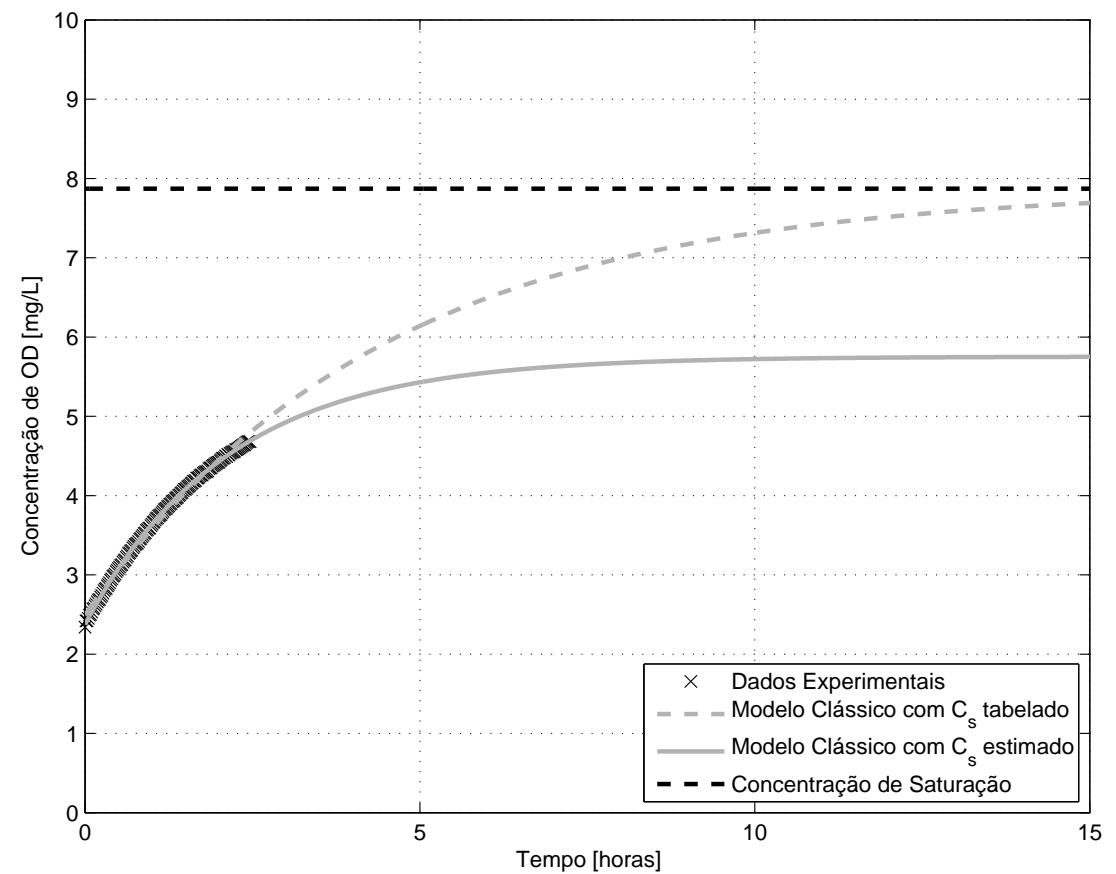

(a) Ajuste com o Modelo Clássico

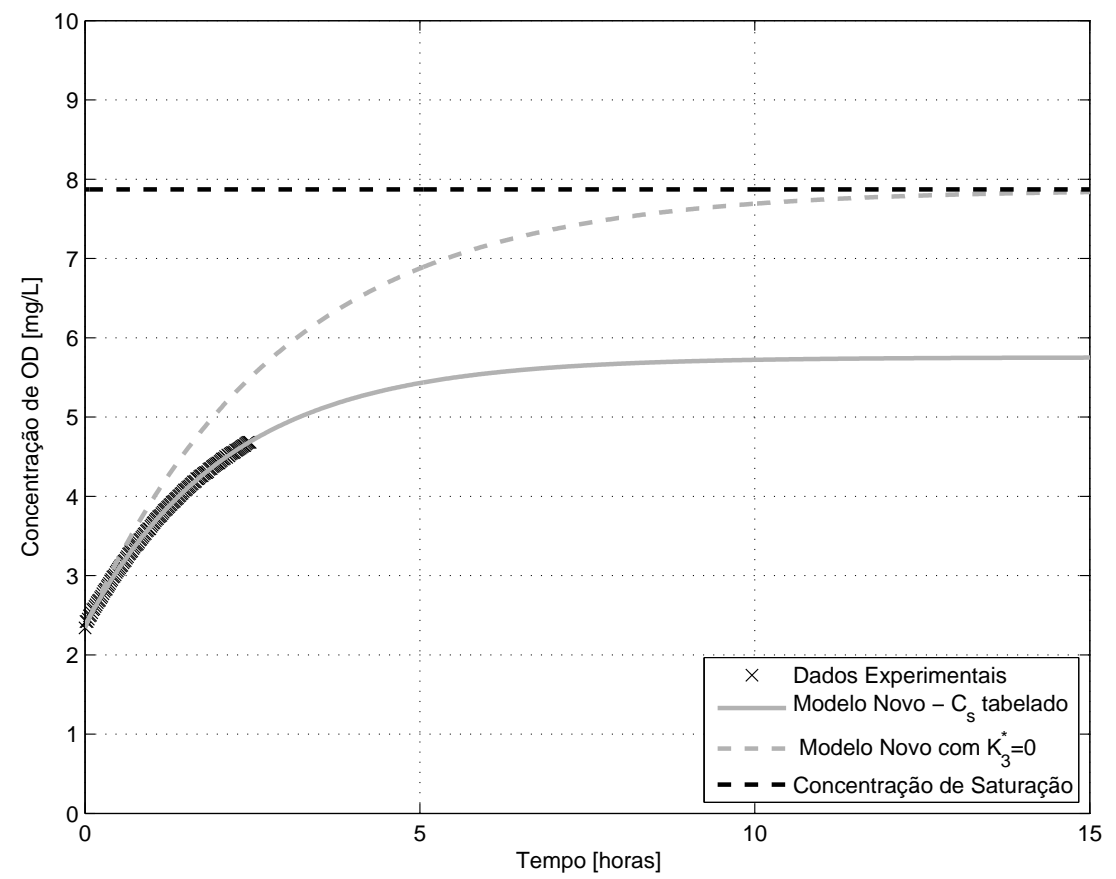

(b) Ajuste com o Modelo Novo

Figura B.60: Curva de reoxigenação para o ensaio 60 


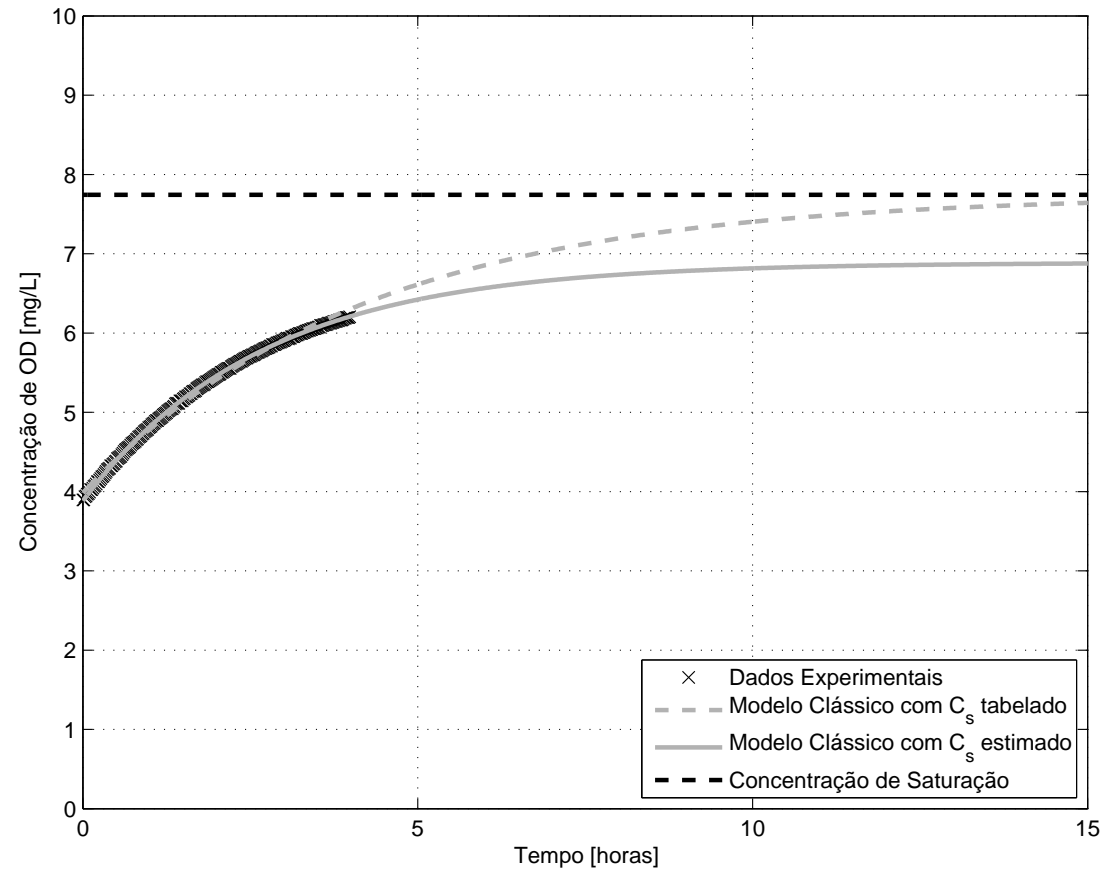

(a) Ajuste com o Modelo Clássico

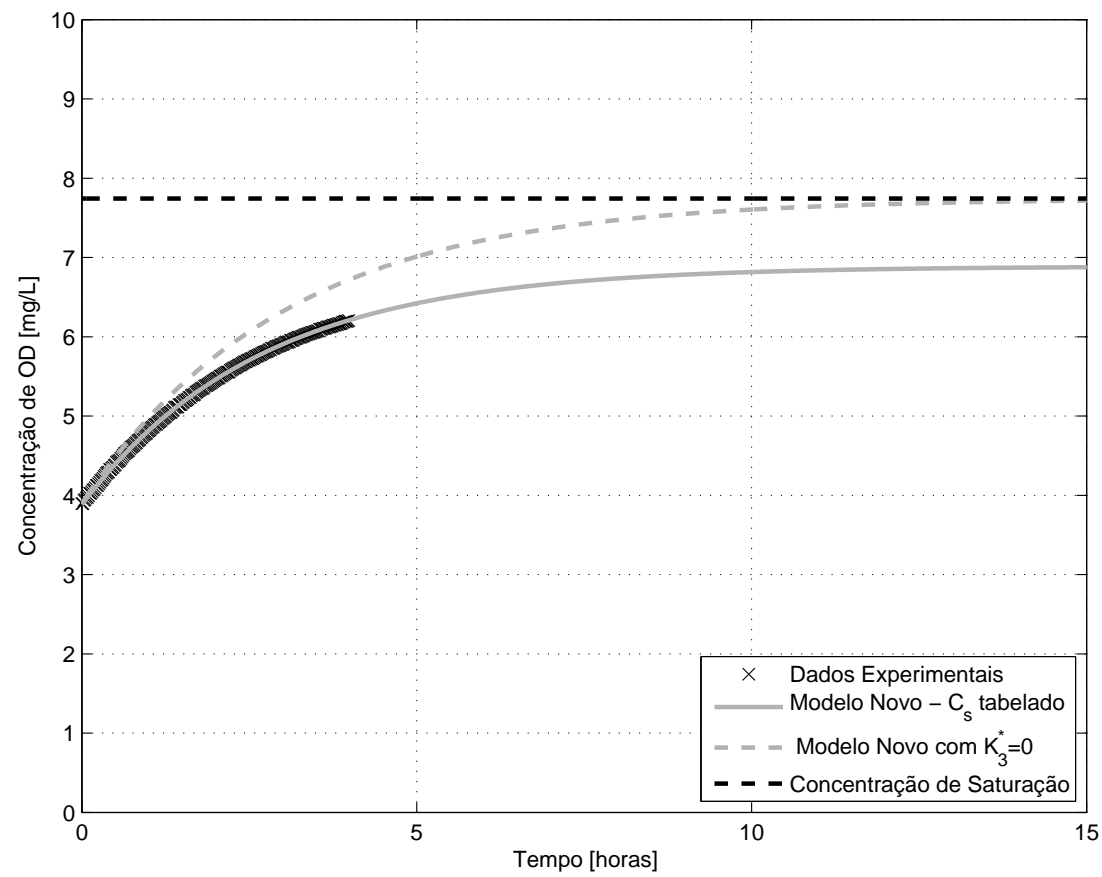

(b) Ajuste com o Modelo Novo

Figura B.61: Curva de reoxigenação para o ensaio 61 


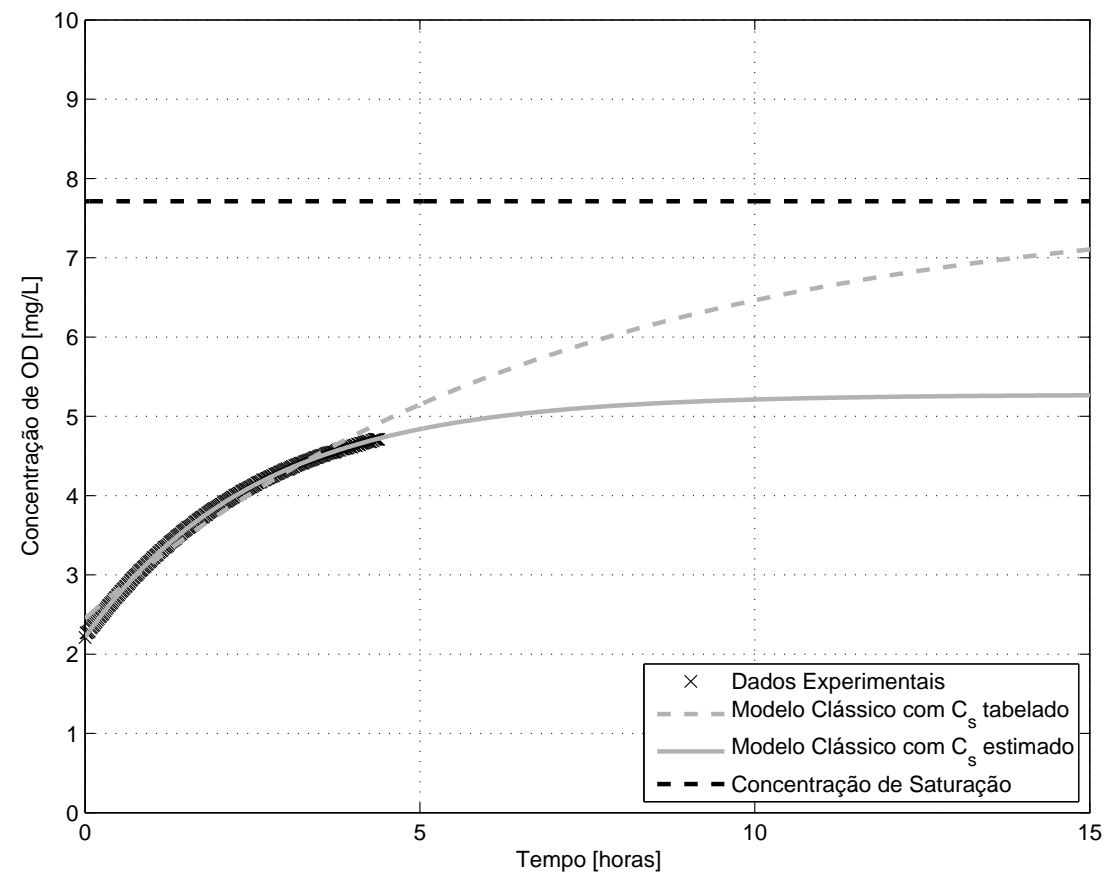

(a) Ajuste com o Modelo Clássico

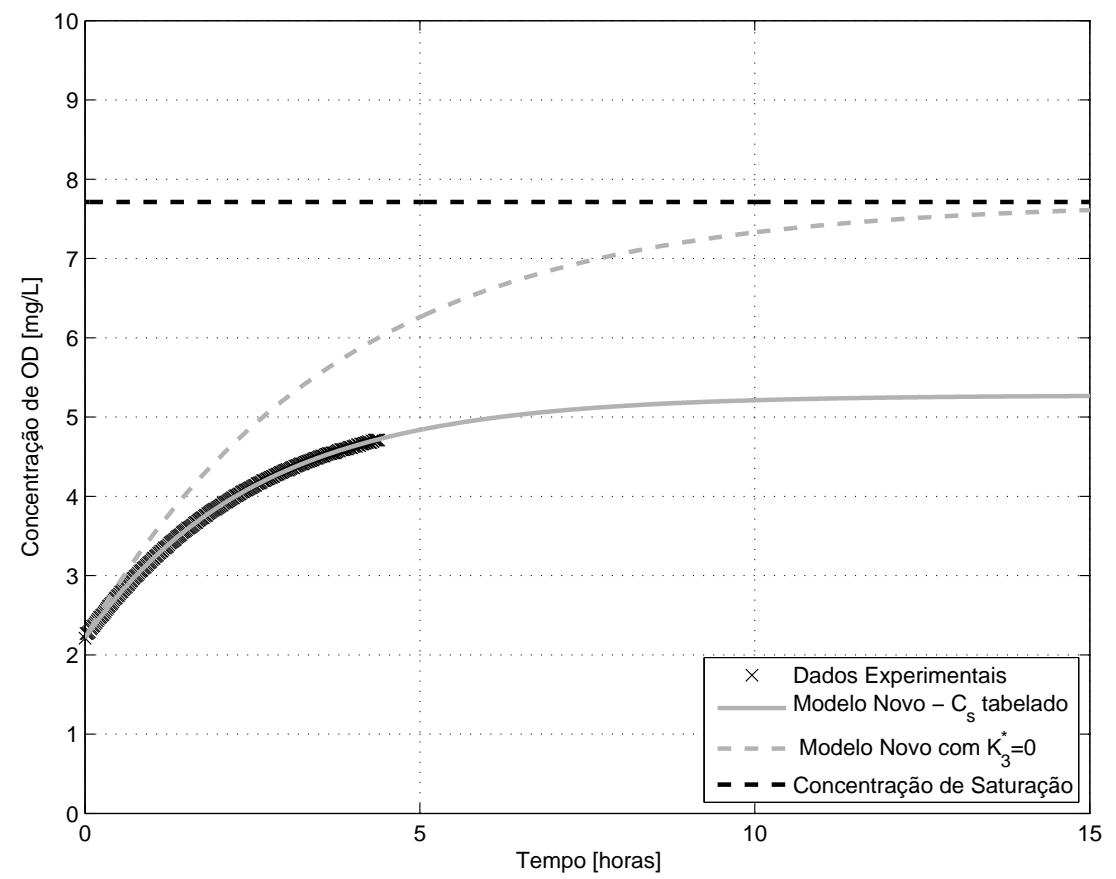

(b) Ajuste com o Modelo Novo

Figura B.62: Curva de reoxigenação para o ensaio 62 


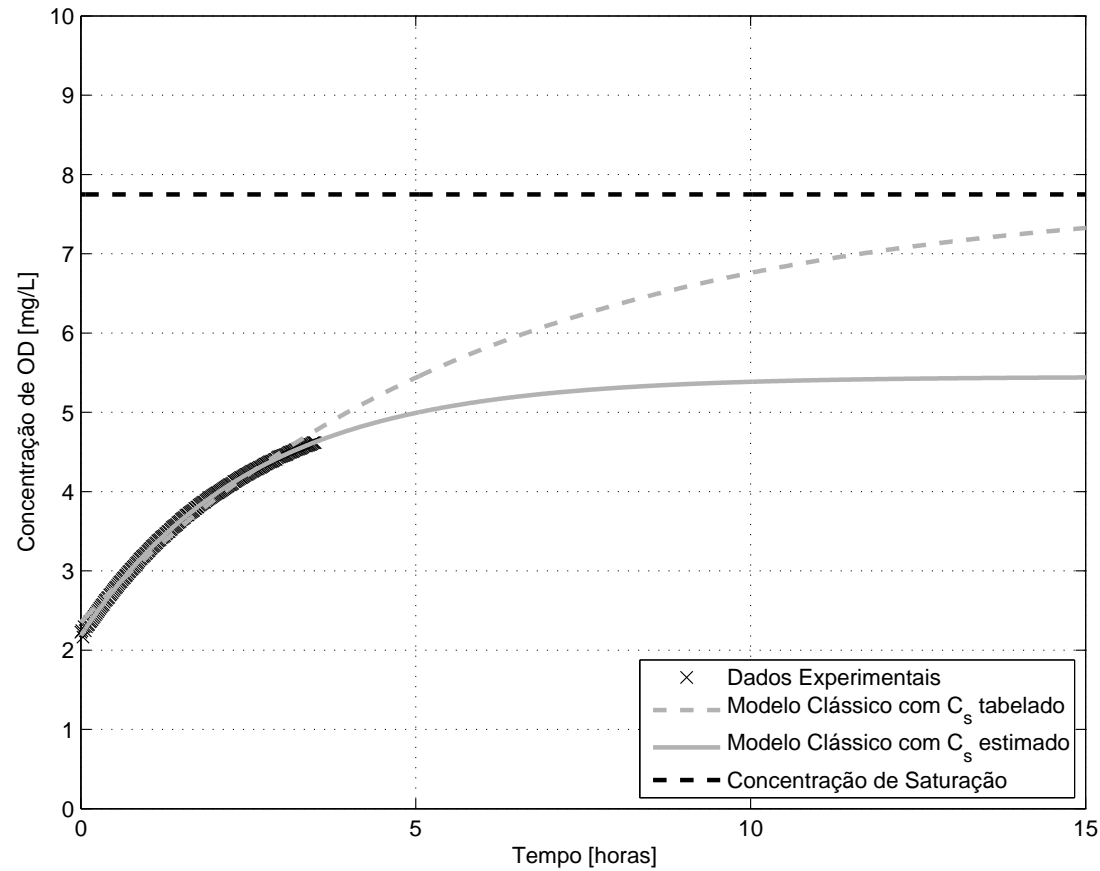

(a) Ajuste com o Modelo Clássico

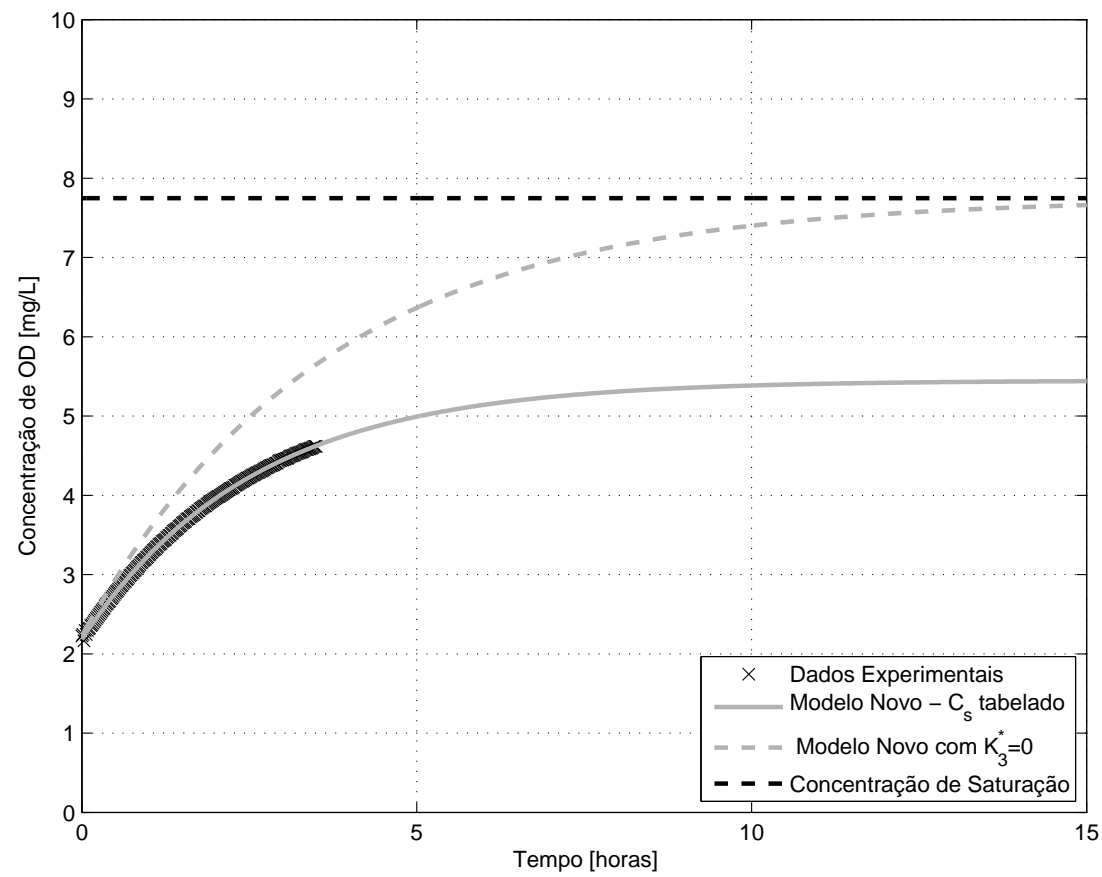

(b) Ajuste com o Modelo Novo

Figura B.63: Curva de reoxigenação para o ensaio 63 


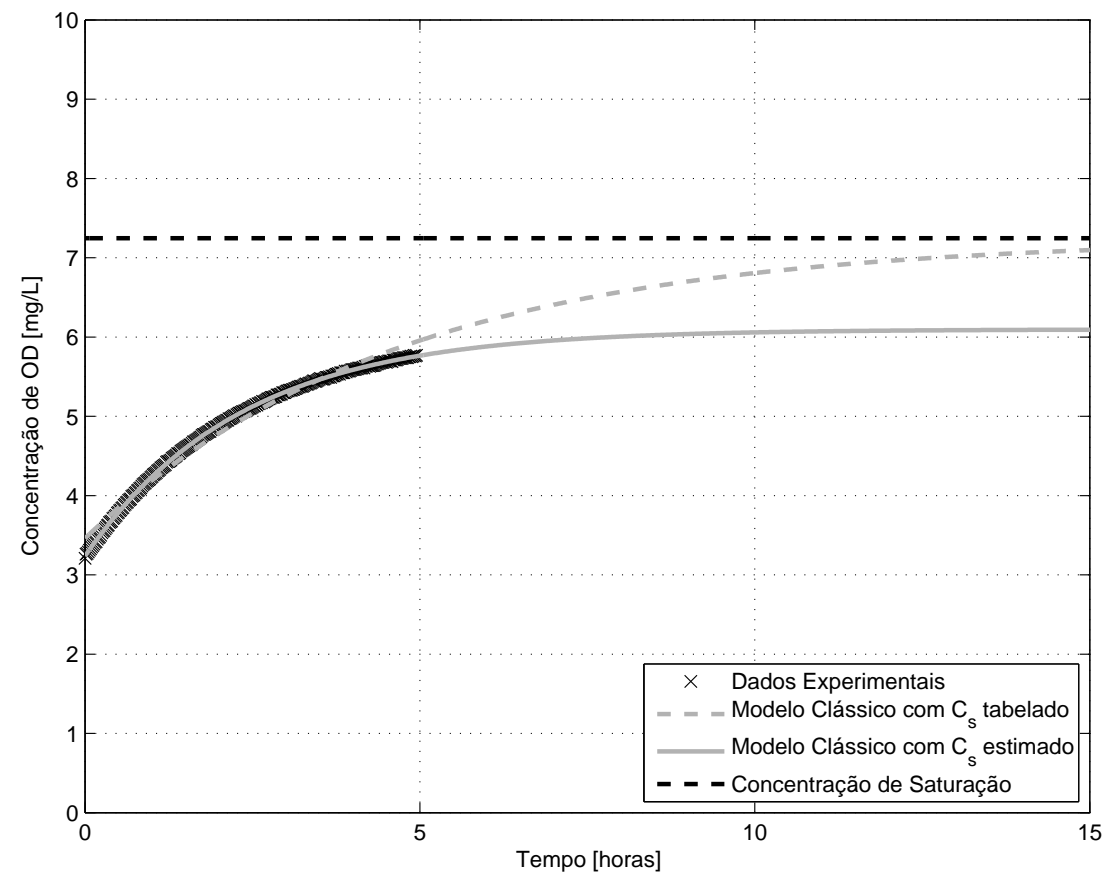

(a) Ajuste com o Modelo Clássico

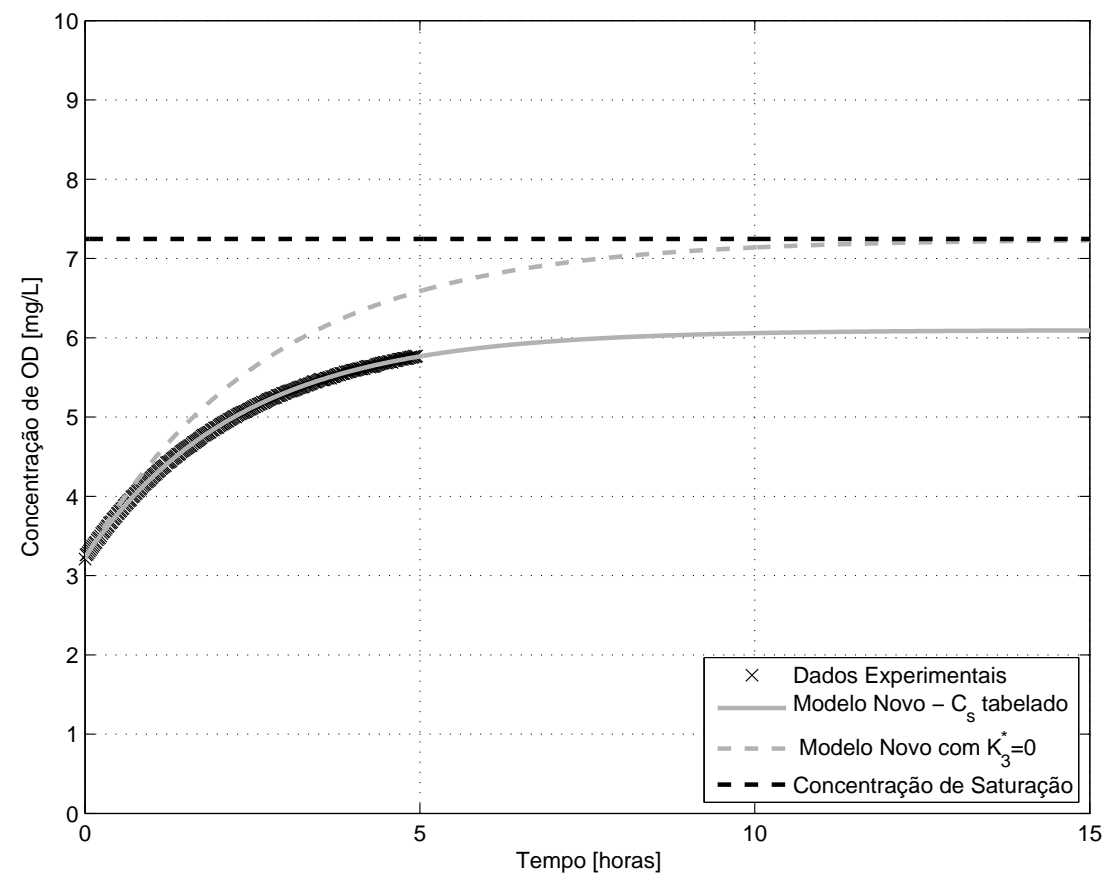

(b) Ajuste com o Modelo Novo

Figura B.64: Curva de reoxigenação para o ensaio 64 


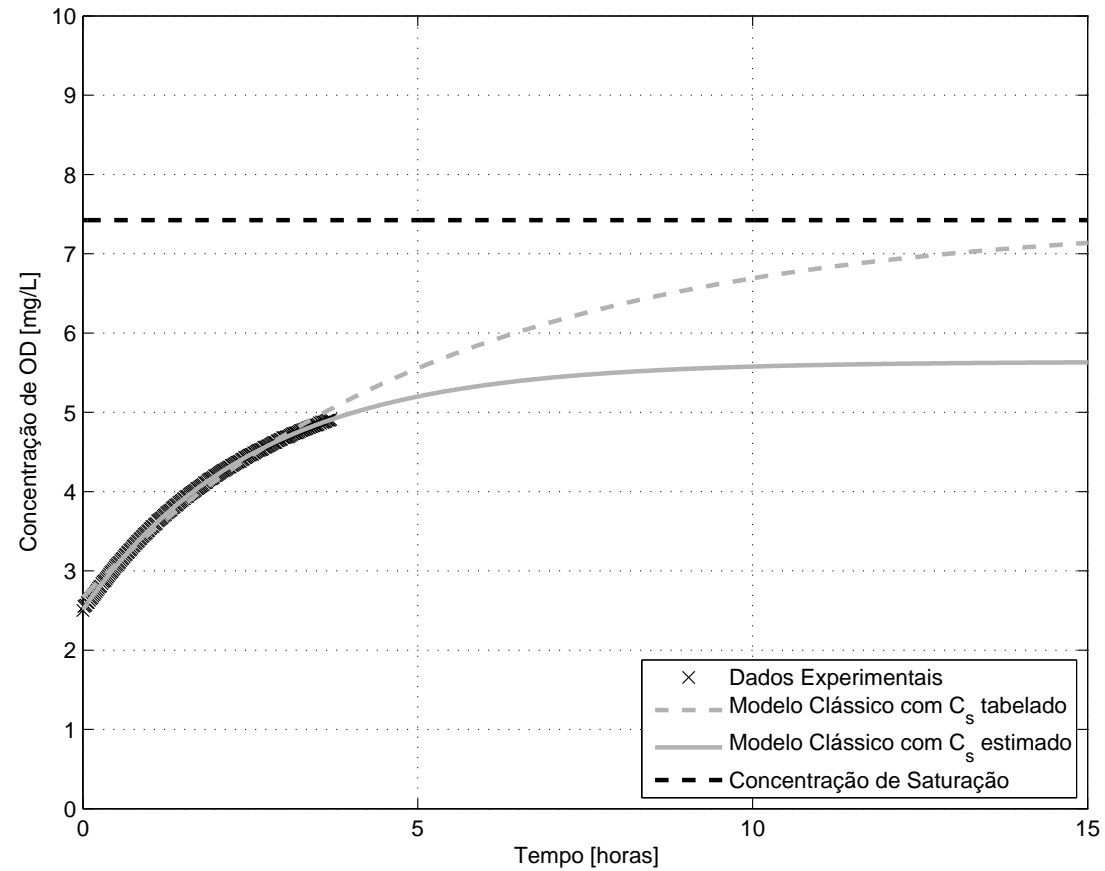

(a) Ajuste com o Modelo Clássico

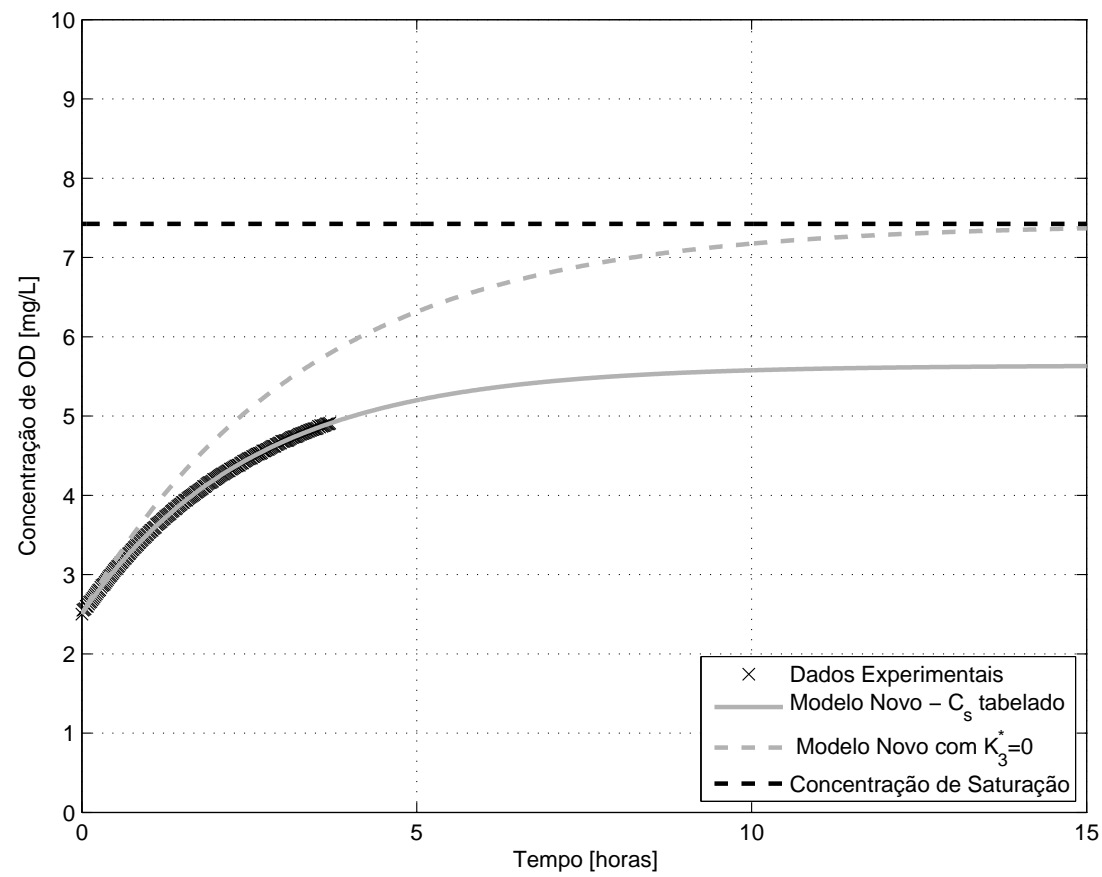

(b) Ajuste com o Modelo Novo

Figura B.65: Curva de reoxigenação para o ensaio 65 


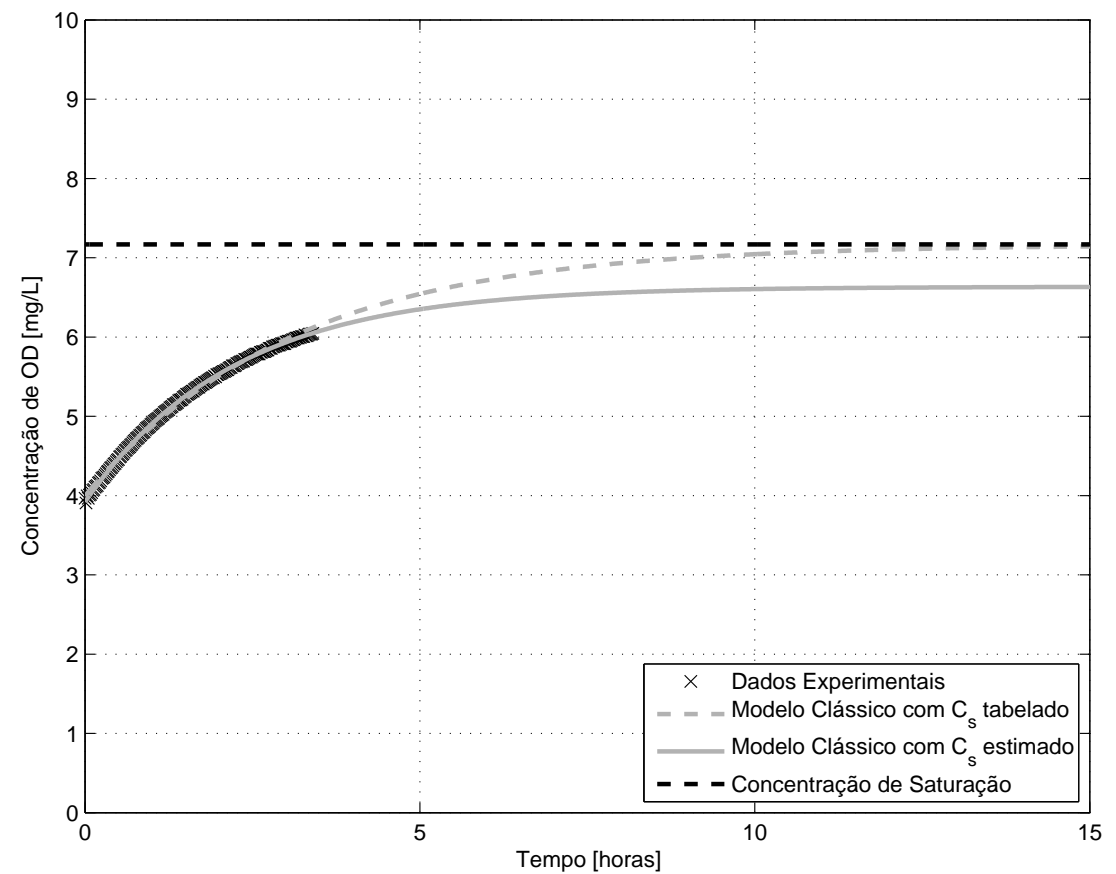

(a) Ajuste com o Modelo Clássico

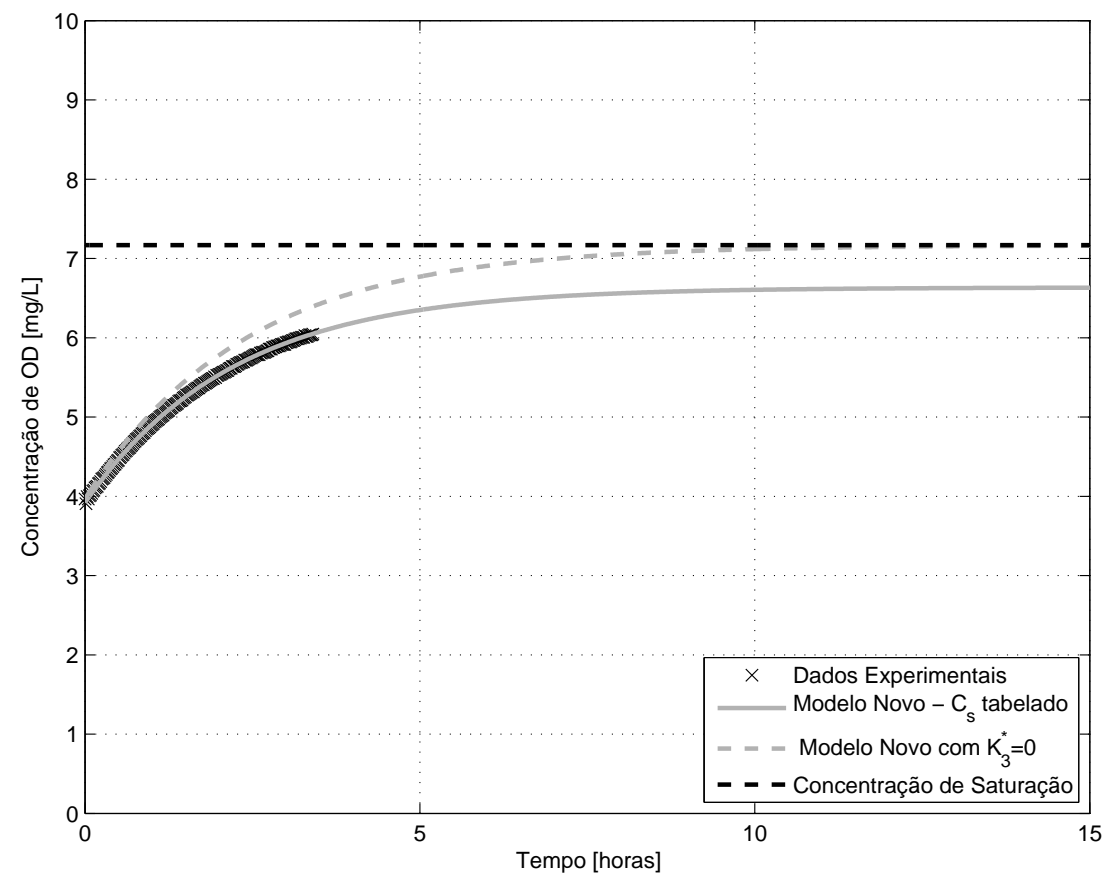

(b) Ajuste com o Modelo Novo

Figura B.66: Curva de reoxigenação para o ensaio 66 


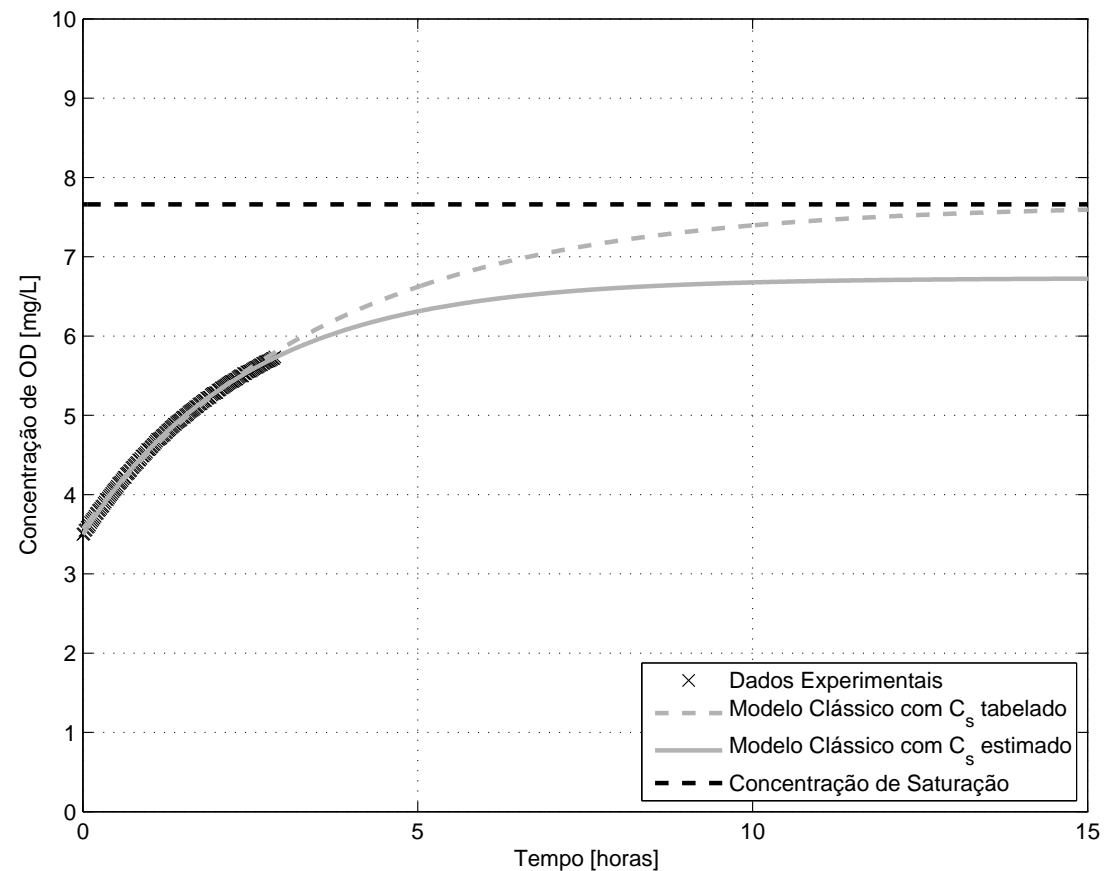

(a) Ajuste com o Modelo Clássico

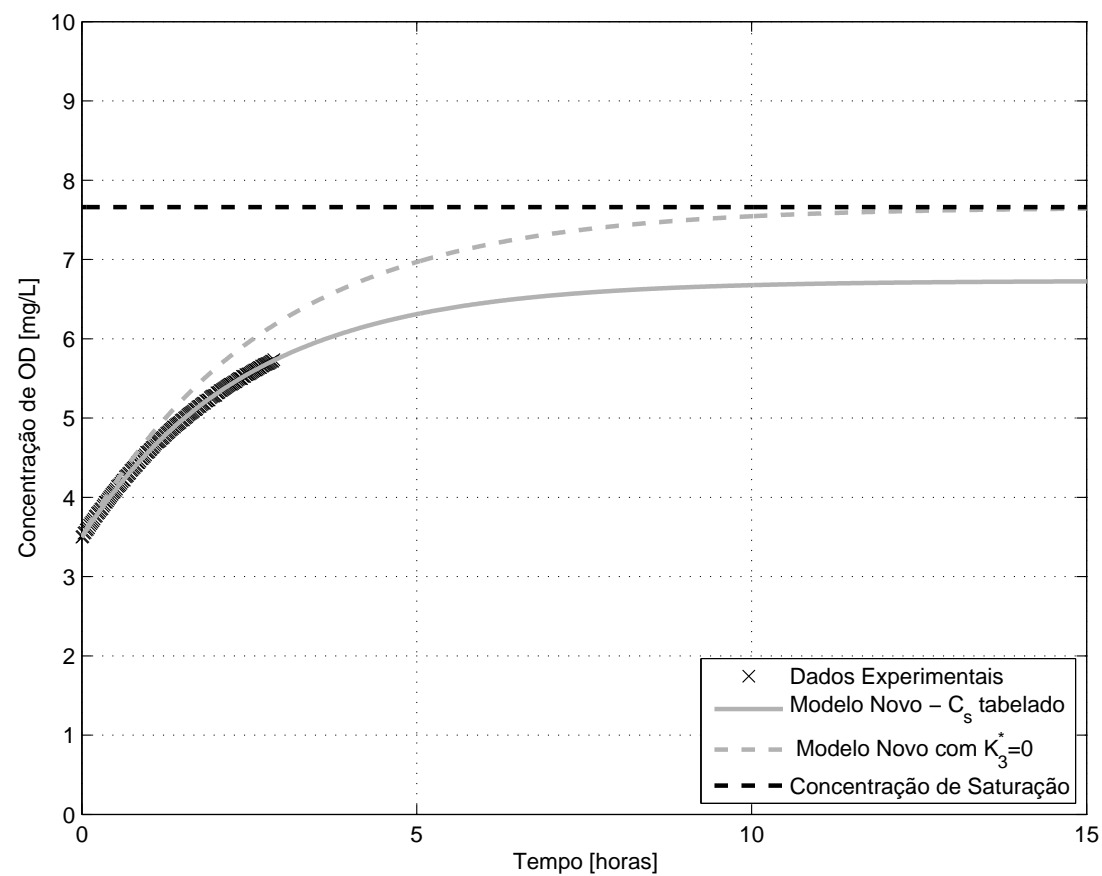

(b) Ajuste com o Modelo Novo

Figura B.67: Curva de reoxigenação para o ensaio 67 


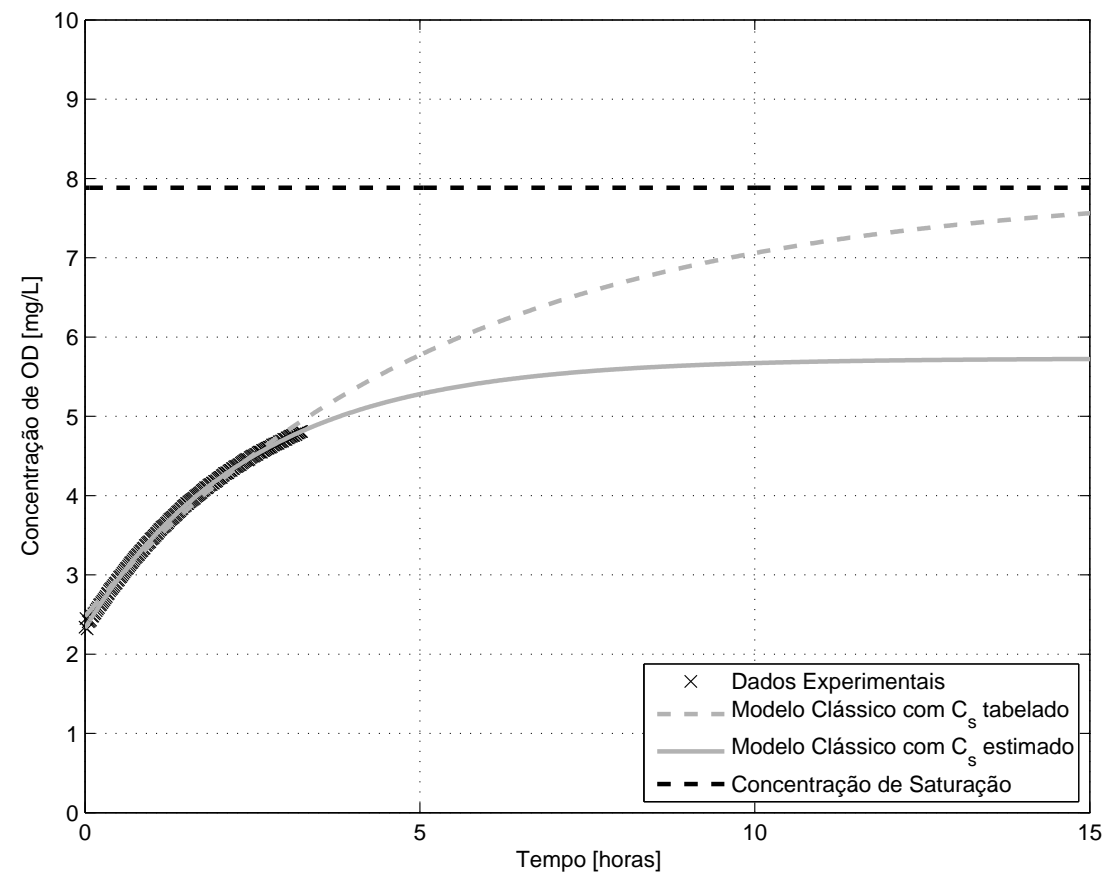

(a) Ajuste com o Modelo Clássico

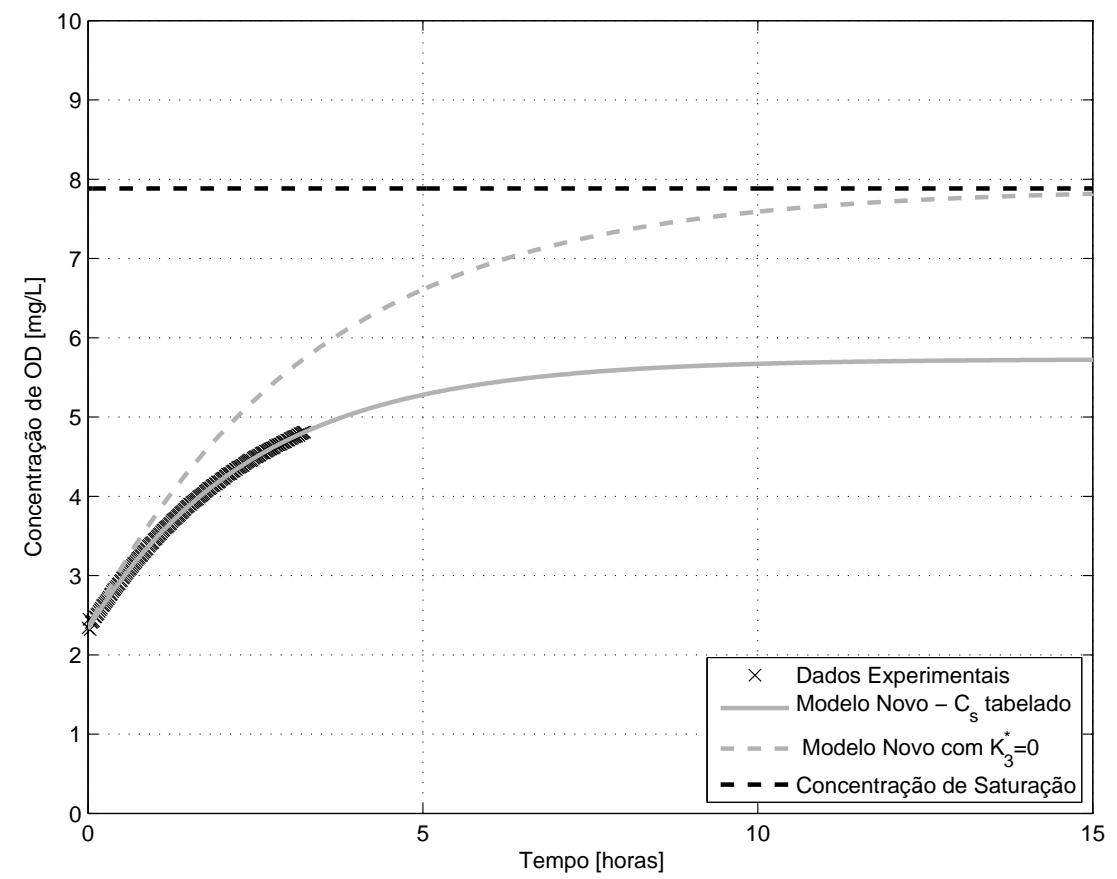

(b) Ajuste com o Modelo Novo

Figura B.68: Curva de reoxigenação para o ensaio 68 


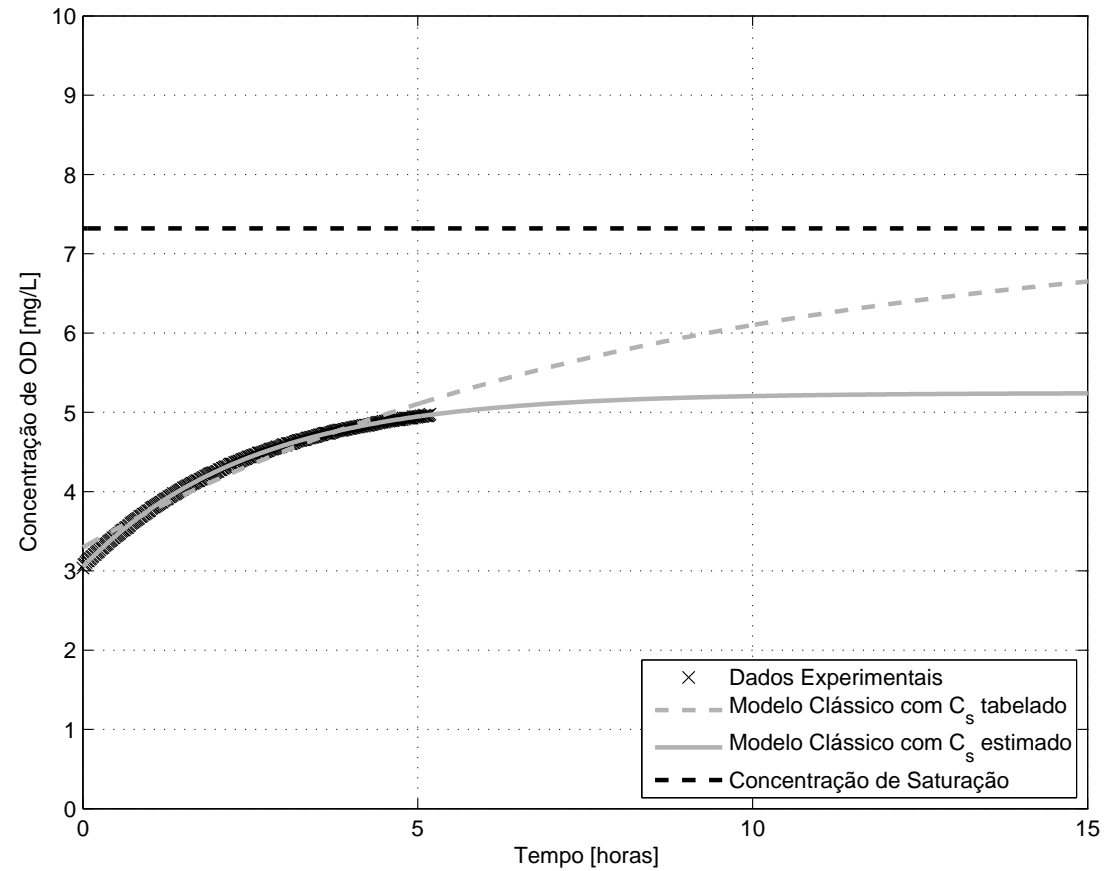

(a) Ajuste com o Modelo Clássico

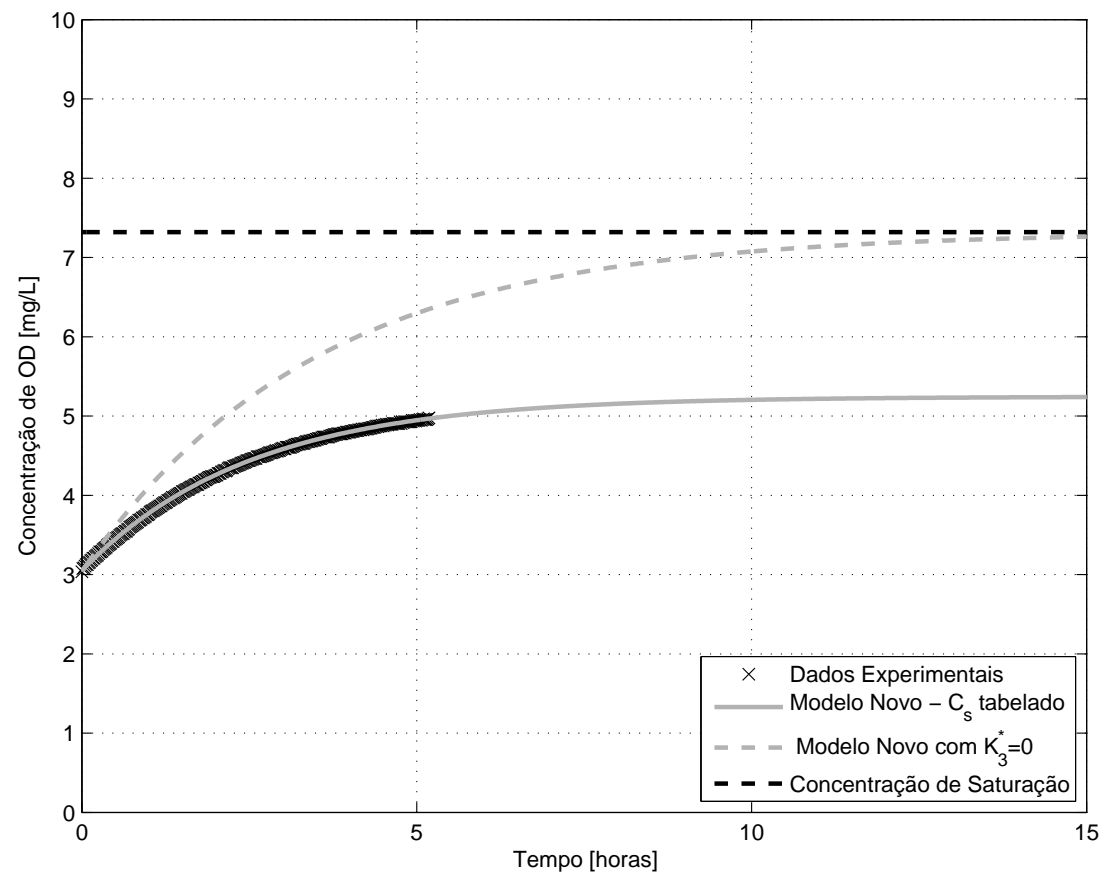

(b) Ajuste com o Modelo Novo

Figura B.69: Curva de reoxigenação para o ensaio 69 


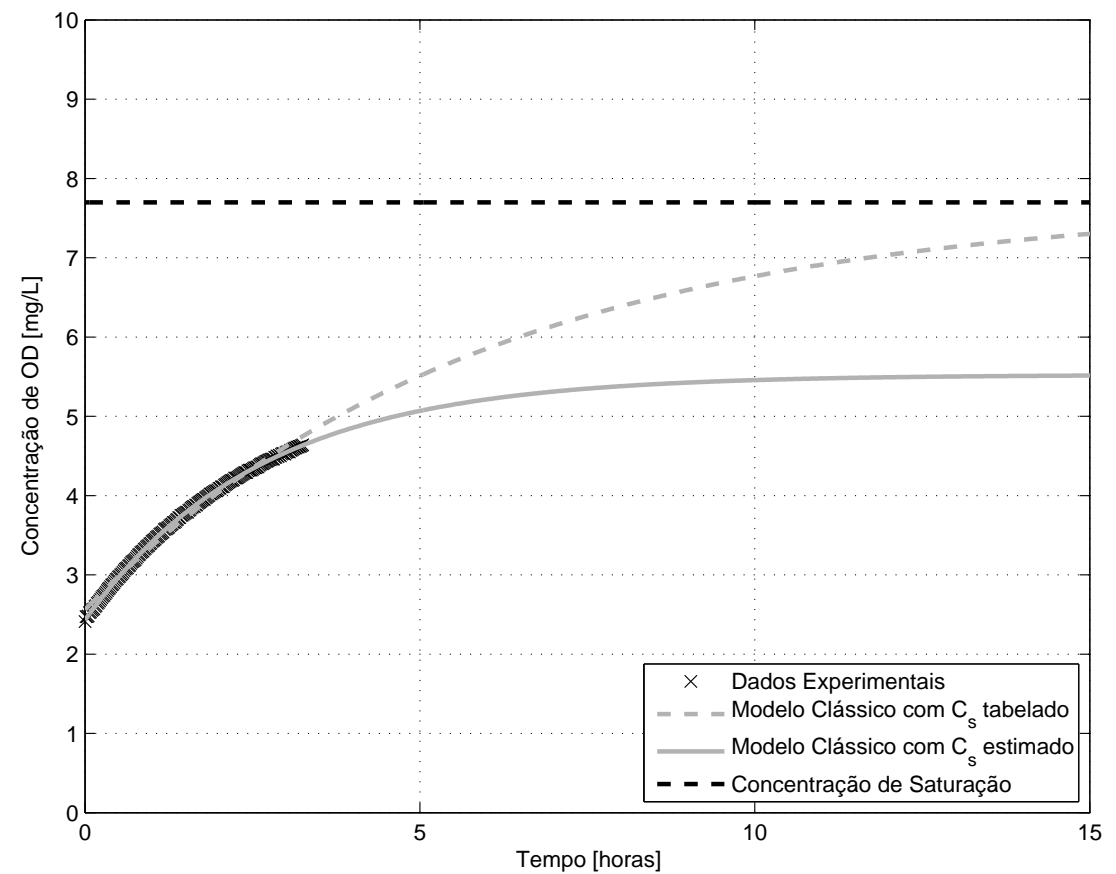

(a) Ajuste com o Modelo Clássico

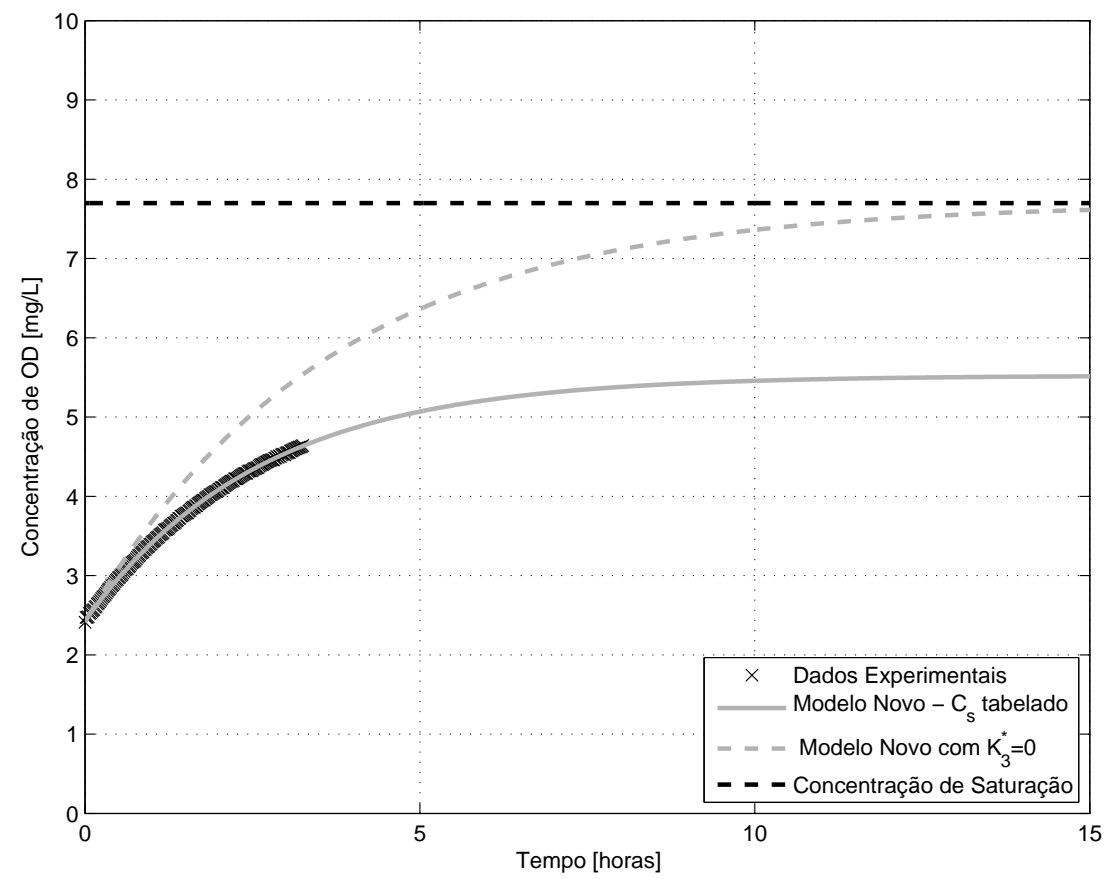

(b) Ajuste com o Modelo Novo

Figura B.70: Curva de reoxigenação para o ensaio 70 


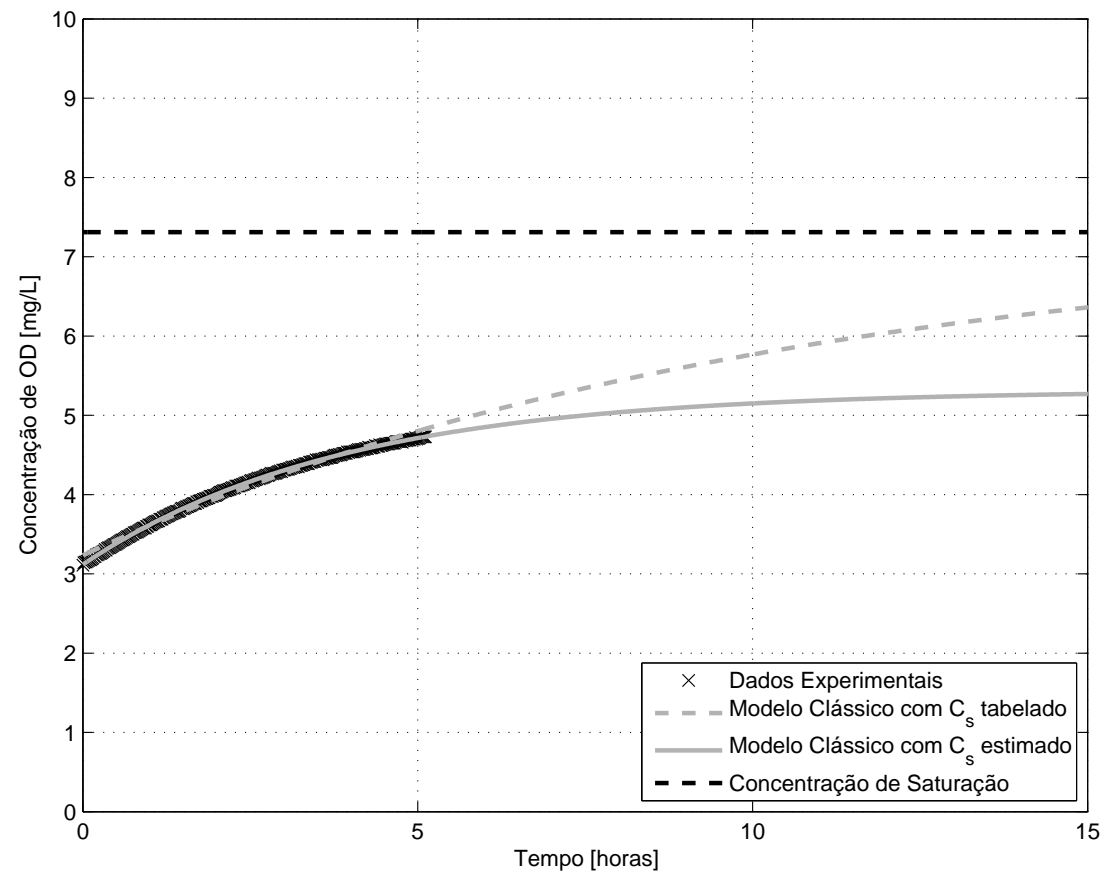

(a) Ajuste com o Modelo Clássico

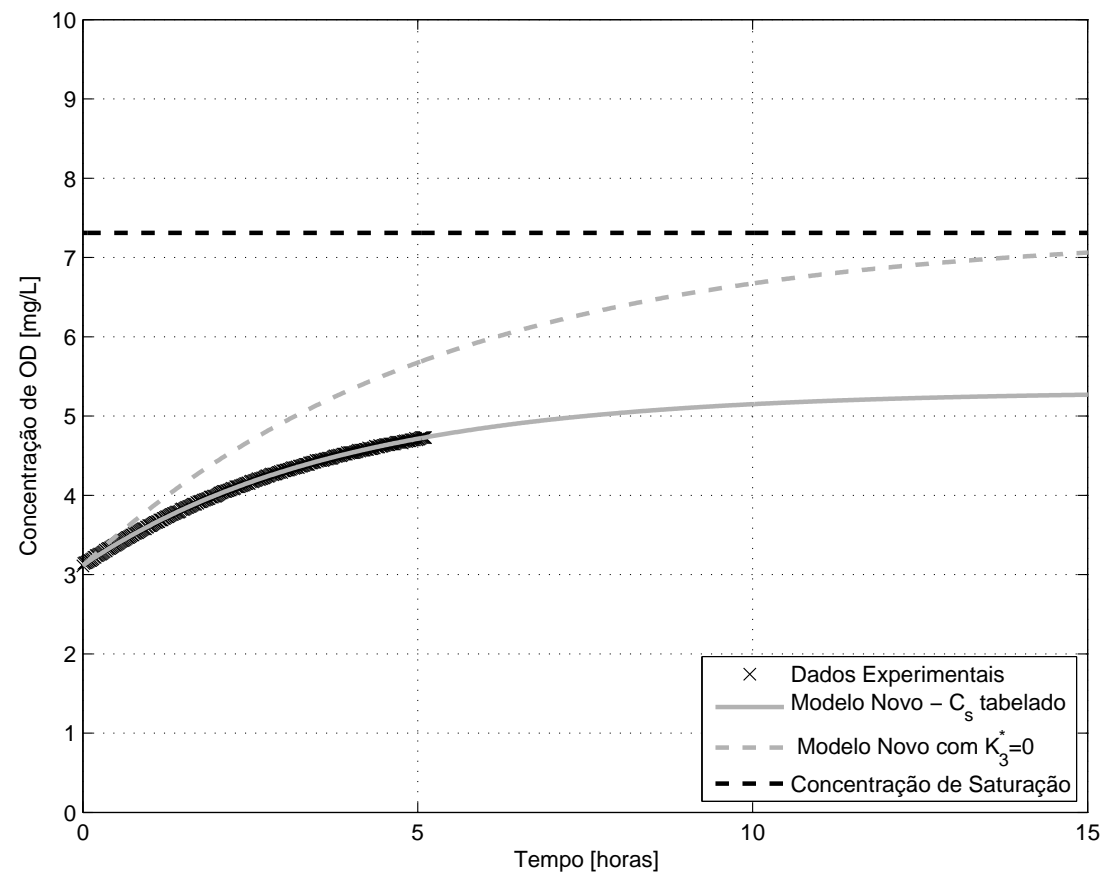

(b) Ajuste com o Modelo Novo

Figura B.71: Curva de reoxigenação para o ensaio 71 


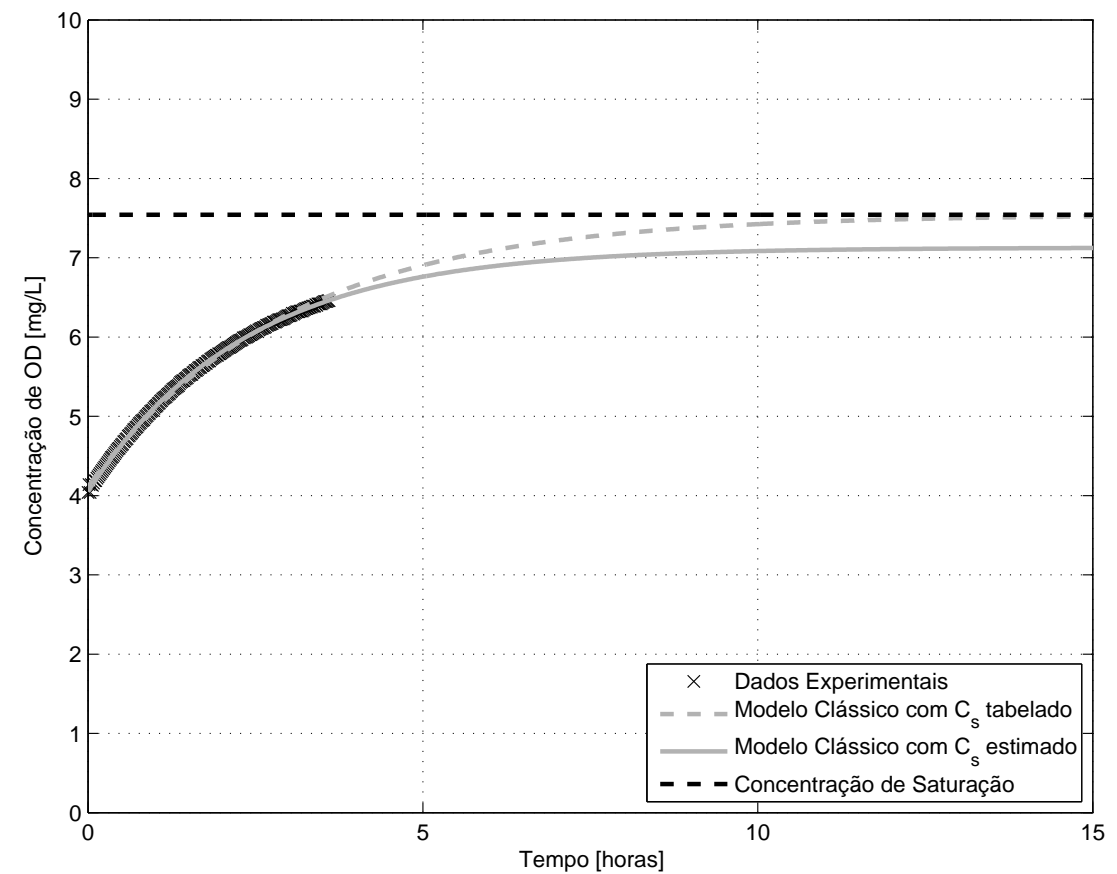

(a) Ajuste com o Modelo Clássico

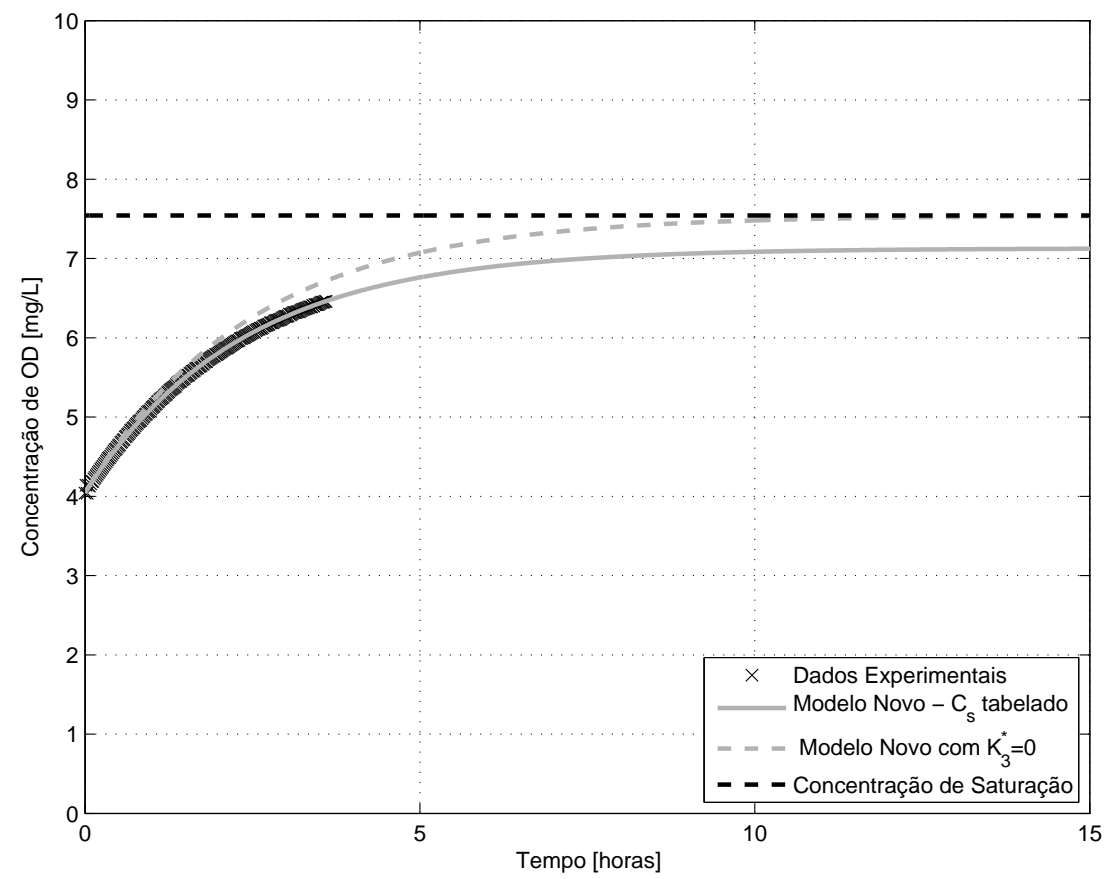

(b) Ajuste com o Modelo Novo

Figura B.72: Curva de reoxigenação para o ensaio 72 


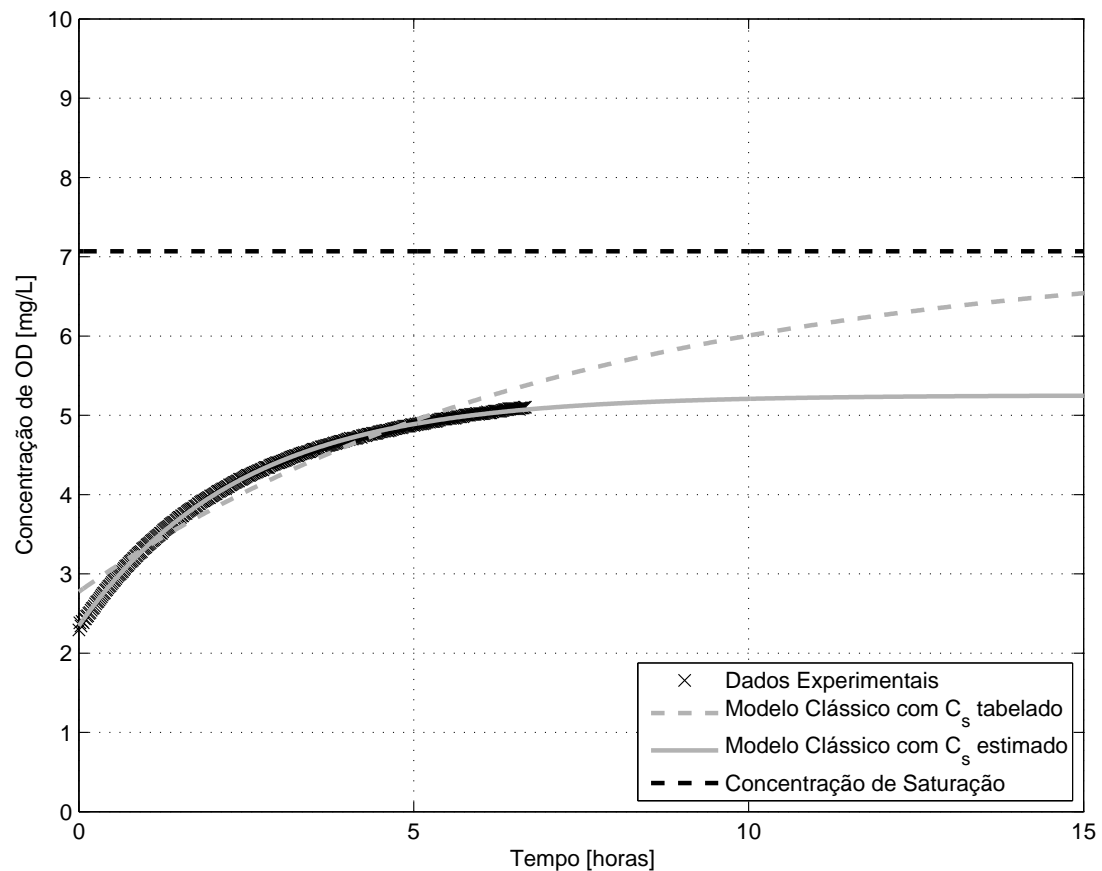

(a) Ajuste com o Modelo Clássico

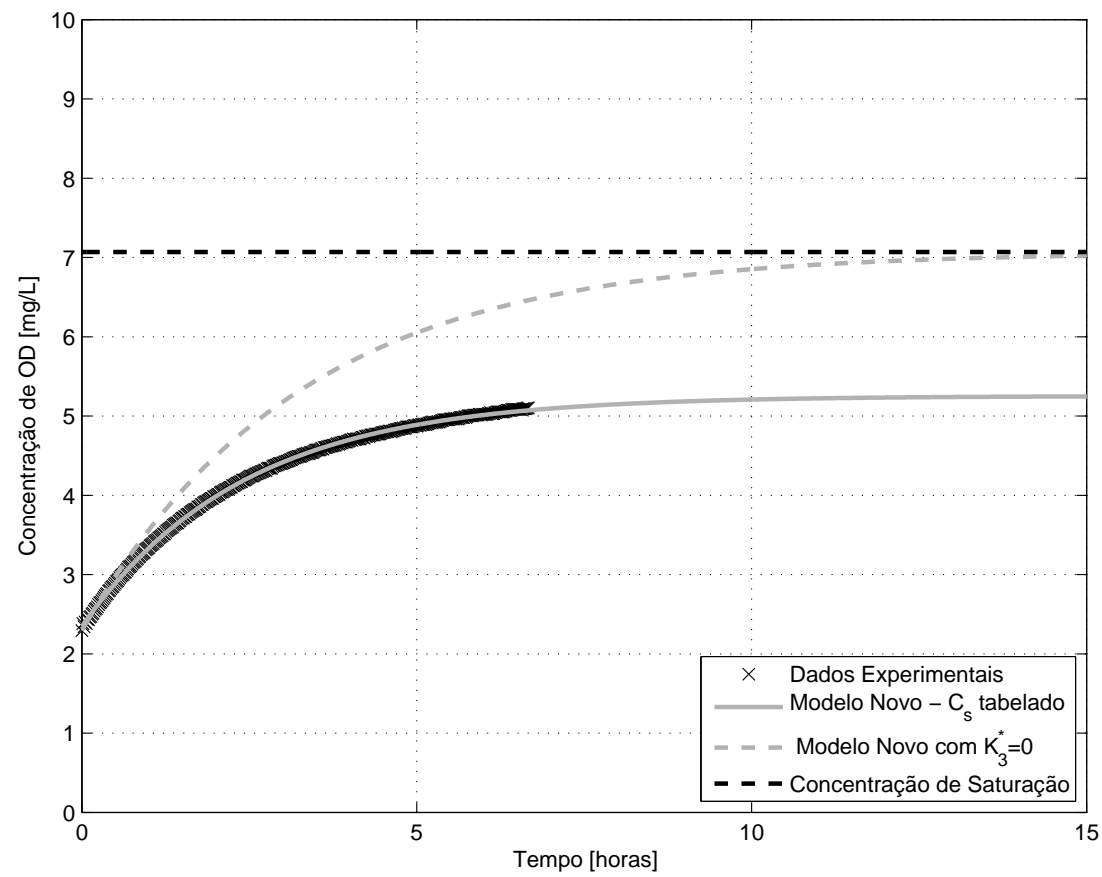

(b) Ajuste com o Modelo Novo

Figura B.73: Curva de reoxigenação para o ensaio 73 


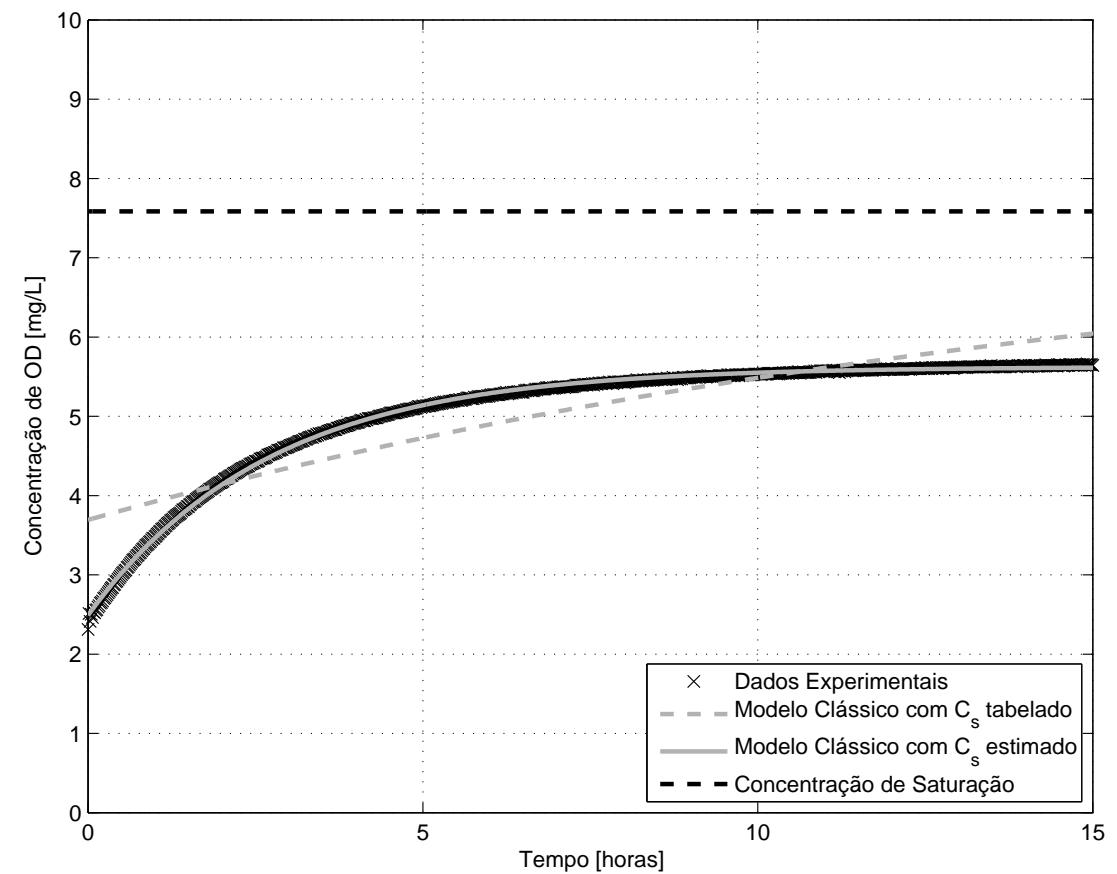

(a) Ajuste com o Modelo Clássico

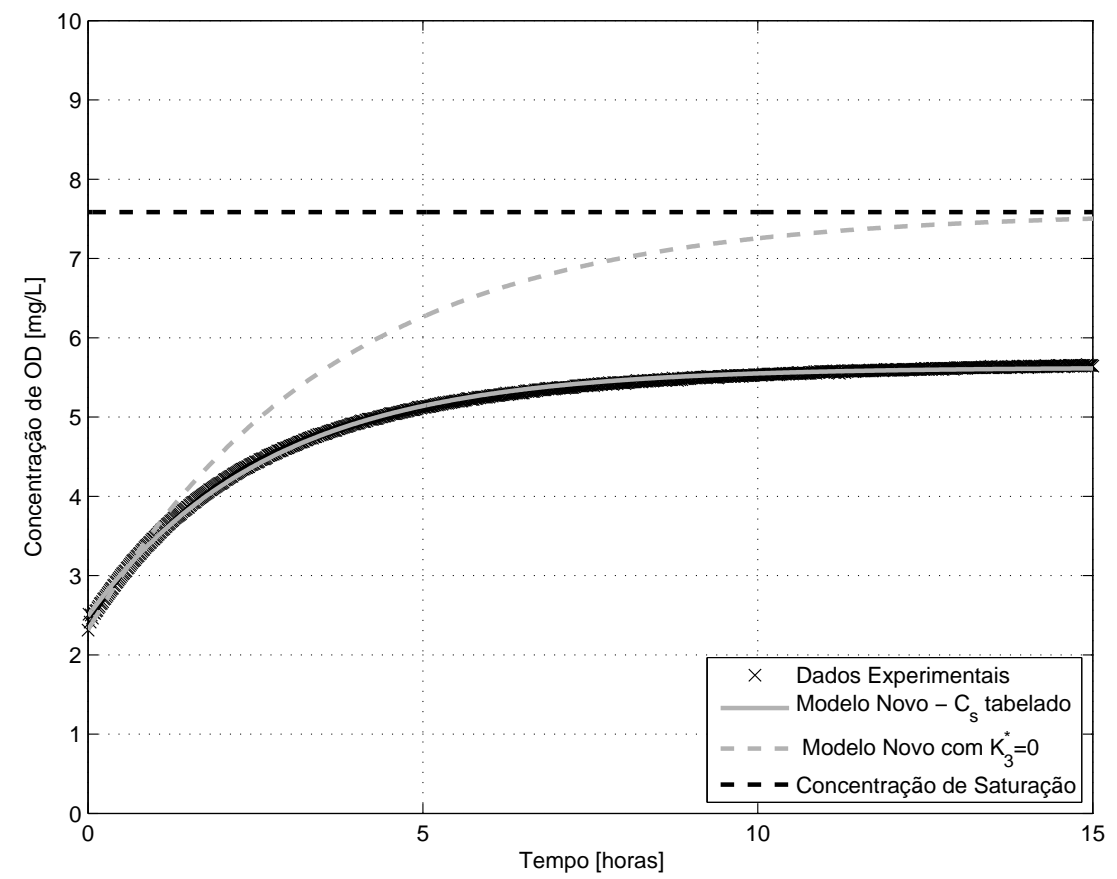

(b) Ajuste com o Modelo Novo

Figura B.74: Curva de reoxigenação para o ensaio 74 


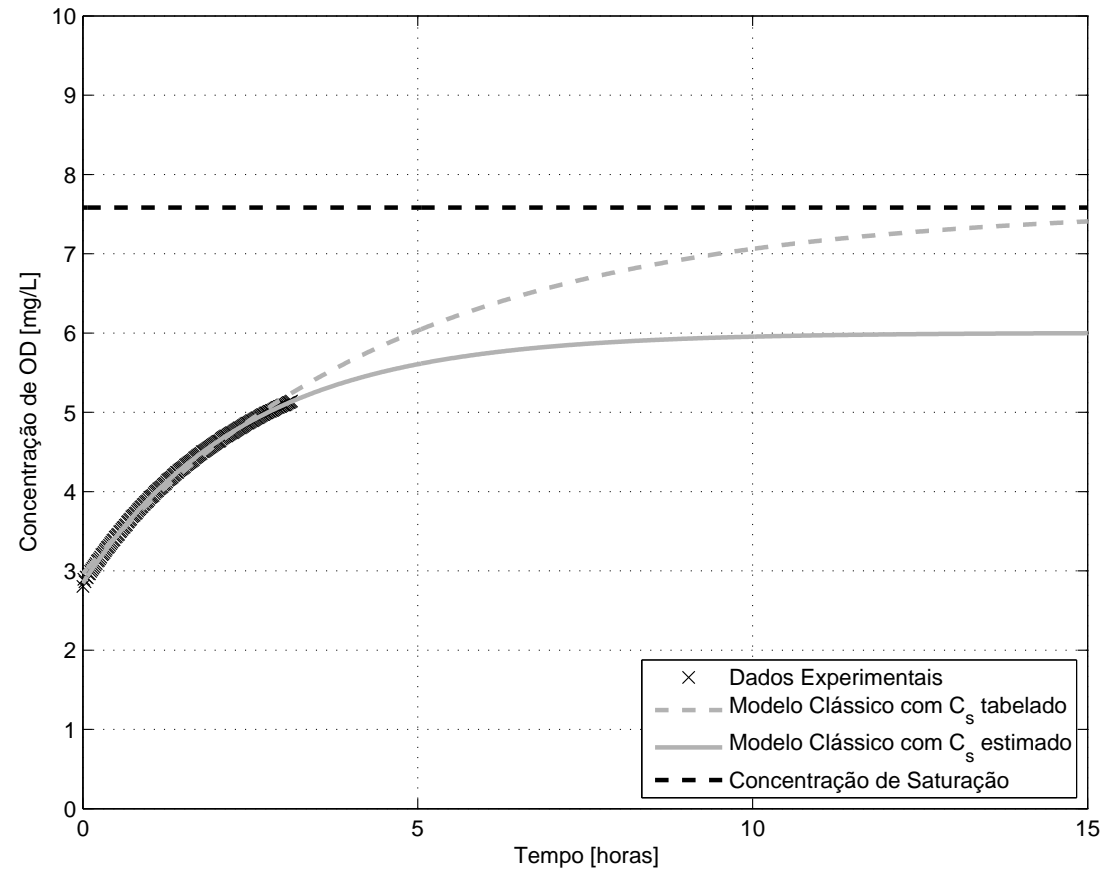

(a) Ajuste com o Modelo Clássico

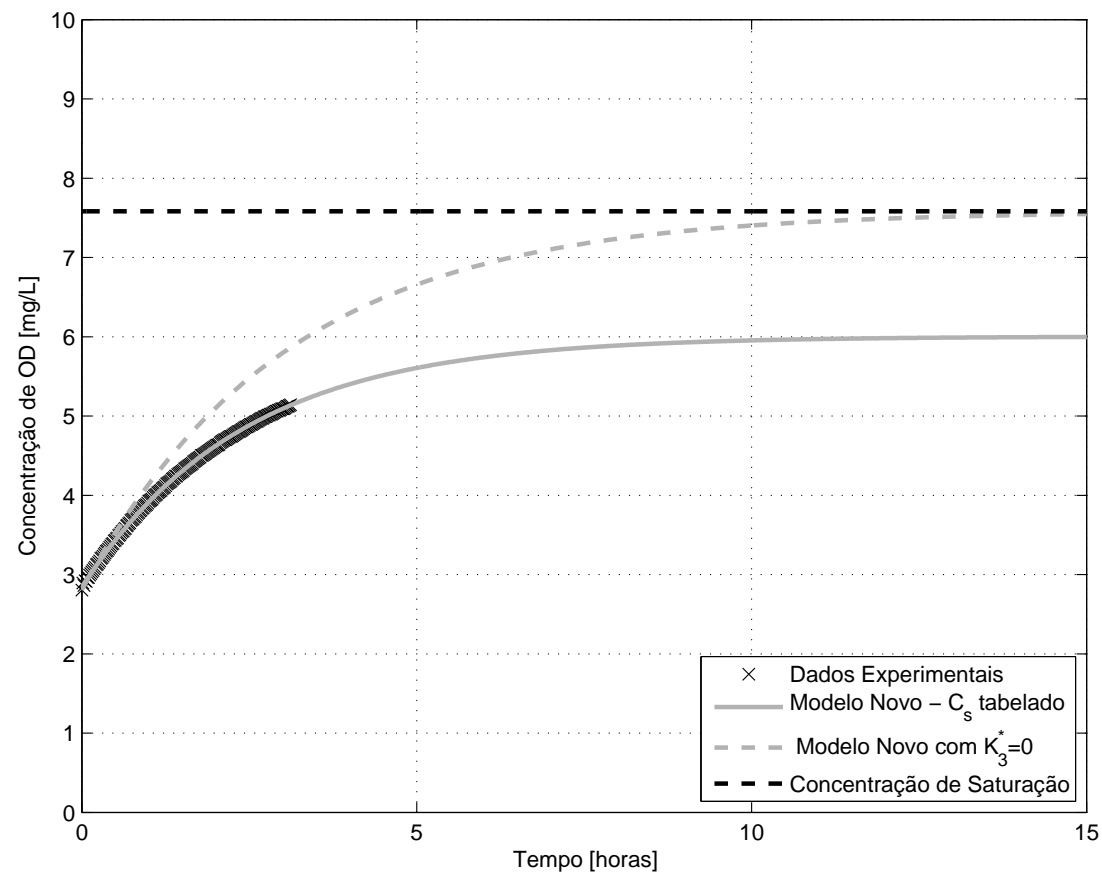

(b) Ajuste com o Modelo Novo

Figura B.75: Curva de reoxigenação para o ensaio 75 


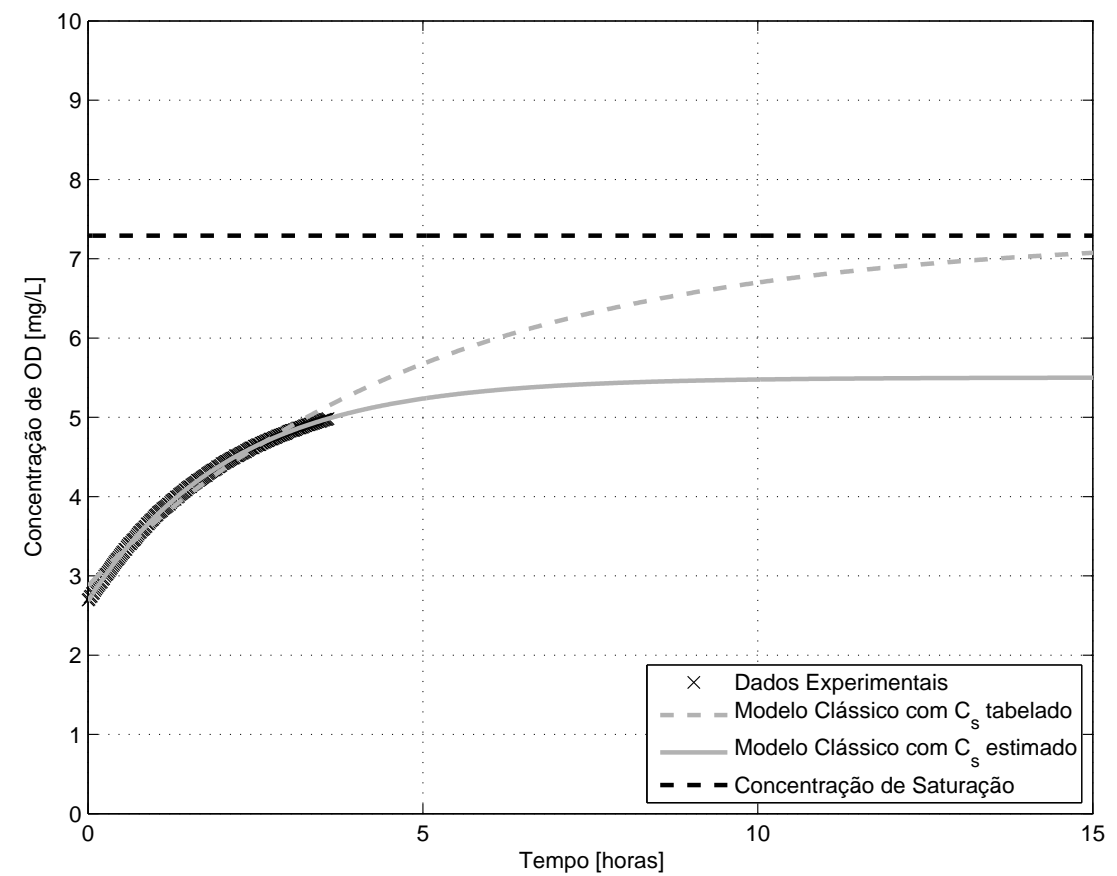

(a) Ajuste com o Modelo Clássico

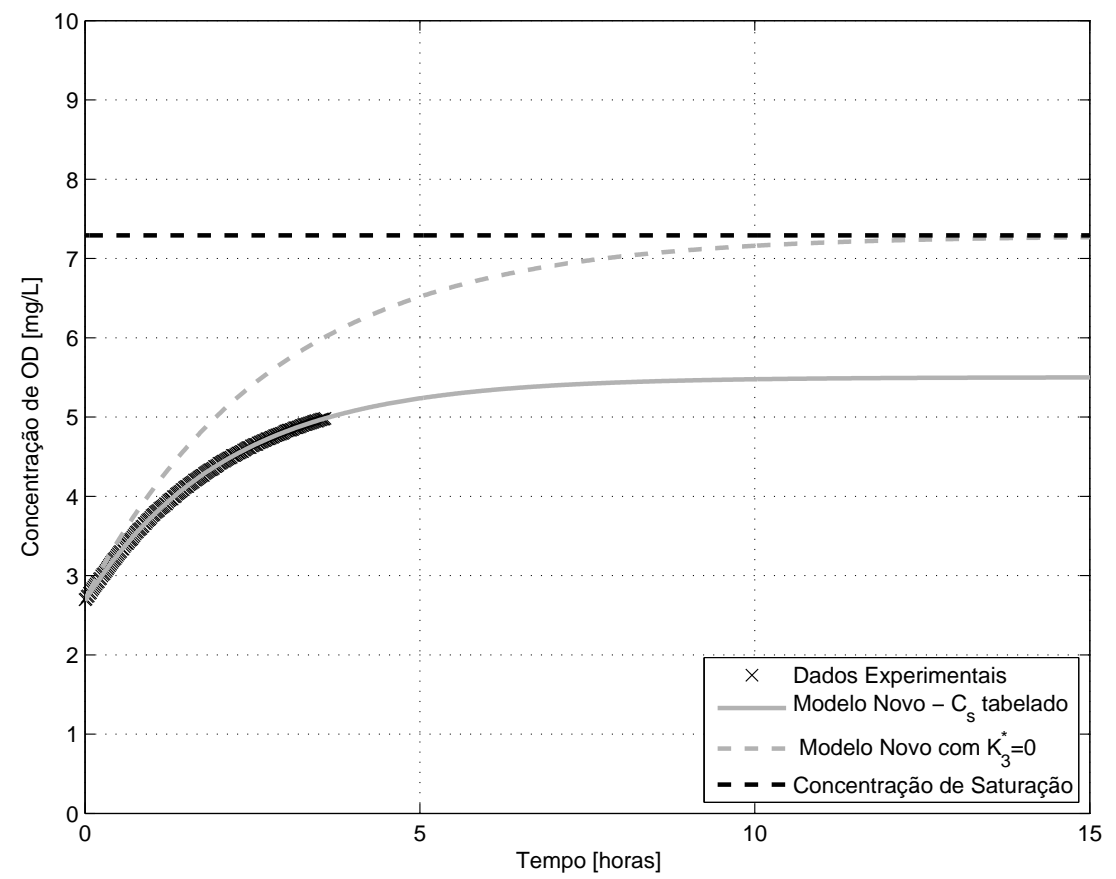

(b) Ajuste com o Modelo Novo

Figura B.76: Curva de reoxigenação para o ensaio 76 


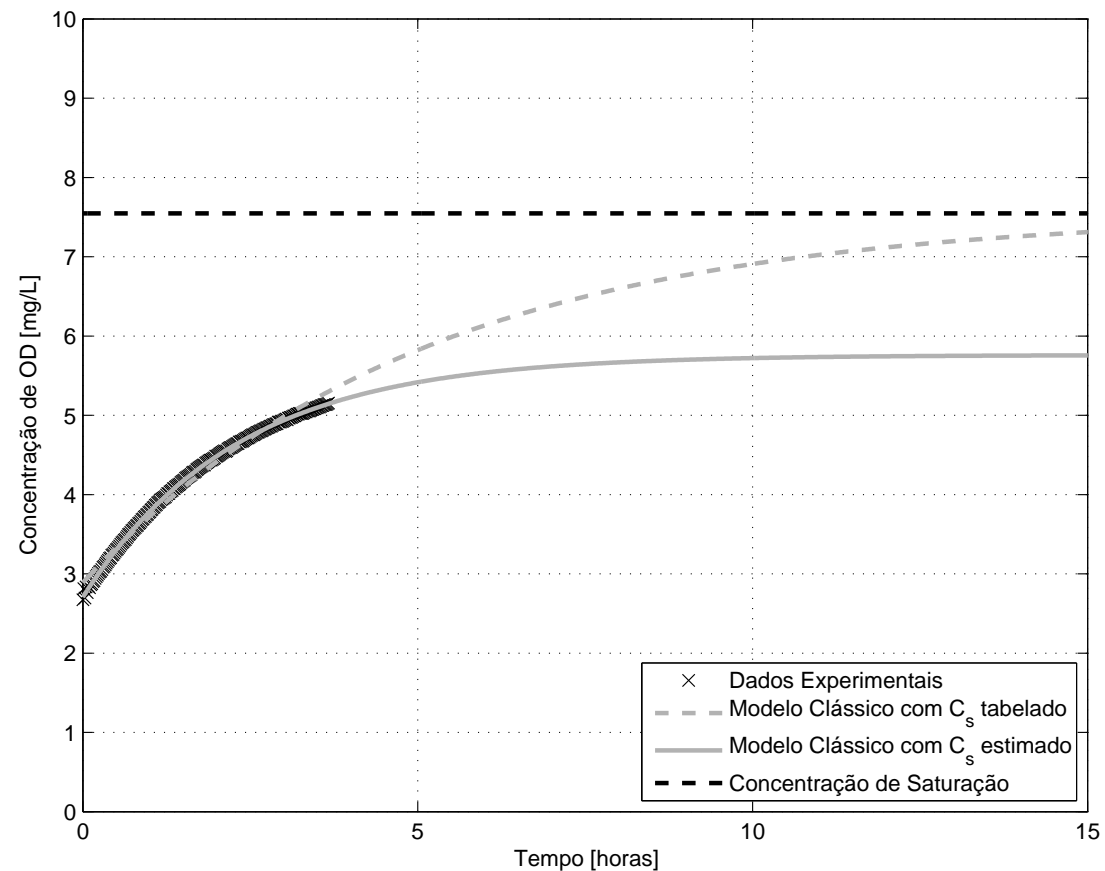

(a) Ajuste com o Modelo Clássico

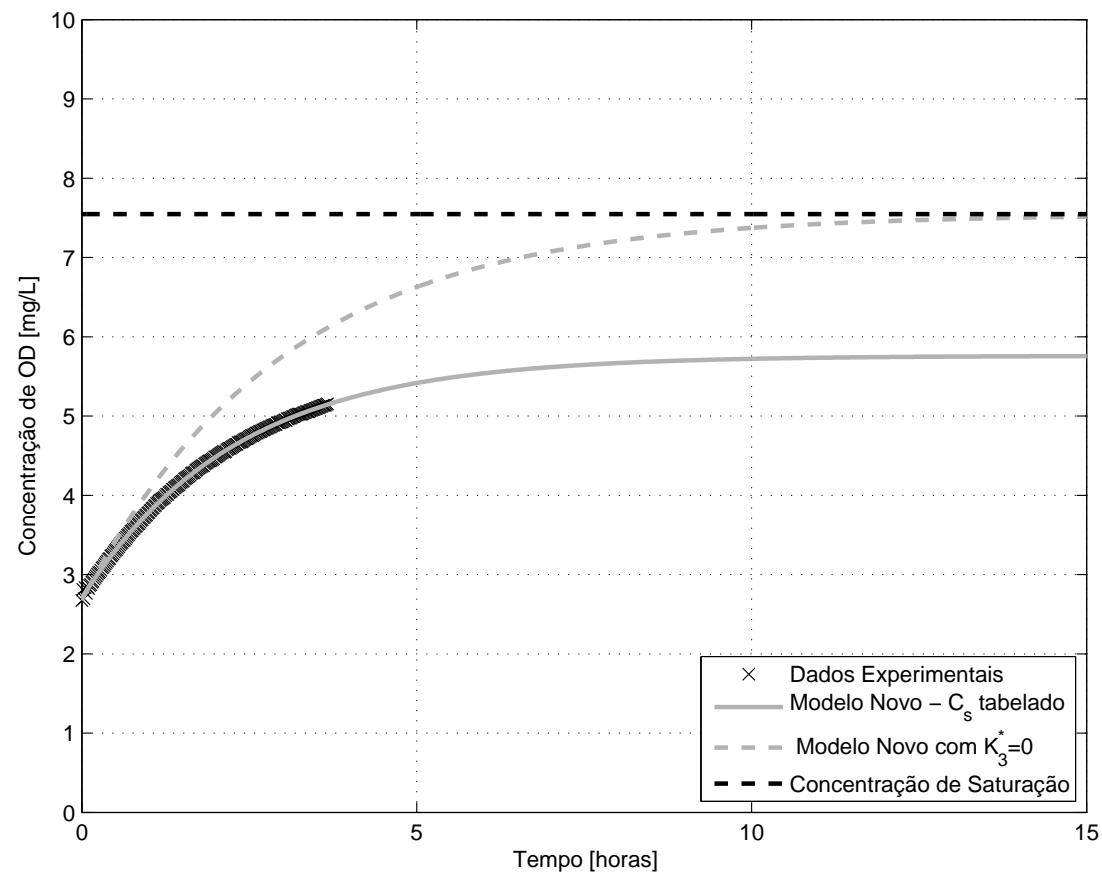

(b) Ajuste com o Modelo Novo

Figura B.77: Curva de reoxigenação para o ensaio 77 


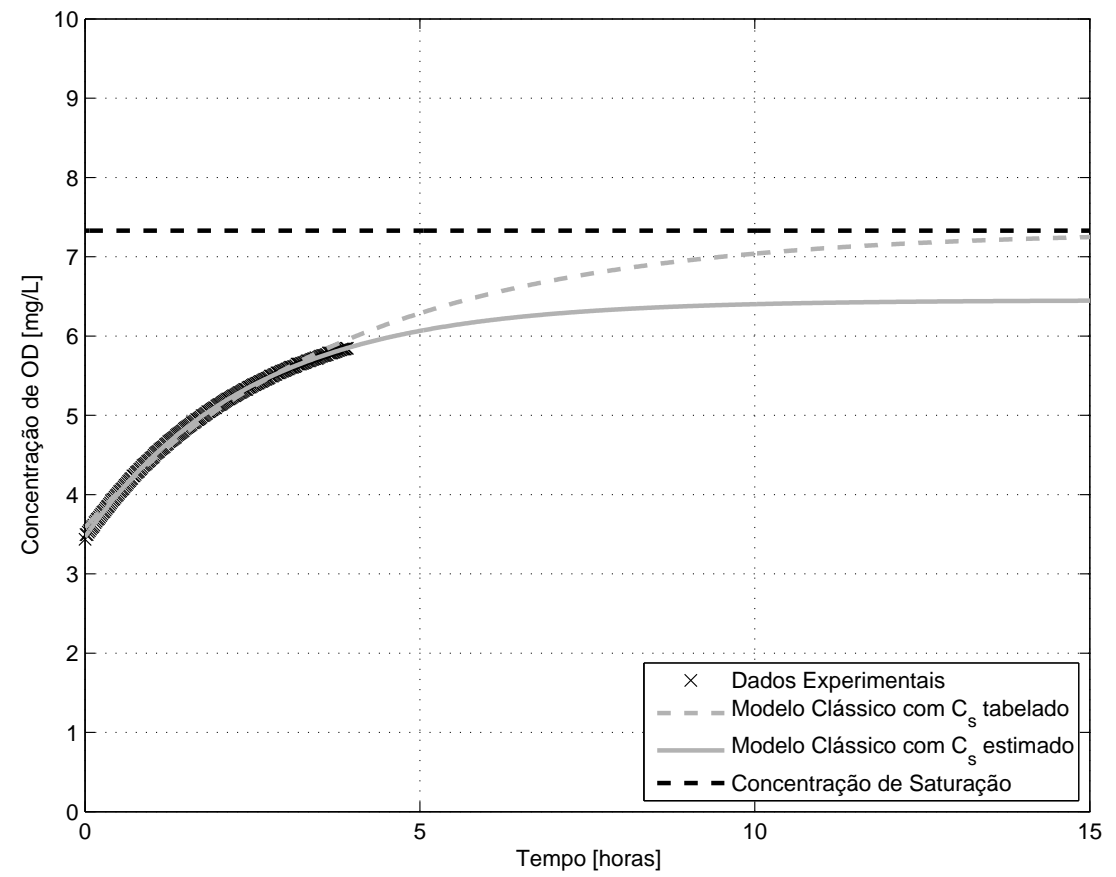

(a) Ajuste com o Modelo Clássico

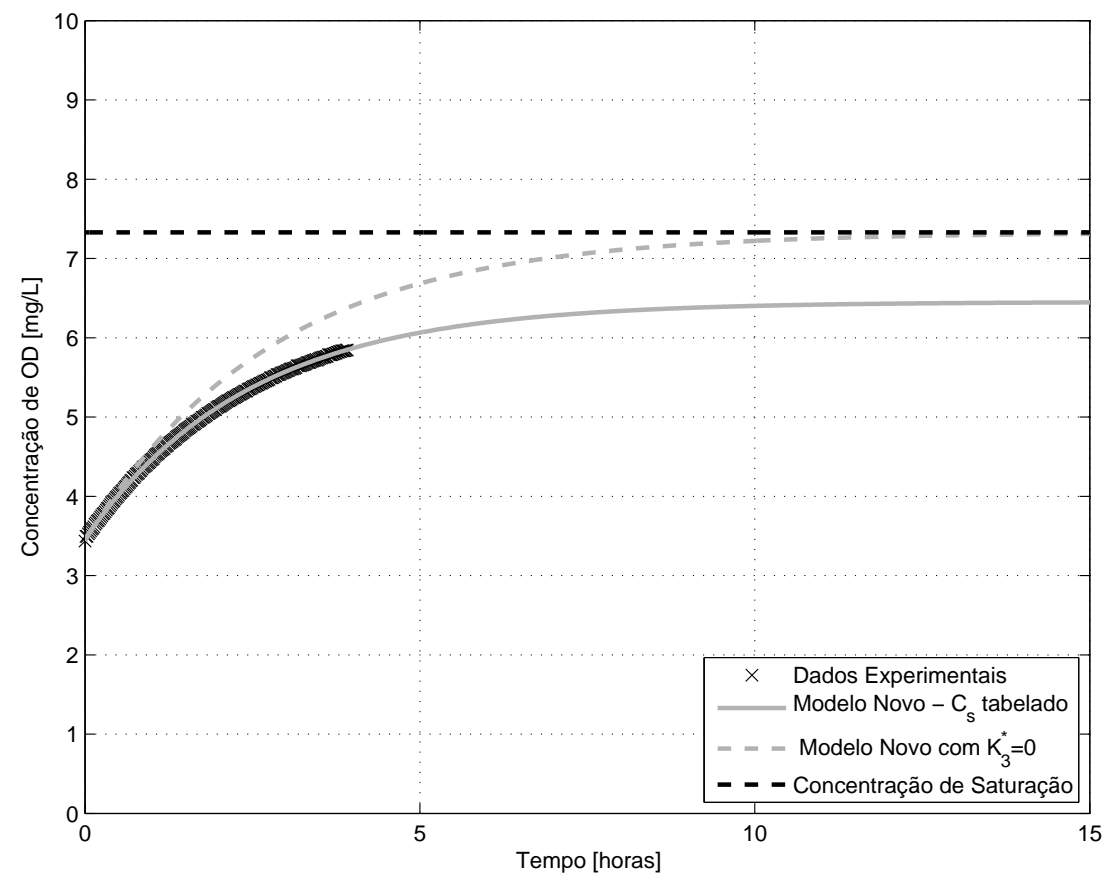

(b) Ajuste com o Modelo Novo

Figura B.78: Curva de reoxigenação para o ensaio 78 


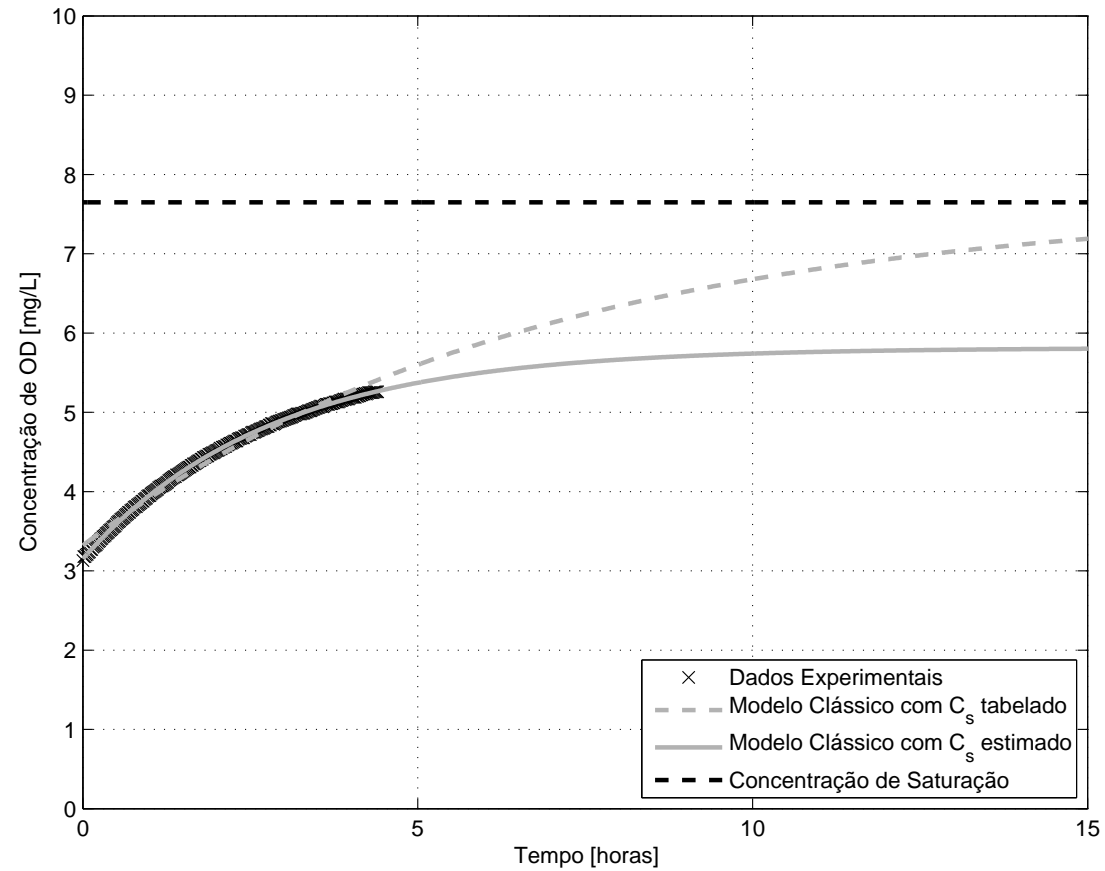

(a) Ajuste com o Modelo Clássico

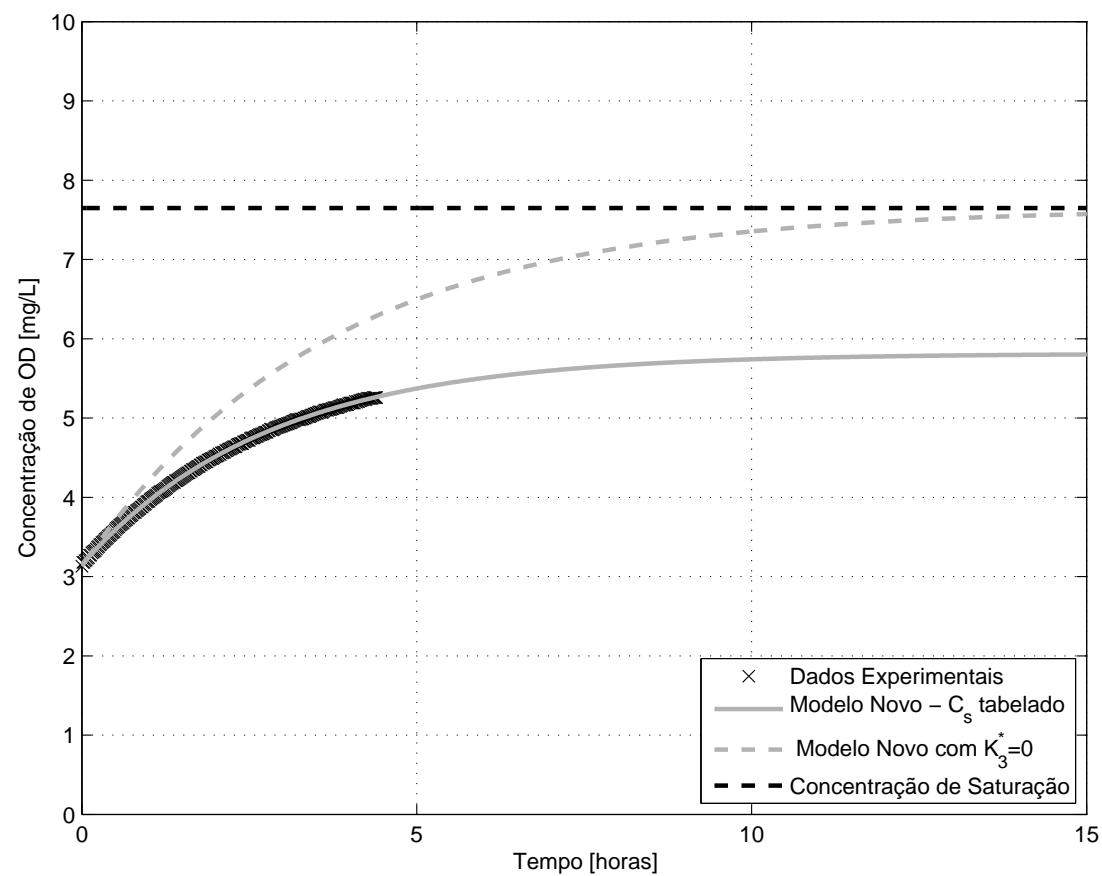

(b) Ajuste com o Modelo Novo

Figura B.79: Curva de reoxigenação para o ensaio 79 


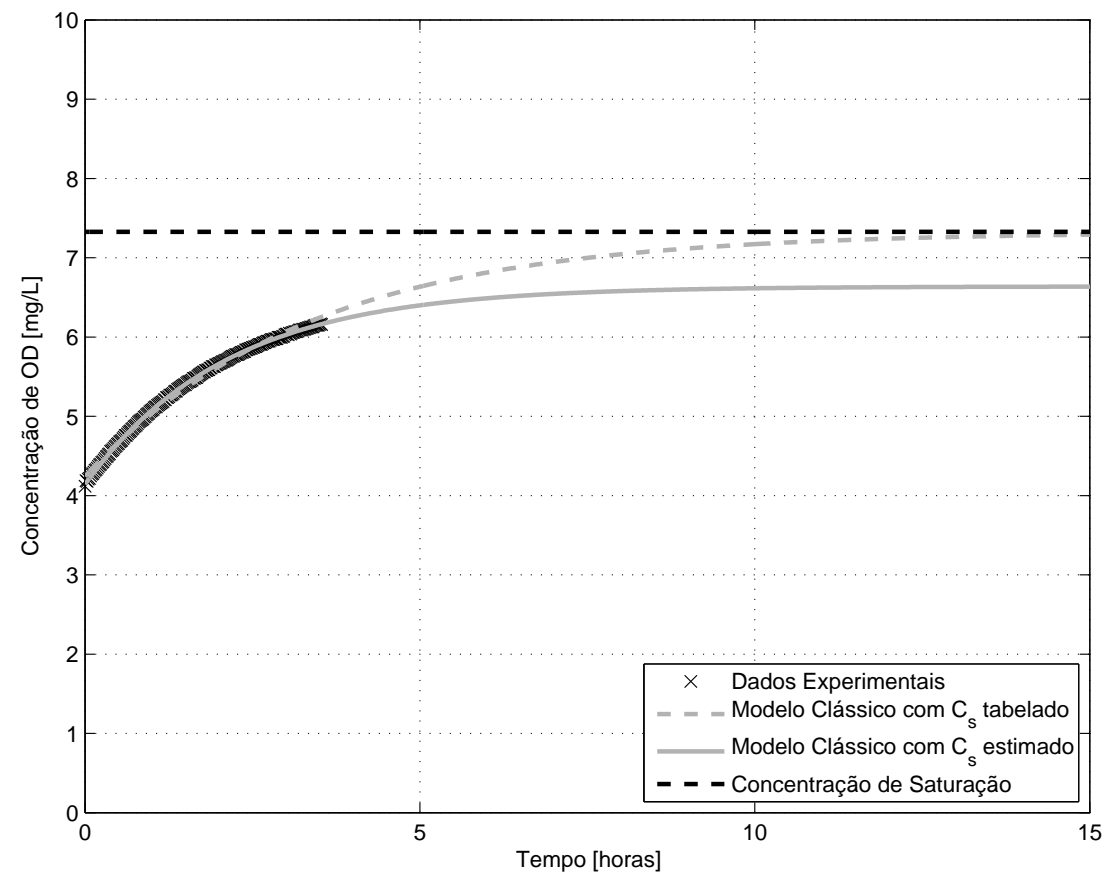

(a) Ajuste com o Modelo Clássico

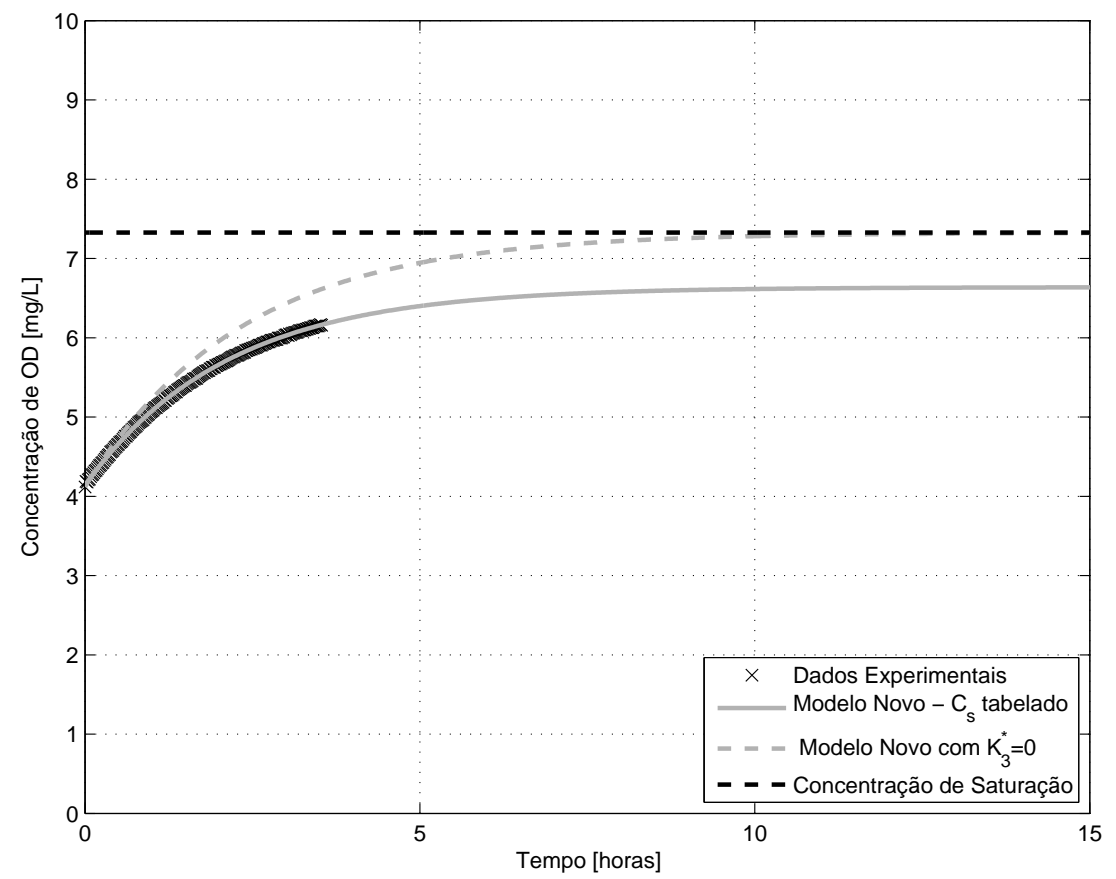

(b) Ajuste com o Modelo Novo

Figura B.80: Curva de reoxigenação para o ensaio 80 


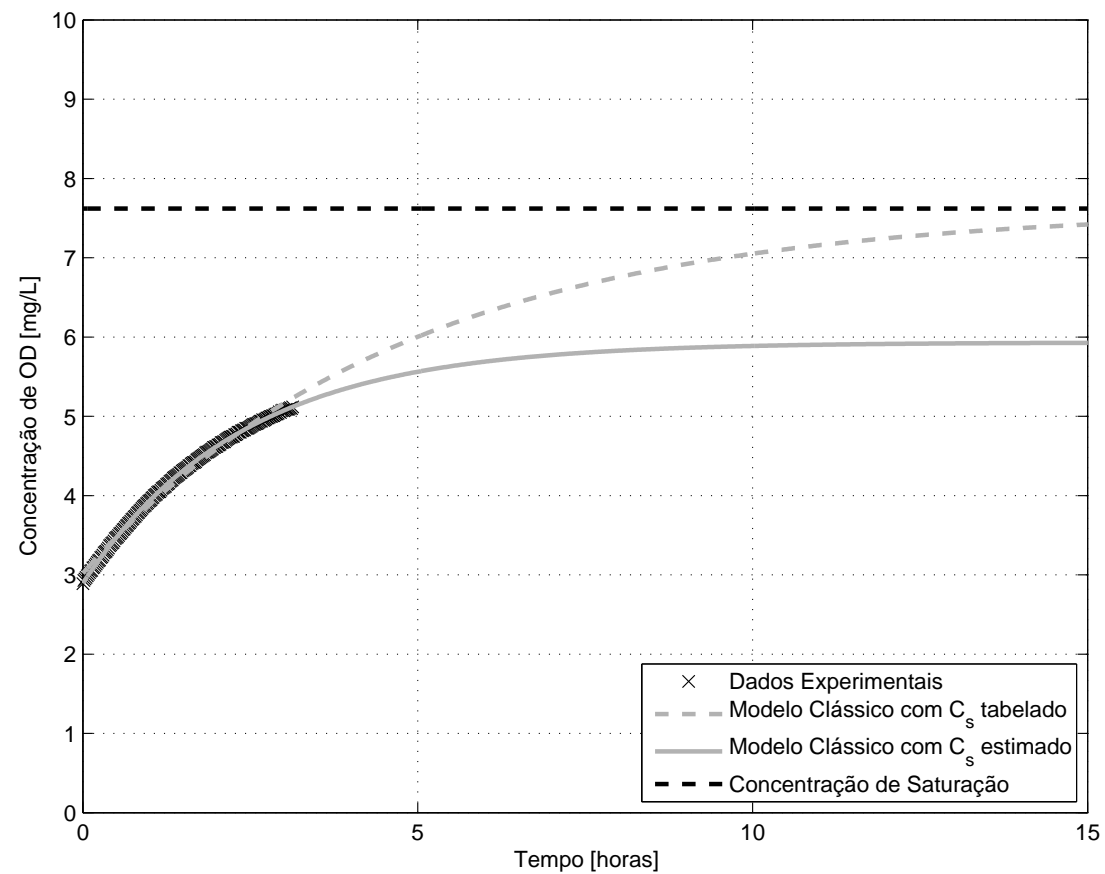

(a) Ajuste com o Modelo Clássico

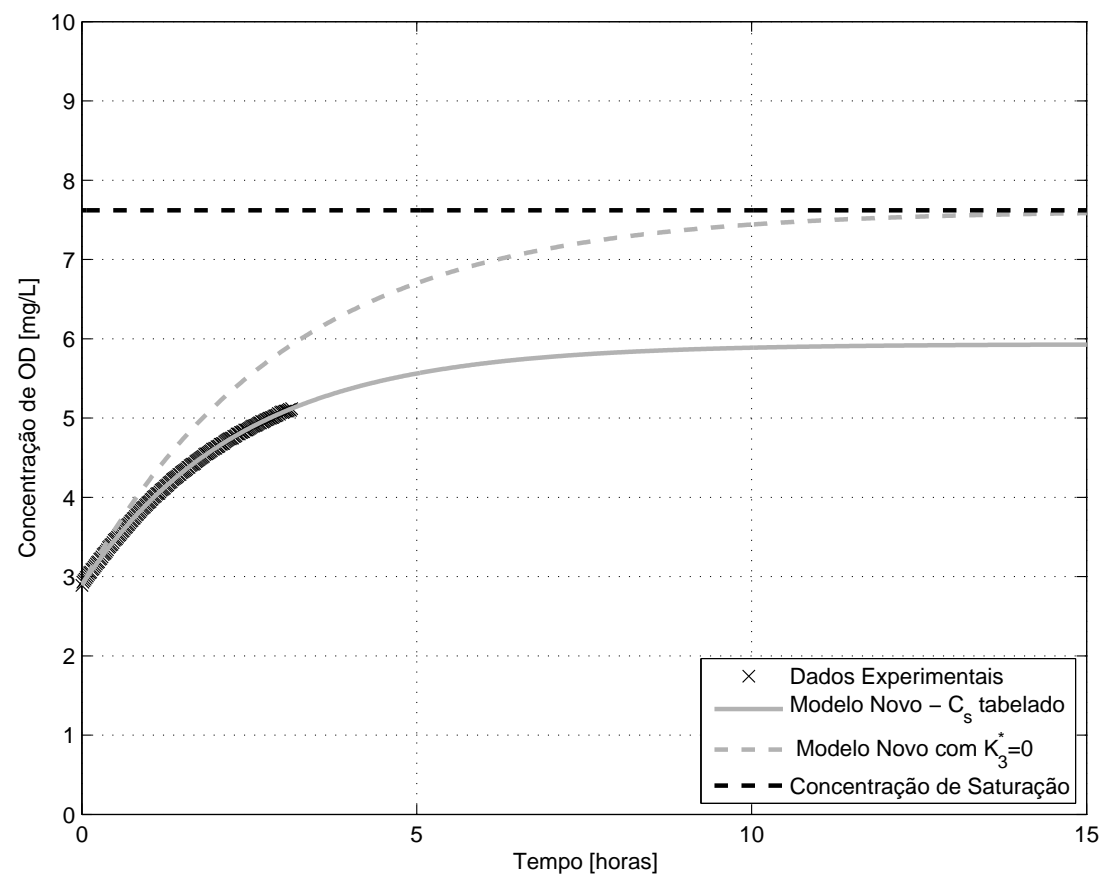

(b) Ajuste com o Modelo Novo

Figura B.81: Curva de reoxigenação para o ensaio 81 


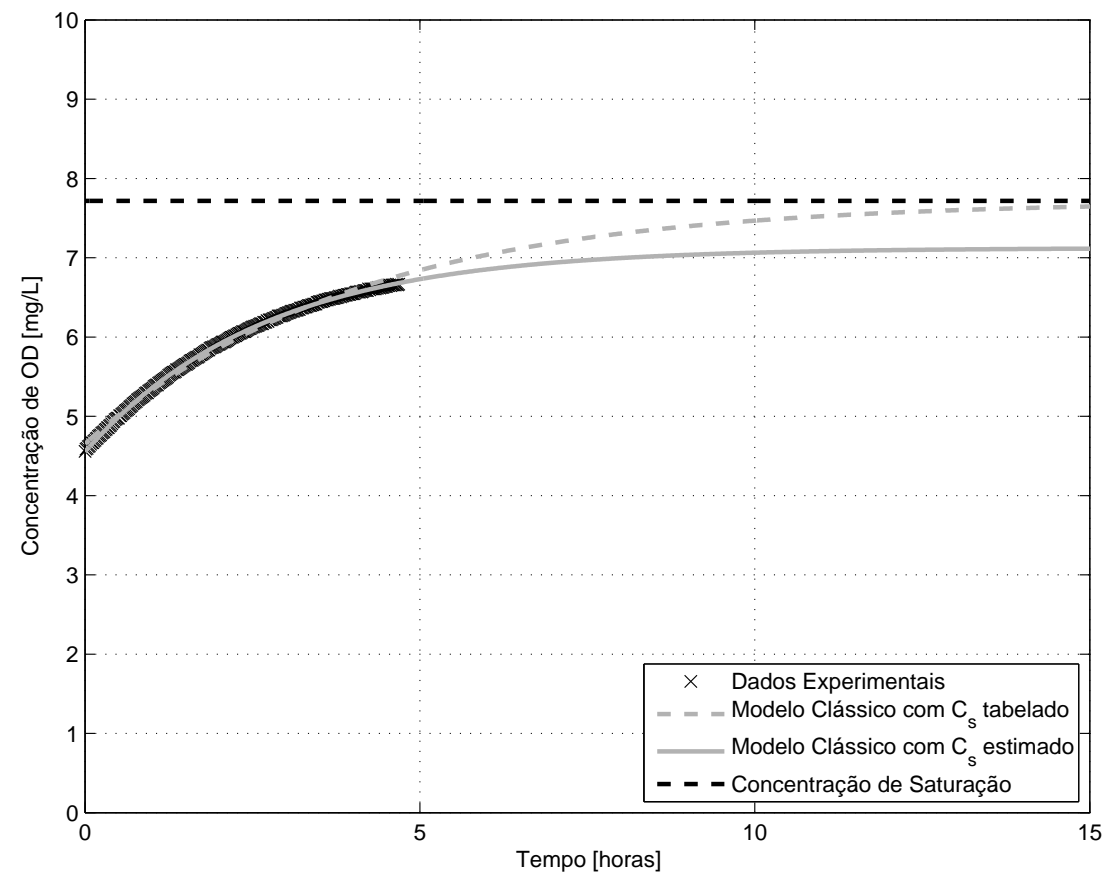

(a) Ajuste com o Modelo Clássico

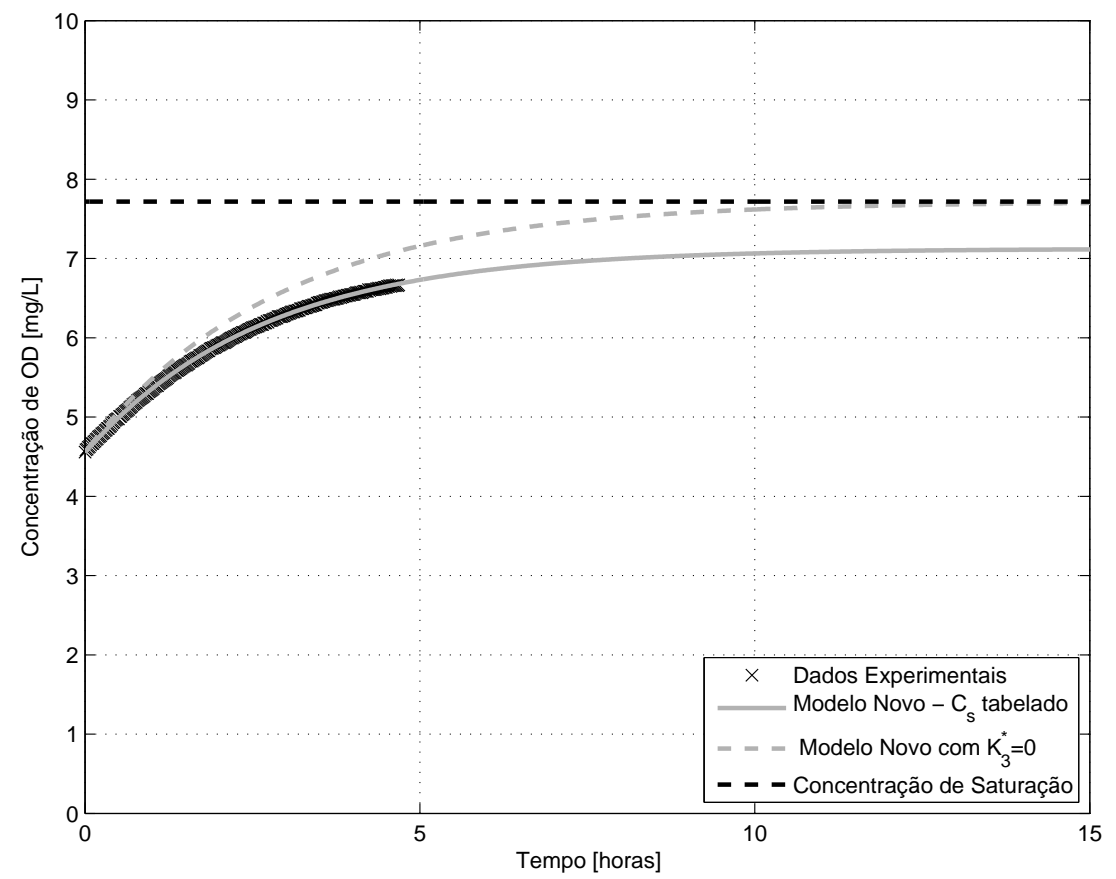

(b) Ajuste com o Modelo Novo

Figura B.82: Curva de reoxigenação para o ensaio 82 


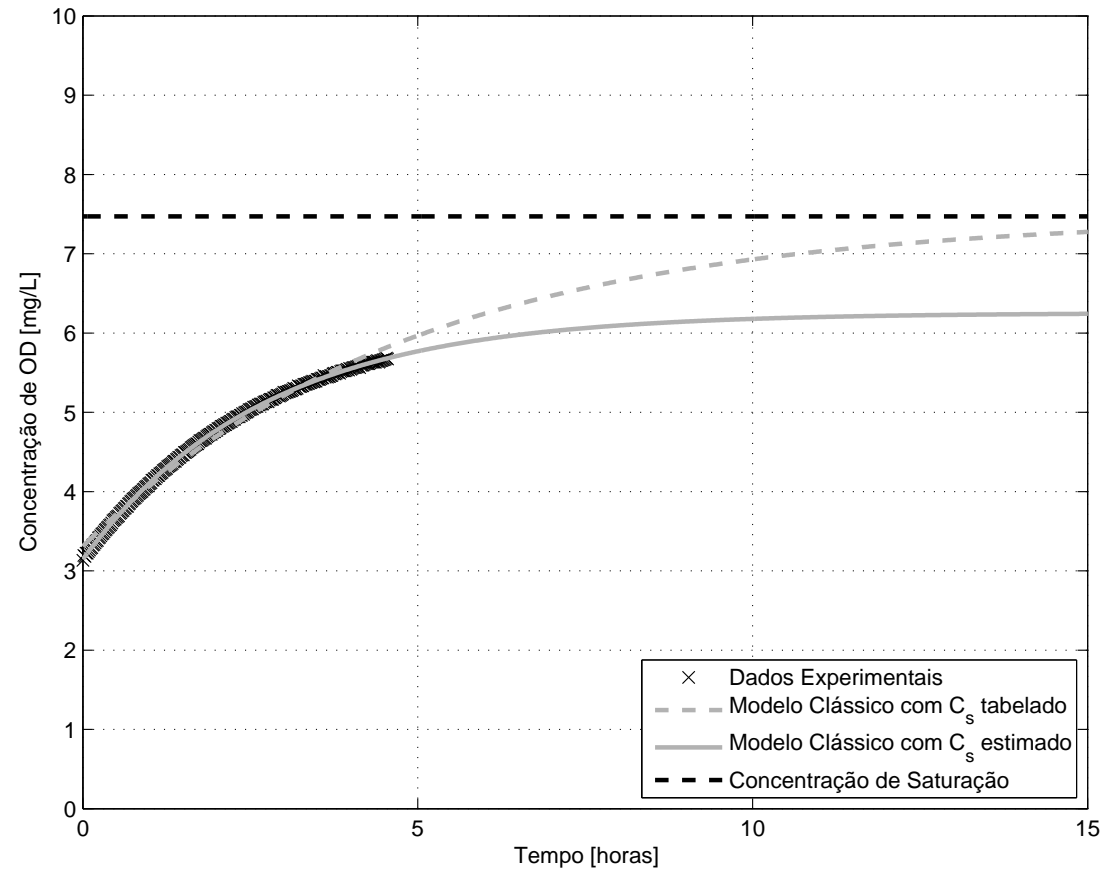

(a) Ajuste com o Modelo Clássico

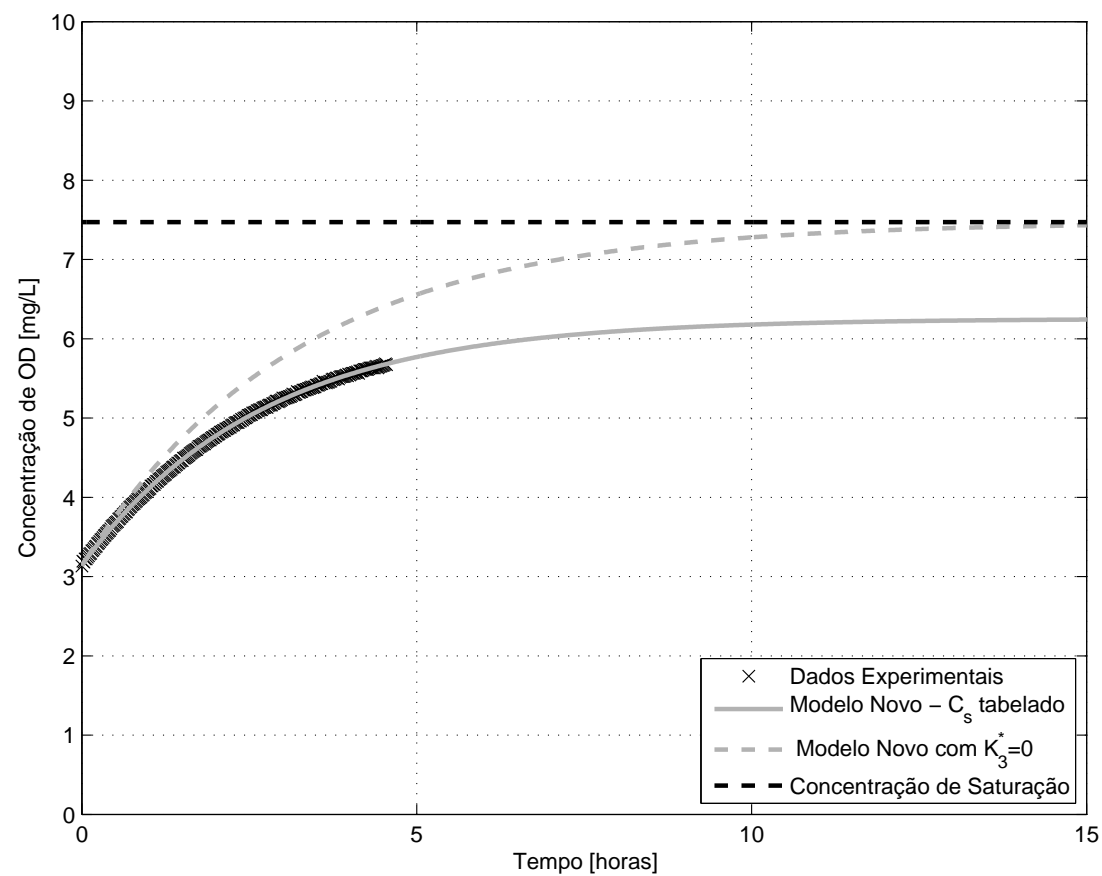

(b) Ajuste com o Modelo Novo

Figura B.83: Curva de reoxigenação para o ensaio 83 


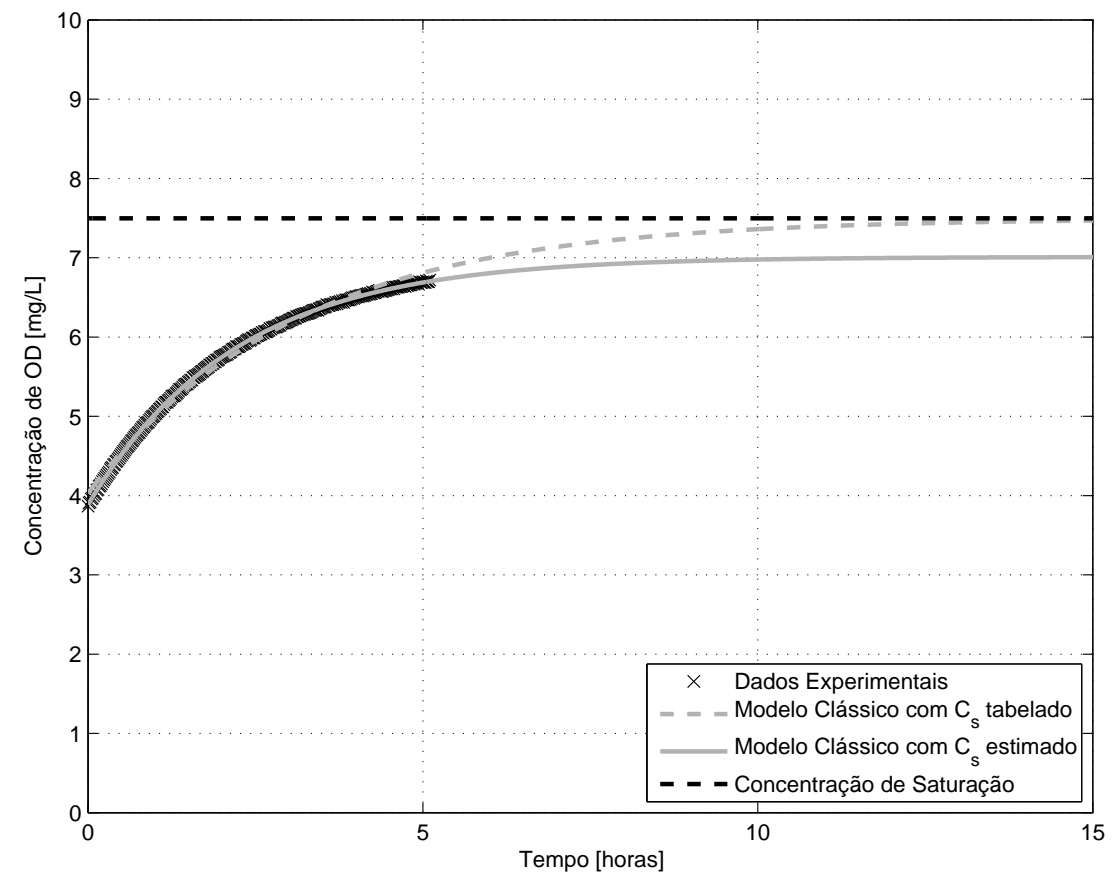

(a) Ajuste com o Modelo Clássico

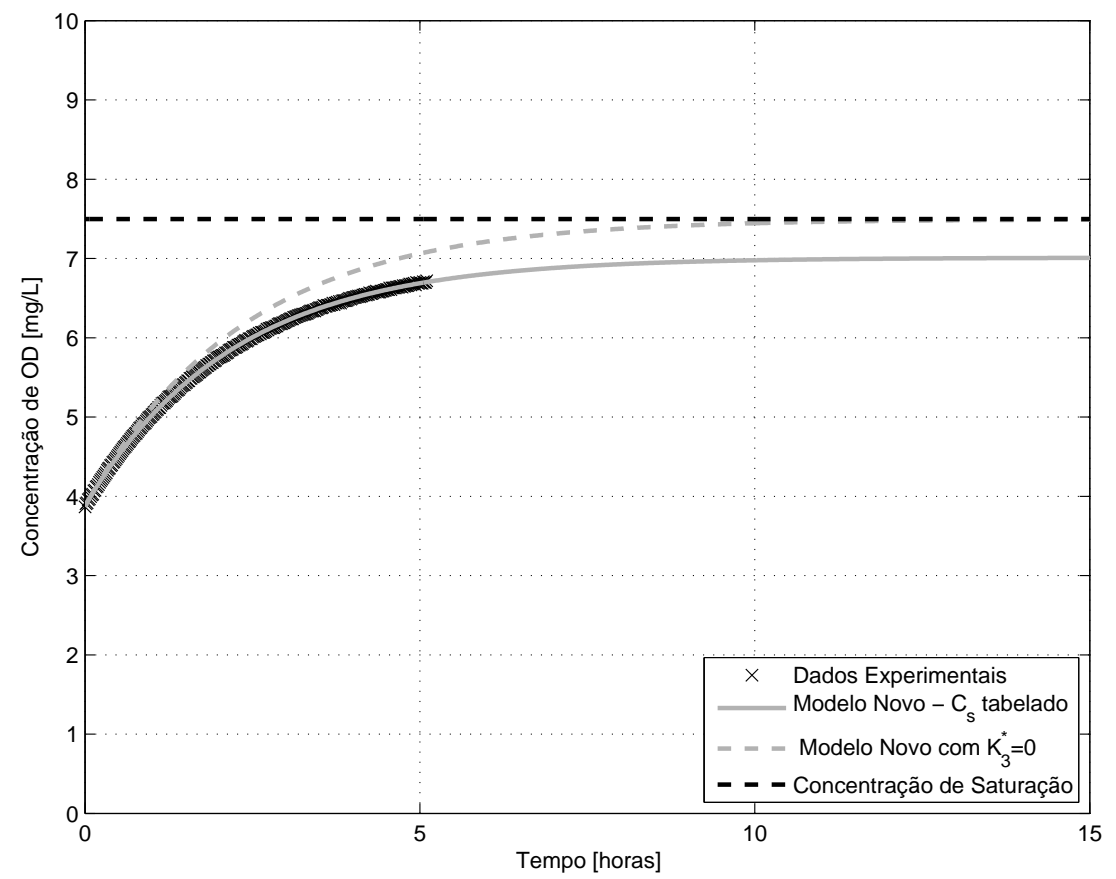

(b) Ajuste com o Modelo Novo

Figura B.84: Curva de reoxigenação para o ensaio 84 


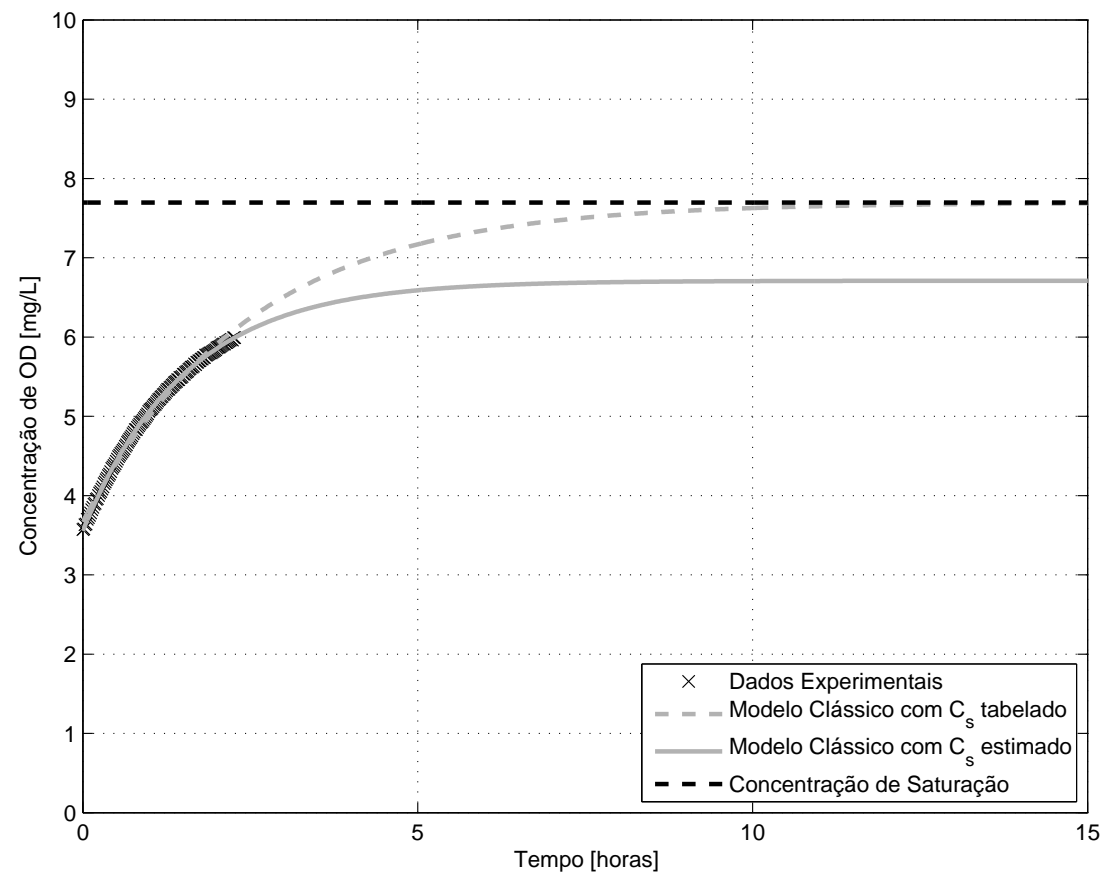

(a) Ajuste com o Modelo Clássico

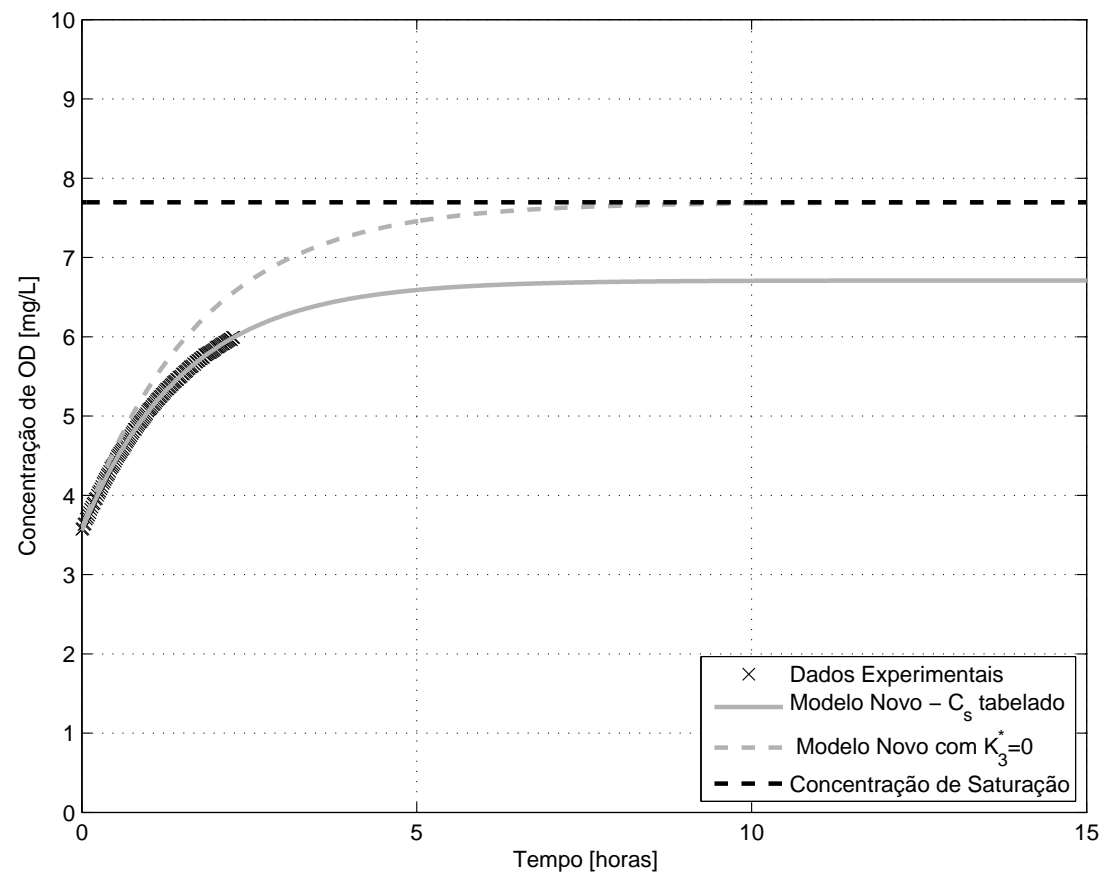

(b) Ajuste com o Modelo Novo

Figura B.85: Curva de reoxigenação para o ensaio 85 


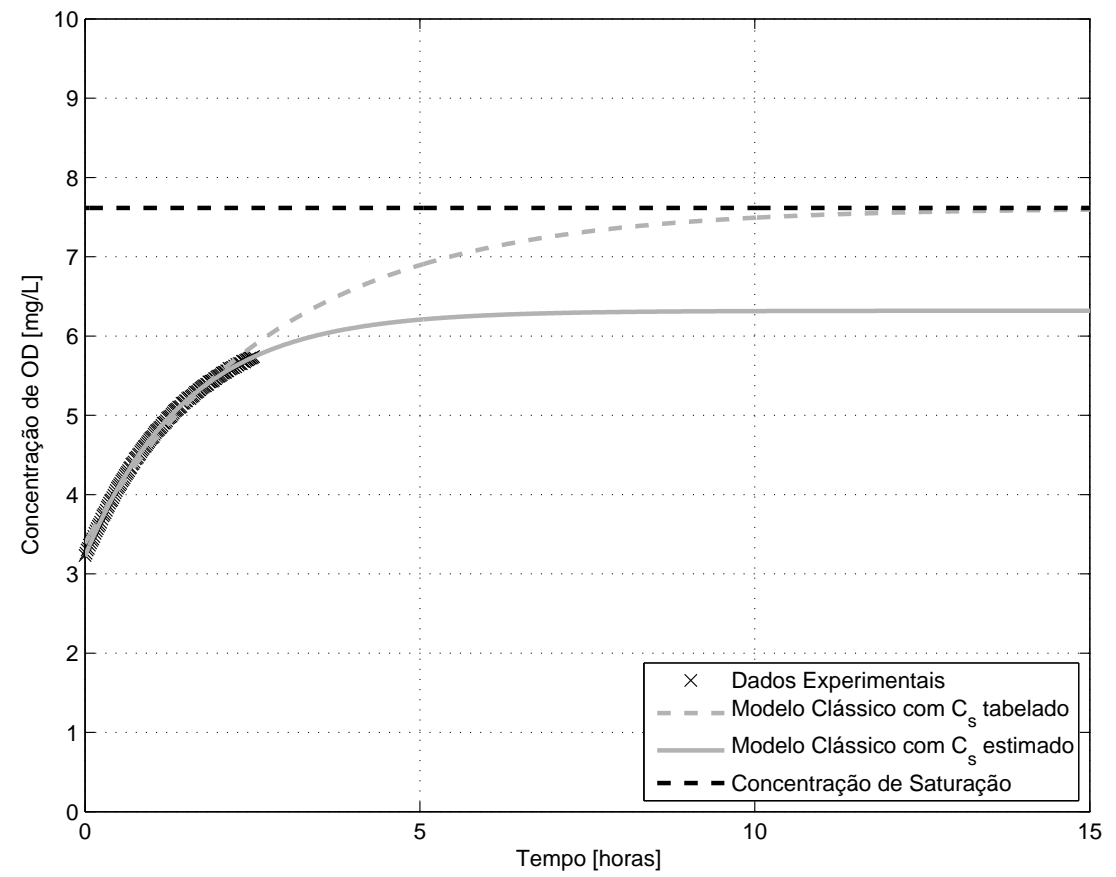

(a) Ajuste com o Modelo Clássico

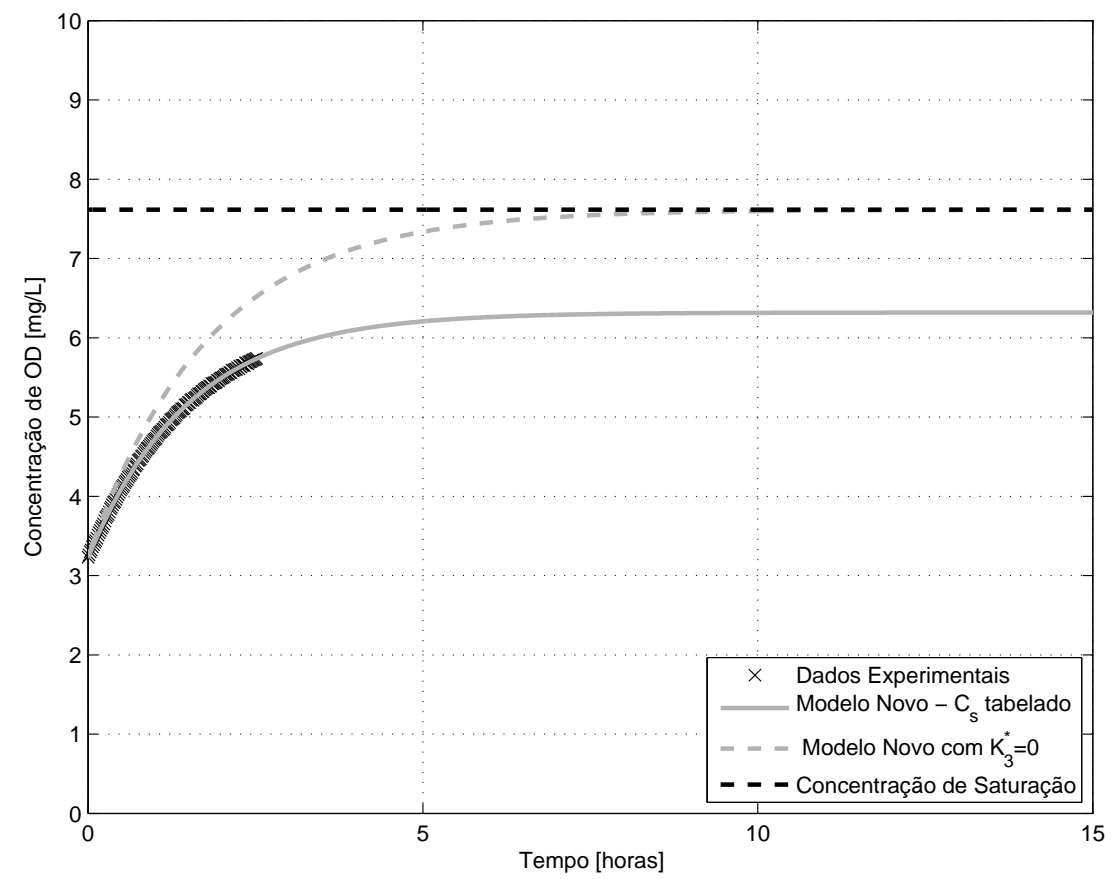

(b) Ajuste com o Modelo Novo

Figura B.86: Curva de reoxigenação para o ensaio 86 


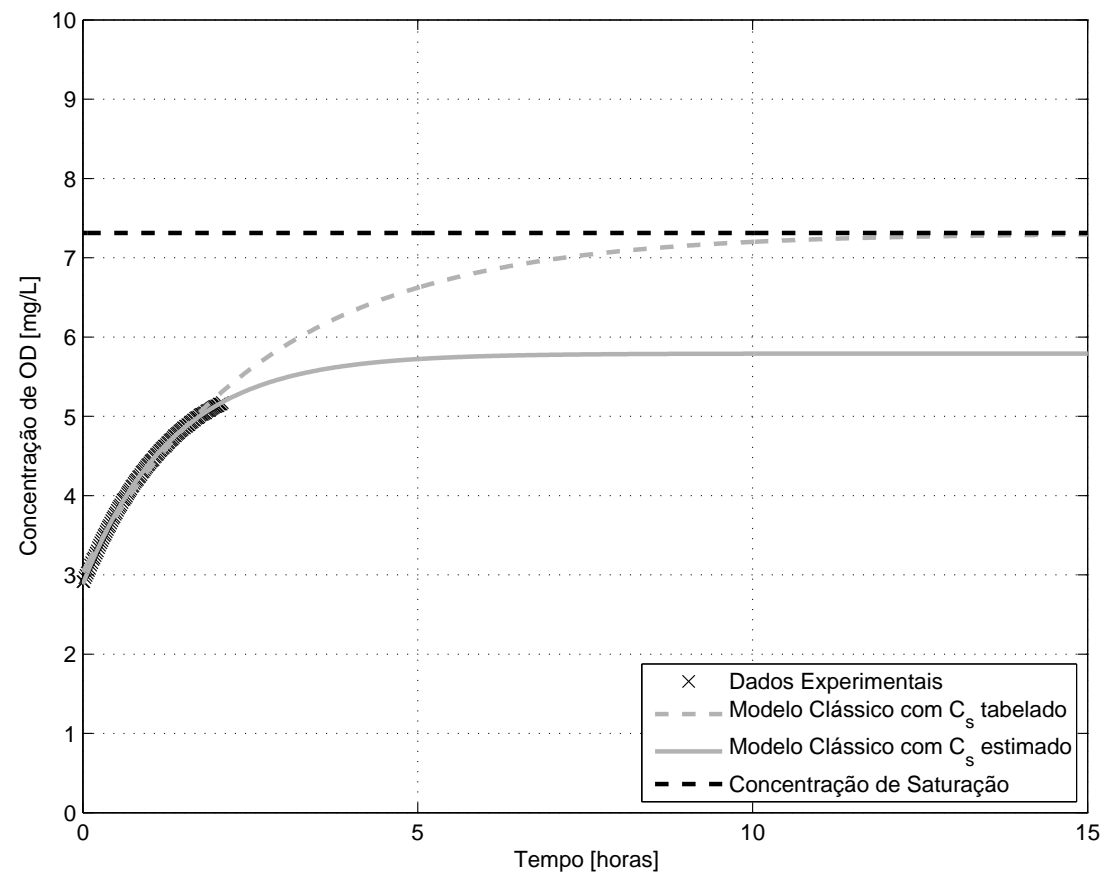

(a) Ajuste com o Modelo Clássico

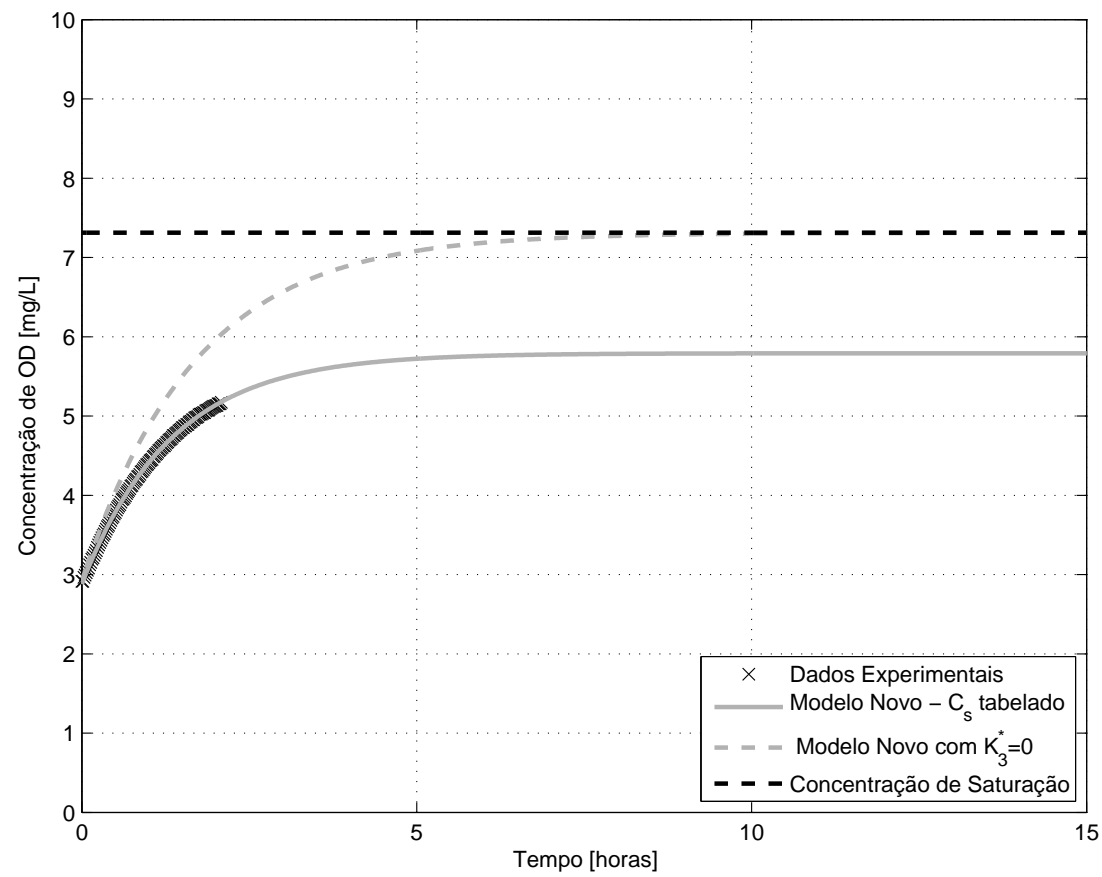

(b) Ajuste com o Modelo Novo

Figura B.87: Curva de reoxigenação para o ensaio 87 


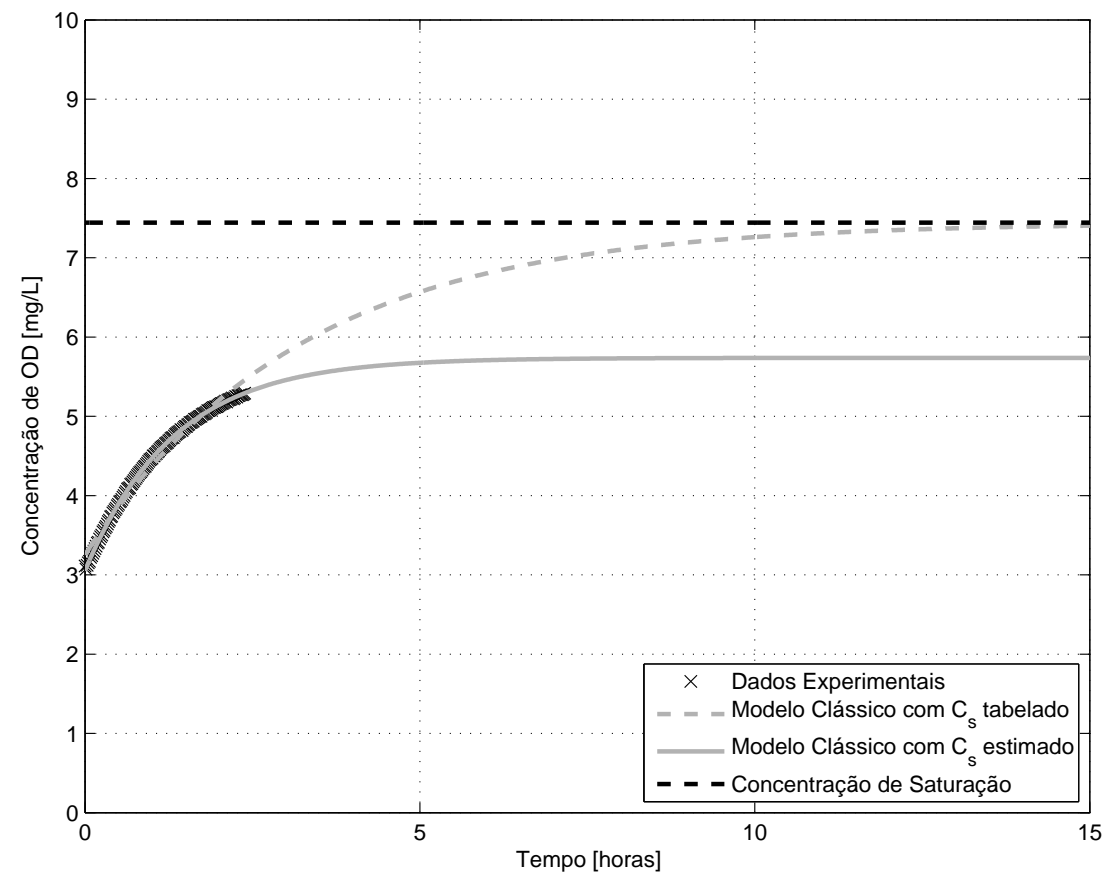

(a) Ajuste com o Modelo Clássico

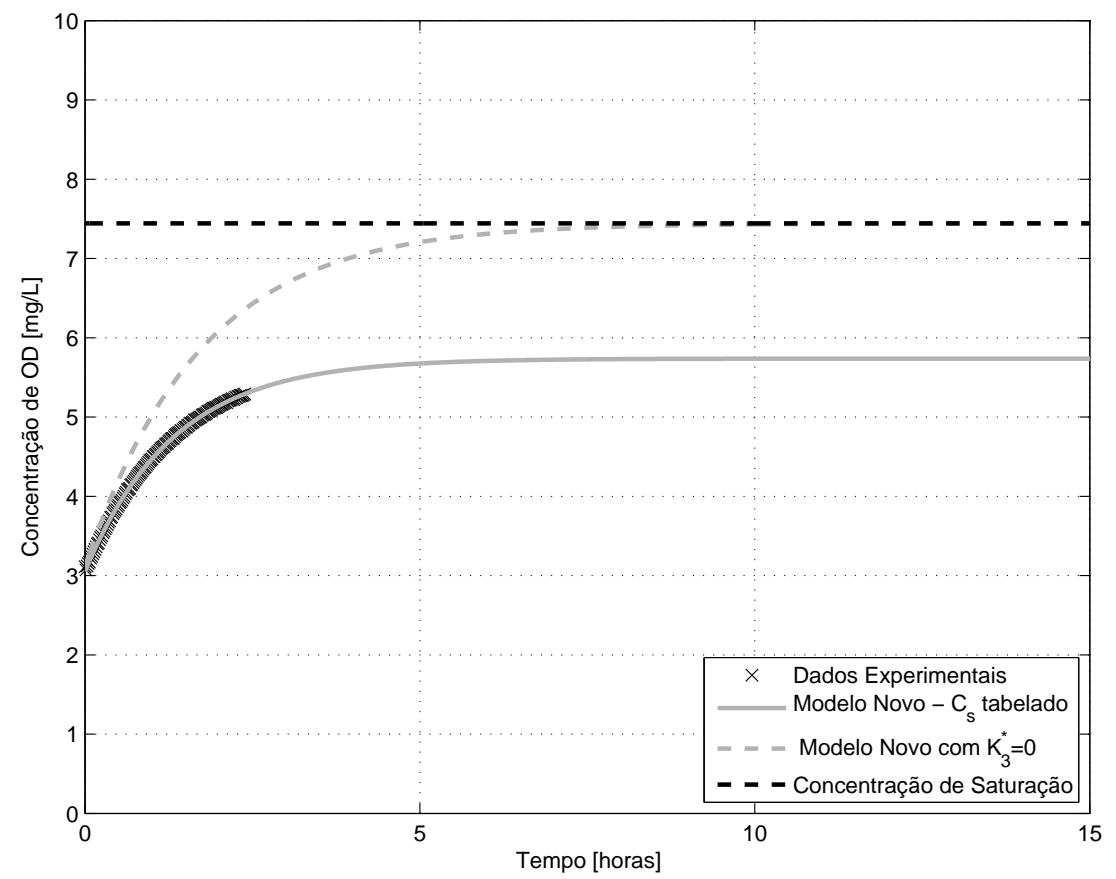

(b) Ajuste com o Modelo Novo

Figura B.88: Curva de reoxigenação para o ensaio 88 


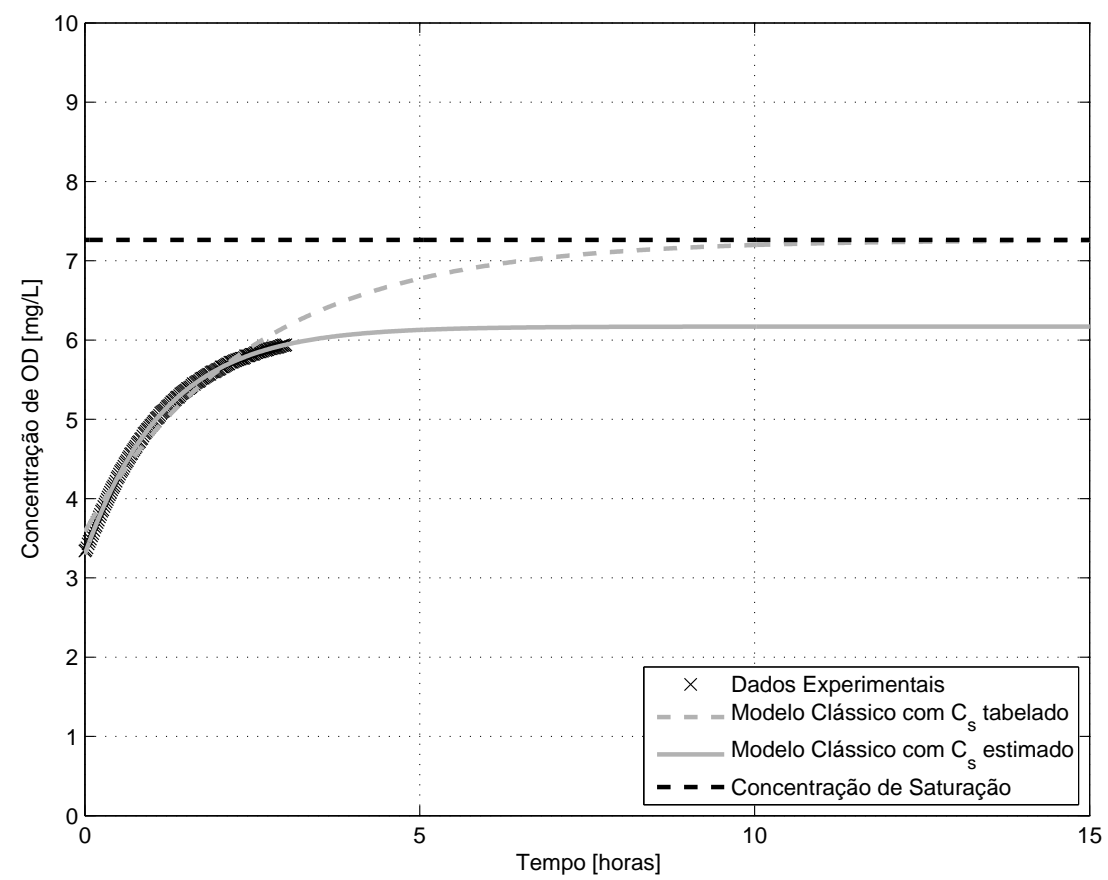

(a) Ajuste com o Modelo Clássico

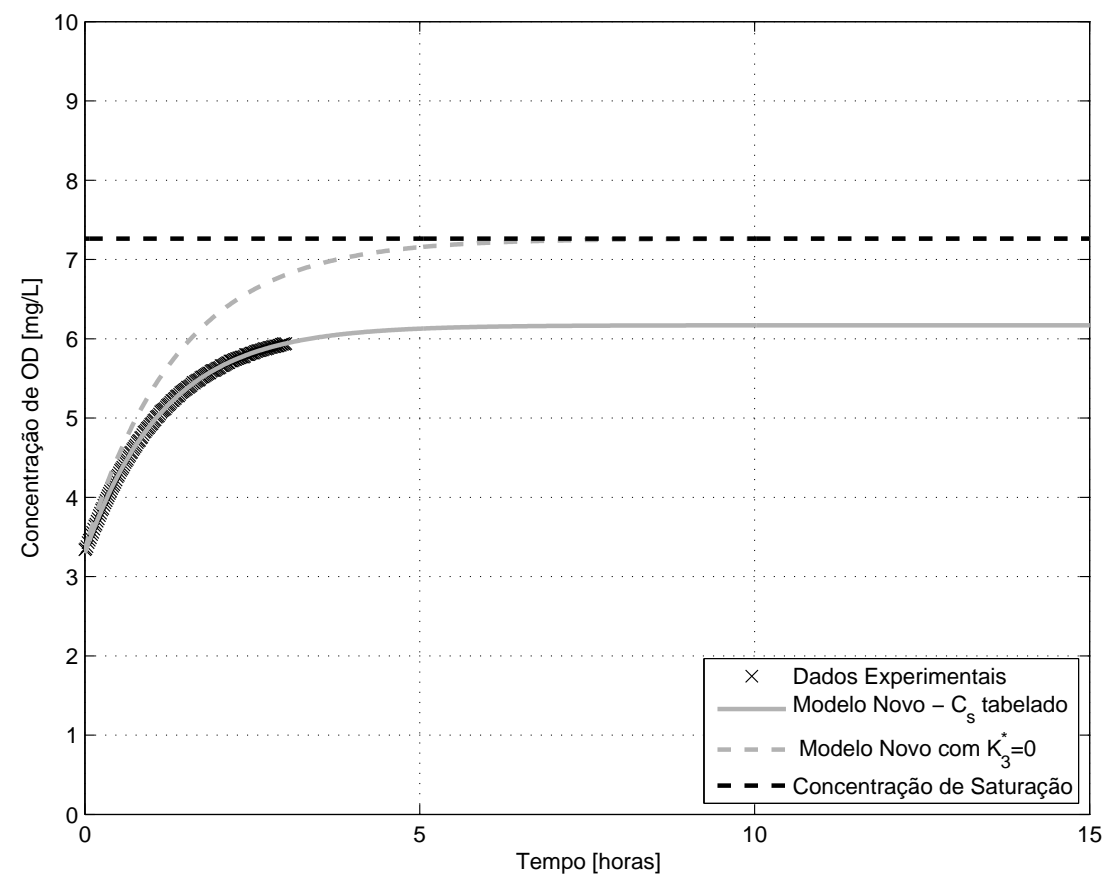

(b) Ajuste com o Modelo Novo

Figura B.89: Curva de reoxigenação para o ensaio 89 


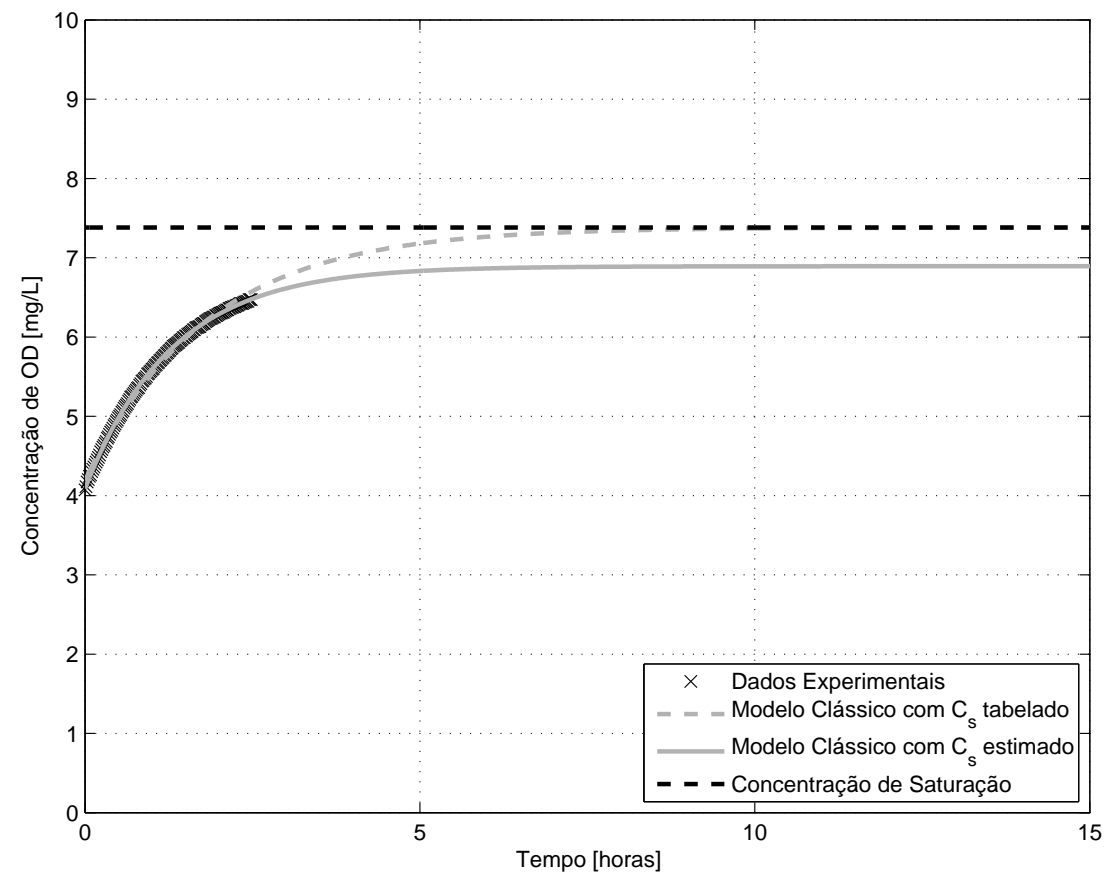

(a) Ajuste com o Modelo Clássico

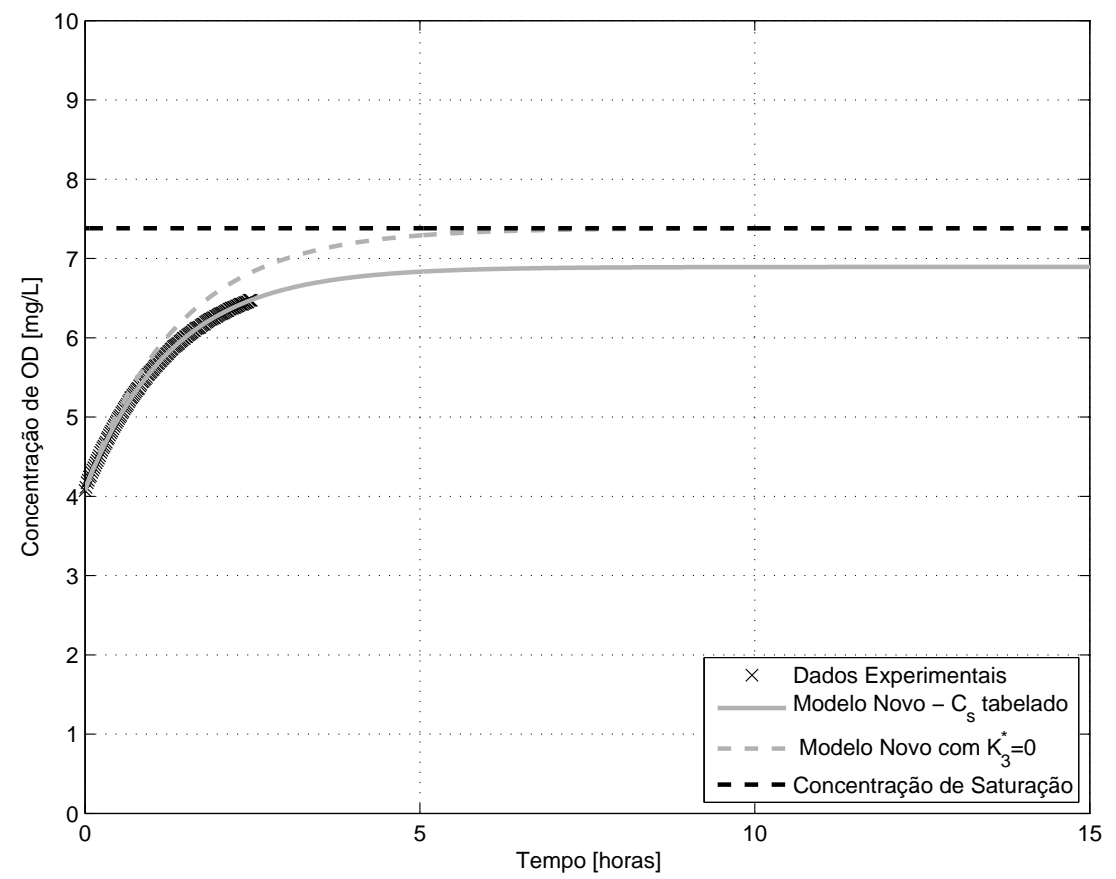

(b) Ajuste com o Modelo Novo

Figura B.90: Curva de reoxigenação para o ensaio 90 


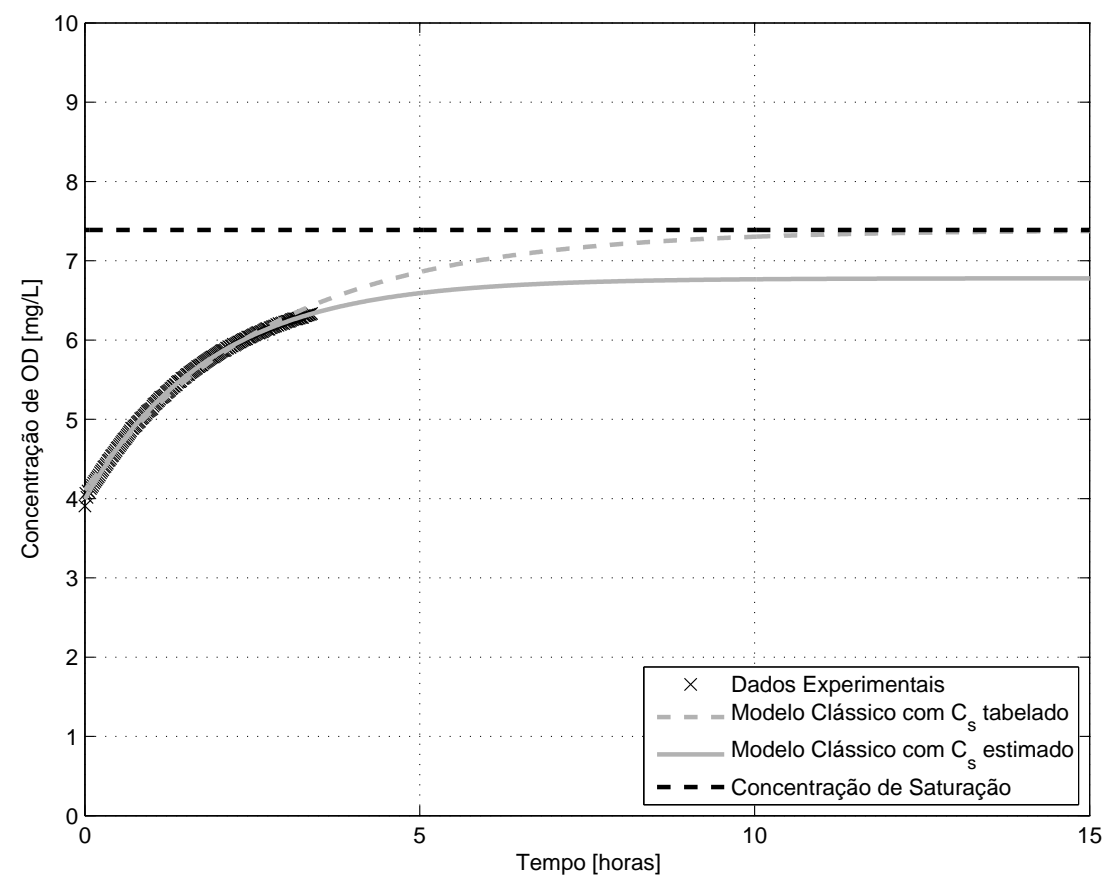

(a) Ajuste com o Modelo Clássico

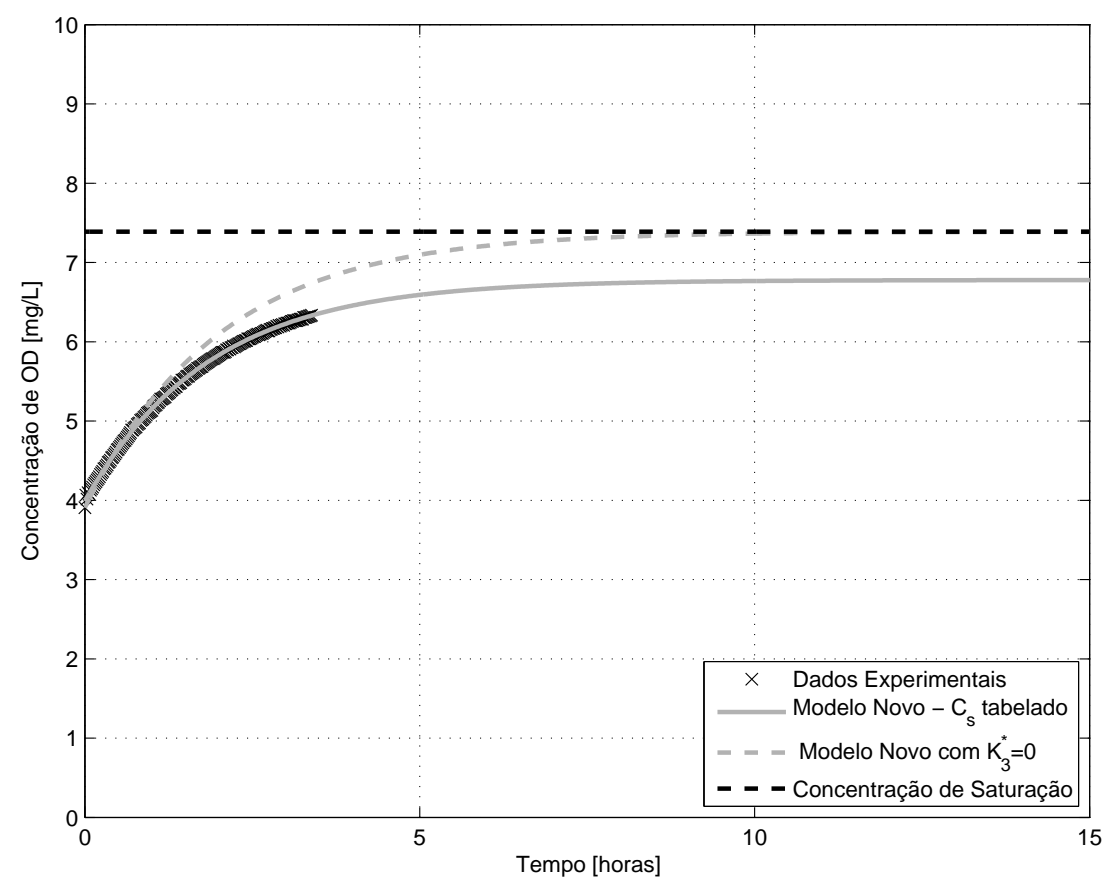

(b) Ajuste com o Modelo Novo

Figura B.91: Curva de reoxigenação para o ensaio 91 


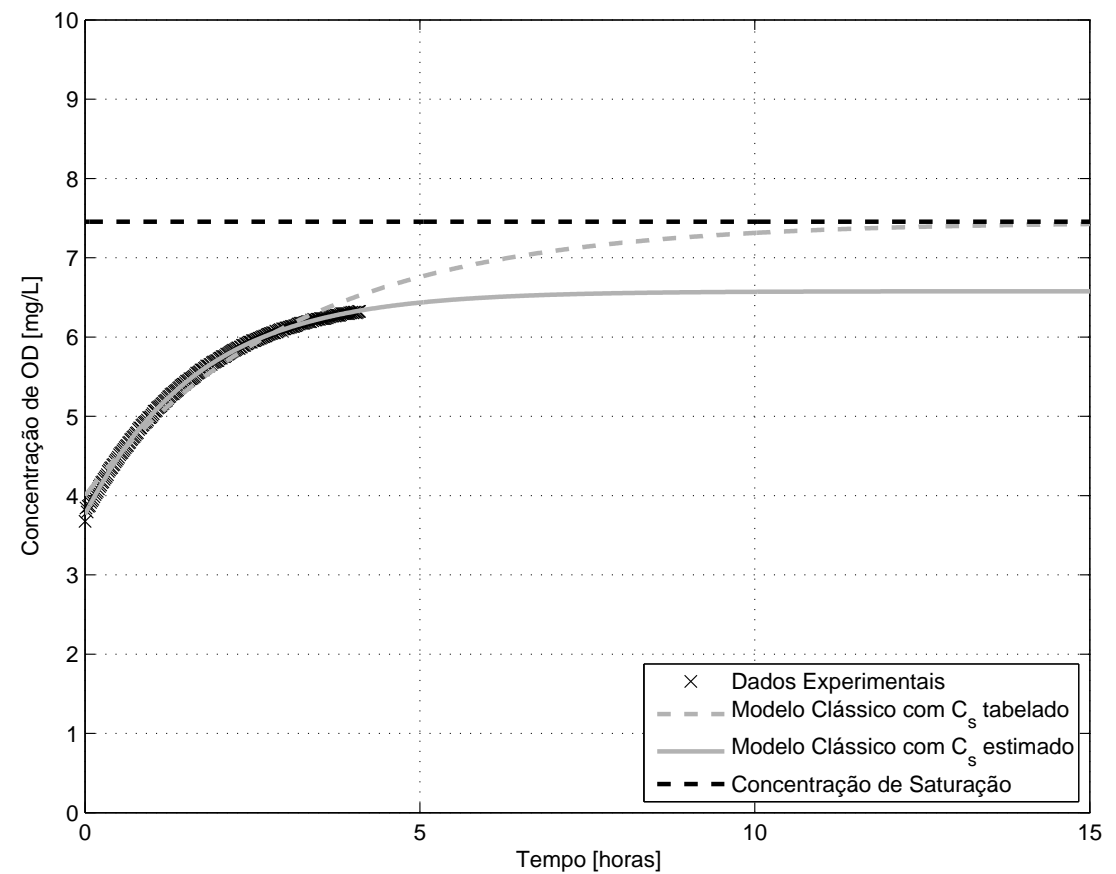

(a) Ajuste com o Modelo Clássico

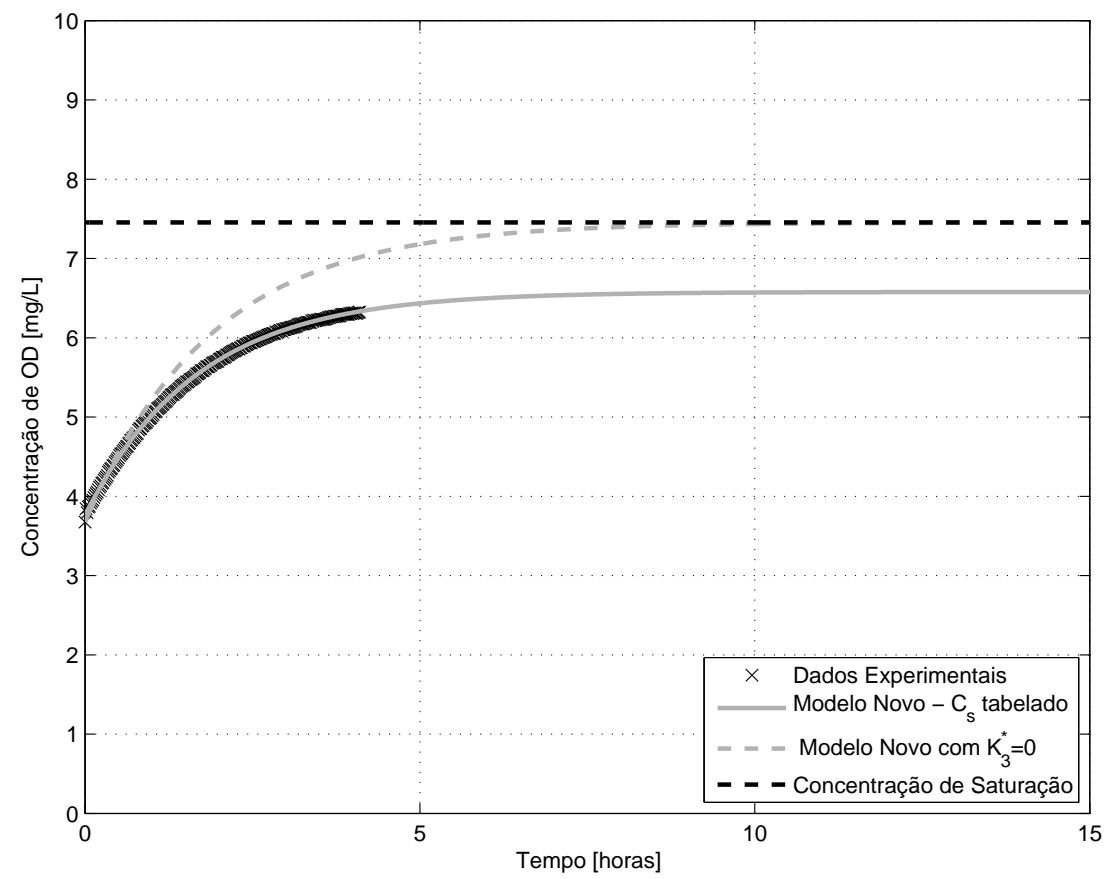

(b) Ajuste com o Modelo Novo

Figura B.92: Curva de reoxigenação para o ensaio 92 


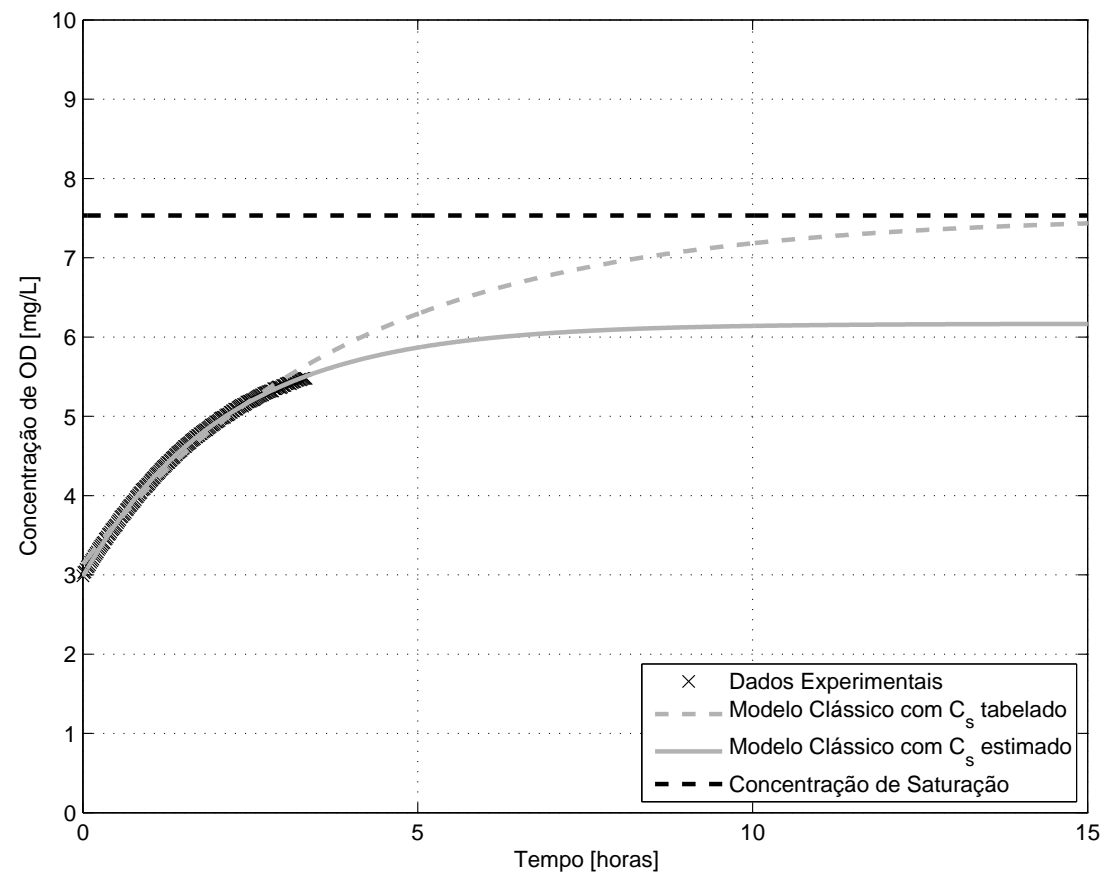

(a) Ajuste com o Modelo Clássico

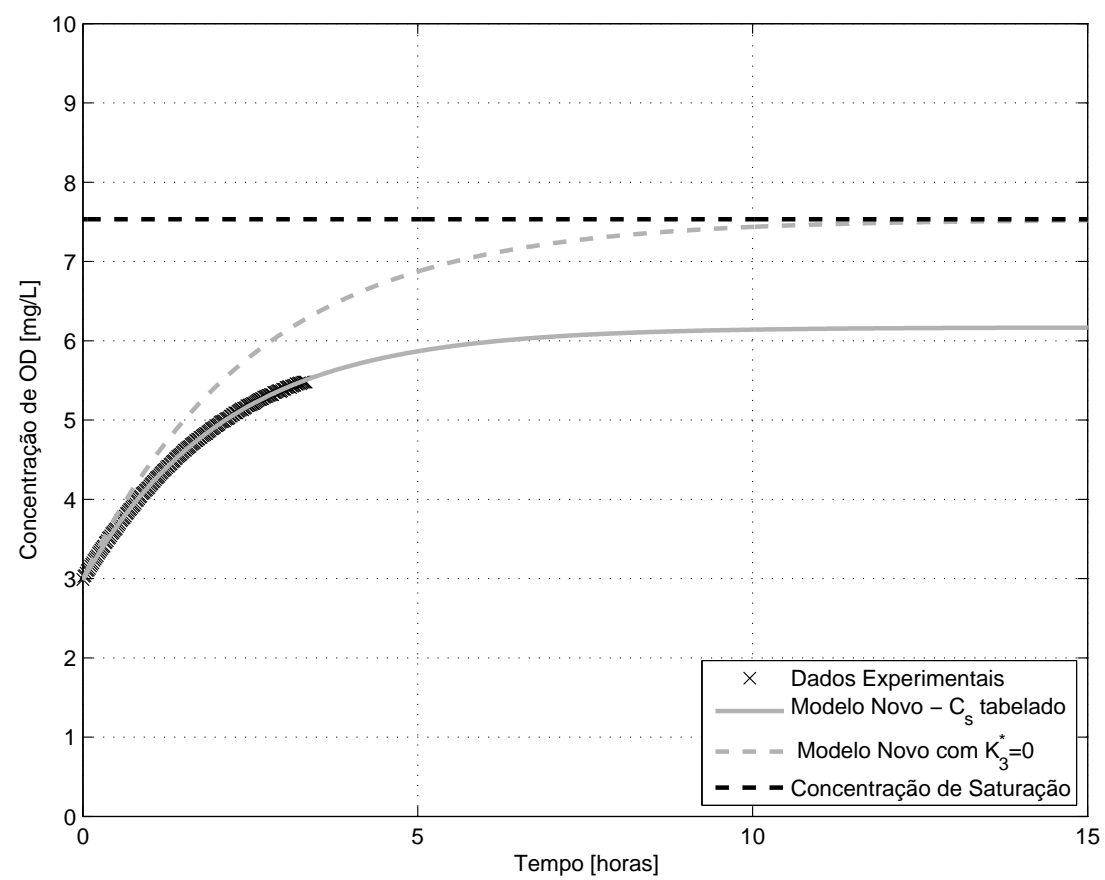

(b) Ajuste com o Modelo Novo

Figura B.93: Curva de reoxigenação para o ensaio 93 


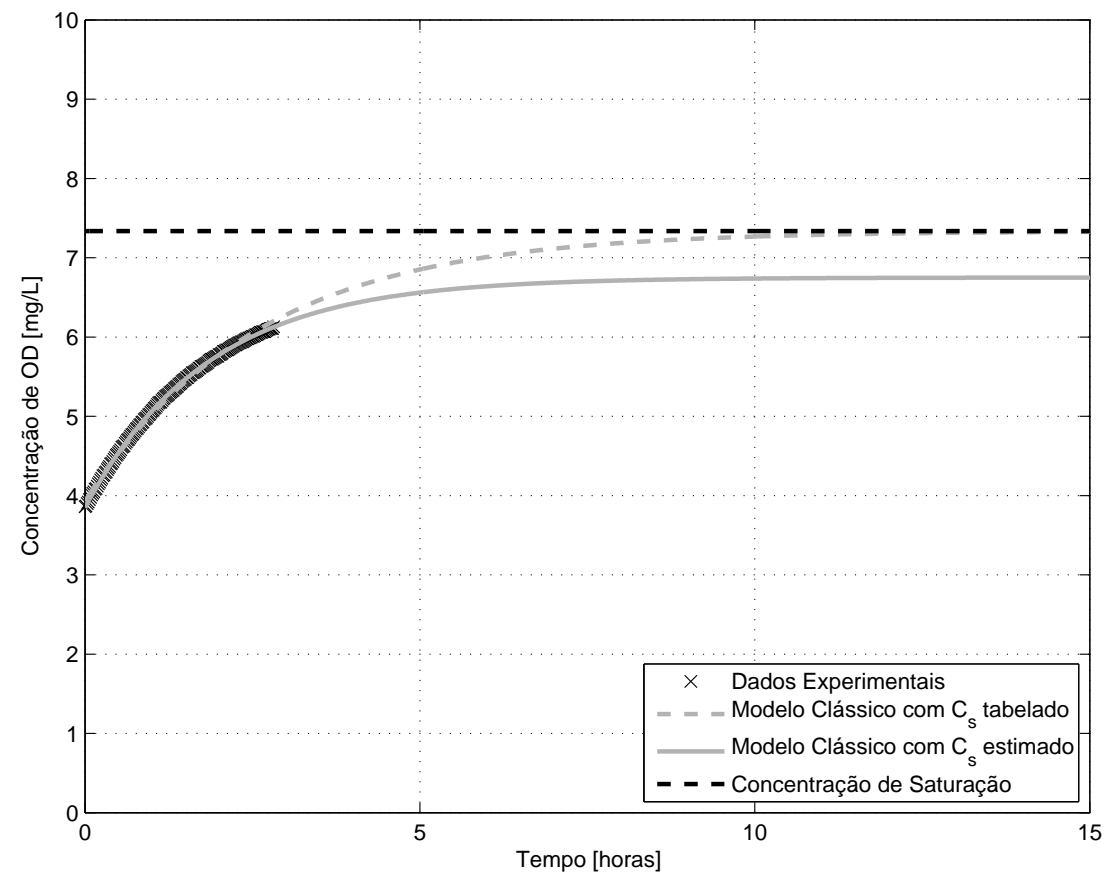

(a) Ajuste com o Modelo Clássico

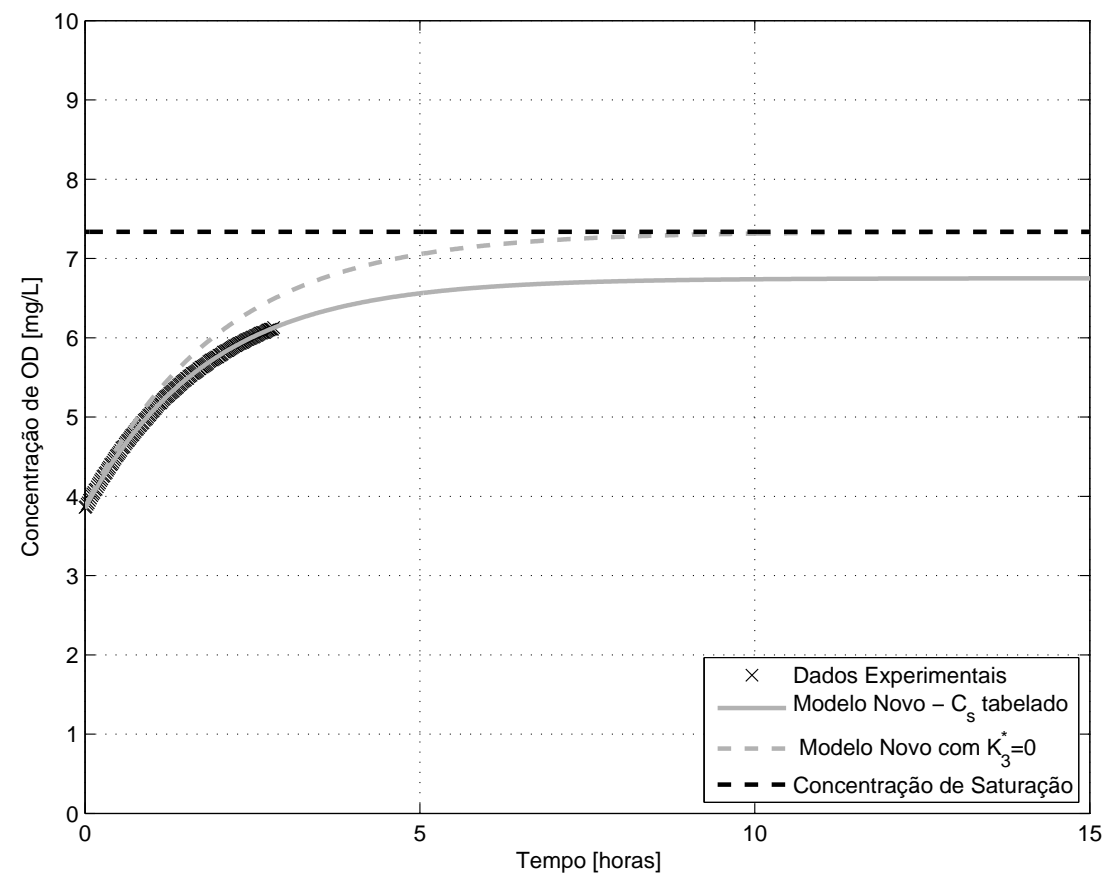

(b) Ajuste com o Modelo Novo

Figura B.94: Curva de reoxigenação para o ensaio 94 


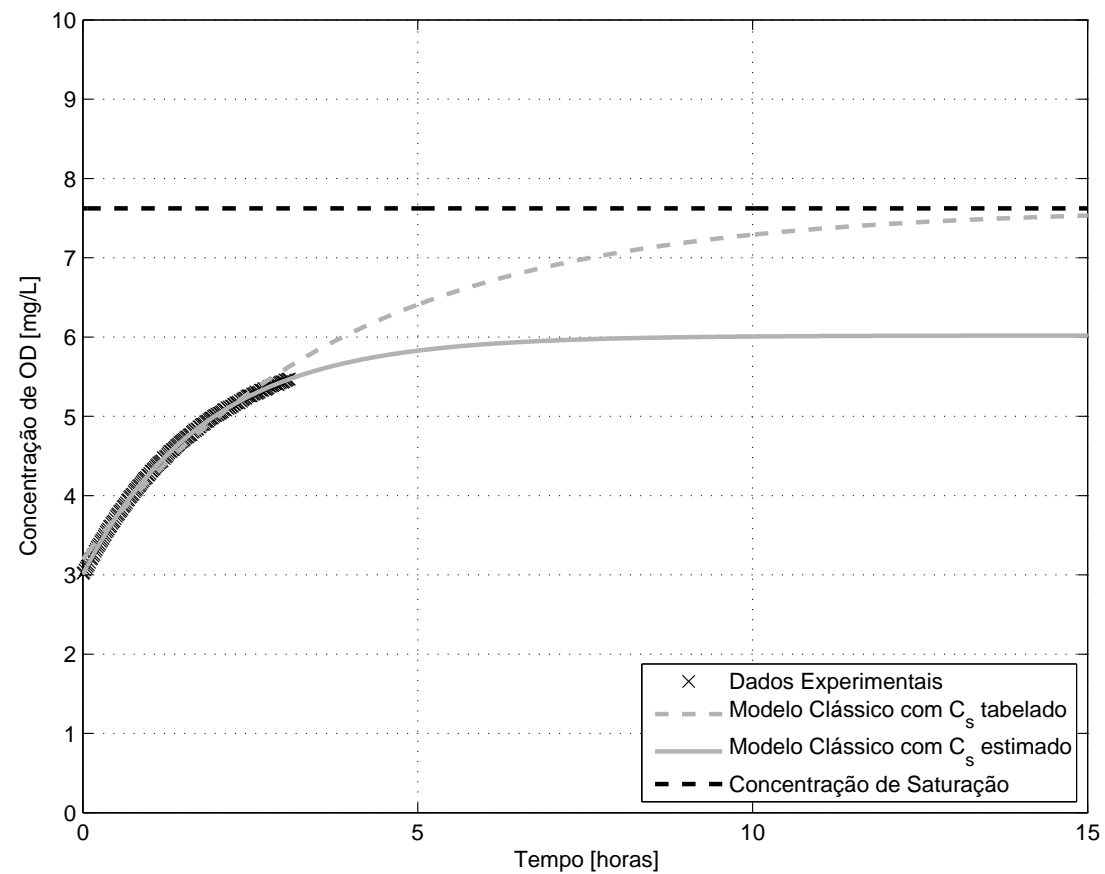

(a) Ajuste com o Modelo Clássico

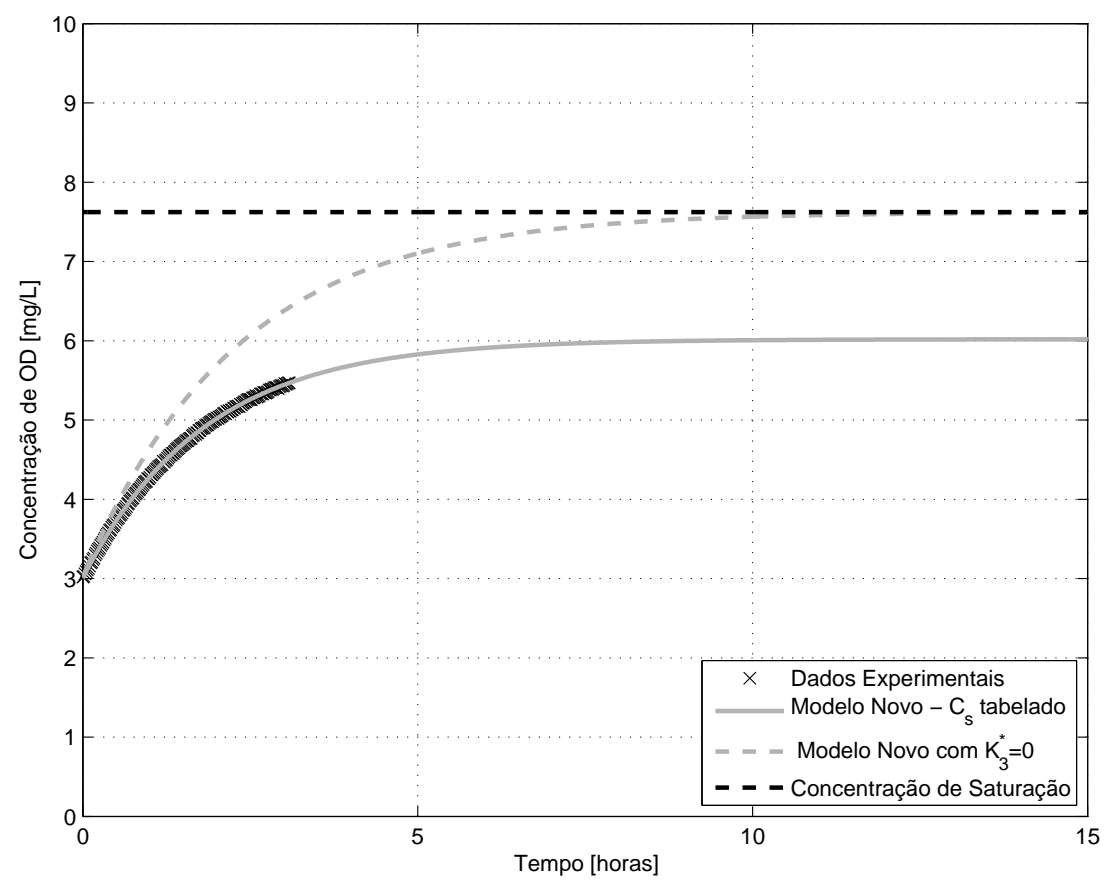

(b) Ajuste com o Modelo Novo

Figura B.95: Curva de reoxigenação para o ensaio 95 


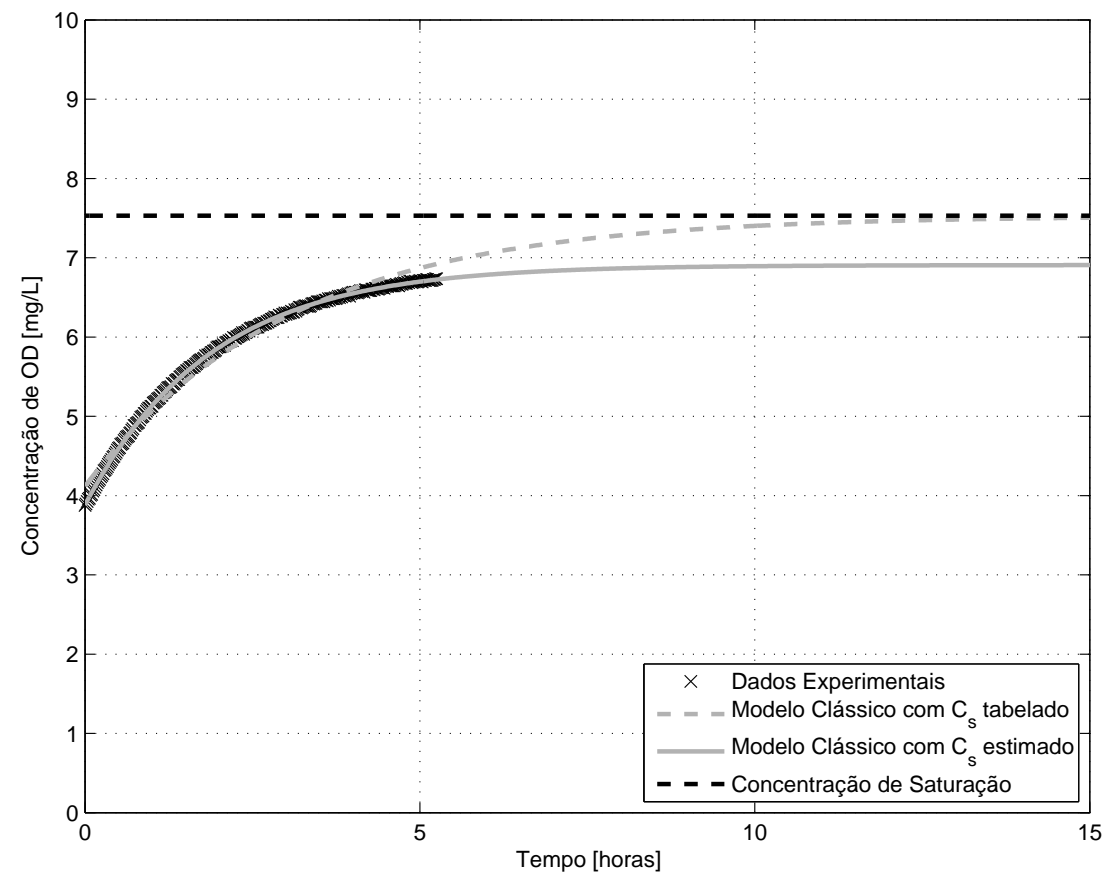

(a) Ajuste com o Modelo Clássico

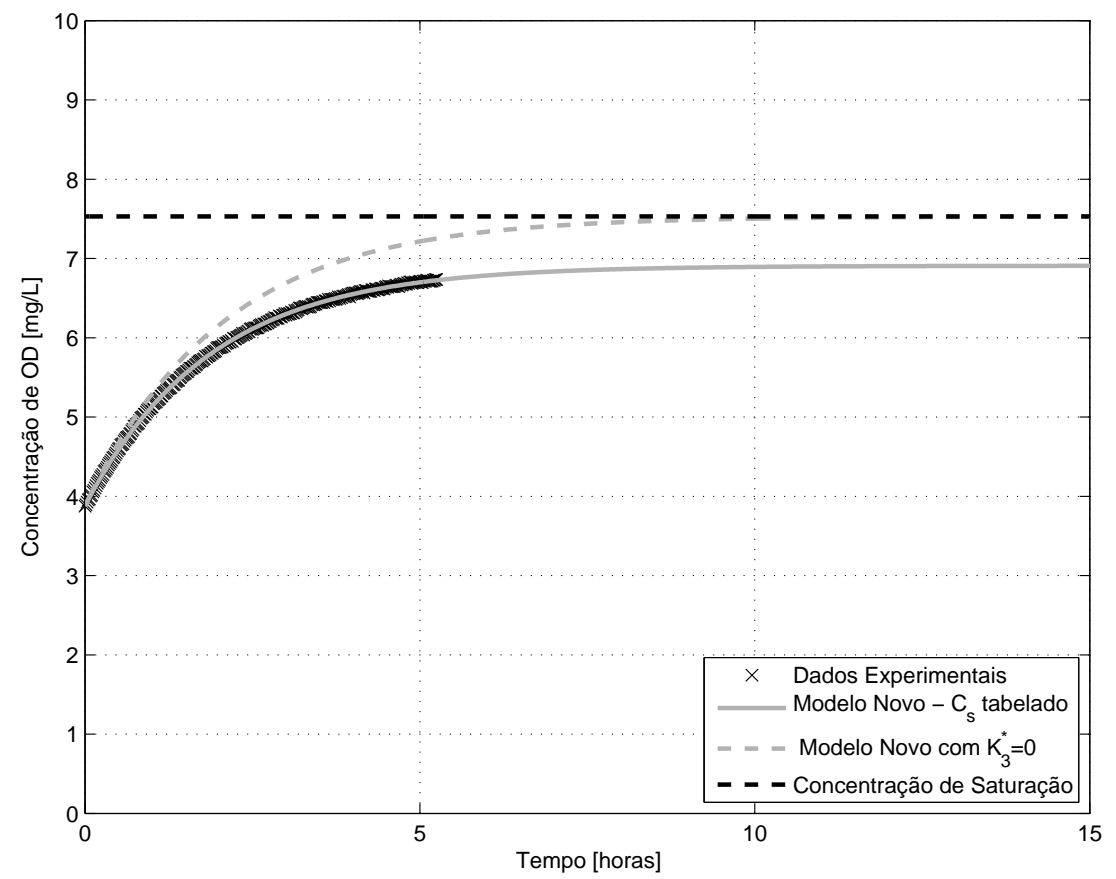

(b) Ajuste com o Modelo Novo

Figura B.96: Curva de reoxigenação para o ensaio 96 


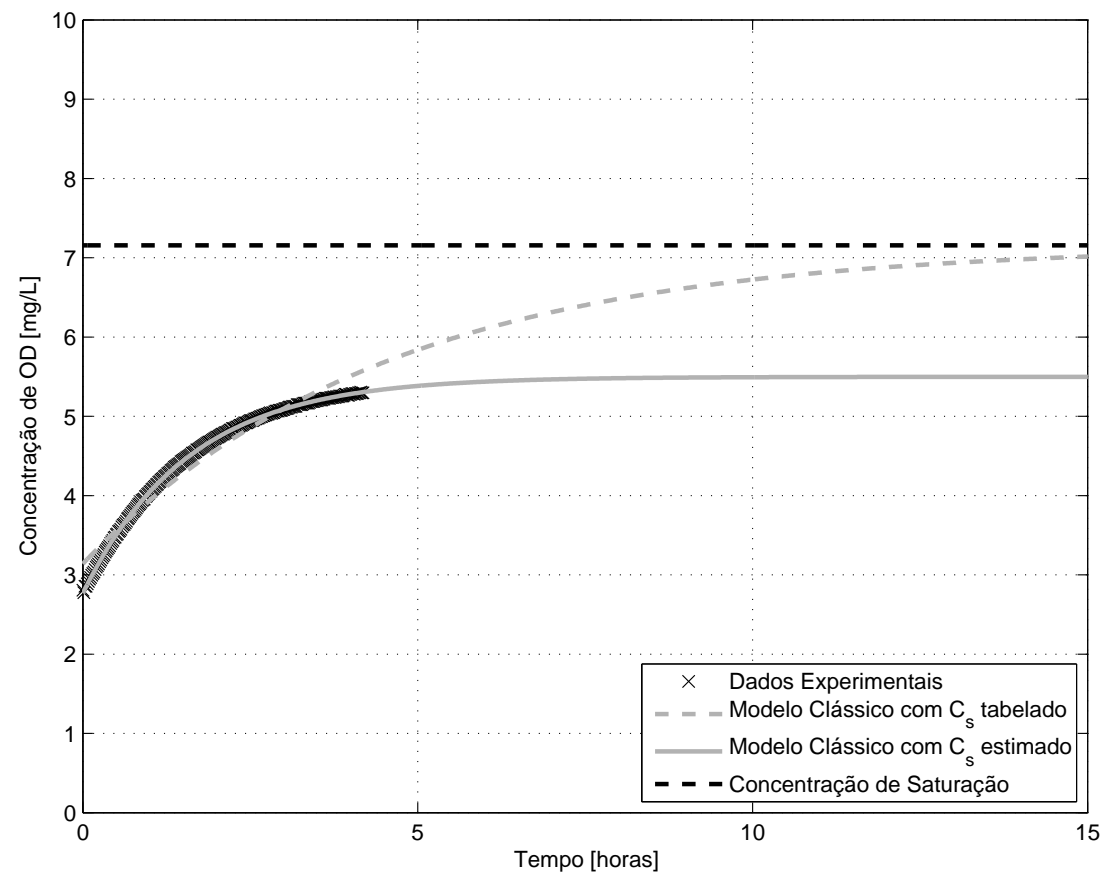

(a) Ajuste com o Modelo Clássico

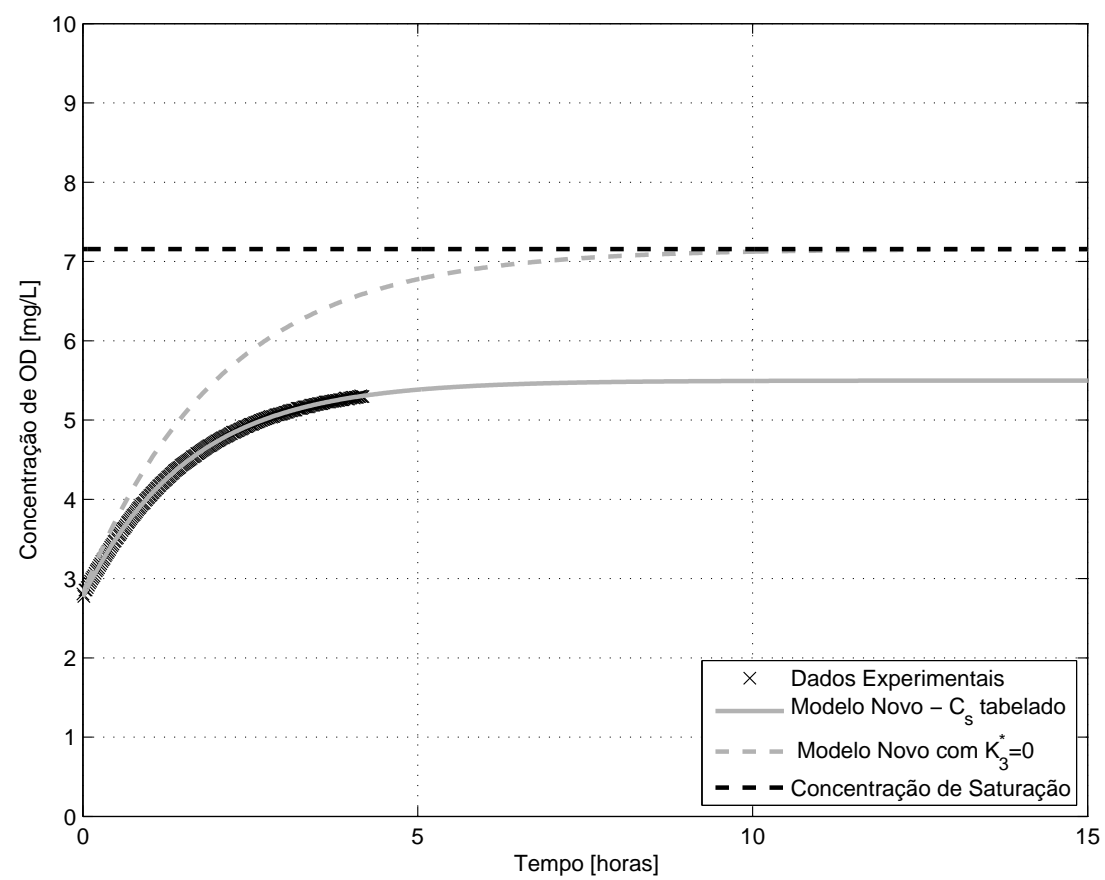

(b) Ajuste com o Modelo Novo

Figura B.97: Curva de reoxigenação para o ensaio 97 


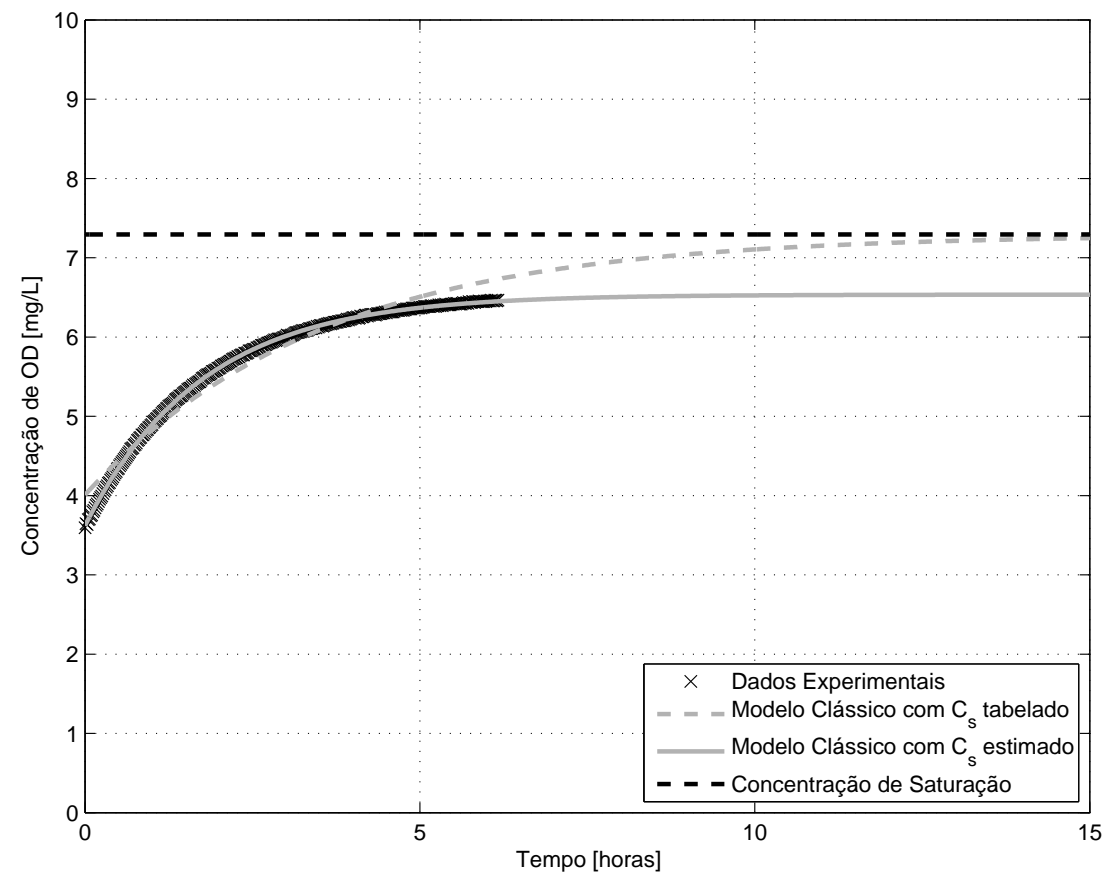

(a) Ajuste com o Modelo Clássico

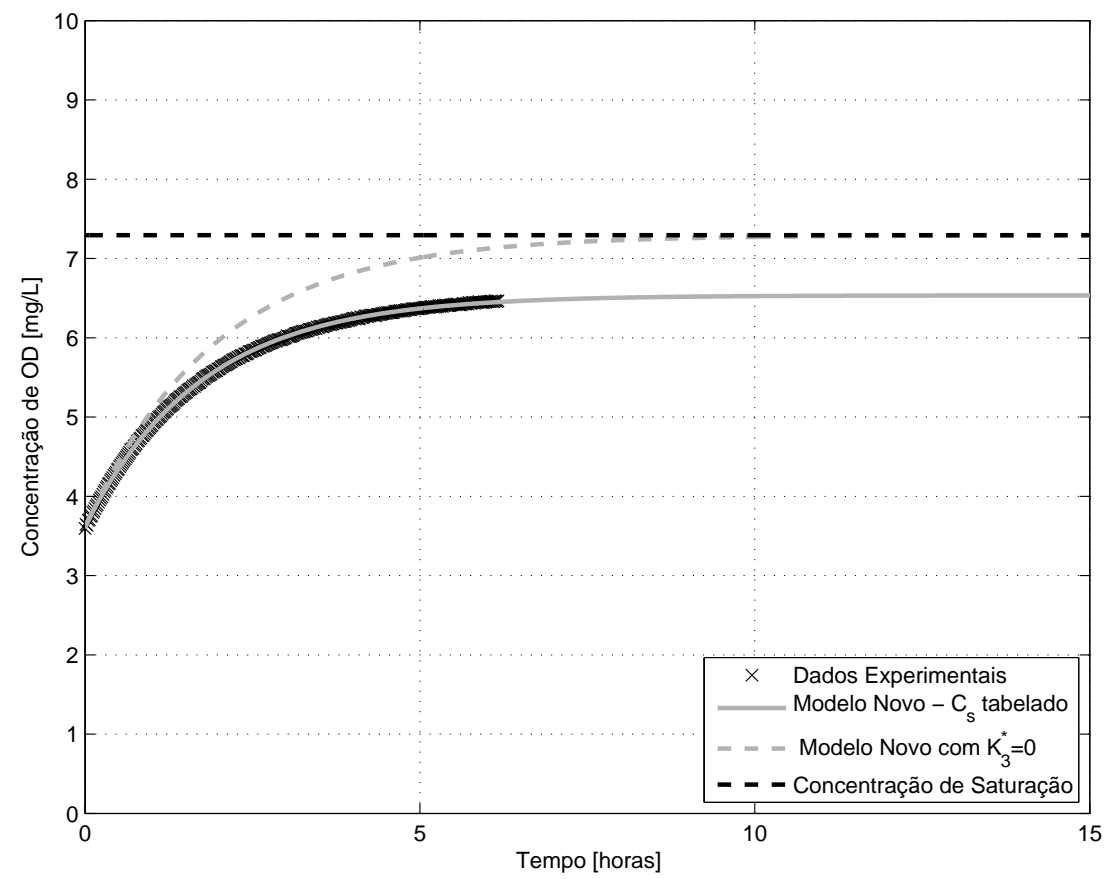

(b) Ajuste com o Modelo Novo

Figura B.98: Curva de reoxigenação para o ensaio 98 


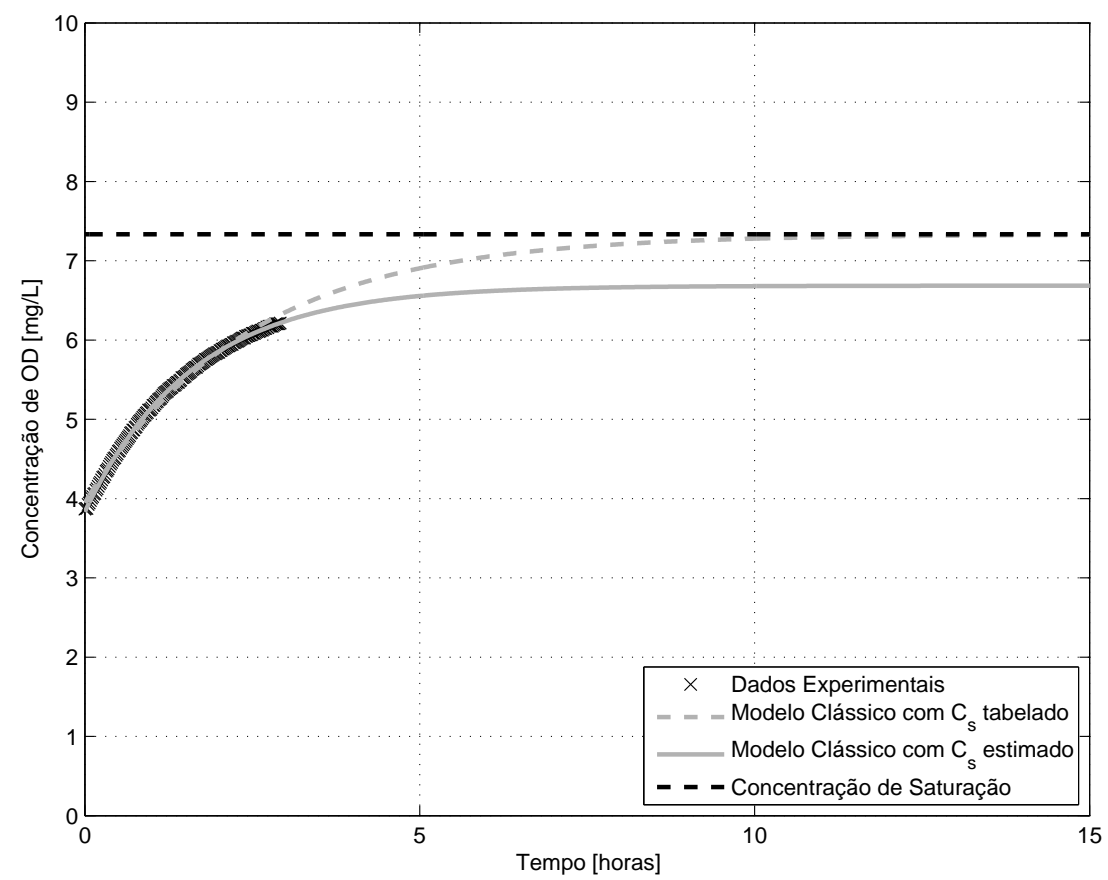

(a) Ajuste com o Modelo Clássico

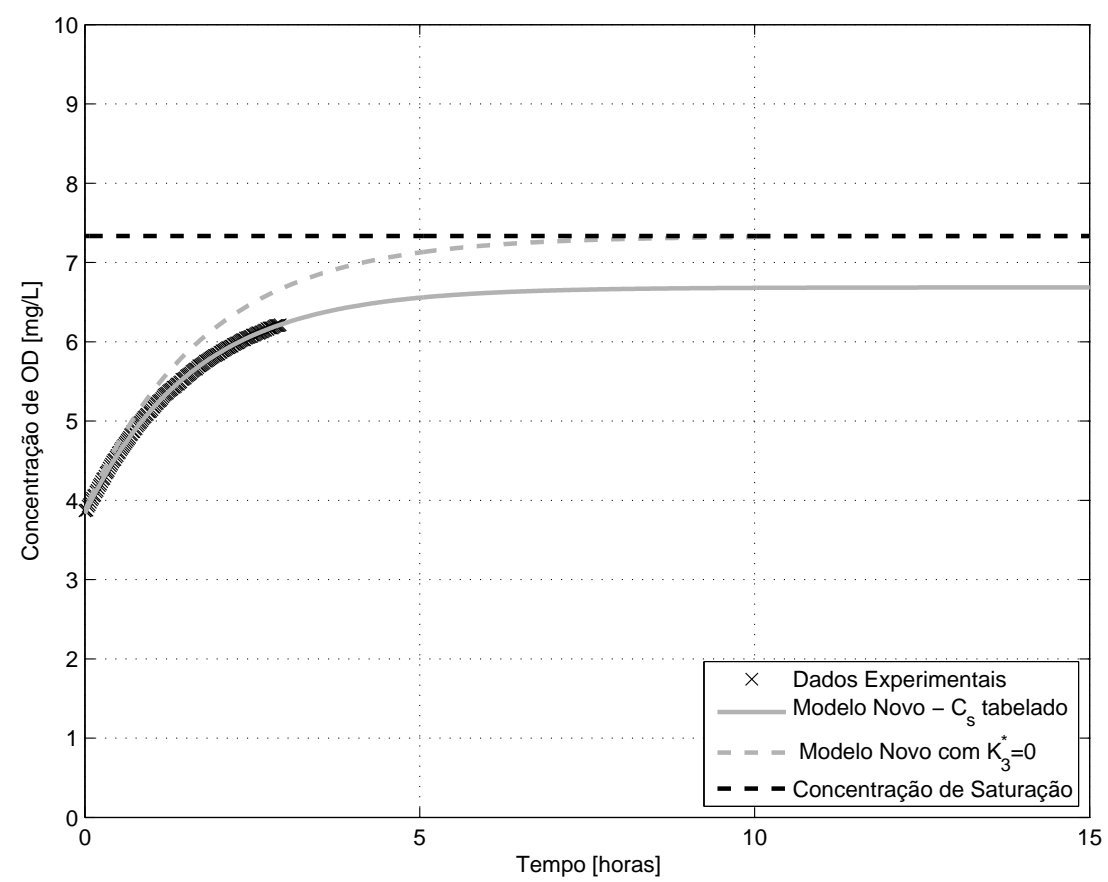

(b) Ajuste com o Modelo Novo

Figura B.99: Curva de reoxigenação para o ensaio 99 


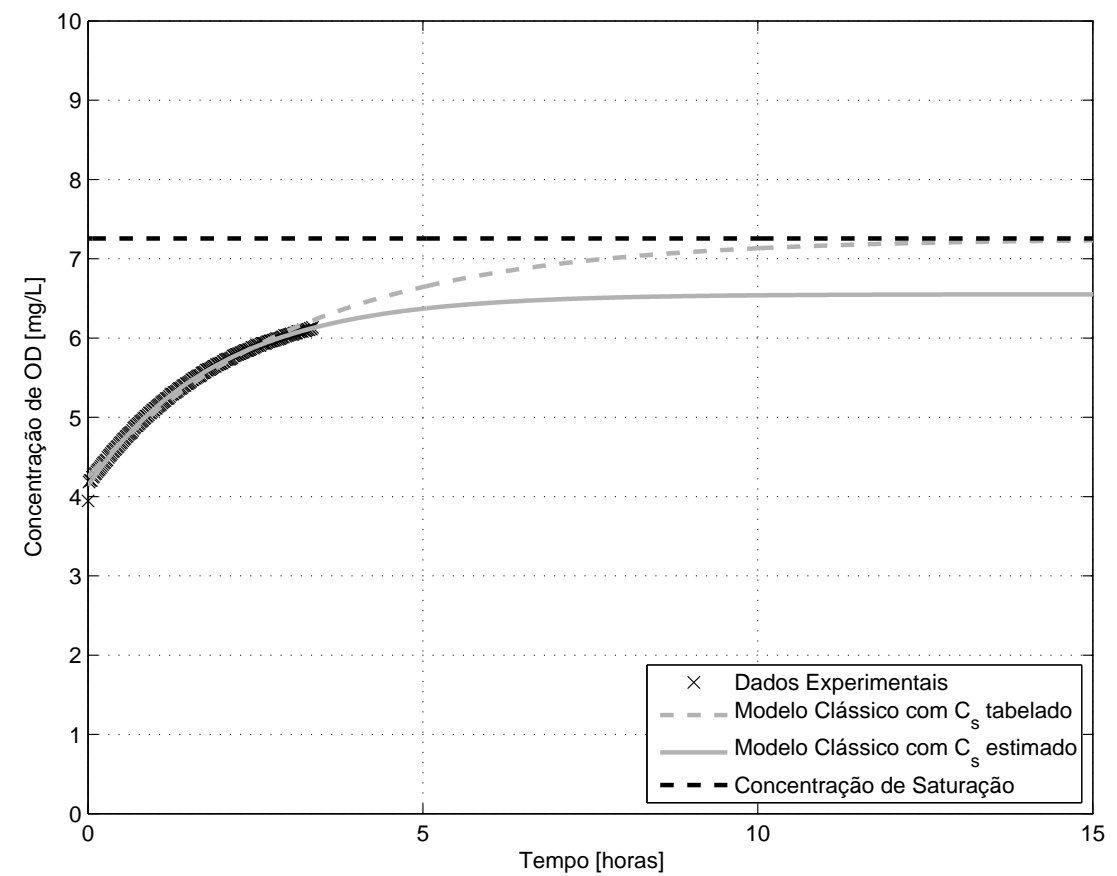

(a) Ajuste com o Modelo Clássico

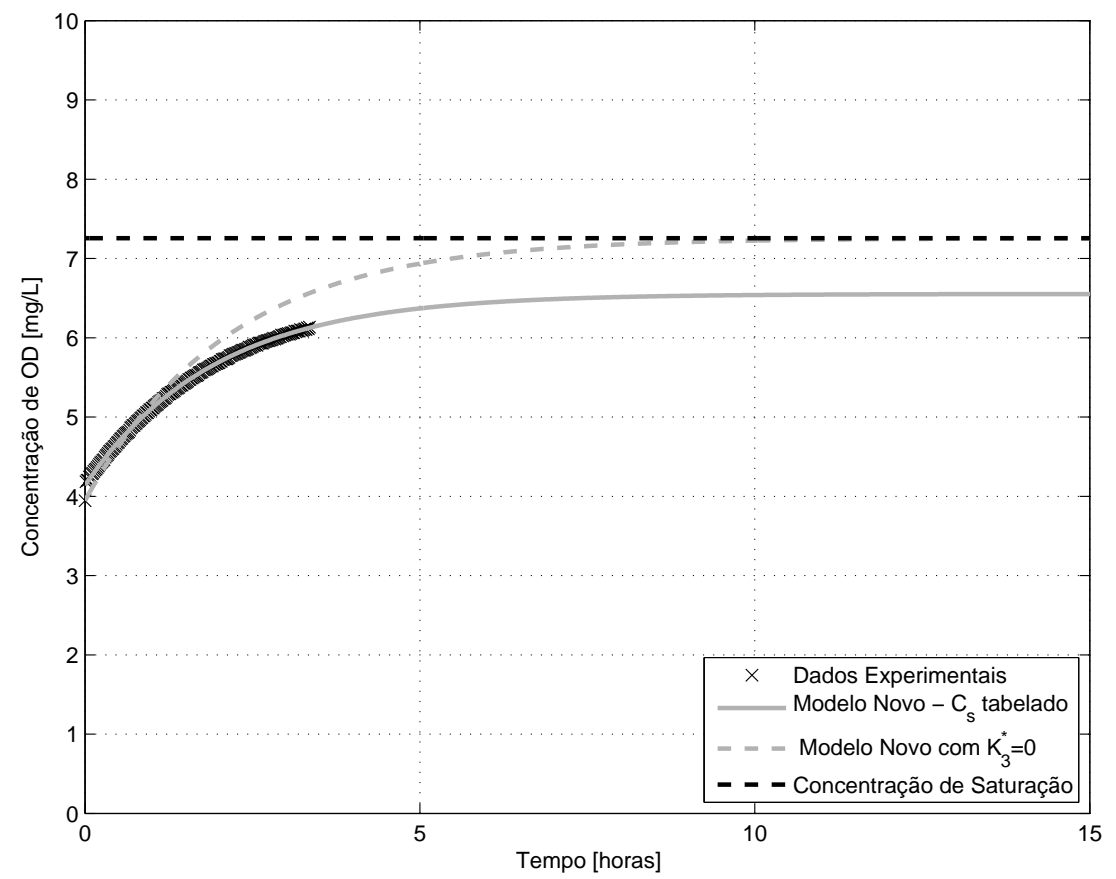

(b) Ajuste com o Modelo Novo

Figura B.100: Curva de reoxigenação para o ensaio 100 


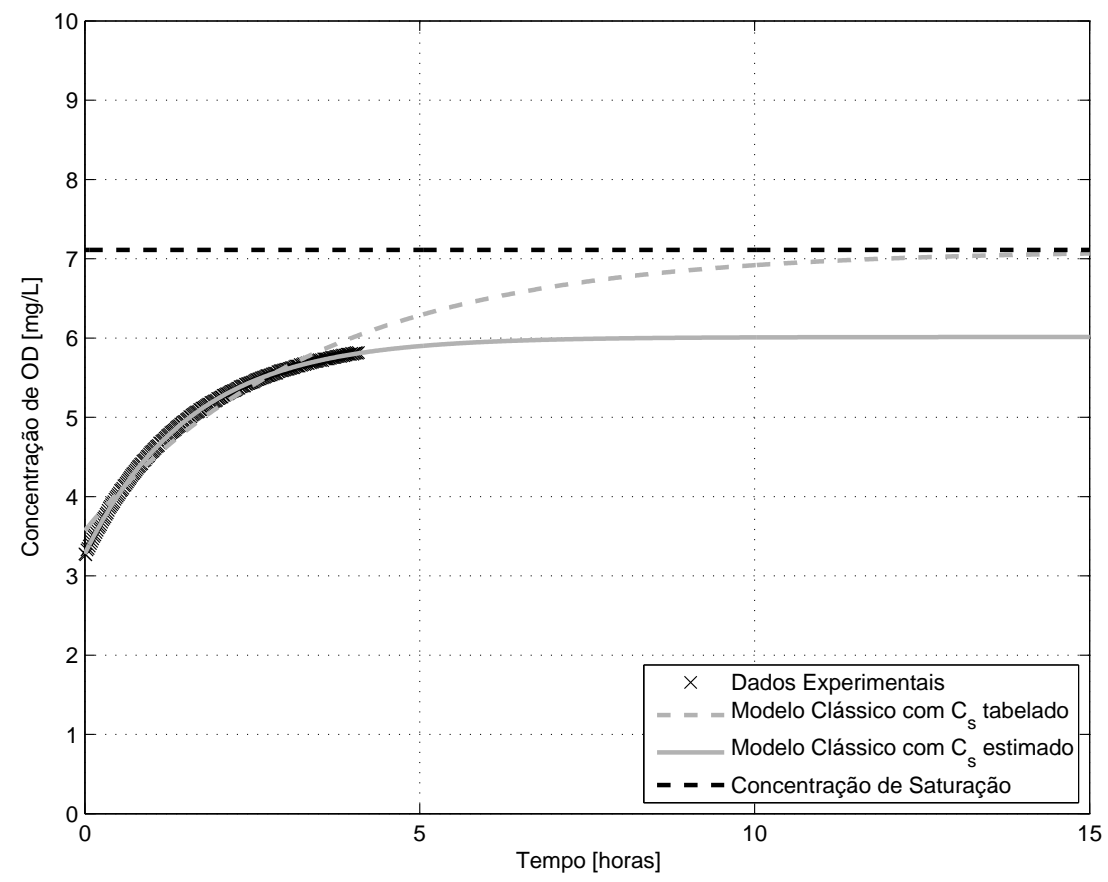

(a) Ajuste com o Modelo Clássico

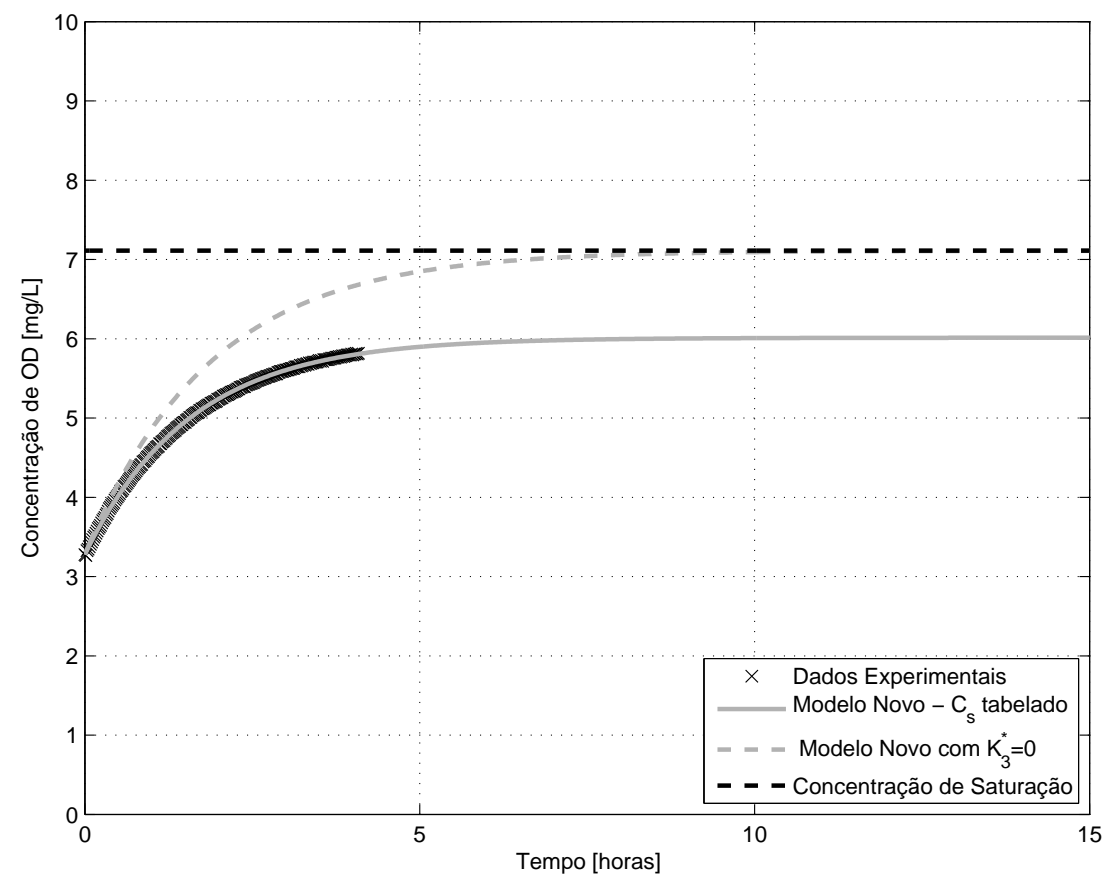

(b) Ajuste com o Modelo Novo

Figura B.101: Curva de reoxigenação para o ensaio 101 


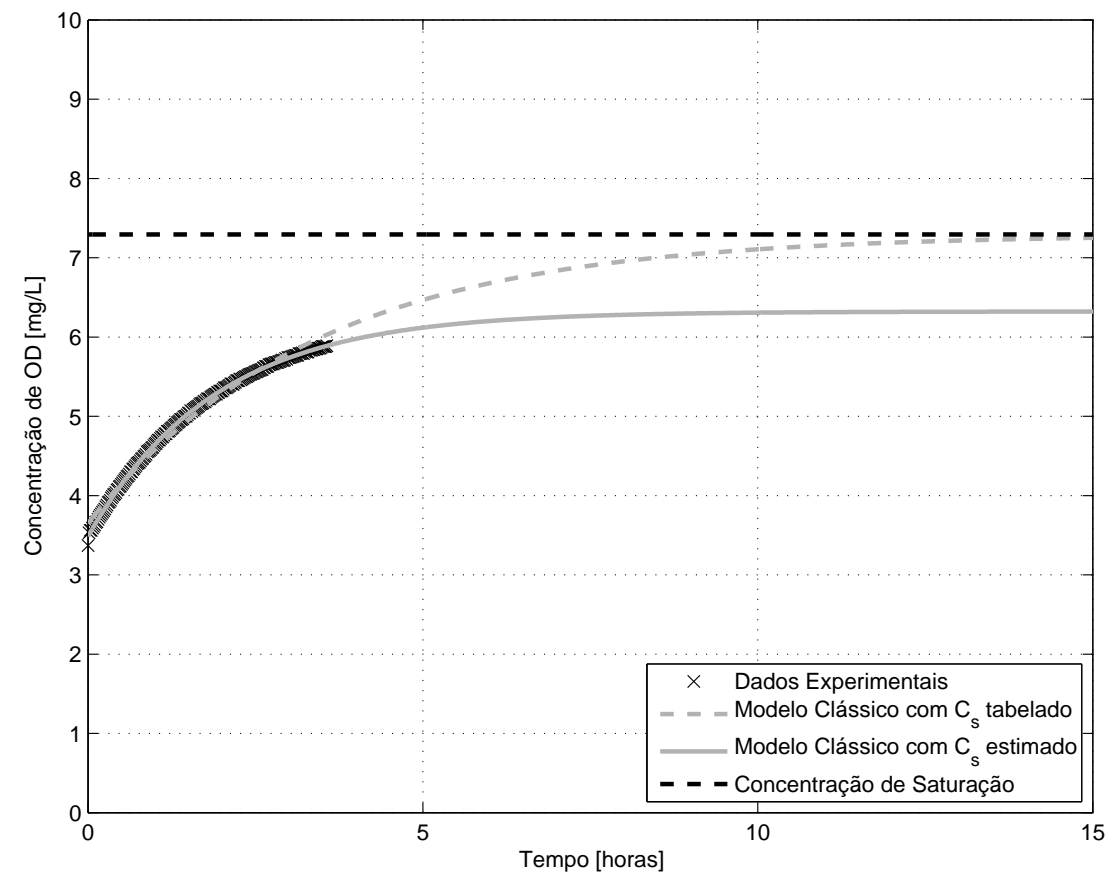

(a) Ajuste com o Modelo Clássico

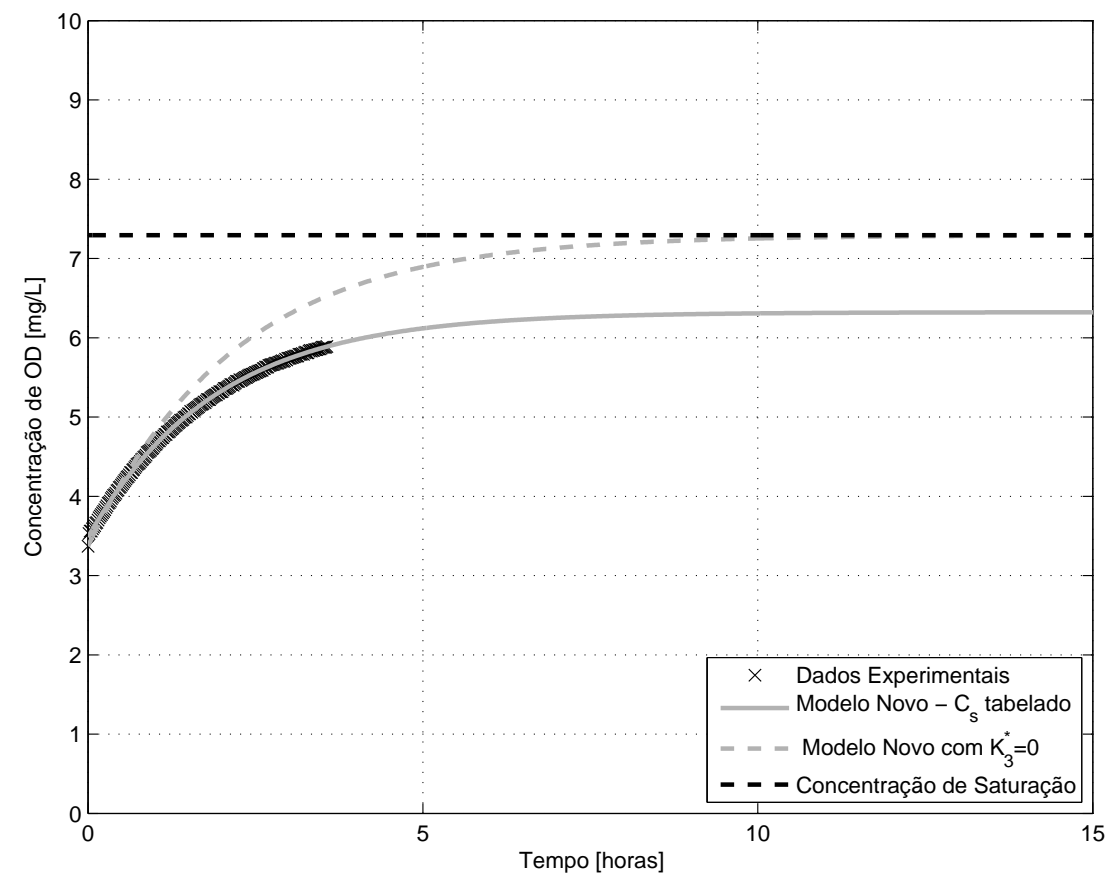

(b) Ajuste com o Modelo Novo

Figura B.102: Curva de reoxigenação para o ensaio 102 


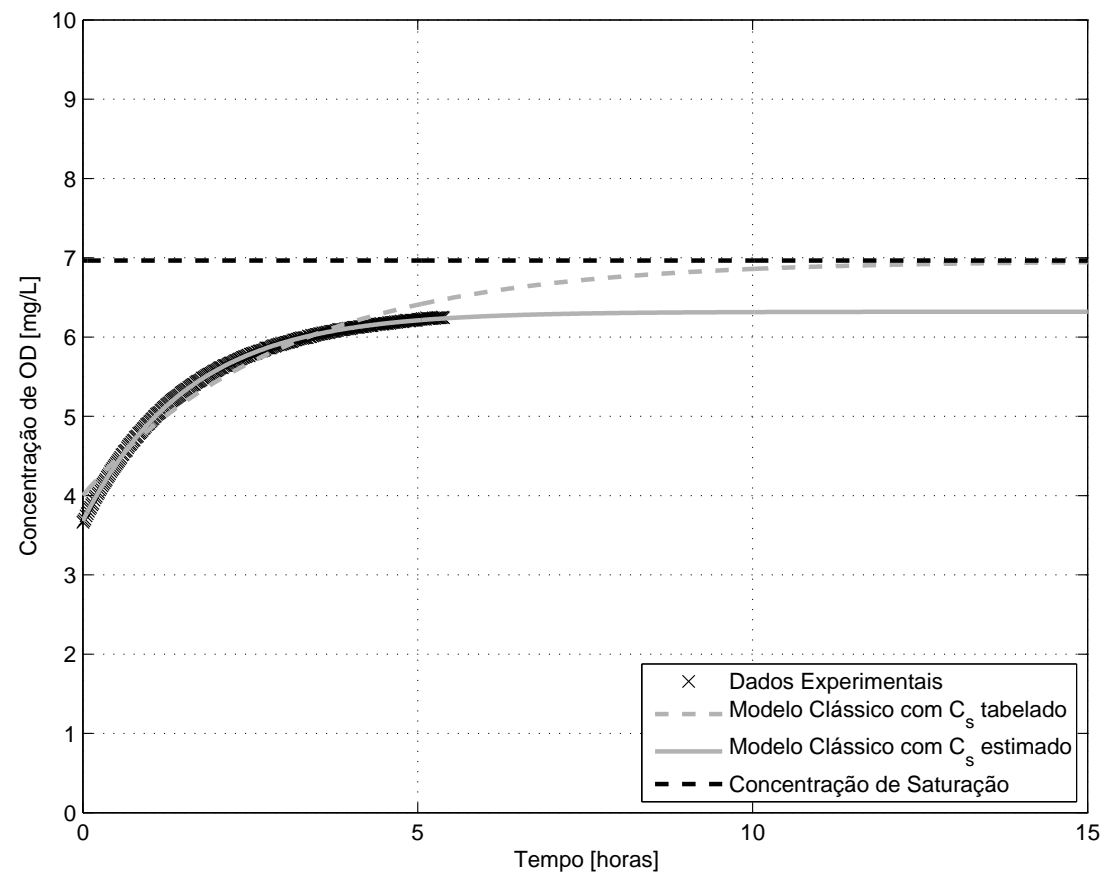

(a) Ajuste com o Modelo Clássico

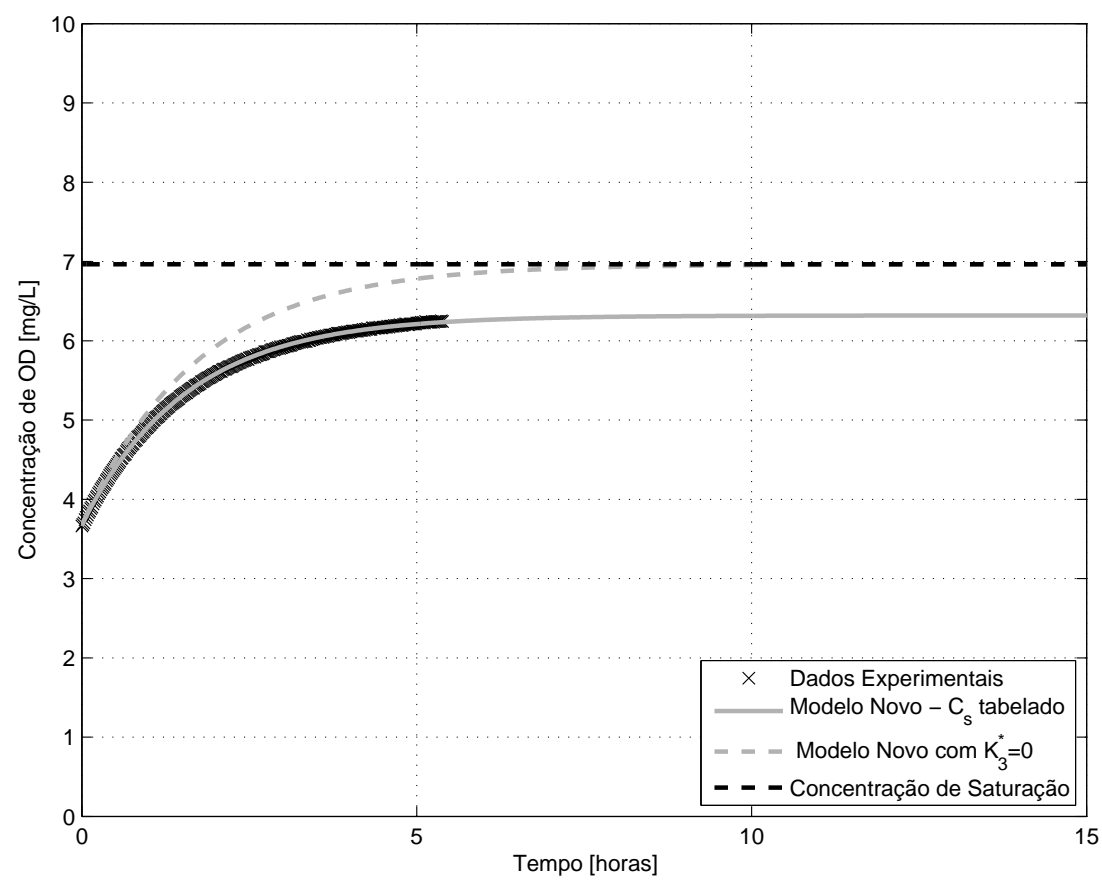

(b) Ajuste com o Modelo Novo

Figura B.103: Curva de reoxigenação para o ensaio 103 


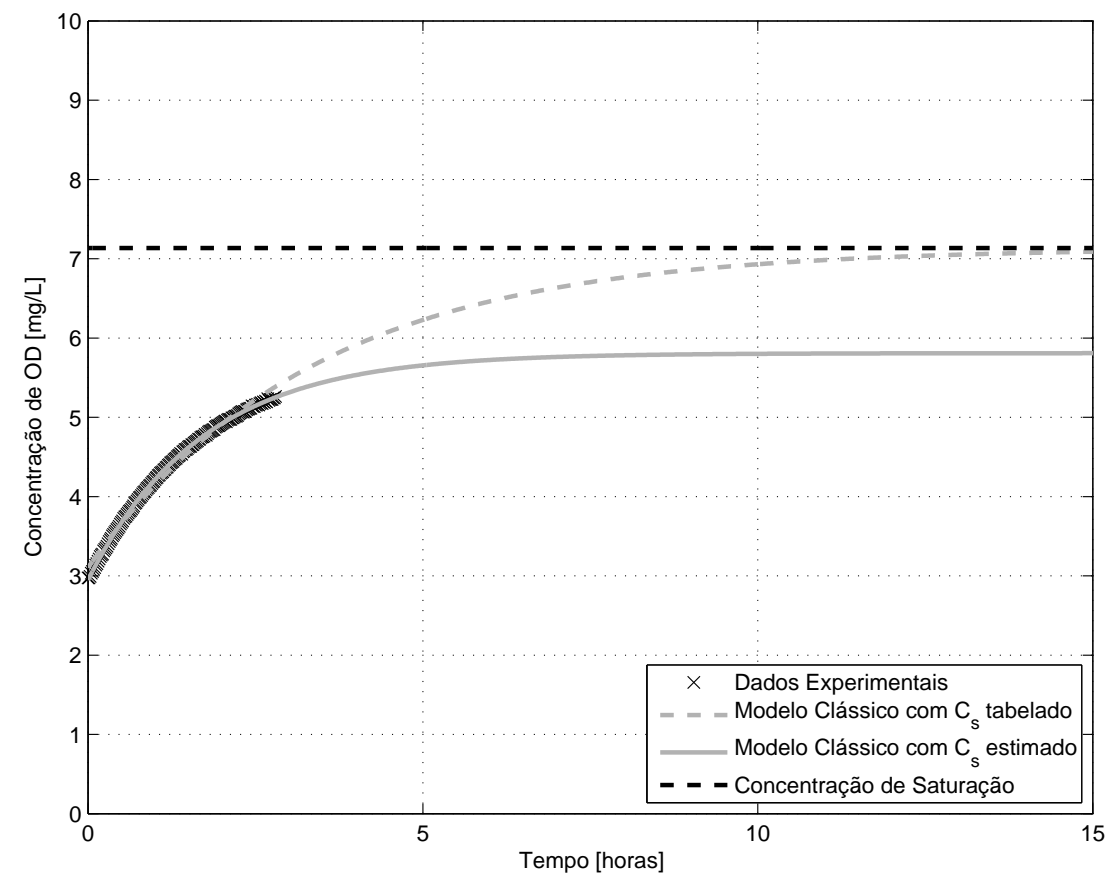

(a) Ajuste com o Modelo Clássico

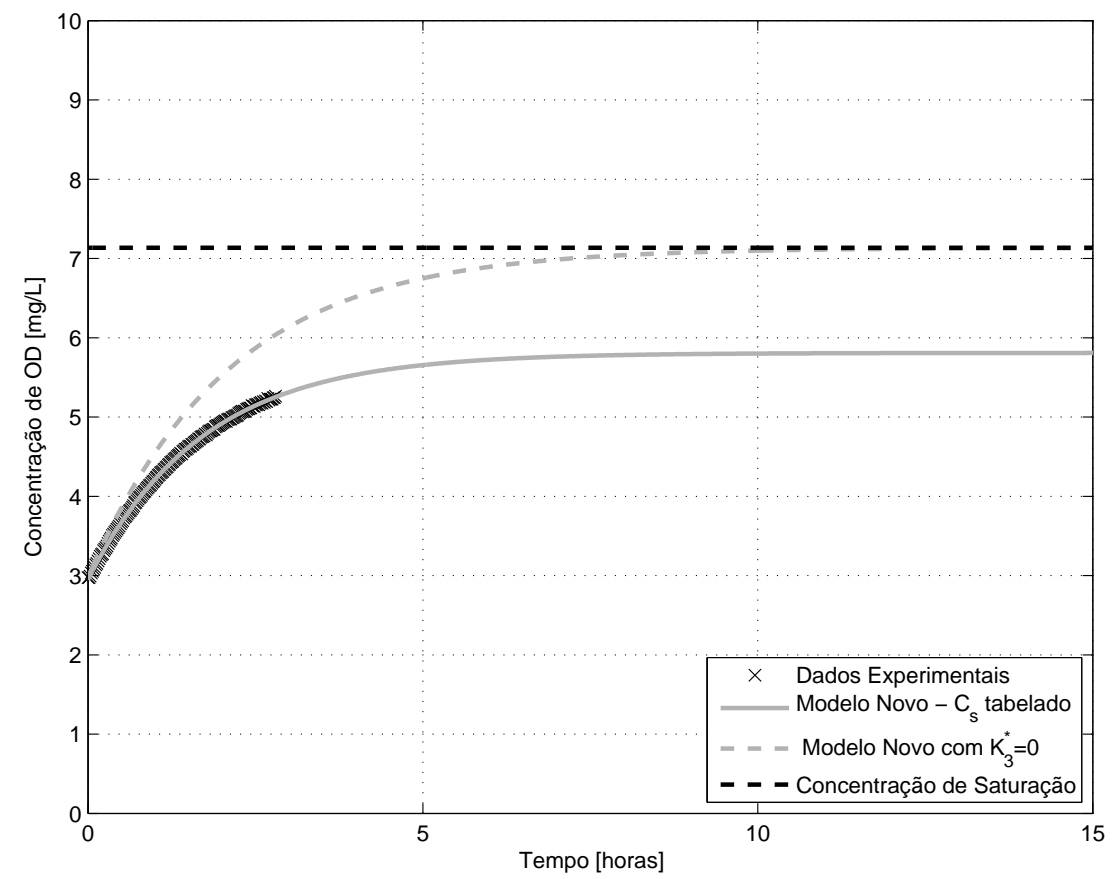

(b) Ajuste com o Modelo Novo

Figura B.104: Curva de reoxigenação para o ensaio 104 


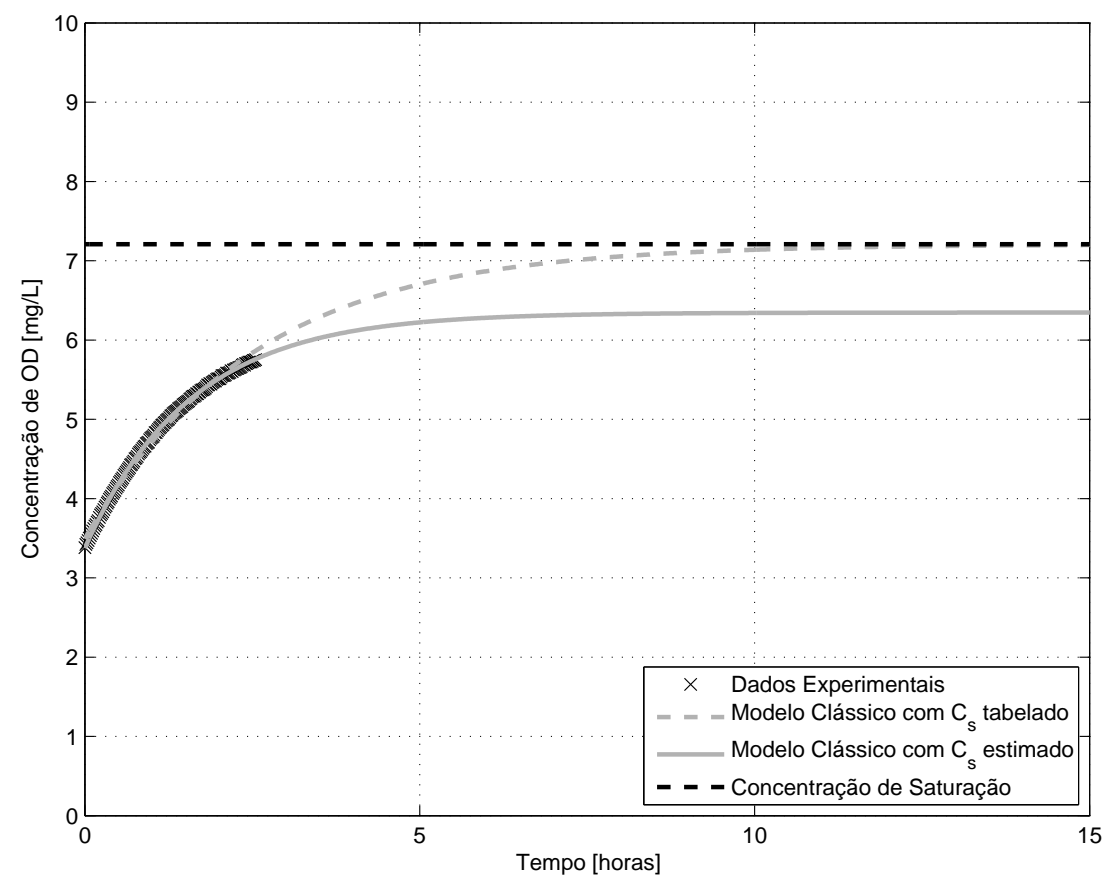

(a) Ajuste com o Modelo Clássico

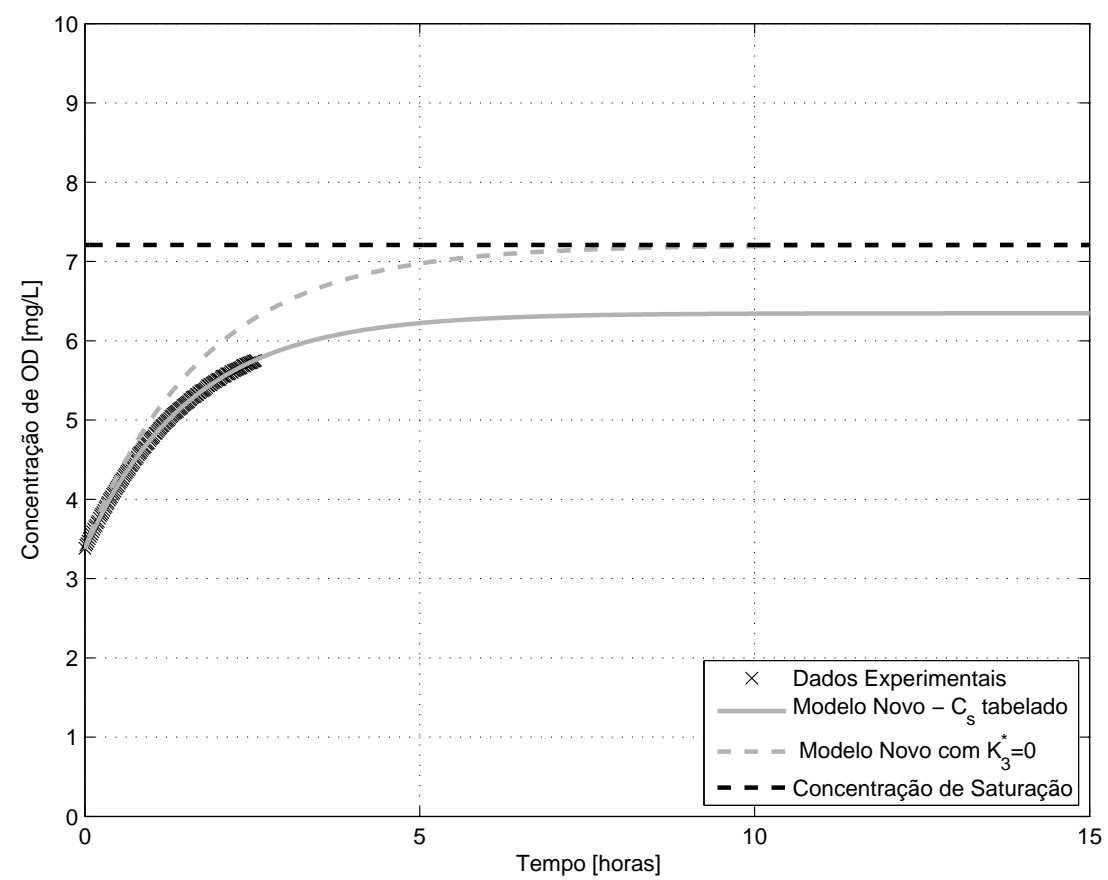

(b) Ajuste com o Modelo Novo

Figura B.105: Curva de reoxigenação para o ensaio 105 


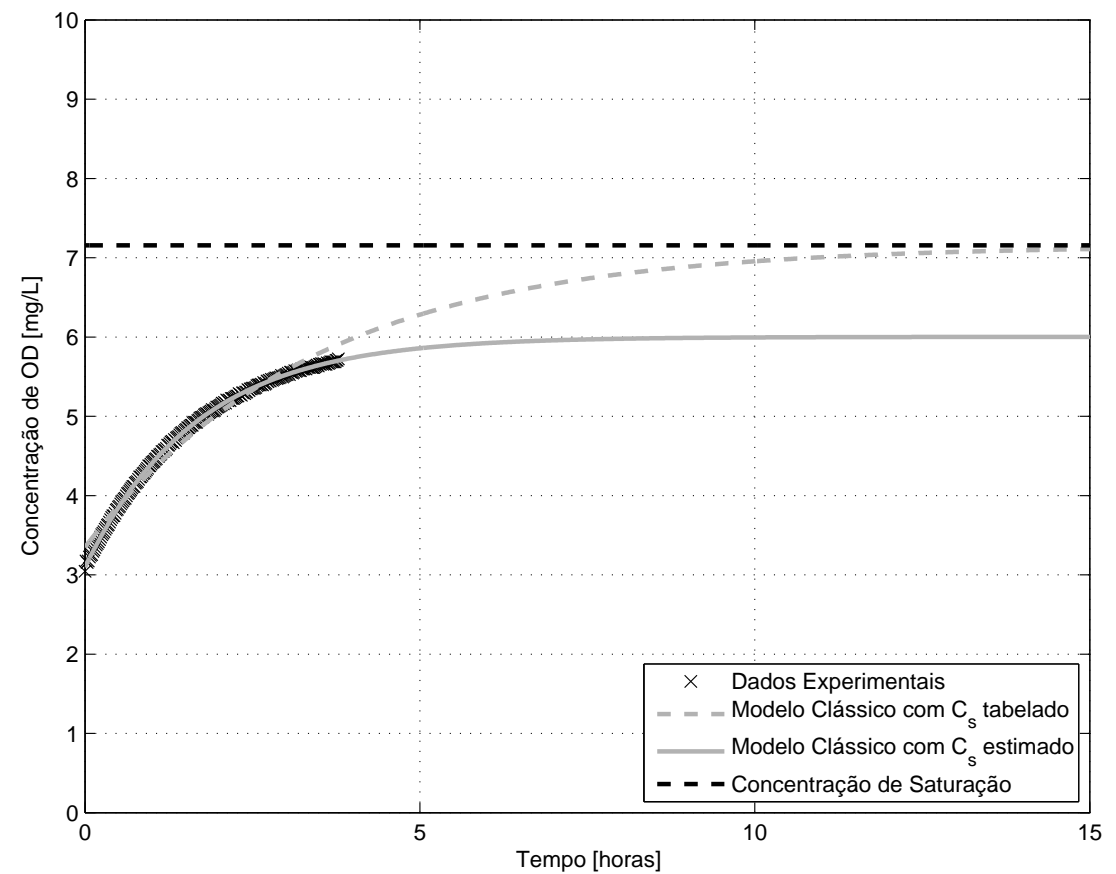

(a) Ajuste com o Modelo Clássico

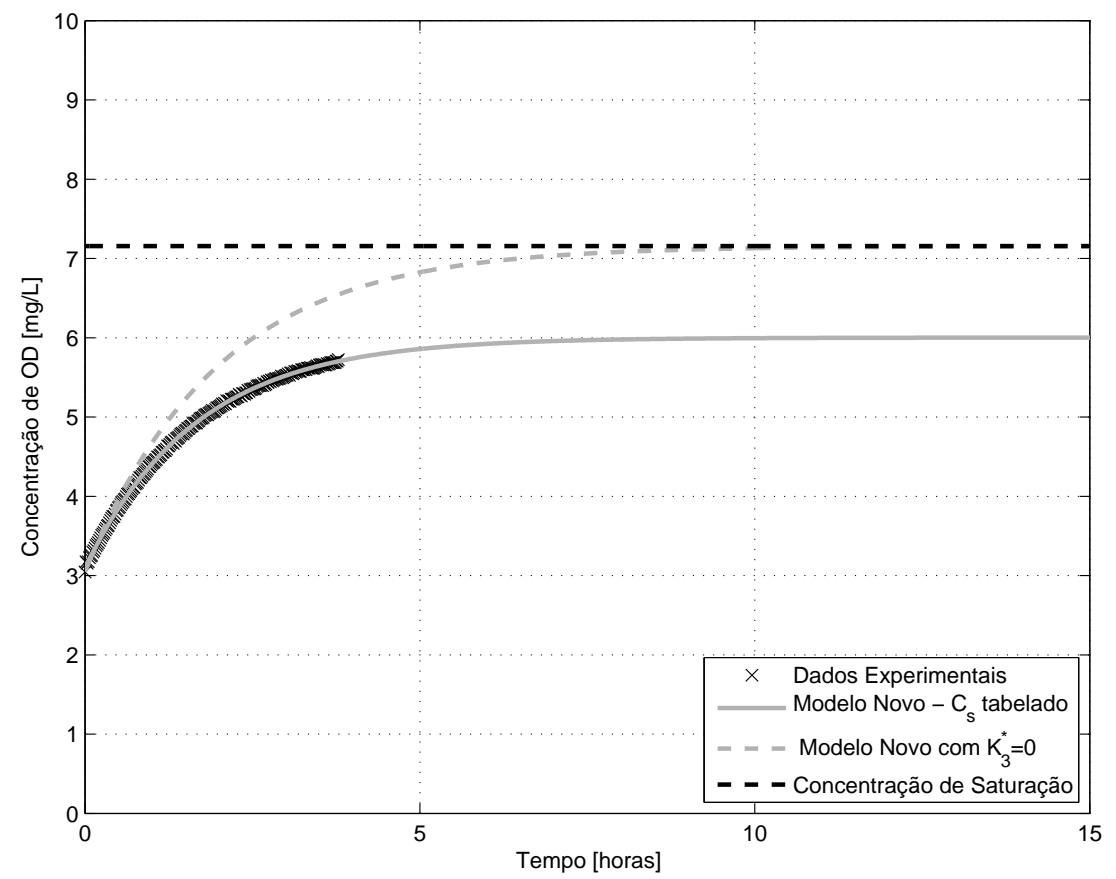

(b) Ajuste com o Modelo Novo

Figura B.106: Curva de reoxigenação para o ensaio 106 


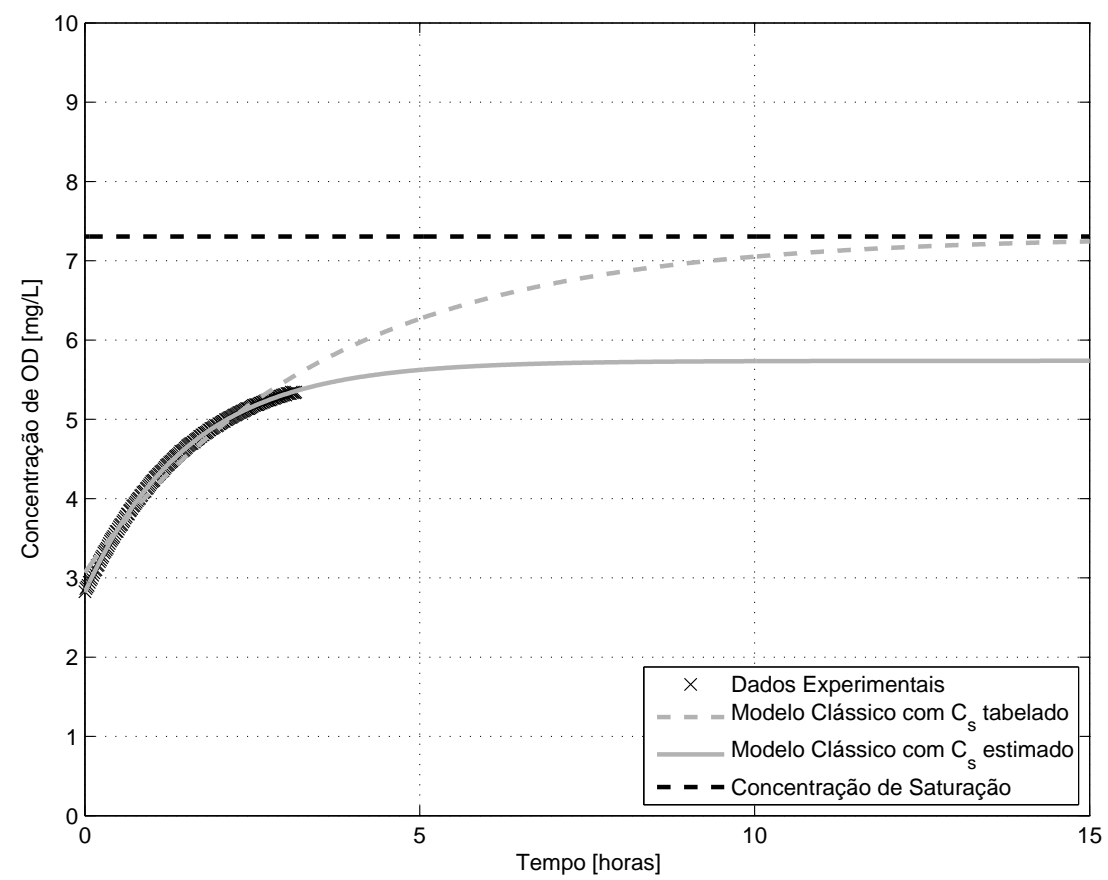

(a) Ajuste com o Modelo Clássico

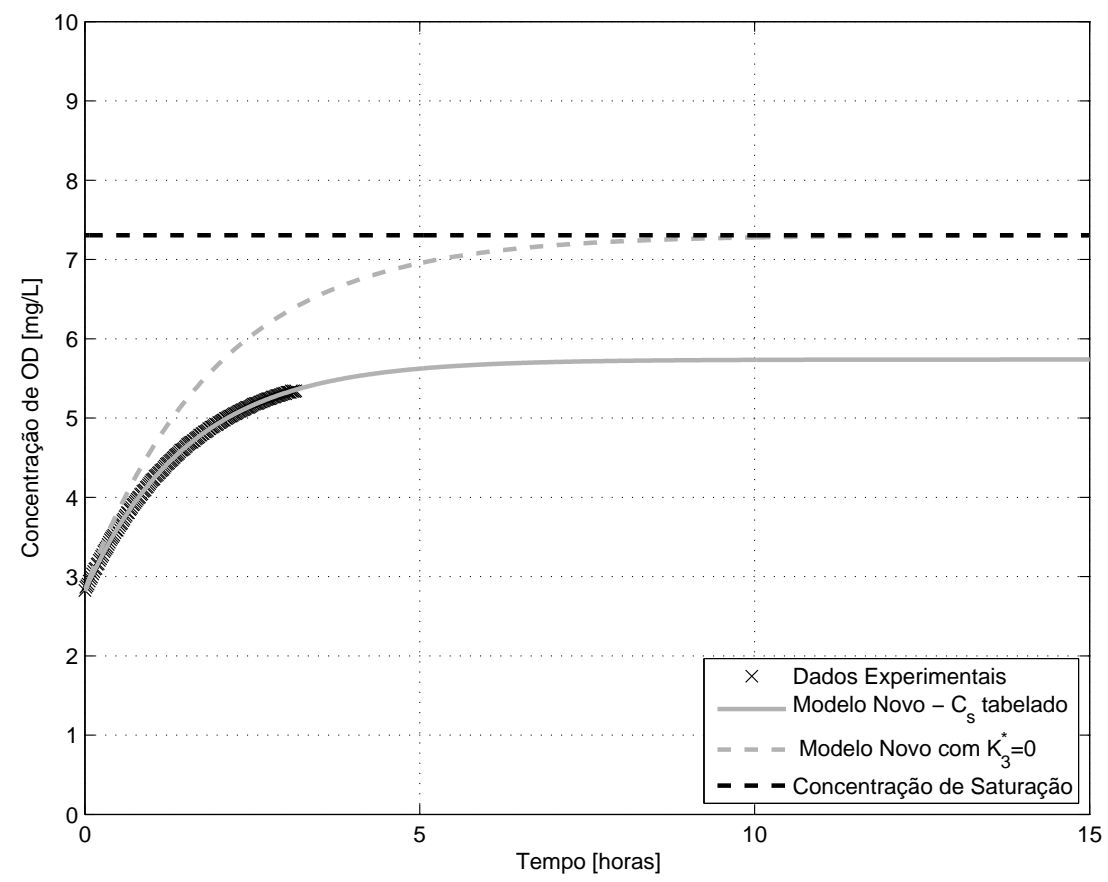

(b) Ajuste com o Modelo Novo

Figura B.107: Curva de reoxigenação para o ensaio 107 


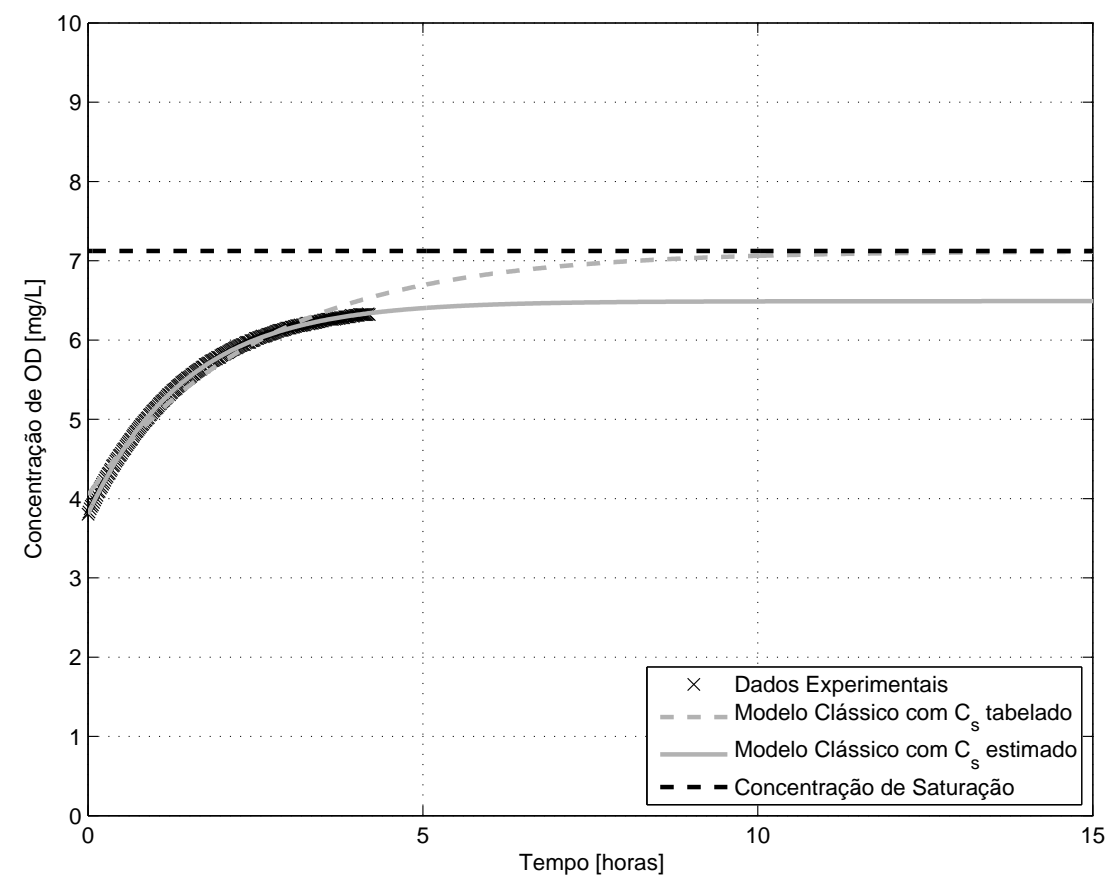

(a) Ajuste com o Modelo Clássico

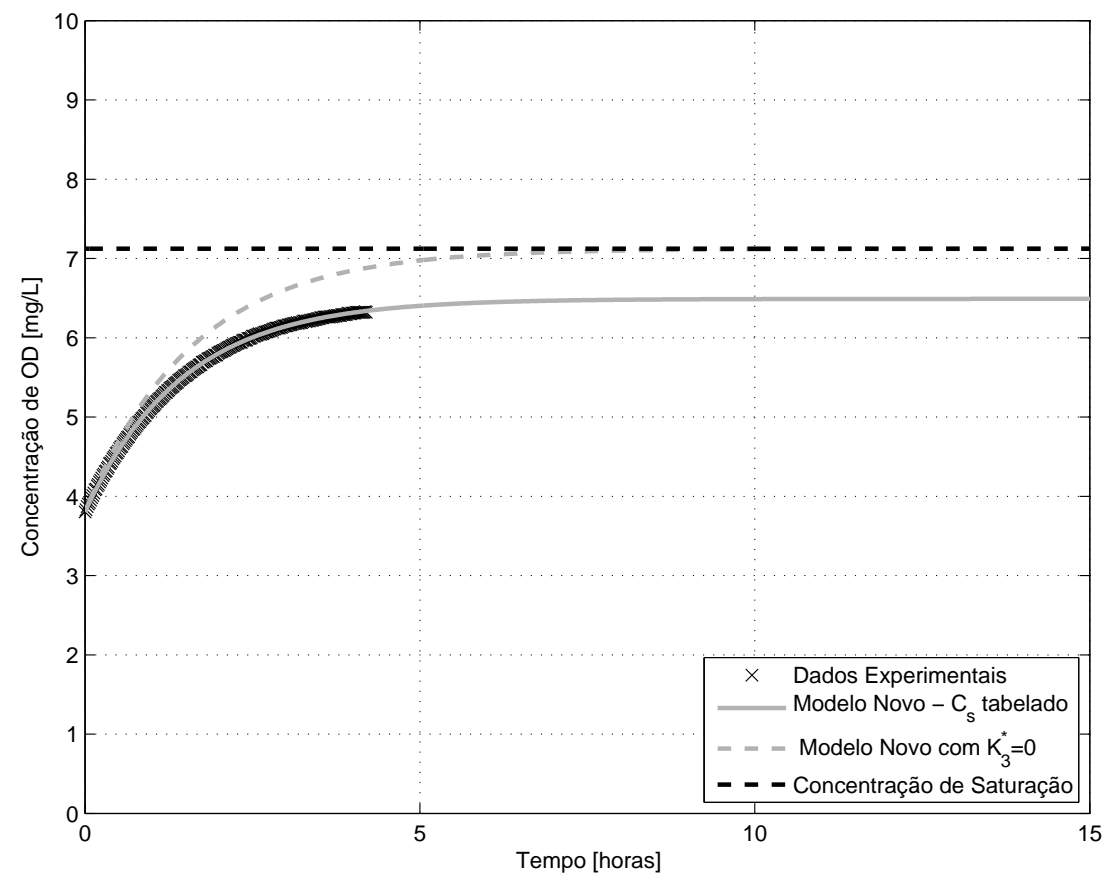

(b) Ajuste com o Modelo Novo

Figura B.108: Curva de reoxigenação para o ensaio 108 


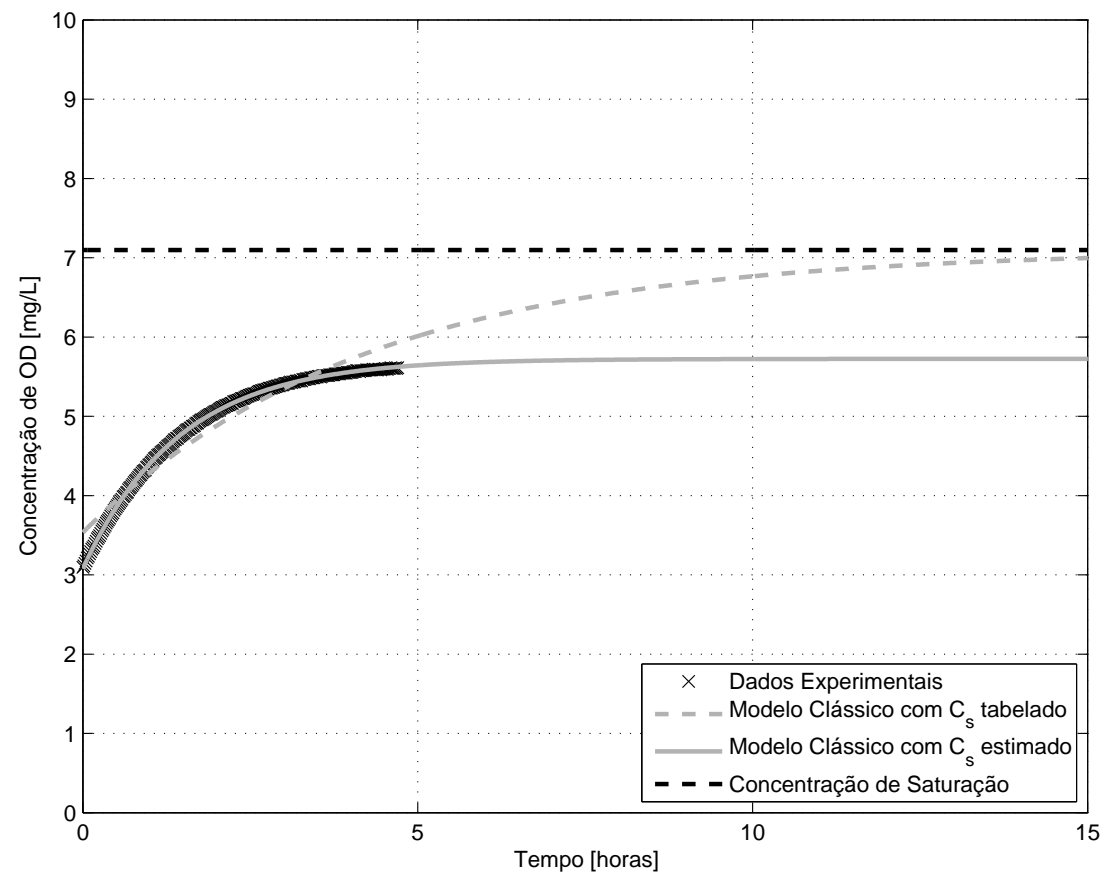

(a) Ajuste com o Modelo Clássico

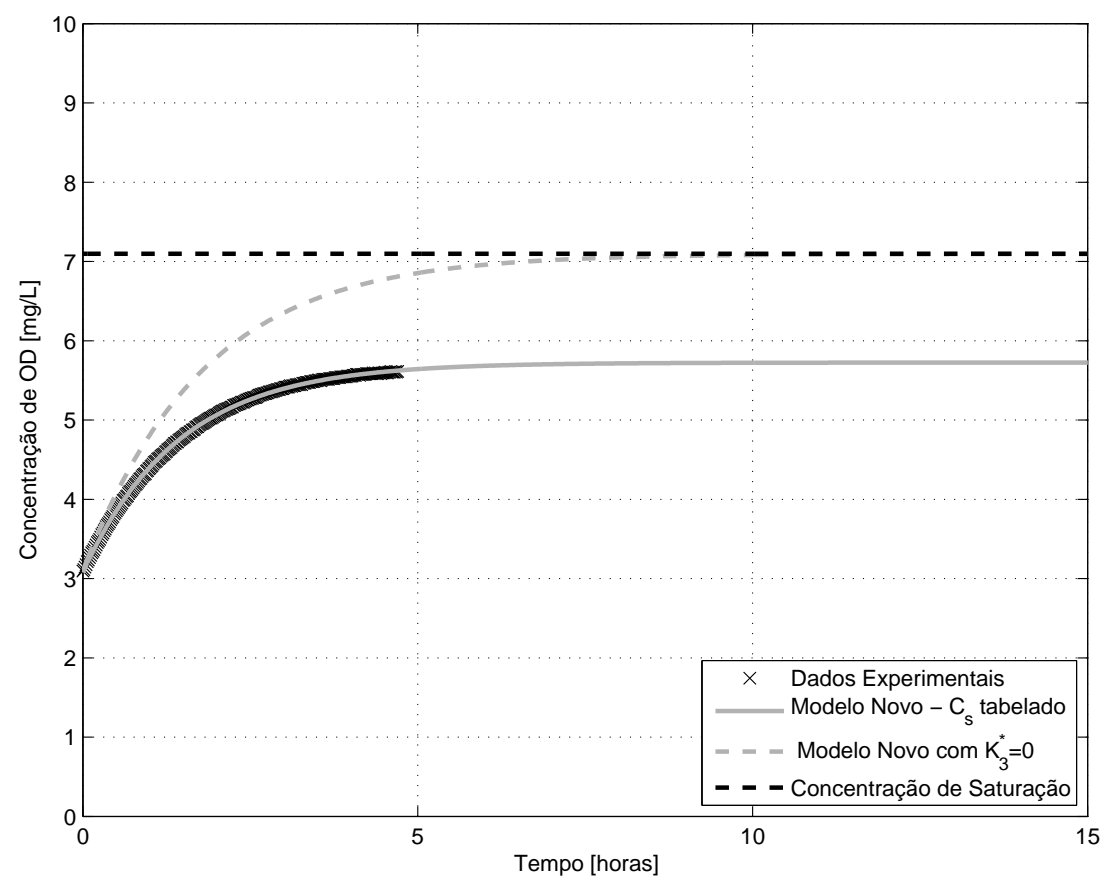

(b) Ajuste com o Modelo Novo

Figura B.109: Curva de reoxigenação para o ensaio 109 


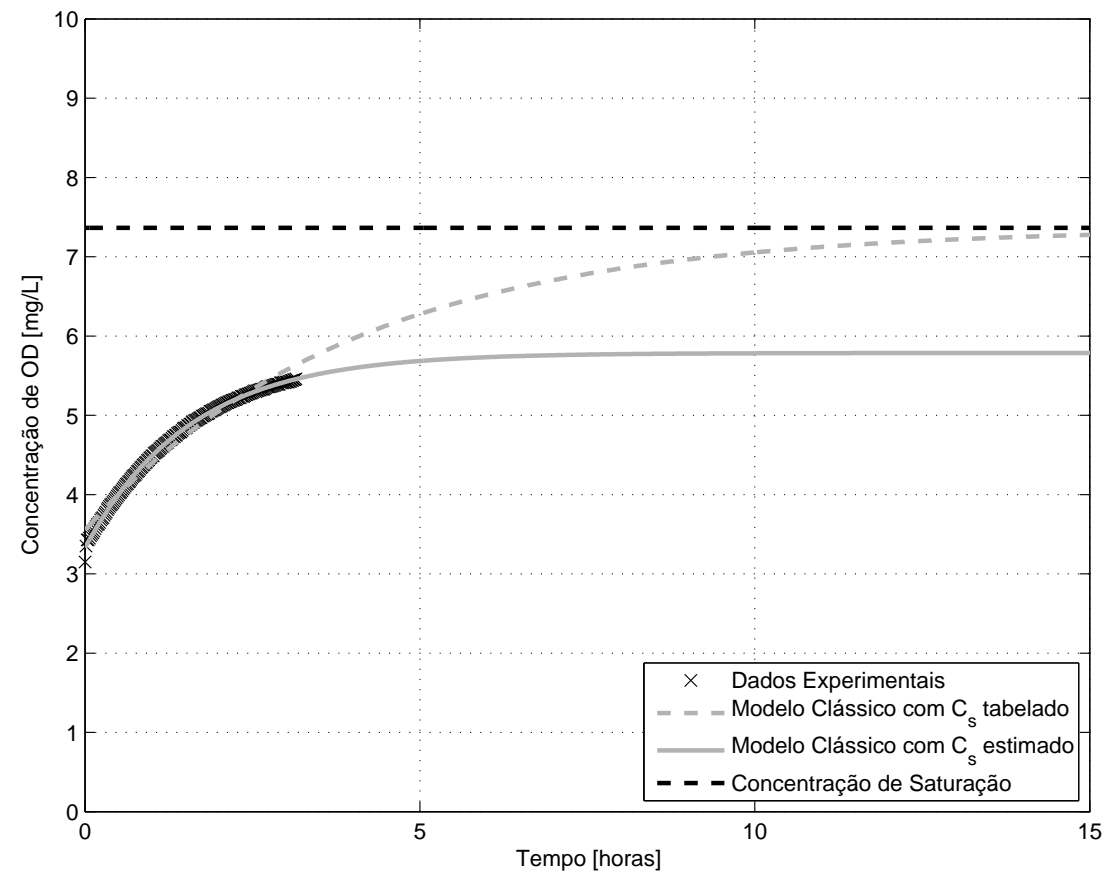

(a) Ajuste com o Modelo Clássico

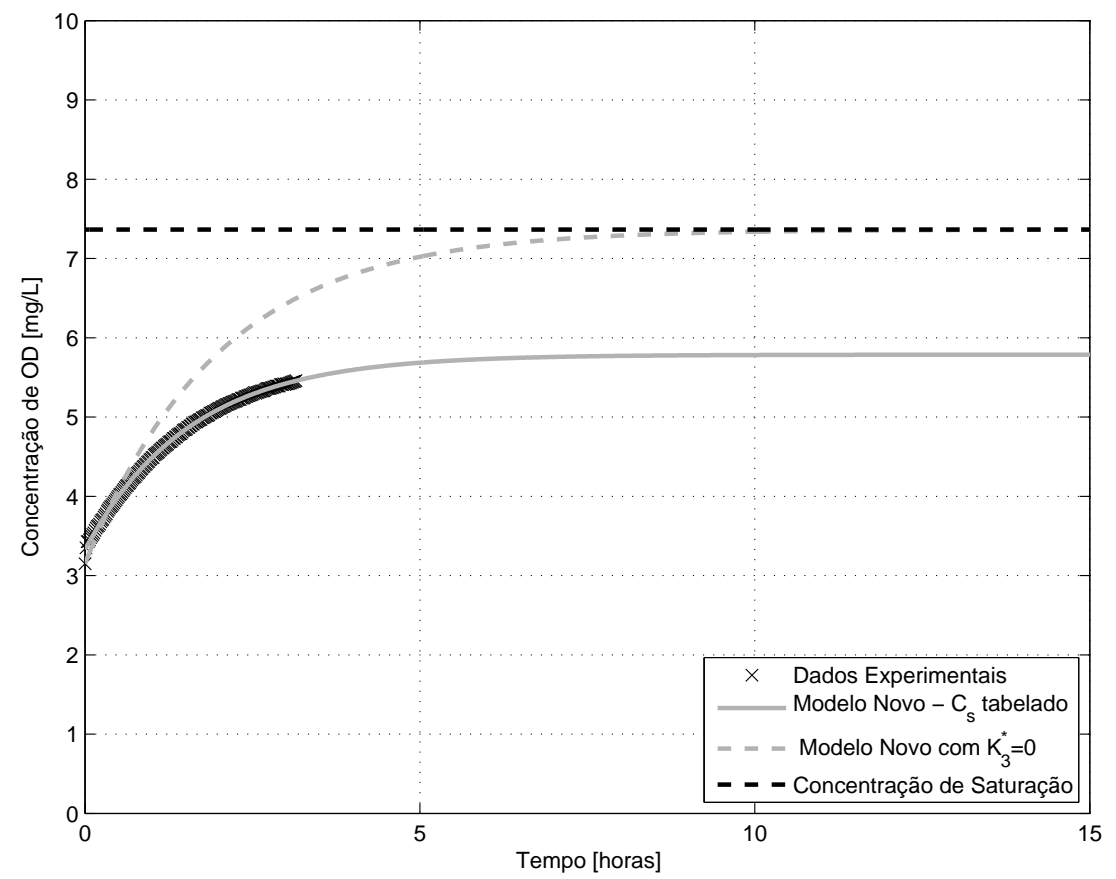

(b) Ajuste com o Modelo Novo

Figura B.110: Curva de reoxigenação para o ensaio 110 


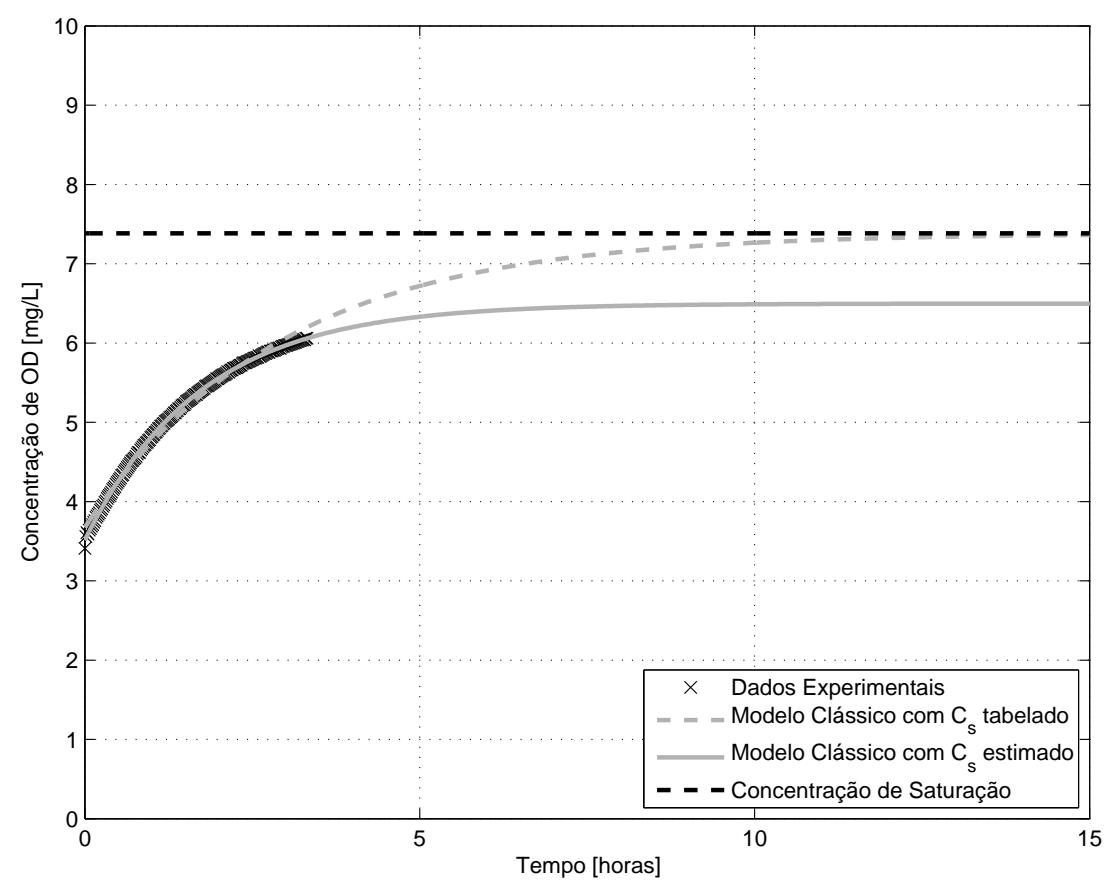

(a) Ajuste com o Modelo Clássico

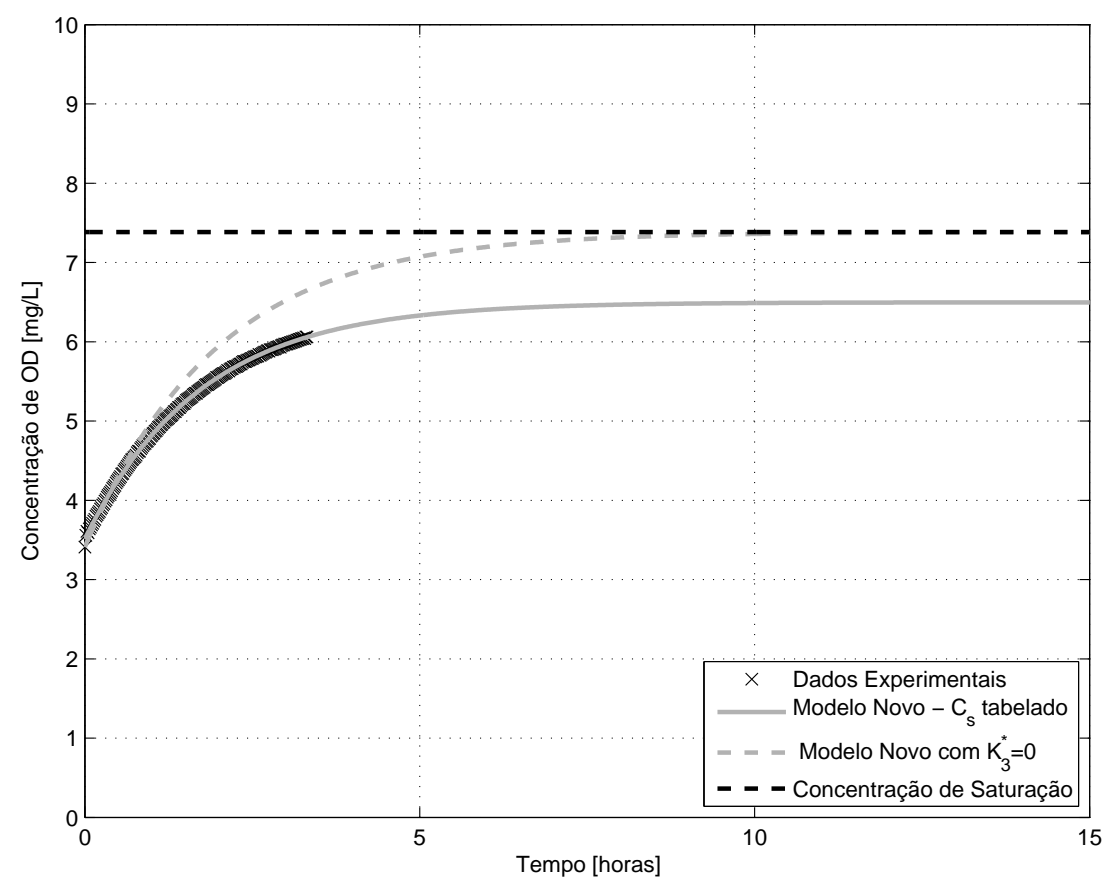

(b) Ajuste com o Modelo Novo

Figura B.111: Curva de reoxigenação para o ensaio 111 


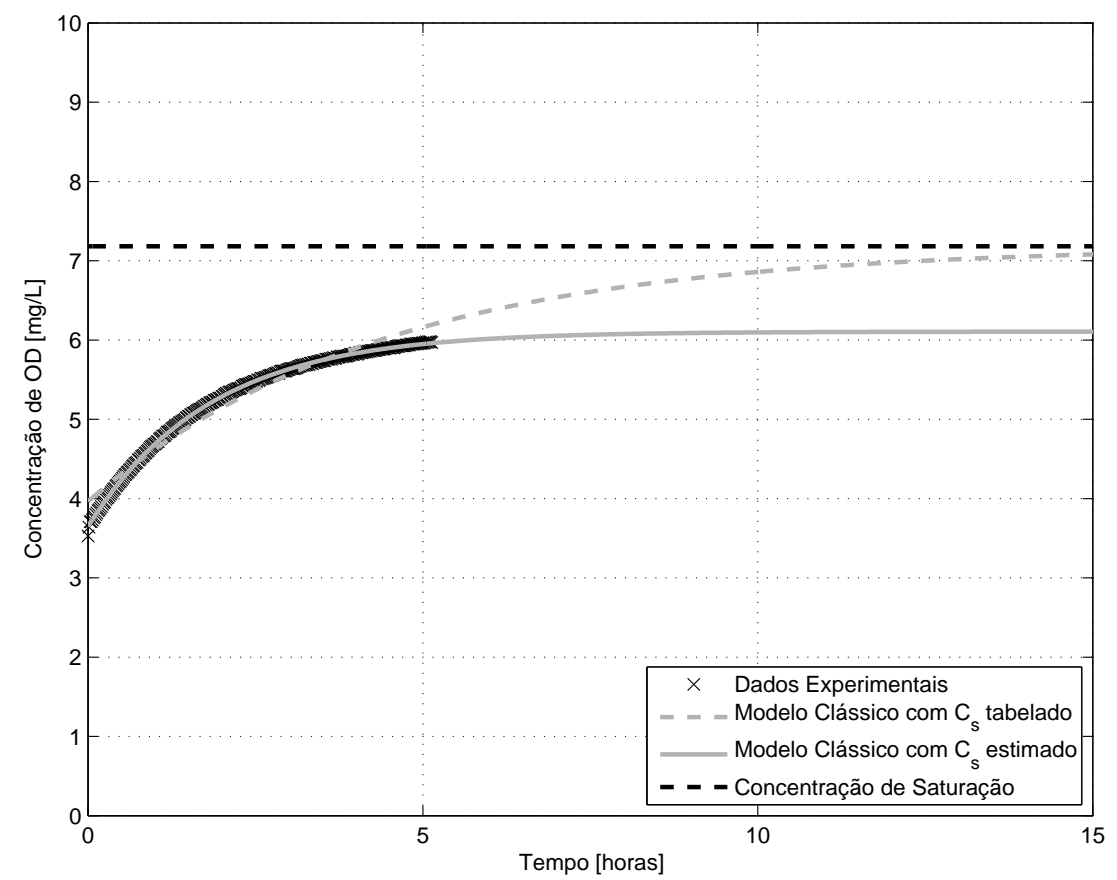

(a) Ajuste com o Modelo Clássico

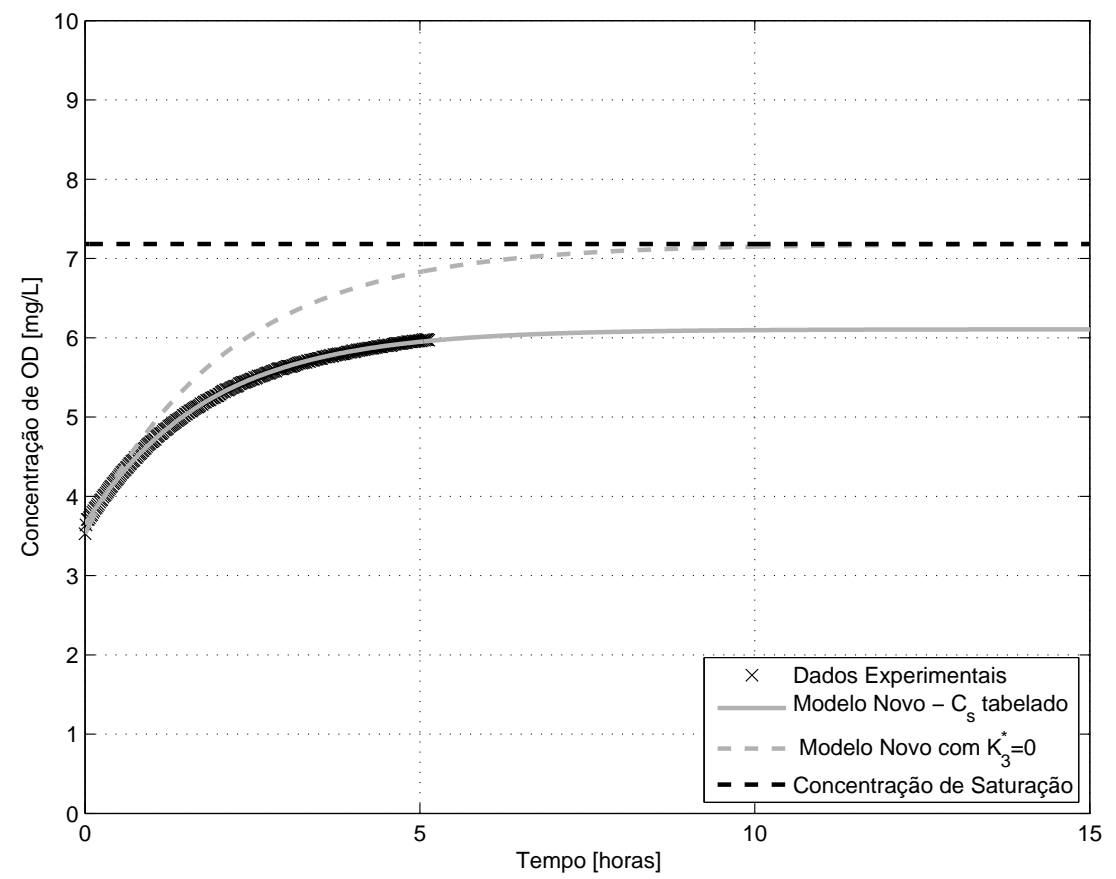

(b) Ajuste com o Modelo Novo

Figura B.112: Curva de reoxigenação para o ensaio 112 


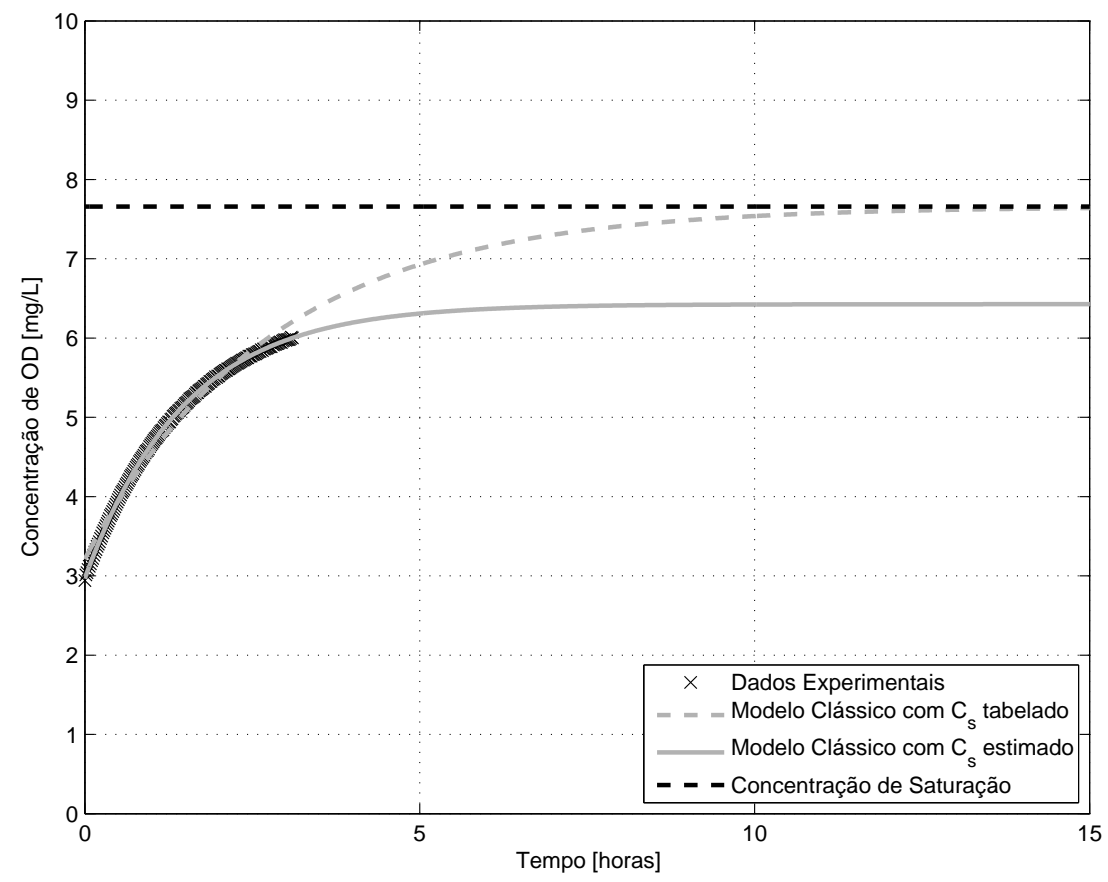

(a) Ajuste com o Modelo Clássico

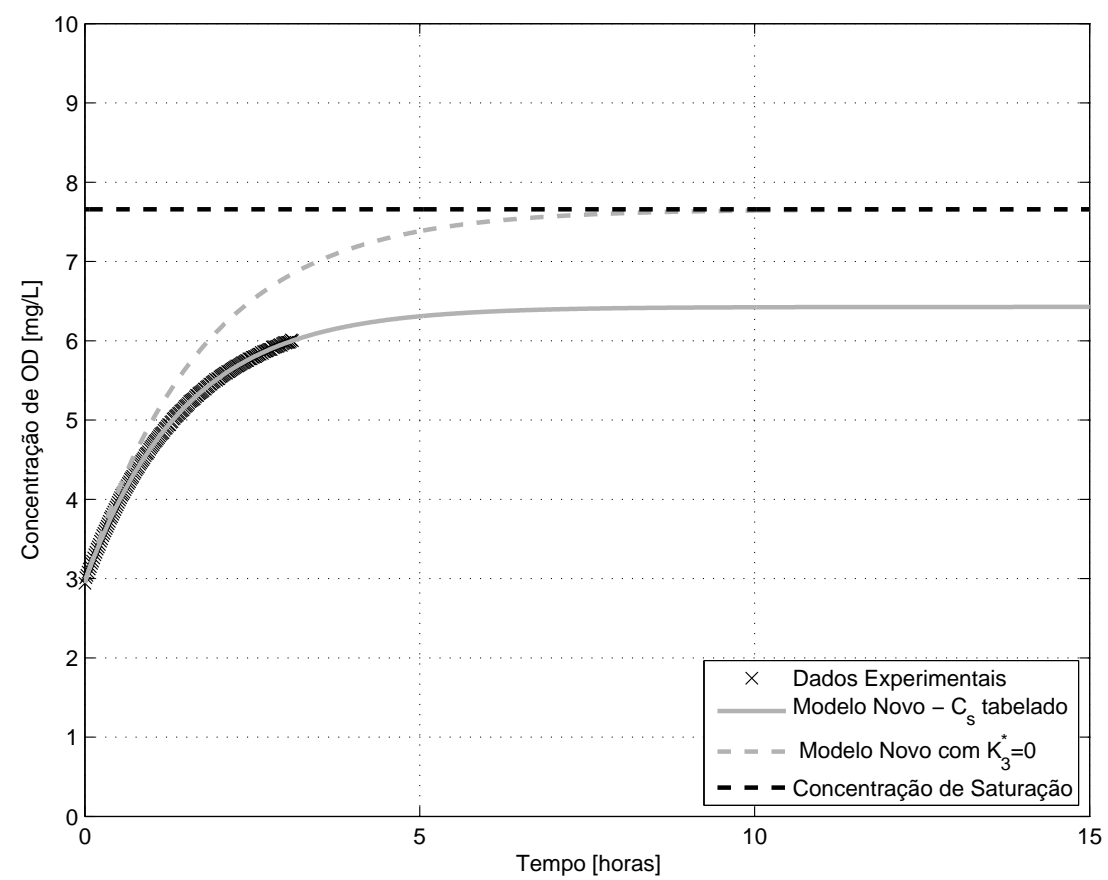

(b) Ajuste com o Modelo Novo

Figura B.113: Curva de reoxigenação para o ensaio 113 


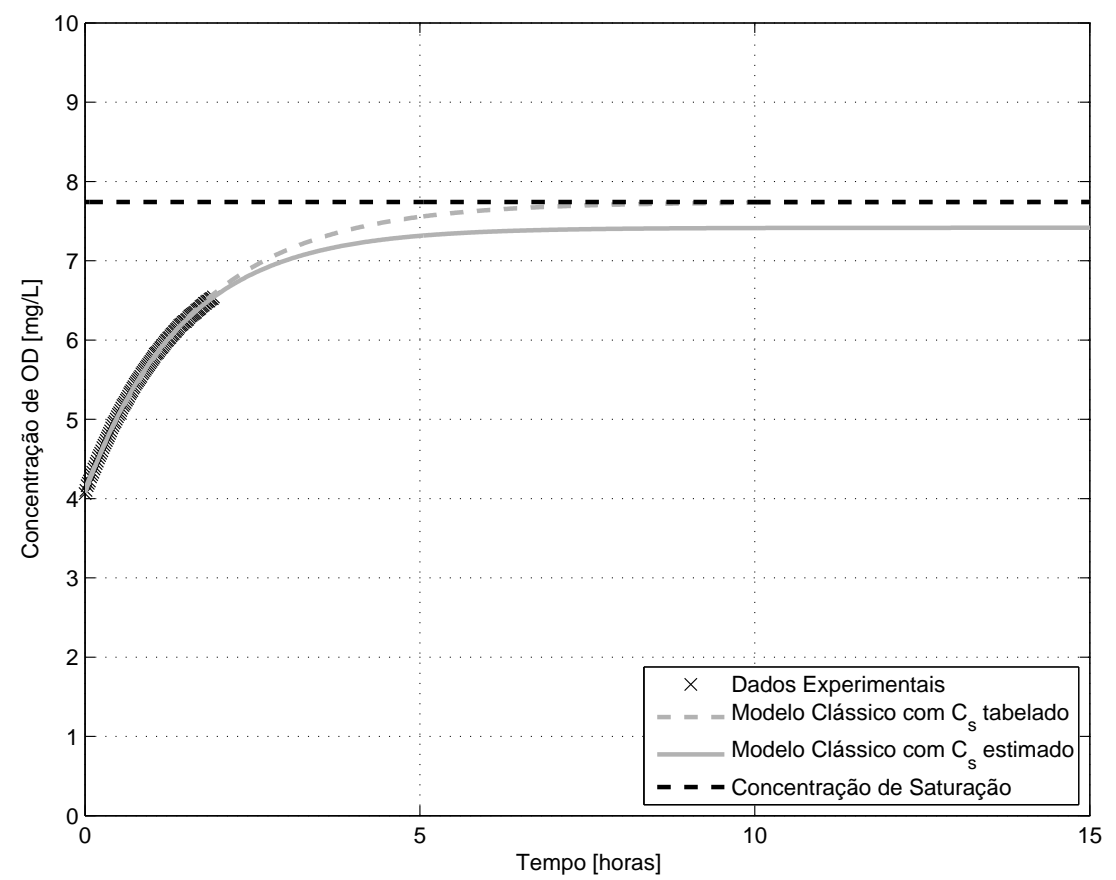

(a) Ajuste com o Modelo Clássico

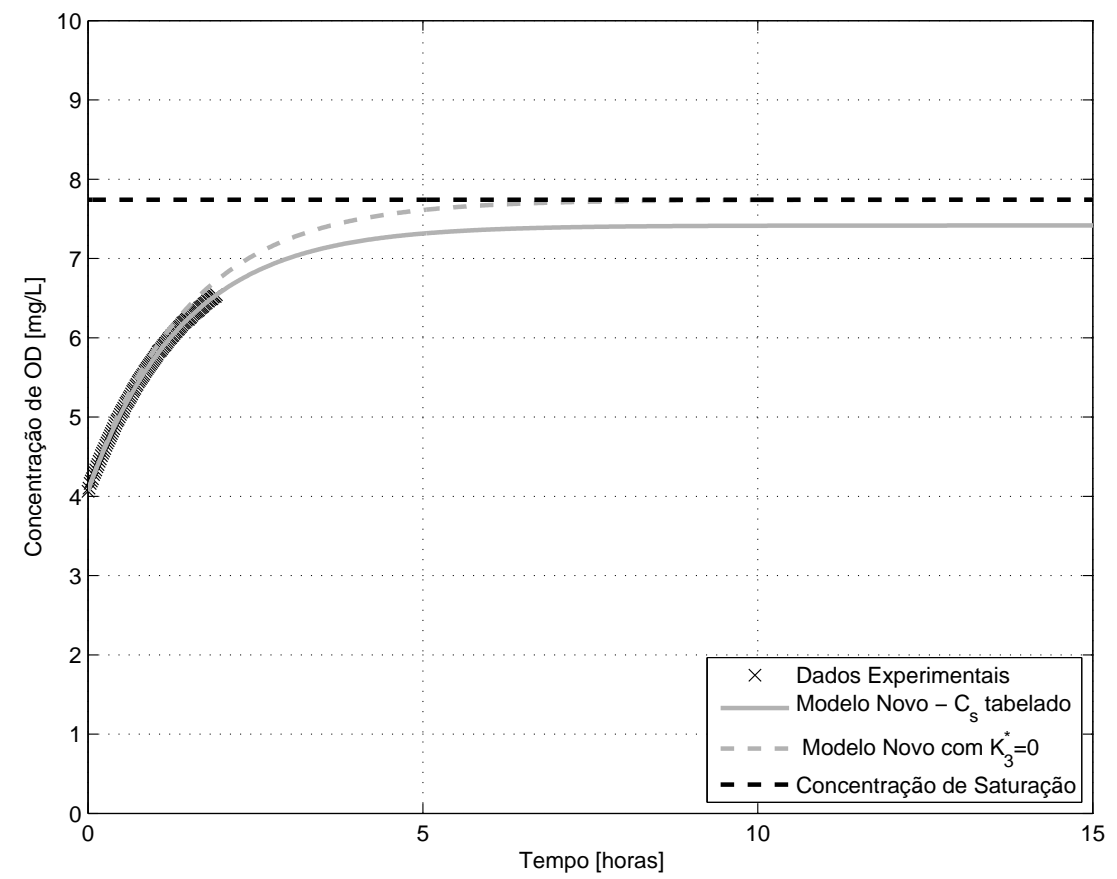

(b) Ajuste com o Modelo Novo

Figura B.114: Curva de reoxigenação para o ensaio 114 


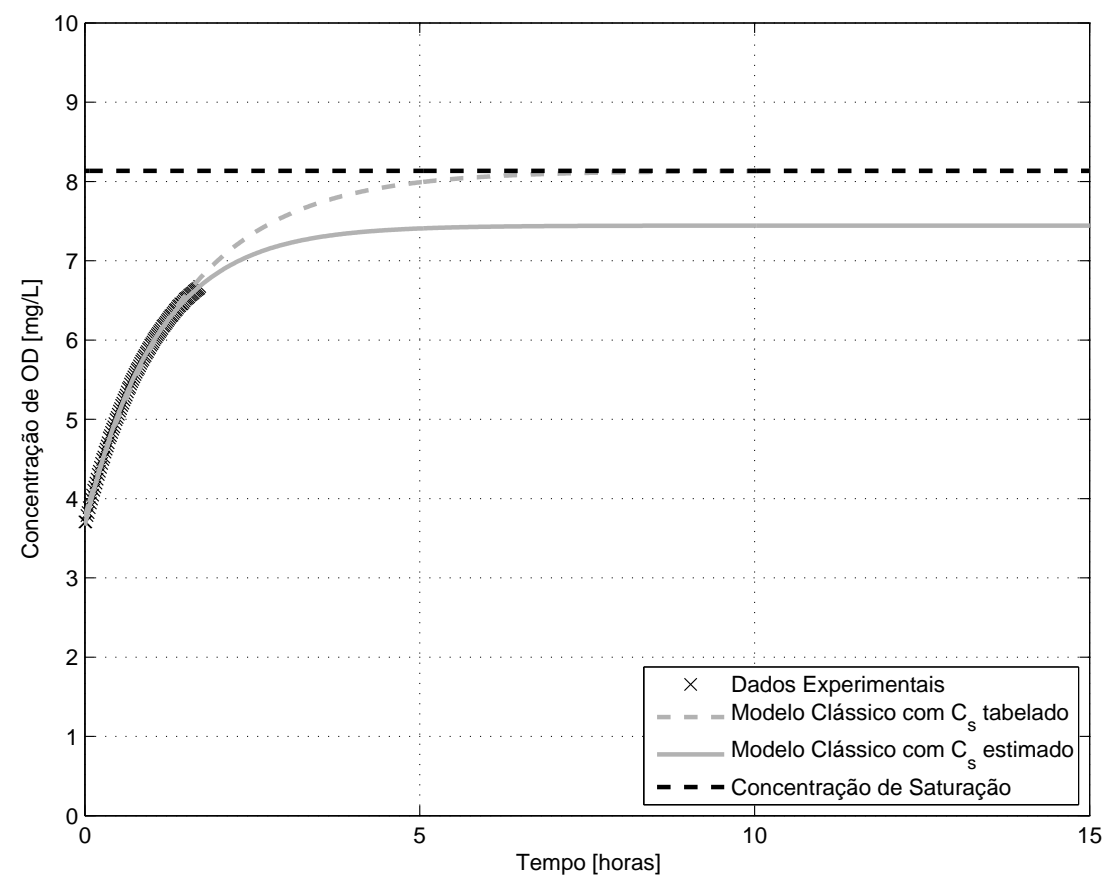

(a) Ajuste com o Modelo Clássico

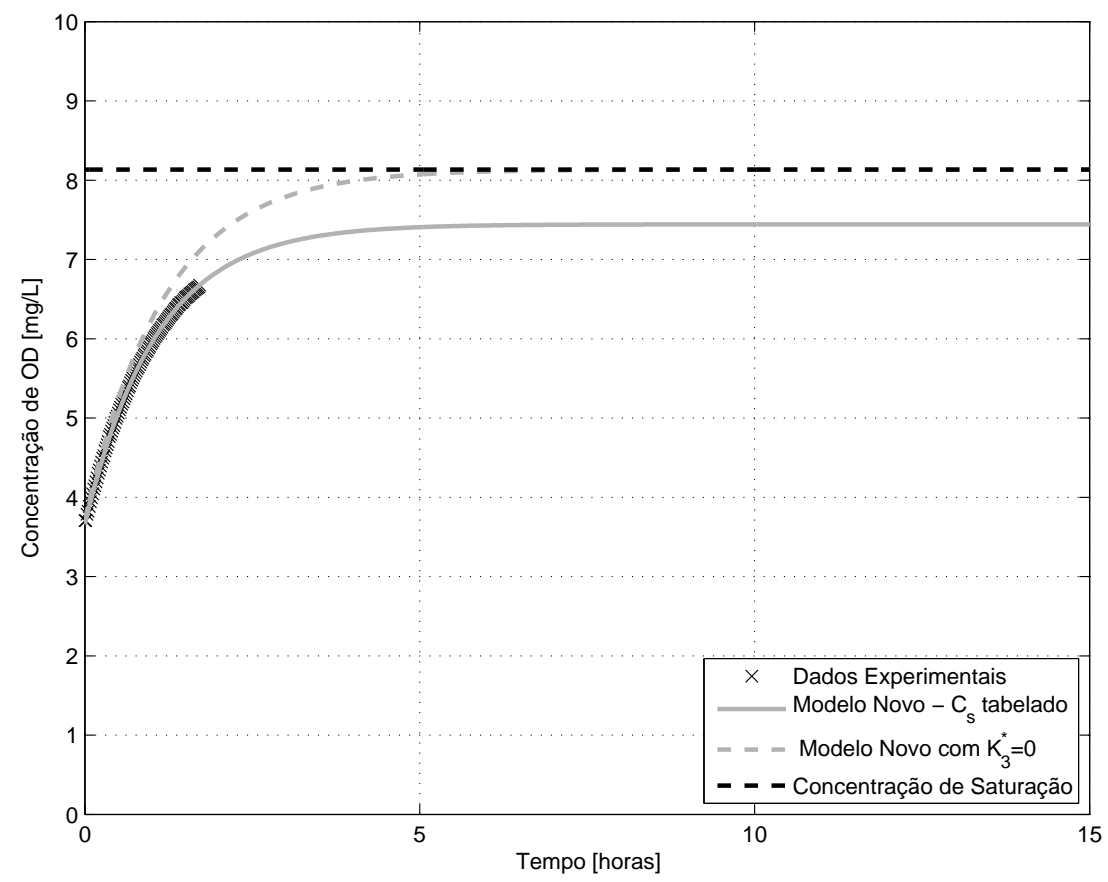

(b) Ajuste com o Modelo Novo

Figura B.115: Curva de reoxigenação para o ensaio 115 


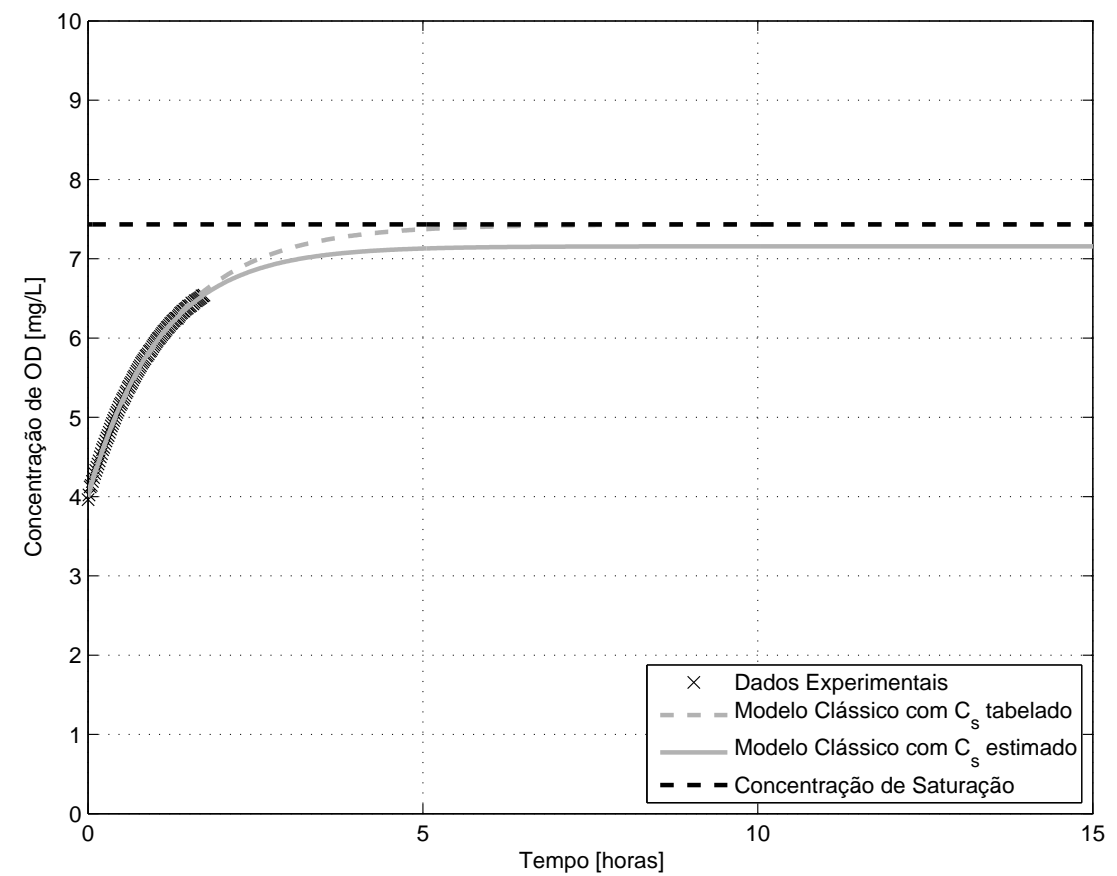

(a) Ajuste com o Modelo Clássico

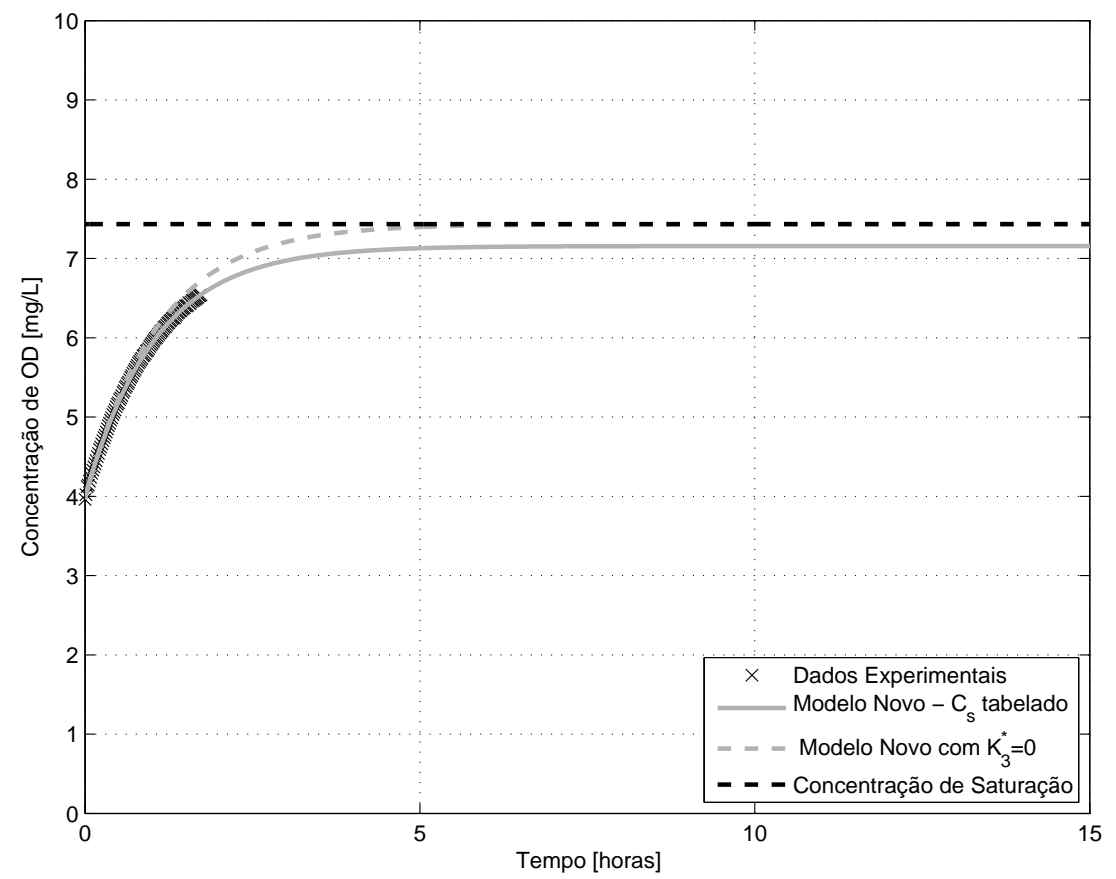

(b) Ajuste com o Modelo Novo

Figura B.116: Curva de reoxigenação para o ensaio 116 


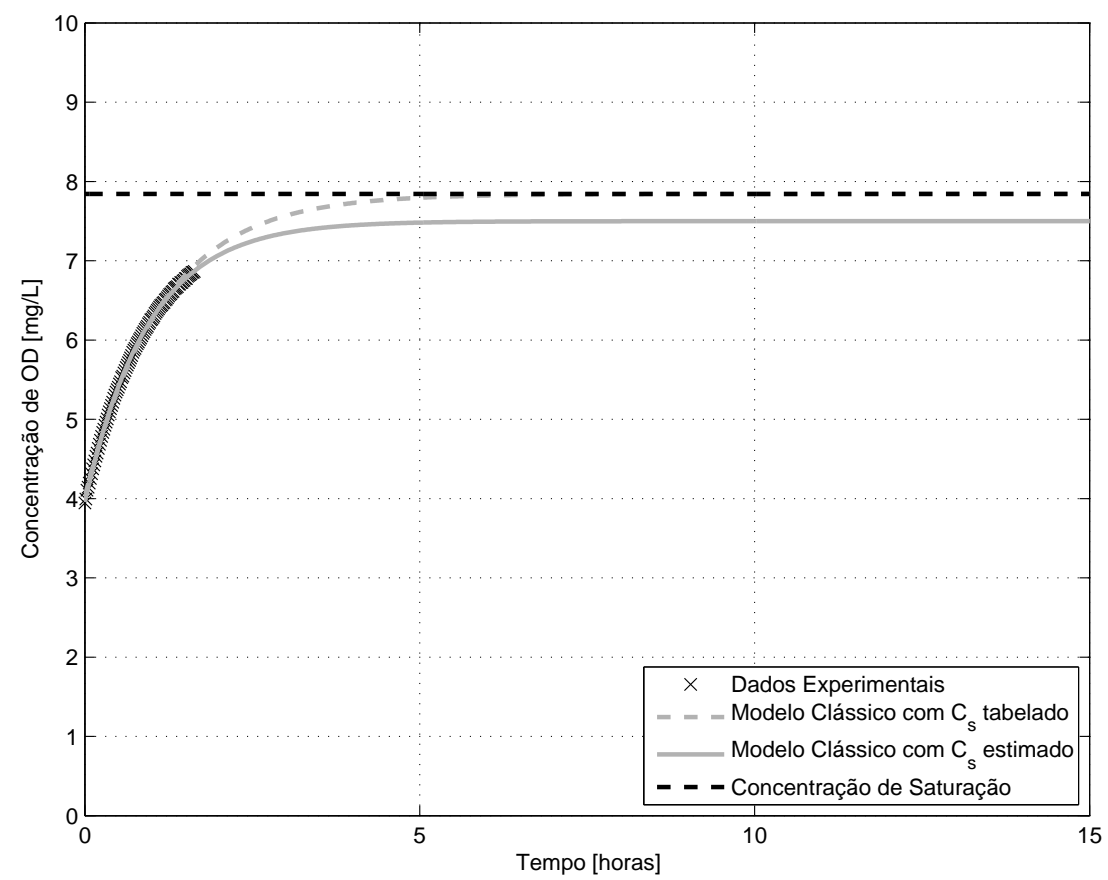

(a) Ajuste com o Modelo Clássico

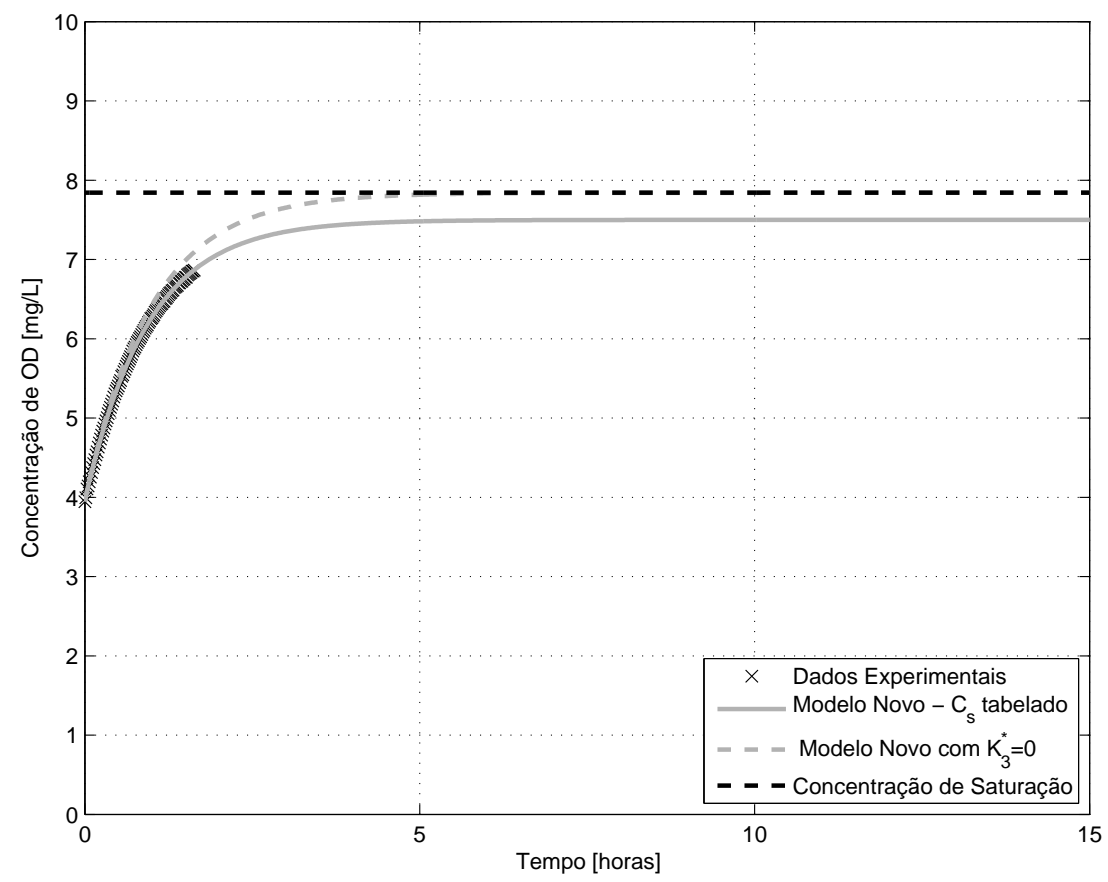

(b) Ajuste com o Modelo Novo

Figura B.117: Curva de reoxigenação para o ensaio 117 


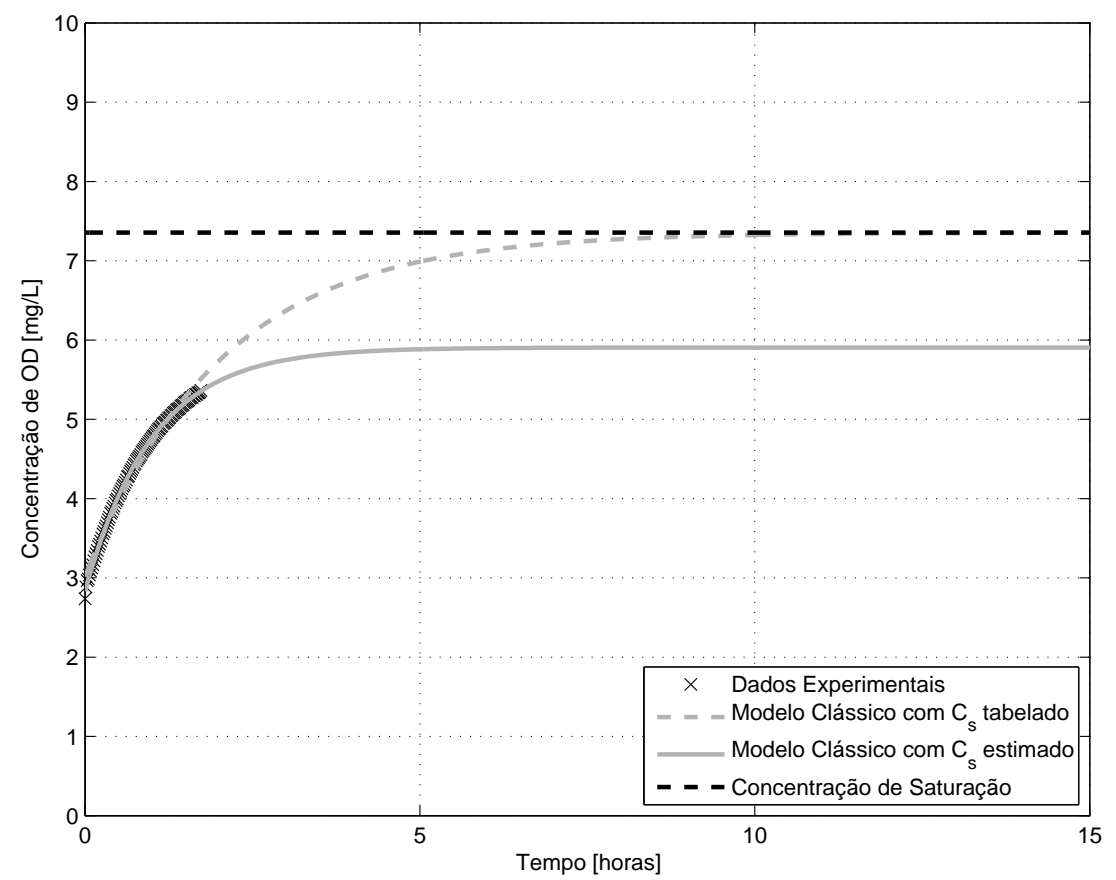

(a) Ajuste com o Modelo Clássico

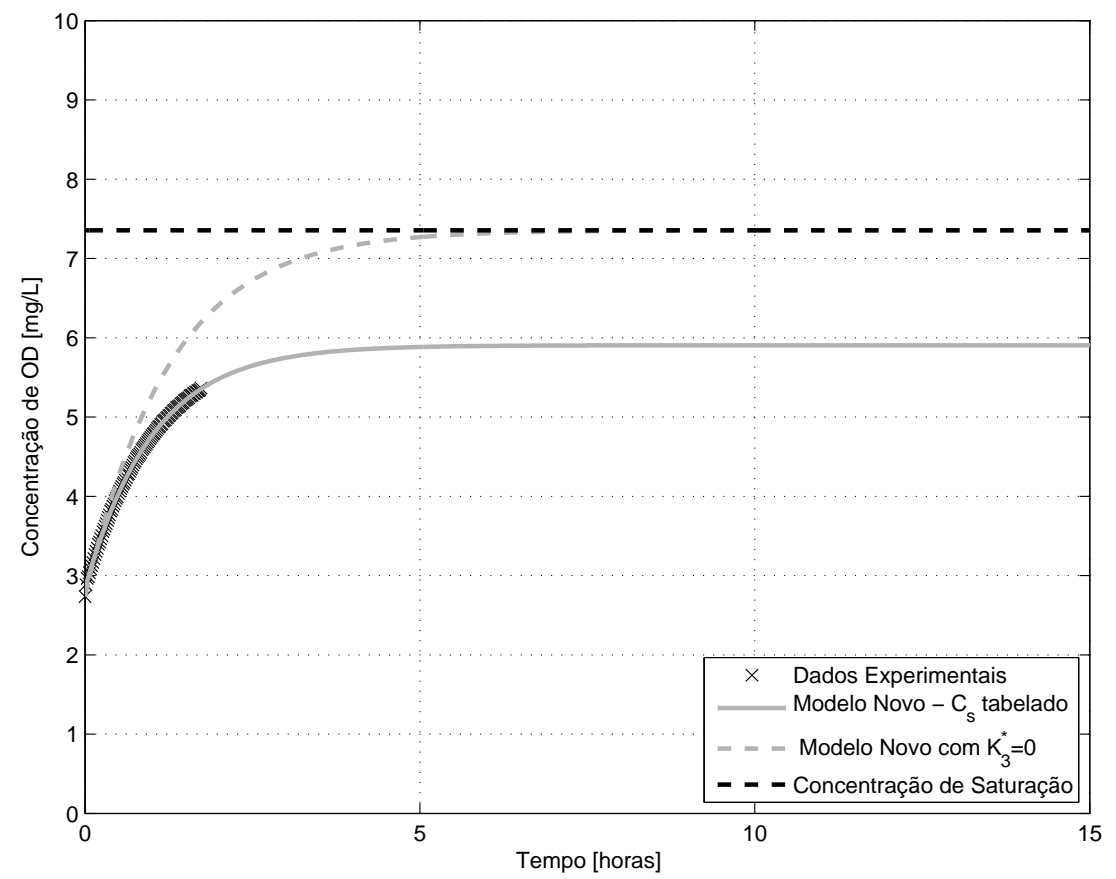

(b) Ajuste com o Modelo Novo

Figura B.118: Curva de reoxigenação para o ensaio 118 


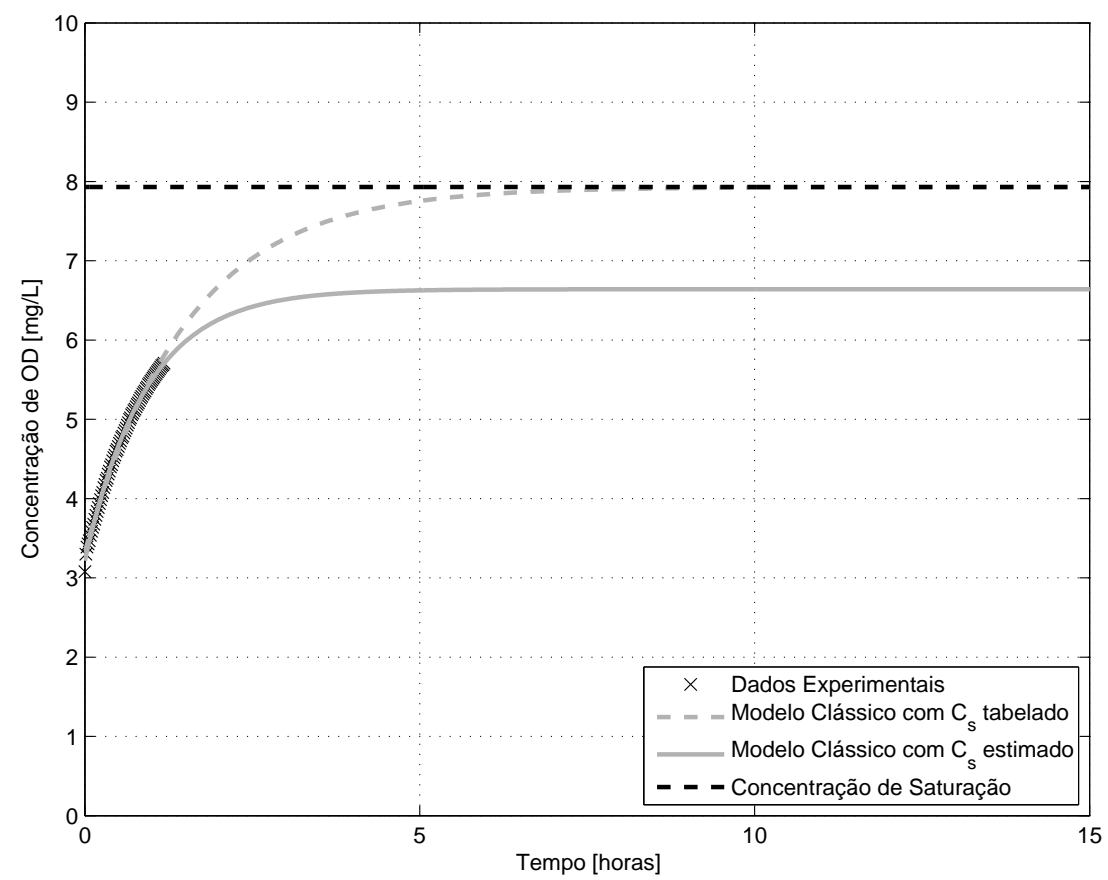

(a) Ajuste com o Modelo Clássico

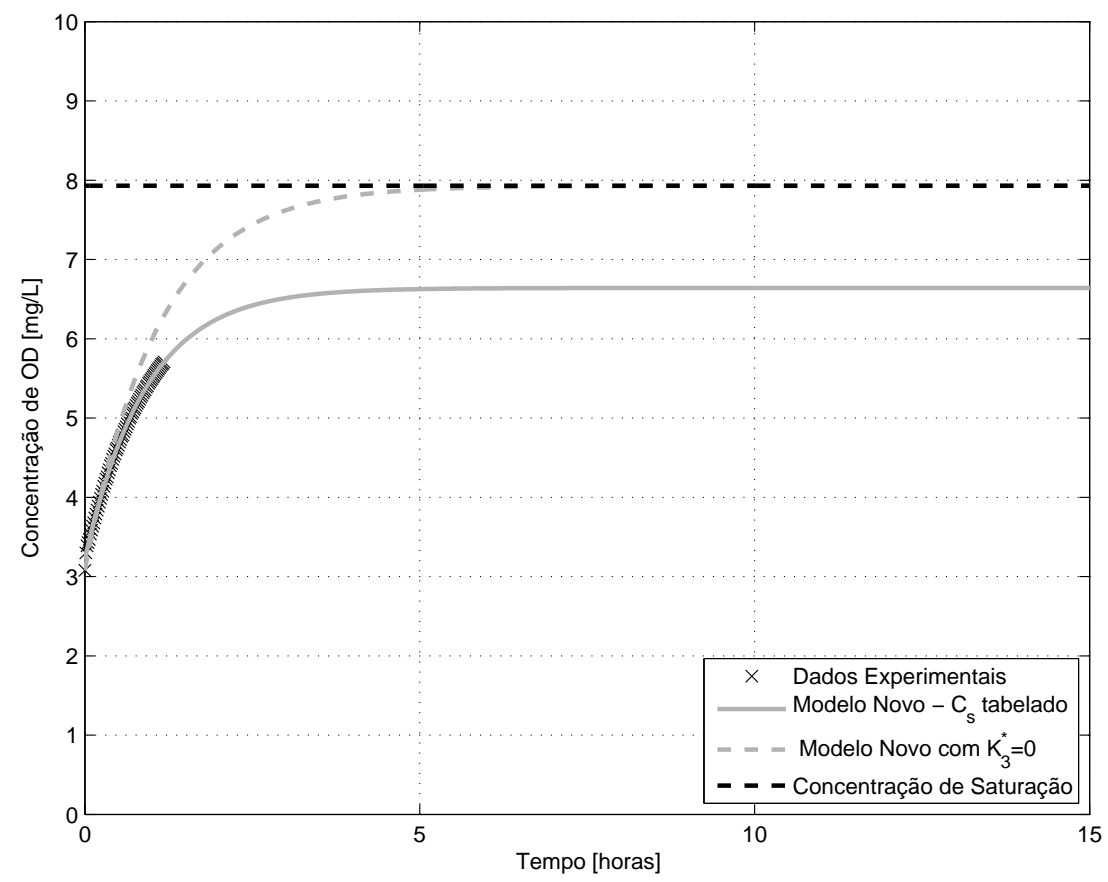

(b) Ajuste com o Modelo Novo

Figura B.119: Curva de reoxigenação para o ensaio 119 


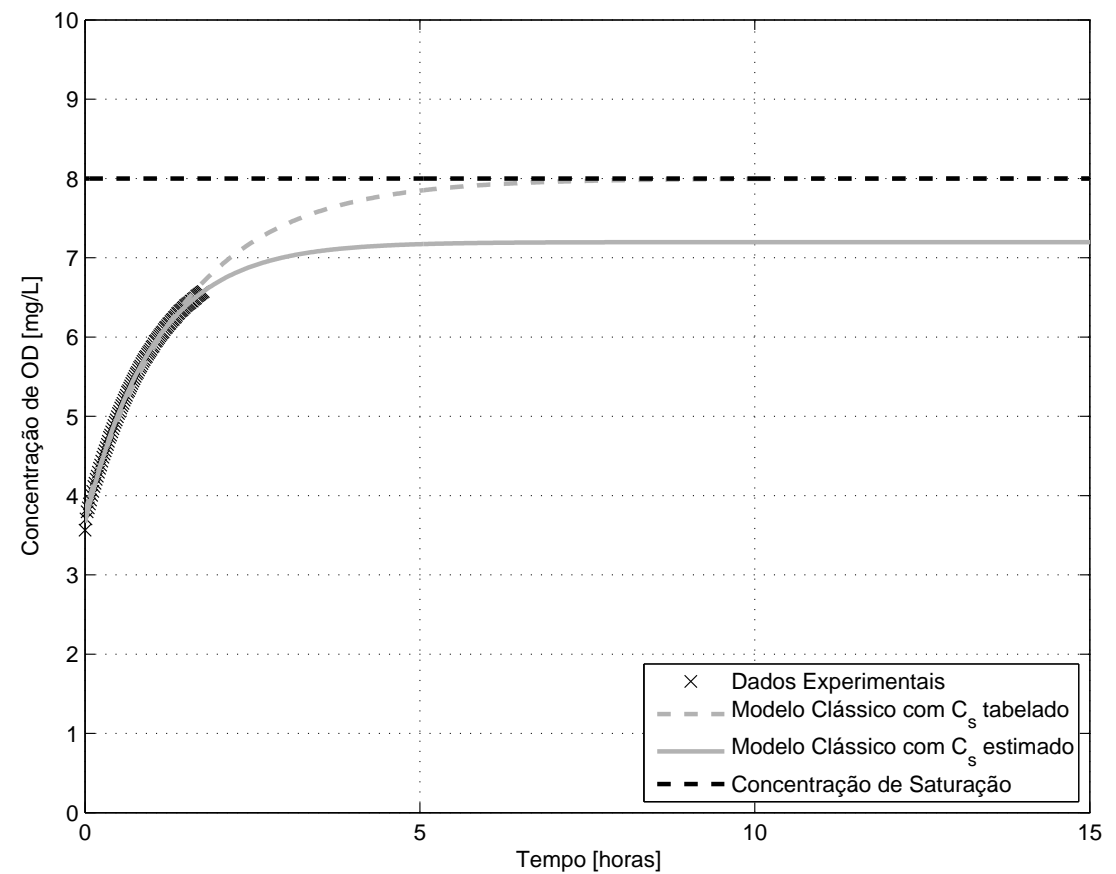

(a) Ajuste com o Modelo Clássico

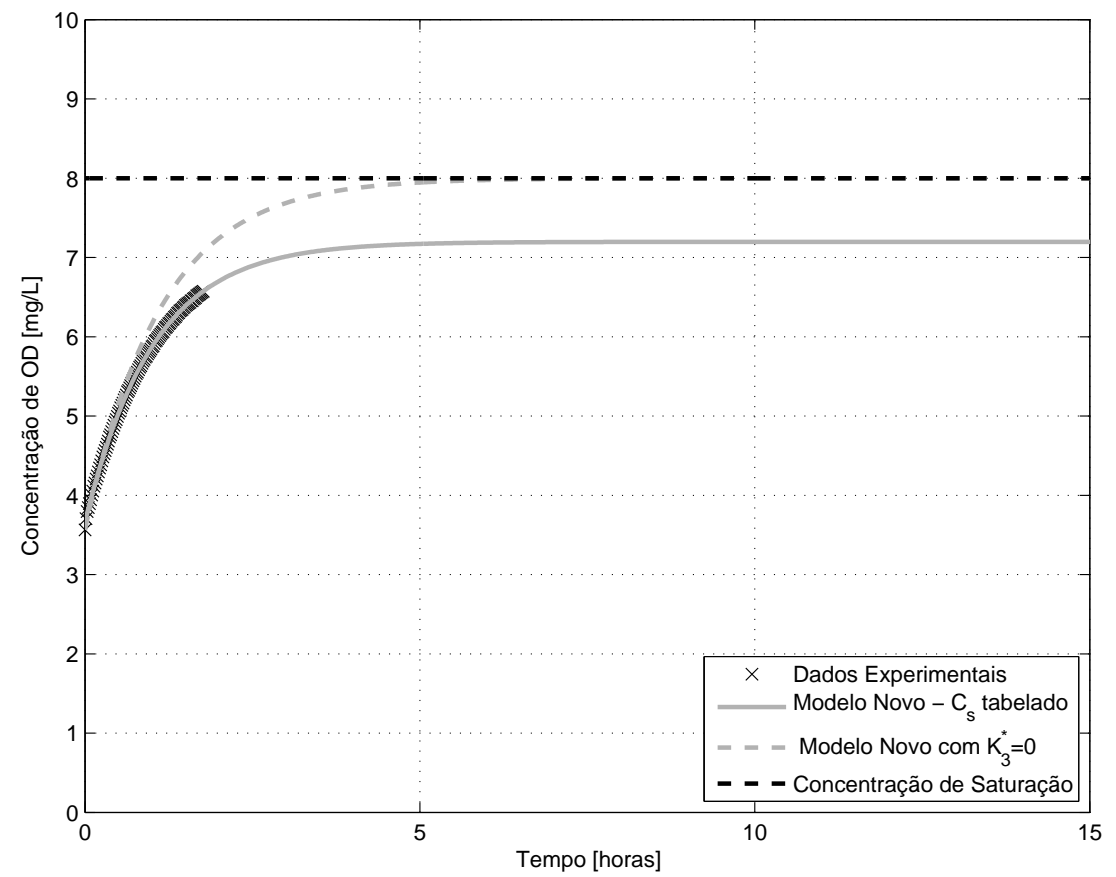

(b) Ajuste com o Modelo Novo

Figura B.120: Curva de reoxigenação para o ensaio 120 


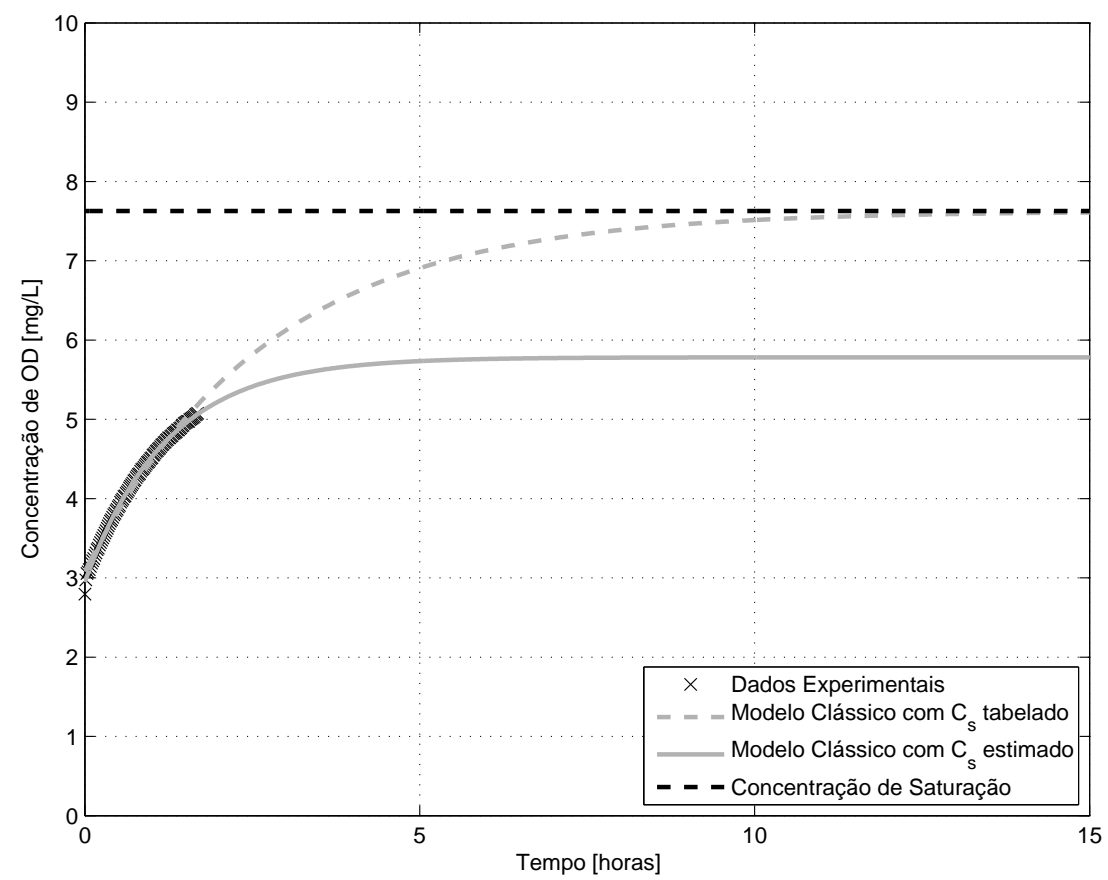

(a) Ajuste com o Modelo Clássico

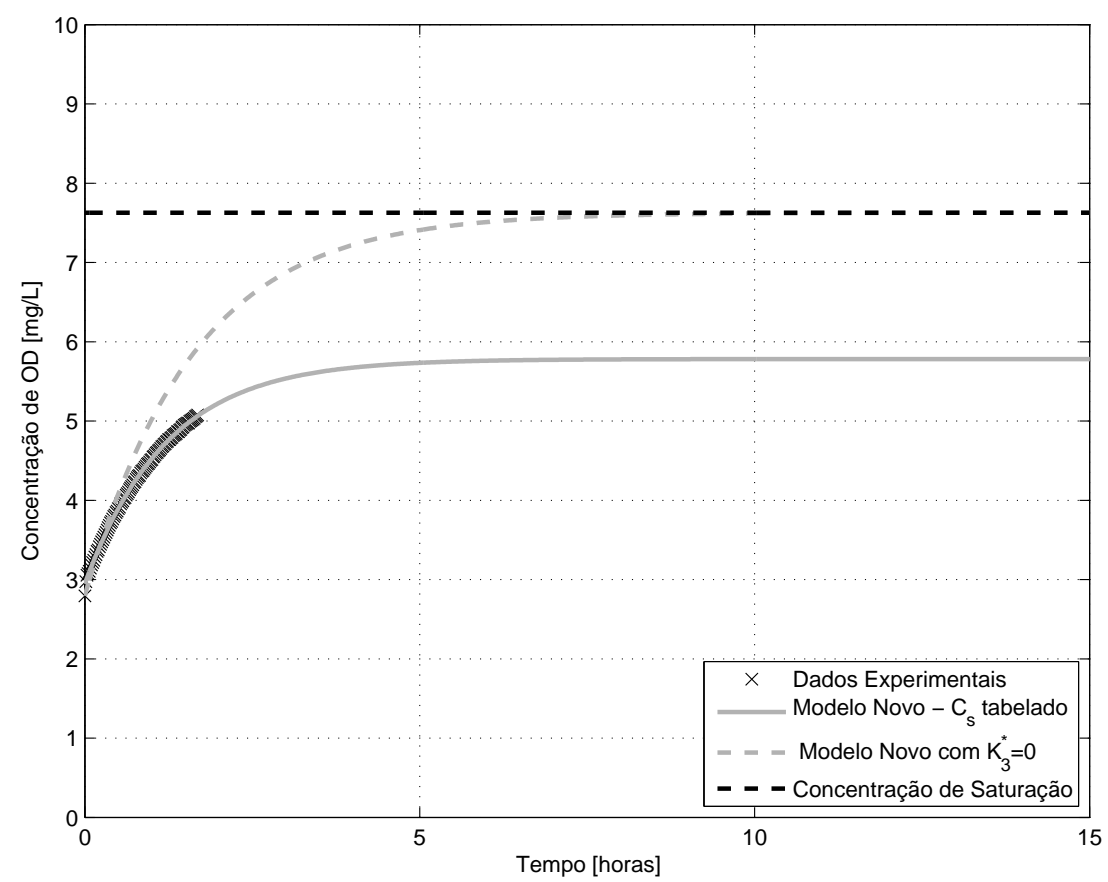

(b) Ajuste com o Modelo Novo

Figura B.121: Curva de reoxigenação para o ensaio 121 


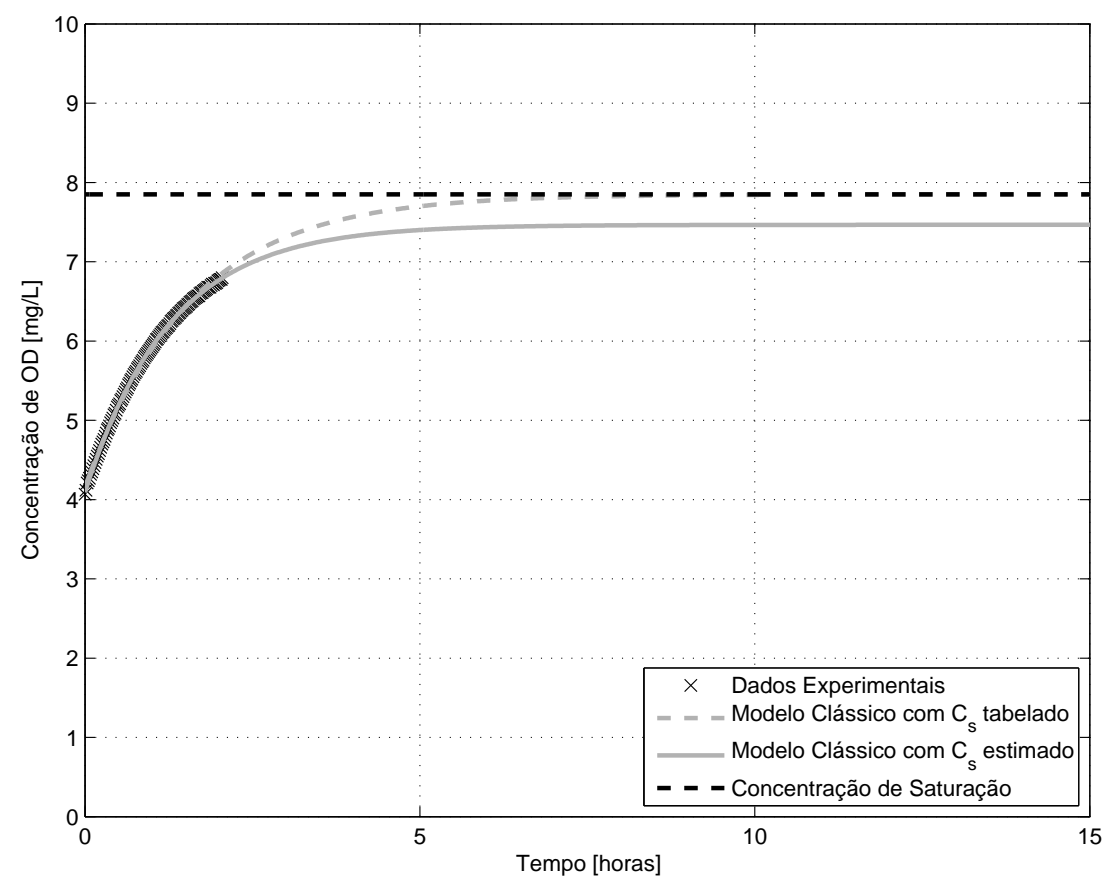

(a) Ajuste com o Modelo Clássico

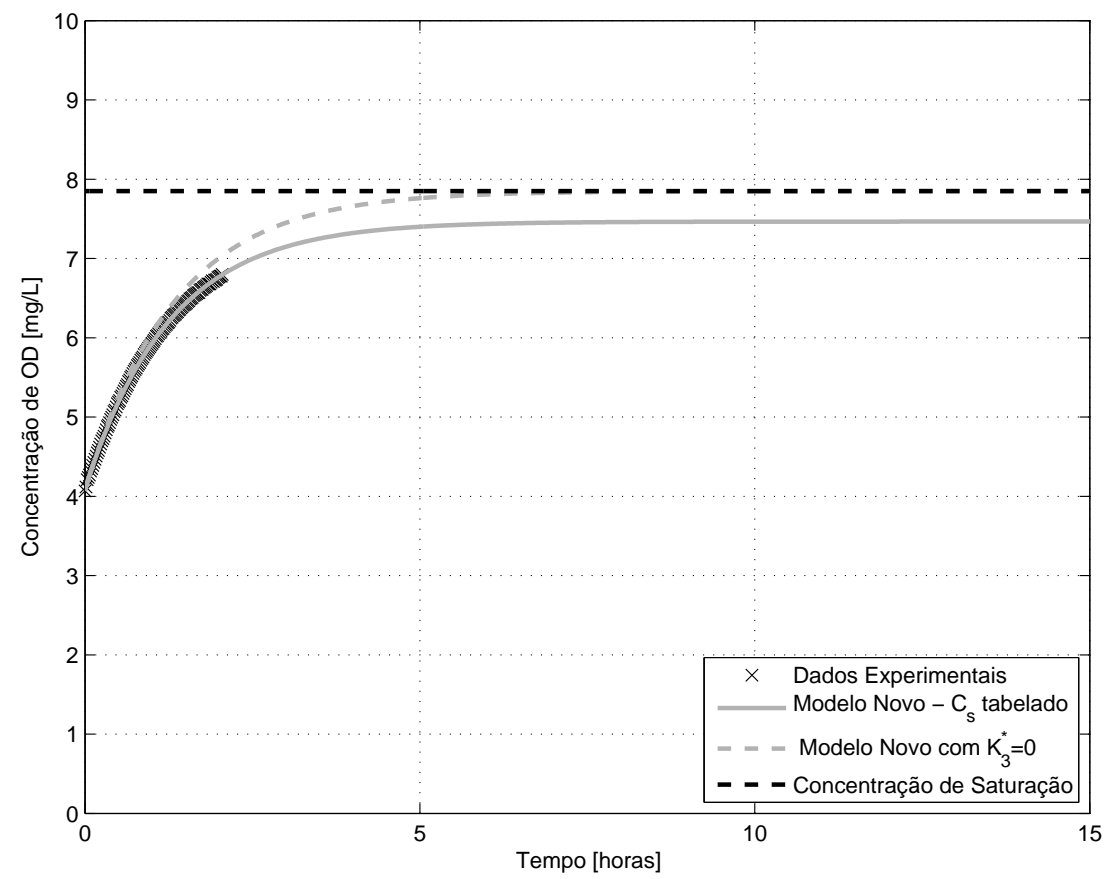

(b) Ajuste com o Modelo Novo

Figura B.122: Curva de reoxigenação para o ensaio 122 


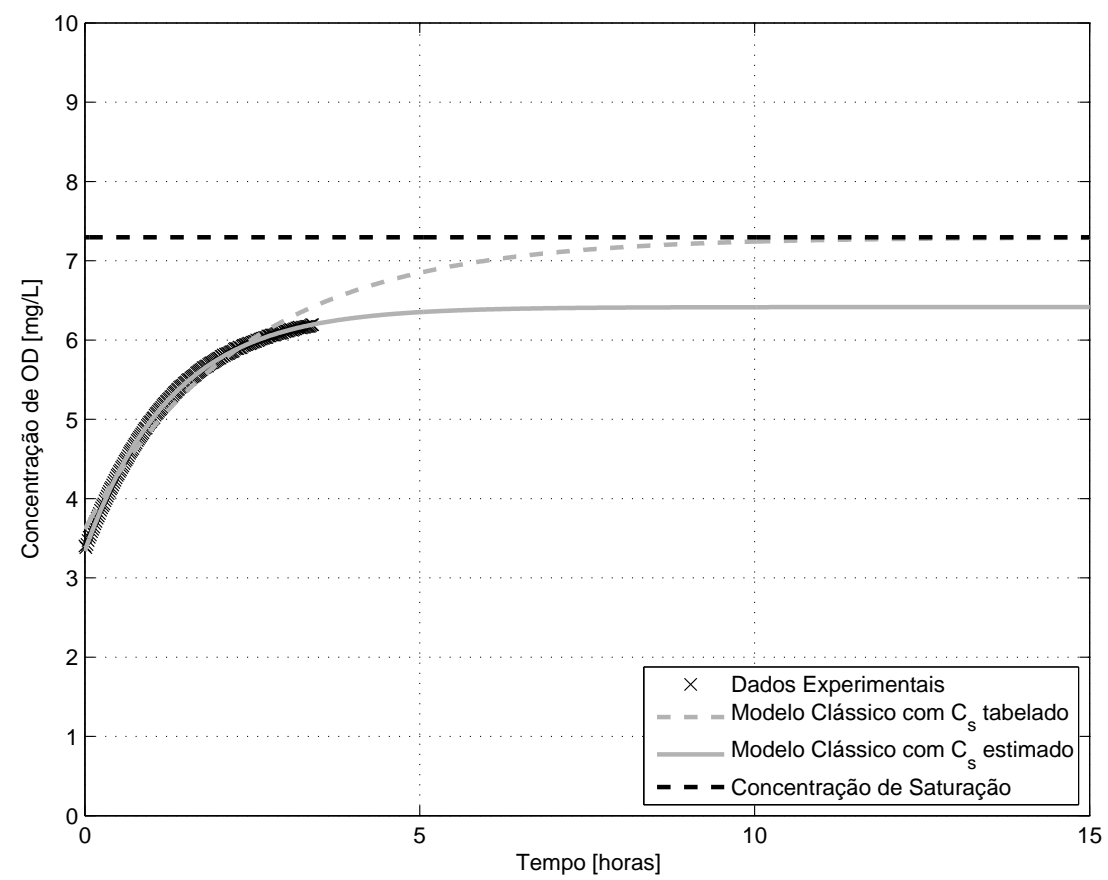

(a) Ajuste com o Modelo Clássico

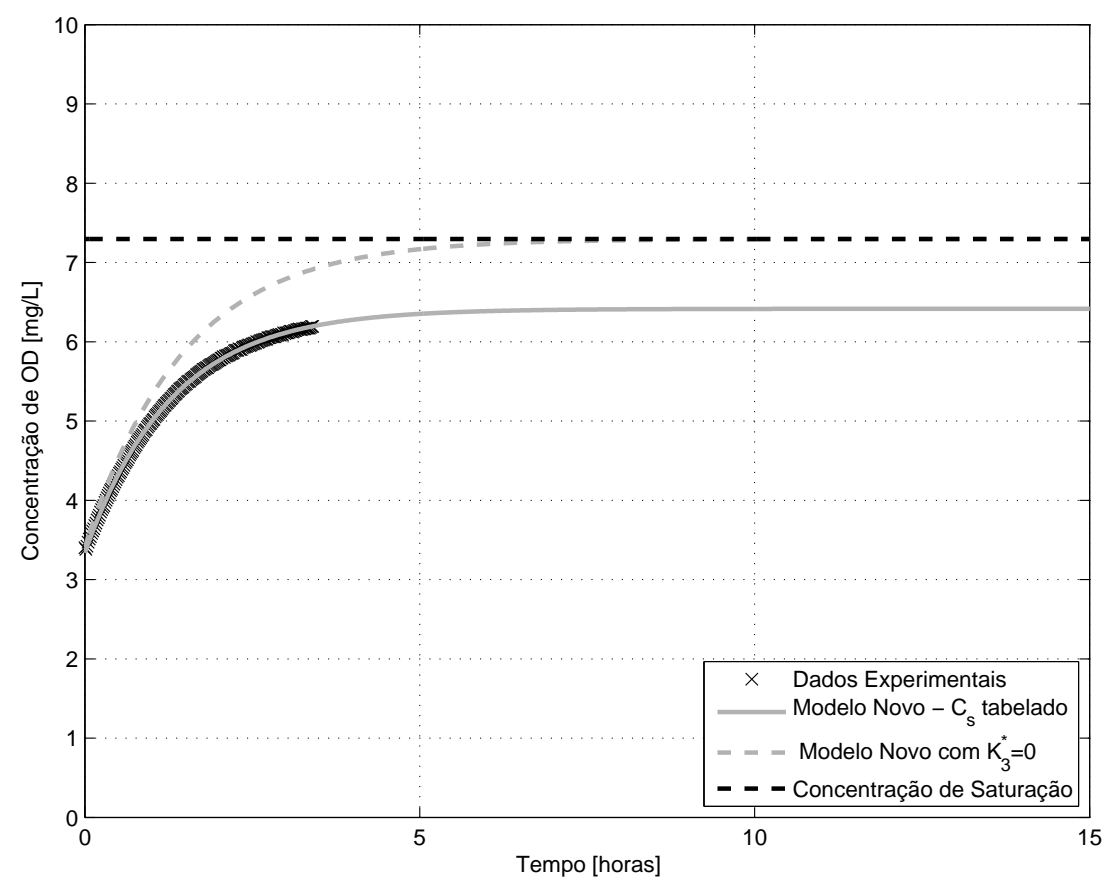

(b) Ajuste com o Modelo Novo

Figura B.123: Curva de reoxigenação para o ensaio 123 


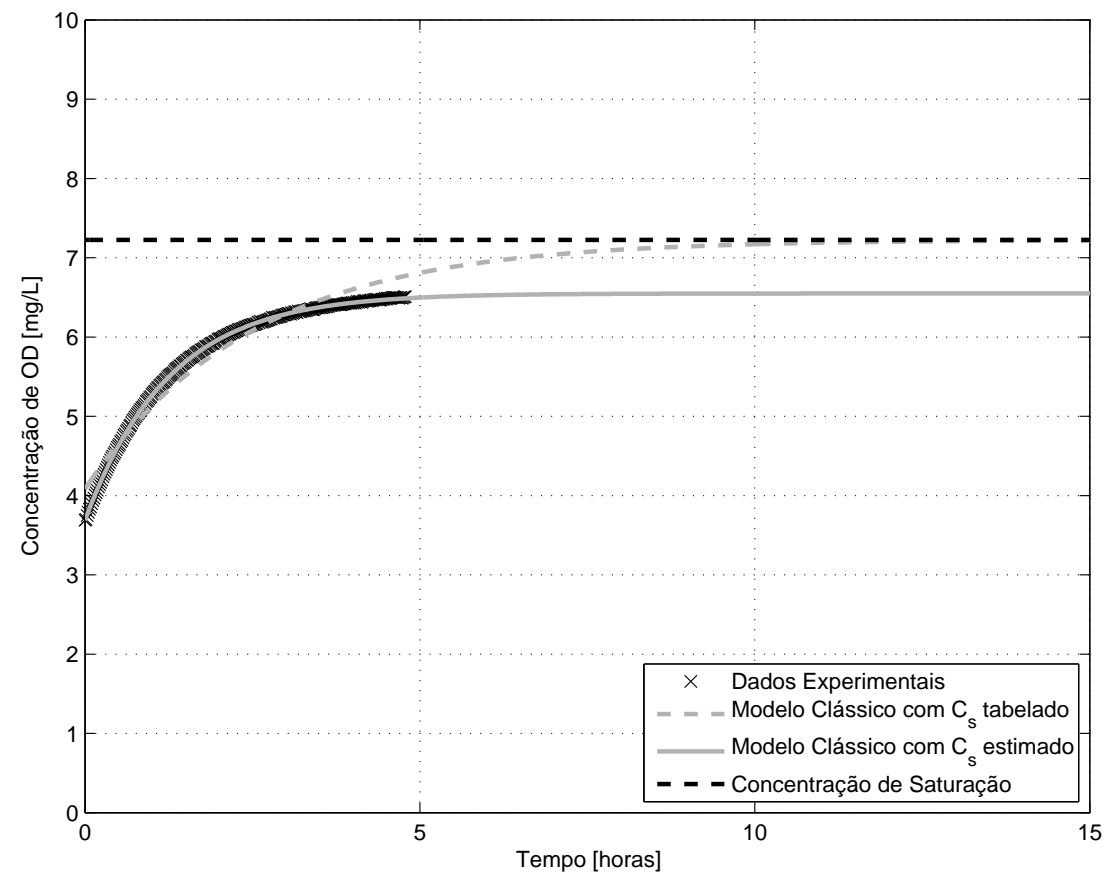

(a) Ajuste com o Modelo Clássico

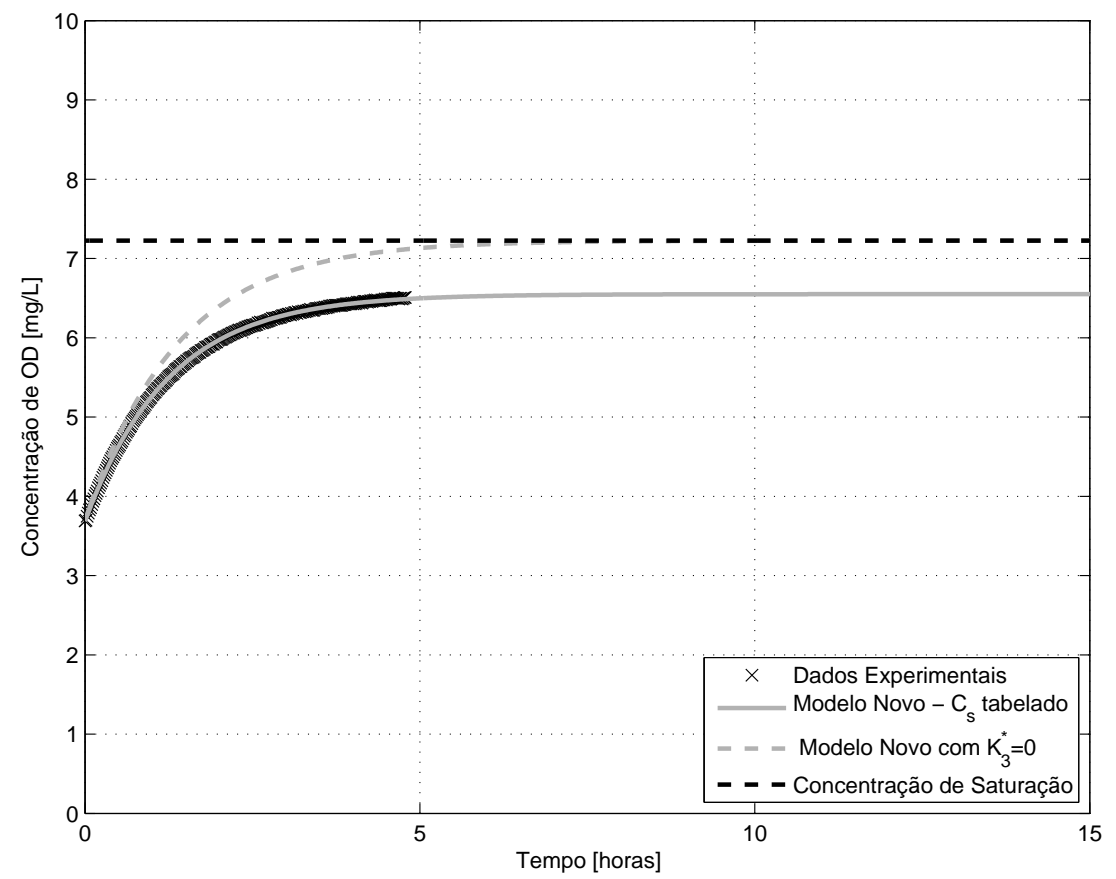

(b) Ajuste com o Modelo Novo

Figura B.124: Curva de reoxigenação para o ensaio 124 


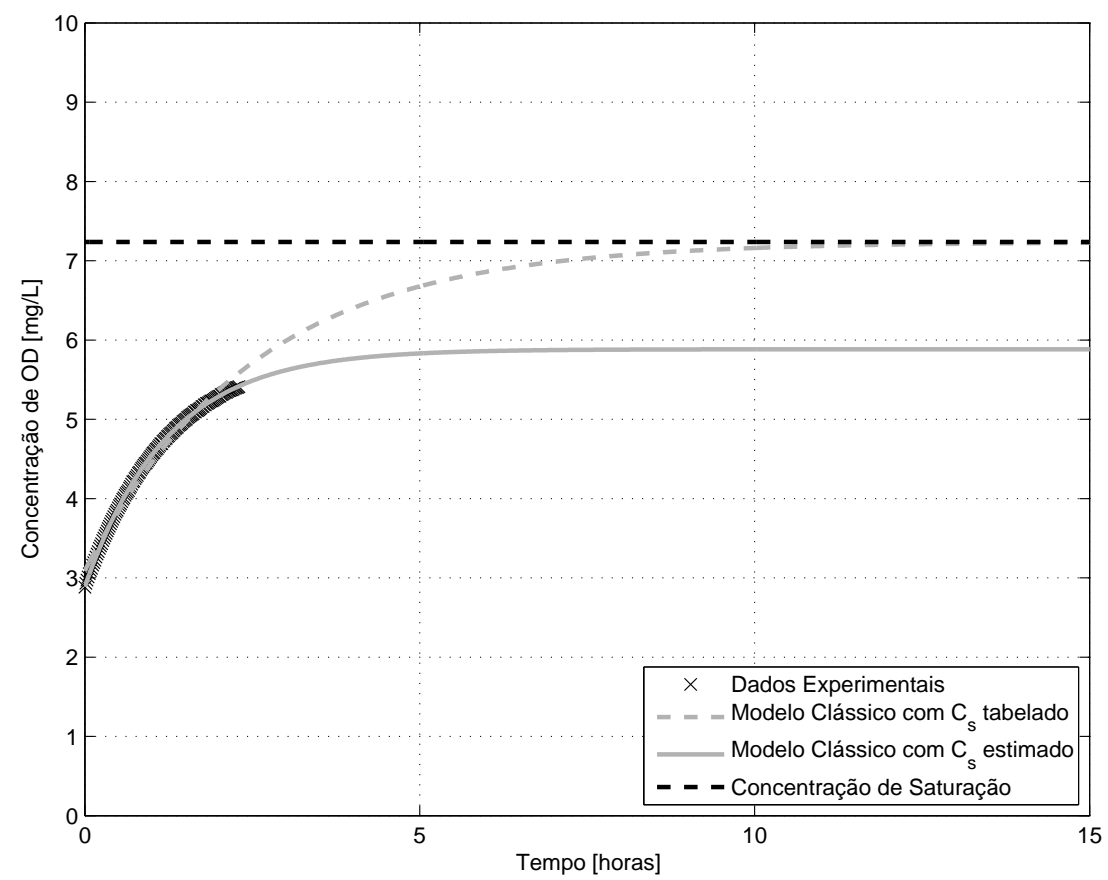

(a) Ajuste com o Modelo Clássico

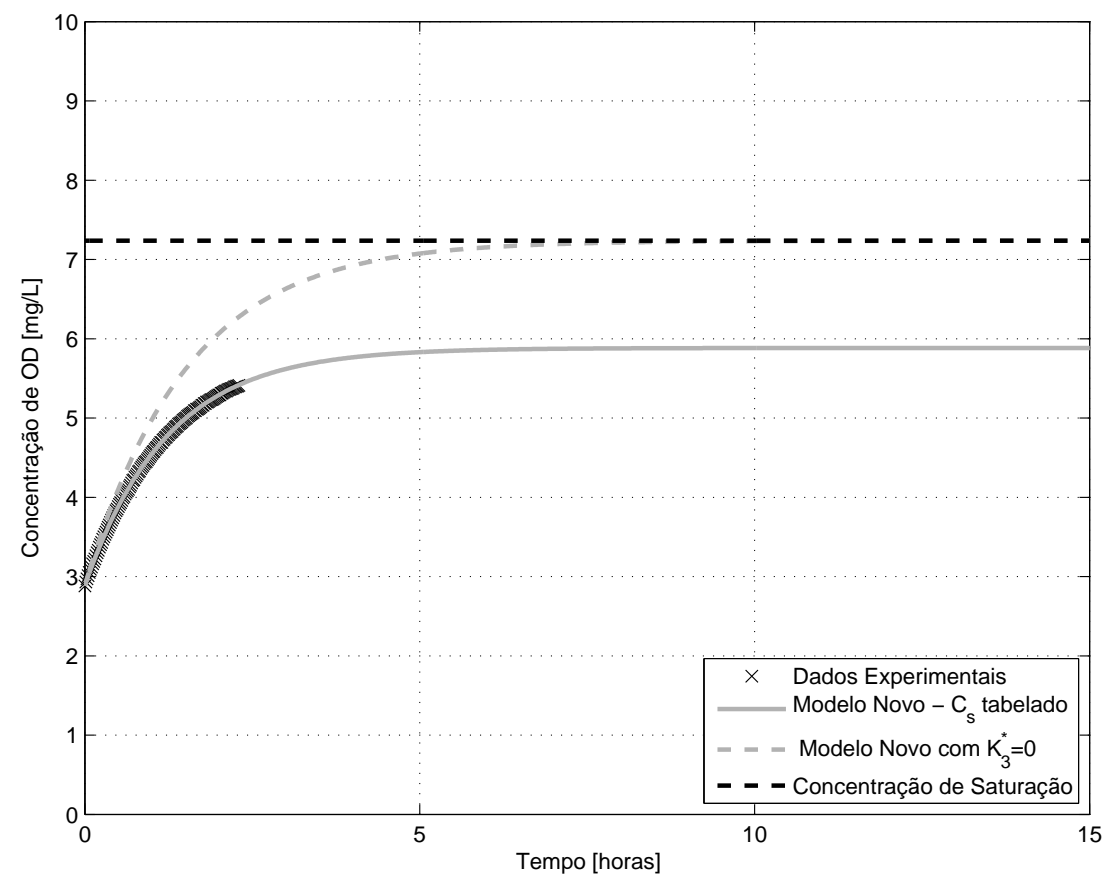

(b) Ajuste com o Modelo Novo

Figura B.125: Curva de reoxigenação para o ensaio 125 


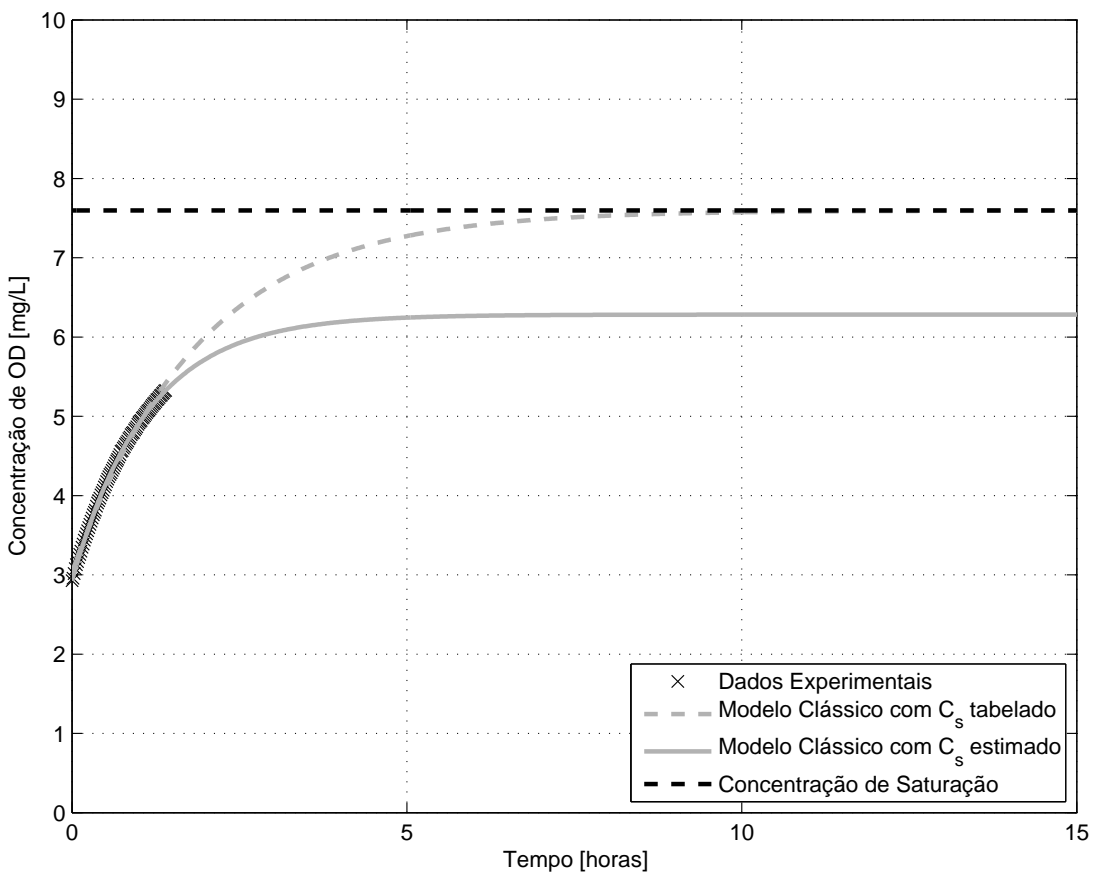

(a) Ajuste com o Modelo Clássico

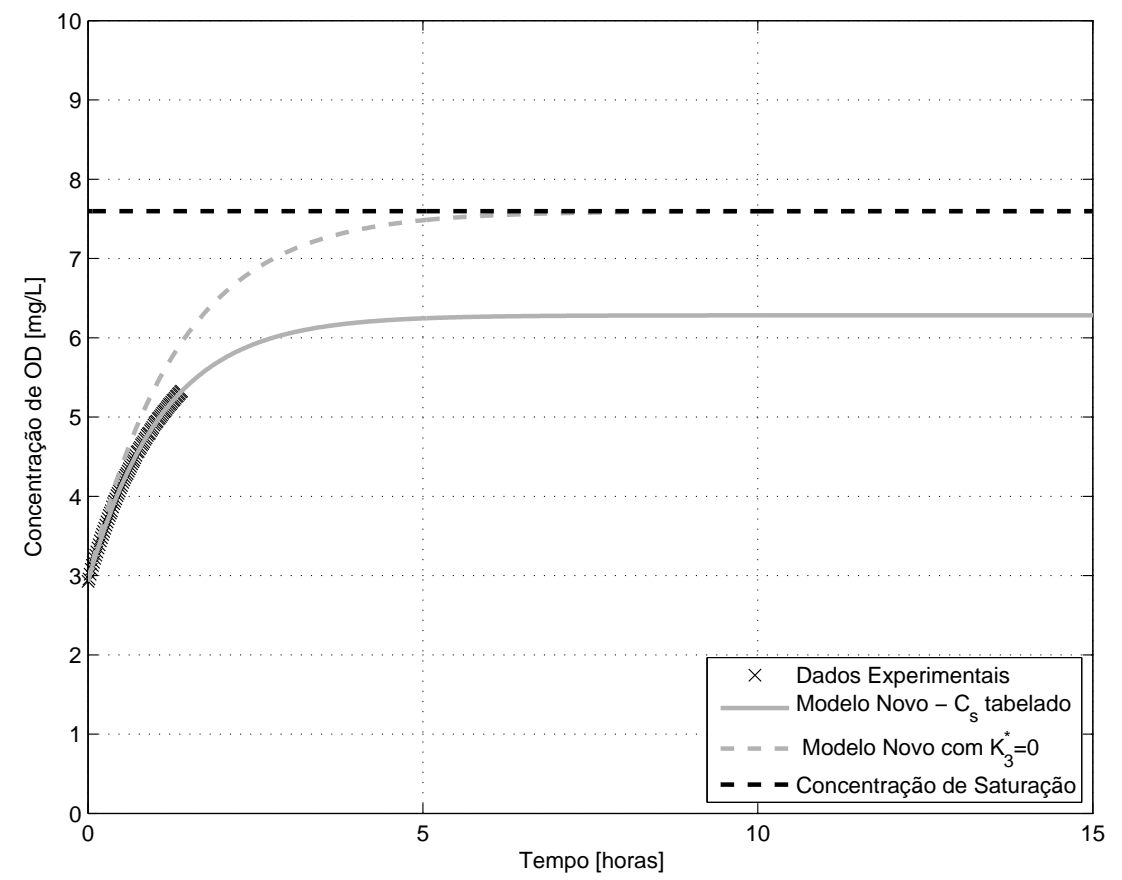

(b) Ajuste com o Modelo Novo

Figura B.126: Curva de reoxigenação para o ensaio 126 


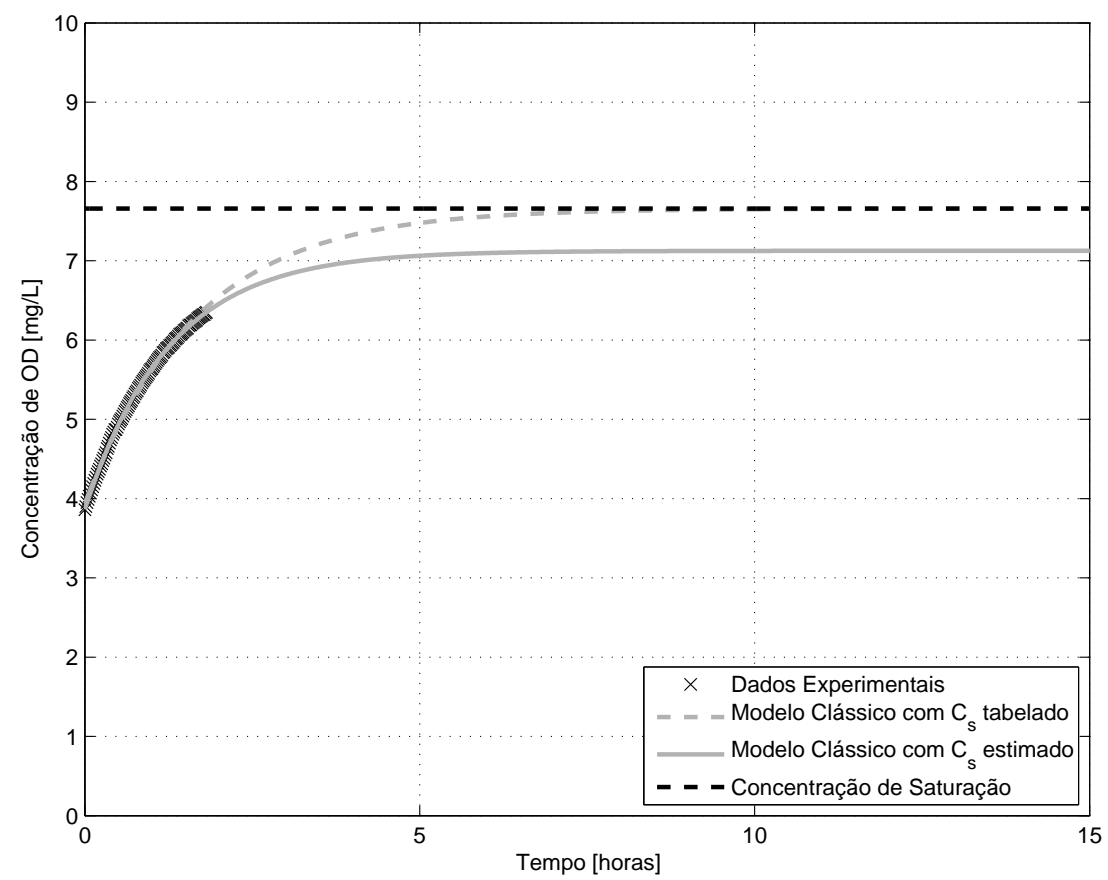

(a) Ajuste com o Modelo Clássico

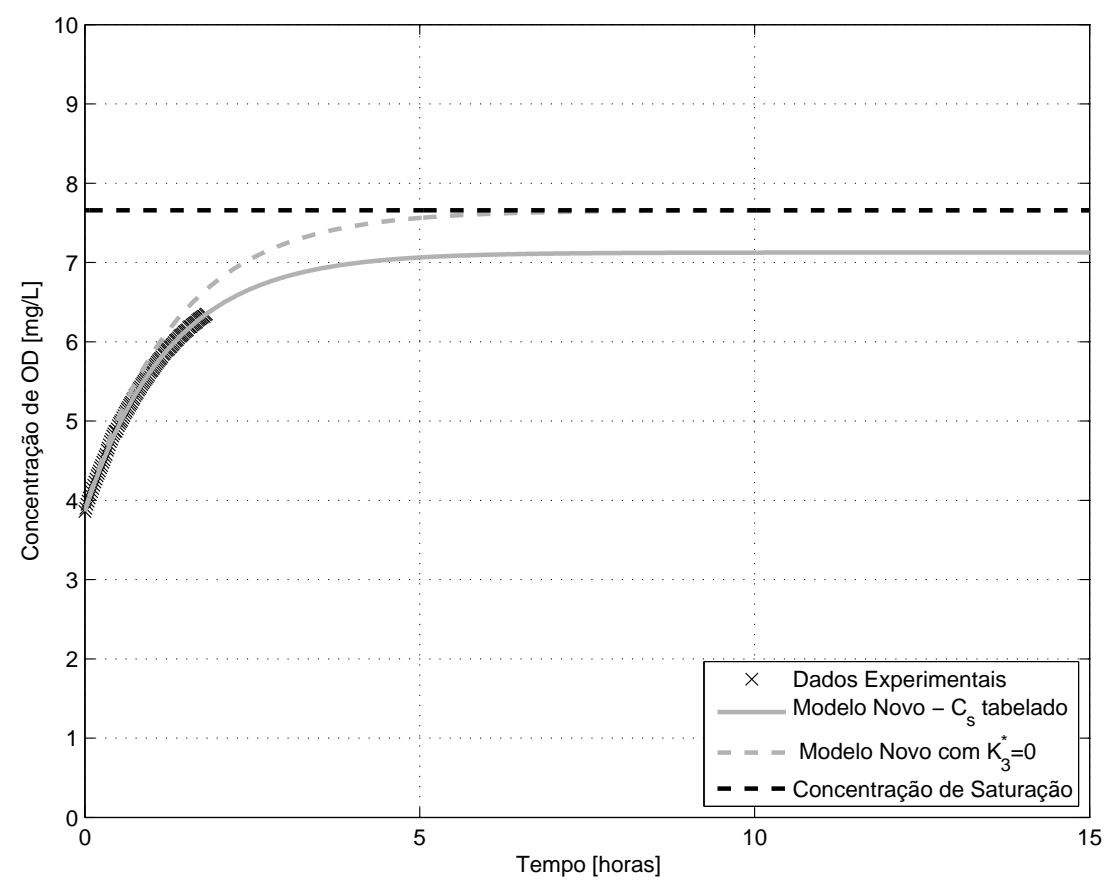

(b) Ajuste com o Modelo Novo

Figura B.127: Curva de reoxigenação para o ensaio 127 


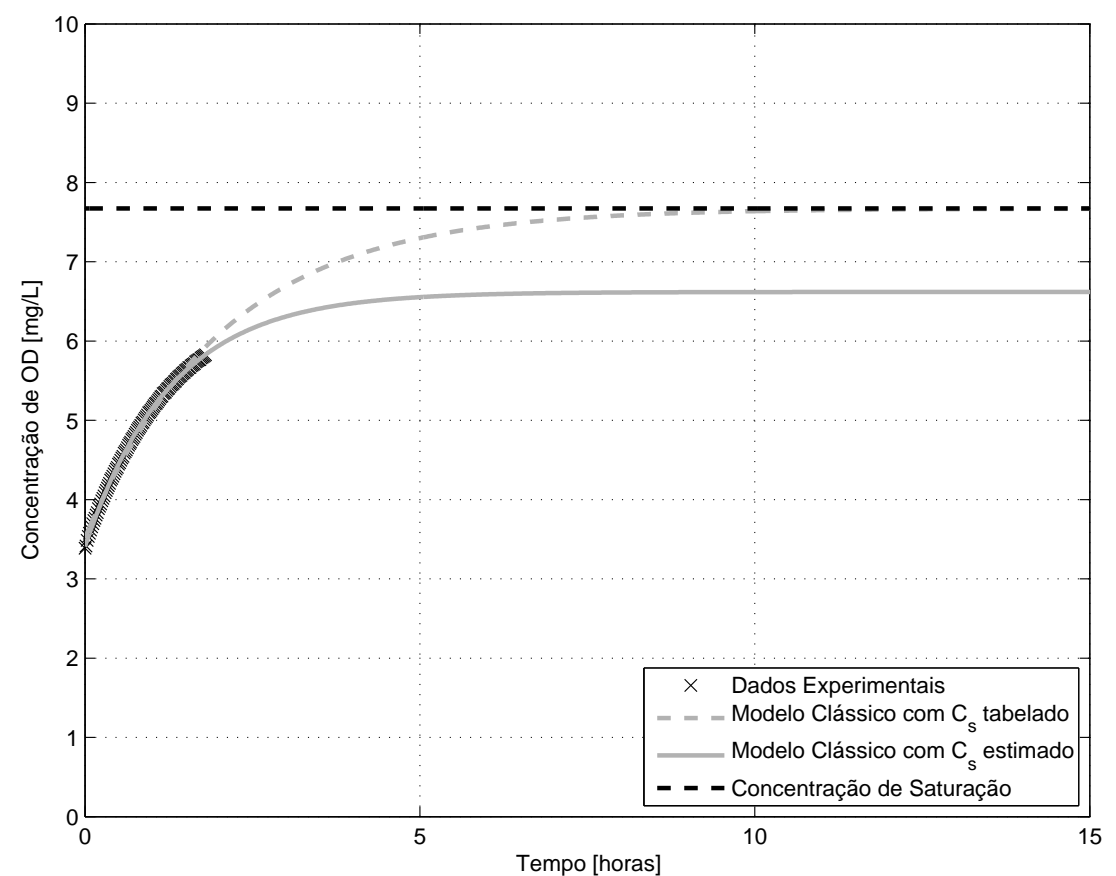

(a) Ajuste com o Modelo Clássico

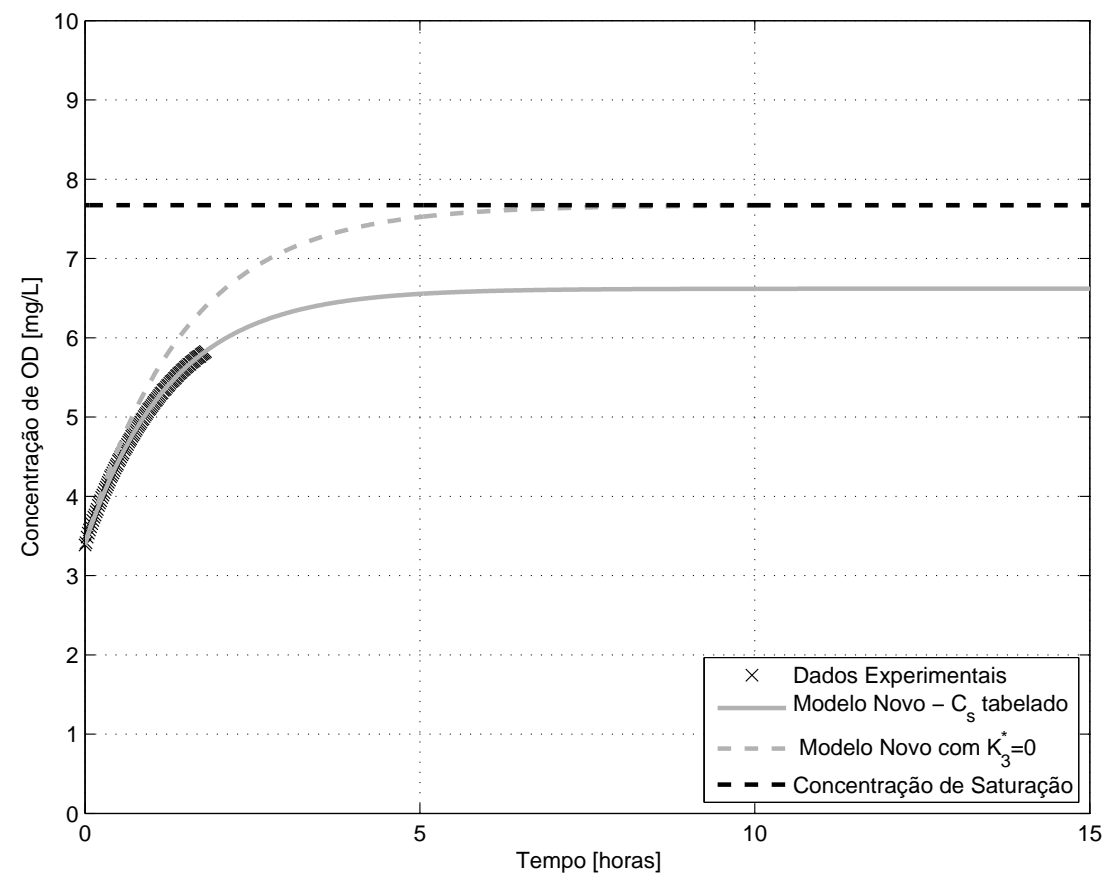

(b) Ajuste com o Modelo Novo

Figura B.128: Curva de reoxigenação para o ensaio 128 


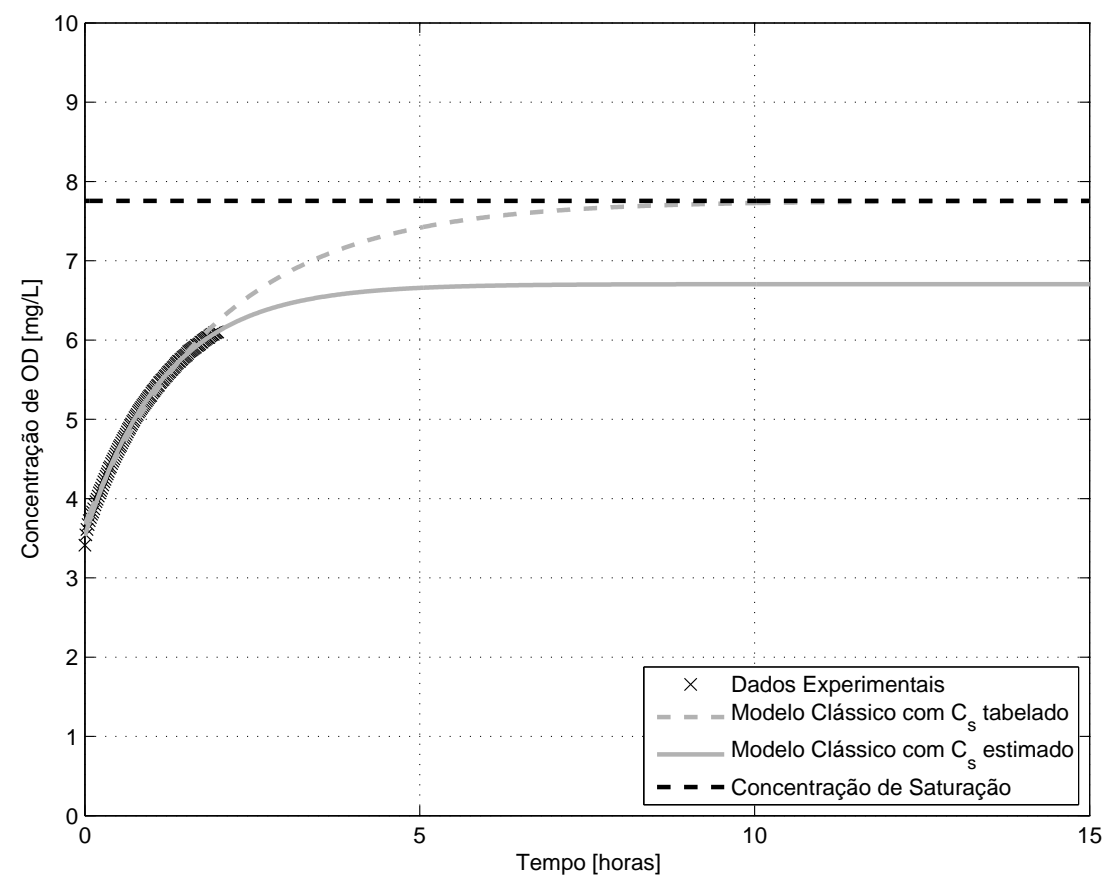

(a) Ajuste com o Modelo Clássico

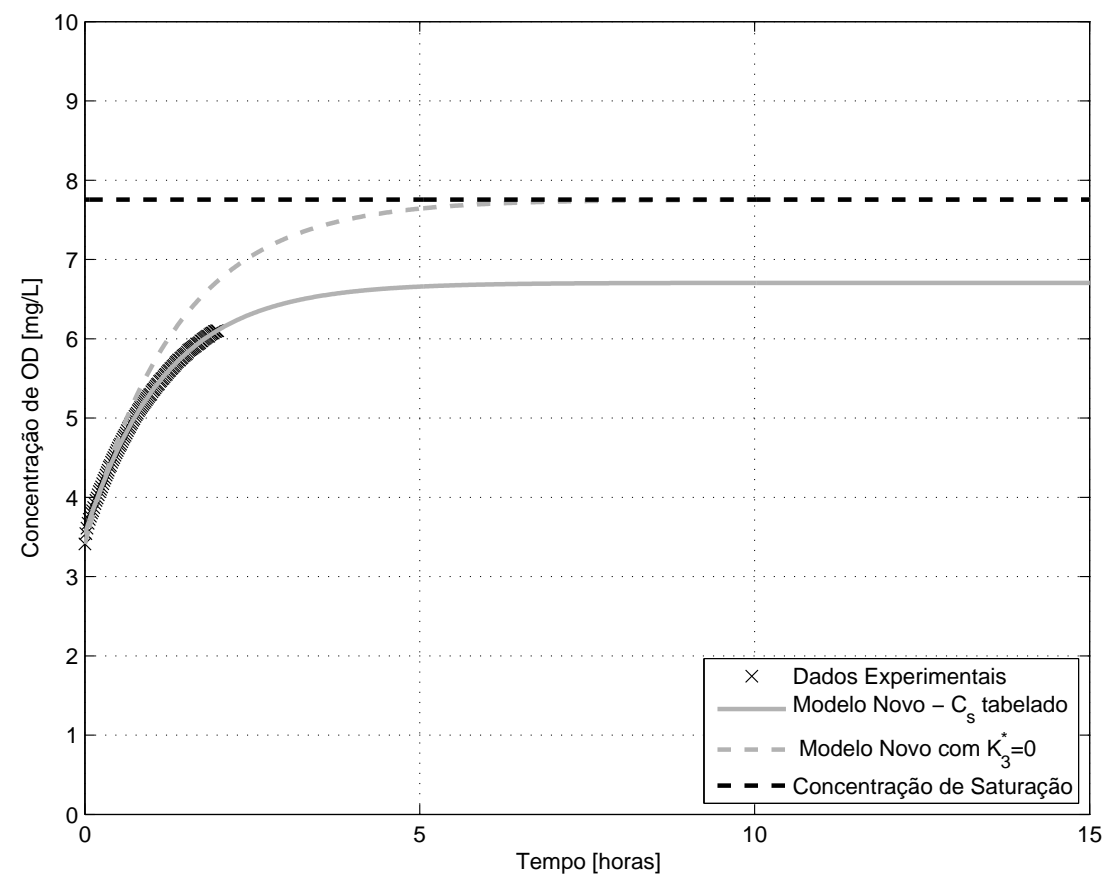

(b) Ajuste com o Modelo Novo

Figura B.129: Curva de reoxigenação para o ensaio 129 


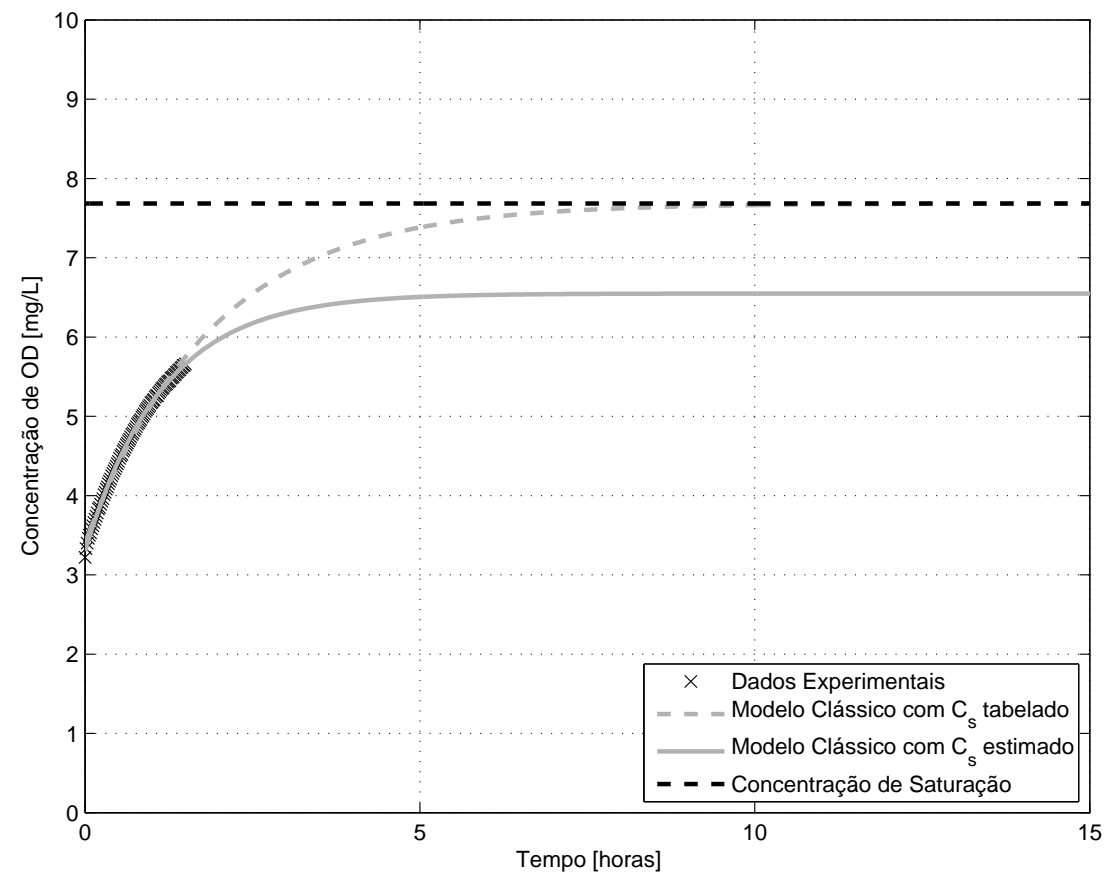

(a) Ajuste com o Modelo Clássico

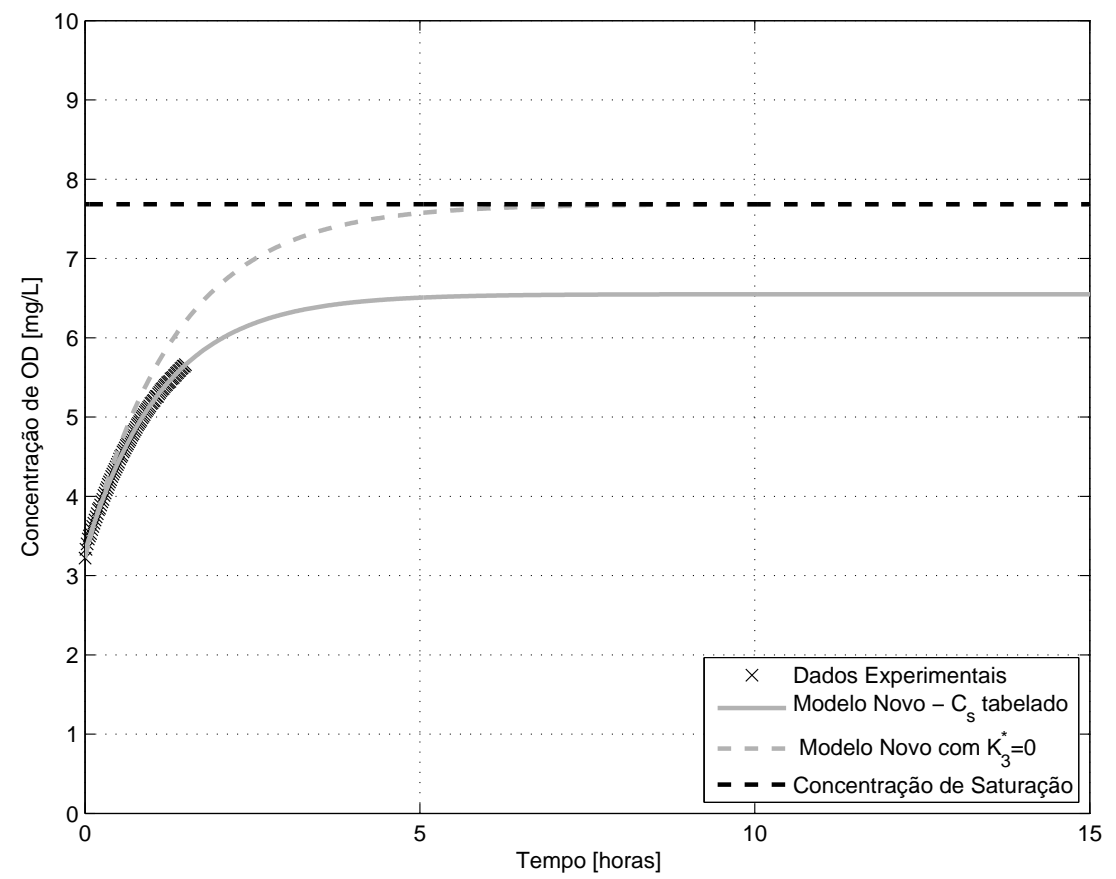

(b) Ajuste com o Modelo Novo

Figura B.130: Curva de reoxigenação para o ensaio 130 


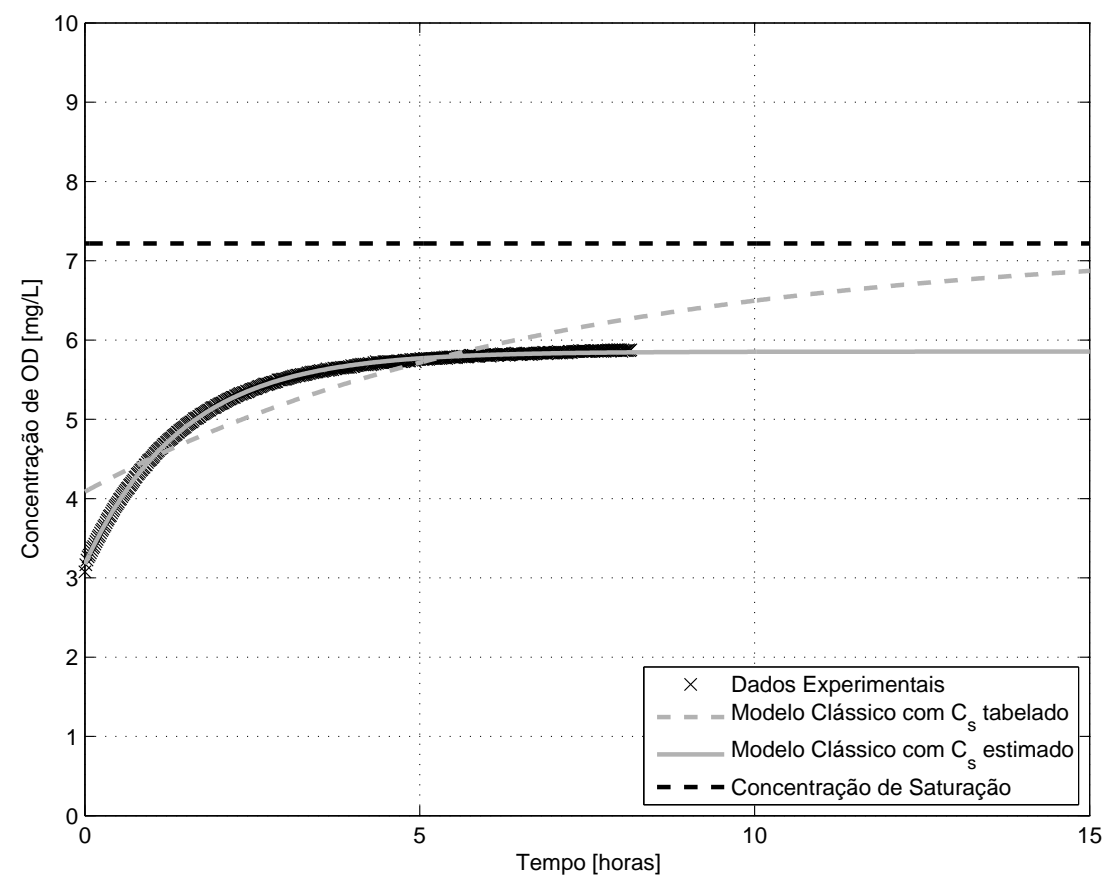

(a) Ajuste com o Modelo Clássico

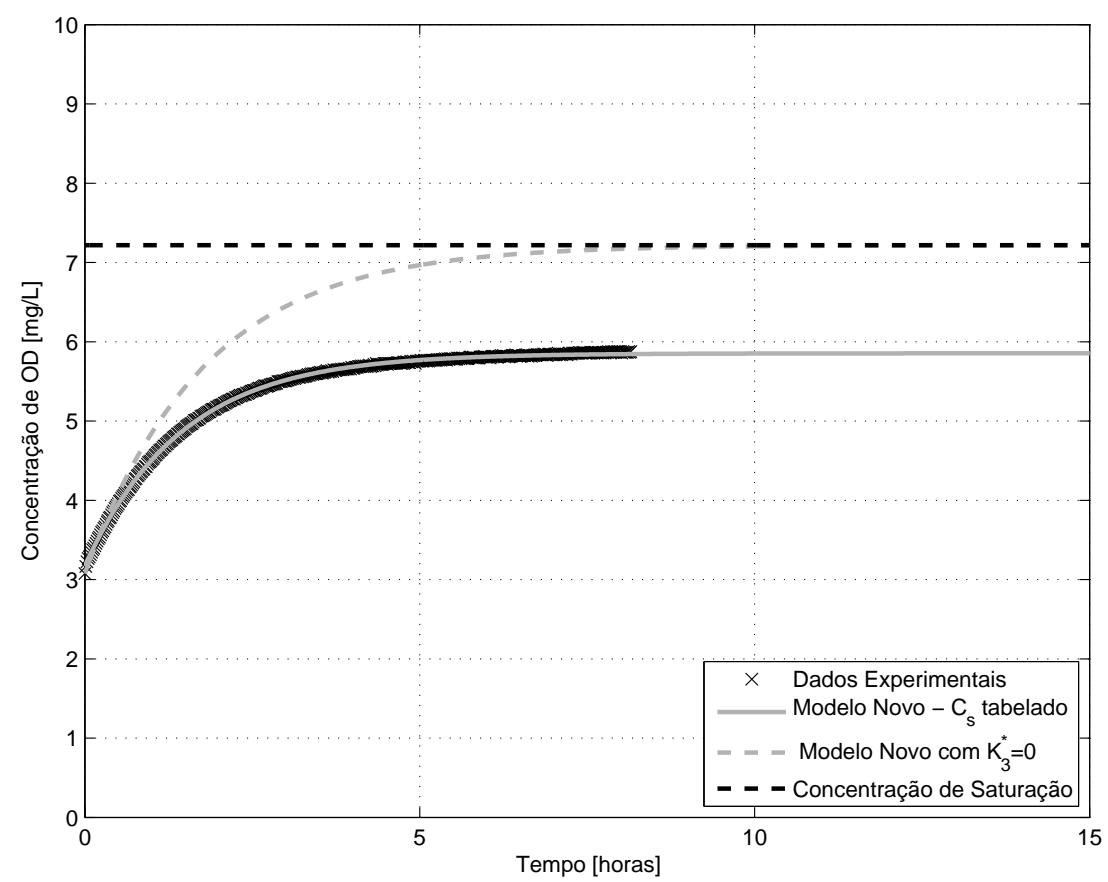

(b) Ajuste com o Modelo Novo

Figura B.131: Curva de reoxigenação para o ensaio 131 


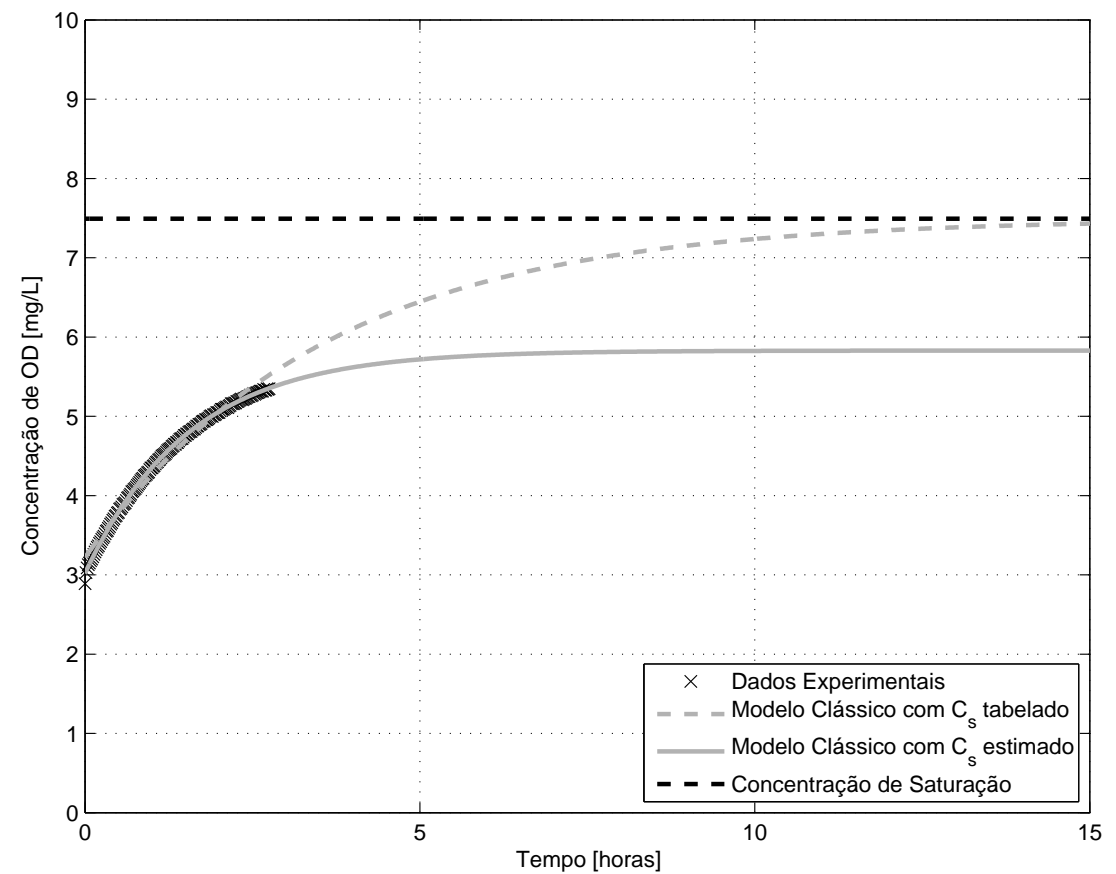

(a) Ajuste com o Modelo Clássico

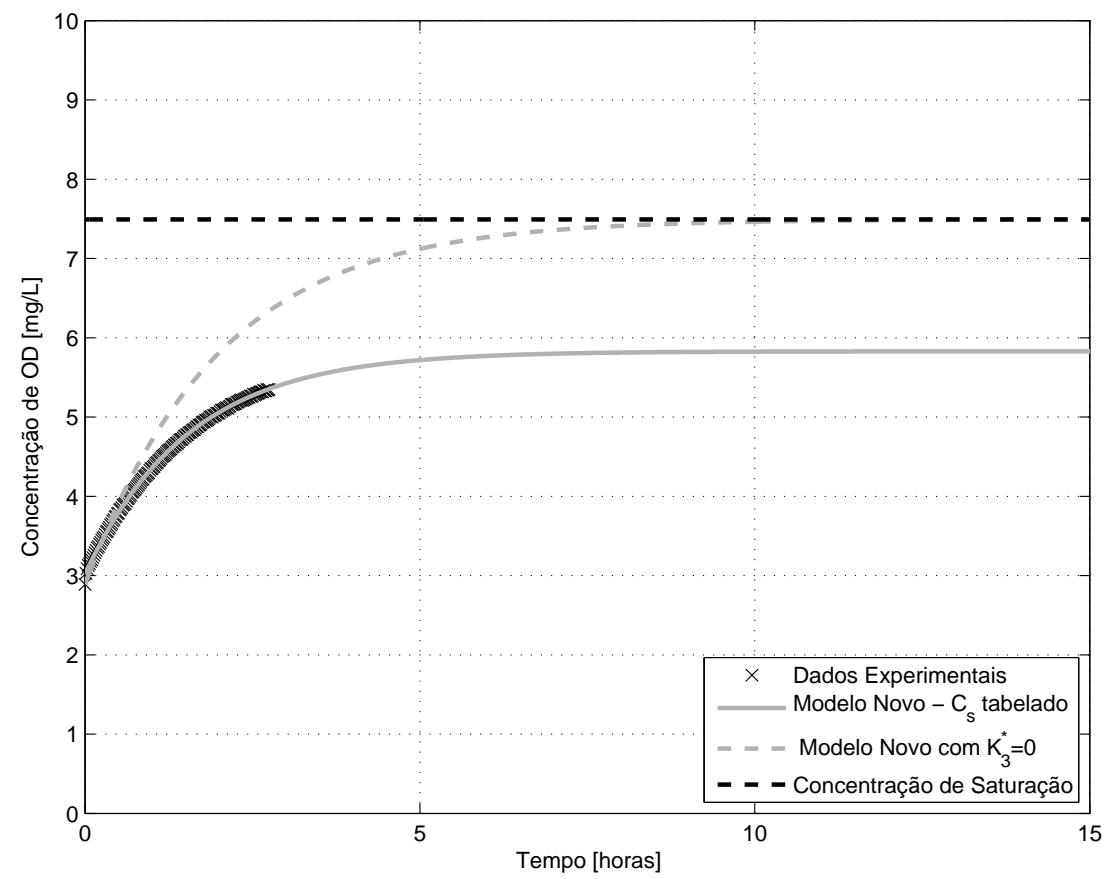

(b) Ajuste com o Modelo Novo

Figura B.132: Curva de reoxigenação para o ensaio 132 


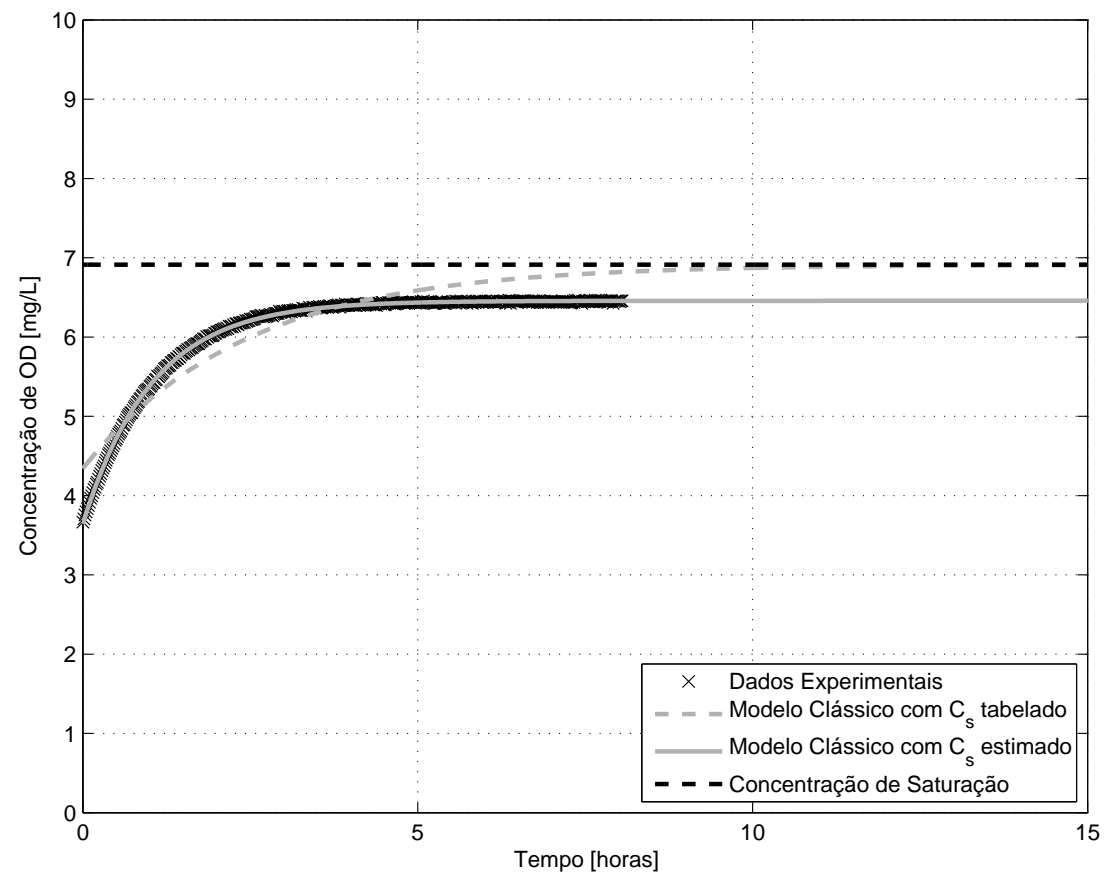

(a) Ajuste com o Modelo Clássico

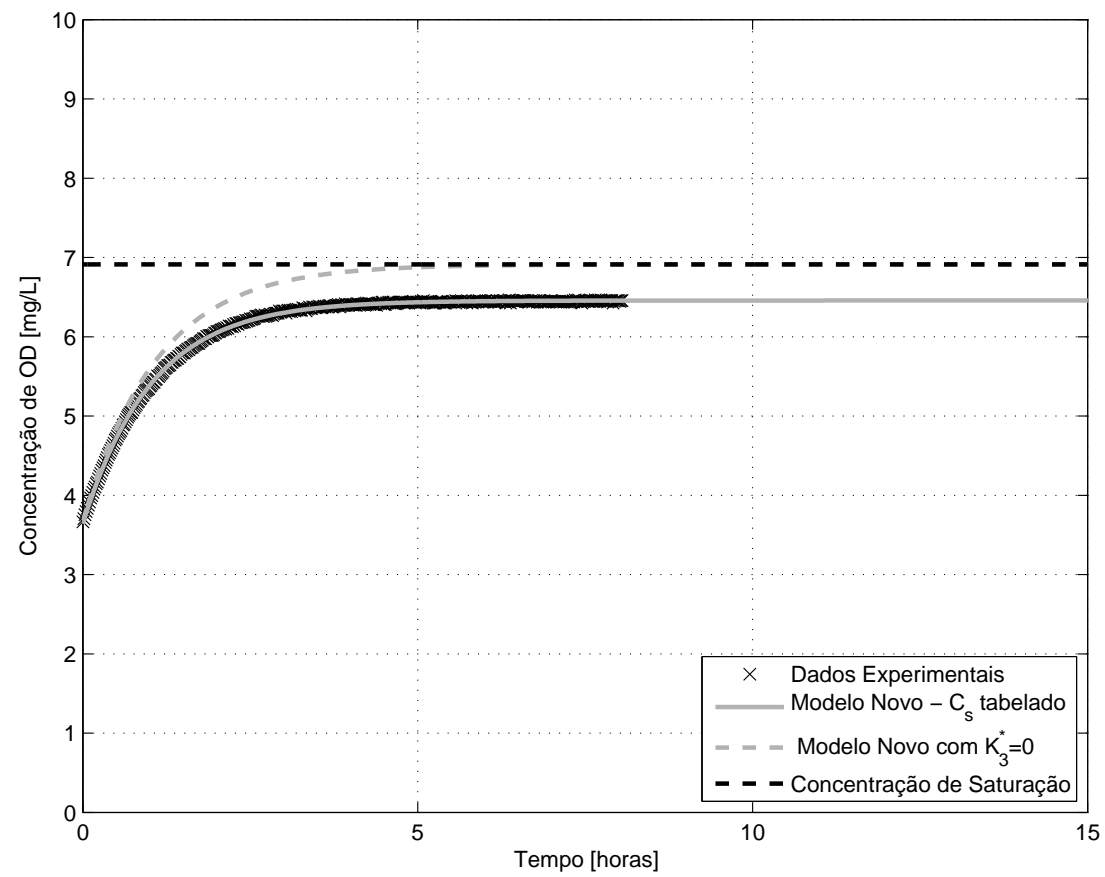

(b) Ajuste com o Modelo Novo

Figura B.133: Curva de reoxigenação para o ensaio 133 


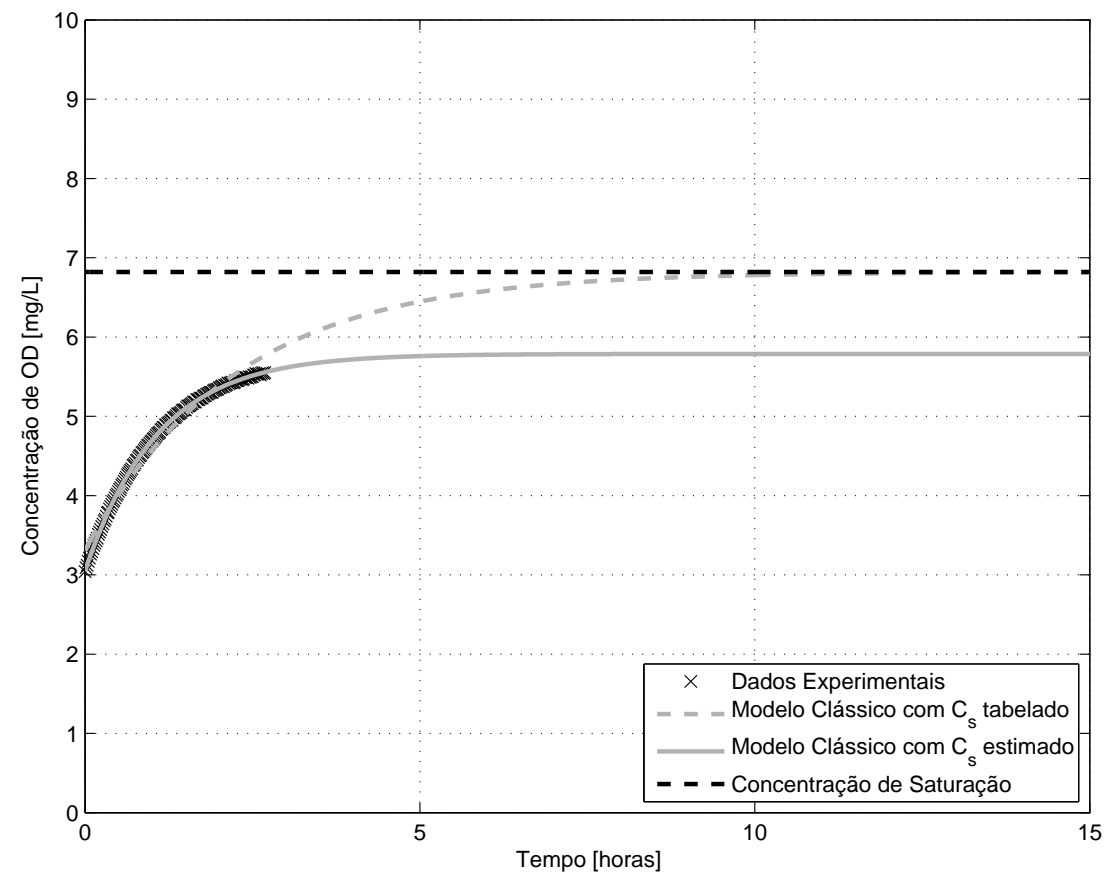

(a) Ajuste com o Modelo Clássico

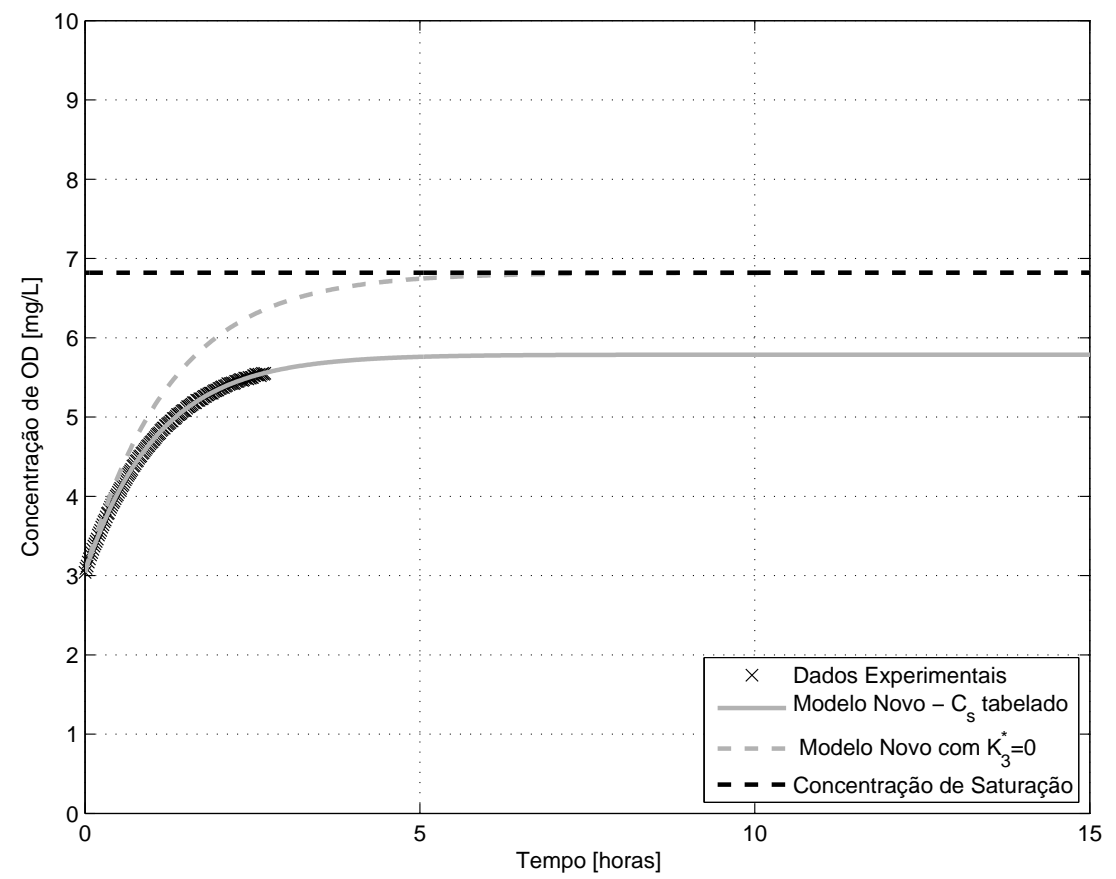

(b) Ajuste com o Modelo Novo

Figura B.134: Curva de reoxigenação para o ensaio 134 


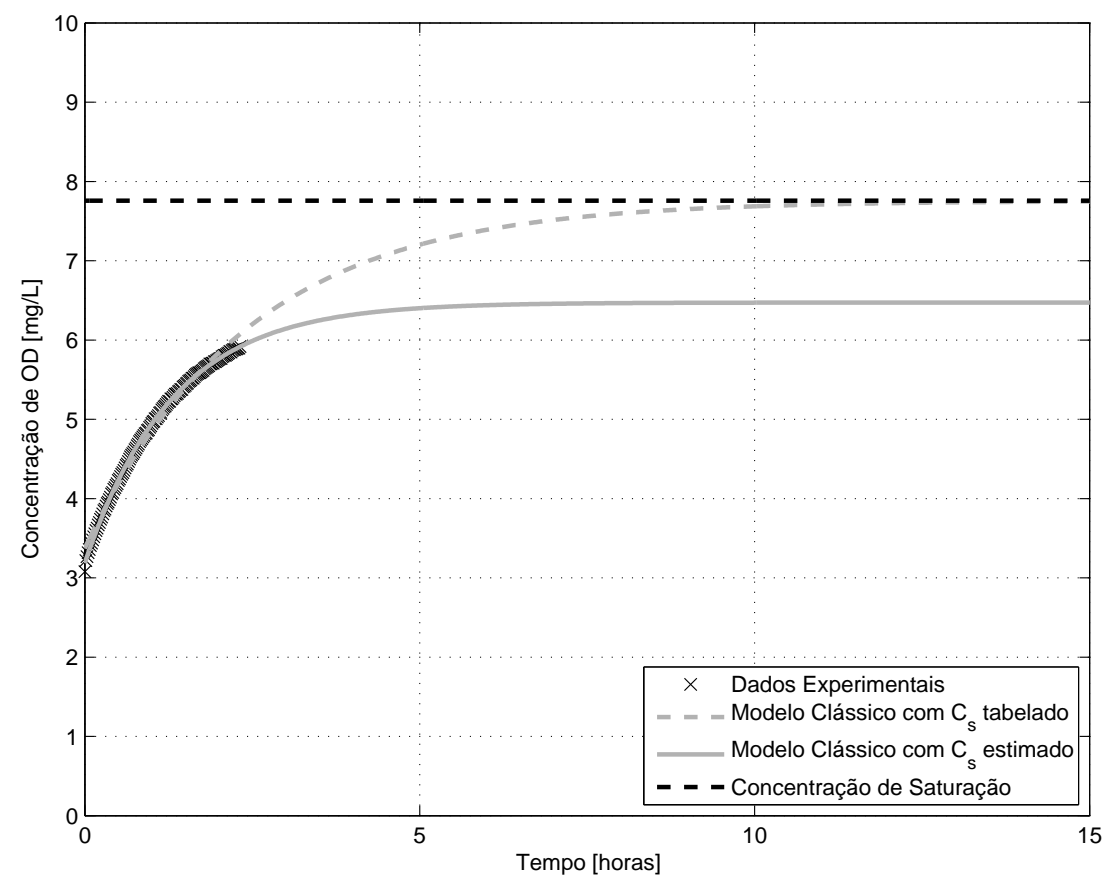

(a) Ajuste com o Modelo Clássico

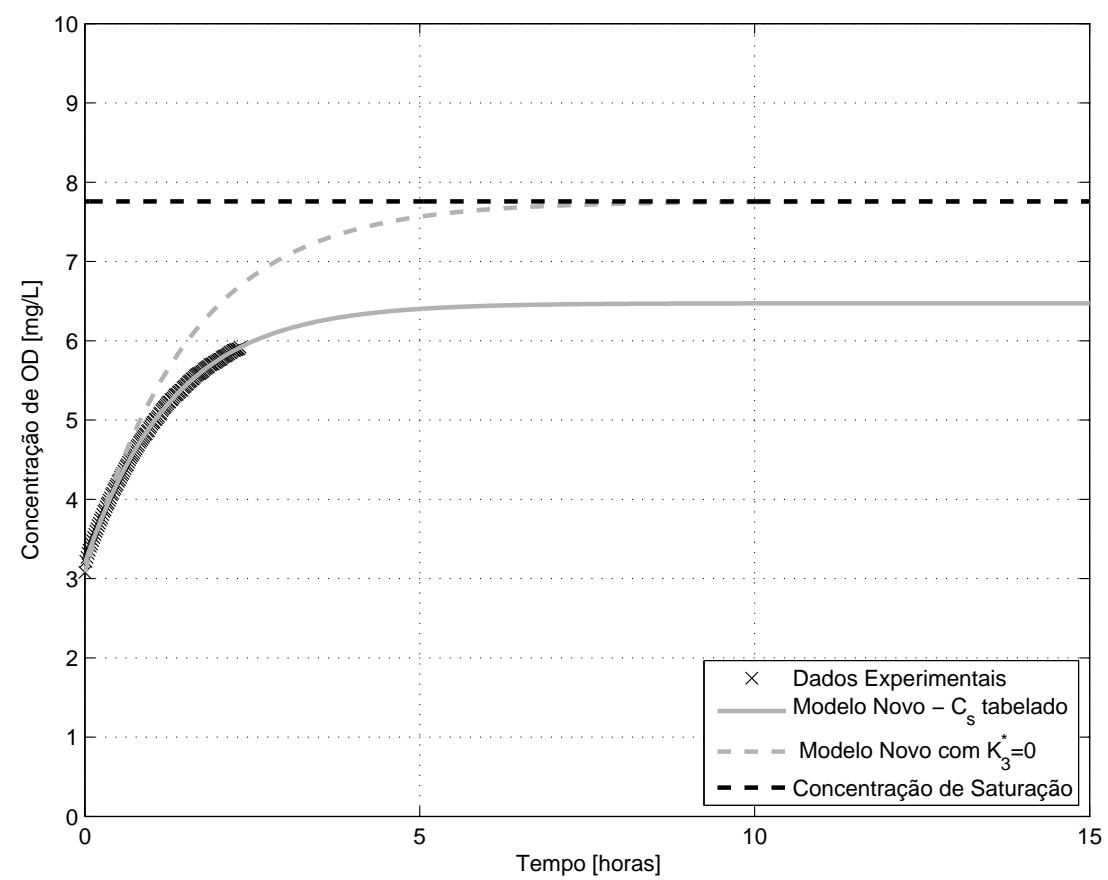

(b) Ajuste com o Modelo Novo

Figura B.135: Curva de reoxigenação para o ensaio 135 


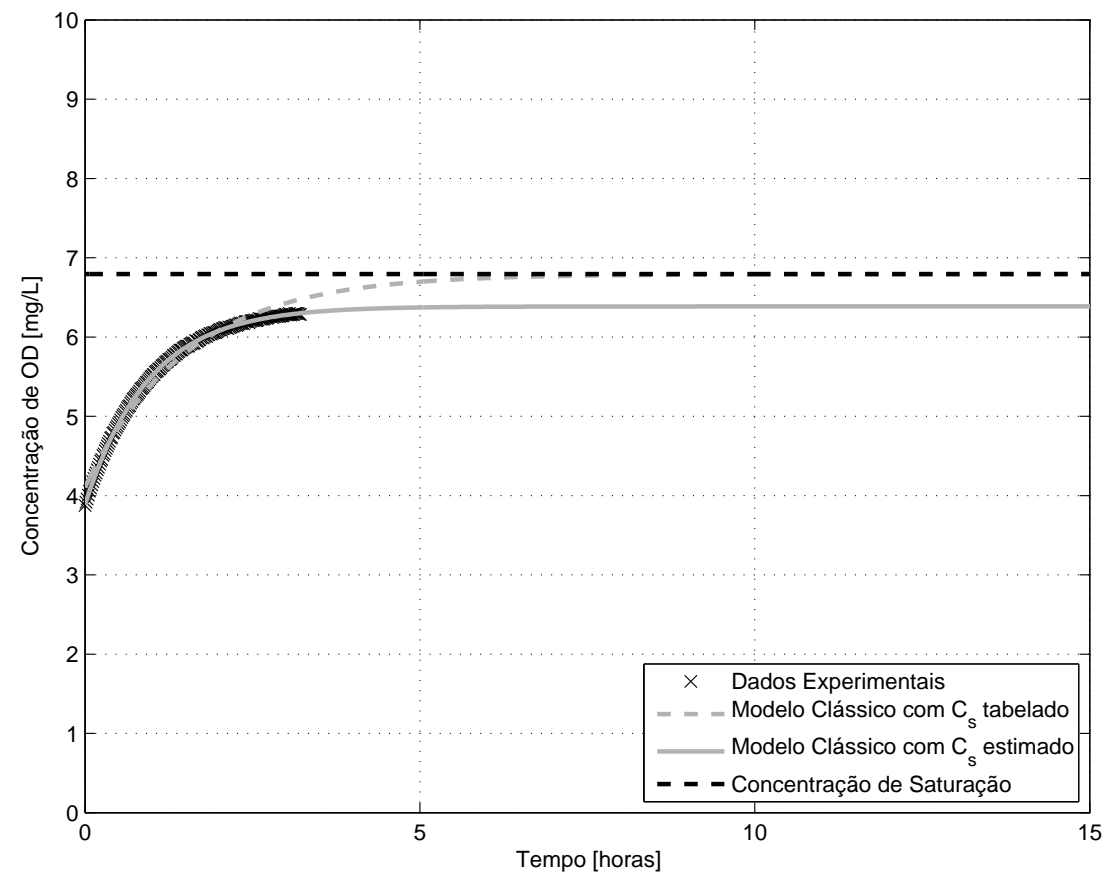

(a) Ajuste com o Modelo Clássico

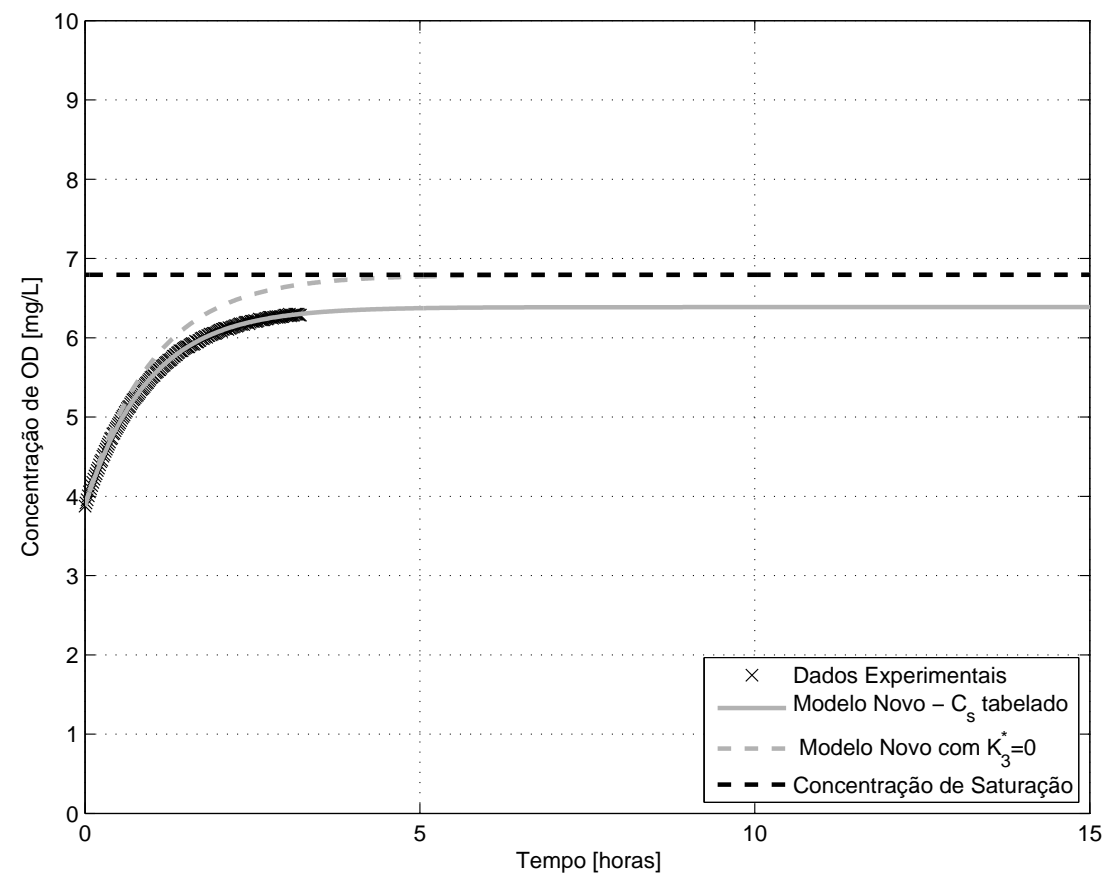

(b) Ajuste com o Modelo Novo

Figura B.136: Curva de reoxigenação para o ensaio 136 


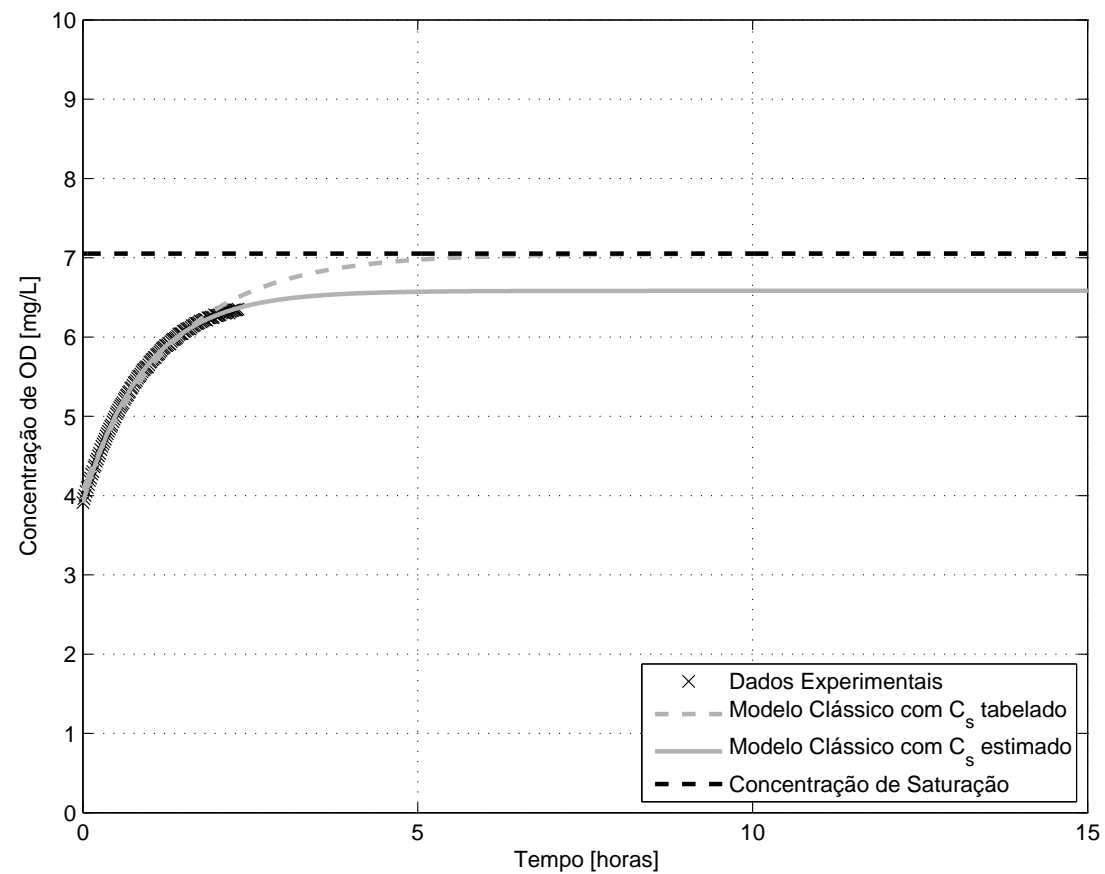

(a) Ajuste com o Modelo Clássico

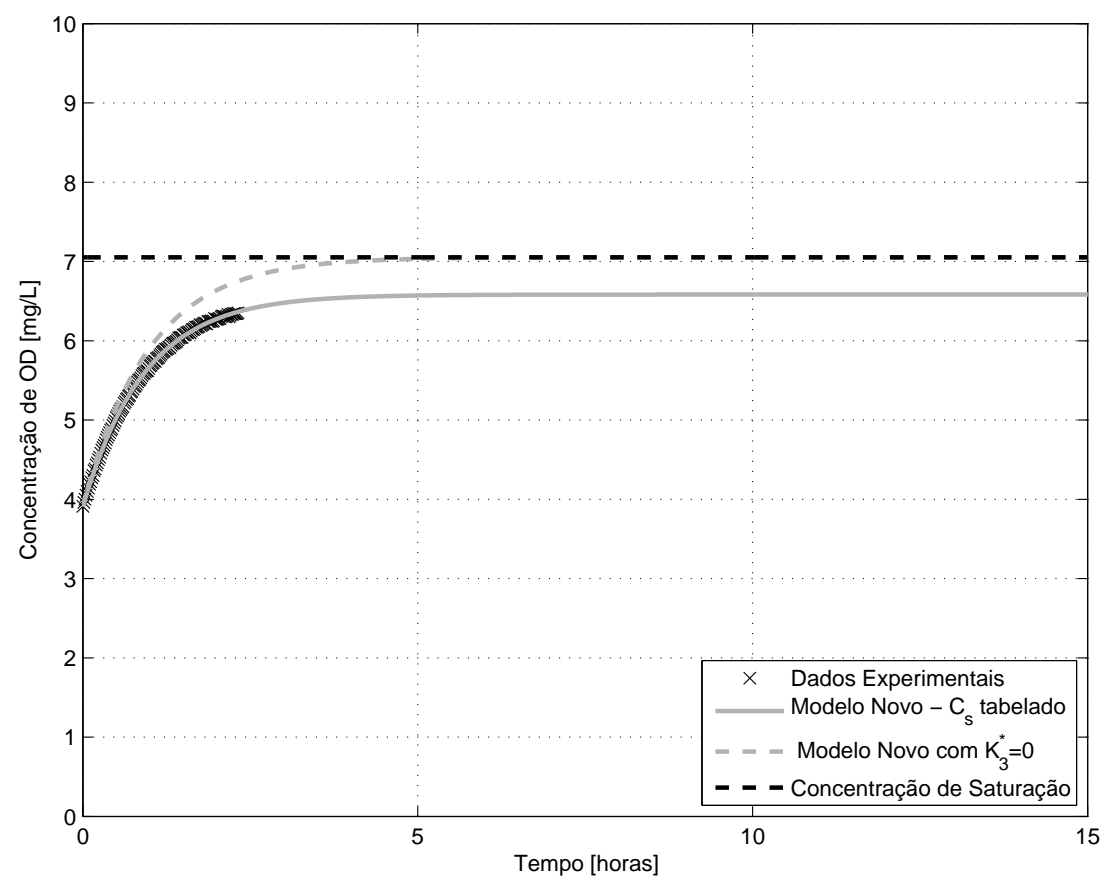

(b) Ajuste com o Modelo Novo

Figura B.137: Curva de reoxigenação para o ensaio 137 


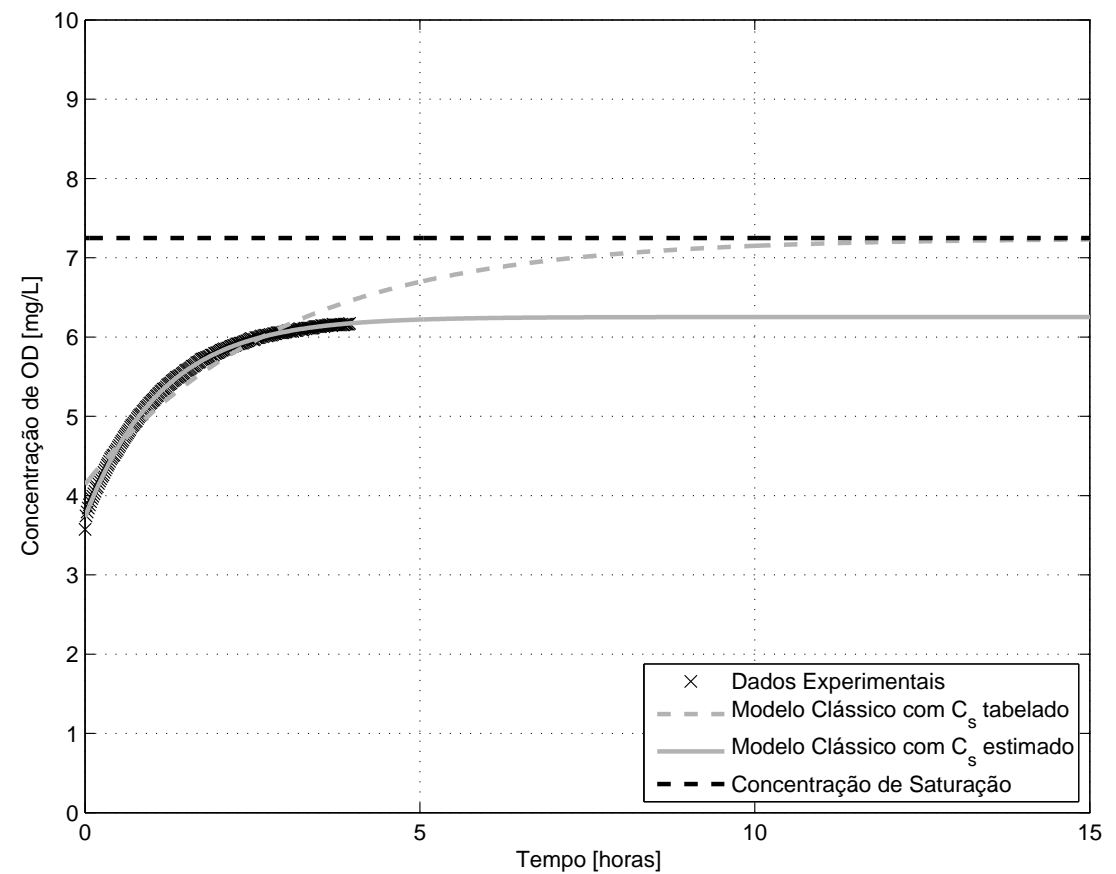

(a) Ajuste com o Modelo Clássico

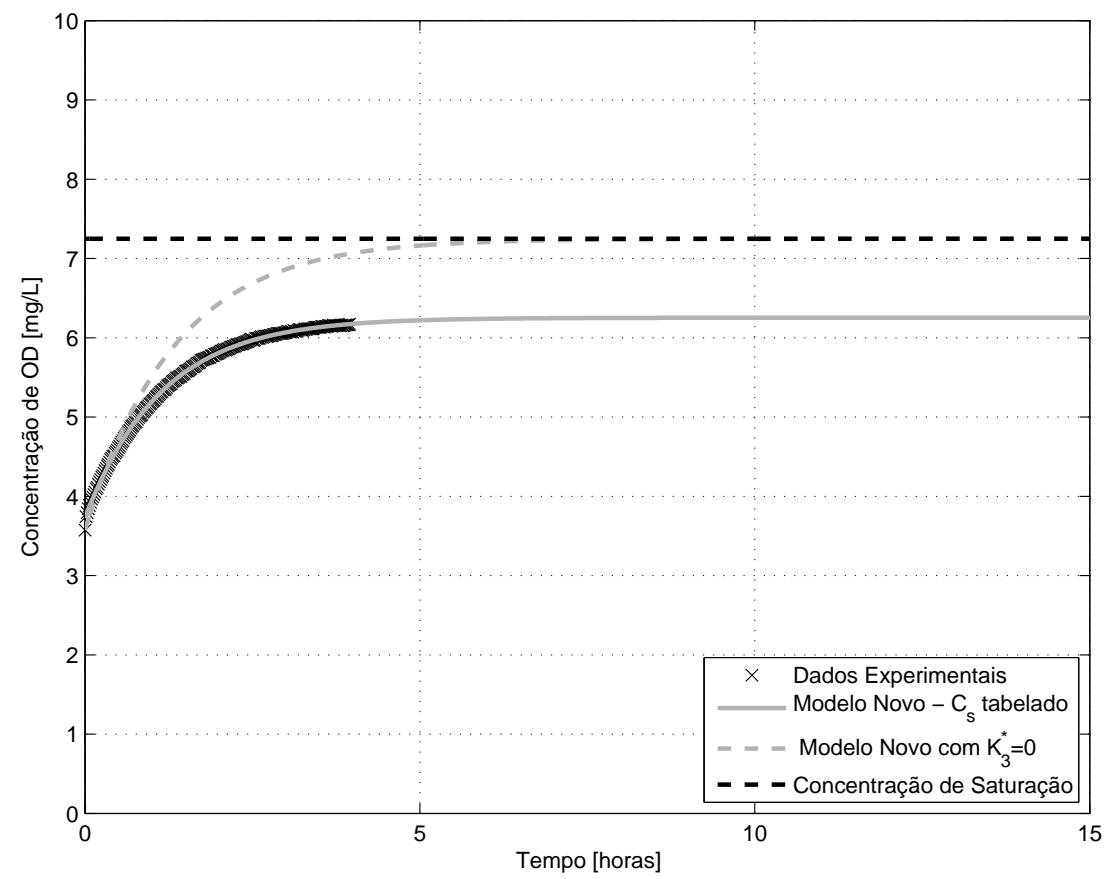

(b) Ajuste com o Modelo Novo

Figura B.138: Curva de reoxigenação para o ensaio 138 


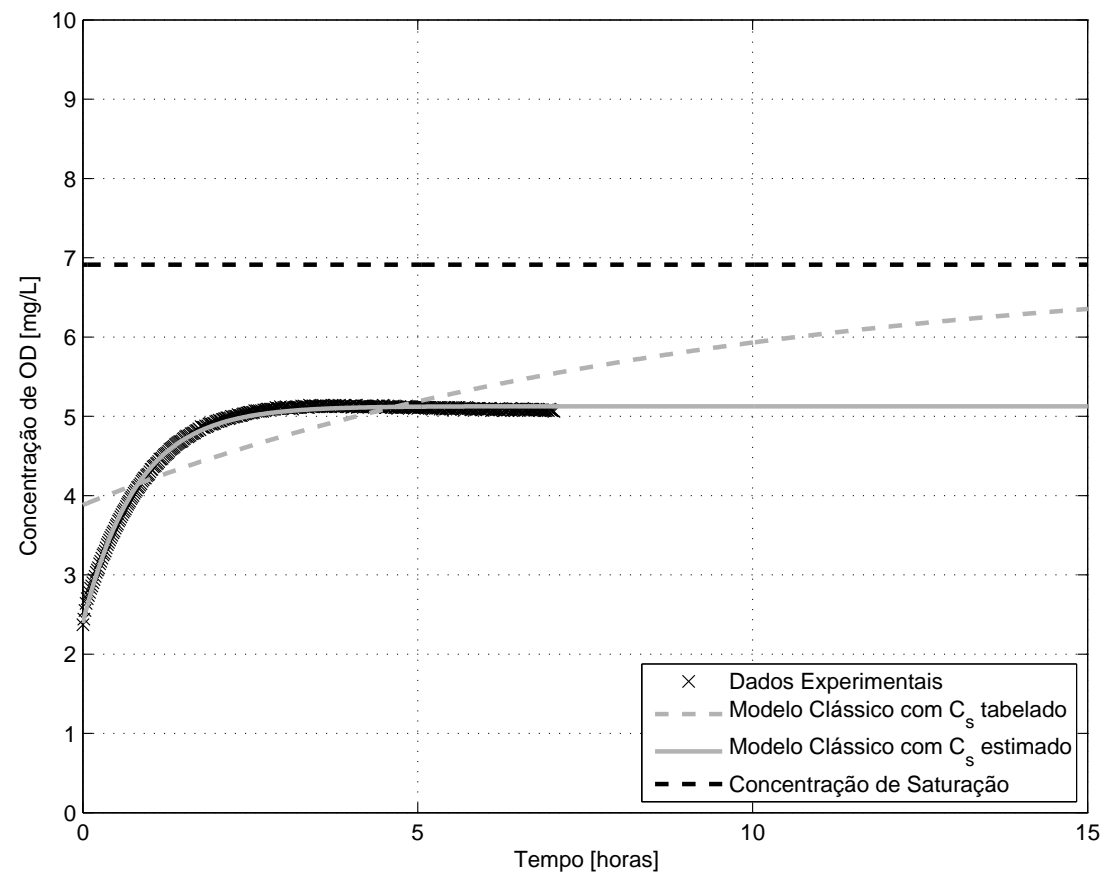

(a) Ajuste com o Modelo Clássico

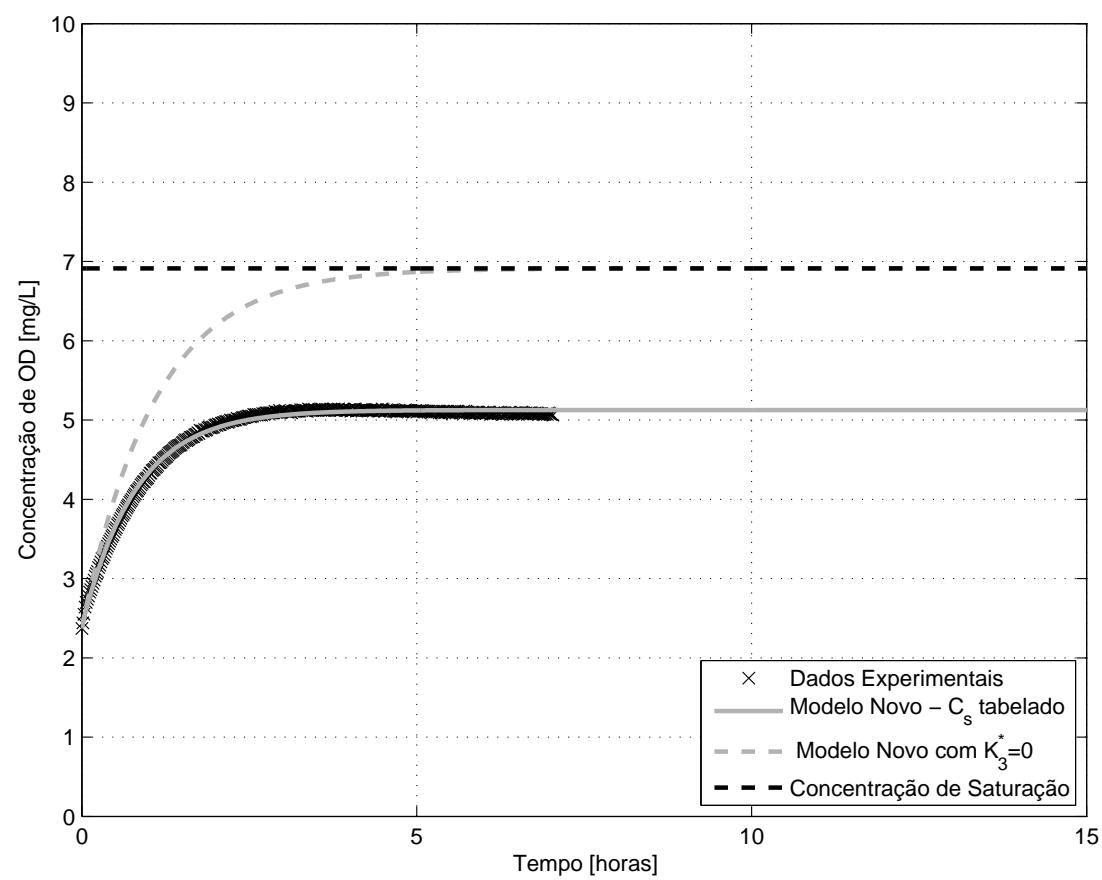

(b) Ajuste com o Modelo Novo

Figura B.139: Curva de reoxigenação para o ensaio 139 


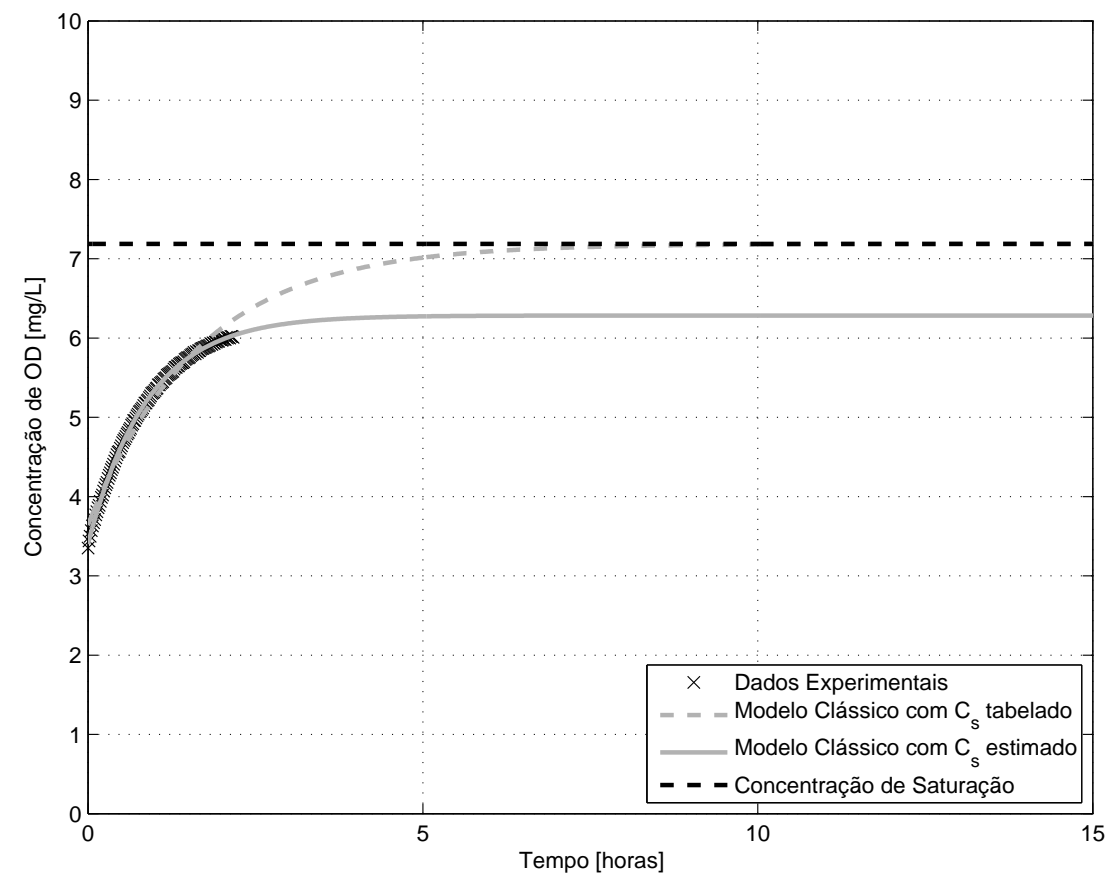

(a) Ajuste com o Modelo Clássico

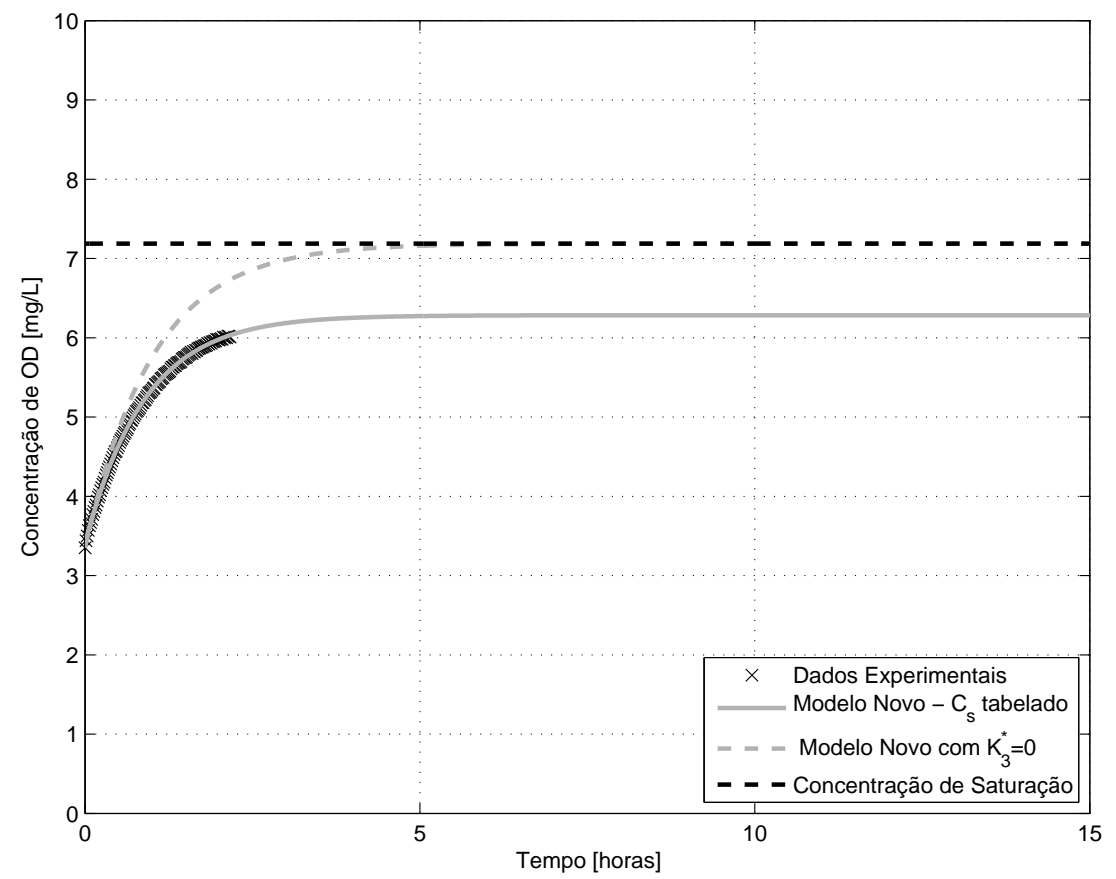

(b) Ajuste com o Modelo Novo

Figura B.140: Curva de reoxigenação para o ensaio 140 


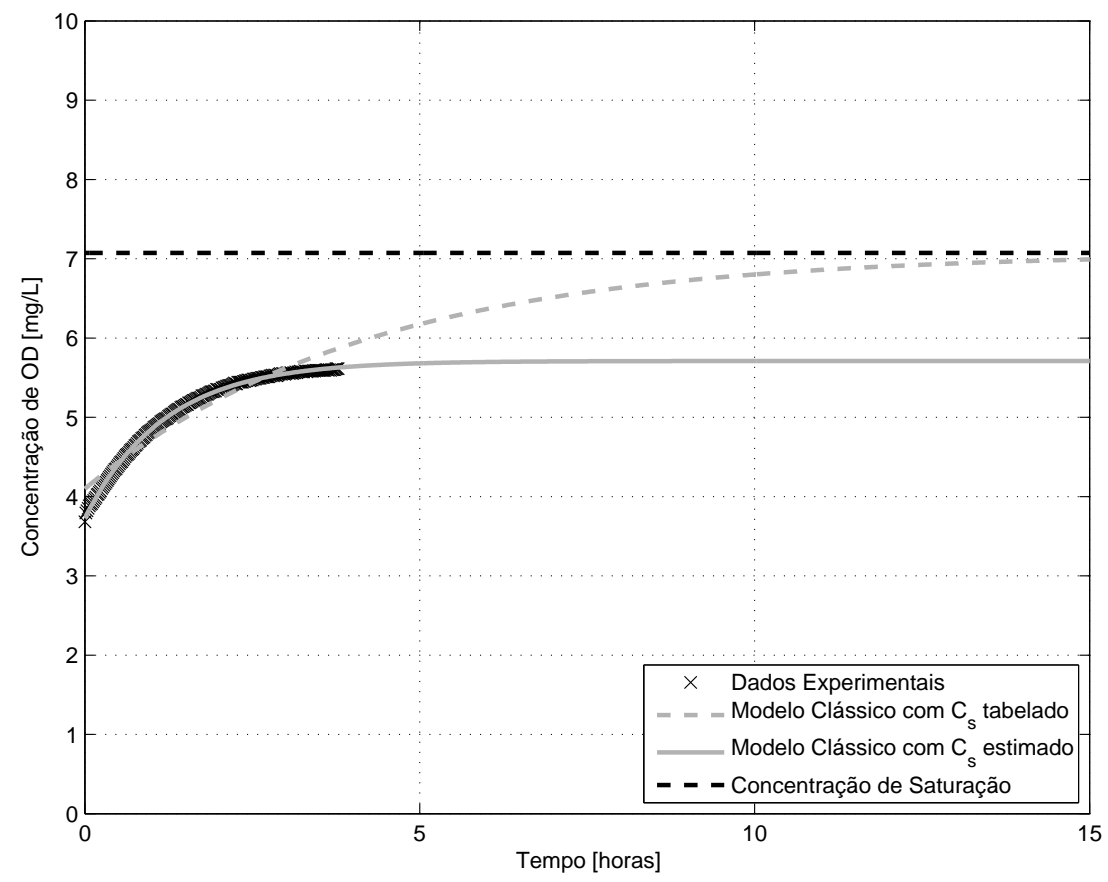

(a) Ajuste com o Modelo Clássico

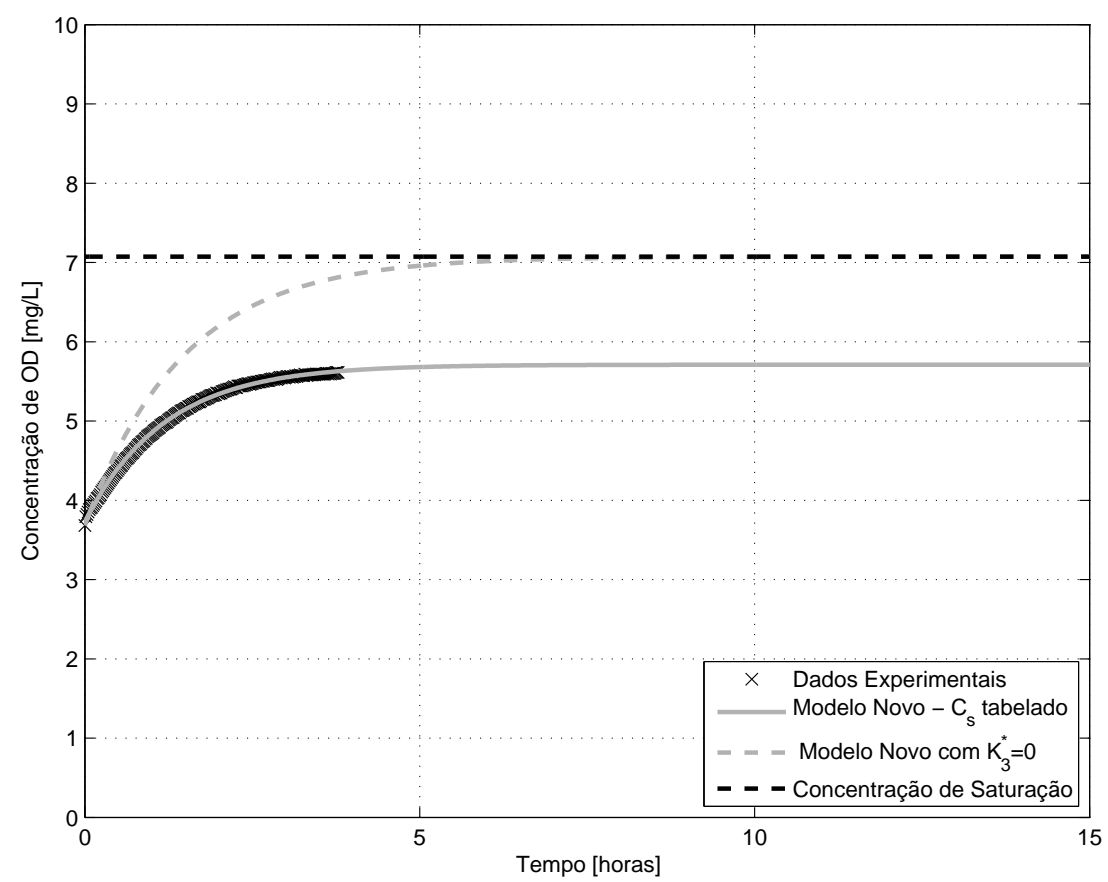

(b) Ajuste com o Modelo Novo

Figura B.141: Curva de reoxigenação para o ensaio 141 


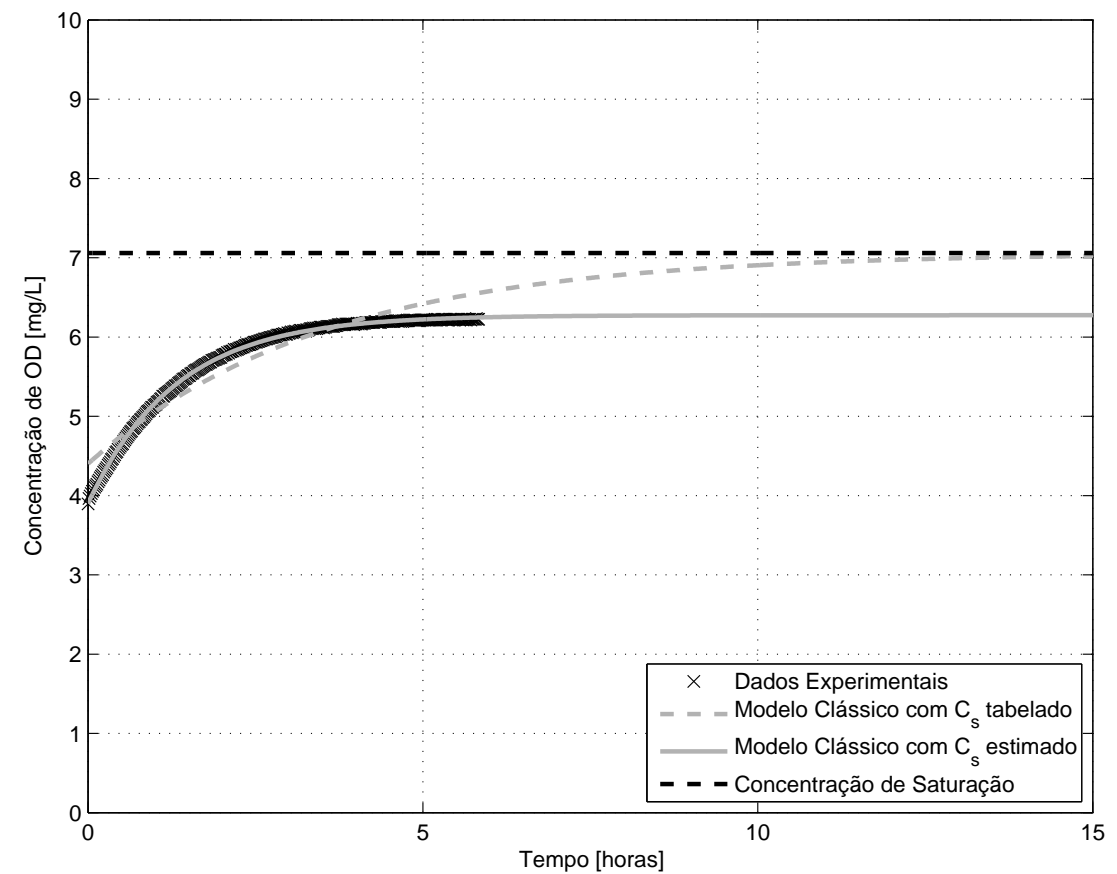

(a) Ajuste com o Modelo Clássico

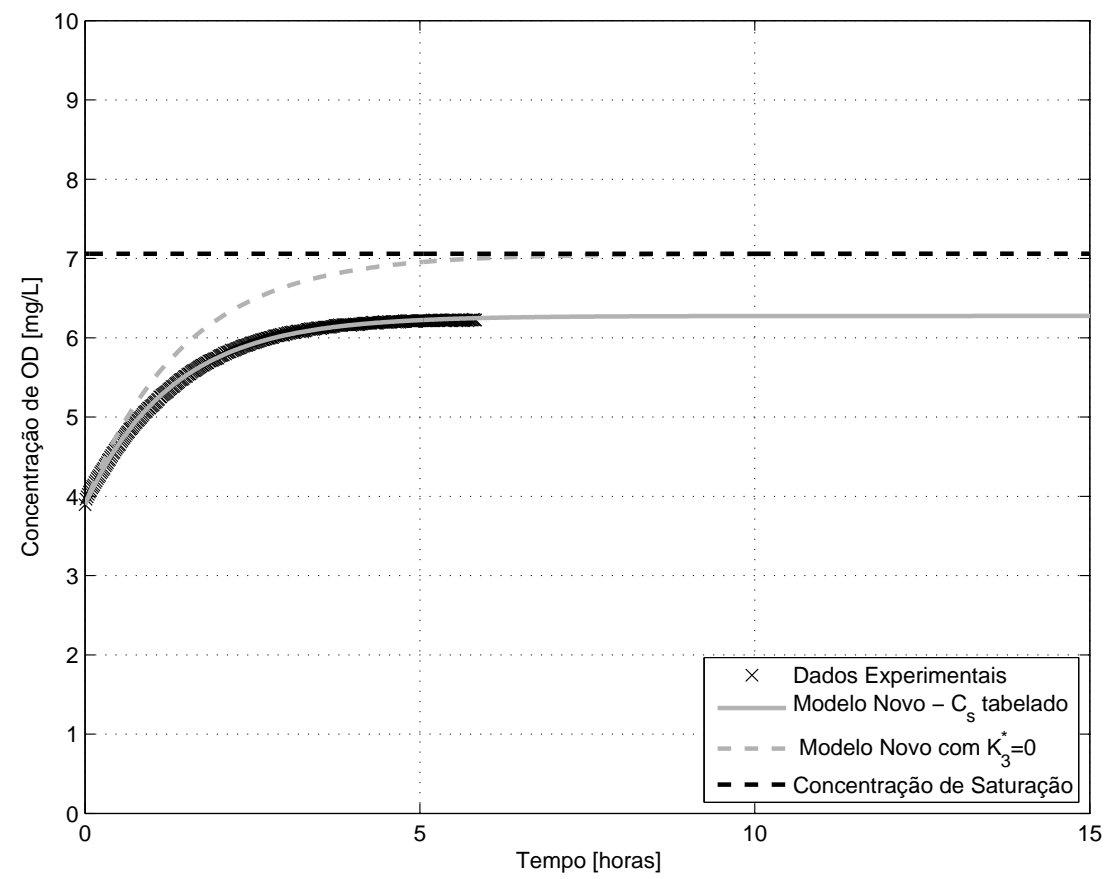

(b) Ajuste com o Modelo Novo

Figura B.142: Curva de reoxigenação para o ensaio 142 